\title{
L'AEMI : longitudinal auxology evaluation of Maastricht infants
}

Citation for published version (APA):

van de Walle, V. E. K. M. (2004). L'AEMI : Iongitudinal auxology evaluation of Maastricht infants. [Doctoral Thesis, Maastricht University]. Universiteit Maastricht. https://doi.org/10.26481/dis.20041111vw

Document status and date:

Published: 01/01/2004

DOI:

10.26481/dis.20041111vw

Document Version:

Publisher's PDF, also known as Version of record

\section{Please check the document version of this publication:}

- A submitted manuscript is the version of the article upon submission and before peer-review. There can be important differences between the submitted version and the official published version of record.

People interested in the research are advised to contact the author for the final version of the publication, or visit the DOI to the publisher's website.

- The final author version and the galley proof are versions of the publication after peer review.

- The final published version features the final layout of the paper including the volume, issue and page numbers.

Link to publication

\footnotetext{
General rights rights.

- You may freely distribute the URL identifying the publication in the public portal. please follow below link for the End User Agreement:

www.umlib.nl/taverne-license

Take down policy

If you believe that this document breaches copyright please contact us at:

repository@maastrichtuniversity.nl

providing details and we will investigate your claim.
}

Copyright and moral rights for the publications made accessible in the public portal are retained by the authors and/or other copyright owners and it is a condition of accessing publications that users recognise and abide by the legal requirements associated with these

- Users may download and print one copy of any publication from the public portal for the purpose of private study or research.

- You may not further distribute the material or use it for any profit-making activity or commercial gain

If the publication is distributed under the terms of Article $25 \mathrm{fa}$ of the Dutch Copyright Act, indicated by the "Taverne" license above, 


\section{L'AEMI \\ LONGITUDINAL AUXOLOGY EVALUATION OF MAASTRICHT INFANTS}


ISBN 90-9018673-5

Copyright (c) 2004 Viviënne van de Walle, Maastricht

Productie: Datawyse | Universitaire Pers Maastricht Omslagillustratie: Sara van de Walle 


\title{
L'AEMI \\ LONGITUDINAL AUXOLOGY EVALUATION OF MAASTRICHT INFANTS
}

\author{
PROEFSCHRIFT
}

ter verkrijging van de graad van doctor aan de Universiteit van Maastricht, op gezag van de Rector Magnificus, Prof. Mr. G.P.M.F. Mols, volgens het besluit van het College van Decanen, in het openbaar te verdedigen op donderdag 11 november 2004 om 14.00 uur.

door

Viviënne Eleonore Katrien Marie van de Walle 


\section{Promotor}

Prof. Dr. C.E. Blanco

\section{Beoordelingscommissie}

Prof. Dr. R.A.M.G. Donckerwolcke (voorzitter)

Dr. W.J.M. Gerver

Prof. Dr. J de Haan

Prof. Dr. R.A. Hirashing, TNO - Leiden

De publicatie van dit proefschrift is mede tot stand gekomen met financiële steun van o.a. AstraZeneca - Zoetermeer, GlaxoSmithKline - Zeist, LeoPharma - Breda, Pfizer BV - Capelle aan den IJssel, Vaxinostics - Rotterdam 


\section{Paranimfen}

Mr. A.P. Timmermans

Ir L.A. van de Walle 
$\longrightarrow$ 


\section{CONTENTS}

INTRODUCTION ........................................................................................11

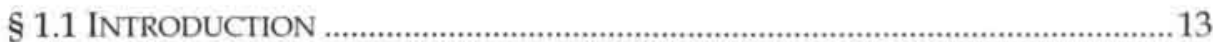

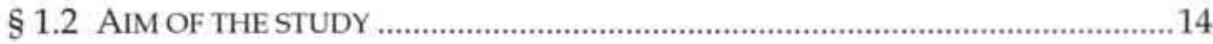

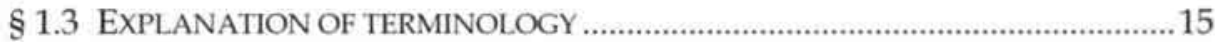

$\S 1.4$ CROSS-SECTIONAL VS, LONGITUDINAL GROWTH STUDIES...............................16

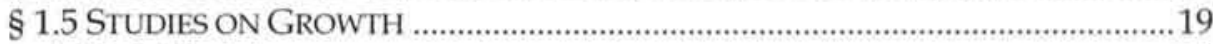

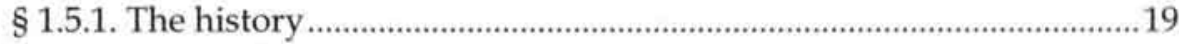

$\S 1.5 .2$ National vs. local reference charts..................................................... 22

$\S 1.5 .3$ Growth studies in The Netherlands.....................................................24

$\S 1.5 .4$ Growth studies outside The Netherlands ..........................................2 25

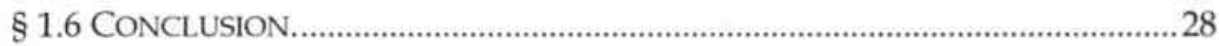

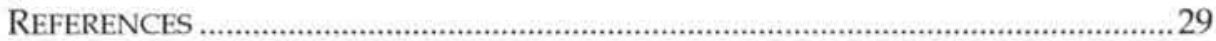

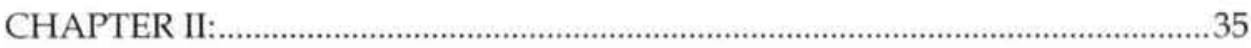

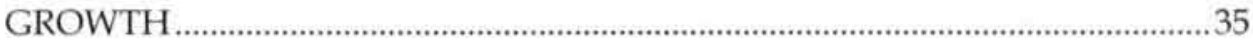

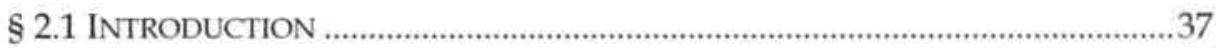

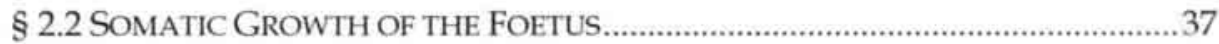

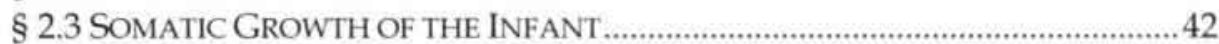

§ 2.4 PROPORTIONAL GROWTH FROM BIRTH ONWARDS..........................................45

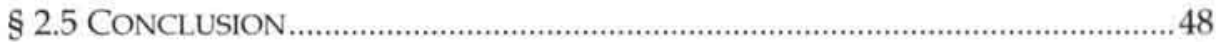

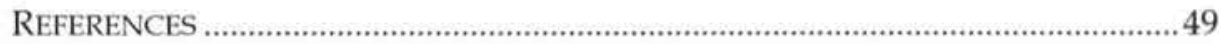

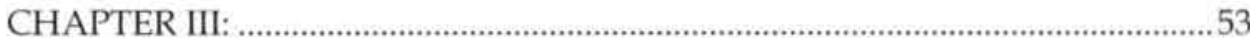

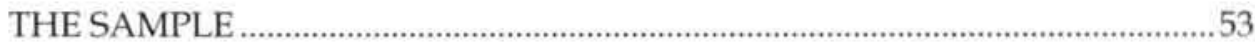

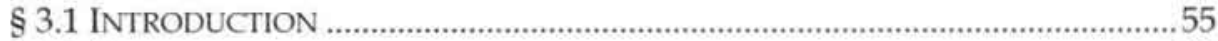

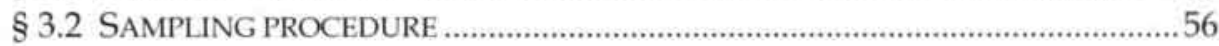

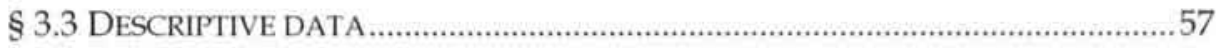

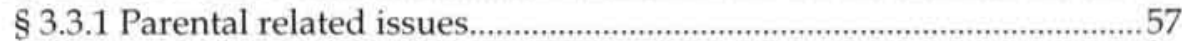

$\$ 3.3 .2$ Pregnancy and perinatal related issues ............................................60

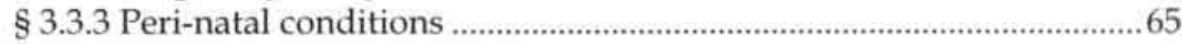

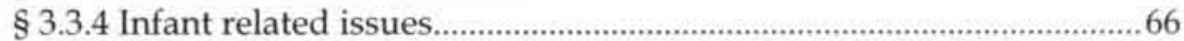

$\S 3.3 .5$ Birth specific anthropometric measurements .....................................67

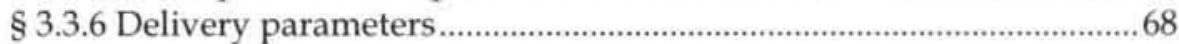

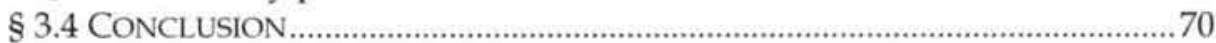

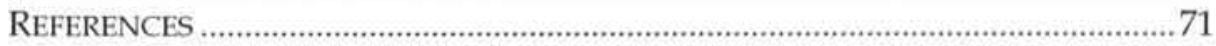

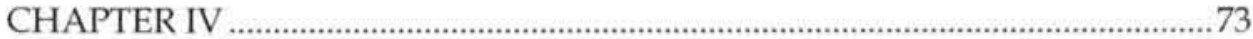

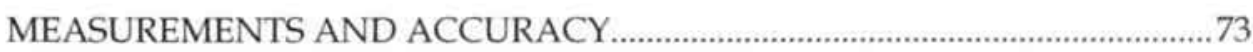

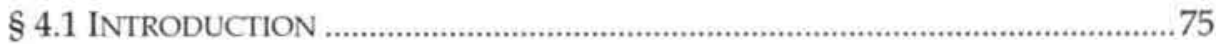

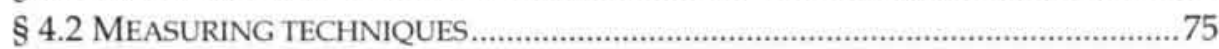




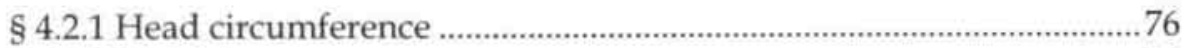

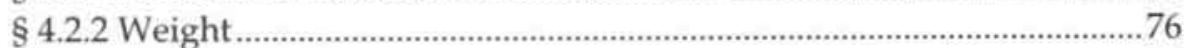

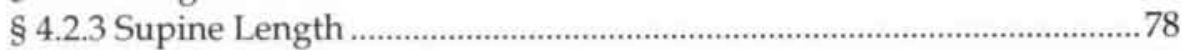

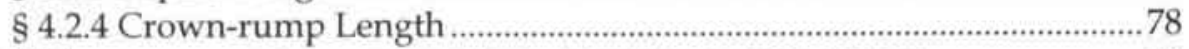

$\S 4.3$ THE ACCURACY OF THE ANTHROPOMETRIC MEASUREMENTS ..........................79

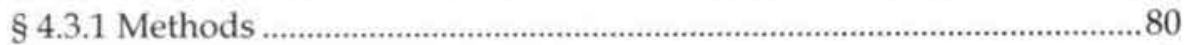

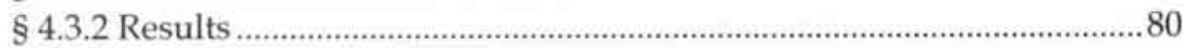

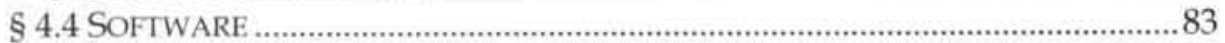

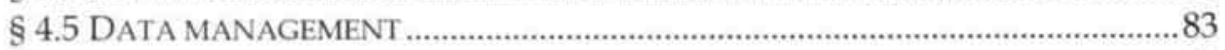

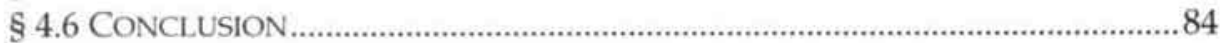

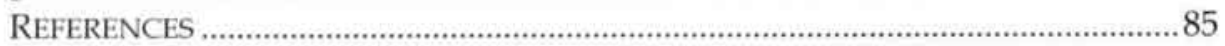

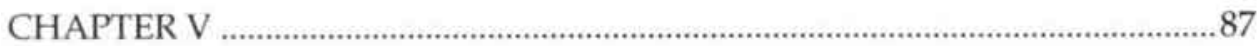

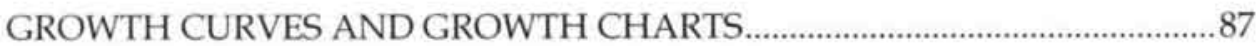

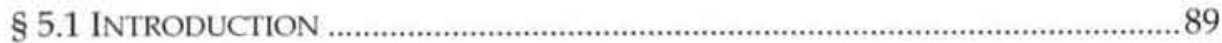

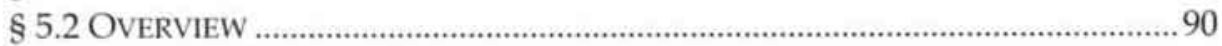

$\$ 5.2 .1$ Describing the human growth curve in structural and non-

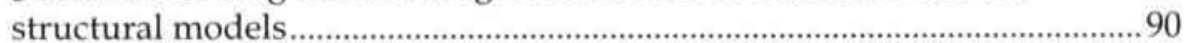

$\S 5.2 .2$ Constructing growth charts ...............................................................93

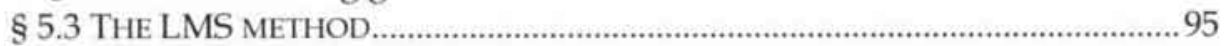

§ 5.4 CHOOSING CENTILES OR STANDARD DEVIATIONS? ……………………..........98

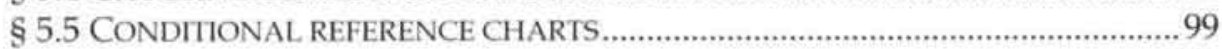

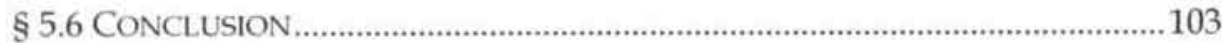

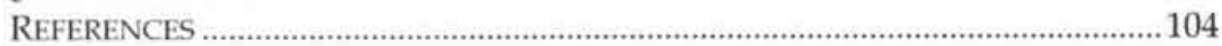

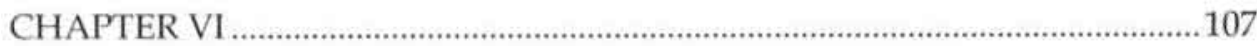

INFLUENCES ON INFANT GROWTH ….......................................................107

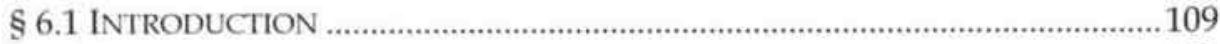

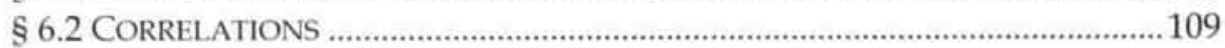

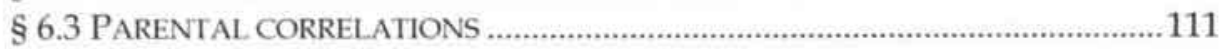

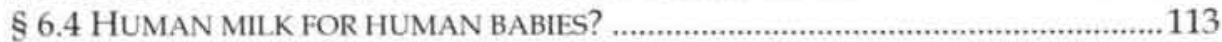

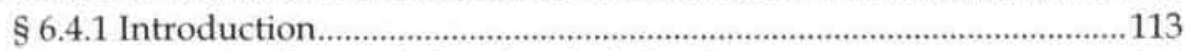

$\$$ 6.4.2 Growth of breast fed vs. bottle fed infants........................................116

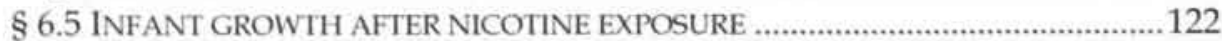

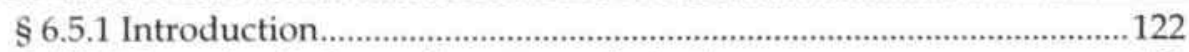

$\S 6.5 .2$ Growth of infants after prenatal nicotine exposure ...........................123

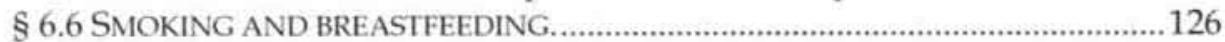

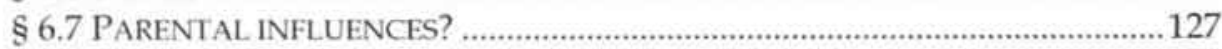

$\$ 6.8$ INFANT AND CHILDHOOD CAUSES OF ADULT DISEASES ................................127

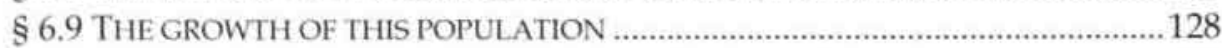

\$ 6.9.1 Analysis of a longitudinal growth curve data set ............................128

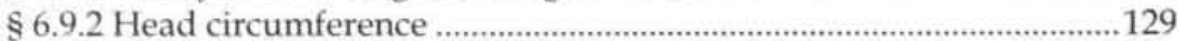

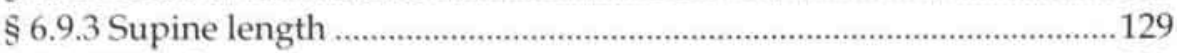

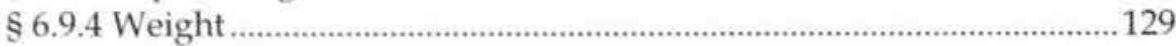


§ 6.10 CORRELATIONS REGARDING BREASTFEEDING AND SMOKING .................... 130

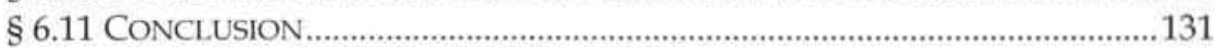

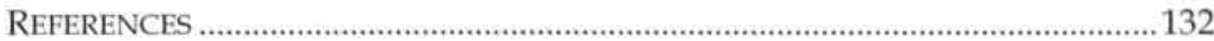

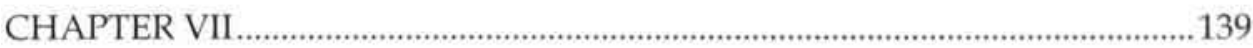

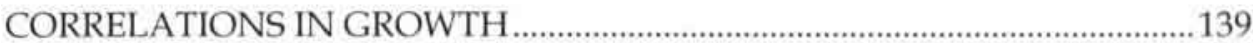

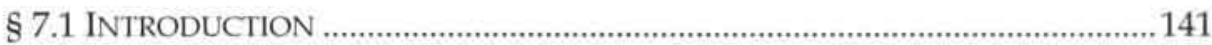

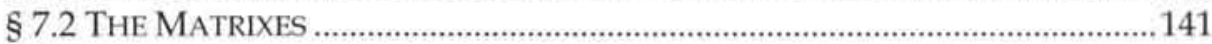

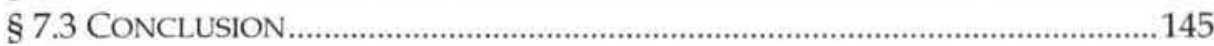

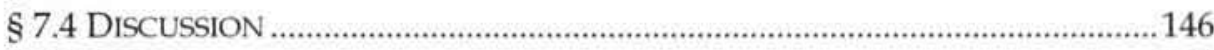

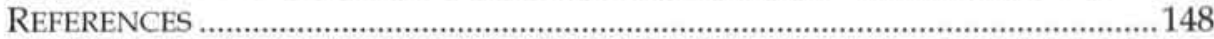

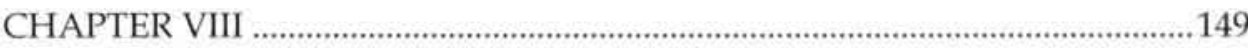

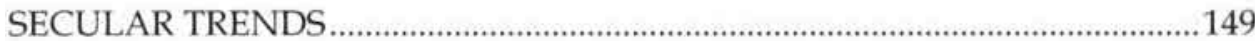

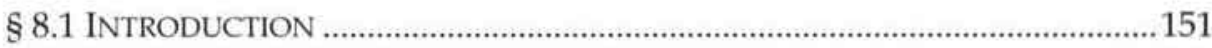

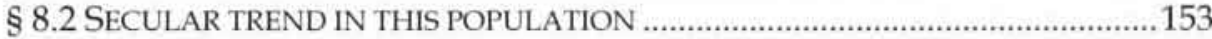

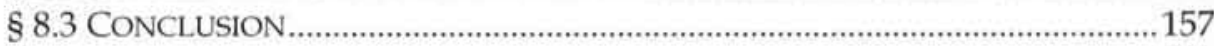

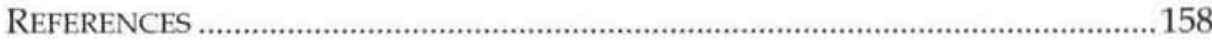

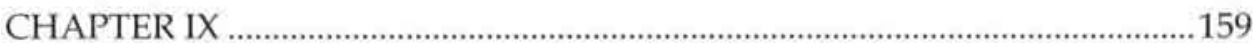

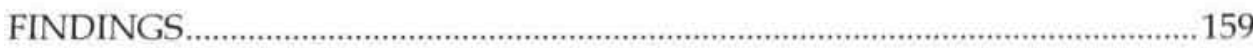

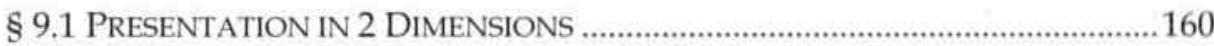

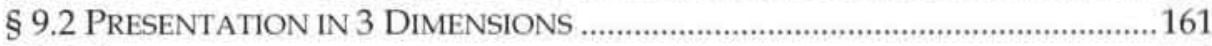

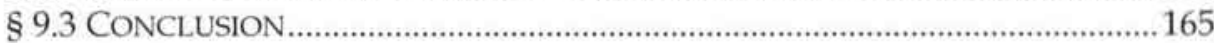

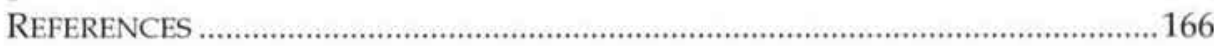

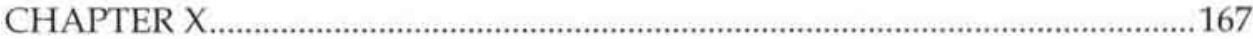

COMPARISON OF GROWTH STUDIES ..........................................................167

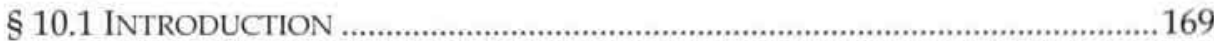

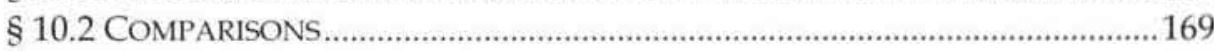

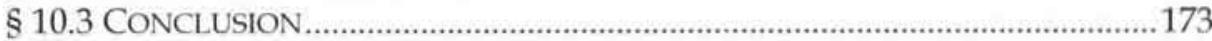

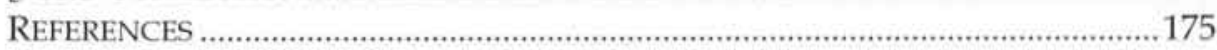

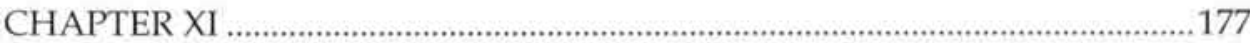

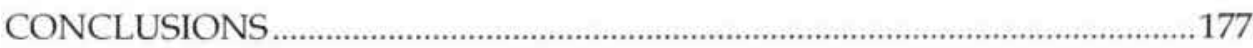

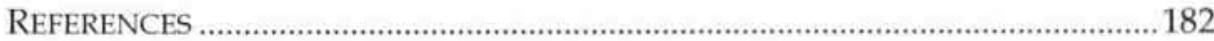

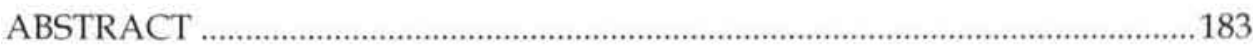

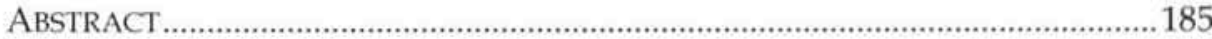

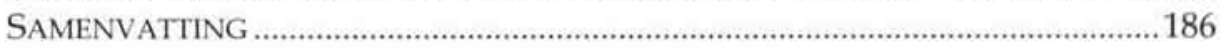




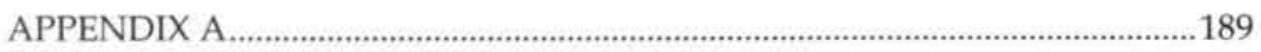

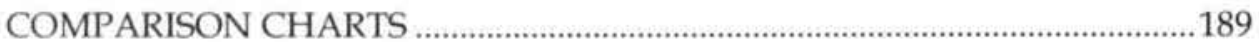

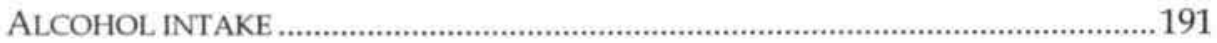

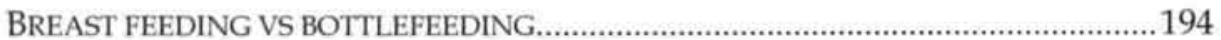

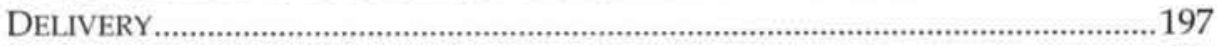

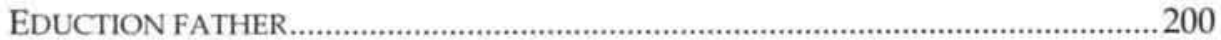

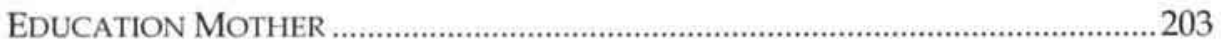

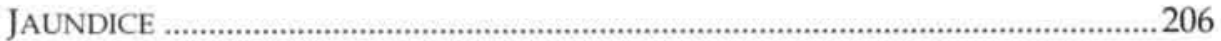

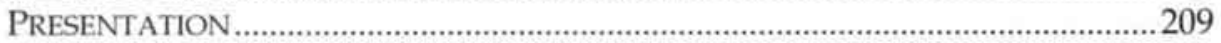

MEDICINE INTAKE

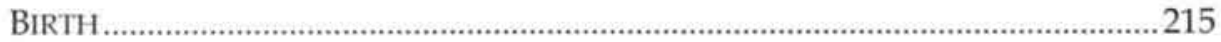

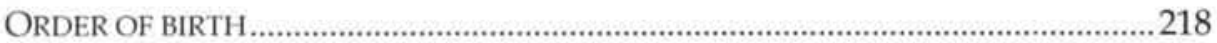

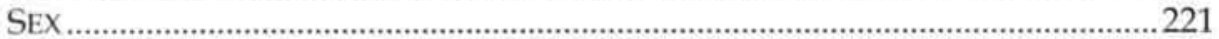

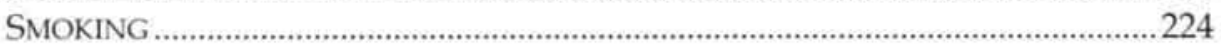

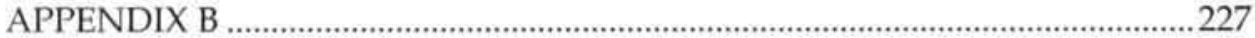

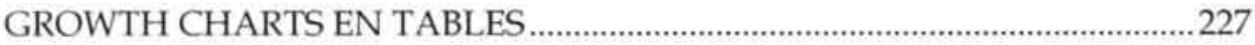

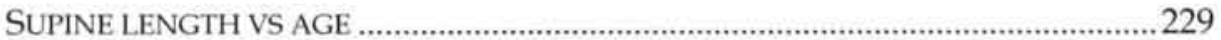

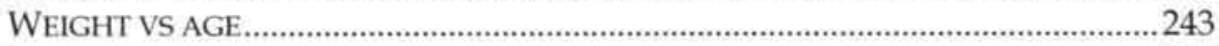

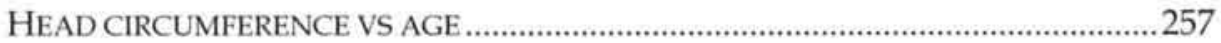

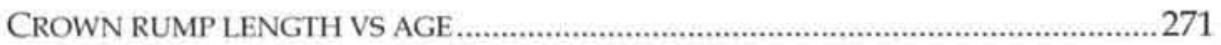

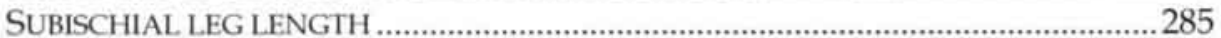

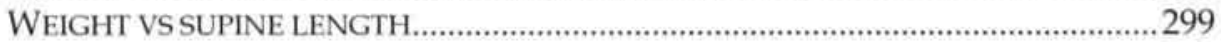

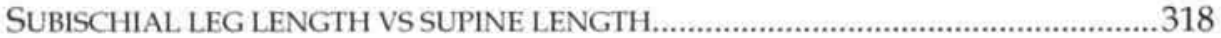

HEAD CIRCUMFERENCE CS CROWN RUMP LELGNTH..............................................337

APPENDIX C

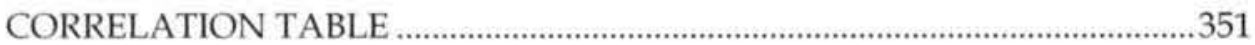

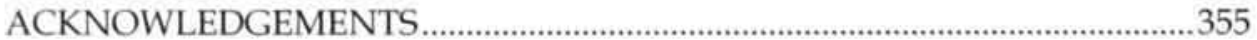

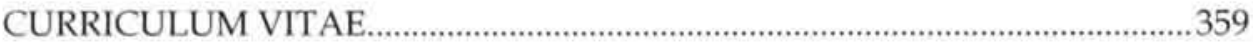




\section{Chapter I \\ Introduction}

Het begin van alles is bewegen, het begin van leven is groei. 


\section{§1.1 Introduction}

Growth is a very dynamic process and to a certain extent, it fascinates us human beings. After all, we have all done it, we have all grown. Some have not quite lived up to what they expected, while others might have gone beyond what they ever imagined to attain in height. Tanner explains that the concept tempo of growth is a metaphor from classical music; ... some children 'play' their growth andante, others allegro, a few lentissimo [1]. For most of us, growing was something that one just did, one did not control it. It was something that just happened. From conception onwards one was growing and then one day, without realizing it for a long time, one stopped.

This dynamic process of growing and maturing shows an intriguing timing. Some organs are fully developed at a young age, while others are still growing during the teenage years. After an episode of growth-delay, due to i.e. illness, a period of catch-up growth, providing the circumstances are adequate [2], will allow the child to eliminate the backlog that has mounted up. The effect of unfavourable conditions on growth depends on the severity and duration of the impact and the age of the child. After such a period of deprivation, a child is able to return to, or at least approach the regular course of growth when conditions improve. The younger the child the better their catch-up growth will be [3]. During this phase of catching up the initial growth velocity upon recovery is above the normal rate for children of that age, or even of the same skeletal maturity [2].

In the first two years of life, growth occurred during short intervals $(\leq 24$ hours), that alternate with longer periods of stasis. So an episode of stasis is actually part of the normal structure of growth and development and a limited time of growth absence does not therefore necessarily imply pathology [4]. The differences between human beings in their tempo of maturation cause their internal varieties. Although growth is determined genetically, health, nutrition, housing, family size and socio-economic status will influence the growth and therefore the final attained height of each child individually. All the time, from conception up to the end of the growth period, environmental factors may cause deviations of the growth pattern outlined by polygenic heredity. So far, only inhibiting factors have been reported [5]. There is no guarantee, however, that all populations have the same growth potential [2]. In The Netherlands children of this generation are taller and mature earlier sexually, than their contemporaries in previous centuries [3].

Only since the middle of the previous century has the process of growth been depicted in numbers. Research into growth has been performed over many decades. Not only can it produce reference values for health-care centres, but the information collected can be of interest for the whole of society and science in particularly. The health of a population is most accurately reflected in the 
growth of its children [2]. Continuous research into growth can detect differences between generations and (sub)populations [1]; it reflects the bio cultural evolution of our species [6]. Historians use the information on variation in growth over the decades when contemplating economic development [3]. The World Health Organisation states that the growth pattern of the youth in a country is a valid gauge for the status of health of that population [3]. Some researchers have even claimed that growth patterns can predict chronic diseases in adults $[7,8]$. Unfortunately the present assumptions regarding the biology of human growth are based primarily on height and weight data, while there are various anthropometric measurements that can be taken on the human body (i.e. head-circumference, crown-rump length, subischial leg length etc.) that will give extensive information about the growth of human beings [4].

\section{$\S 1.2$ Aim of the study}

As will be pointed out later in this chapter and throughout this thesis, there is a difference between the growth of infants and children in the southern region of the Netherlands, in comparison to children in the northern regions and even in comparison with the national references. To be able to evaluate a child's growth, it needs to be compared with a peer group that is representable for this child. A national growth curve might not sustain this criteria. Besides the geographical differences that exists due to historical developments and the composition of the population (immigrants vs natives), there are also differences between consecutive generations. To be able to construct the curves, anthropometric data of healthy infants during their first two years of life were collected and analyzed in order to achieve the following objectives:

Primarily to construct longitudinal growth curves for the first two years of life for supine length, crown-rump length, subischial leg length, headcircumference and weight; to describe the impact of various environmental and social influences on the growth of infants.

Secondarily to determine how much shifting occurs from the original position on a growth curve in the first two years of life in healthy infants by means of a correlation matrix and to describe the proportions at birth and the change of the proportions during the first two years of life, by correlating several measurements.

Thirdly the aim is for the curves to have a practical use. Therefore the curves need to be implemented into paediatric clinics and infant health care centres. This enables the physicians to evaluate the growth of an infant with its peers, which is more reliable. Consequently care for the infants can be improved.

The first two years of life are years of rapid growth and form a base for later growth and development outcome, besides the fact that after this age, children 
are no longer being measured laying down, but rather sitting up. This change in measurement result in a deviation of the growth curve. Therefore the study focused on the first two years of life.

\section{$\S 1.3$ Explanation of terminology}

Before going any further into the aim of this study, it is wise to bring in some definitions and to lay down some ground rules. Anthropometry is the technique of expressing the form of the body quantitatively [9]. It was first introduced by a German physician, Johann Sigismund Elsholtz, when in 1654 the first edition of his graduation thesis entitled 'Antropometria' was published [10]. The techniques used to measure anthropometric measurements are described in the chapter 'Measurements'. Auxology is actually still not a widely used word outside human biology and paediatrics. It is not even mentioned in either the American or International Webster's Dictionary. Not even all medical dictionaries are familiar with the term. In one medical dictionary 'auxo-' appears as: 'In biology a combining form denoting 'concerned with' or 'due to' growth'. A French school doctor, Paul Gordon first introduced the term, in 1919. It is an adaptation from the Greek root 'auxein' (meaning to increase). 'Auxins' is used by botanists to refer to the hormones of plants that promote an increase in size of stems, leaves, and other structures [6]. From this, Gordon developed the term 'la methóde auxologique' referring to the study of human growth. He defined it as a method of studying growth by means of multiple measurements on the same subject over successive time periods. It was J.M. Tanner especially who introduced the term auxology into the English language and scientific journals and broadened the definition into a more general usage of the measurement of growth [11]. One can depict growth of an individual in two types of curves. A distance curve shows the growth of this individual over a period of time. The velocity curve shows the rate at which the individual grows between successive measurements. An ideal human auxology project will combine the results of descriptive studies, experimental research and hypotheses testing into a comprehensive theory of the structural and functional elements of growth [6]. Growth may be defined as a quantitative increase in size or mass i.e. depicted in numbers. Development can be defined as a progression of changes, either quantitative or qualitative, that lead from an undifferentiated or immature state to a highly organized, specialize and mature state. Maturation, in this definition, is measured by functional capacity [6]. There are basically two types of growth-studies that can be performed: cross-sectional and longitudinal studies. Their use and their advantages and disadvantages are explained in the following paragraph. 


\section{§1.4 Cross-sectional vs. longitudinal growth studies}

The two main types of studies on growth are cross-sectional and longitudinal growth studies. Depending on the aim of the study, the number of children participating and to a certain extent the financial support will determine which kind of study is required or the best choice under the circumstances. In a longitudinal study each individual is measured periodically over a period of time, while in a cross-sectional study groups of children of various ages are measured only once. Longitudinal studies provide more information than crosssectional. This additional information from longitudinal surveys enables a better prediction of individual development. Thus, the distinction between the two types of investigation is very important. A longitudinal study may extend over any number of years. In practice it is not always possible to measure exactly the same group of children every time for a prolonged period; inevitably some children leave the study, and others, if that is desired, join it. This specific kind of longitudinal study is called mixed longitudinal. Another approach is to link smaller age groups, either consecutively or by overlapping the age groups, i.e. a follow-up of children from 0 to 2.5 years old, another group starting at 2 years of age and following up till 4.5 years etc.; this too is called a mixed longitudinal study [2]. In both cases special statistical techniques are needed to obtain the maximum information from the data. Both cross-sectional and longitudinal studies have their uses, but they do not give the same information and cannot be dealt with in the same way. Obviously, cross-sectional surveys are cheaper and more quickly done, and can include far larger numbers of children [12]. The number of participating children in each (age) group has to be proportional to the rate of growth [2]. They tell a lot about the growth-curve of height or weight for a given age (the 'distance curve') for the whole of the population. Therefore it is essential to have cross-sectional surveys for the construction of charts for height, weight and other measurements in a given (sub)population. Periodic surveys are valuable in assessing the nutritional progress of a country or of particular socio-economic groups, or the health of the child population as a whole [1]. Nevertheless, cross-sectional surveys have a great draw-back; they do not represent the actual shape of the growth curve of a particular individual and they give no information on the individual increments from one year to the next. Therefore, they do not reveal individual differences in rate or velocity of growth or in the timing of particular phases such as the adolescent growth spurt. In the clinic it is this information which is the most useful, as this enables the paediatrician to compare a given individual's velocity with standards for velocity at his age [2]. Growth-charts for i.e. height should be constructed, ideally, using a combination of both cross-sectional and longitudinal data. The differences between the two types of studies are best shown around puberty. Around this period there is a great variation between individuals in the onset and course of puberty. Generally the spurt is a marked and quite rapid affair, but it differs between individuals [13]. In a cross-sectional study a group of children is measured once, and therefore only the average value for a certain 
age is given. As this is done for various ages, the curve presented this way levels out the actual true shape of a growth curve. So the average curve becomes spread out along the axis of the age and its peak is lowered. Figure 1.1 shows an example of this. Figure 1.1a shows five velocity curves of individuals during adolescent growth spurt (solid lines). The average curve (dashed line) has smoothed the peak height velocity and as a matter of fact is not a true representation of a human growth velocity curve at all; no individual actually follows this $50^{\text {th }}$ centile curve. Figure $1.1 \mathrm{~b}$ shows the same curves but all plotted according to their peak height velocity. So these curves are plotted not against chronological age but against a measure which arranges the children according to how far they have travelled along their course of development; they are arranged according to their true development or physiological growth-status. The dashed line now gives a faithful representation of the correct growth curve. The same phenomenon is shown in figures 1.2a and 1.2b. These figures show the distance curves for length. Although cross-sectional curves give an estimation of the mean rate of growth of a population, they tell nothing about the variability around that mean [2]. So they do not provide useful information about the variation in rate of growth of the children in the population as this can only be obtained by measuring each child at least twice at different ages. A longitudinal study on the other hand is less satisfactory for estimating the population mean at successive ages [12].

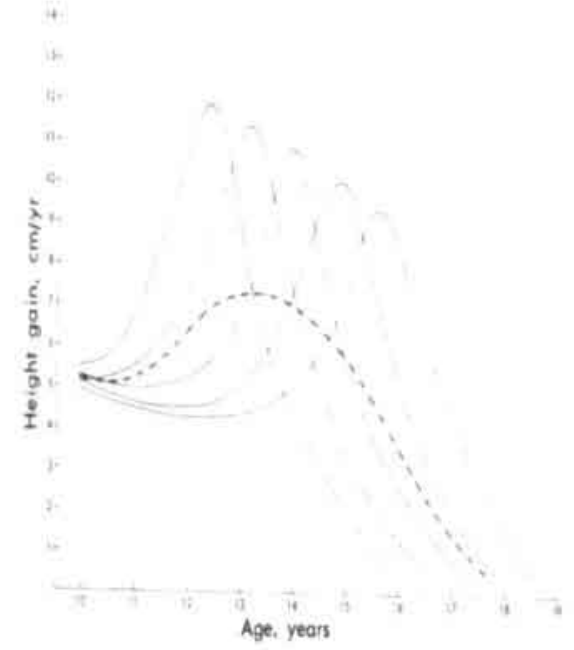

Figure 1.1a: Height velocity chart during the pubertal growth spurt. The five solid lines represent individual velocity curves. The dashed line shows the mean curve, constructed by averaging the values at each age.

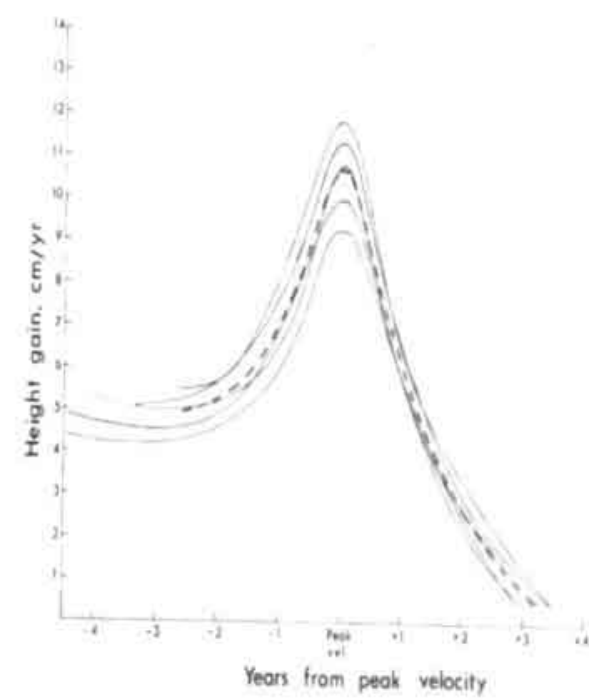

Figure 1.1b: The same curves as in figure 1.1a but plotted according to their peak height velocity. This mean curve sustains the true shape of the curve [14] 


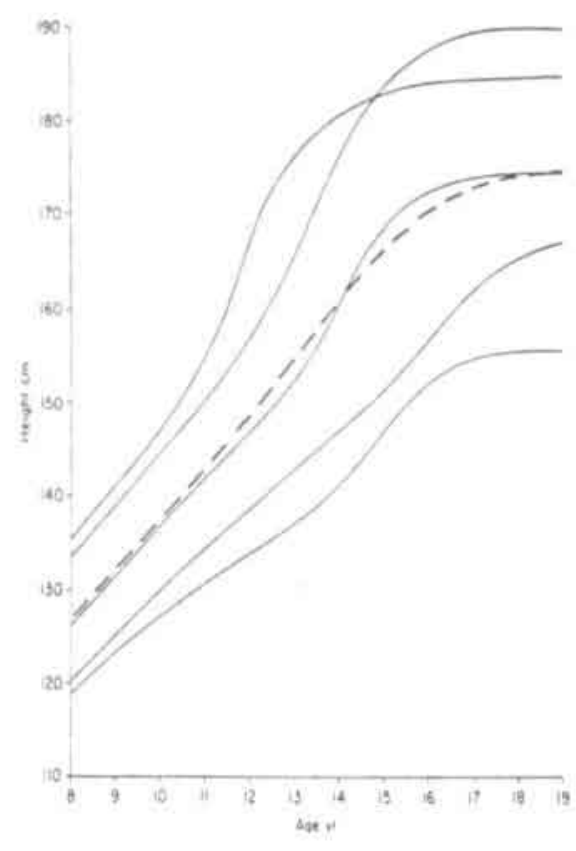

Figure $1.2 a$ Growth in stature of five boys (distance curves). The dashed line indicates the mean stature of the boys at each age.

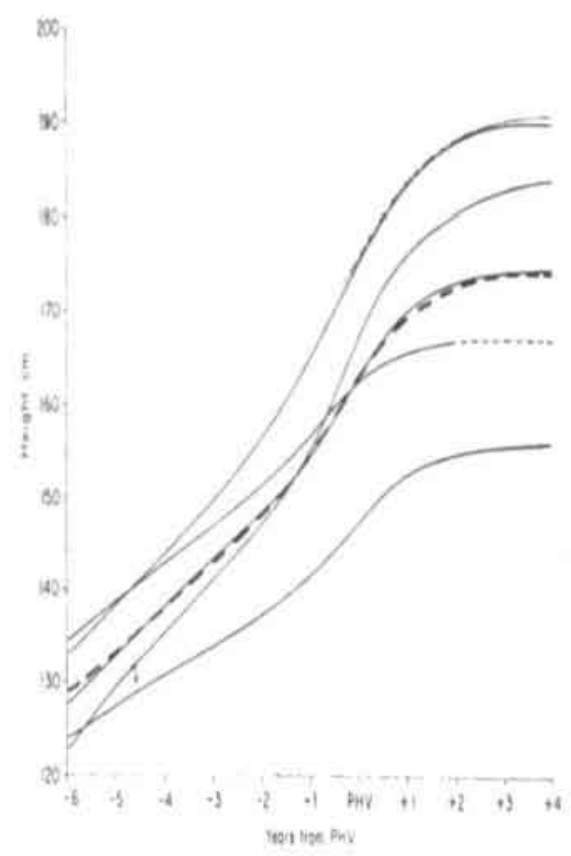

The distance curves of figure $1.2 \mathrm{~b}$ plotted in relation to peak height velocity. The dashed line shows the mean for the group. This mean curve sustains the true shape of the curve [12]

As during the first two years of life, on which this thesis is focused, there is not such a marked growth spurt, the differences will not be as distinct as during puberty. But it would be incorrect and even careless to ignore the existence of this phenomenon.

Because of the duration and the costs of a longitudinal study it is not surprising that so little research on longitudinal growth has been done over the years. Longitudinal growth studies extending over many years are money and timeconsuming and require an exceptional degree of commitment by the child, its parents and the anthropometrist. Preece [15] pointed out that longitudinal studies are often based on a small sample size, inadequate to draw reliable standards. In the past, findings from longitudinal studies often have been presented as cross-sectional as simple methods were used, which are only appropriate to cross-sectional studies. By doing this, unfortunately, vast amounts of information have been thrown away from the costly longitudinal data, wasting the whole great effort [2]. Growth norms based upon cross-sectional studies are entirely suitable for judging the status of a baby examined for the first time, but not for following the infant's growth; only longitudinal studies take into account the infant's tempo of growth and supply unbiased information on growth velocity of the individual [16] [17]. 
Unfortunately, very little Iongitudinal research, even over a small period of time has been done. Especially, the postnatal growth is very suitable for longitudinal research, as the rate of growth during infancy is rapid and abnormalities in growth may often be detected in just a short period of time [18]. Preventive action and clinical controls are advantageous mainly in early childhood, because in this period especially the fastest physical growth and most of the neurological development occur. The first 5 years of life in particular, form the period in which the child is mostly at risk from the combination of malnutrition and infection [2].

In conclusion, one cannot state that longitudinal studies are better than crosssectional, or vice versa. Each has its proper place. Both longitudinal and crosssectional studies are complementary and both are required for a full understanding of the growth process [2]. The important thing is to ensure that the type of study is appropriate to the questions that are being asked and the kind of conclusion the observer intends to draw.

\section{$\S 1.5$ Studies on Growth}

\section{$\S 1.5 .1$. The history}

The earliest written records about human growth date from Mesopotamia, about $3500 \mathrm{BC}$. Both the fertilization and the nine months of pregnancy were depicted in inscribed myths. The Sumerians even recognized the differences in full term and premature birth and recounted their concerns about low birth weight, birth defects and twins. Although there is no evidence that they actually measured the dimensions of the body, several texts mention a positive relationship between health, social status and stature. This was also shown in their artwork. The ancient Egyptian, Chinese, Hindu, Greek and Mesoamerican civilizations follow many of these Sumerians traditions [6]. The Greek poet Solon described the changes in a growing boy in an elegy [10]. The Egyptians and the Hindu Indians, showed careful concern for measurement of the body, including children. The Egyptians even used some kind of grid system to render body proportions correctly. But actual research solely focusing on growth has only been performed for the past two centuries. The earliest research on growth was mainly focused on the changes in body proportions from infant to adult. It wasn't the medical profession that was interested in this phenomenon. Surprisingly, of all professions, it was painters and sculptors. Till the $18^{\text {th }}$ century not much attention was paid to the child's anthropometry, which is very obvious in the majority of the paintings from those days. Children were being painted as a small version of grown-ups, with small heads and long legs. The German physician Elshortz was the first to approach the anthropometry from a medical point of view, which was published in 1654-1672 [5]. In 1723, the painter Bergmüller described for the first time the changes in the infant's human body. Yet, 
he probably never actually measured children [5] [3]. Figure 1.3 shows his drawing.

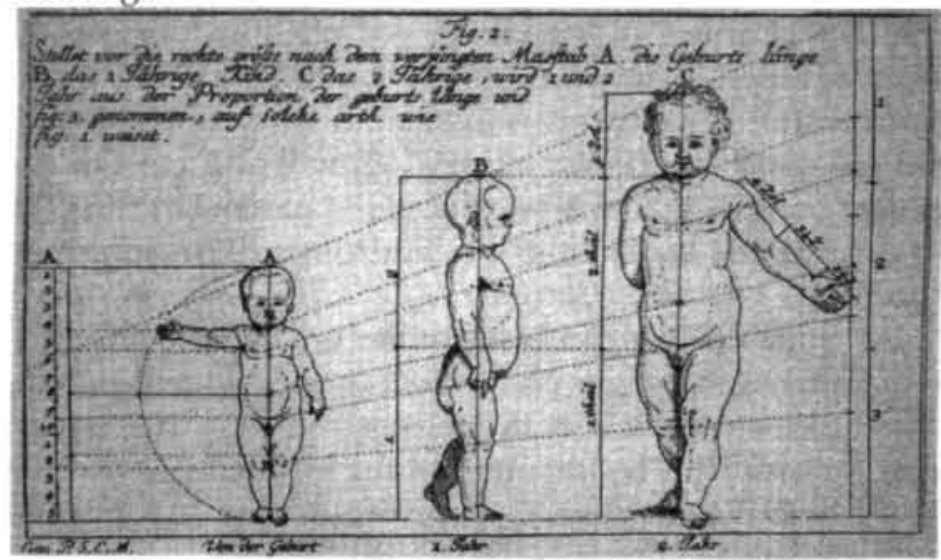

Figure 1.3 Changes in the infants body according to Bergmüller [5] [3]

The first research fully focused on growth was published in 1778 and was conducted in Amsterdam by Martinet. He measured 12 boys from 1770 till 1776 to describe the 'Verwisselingen der Evenredigheden' (= changes in proportions) from 2 to 18 year old boys [19]. Unfortunately he failed to mention absolute values but his drawing is very clear (figure 1.4).

"From this drawing thou can learn so clearly about the astonishing growth of our body downwards and the proportionality of the different parts of the body, that I can offer you nothing better concerning this subject. The order of increase in our body stays a matter of deep wonder, and excellent proof of a divine Goodness towards us" -Martinet; 1778-

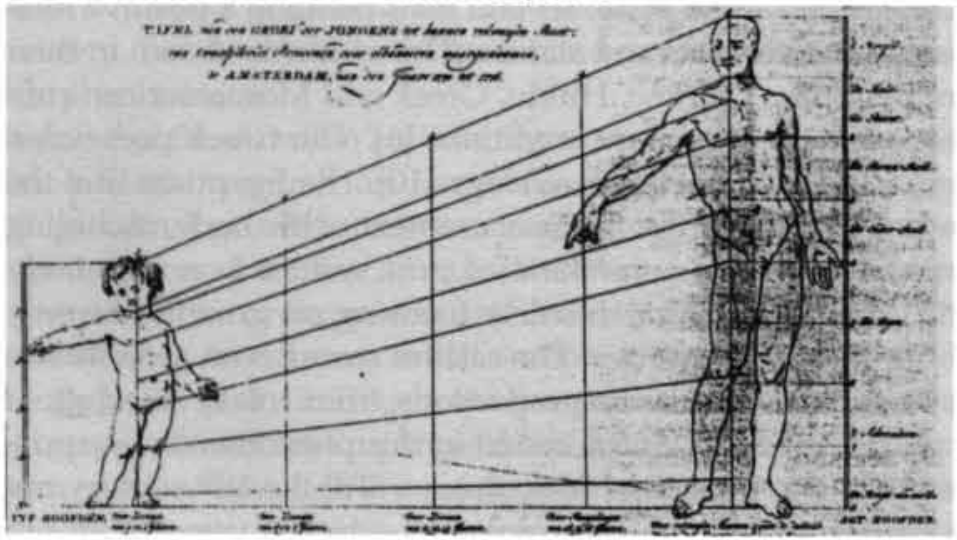

Figure 1.4 The oldest documented growth-study, describing, relatively, the changes in bodyroportions, conducted by Martinet and published in 1778; 'Tafel van den Groei der Jongens tot hun volwaszen Staat, van twaalfderlei Persoonen over elkanderen waargenoomen, te Amsterdam, van de laare 1770 tot $1776^{\prime}$ [19]. 
The oldest documented growth study in which absolute values are given, involved a longitudinal follow-up of one boy, measured nearly every 6 months from birth to 18 years. It was constructed from 1759 to 1777 by Comte Philibert Guénea de Montbeillard and is of his son, born on April 11 th, 1759. It was first published by Montbeillard's friend Comte de Buffon in a supplement to the 'Histoire Naturelle' (figure 1.5) [20]. Unfortunately, Montbeillard omits to describe how he measured his son. Neither the age at which the child was measured standing up instead of lying down was given, nor a description of the equipment used. However, the fact remains that Montbeillard's son was very tall. Compared with the current Dutch standards, he would lay between the $90^{\text {th }}$ and $97^{\text {th }}$ centile. In $1942 \mathrm{D}^{\prime}$ Arcy Thompson used the original data to calculate the increments and plotted the height velocity curve for Montbeillard's son in his revised edition of the book 'On Growth and Form' [21]. The growth-chart of Montbeillard's son is the first longitudinal study of human growth and due to Buffon's commentary, the most famous study. Buffon noted that during the summer the boy grew faster than in the winter. In his commentary, he also wrote about the daily variation in stature; the boy was taller in the morning than at night. All in all, it is considered the classical illustration of human auxology $[6,20]$. Another, less well-known longitudinal study from the eighteenth century is that of students of the Carlschule. The growth data showed that the sons of the nobility were taller than the sons of the bourgeoisie during the growing years, but both groups achieved approximately equal height at the age of 21 years. [6]. Some better-known individual growth-curves were presented by Quételet of the growth of his children [22]. He had also collected data on the length of children living in the capital Brussels, Belgium, from birth till the age of 20 years old [23]. He neglected to mention the number of children participating in this study. It was striking to notice that the girls were always smaller than the boys, while shortly before the onset of puberty girls tends to be taller than the boys. So it's most likely that Quételet made some errors while measuring and/or while processing the data [24]. However, he was the first researcher to make use of the concept of the 'normal curve', which nowadays is called the 'normal distribution' [6]. 

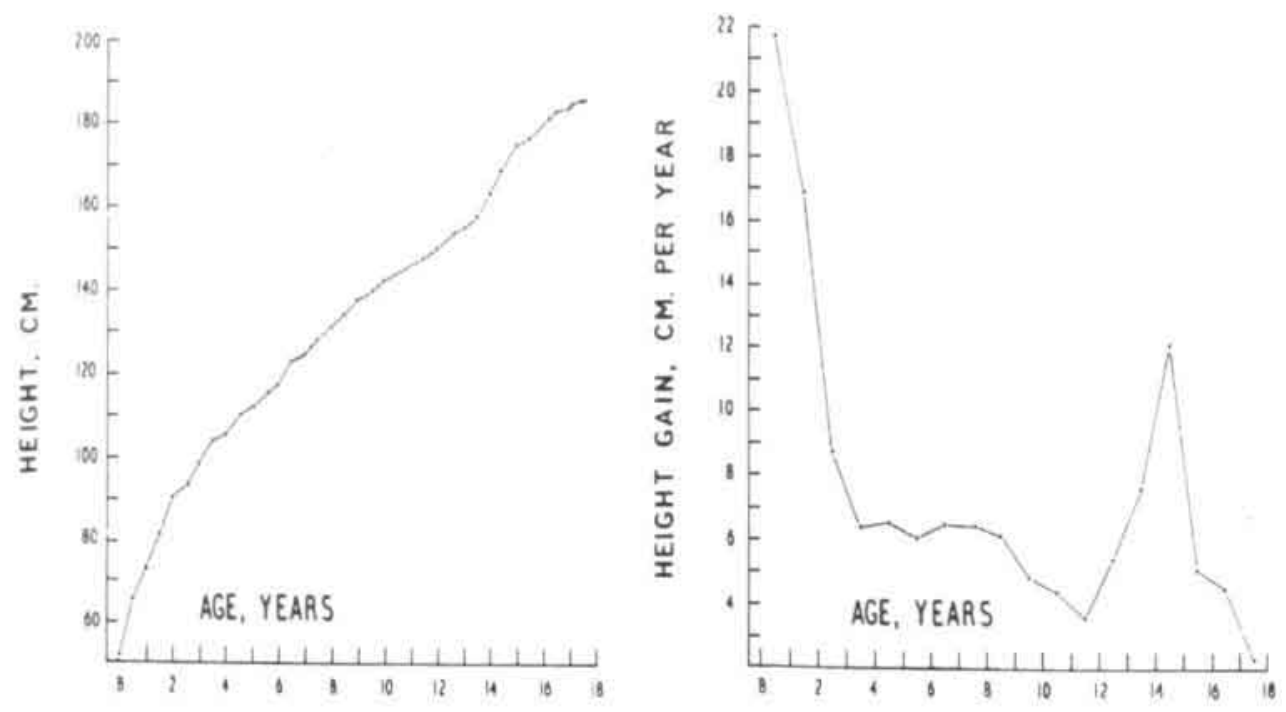

Figure 1.5. The growth curve of the son of Comte Philibert Guenea de Montbeillard. Measured every 6 months from 1759 to 1777 is the oldest documented longitudinal follow-up of growth with absolute values. First published in the Supplement to the Histoire Naturelle in 1777 [20].

Body measurements collected longitudinally have mainly been used to describe and study the growth process as a whole, in particular phenomena which do not occur at the same time in all subjects i.e. growth spurts. A different area of interest concerns the stability or tracking behaviour of the various body parameters, i.e. their tendency to follow or not to follow a percentile. This problem has not received much attention in recent years in auxology [25]. Also of interest is the stability of the individual growth and relation to other auxological or clinical parameters [26]. During the nineteenth century growth research was used for the first time to inform political and legal decisions regarding the treatment of children. The first percentile growth charts were published in 1885 by Bowditch $[6,27]$.

\section{$\S 1.5 .2$ National vs. local reference charts}

Numerous growth studies have been performed around the world. And there has been a controversy on whether or not to develop a global growth curve rather than a national. Or even if in addition to national growth curves there is a necessity for local charts as well. It is a misconception that the growth of healthy populations, at least up to the age of five years, is about the same and therefore universal standards would be justified [28]. In his book on 'Worldwide Variation in Human Growth', Tanner refutes this and showed that both the size and tempo of the growth of infants and children are different amongst various populations. So he stated that it is necessary for countries or at least 
broad regions, to generate their own standards, which should be based on wellnourished healthy individuals, or the nearest approach to that ideal that is practicable [2]. Warrington and Storey carried out a survey in which they compared the growth of children whose parents originated from the Indian sub-continent with that of indigenous, white children both living in the UK [29]. They found that with the exception of birth weight, few significant differences in individual growth parameters between the two populations were found. But still it is unlikely that all populations have the same growth potential. There are obvious differences between the attained height and weight, but also the age of onset of puberty. These differences are partly due to the genetical variation, but are also caused, to a certain extent by environmental differences [2]. Only a limited number of countries possess their own growth standards. The Netherlands are considered precursors on the matter of growth studies. Not only are the first national curves, dated from 1955, a valid national representation, but they have been updated three times to correct for the secular trend [3].

Depending on the purpose of the growth-charts one can distinguish whether to construct and use national or local ones. When an individual falls below the appropriate standards in the growth-chart this individual will be evaluated. It is therefore important to evaluate the growth of this individual with a chart that has been constructed from its peers or a resembling population. If a population or subpopulation falls below the appropriate standards it might indicate that this population need some evaluation. This might result in, i.e. better health care, improved hygienic measures, better nutrition, social improvement etc. [2]. Even in The Netherlands differences between the northern and southern provinces are evident, in which the infants from the northern provinces tend to be taller. In the Third Nation-wide Survey it was found that the infants in the northern provinces were almost $1 \mathrm{~cm}$ taller than their southern contemporaries ( $0.92 \mathrm{~cm}$ for boys and $0.76 \mathrm{~cm}$ for girls). At adolescence, these differences were $1.14 \mathrm{~cm}$ for boys and $2.36 \mathrm{~cm}$ for girls. Weight for height exceeded in the southern provinces in both sexes that of the northern provinces [30]. The differences between North and South are diminishing, but are still evident [3]. The Fourth National Growth Study the most profound difference between the various regions in The Netherlands was again between the North and South. In the northern regions the children remain taller at all ages, when compared to the southern region. Most profoundly these differences were seen at about the age of 8 years for boys and between the $3^{\text {rd }}$ and $5^{\text {th }}$ year for girls $[31,32]$ Even the secular trend shows considerable regional differences, which is most obvious between the north and the south regions of The Netherlands [33]. There are several causes that might explain these differences. First of all, the larger the family size, the smaller the children will be on average, especially the youngest ones in that family. This is partly due to the rising age of the mother at the time of the pregnancy and consequently the declining condition of her uterus. The southern provinces are predominantly catholic while the northern provinces are predominantly protestant. The marital fertility and infant mortality increased in the southern regions till the first decade of the $20^{\text {th }}$ century. So the 
average family size in the southern provinces was larger than in the northern provinces as the protestants were allowed to practice birth-control. Even today there are differences in the health status of people living in the north and south. This is reflected by differences in height, as well as in Socio Economic Status (SES), morbidity, and infant mortality [3, 33, 34]. Another explanation might be that as the South has been sieged by both the French and Spanish, they have left their genetical information in their descendants who, even after all these decades, are still living in the South. So when evaluating individuals of the South by using a national or local northern standards, a greater percentage of the individuals will fall below the third centile. Thus a local southern standard is probably legitimate. They might limit the number of false positive referrals, as there will be growth of individuals that will deviate and fall below the standard (northern) curves, but might lay in between the centiles of a southern standard, implying that the growth is not restricted.

\section{$\S 1.5 .3$ Growth studies in The Netherlands}

The Netherlands have a good reputation in growth research. After all it was Martinet who was one of the first to publish his findings on growth. After Martinet's research, various other research projects have followed. Besides the fact that the majority of the studies that have been carried out were cross-sectional, there are not many studies that were either focused on or have taken into account the first two years of life. Most of the (mixed-)longitudinal studies that have been done only have a small number of children participating.

On a 3 yearly interval from 1960-1977 De Wijn et al measured 8 year old children in different parts of The Netherlands [35]. A comparison was made between the various generations in both sexes and, as was to be expected, an upward shift in height was noticed in both sexes $(2.3 \mathrm{~cm}$ in boys and $2.6 \mathrm{~cm}$ in girls). There was also an upward shift in weight noticeable; $1 \mathrm{~kg}$ in boys and 1.4 $\mathrm{kg}$ in girls. These upwards shifts had occurred mostly during the 1960-1974 period; after that time weight had stayed the same and the gain in height was only limited ( 1 to $2 \mathrm{~mm}$ ) [35]. From 1969 to 1975 Griffioen and De Boer had performed a mixed longitudinal growth study in Marken on 397 children from birth till the age of 6 years. Marken is a small village in The Netherlands with a very intimate community. Marriages amongst blood relations are common. The purpose of this research was to detect the influence of inbreeding and endogamy on the growth of the descendants. Therefore this research is not representative for Dutch children in general [36]. Another mixed-longitudinal study was performed at the department of orthodontics in Utrecht from 1970 till 1972. In total 1132 children ( 504 boys and 628 girls) were followed in overlapping age groups of approximately 2 years from 8 to 17 years old. This study was focused on the skeletal maturation and skin fold thickness in this age group, but length and weight were measured too [37]. The Nijmegen study, performed from 1971 till 1975 was another mixed-longitudinal study with 486 children, from the city of Nijmegen, participating in overlapping age groups of approximately 4 years 
from 4 to 14 years old [38]. One particular and well-known study conducted by Stein and co-workers, was to determine the influence of famine on growth. During the war, the people in the central part of The Netherlands experienced a distinct period of famine: The Dutch Hunger Winter. Infants of mothers who suffered starvation during the last three months of their pregnancy were smaller and lighter at birth but by the age of 19 this group was found to have completely recovered. There were no significant differences in height, weight or mental ability between the group who were undernourished during their foetal development and those who were not. So the conclusion was drawn that as long as post-natal nutrition is adequate and the foetal undernutrition is not accompanied by exposure to noxious substances, the effect on the mature height is not significant [39].

The most extensive research projects that have been carried out were in 1980 and in 1995. It's the Third and Fourth National Growth Survey of The Netherlands. They give the best representation for the whole of the country. In the 1980 survey a total of 42,000 children between birth and 19 years old participated in this cross-sectional study. Length, weight, head-circumference (in infants) and the sexual maturation amongst adolescents were measured [30]. This research is a sequel to two previously held national surveys; in 1955 when only length and weight were measured [40] and in 1965 when length, weight and sexual maturation were measured [41]. The Fourth National Growth Survey is a sequel to the 3 previous ones. This transversal study started in 1996 and collected data of 14507 Dutch children between the age of 0 to 21 years ( 7484 boys and 7023 girls) [31]. In 1979 and 1980 Gerver performed a cross-sectional survey in Oosterwolde: a small city in the north of The Netherlands. From birth till the age of 18 children were being measured once. At the various ages between 17 and 59 boys were measured and between 19 and 56 girls. Various anthropometric measurements were taken; height, sitting height, arm span, length of arm and hand, tibial length, foot length, biacromial diameter, biiliacal diameter, weight, head-circumference, upper-thigh circumference, calf circumference and upper arm circumference. The study is mostly a descriptive study of various parameters [42].

\section{$\S 1.5 .4$ Growth studies outside The Netherlands}

Outside The Netherlands, numerous longitudinal and cross-sectional growth studies have been performed. The aims of these studies have been various; the purpose was not only to develop standards for certain populations or races, but also to detect the influences on growth. For example; the growth of premature infants and twins [43] [44] [45] and the influence of diseases, environment and genetics on growth [46] [47] [48] [49] [50] [51] [52]. Besides the growthstandards for various European countries, some researchers have even looked into the growth of European descendants in Australia, Asia, Africa and America or vice versa [53] [54] [55] [56]. In the various researches different ages and age-groups have been investigated. As this thesis is focused on the first two 
years of life, only those international projects that include (partly) that agegroup will be discussed.

There was a great period between 1920 and 1932 in the USA in which over nine major longitudinal growth studies were initiated. In addition to better quantification of amounts and rates of growth of healthy children, these studies made use of new technologies to characterize the biological maturation of body systems. A second period followed from 1944 till 1960 in which European countries contributed by performing many outstanding studies. Eventually Tanner and Cox set up an archive of longitudinal growth data [57]. This archive includes the Harpenden Growth Study, The Aberdeen Growth Study, The Oxford Child Health Survey and the International Children's Centre Study London.

Several large and long-term studies have been initiated in the USA. These studies were interdisciplinary. They approached the 'whole child' by including among others, physicians, psychologists and anthropologists. These studies were fastidious in terms of the methodology of the data collection. They collected data as a purpose in itself without posing an hypotheses first. These studies continued for at least 15 years and ended when either funding disappeared or there was no longer a justification for the data collection [58]. There is however, one exception to the rule and that is the Fels Longitudinal Study. It began in 1929 and still continues. The sample consists of healthy, wellnourished boys and girls living in small urban communities and rural areas of south-western Ohio. Length, weight, and a variety of other physical and psychological characteristics are measured once a year from the participants [59, 60]. The earliest of the twentieth-century European studies was the longitudinal Aberdeen Study. In 1923 Professor Low took 21 measurements on 900 newborn babies and had a follow-up of 65 boys and 59 girls, who he measured every birthday till the age of 5 in 1927 [61]. Unfortunately this material was never analyzed by Low. In 1953 Whitehouse remeasured 42 of the boys and 38 of the girls and correlations between the measurements at various ages and mature values were calculated [62].

Between 1944 and 1947 about 470 children were recruited to participate in the Oxford Child Health Survey. They were measured 12 times till the age of 5 . At the end of this longitudinal study 375 children were still participating. Besides anthropometric measurements, radiographs of hand and wrist, knee and chest and sometimes hip and skull were taken too. It was the radiographs of the hands that laid the foundation for the determination of skeletal age, by Acheson. He gave scores for the various stages of maturation for every single bone in the hand. Tanner and Whitehouse have expanded this method with information from the Harpenden Growth Study (see below) to the now still clinically used Tanner-Whitehouse-method for assessing skeletal maturation.

In total some 450 boys and 260 girls participated in the mixed longitudinal Harpenden Growth Study which was held from 1948 - 1971. On every child, height, sitting height, hip, shoulder, elbow and knee widths, circumferences of upper arms, calf and thigh, foot length, weight and four skin folds were taken 
by one and the same person [63] [64] [65] [66]. Although the majority of children were over 3 years old when entering the study and therefore not comparable with this Maastricht study, it would be careless not to mention this classic and pioneering study. After all it was the first long-term longitudinal study set up in England and most of the European studies on physical growth were largely derived from the experiences of the Harpenden Study. During this study various tools for anthropometric measurements were developed with greater accuracy and convenience; i.e. the Harpenden infantometer, the Harpenden stadiometer and the Harpenden skin fold caliper [67]. This equipment is still used and an infantometer similar to the Harpenden infantometer was used in the Maastricht study. For The International Children's Centre Study in London between 1951 and 1954 some 224 children were recruited at birth of whom $40 \%$ were successfully followed until their growth was completed and the study finally closed in 1974. One of the largest longitudinal studies from birth to maturity began in 1954 in Zurich. Of the 415 children entering the study (206 boys and 209 girls) 222 were still participating as adults. One of the first publications from this study was focused on increase in height, weight and head-circumference during the first 4 years of life [68] [69]. They were also the first ones to use smoothing spline functions to estimate individual growth curves [70].

In the same year as the Zurich study, the Stockholm study began. Starting with 212 infants of which $80 \%$ were still being followed up after 18 years. Besides growth, ages of menarche and the 5 pubertal stages were determined. The Brussels study is an example of a study in which various influences on growth were investigated. Five socio-economic groups were compared. In the 80 's a semi-longitudinal growth study was performed in Spain (Bilbao) in which some 100 children participated from the age of 3 months till 14 years [71]. A total of 497 children were recruited into the Paris study between 1953 and 1955 but only 119 of them were still available for measurement at the age 16 [72] [73] [74] [75]. And finally Brandt did a follow-up in Dortmund from birth to 5 years of age [76]. More recently a longitudinal study has been carried out in 5 towns in North, South and Central Italy from1973 till 1981. Weight, length and headcircumference standards from 0 to 3 years of age, were developed from a set of 10,414 singletons (4,861 girls and 5,553 boys)[77]. A longitudinal study was performed in Lublin, Poland, from 1964 till 1986 [78, 79] [80]. In 1996 this study was used to study the effect of determinants of growth in body length from birth to 6 years. A very comprehensive longitudinal study which is still in progress but regularly published and updated in reports is being performed in Zaragoza (Spain) at the "Centro Andrea Prader". The children are now over 15 years of age and still being followed up. Over 20 measurements are taken from these children; besides the basic anthropometric measurements like the supine length, subischial leg length, crown-rump length, head circumference and body weight, skin folds, pubertal stages, bone mass, bone maturation and various diameters are measured [81]. 
A cross-sectional study focused on the first couple of years of life is the national study in Denmark. This study was performed between 1973 and 1977 and measured 225 boys and 225 girls between the ages of 0 till 6 [82]. Between 1979 and 1987 children from birth till the age of 16 were measured in Jena, Germany [83]. In Warsaw a small cross-sectional research was conducted and children up to the age of 18 participated [84]. One of the biggest studies comes from Norway (Bergen) in which 3000 children participated up to the age of 4 [85]. Crosssectional standards for crown-heel and head-circumference at birth were based on 16,336 neonates born in six town in North, Central and South Italy, between 1973 and 1981 [86].

\section{$\S 1.6$ Conclusion}

As pointed out in this chapter there are various legitimate reasons for regional growth charts, besides the existing national growth charts, so as to depict a more reliable growth chart, a longitudinal study is preferred compared to a cross-sectional study. The aim is to implement these charts into the paediatric clinics and infant health care centres of the Southern region of the Netherlands, and perhaps even in the EuroRegion to evaluate the growth of these children more reliably, as they are compared with their peers. As physicians are no longer restricted to only evaluating supine length, weight and/or head circumference vs. age, they can evaluate various correlations and possible growth disorders can be detected earlier. And early diagnoses are more likely to give better outcomes. 


\section{References}

1. Tanner, J.M., Foetus into Man: physical growth from conception to maturity. second ed. 1989, London: Castlemead publications. 280.

2. Eveleth, P.B. and T. J.M., Worldwide variation in human growth. Second ed. 1990, Cambridge: Cambridge university Press. 397.

3. Roede, J.M. and feb/mrt, De groeiende mens. Prana, 1995. 87: p. 21-32.

4. Lampl, M., et al., Saltation and stasis: A model of human growth. Science, 1992. 258: p. 801-803.

5. Roede, M.J., A Dutch Precursor on Human Biology. Humanbiol. Budapest, 1985. 16: p. 139-151.

6. Bogin, B., Patterns of Human Growth. 2nd ed. Cambridge studies in biological anthropology, ed. R.A. Foley and N.G. Jablonski. Vol. 23. 1999, Cambridge: Cambrdige University Press. 455.

7. Barker, D.J.P., Fetal and infant origins of adult disease. 1992, London: Britisch Medical Journal. 343.

8. Barker, D.J.P., et al., Growth in utero, blood pressure in childhood and adult life, and mortaility from cardiovascular disease. Britisch Medical Journal, 1989. 298: p. 564-567.

9. Cameron, N., The methods of auxological antropometry, in Human growth: a comprehensive treatise, F. Falkner and J.M. Tanner, Editors. 1986, Plenum Press: New York \& London. p. 3-43.

10. Tanner, J.M., A history of human growth. 1981: Cambridge University Pres.

11. Hauspie, R., G. Lindgren, and F. Falkner, Foreword, in Essays on Auxology: presented to James Mourilyan Tanner by former colleagues and Fellows, H. R., G. Lindgren, and F. Falkner, Editors. 1995, Castlemead Publications: Welwyn Garden City. p. 552.

12. Marshall, W.A., Human growth and its disorders. first ed. 1977, London: Academic press Inc. Ltd. 179.

13. Pomerance, H.H., Growth Standards in Children. 1979, Hagerstown: Harper \& Row Publishers, Inc. 217.

14. Tanner, J.M., R.H. Whitehouse, and M. Takaishi, Standards from birth to maturity for height, weight, height velocity and weight velocity; British children, 1965. Archieves of Disease in Childhood, 1966. 41: p. 454-471:613-635.

15. Preece, M.A., Standardization of growth. Acta Paediatr. Scand. Suppl., 1989. 349: p. 5764.

16. Tanner, J.M. and W.J. Israelsohn, Parent-child correlations for body measurements of children between the ages of one month and seven years. Annals of Human Genetics, 1963. 26: p. 245-259.

17. Tanner, M.J., Use and abuse of growth standards. 2 ed. Human growth: A comprehensive treatise, ed. F. Falkner and J.M. Tanner. Vol. 3. 1986, New York \& London: Plenum Press. 95-109.

18. Fomon, S.J. and September, Reference data for assessing growth of infants. The Journal of Pediatrics, 1991. 9/21/30808: p. 415-416.

19. Martinet, J.F., Verwisselingen der Evenredigheden. Katechismus der Natuur II: Geboorte en groei van den Mensch, ed. J. Allart. 1778, Amsterdam.

20. Tanner, J.M., Physical Growth From Conception to Maturity. 1979, Harvard University Press: Cambridge. p. 37-51. 
21. Thompson, D.A.W., On Growth and Form. Revsied edn ed. 1942, Cambridge: Cambridge University Press.

22. Quételet, A., Anthropométrie, ou mésure des différentes facultés de l'homme. 1870, Brussel: Muquardt.

23. Quételet, A., Sur l'homme et le développement de ses faculté, ou essai de physique sociale. 1835, Paris: Bachelier.

24. Tanner, J.M., ed. A concise history of growth studies from Buffon to Boas. Humn Growth, ed. J.M. Tanner and F. Flkaner. Vol. 3. 1979, Plenum Press: New York. 515-593.

25. Goldstein, H., Measuring the stability of individual growth patterns. Annals of Human Biology, 1981. 8: p. 549-557.

26. Molinari, L, et al., Child-adult correlations for anthropometric measurements, in Essays on Auxology: presented to James Mourilyan Tanner by former colleagues and Fellows, R. Hauspie, G. Lindgren, and F. Falkner, Editors. 1995, Castlemead Publications: Welwyn Garden City, p. 552.

27. Bowditch, H.P., The growth of children, studied by Galton's method of percentile grades. 1891, boston: Wright \& Pooter.

28. Habicht, J.-P., et al., Height and weight standards for preschool children. How relevant are ethnic differences in growth potential. Lancet, 1974. I: p. 611-615.

29. Warrington, S. and D.H. Storey, Comparative studies on asian and caucasian children I: growth. European Journal of Clinical Nutrition, 1988. 1988(42).

30. Roede, M.J. and J.C. van Wieringen, Growth Diagrams 1980, Netherlands Third Nationwide Survey. Tijdschrift voor Sociale Gezondheidszorg, supplement, 1985. 63(supplement 1985): p. 1-34.

31. Frederiks, A.M. Nederlandse Groeidiagrammen 1997: in historisch perspectief. in De vierde landelijke groeistudie (1997); Presentatie nieuwe groeidiagrammen. 1998. Den Haag: Bohn Stafleu Van Loghum.

32. WHO Working group on infant growth, N.U., An evaluation of infant growth: A summery of analyses performed in preparation for th WHO Expert Committee on "Plrysical Status; The use and interpretation of anhtropometry., in Doc WHO/NUT/94.8. 1994, WHO: Geneva.

33. Burgmeijer, R.J.F. and J.C. Wieringen van, Secular changes of growth in The Netherlands. Secular changes in Europe, ed. B.É. Bodzsar and C. Susanne. 1998, Budapest: Eötvös Univ Press. 233-262.

34. Frederiks, A.M., et al., Continuing Positive Secular Growth Changes in The Netherlands 1955-1997. Pediatric Research, 2000. 47(3): p. 316-323.

35. Wijn de, J.F., 1981.

36. Griffioen, F.M.M. and W. Boer de, Groei van Kinderen van 0-6 jaar op Marken. 1981, Universiteit van Amsterdam.

37. Venrooy - Yselmuiden van, M.E., Growth and maturation of Dutch children: A mixed longitudinal study, in Dept of Orthodontics. 1978, Rijksuniversiteit Utrecht: Utrecht. p. 134.

38. Prahl-Andersen, B., The conduct of the Nijmegen growth study. A mixed-longitudinal interdisciplinary study of growth and development, ed. B. Prahl-Anderson, C.J. Kowalski, and P.H.J.M. Heyendael. 1979, New York: Academic Press. 61-70.

39. Stein, Z., et al., Famine and human development: the Dutch Hunger Winter of 1944-1945. 1975, New York: Oxford University Press.

40. Wijn de, J.F. and J.H. Haas de, De 1960 Groeidiagrammen van 1 - 25 jarigen in Nederland. Verhandelingen Nederlandsche Instituut voor Preventieve Geneeskunde, 1960. 49: p. 30pp. 
41. van Wieringen, J.C., et al., Growth diagrams 1965, Netherlands. 1971, Groningen: Walters-Noordhoff Publishing.

42. Gerver, W.J.M., Measurement of the body proportions in children, in Paediatrics. 1988, Thesis, Rijksuniversiteit Groningen: Groningen. p. 187.

43. Wilson, R.S., Concordance in physical growth for monozygotic en dizygotic twins. Annals of Human Biology, 1976. 3: p. 1-10.

44. Osborne, R.H. and F.V. DeGeorge, Genetic basis of morphological variation: an evaluation and application of the twin study method. 1959, Cambridge, Massachusetts: Harvard University Press.

45. Falkner, F., ed. Implication for growth in human twins. Human Growth, ed. F. Falkner and J.M. Tanner. Vol. 1. 1978, Plenum: New York.

46. Rosenbaum, S., et al., A survey of heights and weights of adults in Great Britain. Annals of Human Biology, 1985. 12: p. 115-127.

47. Schmitt, L.H. and G.A. Harrison, Patterns in the within-population variability of stature and weight. Annals of Human Biology, 1988. 15: p. 353-364.

48. Smith, A.M., S. Chinn, and R.J. Rona, Social factors and height gain of primary school children in England and Scotland. Annals of Human Biology, 1980. 7: p. 115-124.

49. Elwood, P.C., et al., Growth of children 0-5 years with special reference to mothers smoking in pregnancy. Annals of Human Biology, 1987. 14: p. 543-558.

50. Livshits, G., Growth and development of body weight, height and circumference during the two years of life: quantitative genetic aspects. Annals of Human Biology, 1986. 13: p. 387-396.

51. Fischbein, S. and N.L. Pederson, Multivariate analysis of genetic and environmental influences for longitudinal height and weight data. Acta Geneticae Medicae et Gemollogiae, 1987. 36: p. 171-182.

52. Byard, P.J., R.M. Siervogel, and A.F. Roche, Age trends in transmissible and nontransmissible components of family resemblance or stature. Annals of Human Biology, 1988. 15: p. 111-119.

53. Stinson, S., The effect of a high altitude on the growth of children of high socioeconomic status in Bolivia. American Journal of Physical Anhtropology, 1982. 59: p. 61-72.

54. Greksa, L.P., H. Spielvogel, and E. Caceres, Effects of altitude on the physical growth of upper-class children of European ancestry. Annals of Human Biology, 1985(12): p. 225232.

55. Foster, T.A., et al., Anthropometric and maturation measurements of children ages 5 to 14 years in a biracial community - the Bogalusa Heart Study. American Journal of Clinical Nutrition, 1977. 30: p. 582-591.

56. Gracey, M. and N.E. Hithcock, Studies of growth of Australian infants, in Nutritional Needs and Assessment of Normal Growth, M. Gracey and F. Falkner, Editors. 1985, Nestle Nutrition, Vevey/Raven Press: New york.

57. Tanner, J.M. and C. L.A., London archive of longitudinal growth data. Annals of human biology, 1986. 13(2): p. 179-182.

58. Roche, A.F., S.S. Guo, and B. Towne, Opportunities and difficulties in long-term studies of growth. Int J Sports Med, 1997. 18(suppl): p. S151-S161.

59. Roche, A.F., Maturation and Body Composition: The Fels Longitudinal study 1929-1991, in Maturation and Body Composition: The Fels Longitudinal study 1929-1991. 1992, Cambridge University Press: Cambridge.

60. Roche, A.F., Recent work on growth, maturation and body composition: A personal retrospective. Acta Med. Auxol., 1992. 24: p. 137-147.

61. Low, A., Mensurements of infants at birth. Annals of Eugenics, 1950. 15: p. 210-218. 
62. Tanner, J.M., et al., Aberdeen growth study I, The prediction of adult body measurements from measurements taken each year from birth to five years. Archives of disease in childhood, 1956. 31: p. 372-381.

63. Marshall, W.A. and J.M. Tanner, Variation in the pattern of pubertal changes in girls. Archives of disease in childhood, 1969. 44: p. 291-303.

64. Marshall, W.A. and J.M. Tanner, Variation in the pattern of pubertal changes in boys. Archives of disease in childhood, 1970. 45: p. 13-23.

65. Marubini, E, et al., The fit of Gompertz and logistic curves to longitudinal data during adolescence on height, sitting height and biacromial diameter in boys and girls of the Harpenden Growth Study. Human Biology, 1972. 44: p. 511-524.

66. Tanner, J.M., et al., The adolescent growth spurt of boys and girls of the Harpenden Growth Study. Annals of human biology, 1976. 3: p. 109-126.

67. Tanner, J.M., A history of the study of human growth. 1981, Cambridge: Cambridge University Press.

68. Heierli, E., Longitudinale Wachstumstudien: Resultate von Länge, Gewicht und Kopfumang in den ersten vier Lebensjahren. Helvetica paediatrica acta, 1960. 15: p. 311-335.

69. Prader, A. and H. Budliger, Body measurements, growth velocity and bone age of healthy children up to 12 years of age (longitudinal growth study Zurich). Helvetica Paediatrica Acta, 1977. Supple(37): p. 5-44.

70. Largo, R.H., et al., Analysis of the adolescent growth spurt using smoothing spline functions. Annals of Human Biology, 1978. 5: p. 421-434.

71. Hernandez, M., et al., eds. Curvas de Cremiento. ed. Garsia. 1985: Madrid.

72. Roy-Pernot, M.-P., Etude longitudinale sur l croissance de l'enfant. Résultats de quelques mésures somatiques efféctives pendant les tois premiers années de la vie. Archives françaises de pédiatrie, 1959. 16: p. 202-214.

73. Sempé, M., C. Tutin, and N. Masse, -P., La croissance de l'enfant de 0 à 7 ans. (Mésures pratiquées sur des enfants de la région parisienne de 1953-1962.). Archives françaises de pédiatrie, 1964. 21: p. 111-134.

74. Roy-Pernot, J.-M., et al., Evolution clinique de la puberté de la fille. Archives française de pédiatrie, 1972. 29: p. 155-168.

75. Roy-Pernot, J.-M., M. Sempé, and A.-M. Filliozat. Rappor d'activité terminal de l'équipe française. in Supplement to: Compte rendu de la 13ieme Réunion des Equipes Chargées des Etudes sur la croissance et le Dévelopment de l'Enfant Normal. 1976. Paris; Centre International de l'Enfance.

76. Brandt, I., Perzentilkurven fur das Längenwachstum bei Früh- und Reif gebornen inden ersten fünf Jahren. Der Kinderarzt, 1980. 11: p. 43-51.

77. Cortinovis, I., A. Bossi, and S. Milani, Longitudinal growth charts for weight, length and head-circumference of Italian children up to three years of age. Acta Med. Auxol, 1993, 25: p. 13-29.

78. Hauspie, R.C., et al., Determinants of growth in body length from birth to 6 years of age: a longitudinal study of Lublin children. American Journal of Human Biology, 1996. 8: p. 21-29.

79. Schrzastek-Spruch, H., Longitudinal study on physical development in Lublin infants. Prace i Materialy Naukaukow, 1968. Instytut Matki I Dzicka(11): p. 65-76.

80. Schrazastek-Spruch, H. and J. Stachyra, Longitudinal studies of psychophysical development of children 1 - 7 years. Stud. Hum. Ecol., 1986. 7: p. 177-188.

81. Longás, A.F., Estándares longitudinales normales del crecimiento de los ñinos aragonesis. 1994, Centr "Andrea Prader": Zaragoza.

82. Andersen, E., et al., Hojde og vaegt hos danske born. Ugeskrift vor Laeger, 1982. 144: p. 1760-1765. 
83. Hesse van, V., unpublished, 1981.

84. Kurniewicz-Witczakowa, R., et al., Rozwoj Fizycyny Dzieci I Mlodzieizy Warszawkiej. 1983, Warsaw; Poland: Institute of Mother and Child.

85. Knudtzon, J., et al., eds. Growth data for Norwegian children 0-4 years and new clinical growth charts. Auxology '88: Perspectives in the Science of Growth and Development, ed. J.M. Tanner. 1989, Smith Gordon: London.

86. Bossi, A. and S. Milani, Italian standards for crown-heel length and head-circumference at birth. Annals of Human Biology, 1987. 14(4): p. 321-335. 


\section{Chapter II: Growth}

Height, foot length, head-circumference are areas, when we were kids, kept growing along with everything else and then just stopped. No warning. No fanfare; they just hit a number and stayed there. And back when we were children, getting bigger was a good (!) thing. You were proud to be expanding. You showed off your progress. "Look - I'm over four feet already." Then one day you notice you've been wearing the same sizes several years in a row, and you realise, "I guess I'm done. This is who I am. Five foot ten, and not an inch more. $I^{\prime} m$ 5'10", 91/2 shoe. Forever. That's me "I think it would have been nice to know about it when it happened. You could have had a party. "Hey, what's everybody celebrating?"

"I finished growing."

"Well, congratulations!! How'd you make out?" "Five seven and a half, size eight in a dress shoe." 


\section{$\S 2.1$ Introduction}

The basic distinction between a paediatrician or a youth health doctor and other physicians is the fact that the first are dealing with human beings that are growing. Growth and maturation begin at the moment of conception and cease with the end of puberty. Specific issues arise during this very dynamic period. After all, the new-born infant must successfully make the transition from a regulatory system, largely dependent on characteristics of the maternal organism to one based on its own mechanisms; its genes and hormones [1]. The growth pattern before and after birth also seems to be related to diseases in adults, as diabetes mellitus, hypertension, cardiovascular diseases and hypercholesterolemia [2-4]. Under proper circumstances, the growth of a child follows an extraordinary regular path, so much so, that the rate of growth is one of the indices of a child's general health [5]. In a model proposed by Tanner in 1963, for the biological regulation of human growth, he suggested that growth is target seeking and self-stabilizing [6]. Basically growth occurs by means of changes in cell number and size [7]. Human growth is related to evolutionary biology, bio cultural factors, intrinsic and extrinsic factors, such as genes, hormones, the physical and social environment and mathematics $[6,8]$. As this thesis focuses on normal growth, this chapter will shed some light on the processes that lay the foundation of a child's physical growth.

\section{$\S 2.2$ Somatic Growth of the Foetus}

Ancient, Classical and Medieval scholars have written a great deal on human growth and development prior to birth. Some of this was undoubtedly based on observation of human and non-human foetuses, but more so, it was a result of imagination, myth and wishful thinking [6]. Growth of the embryo, foetus and child is a multifaceted process. Essentially, it adds up cell replication, hypertrophy and differentiation, and the ordered migration of cells to defined anatomical sites to develop into organs [9]. Every stage of the growth process is influenced by different factors. The period of prenatal growth is vitally important to the child's future well-being [10]. Unfortunately, while this is the period in which the foetus is the most vulnerable to outside influences, the examination of the foetus is hard. Besides foetal factors, prenatal growth is mostly influenced by maternal, genetical and placental factors [7]. In his study HustonPresley looked into factors associated with foetal growth and body composition as measured by ultrasound [11]. The objective was to determine which parental demographic and metabolic factors correlated best with foetal growth and body composition as estimated by ultrasound. The abdominal subcutaneous fat and/or thigh subcutaneous fat thickness was measured and an estimation was 
made of the foetal weight. The independent variables included diagnosis of gestational diabetes, parental demographic factors, sex and late gestation estimates of carbohydrate metabolism. The strongest predictor of ultrasound estimated foetal weight, was found to be the basal hepatic glucose production, followed by late gestation insulin sensitivity. The strongest predictors of abdominal subcutaneous fat thickness were weight gain and presence of gestational diabetes. Factors other then maternal carbohydrate metabolism further explain the variances of foetal adiposity [11].

Both the wet and dry weight of placentas correlate significantly with birth weight [12]. Placental weight is correlated to nutrient intake during pregnancy; surprisingly the placental weight is higher, close to term. Maternal nutrient restriction over the period of rapid placental growth results in a larger placenta and a lower foetal to placental weight ratio $[13,14]$. Maternal factors are various. Small mothers tend to have smaller babies. Location of body fat stores affects a variety of metabolic processes in women, and some of these could affect the foetal growth during pregnancy. The waist to hip circumference ratio (WHR), can be an indication of the location of these fat stores [15]. The Diana Project looked at the maternal WHR as a predictor of newborn size and found that a 0.1 unit increase in WHR predicts a 120 gram greater birth weight; a 0.2 inch greater length and a $0.3 \mathrm{~cm}$ greater head-circumference. [15]. A lot of research has been done on the genetical influences. How genetic control of foetal development is exercised is given in a model by Roberts. According to this model, the embryonic and foetal development occurs as a result of switch mechanisms, switching on and off the activity of particular genes at specific times in the development, and so producing specific substances. So, variations in foetal growth and development, as well as intrinsic malformations, may arise by variation in efficiency or failure of the switching mechanism, variation in its timing and variations or errors in the substances synthesized [16]. According to Falkner, genetical influences on the variance in foetal growth are thought to be about $20 \%$ maternal, $20 \%$ intrinsic foetal, 5 to $10 \%$ paternal, and the rest 'nonnutritional' [17]. In a research conducted by Penrose, it was stated that the contribution of the foetus's own genes in determining its size at birth is small and the contribution of maternal factors, being either environmental or genetical, is overwhelming. He concluded that some $38 \%$ of the variation between different individual birth weights was by means of heredity. This heredity factor was made up of $16 \%$ foetal heredity, $2 \%$ foetal sex and $20 \%$ maternal hereditary. The remaining bulk of $62 \%$ was caused by environmental factors. These were divided into: mother's general health and nutrition $(18 \%)$, mother's health during the pregnancy $(6 \%)$, mother's parity $(7 \%)$, mother's age $(1 \%)$, unknown intrauterine influences, posture, etc. $(30 \%)$ [18]. The genetic control of the foetal growth seems to involve loci widely distributed through the various autosomes. It is unclear how the sex chromosomes contribute to the foetal growth. No alteration in foetal growth is noticeable in individuals with excess material of the $\mathrm{X}$ or $\mathrm{Y}$ chromosome (even three, four and more $\mathrm{X}$ chromosomes and two 
$\mathrm{Y}$ chromosomes cause no alteration in intra-uterine growth). The exception is the $\mathrm{XO}$ aberration (Turner syndrome), which is almost always associated with a reduced growth rate [16] continuing after birth. Other alternations will have an (visable) impact on the growth and development mostly after birth. The crownrump length in these foetuses is severely retarded compared to normal foetuses of the same gestational age [19]. However, when a karyotype is found indicating a specific chromosome defect, it is possible to make a rough prediction on the errors of growth and development in this patient without having seen him [16]. It's a challenge to determine exactly which influences dominate at each stage of foetal and placental growth [20].

Basically, there are many genes involved, and many of these are pleiotropic. There is an interaction of quantitative and qualitative control. Genetic control is partly exercised by switch mechanisms activating and deactivating a succession of genes with a tissue specific effect. These effects are time specific and temporal variations do not coincide in all tissues [16]. The growth during pregnancy has been described in various cross-sectional studies. The draw back of most of these studies is that anthropometric measurements have been taken of foetuses after intrauterine death or after (spontaneous) abortions [21-23] and of viable (preterm) neonates [24] [25] [26, 27] [28] [29]. These data are used to construct the curves. It can be discussed if these data are representable to use for the construction of the curves, as there is not an equal distribution over the period of time. Besides the fact that there is a chance that these infants have suffered an adverse event that has caused them to be aborted or be born prematurely, implies that their growth is not necessarily normal and therefore representable. This implies the risk for an underestimation of the incidence of intrauterine growth retardation [30].

The growth during pregnancy can be followed using ultrasound measurements. A number of studies have assessed the validity of ultrasonic monitoring and it was concluded that they are more reliable than the fundal height measurements [30]. The growth process can be divided into three stages: the three trimesters. The first trimester is characterized by the increase in the number of cells. This period is important for the differentiation of the homogeneous group of cells into regions, which will eventually develop into organs [10]. Any disturbance during this crucial time will most likely result in a spontaneous abortion [7]. During the second trimester there is a stable cell division rate together with hypertrophy of cells. In the third trimester the cells keep on increasing in size, but the rate of the cell division diminishes [7]. Bare in mind that the first two trimesters are needed to develop a foetus with a weight of approximately $1.5 \mathrm{~kg}$, which is half the weight of the birth weight of an infant. Of this $1.5 \mathrm{~kg}$, $50 \mathrm{~g}$ is fat. Most of the increase in weight, in the first two trimesters, is due to protein build-up in the main body cells. The next $1.5 \mathrm{~kg}$ is acquired in the final trimester of the pregnancy, which gives a total birth weight of about $3 \mathrm{~kg}$ of which $500 \mathrm{~g}$ is energy storage in the form of fat [17]. But the increase is also 
depending on the BMI of the mother. Foetal growth rate is slower in the first two trimesters and faster in the third, for women with a low BMI, compared with women with an average BMI [31]. But alternatively foetal and placental metabolisms have certain characteristics which appear to bridge species differences [32]. There is actually a period of peak height velocity in foetal growth as in human adolescence. The gestational period at which this occurs is estimated to be somewhere between 20 and 24 weeks of gestation. This is followed by a period of linear deceleration of growth velocity, which joins the infant's postnatal deceleration of velocity at birth. Weight gain of the foetus follows basically the same pattern, except that the peak weight velocity occurs at 32 to 34 weeks of gestation. At the beginning of 34 to 36 weeks of gestation, the foetal growth slows down due to the size of the uterus which restricts further growth as does the functionality of the placenta. This phenomenon is obvious in twin pregnancy, where the growth slows down earlier, around the time that the combined weight of the twins is approaching that of a 36-week single foetus [17]. Abnormal slowing of the cell division rate and/or disturbance of the cell hypertrophy process will result in a growth retarded infant at birth. This is called intrauterine growth retardation (IUGR). The earlier the IUGR occurred during the pregnancy the less likely it will be reversible. A way of describing the IUGR infant at birth is by means of its shape. Chronic growth retardation produces a short underweight infant: a proportionate IUGR baby. Although the peak weight velocity drops after the age of 34 weeks mainly due to uterine constraint, the foetus still doubles its body weight in the last trimester [7]. So an acute growth arrest at the end of the pregnancy will result in a long, skinny baby: a so-called disproportionate IUGR baby [10]. The outcome at birth serves as a long-term prediction of development [33]. For instance, there is a significant correlation between IUGR and neonatal mortality. Of infants born between 34 and 36 weeks of gestation with weight on the 10th centile for their age, 74 in 1,000 will die, while only 3.8 in 1,000 will die if weight is on the 90 th centile. At the ages between 40 and 42 weeks of gestation these numbers are 3.7 and 1.4 respectively [34]. Infants born with a birth weight below $1500 \mathrm{~g}$ account for $1 \%$ of all live births, but provide $50 \%$ of perinatal deaths [35]. But babies born with an umbilical artery $\mathrm{pH}<7$ are also at greater risk to experience considerable short-term morbidity [36]. So although the World Health Organization discerns low-, very low-, and extremely low birth weight infants only by means of their birth weight $(2500 \mathrm{~g}, 1500 \mathrm{~g}$ and $1000 \mathrm{~g}$ respectively), it is more accurate to relate birth weight to gestational age of the infant. This gives the large for gestational age infants (LGA) being those that are on or above the 90th centile for their age and small for gestational age infants (SGA) if they are on or below the 10 th centile. In between these centiles infants are referred to as appropriate for gestational age (AGA). Each of these three groups of infants show a different growth pattern during their first year of life [37]. Patterns of disproportionate foetal growth are associated with cardiovascular disease in adult life. Protein restriction during pregnancy is known to impair foetal growth and is associated with increased systolic blood pressure in later life [3]. Early detection, prefera- 
bly non invasive, of foetal growth retardation is crucial. This allows for interventions and strategies in the treatment of the foetus. In her animal study Jones showed that foetal growth retardation can be detected non-invasively by ultrasound after approximately 5 weeks of exposure to heat stress. Foetal growth continues throughout gestation but at a slower rate than normal and according to a pattern similar to that observed in asymmetrically growth retarded human foetuses [38]. Unfortunately the predictive value of Doppler ultrasonography is less for long-term growth and neurodevelopment than for perinatal outcome in the high risk foetus [39]. Meier stated that there is an inverse relation of foetal heart rate to body mass in adult mammals; while the heart rate of immature foetuses is unrelated to body mass and approximately constant among different species. With maturation, the foetal heart rate decreases in a large mammal but tends to increase in a small mammal. These maturational changes reduce the difference between the heart rate of a term foetus and the heart rate which is "appropriate for body mass" [40].

The growth velocity of body mass and length increases are greater at 32 weeks gestation than at any subsequent period of an individual life, that includes puberty. Growth of length consists of the growth of the head, trunk and the long bones of the legs. During the prepubertal stage of life the head size increases most rapidly after 28 weeks gestation but the growth velocity ceases before the age of 2 years. The trunk increases during the same period but it continues to grow at a slower rate from 2 years onwards, till the end of puberty. The legs grow mainly during the last 14 weeks of gestation and the first 6 months of life [41]. The culmination of foetal growth and the beginning of the postnatal phase are represented by birth weight [16]. One other important issue to take into account when evaluating the growth of infants is the difference in gestation. A one-month old infant born after a pregnancy of 36 weeks cannot be compared with a one-month infant after a 40 weeks pregnancy. During the first two years of life, this difference in gestation should be corrected for [37]. The best way to do this is to use the biological age. One uses the gestational age of the infants and continues counting after birth. So in the above example, if both children have a calendar age of 4 weeks, the first infant has a biological age of 40 weeks, while the other has a biological age of 44 weeks. Over the period of two years this difference will gradually dissolve. There is general consensus that infants born with a growth retardation will catch-up in the first two years of life. If they have not caught up in those two years, it's unlikely that they will after this period. The same goes for premature infants. By the age of two years, they can be compared with all two-year-olds, independently of the duration of the pregnancy [37]. The overall question that remains is 'what is normal'. Up till now it is assumed that small for gestational age or premature infants have to have a (fully) catch up growth and eventually follow the normal growth curve. But it might be that these infants will have their own growth pattern and a full catch up growth does not exist within this group. There is not a general consen- 
sus or definition for catch up growth for these infants, other then a growth that regresses to the mean.

\section{§2.3 Somatic Growth of the Infant}

Growth during the postnatal phases is basically a continuation of the growth during the foetal phase, yet the problems are different [16]. The first 4 years of life for a child are very crucial as during this period the individual makes adjustments for the extra-uterine environment. Two types of environment can be distinguished: physical and socio-cultural. Examples of the former are altitude, temperature and light, and of the latter, nutrition, education and occupation of the parents, family composition and income [42]. It is this rich, varied, sometimes even hostile surrounding that stimulates the child's biological system to change, compensate and initiate adapting from the very protective and limited intra-uterine life it has lived. So there is adjustment to the experienced environmental changes, compensation for the new levels of stress that goes along with these changes and internal mechanisms will incite to developmental and physiological regulations [1]. At birth, the dominant maternal and placental influences on the foetal growth are being replaced. Postnatal growth is determined by a complex interaction between genetic, environmental and hormonal influences [43]. The high rate of growth of the foetus compared with that of a child is merely due to the fact that cells are still multiplying. The proportion of cells that undergo division in any tissue, becomes progressively less as the foetus gets older and the velocity drops sharply by the age of 30 weeks [10]. The mean weight at birth is approximately $3.5 \mathrm{~kg}$ and the length is about $50 \mathrm{~cm}$. The head-circumference lies in between 32 and $37 \mathrm{~cm}$, which is three-quarters of its adult value [44]. Already at birth boys tend to be taller and heavier then girls [45]. During the first week of life an infant will most likely lose some weight, but the total loss, in grams, may never exceed $10 \%$ of the infant's birth weight. At approximately the 10 th day after birth, the infant will be back on its original birth weight. The average gain in weight hereafter is approximately $150 \mathrm{~g}$ per week, but during the course of the year this amount will decrease. The same accounts for the velocity of length during infancy. It starts high at birth but decelerates rapidly during the first 18 months of life [44]. At the end of the first year of life, the weight of a child will almost have tripled and be around $10 \mathrm{~kg}$ while its length will be around $75 \mathrm{~cm}$ [45]. There is a significant negative correlation between birth weight and weight gain in early postnatal months, as there is indeed for length [17]. As during infancy a re-assortment of relative sizes amongst children comes about, those who are larger at birth will grow less, and those who are smaller will grow more $[17,46]$. So the first year of life is obviously a time of very rapid growth. One interesting phenomenon in the growth process is that the legs grow faster than the body in childhood, with an exponential fall in the lower body segment ratio from approximately 1.7 at birth 
to 1.0 in the adult female and 0.9 in the adult man [43]. Although there might be differences in adult stature, either between individuals or (sub)populations this does not imply similar differences throughout childhood, as children vary in their rates of maturation. Tall children may mature relatively early to become adults with a relative small stature, while small children may continue to grow for a longer time and end up as relatively tall adults [42]. Children of different populations may not only vary in stature at any given age, but also in body weight at a given stature, regardless of the age at which they achieve this stature [42]. Organ and tissue growth in general parallels skeletal growth, with some notable exceptions. For instance, while the eyes and brain are highly developed at birth and attain most of their adult size within the first few years of life, the reproductive tissues are relatively underdeveloped until the onset of puberty [43]. Luecke has presented a mathematical representation of organ growth in the human embryo and foetus, based to the Gompetz equation for growth [47, 48]. (The Gompetz equation assumes a self limiting growth process.) Out of the growth process of 16 organs, most could be fitted using an algometric equation, but for some, fat, kidney, lung and spleen, it was necessary to use a quadric form [48].

The factors that influence the growth can be divided into 3 main groups: genetic, environmental and hormonal [43]. Despite the appearance of selfregulatory systems, children are still dependent on the elder members of the community for their development. According to Johnston, the prepubertal stage of growth appears to be mainly determined by the environment, while growth during adolescence is mainly genetically determined [49] Any racial or ethnic effect on pre-school growth is small compared with environmental effect [42]. From conception onwards a child is given an intrinsic growth potential, which is genetically determined [50]. This genetical information is given to the child by both parents and it determines the potential length a child will reach at adulthood while growing under the most ideal circumstances. Whether or not a child will actually grow to this potential depends on various factors. Most importantly environmental influences can cause growth retardation. Environmental factors include for instance emotional neglect. The contribution of love and emotional security in promoting growth in children has been confirmed by several studies [51]. Emotionally deprived or abused children have been shown to have decreased growth hormone secretion, low serum IGF-I levels and abnormalities of ACTH secretion and thyroid function. In general these return to normal, along with growth rate, on removal from the harmful environment [43]. In his article Le Fanu describes that although failure to thrive can occur in all socio-economic layers of a population it is more common among children in problem families, and care proceedings followed by fostering can lead to dramatic gains in length and weight within a few weeks [51]. Growth may also be seasonal, often more rapid during spring time and summer compared to autumn and winter [43]. Factors that may influence the difference in growth between various populations are not so much their density, but a country's char- 
acteristics (social structure and development) which are related to it [42]. Another environmental factor that can influence somatic growth of a child is nutrition. Especially protein deficiency is a major world-wide cause of poor growth. A balanced diet with sufficient calories, essential amino and fatty acids, vitamins and trace elements are essential for an optimal growth. Although the foetal glucose metabolism is altered by severe hypoxia there is little effect of uterine blood flow on foetal glucose uptake in the normal physiological range [52]. A temporary period of malnutrition will cause a decrease in growth velocity as this is an adaptive response to allow undisturbed metabolic and homeostatic functions. After all it is more important to stay alive than to grow under stressful circumstances [43]. As long as such a period of deprivation is temporary, it will be followed by a period of catch-up growth when adequate nutrition is given. Unfortunately if it affects a younger child, or the period of malnutrition was longer or more severe, the catch-up growth will be incomplete or even non-existent. The completeness and speed of catch-up may depend on the nature of the growth-retarding influence and it seems that those measurements increasing the most, normally speaking, at the time of the growth-retarding influence, are affected the most [5]. The nutritional status of a child interacts with the endocrine regulations of growth, which brings us to the next factor that influences growth. The major hormones that influence somatic growth are growth hormone (GH), IGF-I, thyroxin, corticosteroids, sex steroids and insulin. Severe undernourishment is associated with increased mean serum GH levels and increased GH pulse amplitude next to decreased serum IGF-I levels [43]. Naturally, there are all kinds of disorders that prohibit normal growth. Abnormalities in sex chromosomes have significant effects on growth and stature, which can be noticeable already at birth (i.e. Turner syndrome) or later in life. Abnormalities in autosomes can also lead to profound effects on growth (i.e. Down syndrome). There are also a large number of genetically determined disorders that affect skeletal growth and stature (i.e. achondroplasie) and some genetical disorders cause diseases of the metabolic and organ system which indirectly via nutritional and other secondary effects, will influence growth too (i.e. cystic fibrosis). There is not one chromosome or gene responsible for the whole growth process. Genes controlling growth are widely distributed across the chromosomes. For instance, chromosome 21 seems to carry genes controlling or interacting with those controlling, the postnatal growth in leg length, but not the trunk and the timing of growth of the head-circumference and facial height [16]. There are also specific genetic defects that affect endocrine functions and might influence the growth too. In addition to genetical disorders there are also non-genetical disease processes that may lead to malnutrition and consequently affect the growth. This includes a wide range of malabsorptive conditions (i.e. celiac disease), chronic diseases outside the gastrointestinal system and disorders of increased energy utilization (i.e. diabetes mellitus) [43]. So, genetic control operates throughout the whole process of postnatal growth, but is stricter for some features than for others. It is mostly multifactorial, though there are some single-locus effects and different groups of genes that 
operate at different times [16]. Nevertheless, there does not seem to be a universal rule by which a set proportion of growth is determined by genes and another fixed proportion by environment. Growth of children will depend on the genetic and environmental variability in each country and these are changing over time [42].

\section{§ 2.4 Proportional growth from birth onwards.}

Growth is basically an increase in the number of cells and cell-volume and is affected by various factors. The factors affecting the rate or tempo of growth are different from those affecting size, shape and body composition of the infant. The genetical control of tempo seems to be independent of the genetical control of final adult size, and, to a large extent of final shape. Environmentally caused changes in tempo do not necessarily affect final size or shape. As a matter of fact, size and shape themselves seem to be separately controlled, both by genetical and environmental factors. Shape represents the distribution of cells, while size merely represents the sum of sizes of the various cells. The number of cells is fixed early, in the uterus, their size continues to alter during much of childhood and in some cases even throughout life. So the genetical control of shape is more strict than that of size [10]. In addition, the genes controlling the rate of growth are partly independent of those controlling final size [16]. Therefore, another way of evaluating growth is by describing the (changes in) shape. After all, the proportions of the human body change while growing and therefore the interrelationships between various measurements provide additional information [1] [25, 27, 53-60]. To date, the only evidence that specific genes exist for growth in size, body proportions, body composition, and rate of maturation is derived from studies of sex hormones. The $X$ chromosome carries genes that could control some aspects of the development of skeletal and dental tissue [61]. The $Y$ chromosome carries genes that stimulate the growth of skeletal tissue to produce the greater average stature, arm length, and biacromial breadth of males [62].

The usefulness of calculating proportions is based on the difference in timing of the peak velocities of the various measures. Especially at birth it can be helpful to determine the shape of the infant as this is a way to distinguish between proportional and disproportional intra-uterine growth retardation. Body size and composition at birth reflect the foetal growth [1]. In utero the various measures have their peak-velocity at different ages. For instance, total length has its peak velocity at about 20 weeks of gestational age, shortly after that of the headcircumference. The peak sitting height velocity is at around 16 weeks while the foetal weight velocity peaks at about 34 weeks $[7,63]$. Depending on the timing and the severity of the stress episode for the foetus in utero, the correlation between the measurements at birth describing the shape of the infant will determine a proportional or disproportional growth retardation. Describing the 
ing the change in shape of a child during the course of its life can give additional information. The ratio of crown-rump length to length can assist in diagnosing particular types of growth failure, as can ratio of fat to lean body mass, arm span to height, biacromial to bicristial breadth and the like [1].

The various measurements can be related to each other by means of an index. A commonly used manner to describe proportions is by means of the Ponderal Index:

$$
\mathrm{PI}=\mathrm{W} / \mathrm{L}^{3}
$$

in which $\mathrm{W}$ stands for weight in kilograms and $\mathrm{L}$ stands for length in centimetres. One drawback of this formula is that a simple ratio of two measurements can be misleading since the ratios of two individuals may be equal while their nominators and denominators are not equal. Another note of caution is that the interpretation of the PI needs care when an infant has a disproportionately large or small head, since the head contributes such a large component to body weight of the infant [64]. Thereby the age of the child is not taken into account. As an infant has a relatively larger head than trunk in comparison to an adolescent, this will be reflected in a different ratio for an infant and an adolescent. Therefore, a ratio can be normal for a certain age, but abnormal for another. The same drawback is found when using the Quetelet Index:

$$
\mathrm{QI}=\mathrm{W} / \mathrm{L}^{2}
$$

or other weight for height indices:

$$
\begin{aligned}
& W / L^{1.75} \\
& (W / L)^{1 / 3}
\end{aligned}
$$

The relative weight can be calculated by comparing the weight of the infant with the standard weight of that age [1]:

$$
\text { (weight/standard weight) } \times 100
$$

Another way to describe body shape, more specifically the relative lengths of the limbs and trunk, is by the relative sitting height index (RSHI):

$$
\text { (sitting height/ length) } \times 100
$$

A low value implies relatively long legs, while a higher value implies relatively short legs. Between various countries and ethnic groups, the RSHI will be different. While in Middle Africa the RSHI is 43.0, the index in Europe varies from 51.4 to $53.0[65]$. 
Measurements of length and weight provide only a basic estimation of body composition. The weight of various organs increases with maturation; some organs assume a smaller proportion of the total body mass (i.e. the brains) while the percentage of body mass that is composed of muscle and adipose tissue increases. Little adipose tissue is depositing during early foetal development, but a rapid deposition occurs the last 3 months of gestation. So the term infant's body consists approximately of 20 to $25 \%$ adipose tissue (of which $80 \%$ is subcutaneous and $20 \%$ visceral). After early infancy the percentage of fat decreases to $15 \%$ until the acceleration during the pubertal period. During this period the proportion of fat increases to somewhere between 20 and $30 \%$ in girls and 15 to $25 \%$ in boys. Skeletal muscles make up $25 \%$ of body mass during foetal life and $45 \%$ in adults, which makes it the largest tissue of the body. The period of greatest increase is especially during the first 5 years of life and to a smaller extent for boys during their puberty. For the estimation of non-adipose tissue (lean body mass), body water volume can be used. The smallest embryo consists for $95 \%$ of water. By 28 weeks of gestation, the total body water volume is $80 \%$ of the total body mass and this decreases to about $72 \%$ at birth. This is mainly due to the earlier described deposition of adipose tissue during the last trimester of the pregnancy. Further growth during infancy and childhood will cause the water content of the lean body mass to decrease to reach the adult value of $60 \%$ already at the age of 8 years [41] [66]. Figure 2.1 illustrates the relative changes of the various components of the body over the course of life. Body water can be divided into extracellular and intracellular compartments. These too will change during development. During foetal life the extracellular fluid compartment is substantially greater than that of the intracellular fluid compartment. However, the intracellular fluid compartment will eventually be twice the volume of the extracellular compartment in adulthood. The relatively high extracellular fluid volume in the young infant results in vulnerability to abnormal fluid losses during illness [41].

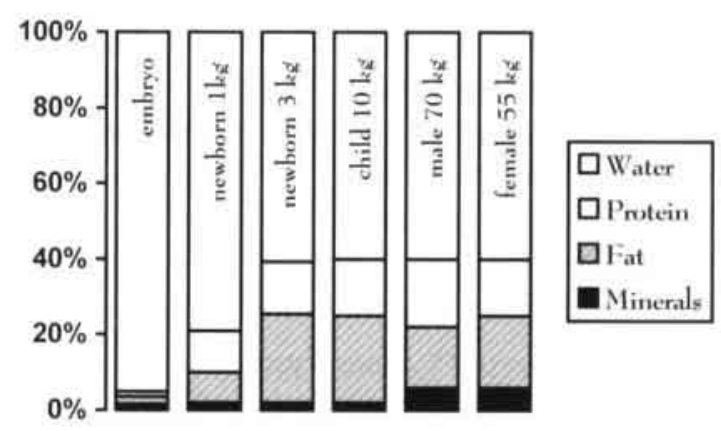

Figure 2.1 The changes in the proportions of body composition with growth (adapted from Pencharz [66]) 
The environment can have an influence on the shape, size and composition of the body. Especially extreme climatic conditions will demand adaptations of the body. For instance a body shape which facilitates dissipation of heat would be a useful adaptive feature in hot climates, whereas the inhabitants of polar regions might have physiques that assist in the conservation of heat, which means a reduced ratio of body mass surface area [65]. The degree to which the different dimensions of the body are affected during a period of growthretardation is variable. It seems that those measures that are nearer to their adult size are more affected than those that still need more time to develop. This, of course, would be those parts that were growing the fastest. Apparently the individual is trying to preserve its shape as long as possible; equal partition of resources would at once lead to the fastest growing dimensions falling behind the others. Of course it is inevitable to preserve the shape when the growth retardation is too severe, but it is suggested that changes of body shape require levels of growth restriction much more drastic than those which can bring about ultimate changes in body size [5]. But, in a recent research conducted by Nijhout and Emlen on insects, indications were found for an interaction between body parts in their growth. A greater amount of investment in the size of one part may limit the size of another part. If this is true, then there is no simple genetic determination of the final size and shape of the organism. Nor is there a single, central time- or size regulating mechanism. Instead animals may be able to adjust their final size and shape during development in response to many external stimuli [67].

\section{$\S 2.5$ Conclusion}

Unfortunately, both ratios and correlation coefficients are not so simple or as informative as they seem or suggest to be. Most physiological functions are related to the size of the various organs and depend on the age of the individual. It is essential when evaluating the variety of influences on growth and development of the physiological systems of an individual, to explain sizeassociated variance or keep it constant [68]. The main drawback of ratios is the fact that the age of a child is hardly ever taken into account. The shape of an infant is different from a toddler, which again is different from an adolescent. The PI at birth can give valuable indications regarding previous foetal growth, but it should be used carefully when following the growth of disproportional and proportionally growth retarded foetuses [64]. Therefore, it depends on the purpose and interpretation of the calculations whether or not ratios or correlations are helpful. 


\section{References}

1. Johnston, F.E., Somatic growth of the infant and preschool child. 2 ed. Human growth: A comprehensive treatise, ed. F. Falkner and J.M. Tanner. Vol. 2. 1986, New York \& London: Plenum Press. 3-24.

2. Barker, D.J.P., Fetal and infant origins of adult disease. 1992, London: British Medical Journal. 343.

3. Langley-Evans, S.C., D.S. Gardner, and A.A. Jackson, Association of disproportionate growth of fetal rats in late gestation with raised systolic blood pressure in later life. J. Reprod Fertil, 1996. $\operatorname{mar}(106(2)):$ p. 307-312.

4. Crowe, C., L. Bennet, and M.A. Hanson, Blood pressure and cardiovascular reflex development in fetal sheep. Relation to hypoxaemia, weight and blood glucose. Reprod Fertil Dev, 1995. 7(3): p. 553-558.

5. Tanner, J.M., Catch-1up Growth in Man. British Medical Bulletin, 1981. 37(3): p. 233238.

6. Bogin, B., Patterns of Human Growth. 2nd ed. Cambridge studies in biological anthropology, ed. R.A. Foley and N.G. Jablonski. Vol. 23. 1999, Cambridge: Cambridge University Press. 455.

7. Milner, R.D.G., Prenatal growth control. Growth, 1993. 5: p. 162-170.

8. Fomon, S.J., et al., Requirements for sulfur-containing amino acids in infancy. J. Nutr., 1986. 116: p. 1405-1422.

9. Hill, D.J. and V.K.M. Han, Cell and Tissue Growth. Growth, 1993. 5: p. 155-162.

10. Tanner, J.M., Foetus into Man: physical growth from conception to maturity. second ed. 1989, London: Castlemead publications. 280.

11. Rohl, J., et al., Factor associated with fetal growth and body composition as measured by ultrasound. Am J Obstet Gynecol, 2001. dec(185 (6)): p. 1416-1420.

12. Falkner, T., Twin Growth in Relation to Placentation, in Human Growth; A compreltensive treatise, T. Falkner and J.M. Tanner, Editors. 1986, Plenum Press: New York and London. p. Chapter 10.

13. Heasman, L., et al., Influence of restricted maternal nutrition in early to mid gestation on placental and fetal development at term in sheep. Paediatr. Res, 1998. oct(44(4)): p, 546551.

14. Michael, K., B.S. Ward, and W.M. Moore, Relationship of fetal to placental size: the pig model. Eur J Obstet Gynecol Reprod Biol, 1983. sep(16(1)): p. 53-62.

15. Brown, J.E., et al., Maternal waist-to-hip ratio as a predictor of newborn size; Results of the Diana Project. Epidemiology, 1996. jan(7(1)): p. 62-66.

16. Roberts, D.F., Genetics of Growth. British Medical Bulletin, 1981. 37(3): p. 239-246.

17. Falkner, F., Key issues in perinatal growth. Acta paediatr scand, suppl, 1985. 319: p. 2125.

18. Penrose, L.S. and supplement, ? Caryologica, 1954. 6: p. 521.

19. Wright, E.V. The biology of human Foetal Growth. in Symposia of the Society for the Study of Human Biology. 1976: Taylor \&Francis London.

20. Robinson, J., et al., Placental control of fetal growth. Reprod Fertil Dev, 1995. 7(3): p. 333-344. 
21. Chambers, H.M., et al., Anthropometric measurements in the second trimester fetus. Early Hum Dev, 1993. 33: p. 45-59.

22. Keen, D.V. and R.G. Pearce, Weight, length and head circumference curves for boys and girls between 20 and 42 weeks of gestation. Arch Dis Child, 1988. 63: p. 1170-1172.

23. Potter, E.L. and C. J., Pathology of the fetus and infant. Vol. 18, 1975: Year Book Medical Publishers.

24. Largo, R.H., et al., Evaluation of perinatal growth-Presentation of combined intrauterine and extrauterine growth standards for weight, length and head circumference. Helv. Paediatr. Acta, 1980. 35: p. 419-436.

25. Kloosterman, G.L., On intrauterine growth, the significance of prenatal care. Int J Gynaecol Obstet, 1970. 8: p. 895-912.

26. Lubchenko, L.O., et al., Sequelae of premature birth. Evaluation of premature infants of low weights at ten years of age. Am. J. Dis. Child., 1963. 106: p. 101-115.

27. Lubchenco, L.O., C. Hansman, and E. Boyd, Intrauterine growth in length and head circumference as estimated from live births at gestational ages from 26 to 42 weeks. Ped., 1966. 37: p. 403-408.

28. Bossi, A. and S. Milani, Italian standards for crown-heel length and head-circumference at birth. Annals of Human Biology, 1987. 14(4): p. 321-335.

29. Rooth, G., O. Meirik, and P. Karlberg, Estimation of the 'normal' growth of swedisch infants at term. Acta Paediatr Scand, Suppl, 1985. 319: p. 76-79.

30. Nienhuis, S.J., Costs and effect of Doppler ultrasound measurements in suspected intrauterine growth retardation, in Gynaecology. 1995, University of Maastricht: Maastricht. p. 156.

31. Shepard, M.J., et al., Maternal body mass, proportional weight gain, and fetal growth in parous women. Paediatr Perinat Epidemiolo, 1996. apr(10(2)): p. 207-219.

32. Battaglia, F.C. and G. Meschia, Foetal and placental metabolisms: their interrelationship and impact upon maternal metabolism. Proc Nutr Soc, 1981. jan(40(1)): p. 99-113.

33. Walther, F.J. and H.J. Ramaekers, Neonatal morbidity of S.G.A. infants in relation to their nutritional status at birth. Acta Paediatr Scand, 1982, 71: p. 437-440.

34. Williams, R.L., et al., Fetal growth and perinatal viability in California. Obstet. Gynaecol, 1982. 59: p. 624.

35. Unknown, Immaturity and Disorders in Growth, in Obstetrics and the Newborn. unk. p. 598-617.

36. Nagel, H.T., et al., Follow-up of children born with a umbilical arterial blood $\mathrm{pH}<7$. Am J Obstet Gynecol, 1995. dec(173(6)): p. 1758-1764.

37. Brandt, I., Growth dynamics of low-birth-weight infants with emphasis on the perinatal period. 2 ed. Human growth: A comprehensive treatise, ed. F. Falkner and J.M. Tanner. Vol. 1. 1986, New York \& London: Plenum. 415-475.

38. Babera, A., et al., Early ultrasonograhic detection of fetal growth retardation in an ovine model of placental insufficiency. Am J Obstet Gynecol, 1995. oct(173 (4)): p. 1071-1074.

39. Wilson, D.C., et al., Long term predictive value of Dopplet studies in high risk fetuses. Br J Obstet Gynaecol, 1992. jul(99(7)): p. 575-578.

40. Meier, P.R., et al., Fetal heart rate in relation to body mass. Proc Soc Exp Biol Med, 1983. jan(172 (1)): p. 107-110.

41. Nichols, B.L., Pediatric Nutrition and Nutritional Disorder, in Nelson Essentials of Pediatrics, R.E. Behrman and R. Kliegman, Editors. 1990, W.B. Saunders Company: Philadelphia, London, Toronto, Motreal, Sydney, Tokyo, p. 57-90.

42. Rona, J.R., Genetic and Environmental Factors in the Control of Growth in Childhood. Birtisch Medical Bulletin, 1981. 37(3): p. 265-272. 
43. Ambler, G.R. and P.D. Gluckman, Postnatal growth - an overview. Growth, 1993. 5: p. 170-174.

44. Hull, D. and D.I. Johnston, Essential Paediatrics. Third ed. 1993, Edinburgh: Churchill Livingstone. 365 .

45. Smolders-de Haas, H., Groei van zuigelingen, in Neonatologie, J.G. Koppe, Editor. 1992, Bohn Stafleu Van Loghum: Houtem/Zaventem. p. 143-148.

46. Tanner, J.M., The Regulation of Human Growth. Child Development, 1963. 34: p. 817847.

47. Kowald, A., Lifespan does not measure ageing. Biogerontology, 2002. 3: p. 187-190.

48. Luecke, R.H., W.D. Wosilait, and J.F. Young, Mathematical representation of organ growth in the human embryo/fetus. Int J Biomed Comput, 1995. jun(39(3)): p. 337-347.

49. Johnston, F.E., et al., unknown. Am. J. Phys. Anthropol., 1976. 44: p. 469-476.

50. Polani, P. Chromosomal and other genetic influences on birth weight variation. in Size at birth. 1974. Amsterdam: Elsevier.

51. Le Fanu, J., Failure to Thrive, in Times. 1994: London.

52. Wilkening, R.B., F.C. Battaglia, and G. Meschia, The Relationship of umbilical glucose uptake to uterine bloodflow. J Dev Physiol, 1985. oct(7(5)): p. 313-319.

53. Kramer, M.S., etal., Body Proportionality and Head and Length 'Sparing' in Growth-Retarded Neonates: A Critical Reappraisal. Ped., 1989. 84: p. 717-723.

54. Usher, R. and F. McLean, Intrauterine growth of live-born Caucasian infants at sea level: standards obtained from measurements in 7 dimensions of infants born between 25 and 44 weeks of gestation. J Pediatr., 1969. 74: p. 901-910.

55. Campbell, S. and G.B. Newman, Growth of the fetal biparietal diameter during normal pregnancy. J Obstet Gynaecol Br Commonw, 1971. 78: p. 513-519.

56. Birkbeck, J.A., W.Z. Billewicz, and A.M. Thomson, Human foetal measurements between 50 and 150 days gestation, in relation to crown-heel length. Ann Hum Biol, 1975. 1: p. $173-178$.

57. Tanner, J.M., Physical Growth From Conception to Maturity. 1979, Harvard University Press: Cambridge. p. 37-51.

58. Kaul, S.S., A. Bahn, and S.R.K. Chopra, Fetal growth from 12 to 26 weeks of gestation. Ann Hum Biol, 1986. 13: p. 63-570.

59. Keen, D.V. and R.G. Pearse, Weight, length, and head circumference curves for boys and girls of between 20 and 42 weeks' gestation. Arch Dis Child, 1988. 63: p. 1170-1172.

60. Campbell, S., Assessment of fetal development by ultrasound. Perinatol, 1974. 1: p. 507.

61. Tanner, J.M., Growth at adolescence, with a general consideration of the effects of hereditary and environmental factors upon growth and maturation from birth to maturity. second edition ed. 1962, Oxford: Blackwell.

62. Dweck, H.S., et al., Early development of the tiny premature infant. Am. J. Dis. Child., 1973. 126: p. 28-34.

63. Streeter, G.L., Weight sitting height, head size, foot length and menstrual age of the human embryo. Contrib Embryology, 1920. 11: p. 142.

64. Falkner, F., Some introductory concepts of human growth: an overview. Acta Paediatr Scand, Suppl, 1985. 319: p. 17-20.

65. Marshall, W.A., Geographical and Ethic Variations in Human Growth. Britisch Medical Bulletin, 1981. 37(3): p. 273-279.

66. Pencharz, P., Body Composition and Growth, in Nutrition in Pediatrics: Basic Science and Clinical Application, W. Walker and J. Watins, Editors. 1985, Little Brown \& CO Inc: Boston. p. 81.

67. Nijhout, H.F., The nature of robustness in development. Bioessays, 2002. 6(24): p. 553563. 
68. Ross, W.D., On ratios and proportions, in Essays on Auxology: presented to James Mourilyan Tanner by former colleagues and Fellows, R. Hauspie, G. Lindgren, and F. Falkner, Editors. 1995, Castlemead Publication: Welwyn Garden City. p. 119-125. 


\section{Chapter III: \\ The Sample}

Nothing in biology makes sense except in the light of evolution. 


\section{$\S 3.1$ Introduction}

Maastricht is situated in the south-eastern part of The Netherlands, on the river Maas, near the border of Belgium and is the capital of the province Limburg. Maastricht was founded by the Romans about 2000 years ago as Trajectum ad Mosum, meaning a ford through the river Maas. After the Romans, Charlemagne ruled over Maastricht and visited the city regularly. Because of the possibility to cross the river Maas, it was a strategically important town, and Dutch, Spanish and French armies laid siege to Maastricht frequently. Nowadays the French, Spanish, German and Belgium influences are still clearly visible in Maastricht. It is an industrial centre where textiles, chemicals, ceramics, and glass are produced. Maastricht is also a noted cultural centre with a music conservatory, symphony orchestra, and natural history museum. The city gained international prominence in December 1991 as the site of a historic summit meeting where the leaders of the 12 European Community nations agreed on a treaty to speed their economic and political integration. This treaty, officially called the Treaty on European Union, became known as the Maastricht Treaty [1].

The town's area covers $56.02 \mathrm{~km}^{2}$ and has 118,314 inhabitants of whom 56,622 are men and 61,692 women (31 December 1992). In Maastricht 113,122 inhabitants have the Dutch nationality and 5,192 have a foreign nationality. Of these foreigners 2,762 are from non-western countries.

The average number of live births over the past 10 years was 1217 per year, which corresponded with 10.5 per 1000 inhabitants of which 622 were boys, and 595 were girls. In 1992 the number of live births was 1198 ( 595 boys and 603 girls) which corresponded with 10.1 per 1000 inhabitants. No reason was found why the ratio girls vs boys was in favor of the girls, while normally more boys are being born. The average number of stillbirths in Maastricht was 17. In 1992 this number was $27(2.24 \%)$, which is higher when compared to the average for both Maastricht and for The Netherlands. The average mortality in the first year of life was 7, and in 1992 it was $6(0.50 \%)$, which is comparable to the average for both Maastricht and The Netherlands ( $0.55 \%$ ) (information from city hall business-public relation/information department). The distribution for the first two years of life was 1,248 boys $(1.1 \%)$ and 1,217 girls $(1.0 \%)$, which accounts for 20.8 per 1,000 habitants. The distribution of the whole population according to sex and age-group is shown in table 3.1 . 


\begin{tabular}{|l|l|l|l|l|l|l|}
\hline Age & $\begin{array}{l}\text { Males } \\
\text { abs }\end{array}$ & $\%$ & $\begin{array}{l}\text { Females } \\
\text { abs }\end{array}$ & $\%$ & $\begin{array}{l}\text { Total } \\
\text { abs }\end{array}$ & $\begin{array}{l}\text { per 1,000 } \\
\text { habitants }\end{array}$ \\
\hline $\mathbf{0 - 9}$ & 6,090 & 5.1 & 5,784 & 4.9 & 11,874 & 100.3 \\
$\mathbf{1 0 - 1 9}$ & 5,852 & 4.9 & 6,117 & 5.2 & 11,969 & 101.2 \\
$\mathbf{2 0 - 2 9}$ & 10,359 & 8.8 & 11,515 & 9.7 & 21,874 & 184.9 \\
$\mathbf{3 0 - 3 9}$ & 9,415 & 8.0 & 9,395 & 7.9 & 18,810 & 159.0 \\
$\mathbf{4 0 - 4 9}$ & 8,683 & 7.3 & 8,216 & 6.9 & 16,899 & 142.8 \\
$\mathbf{5 0 - 5 9}$ & 6,432 & 5.4 & 6,499 & 5.5 & 12,931 & 109,3 \\
$\mathbf{6 0 +}$ & 9,791 & 8.3 & 14,166 & 12.3 & 23.957 & 202.5 \\
\hline Total & 56,622 & $47.9 \%$ & 61,692 & $52.1 \%$ & 118,314 & 1000.0 \\
\hline
\end{tabular}

Table 3.1 Distribution of the population of Maastricht according to sex and age in 1992 (abs = absolute values)

\section{§3.2 Sampling procedure}

The Green Cross organization in The Netherlands provides several services for parents and their children. One of the most important services is the infanthealth-care centre. The aim of this service is to screen the development of infants and children up to 4 years of age. Monitoring the growth of an infant is a tool for this evaluation [2]. Employees of this organization screen on mental and physical development, anthropometry, hearing and vision and give advice on feeding, physical and dental care and vaccinate against measles, mumps, rubella, diphtheria, tetanus, polio, pertussis, HI-B and meningococ C. Furthermore they provide education on these various subjects. Specialized nurses and doctors give all these services, while physiotherapists, dieticians, social workers and educationalists can be consulted, if necessary. The infant health-care centres in Maastricht are situated in all major districts of the city and cover all socio-economic layers of the population.

The parents of infants visiting the infant-health-care centres were asked in a letter to participate in this research. During the measurements the parents were present and if necessary made a contribution by helping the assistant during the measurements. In total 1234 infants enrolled in this survey; 651 boys $(52,8 \%)$ and 583 girls $(47,2 \%)$. These infants were followed for one year at the infanthealth-care centre. They were measured during their regular visits at the ages of approximately 3, 9, 13, 21, 31, 40 and 50 weeks. After this first year of life the visits to the health-care centres are usually on an annual basis. For this study parents were asked to participate in a follow-up survey, in which their child would be measured twice in the second year. In total 51,0\% (629 infants) volunteered to participate; 348 boys $(55,3 \%)$ and 281 girls $(44,7 \%)$. One and the same person measured these infants at the ages of 15 and 21 months. During these voluntary visits the measurements were depicted on a growth-chart from the Third Nation-wide Survey[3]. The exact measurements were written down on 
two forms. One of the forms and the chart were given to the parent to take home. The other form was used for filing. When a child had grown one meter or beyond, it was given a '1-metre-diploma'. During the voluntary visits further information was also given on the aim of this study and general questions on growth were answered. At the end 5677 visits were registered for boys and 4808 visits for girls. The average visits for boys was 8.7 and for girls 8.2.

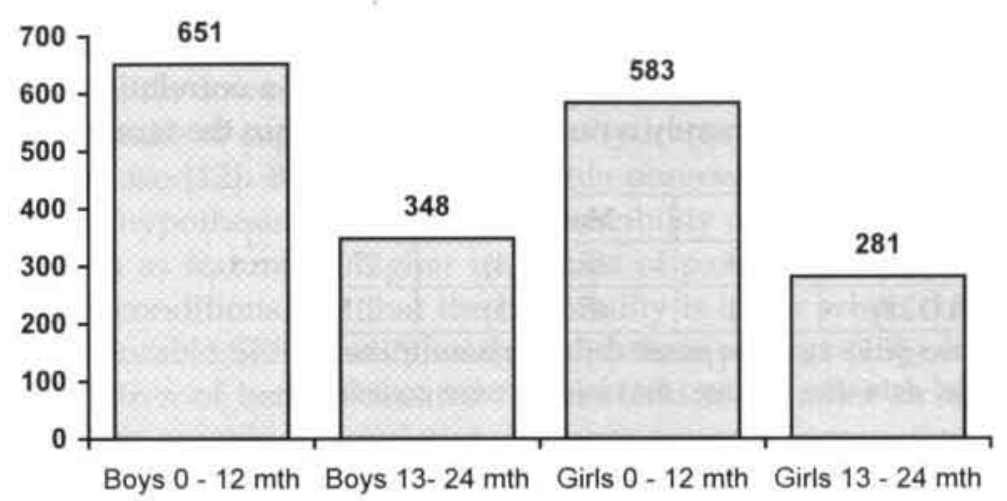

Figure 3.1 Composition of the sample and follow-up

\section{$\S 3.3$ Descriptive data}

In a written questionnaire, either the parents or another person responsible for the infant's upbringing, were asked additional information about the infant and its family. In total $81,7 \%$ of the follow-up group (282 boys and 231 girls) responded by filling in and returning the questionnaire

\section{$\S$ 3.3.1 Parental related issues}

\section{Parental Height}

The approximate height of the parents was asked, as the corrected mid-parental height correlates well with the height of the child. According to Garn [4], this relationship is evident from the age of one year onward, but Tanner [5] stated that there is no close correlation during the first 18 months to two years, but by the age of two years the correlation is considered to be significant. Both parents contribute equally to each offspring. But there is no tendency for daughters to resemble their mothers or for sons to resemble their fathers [5]. The mean height for the parents is given in table 3.2. Mid-parental (or target height) is calculated by the following formulas [6]

for boys: [(height mother in $\mathrm{cm}+13+$ height father in $\mathrm{cm}) / 2$ ] +4.5

for girls: [(height father in $\mathrm{cm}-13+$ height mother in $\mathrm{cm}) / 2]+4.5$ 


\begin{tabular}{|l|c|c|c|c|c|}
\hline & \multicolumn{3}{|l|}{ Father $(\sigma)$} & $\mathbf{n}$ & \multicolumn{2}{l|}{ Mother $(\sigma)$} & n & Target height $(\sigma)$ \\
\hline Boys & $180.1(7.1)$ & 503 & $167.4(6.9)$ & 503 & $184.7(5.5)$ \\
\hline Girls & $179.3(7.0)$ & 433 & $166.7(6.3)$ & 433 & $171.0(5.2)$ \\
\hline
\end{tabular}

Table 3.2 Average height in $\mathrm{cm}$ of the parents of the infants. If one or both parent's data was missing, the children were excluded from this table.

\section{Parental Weight}

The weight of both parents was asked to determine if there is a correlation between parental weight and their children's weight, especially concerning obesity. The main question that has to be answered is whether a correlation is due to genetical predisposition or merely a nutritional habit within the family.

\begin{tabular}{|c|c|c|c|c|}
\hline & Father $(\sigma)$ & $\mathrm{n}$ & Mother $(\sigma)$ & $\mathrm{n}$ \\
\hline Boys & 81.1 (122) & 268 & $65.3(11.4)$ & 270 \\
\hline Girls & $80.1(12.8)$ & 214 & $65.5(13.5)$ & 215 \\
\hline
\end{tabular}

Table 3.3 Average weight in $\mathrm{kg}$ of the parents of the infants. If either one or both parental data was missing, the children were excluded from this table

\section{Parental Body Mass Index}

The body mass index is an index that can determine if a person is overweight or obese. The body mass index is a calculation: weight/length ${ }^{2}$. There is a correlation between parental obesity and the tendency for a child to develop obesity [7].

\begin{tabular}{|c|c|c|c|c|}
\hline & Father $(\sigma)$ & $\mathrm{n}$ & Mother $(\sigma)$ & $\mathrm{n}$ \\
\hline Boys & $24.8(3.2)$ & 268 & $23.1(3 . .9)$ & 270 \\
\hline Girls & $24.8(3.5)$ & 214 & $23.6(5.0)$ & 215 \\
\hline
\end{tabular}

Table 3.4 Average body mass index of the parents. If either one or both parental data was missing, the children were excluded from this table

\section{Highest level of education of the parents}

The highest obtained level of parental education is an important indicator of the socio-economic status and therefore also for health. [8]. Many relations between parental socio-economic status and children's growth have been investigated. Rich versus poor, manual versus non-manual and professional versus unskilled labor. However, the status is mostly defined in terms of father's occupation, mother's status is hardly taken into account. Children from different socioeconomic levels differ in size and timing of growth in almost every population examined. The upper classes show more and more rapid growth, and therefore tend to be taller. In most European countries, the chief difference is between those children whose fathers are in occupations classified as 'manual' or 'working' and those whose fathers have a 'non-manual' or 'intellectual' occupation [5]. The difference in height between children of professional and managerial fa- 
thers and those of unskilled manual laborers in the UK in 1985, for example, was nearly $2 \mathrm{~cm}$ for three year old boys and rises to $4 \mathrm{~cm}$ at adolescence and falling again to $3 \mathrm{~cm}$ at young adulthood. In girls these differences alter over the years from $1.5 \mathrm{~cm}$ to $3 \mathrm{~cm}$ to $2 \mathrm{~cm}$ in adults [9]. In a survey conducted in two small towns in South Wales in 1987, no differences in length were found between the social classes for children at three months of age but a manual/nonmanual difference of $0.5 \mathrm{~cm}$ at 6 months to $1 \mathrm{~cm}$ at age 3 years [10]. Similar findings have been reported in the HANES I and II surveys and in the British National Development Survey $[4,11]$. For weight the differences are somewhat less, since the lower classes have a higher weight for height partly because of a higher intake of sugar and other carbohydrates relative to fat and protein and less exercise [12]. Bloom formalized his observations into the 'powerful environment hypothesis'. He found that heritability of some phenotypic characteristics (such as stature) is higher in groups of parents and children living under low SES conditions, but that the heritability is lower when children live under more favorable SES conditions than did their parents [13]. It was also found that children of better educated fathers tend to be taller as adults [14]. In the Maastricht sample a correlation between parental occupation and growth of infants and their eventual length was a point of interest. The fact that most people do not like to provide information on their annual income and the fact that many women stopped working after the birth of their first or second child, made it difficult to classify parental occupation. So, it was decided to focus on the education of both parents in relation to infant weight and length at birth and growth in general. The different kinds of education are divided into 4 groups. I: being unknown, no education or primary school, II: being lower general secondary education (Mavo) and lower vocational education (Lbo), III: being higher general secondary education (Havo), pre-university education (VWO) and intermediate vocational education (Mbo) and IV: being higher vocational education ( $\mathrm{Hbo}$ ) and university. Table 3.5 gives an overview of the distribution of the various levels of education of the parents.

\begin{tabular}{|l|c|c|c|c|c|c|c|c|c|c|}
\hline & \multicolumn{2}{|c|}{ I } & \multicolumn{2}{|c|}{ II } & \multicolumn{2}{c|}{ III } & \multicolumn{2}{c|}{ IV } & \multicolumn{2}{c|}{ Total } \\
& $\mathrm{n}$ & $\%$ & $\mathrm{n}$ & $\%$ & $\mathrm{n}$ & $\%$ & $\mathrm{n}$ & $\%$ & $\mathrm{n}$ & $\%$ \\
\hline Boys' father & 9 & 3.5 & 70 & 27.3 & 83 & 32.4 & 94 & 36.7 & 256 & 28.3 \\
Boys' mother & 4 & 1.6 & 74 & 28.8 & 103 & 40.1 & 76 & 29.6 & 257 & 28.5 \\
Girls' father & 9 & 4.6 & 59 & 30.3 & 66 & 33.8 & 61 & 31.3 & 195 & 21.6 \\
Girls' mother & 3 & 1.5 & 66 & 33.8 & 83 & 42.6 & 43 & 22.1 & 195 & 21.6 \\
\hline Total & 25 & 2.8 & 269 & 29.8 & 335 & 37.1 & 274 & 30.3 & 903 & 100.0 \\
\hline
\end{tabular}

Table 3.5 The distribution of the various levels of education (I to IV) of the parents

\section{Correlations in education}

It has been said that taller men choose taller women and vice versa. And it is not unlikely for higher educated women to choose higher educated men. There is a correlation between parental education and adult height of their children. If there is also a correlation between the level of education of the father and the 
level of education of the mother, it might be difficult to determine if the correlation between parental education and the growth of a child, is due to the maternal or the paternal influence, or maybe a combination of the two.

\begin{tabular}{|l|c|c|c|c|}
\hline & \multicolumn{4}{|c|}{ Education Mother } \\
Education & Group I & Group II & Group III & Group IV \\
Father & & & & \\
\hline Group I & $1.1 \%$ & $1.8 \%$ & $0.9 \%$ & $0.2 \%$ \\
Group II & $0.4 \%$ & $17.1 \%$ & $9.8 \%$ & $1.3 \%$ \\
Group III & $0.0 \%$ & $8.4 \%$ & $19.5 \%$ & $5.1 \%$ \\
Group IV & $0.0 \%$ & $3.5 \%$ & $11.1 \%$ & $19.7 \%$ \\
\hline
\end{tabular}

Table 3.6 Correlation between the level of education (I to IV) of father and the level of education of mother

\section{Origin}

In this study two groups of infants were distinguished according to their origin. Infants of Caucasian origin and infants who had at least one parent who was not of Caucasian origin. The data of these infants were not included in the analysis of this thesis. As the number is small and the group too diverse, no curves were constructed. Table 3.7 gives an overview of the distribution of infants of non-Caucasian origin.

\begin{tabular}{|l|c|c|c|c|}
\hline & \multicolumn{2}{|c|}{ One parent } & \multicolumn{2}{c|}{ Both parents } \\
& non Caucasian & \multicolumn{2}{c|}{ non Caucasian } \\
& $\mathrm{n}$ & $\%$ & $\mathrm{n}$ & $\%$ \\
\hline Boys & 13 & 1.1 & 20 & 1.6 \\
Girls & 20 & 1.6 & 14 & 1.1 \\
\hline Total & 33 & 2.7 & 34 & 2.8 \\
\hline
\end{tabular}

Table 3.7 Percentage of infants born from a single or both non-Caucasian parents

\section{§3.3.2 Pregnancy and perinatal related issues}

\section{Mothers' smoking habit during pregnancy}

One in four women had smoked during the pregnancy. This is lower than the $40 \%$ reported for the whole of The Netherlands [15]. In average, the birth weight might be 200 to 300 grams less because of smoking. Unfortunately it was recorded that some women try, by smoking during the pregnancy, to have a smaller foetus which would hopefully guarantee an easier delivery [15]. Although the duration of the pregnancy and the number of congenital malformations is not different from non-smokers, the perinatal mortality is higher in the smokers group due mainly to intrauterine growth-retardation and to a certain extent the higher number of solutio placentae cases [16]. Table 3.8 gives an overview of the distribution of smoking and non-smoking mothers. 


\begin{tabular}{|l|c|c|c|c|}
\hline & \multicolumn{2}{|c|}{ Smokers } & \multicolumn{2}{c|}{ Non-smokers } \\
& $\mathbf{n}$ & $\%$ & $\mathbf{n}$ & $\%$ \\
\hline Boys & 68 & 26.5 & 189 & 73.5 \\
Girls & 61 & 31.4 & 133 & 68.6 \\
\hline Total & 129 & 28.6 & 322 & 71.4 \\
\hline
\end{tabular}

Table 3.8 Percentage of smoking and non-smoking mothers during pregnancy

The intake of medicine by the mother during pregnancy

The intake of certain medicines during pregnancy can be teratogenic or can influence the growth and development of a foetus. The distribution of women that took medication during pregnancy is given in table 3.9.

\begin{tabular}{|l|c|c|c|c|}
\hline & \multicolumn{2}{|c|}{ Medicine intake } & \multicolumn{2}{c|}{ No medicine intake } \\
& $\mathrm{n}$ & $\%$ & $\mathrm{n}$ & $\%$ \\
\hline Boys & 50 & 19.5 & 207 & 80.5 \\
Girls & 28 & 14.3 & 168 & 85.7 \\
\hline Total & 78 & 17.2 & 375 & 82.8 \\
\hline
\end{tabular}

Table 3.9 Percentage of mothers taking medication during pregnancy

Two women had taken anti-epileptic drugs (Diazepam and Carbamazepine) in the beginning of the pregnancy, as they didn't know at that time they were pregnant. Both children from these mothers had developed normally without any complications, although this specific drug has been associated with congenital defects. No other medication was reported by the other mothers that might have interfered with the normal development of the foetus. The most used medication during pregnancy, besides folium acid, vitamins and the occasional painkiller is given in table 3.10 . 


\begin{tabular}{|l|c|l|}
\hline Type of medication & Number & Effects reported when used during pregnancy \\
\hline & used & \\
\hline Penicillin & 19 & None \\
Salbutamol & 7 & Not known \\
Corticosteroids & 8 & None \\
Methyldopa (hypertension) & 3 & None \\
Flecaïnide & 2 & Not known \\
Heparin & 2 & None \\
Anti-pepticum & 3 & None \\
Eythyrox & 2 & None \\
Fenoterol & 2 & none, if used late in pregnancy \\
Insulin & 2 & None \\
Various & 14 & None \\
Unknown & 14 & - \\
\hline
\end{tabular}

Table 3.10 Used medication reported and effects according to the

Central Medical Pharmaceutical board of the 'Ziekenfondsraad' of The Netherlands 2003

\section{Alcohol intake of the mother during pregnancy}

The 'foetal alcohol syndrome' is a direct consequence of the consumption of great amounts of alcohol. There was no report of this syndrome in the sample. It is still unclear what the minimum amount of alcohol intake needs to be to have a distinct influence on the development of the foetus. It is therefore advisable to refrain from the consumption of alcohol during pregnancy [15]. Table 3.10 gives an overview of the alcohol c.q. non-alcohol intake by mothers during pregnancy.

\begin{tabular}{|l|c|c|c|c|}
\hline & \multicolumn{2}{|c|}{ Alcohol intake } & \multicolumn{2}{c|}{ No alcohol intake } \\
& $\mathrm{n}$ & $\%$ & $\mathrm{n}$ & $\%$ \\
\hline Boys & 28 & 14.3 & 168 & 85.7 \\
Girls & 27 & 10.5 & 230 & 89.5 \\
\hline Total & 55 & 12.1 & 398 & 87.9 \\
\hline
\end{tabular}

Table 3.11 Percentage of mothers taking or not taking alcohol during pregnancy

\section{Order of birth}

The order of birth of each child was given, as children from large families tend to be shorter and mature later than children from smaller families [5], furthermore first-born children are during their childhood somewhat taller than laterborn children with the same number of siblings. 


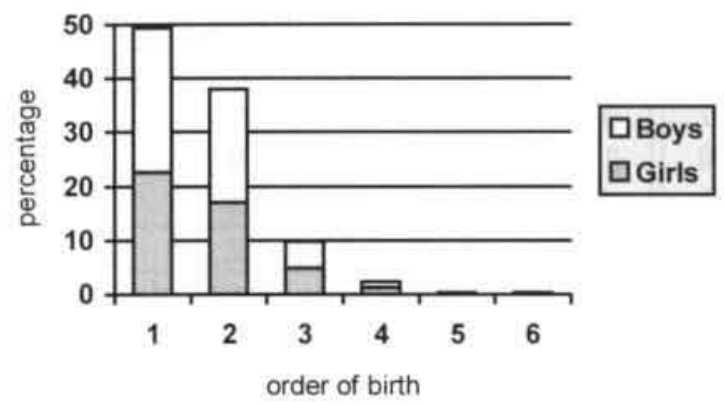

Figure 3.2 Distribution of the order of birth in percentages

\begin{tabular}{|l|c|c|c|c|c|c|}
\hline $\begin{array}{l}\text { Order } \\
\text { birth }\end{array}$ & \multicolumn{2}{|c|}{ Boys } & \multicolumn{2}{c|}{ Girls } & \multicolumn{2}{c|}{ Total } \\
& $\mathrm{n}$ & $\%$ & $\mathrm{n}$ & $\%$ & $\mathrm{n}$ & $\%$ \\
\hline $\mathbf{1}$ & 246 & 49.3 & 208 & 49.2 & 454 & 49.2 \\
$\mathbf{2}$ & 194 & 38.9 & 157 & 37.1 & 351 & 38.1 \\
$\mathbf{3}$ & 46 & 9.2 & 44 & 10.4 & 90 & 9.7 \\
$\mathbf{4}$ & 10 & 2.0 & 11 & 2.6 & 21 & 2.3 \\
$\mathbf{5}$ & 1 & 0.2 & 22 & 0.5 & 23 & 0.3 \\
$\mathbf{6}$ & 2 & 0.4 & 1 & 0.2 & 3 & 0.3 \\
\hline Total & 499 & 54.1 & 443 & 45.9 & 942 & 100.0 \\
\hline
\end{tabular}

Table 3.12 Percentages of order of birth

Number of pregnancies, previous to the pregnancy of this infant

The number of siblings has an influence on the growth of the individual child. In this research it has been investigated if the number of pregnancies has a comparable influence.

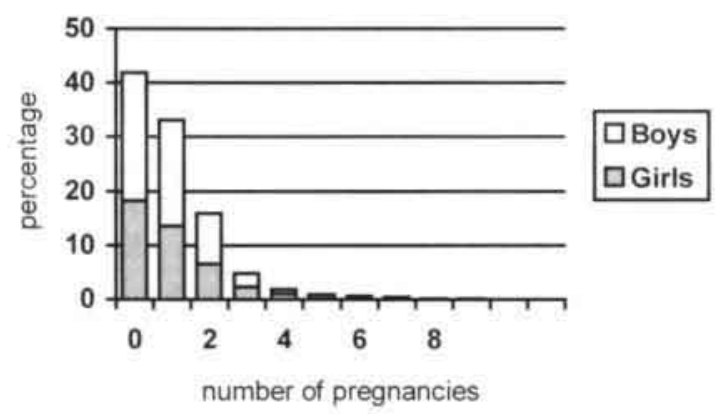

Figure 3.3 Distribution of the number of pregnancies previous to the pregnancy of this infant in percentage 


\begin{tabular}{|l|c|c|c|c|c|c|}
\hline Number of & \multicolumn{2}{|c|}{ Boys } & \multicolumn{2}{c|}{ Girls } & \multicolumn{2}{c|}{ Total } \\
Pregnancies & $\mathrm{n}$ & $\%$ & $\mathrm{n}$ & $\%$ & $\mathrm{n}$ & $\%$ \\
\hline 0 & 107 & 41.6 & 83 & 42.3 & 190 & 41.9 \\
1 & 89 & 34.6 & 61 & 31.1 & 150 & 33.1 \\
2 & 42 & 16.3 & 30 & 15.3 & 72 & 15.9 \\
3 & 11 & 4.3 & 11 & 5.6 & 22 & 4.9 \\
4 & 3 & 1.2 & 5 & 2.6 & 8 & 1.8 \\
5 & 3 & 12 & 1 & 0.5 & 4 & 0.9 \\
6 & 1 & 0.4 & 2 & 1.0 & 3 & 0.7 \\
7 & 1 & 0.4 & 1 & 0.5 & 2 & 0.4 \\
8 & 0 & 0.0 & 1 & 0.5 & 1 & 0.2 \\
11 & 0 & 0.0 & 1 & 0.5 & 1 & 0.2 \\
\hline Total & 257 & 56.7 & 196 & 43.3 & 453 & 100.0 \\
\hline
\end{tabular}

Table 3.13 Number of pregnancies previous to this one in percentnge

\section{The delivery}

The average duration of the pregnancy was 39.9 weeks for girls $(\sigma=1.4)$ and 40.0 weeks for boys $(\sigma=1.5)$.

The following table (3.14) gives a more detailed overview on matters concerning the delivery. Tables $3.15 \mathrm{a}$ and $3.15 \mathrm{~b}$ show combinations of facts concerning the delivery.

\begin{tabular}{|c|c|c|c|c|c|c|c|}
\hline & \multicolumn{2}{|c|}{ Boys } & \multicolumn{2}{|c|}{ Girls } & \multicolumn{2}{|c|}{ Total } \\
\hline & & $\mathrm{n}$ & $\%$ & $\mathrm{n}$ & $\%$ & $\mathrm{n}$ & $\%$ \\
\hline \multirow[t]{3}{*}{ Presentation } & Vertex & 254 & 92.7 & 209 & 91.3 & 463 & 92.0 \\
\hline & Breech & 19 & 6.9 & 19 & 8.3 & 38 & 7.6 \\
\hline & Transversal & 1 & 0.4 & 1 & 0.4 & 2 & 0.4 \\
\hline & & & & & & & \\
\hline \multirow{2}{*}{$\begin{array}{l}\text { Onset of } \\
\text { delivery }\end{array}$} & Spontaneous & 210 & 76.4 & 181 & 80.1 & 391 & 78.0 \\
\hline & Induced & 65 & 23.6 & 45 & 19.9 & 110 & 22.0 \\
\hline & & & & & & & \\
\hline \multirow[t]{4}{*}{ Delivery } & Normal & 213 & 77.5 & 187 & 82.7 & 400 & 79.8 \\
\hline & Forceps & 19 & 6.9 & 12 & 5.3 & 31 & 6.2 \\
\hline & Vacuum & 21 & 7.6 & 5 & 2.2 & 26 & 5.2 \\
\hline & Caesarean & 22 & 8.0 & 22 & 9.7 & 44 & 8.8 \\
\hline
\end{tabular}

Table 3.14 Facts concerning the delivery in percentage 


\begin{tabular}{|l|c|c|c|c|c|c|c|c|}
\hline & \multicolumn{2}{|c|}{ Breech } & \multicolumn{2}{c|}{ Vertex } & \multicolumn{2}{c|}{ Transversal } & \multicolumn{2}{c|}{ Total } \\
& $\mathrm{n}$ & $\%$ & $\mathrm{n}$ & $\%$ & $\mathrm{n}$ & $\%$ & $\mathrm{n}$ & $\%$ \\
\hline Spontaneous & 11 & 2.2 & 387 & 77.6 & 0 & 0.0 & 398 & 79.8 \\
Forceps & 0 & 0.0 & 31 & 6.2 & 0 & 0.0 & 31 & 6.2 \\
Vacuum & 0 & 0.0 & 26 & 5.2 & 0 & 0.0 & 26 & 5.2 \\
Caesarean & 24 & 4.8 & 18 & 3.6 & 2 & 0.4 & 44 & 8.8 \\
\hline Total & 35 & 7.0 & 462 & 92.6 & 2 & 0.4 & 499 & 100.0 \\
\hline
\end{tabular}

Table 3.15 a Overview of combinations of type of delivery and presentation

\begin{tabular}{|l|c|c|c|c|c|c|c|c|}
\hline & \multicolumn{2}{|c|}{ Breech } & \multicolumn{2}{c|}{ Vertex } & \multicolumn{2}{c|}{ Transversal } & \multicolumn{2}{c|}{ Total } \\
& $\mathrm{n}$ & $\%$ & $\mathrm{n}$ & $\%$ & $\mathrm{n}$ & $\%$ & $\mathrm{n}$ & $\%$ \\
\hline Spontaneous & 17 & 3.4 & 370 & 74.3 & 1 & 0.2 & 388 & 77.9 \\
Induced & 18 & 3.6 & 91 & 18.3 & 1 & 0.2 & 110 & 22.1 \\
\hline Total & 35 & 7.0 & 461 & 92.6 & 2 & 0.4 & 498 & 100.0 \\
\hline
\end{tabular}

Table $3.15 b$ Overview of combinations of the onset of delivery and presentation

\section{$\S 3.3 .3$ Peri-natal conditions}

In total 44 infants ( 23 girls and 21 boys) were born in meconium-stained amniotic fluid. Jaundice occurred in 172 infants, 68 girls and 104 boys. The mean period of jaundice was 4.4 days for boys and 4.1 days for girls. Most parents did not know the cause of the jaundice, but no infant had any long-term effect as a result of the jaundice. Of the 172 infants that developed jaundice, 95 were fed breast-milk at the time they developed the jaundice ( 42 boys and 53 girls).

\section{Duration of pregnancy and age of the infant}

There are several ways to determine the age of the infant at birth. Postconceptional age is the time from conception to birth, while the postmenstrual, foetal or gestational age is the time from the first day of the mother's last menstrual period until birth. To verify the age one can use ultrasound during the pregnancy or use the Dubowitz method at birth. In this study the gestational age was determined through the medical history given by the mother about her last menstrual period. Either the midwife or gynaecologist calculated the gestational age with this information, which was verified during the pregnancy with at least one ultrasound. The mean number of ultrasounds performed during the pregnancy was 2.3 in boys and 2.5 in girls ( $\sigma=2.0$ and 2.1 respectively). The age of the child at each measurement was calculated from the birth date, with the exception of preterm infants. In these infants, postmenstrual age is used at all examinations up to 40 postmenstrual weeks, irrespective of birth [17]. The average duration of the pregnancy in weeks was 39.6 weeks for girls $(\sigma=2.0)$ and 39.9 weeks for boys $(\sigma=1.8)$, which is around and about the length of full term for both the boys and girls. 


\section{Twins}

The smaller child at birth of a twin, by however small amount, usually remains smaller throughout life. If there is a large difference in size at birth, indicating some intrauterine stress to the smaller twin, the differences later in life, are usually still quite small because of strong recuperative force [5]. In total 22 twins were born $(3.6 \%)$. One twin pregnancy ended in a spontaneous abortion of one of the twins at almost 4 months into the pregnancy. The remaining foetus developed into a normal boy and was born at 40 weeks gestational age. The data of this infant were included in the overall analysis of this thesis. Table 3.16 gives an overview of the distribution of the sexes in the twins.

\begin{tabular}{|c|c|c|}
\hline Both females & $\begin{array}{c}\text { Female and } \\
\text { Male }\end{array}$ & Both males \\
\hline 9 & 7 & 6 \\
\hline
\end{tabular}

Table 3.16 Distribution of the sexes in the twins (absolute values). (One of the female/male twins was a twin in which the boy was diagnosed as having Down syndrome, the girl was a normal child.)

\section{$\S 3.3 .4$ Infant related issues}

\section{Health of the infants}

Those children that were known to suffer from any severe systemic disease, chromosomal abnormalities and syndromes or any other impairment that might limit the growth potential were excluded. Infants that were not registered as suffering from such a condition at birth but showed clinically significant indications were also excluded, prior to entering the trial. No information regarding how many infants were excluded due to these criteria is available.

One child with Down syndrome enrolled as it was one of a twin, and the mother preferred both children to participate. In the final calculations, the data of this child were not included.

During their first year of life two infants died. One as a result of complications from an acute meningitis infection and one died in a car-accident. The data available from these children were included in the calculations as neither cause of death had any influence on the growth of the child during its life.

\section{Duration of breast-feeding (if given)}

In chapter 6 a broad overview on breastfeeding is given.

\section{Age at which the child started to crawl/walk}

The mean age at which the boys started to crawl was 8.8 months $(\sigma=2.1)$ while girls started slightly earlier, at 8.5 months $(\sigma=2.1)$. There was not an obvious difference in age when boys and girls started walking, 13.0 months for boys and 12.9 for girls $(\sigma=2.4$ and 2.2 respectively). 


\section{Age at which the child started teething}

Some lack of appetite and therefore loss of weight can accompany teething. This has to be taken into account when evaluating the weight change of infants. The mean age to start teething was 7.0 months for both sexes $(\sigma=2.3$ for boys and 2.5 for girls).

\section{$\S 3.3 .5$ Birth specific anthropometric measurements}

At birth the midwife or gynecologist routinely measured the weight and often length and about $50 \%$ of the new-borns also had their head-circumference measured. Table 3.17 gives an overview of the averages of the measurements at birth for both the boys and girls. Unfortunately the accuracy of these measurements can not be determined as no double measurements were being performed by either the midwives or in the hospitals. For the other measurements during the course of the trial, double measurements were being performed to determine the accuracy. Chapter 4 will give the description and present the findings.

\begin{tabular}{|l|c|c|c|c|c|c|}
\hline & \multicolumn{2}{|c|}{ Weight at birth } & \multicolumn{2}{c|}{ Length at birth } & \multicolumn{2}{c|}{ Head-circumference at birth } \\
& $\mathrm{kg}(\sigma)$ & $\mathrm{n}$ & $\mathrm{cm}(\sigma)$ & $\mathrm{n}$ & $\mathrm{cm}(\sigma)$ & $\mathrm{N}$ \\
\hline Boys & $3.467(0.520)$ & 517 & $50.6(2.6)$ & 458 & $34.8(1.5)$ & 349 \\
Girls & $3.333(1.786)$ & 443 & $49.7(2.3)$ & 406 & $34.2(1.5)$ & 294 \\
\hline
\end{tabular}

Table 3.17 Anthropometric data at birth

For various parameters the head circumference $(\mathrm{HC})$ in $\mathrm{cm}$, the supine length (SL) in $\mathrm{cm}$ and weight (in $\mathrm{kg}$ ) at birth was calculated with the standard deviation. To retain a dataset of sufficient size the sample was not split up further into boys and girls for the other comparisons.

\section{External influences during pregnancy}

Various mothers took prescribed medication during (a period of the) pregnancy. There is no significant difference between the anthropometric measurements at birth for the group of infants that have been exposed to medication during the pregnancy and those who have not been exposed.

\begin{tabular}{|l|c|c|c|c|c|c|}
\hline & \multicolumn{2}{|c|}{ HC } & \multicolumn{2}{c|}{ SL } & \multicolumn{2}{c|}{ W } \\
& Mean & $\sigma$ & Mean & $\sigma$ & Mean & $\sigma$ \\
\hline No Medication & 34.7 & 1.7 & 50.4 & 2.4 & 3.413 & 0.524 \\
Medication & 34.4 & 1.4 & 50.3 & 2.5 & 3.356 & 0.499 \\
\hline
\end{tabular}

Table 3.18 Anthropometric data at birth in relation to medication intake of mother during pregnancy (HC: head circumference in $\mathrm{cm} ; \mathrm{SL}$ : supine length in $\mathrm{cm} ; \mathrm{W}:$ weight in $\mathrm{kg}$ )

Some mothers did not refrain from alcohol consumption during the pregnancy. There were no mothers in this sample that could be defined as abusing alcohol. Only 'social' alcohol consumption occurred. There was no significant difference 
between the anthropometric measurements at birth for the group of children that had been exposed to alcohol during the pregnancy and those who had not been exposed.

\begin{tabular}{|l|c|c|c|c|c|c|}
\hline & \multicolumn{2}{|c|}{ HC } & \multicolumn{2}{c|}{ SL } & \multicolumn{2}{c|}{ W } \\
& Mean & $\sigma$ & Mean & $\sigma$ & Mean & $\sigma$ \\
\hline No Alcohol & 34.6 & 1.6 & 50.4 & 2.4 & 3.398 & 0.529 \\
Alcohol & 35.0 & 1.3 & 50.5 & 2.4 & 3.436 & 0.455 \\
\hline
\end{tabular}

Table 3.19 Anthropometric data at birth in relation to alcohol intake of mother during pregnancy (HC: head circumference in cm; SL: supine length in $\mathrm{cm} ; \mathrm{W}$ : weight in $\mathrm{kg}$ )

Some mothers did not refrain from smoking during the pregnancy. Smoking during pregnancy can result in smaller children, both for weight and supine length. This can also be seen in this population.

\begin{tabular}{|l|c|c|c|c|c|c|}
\hline & \multicolumn{2}{|c|}{ HC } & \multicolumn{2}{c|}{ SL } & \multicolumn{2}{c|}{ W } \\
& Mean & $\sigma$ & Mean & $\sigma$ & Mean & $\sigma$ \\
\hline No Smoking & 34.9 & 1.5 & 50.7 & 2.2 & 3.473 & 0.497 \\
Smoking & 34.1 & 1.4 & 49.6 & 2.6 & 3.235 & 0.539 \\
\hline
\end{tabular}

Table 3.20 Anthropometric data at birth in relation to smoking of mother during pregnancy (HC: head circumference in $\mathrm{cm} ; S L$ : supine length in $\mathrm{cm} ; \mathrm{W}$ : weight in $\mathrm{kg}$ )

\section{$\S 3.3 .6$ Delivery parameters}

It isn't likely that either the supine length or weight can be of influence in the type of delivery. The head-circumference can be influenced by the type of delivery, as with a vaginal delivery moulage will occur, decreasing the headcircumference the first days, compared to a delivery by Caesarean section. Breech delivery is a sign of congenital malformations [18] [16].

\begin{tabular}{|l|c|c|c|c|c|c|}
\hline & \multicolumn{2}{|c|}{ HC } & \multicolumn{2}{c|}{ SL } & \multicolumn{2}{c|}{ W } \\
& Mean & $\sigma$ & Mean & $\sigma$ & Mean & $\sigma$ \\
\hline Spontaneous & 34.4 & 1.6 & 49.8 & 2.8 & 3.279 & 0.632 \\
Induced & 34.7 & 1.5 & 50.5 & 2.3 & 3.434 & 0.482 \\
\hline
\end{tabular}

Table 3.21 Anthropometric data at birth in relation to onset of birth (HC: head circumference in $\mathrm{cm}$; SL; supine length in $\mathrm{cm} ; W$ : weight in $\mathrm{kg}$ )

\begin{tabular}{|l|c|c|c|c|c|c|}
\hline & \multicolumn{2}{|c|}{ HC } & \multicolumn{2}{c|}{ SL } & \multicolumn{2}{c|}{ W } \\
& Mean & $\sigma$ & Mean & $\sigma$ & Mean & $\sigma$ \\
\hline Vertex & 34.2 & 1.9 & 48.8 & 3.1 & 3.059 & 0.698 \\
Breech & 34.7 & 1.5 & 50.5 & 2.3 & 3.422 & 0.502 \\
\hline
\end{tabular}

Table 3.22 Anthropometric data at birth in relation to presentation at birth (HC: head circumference in cm; SL: supine length in $\mathrm{cm} ; \mathrm{W}:$ weight in $\mathrm{kg}$ ) 


\begin{tabular}{|l|c|c|c|c|c|c|}
\hline & \multicolumn{2}{|c|}{ HC } & \multicolumn{2}{c|}{ SL } & \multicolumn{2}{c|}{ W } \\
& Mean & $\sigma$ & Mean & $\sigma$ & Mean & $\sigma$ \\
\hline First born & 34.7 & 1.5 & 50.4 & 2.4 & 3.444 & 0.523 \\
$\begin{array}{c}\text { Second born or } \\
\text { later }\end{array}$ & 34.4 & 1.5 & 49.9 & 2.3 & 3.376 & 1.769 \\
\hline
\end{tabular}

Table 3.23 Anthropometric data at birth in relation to first or later born (HC: head circumference in $\mathrm{cm} ; \mathrm{SL}$ : supine length in $\mathrm{cm} ; \mathrm{W}$ : weight in $\mathrm{kg}$ )

Events during the first months of life

Sometimes jaundice occurs in the first weeks of life. There is no significant difference between the anthropometric measurements at birth for the group of infants that developed jaundice and the ones that did not develop jaundice. Infants that receive breast feeding are more prone to develop (physiological) jaundice.

\begin{tabular}{|l|c|c|c|c|c|c|}
\hline & \multicolumn{2}{|c|}{ HC } & \multicolumn{2}{c|}{ SL } & \multicolumn{2}{c|}{ W } \\
& Mean & $\sigma$ & Mean & $\sigma$ & Mean & $\sigma$ \\
\hline Jaundice & 34.7 & 1.5 & 50.4 & 2.5 & 3.426 & 0.548 \\
No jaundice & 34.7 & 1.6 & 50.3 & 2.3 & 3.365 & 0.470 \\
\hline
\end{tabular}

Table 3.24 Anthropometric data at birth in relation to the occurrence of jaundice (HC: head circumference in $\mathrm{cm}$; SL: supine length in cm; W: weight in $\mathrm{kg}$ )

\section{Parental parameters}

It has been stated that the education of the father is correlated to the final height of his children [14]. In this population, the higher educated parents did give birth to taller and heavier children.

\begin{tabular}{|l|c|c|c|c|c|c|}
\hline & \multicolumn{2}{|c|}{ HC } & \multicolumn{2}{c|}{ SL } & \multicolumn{2}{c|}{ W } \\
Education & Mean & $\sigma$ & Mean & $\sigma$ & Mean & $\sigma$ \\
Father & & & & & & \\
\hline Group I & 34.5 & 1.6 & 50.6 & 2.1 & 3.254 & 0.576 \\
Group II & 34.7 & 1.6 & 50.2 & 2.4 & 3.359 & 0.563 \\
Group III & 34.6 & 1.4 & 50.2 & 2.3 & 3.388 & 0.461 \\
Group IV & 34.7 & 1.6 & 50.8 & 2.5 & 3.480 & 0.521 \\
\hline
\end{tabular}

Table 3.25 Anthropometric data at birth in relation to the education of father (HC: head circumference in cm; SL: supine length in $\mathrm{cm} ; \mathrm{W}$ : weight in $\mathrm{kg}$ )

\begin{tabular}{|l|c|c|c|c|c|c|}
\hline & \multicolumn{2}{|c|}{ HC } & \multicolumn{2}{c|}{ SL } & \multicolumn{2}{c|}{ W } \\
Education & Mean & $\sigma$ & Mean & $\sigma$ & Mean & $\sigma$ \\
\hline Group I & 34.2 & 2.2 & 50.4 & 1.9 & 3.123 & 0.616 \\
Group II & 34.4 & 1.5 & 49.9 & 2.4 & 3.324 & 0.540 \\
Group III & 34.7 & 1.6 & 50.2 & 2.3 & 3.398 & 0.488 \\
Group IV & 34.9 & 1.5 & 51.2 & 2.4 & 3.524 & 0.518 \\
\hline
\end{tabular}

Table 3.26 Anthropometric data at birth in relation to the education of mother (HC: head circumference in cm; SL: supine length in $\mathrm{cm}$; W: weight in $\mathrm{kg}$ ) 


\section{§3.4 Conclusion}

This chapter describes the trial population in numbers, depicted in figures and tables. Most data are in accordance with the national data, with the exception of the ratio girls : boys being born that year. For some reason, more girls than boys were being born. No explanation was found for this phenomenon. 


\section{References}

1. Various, Encarta. 1995, Microsoft: USA.

2. Verhulst, F.C., De ontwikkeling van het kind. 2001, Assen: Van Gorcum.

3. Roede, M.J. and J.C. van Wieringen, Growth Diagrams 1980, Netherlands Third Nationwide Survey. Tijdschrift voor Sociale Gezondheidszorg, supplement, 1985. 63(supplement 1985): p. 1-34.

4. Garn, S.M. and S.M. Bailey, The genetics of maturation, in Human Growth, J.M. Tanner and F. Falkner, Editors. 1986, Plenum: New york.

5. Tanner, J.M., Foetus into Man: physical growth from conception to maturity. second ed. 1989, London: Castlemead publications. 280.

6. Frederiks, A.M. De 'target height' als hulpmiddel bij het opsporen van groeistoornissen. in De vierde landelijke groeistudie (1997); Presentatie nieuwe groeidiagrammen. 1998. Den Haag: Bohn Stafleu Van Loghum.

7. Haworth, J., et al., Relation of maternal cigarette smoking, obesity, and energy consumption to infant size. Am J Obstet Gynecol, 1980. 138: p. 1185-1189.

8. Burgmeijer, R.J.F. and J.C. Wieringen van, Secular changes of growth in The Netherlands. Secular changes in Europe, ed. B.É. Bodzsar and C. Susanne. 1998, Budapest: Eötvös Univ Press. 233-262.

9. Rosenbaum, S., et al., A Survey of heights and weights of adults in Great Britain, 1980. Annals of Human Biology, 1985. 12: p. 115-127.

10. Elwood, P.C., et al., Growth of children 0-5 years with special reference to mothers smoking in pregnancy. Annals of Human Biology, 1987. 14: p. 543-558.

11. Jones, D.Y., M.C. Nesheim, and J.-P. Habicht, Influences on child growth associated with poverty in the 1970's: an examination of HANES I and HANES II. Cross sectional US national survey's. American Journal of Clinical Nutrition, 1985. 42: p. 714-724.

12. Wenlock, R.W., et al., The Diets of British Schoolchildren. 1986, London: HMSO.

13. Wieringen van, J.C., Seculaire groeiverschiving. Lengte en gewicht surveys 1964-1966 in Nederland in histories perspectief. 1972, Universiteit van Leiden.

14. Golab, S., Differentiation of the physical development in children and youth in relation to the socioeconomic and health status on the example of longitudinal studies in Nowa Huta, Poland. Acta medica auxologica, 1992. 24(3): p. 189-197.

15. Treffers, P.E., Praktische Verloskunde. 8 th ed. 1992, Houten/Zaventem: Bohn Stafley Van Loghum. 277.

16. Treffers, P.E., et al., eds. Obstetrie en Gynaecologie. 1st ed. 1993, Wetenschappelijke Uitgeverij Bunge: Utrecht. 795.

17. Brandt, I., Growth dynamics of low-birth-weight infants with emphasis on the perinatal period. 2 ed. Human growth: A comprehensive treatise, ed. F. Falkner and J.M. Tanner. Vol. 1. 1986, New York \& London: Plenum. 415-475.

18. Kloosterman, G.L., On intrauterine growth, the significance of prenatal care. Int J Gynaecol Obstet, 1970. 8: p. 895-912. 


\section{Chapter IV \\ Measurements and Accuracy}




\section{$\S 4.1$ Introduction}

When monitoring growth, the first step is the evaluation of single parameters. However, an essential second step, yielding much more information is the study of the relationships between several measurements and their changing in time. Anthropometry is the technique of quantitatively expressing the shape of the body. The shape of an infant changes rapidly, especially in the first year of life. To be able to observe the changes in man's body various measurements have to be taken. Besides uniformity in the technique of measuring, accuracy of the measurements is crucial. Supine length, weight and head circumference are widely used as parameters to monitor infant growth, of which weight is the most widely used parameter. However, considering that growth is defined as an increase in size and the process of maturing [1], then body weight is only partially informative since it is a derived value of growth and basically it only reflects the nutritional status of an infant [2]. So the supine length is more informative when evaluating the growth of an infant. To study the changes in body proportions in the growing infant the crown-rump length is necessary as an additional measurement to supine length. With the crown-rump length the change in the relationship between the lower extremities vs. supine length can be observed and the relationship between crown rump length versus subischial leg length. Next to these measurements the head circumference is a good parameter for short term growth and correlates well with skull volume [2].

\section{$\S 4.2$ Measuring techniques}

All children from birth onwards participating in this survey were measured at the infant-health-care centre by an assistant from the centre. In July 1993 and again in June 1994 all assistants were trained in measuring the infants according to one standard method. This is the same method as described by Cameron in his essay 'The Methods of Auxological Anthropometry' in the book Human Growth [3]. The measuring technique of the assistant was regularly observed by the author and where necessary further instructions were given. In order to evaluate the intra- and inter-individual reliability, several infants were being measured twice, either once by the assistant and once by the author or twice by the assistant or author. The outcome of these measurements will be discussed later in this chapter in the paragraph on reliability of the measurements.

The ages at which the infants were measured started at 3 weeks after birth. Then the infants were measured again at the ages of approximately 9, 13, 21, 31,40 and 50 weeks in the first year of life. Where necessary the author stood in for the assistants. In the second year of life the infants were measured at the age of 15 and 21 months. These measurements were all performed by the au- 
thor. It was decided, in order to create uniformity in the measurements, to measure the supine length and crown-rump length of all infants laying down till the age of two years as suggested by Tanner because it is sometimes difficult to get these infants to stand correctly [4].

\section{$\S 4.2 .1$ Head circumference}

At birth the head-circumference is about three-quarters of its adult value and the majority of postnatal growth occurs in infancy [5]. Therefore following the growth of the head during this period is very important. Head-circumference can also be used to describe changes in the shape of the body, when related to supine length and crown-rump length. To measure the head-circumference the young infant was held by one of the parents, preferably on the parent's lap, while the assistant measured the head-circumference, with a plastic non stretchable tape measure. Older infants may sit independently while being measured. The head-circumference should be the maximum circumference of the head. In general this is the circumference over the most extending point of the occiput and the most anterior protuberance of the forehead. In younger infants a protuberance of the forehead is not present, therefore the tape was placed just above the brow bridges. Having located the maximum circumference, the tape was gently tightened so as to compress hair. The headcircumference was recorded to the last completed millimetre accurate (i.e. it was not 'corrected up' if it appears to be nearer to the next millimetre). Figures $4.1 \mathrm{a}$ and $\mathrm{b}$ show the technique used to measure the head-circumference of infants.

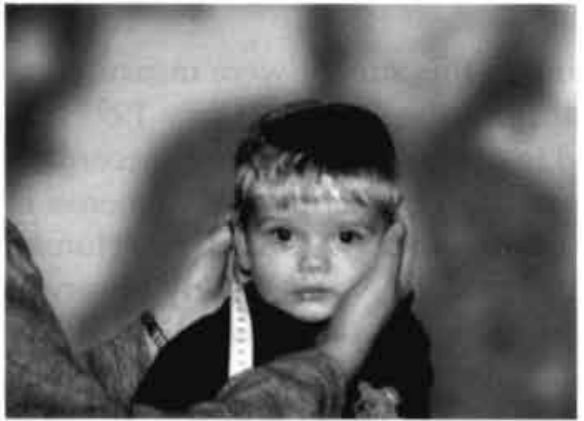

Figure 4.1a Front-view of the technique used to measure the head-circumference of infants

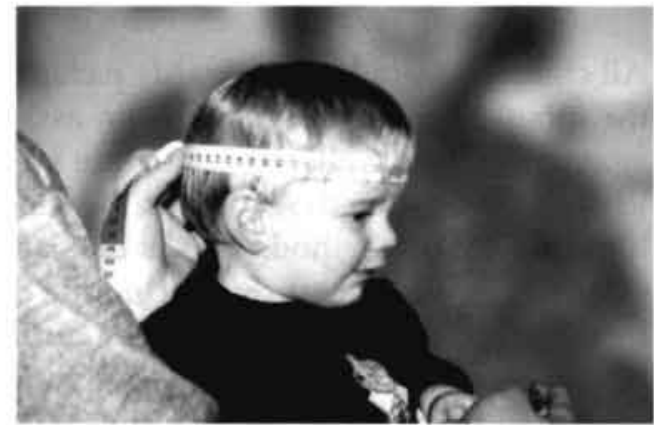

Figure $4.1 \mathrm{~b}$ Side-view of the technique used to measure the head-circumference in infants

\section{$\S 4.2 .2$ Weight}

Weight is frequently used as an index for growth. Although it is widely used, it is not always a very useful indicator for growth as an increase in weight can either be due to physical maturation of the body or to an increase in the fat or 
water content of the body or any combination of the above [6]. On the other hand even adequate growth might not be accompanied with an increase in weight, if, at the same time, the infant lost fat. Nevertheless, a very abnormal weight, or failure to gain weight at a satisfactory rate over a certain period of time, indicates that something is wrong and is a signal for further investigation of the infant's physical/mental health and/or diet [6]. Because weight is a very easy measurement and parents are always curious to know the infant's weight, it is important to take several items into account while evaluating the infant's weight. For instance; an infant who is very light as compared to his peers may be abnormally small or abnormally thin or both, while an infant who is unusually heavy for its age might be too fat or be just a big child and so proportionately be in balance. If an infant is not gaining weight at the expected rate for its age, he may be growing too slowly, or he might be growing at a satisfactory rate and losing fat (and if he was too fat in the beginning, this might be a good thing happening to him!). And finally, if an infant is gaining weight very rapidly he might be gaining too much fat, or he might be just growing fast and again from an anthropometrical point of view be in balance. Weight of the naked infant was measured with an electronic scale with digital readings. Before weighing an infant the scale was adjusted to zero. This was done each time an infant was weighed. The scale itself weighed the infant 8 times and displayed the average weight of these 8 independent measurements. Depending on the infants preference it was weighed either while laying down or sitting on the scale. Weight was recorded to the last completed 10 grams accurate. Figure 4.2 shows the technique used to weigh an infant. A cuddly toy, with a known weight, was available for infants if they needed distraction to sit calmly on the scale. In the unfortunate event that an infant was not willing to cooperate, both the parent and the infant were weighed on an electronic scale. The infant was then transferred to an assistant and the parent was weighed alone, so as to calculate the weight of the infants by the difference: (weight of parent + infant) weight of parent.

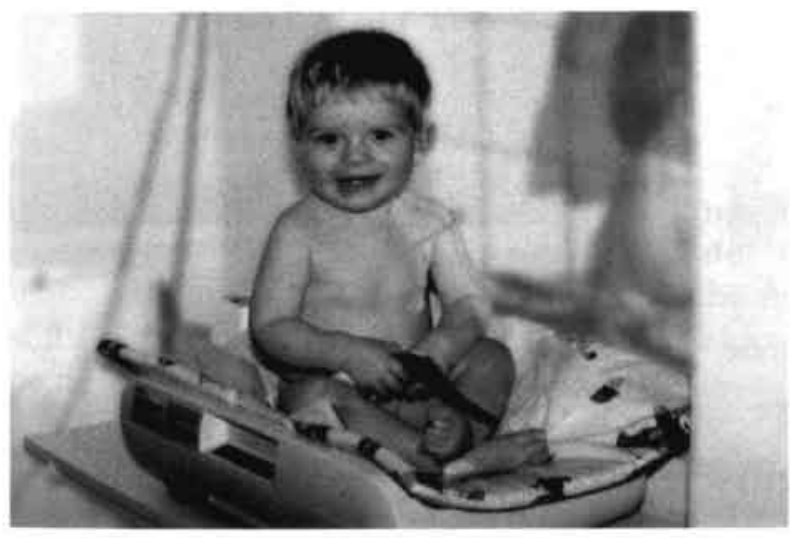

Figure 4.2 Techmique for measuring the weight of an infant. 


\section{$\S 4.2 .3$ Supine Length}

To evaluate the growth velocity of a child it is essential to measure the supine length on several occasions over a period of time. The minimum of time between the various measurements to be able to determine the growth velocity accurately depends on the age of the child and the accuracy of the measurements. The expected increment in supine length has to be greater than the cumulative errors in the two measurements independently. In infants this time span will be considerably smaller than in toddlers [7]. The supine length was measured with the aid of the infantometer similar to the well known Harpenden Infantometer. Infantometers are designed especially to monitor the post neonatal growth. The infant was measured naked. One of the parents stood directly behind the fixed headboard and held the infant's head so that the lower border of the orbits and the external auditory meati were in vertical plane firmly against the headboard. The assistant pulled the footboard firmly against the heels of the infant after the legs were straightened, the ankles right-angled and the toes pointing directly upward. The supine length was recorded to the last completed millimeter accurately. Figures $4.3 \mathrm{a}$ and $\mathrm{b}$ show the technique used to measure the supine length in infants.

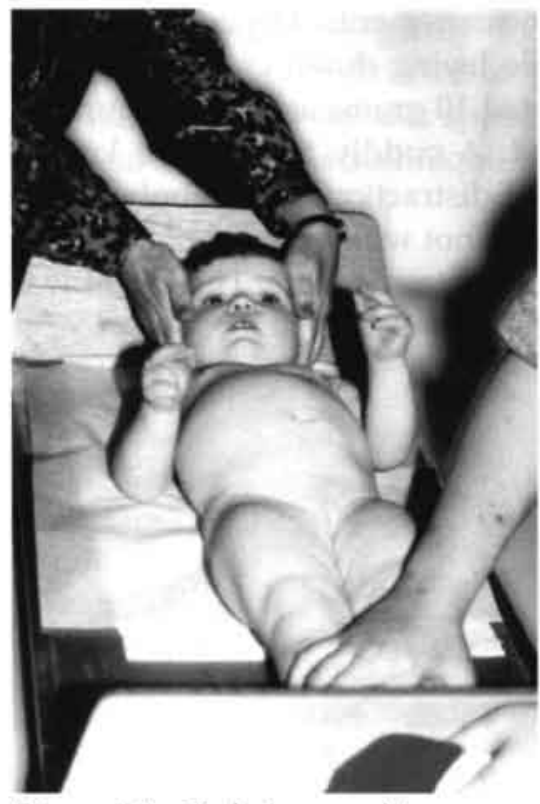

Figure $4.3 a$ Technique used to measure the supine length in infants

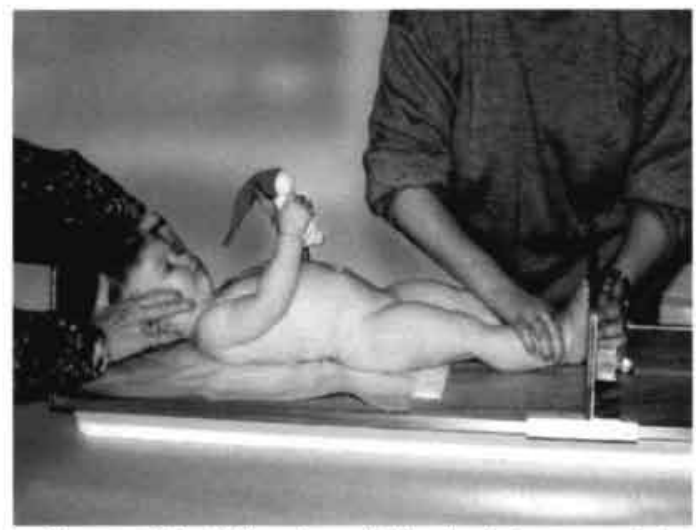

Figure $4.3 \mathrm{~b}$ Side-view of the technique used to measure the supine length in infants

\section{§ 4.2.4 Crown-rump Length}

The same infantometer was used to measure crown-rump length. The head of the naked infant is held against the fixed headboard by a parent standing di- 
rectly behind it. Gentle pressure is applied by the parent to bring the head into contact with the headboard while the assistant ensured that both the legs were bent at a right angle and the thighs were vertical. The movable footboard was brought into firm contact with the buttocks. The crown-rump length was recorded to the last completed millimeter accurate. Figure 4.4 shows the technique used to measure the crown-rump length in infants.

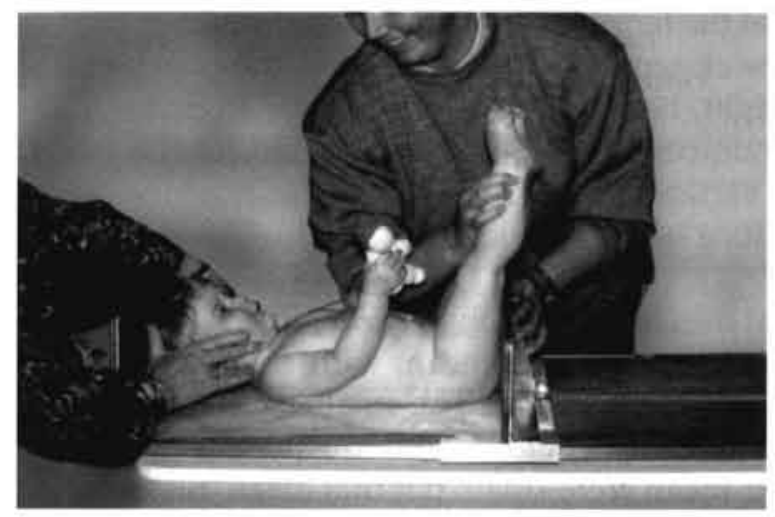

Figure 4.4 Technique used to measure the crown-rump length in infants

\section{$\S 4.3$ The accuracy of the anthropometric measurements}

Growth studies need to be evaluated on the accuracy of the anthropometric measurements because this gives information about the reliability of the study. Hindmarsh and Brook stated that the measurement of height can be 'extremely accurate' but Tanner warns that the 'heights measured in the average clinic can be inaccurate or even unreliable'. There is an error in all measurements and the validity of growth data depends critically on the reliability of the instruments, the measurers and the infant to be measured. Instruments today are definitely more accurate, which may be why many recent growth studies make no reference to any error of measurement at all. According to Vos et al. the difference in heights recorded by two different measurers may imply that either one or both the measurers is not measuring the 'true' height of the child, that is, the measurements are biased or there is no such a thing as the true height of a child. The variation of these differences may also be due to the variation of the actual value during the day, or the accuracy of the measurer, but still the greatest source of variability is the infant itself, as the ideal infant to be measured would be rigid [8].

Measurements taken by the same measurer on the same infant is called the intra-individual reliability, As mentioned earlier, one will discover that even dedicated well-trained measurers using the same protocol may nevertheless show some differences in precision. However, as long as these differences are not statistically significant, one can still use the data. The SD of a height meas- 
urement (or crown-rump length c.q head circumference for that matter), should not vary greatly with height (crown-rump length c.q head circumference) itself. The results of the reliability of the measurements should be used to improve the quality of future measurements, or even to ignore past measurements.

The definitions used are:

Reliability: the reliability of growth data depends on both accuracy and reproducibility. These are different, yet the terms are sometimes confused.

Accuracy: This is a measure of the closeness of observations to the target, in this case the 'true' height/sitting height/head circumference. With an accurate instrument, the mean of a large number of measurements would hit the target, irrespective of the size of their variance, provided the error is random. Badly installed equipment will introduce a systematic error, leading to inaccurate measurements.

Reproducibility (precision): Repeat measurements on the same infant often differ. Measurements will be distributed around their mean, with some spread that could be expressed as, for example, the variance. The smaller the variance the greater the reproducibility. Measurements could be reproducible without being accurate, if the spread about their mean were small, but that mean did not coincide with the target value.

Sources of variance: The instrument, measurer and infant are all sources of error, and the variance of each contributes to the total variance of measurement.

\section{$\S 4.3 .1$ Methods}

The double measurements were carried out within 10 minutes of the first measurement. The following double measurements were performed: height, sitting-height and head circumference. Weight was not re-measured, as an automatic, electronic, digital balance was used which integrates repetitive weightings and displays a figure when consistent.

The following questions are of interest:

1. Are there outliers and if so how often do these appear and are they related to the age of the infant?

2. Is the mean or the median of the differences in the double measurements close to zero?

3. Can the variability be expressed in terms of a common standard deviation and if so what are the precise values; in respect of these values are there differences between the various anthropometric measurements?

\section{$\S 4.3 .2$ Results}

Over the course of two years at various time point infants were being remeasured according to the protocol. In total 167 infants were being remeasured. The head-circumference was being remeasured on 121 occasions, the crown-rump length on 123 occasions and the supine length on 80 occasions. There was a 
general assumption at the infant welfare centers that measuring the supine length in newborns needed to be restricted due to any potential hip problems when stretching the legs and the unwillingness of newborns to cooperate. Therefore the number of re-measurements for supine length were less. The mean, medians and SD values of the difference (in $\mathrm{cm}$ ) as measured are given in table 4.1

\begin{tabular}{|l|c|c|c|}
\hline & $\begin{array}{c}\text { Head } \\
\text { circumference }\end{array}$ & $\begin{array}{c}\text { Crown rump } \\
\text { length }\end{array}$ & Supine length \\
\hline Minimum difference measured & -1.6 & -2.0 & -1.7 \\
\hline Maximum difference measured & 0.9 & 1.4 & 1.4 \\
\hline Mean of the difference measured & -0.03 & -0.10 & -0.01 \\
\hline Median of the difference measured & 0 & 0 & 0 \\
\hline SD of the difference measured & 0.27 & 0.56 & 0.54 \\
\hline $\begin{array}{l}\text { Standard error of the difference meas- } \\
\text { ured }\end{array}$ & 0.02 & 0.05 & 0.06 \\
\hline
\end{tabular}

Table 4.1 Statistical analysis of the accuracy of the various anthropometric measurements given in $\mathrm{cm}$

There isn't a significant difference between the measuring errors for the various anthropometric data. The difference between measurement one and two is equally distributed. This means that equally often the first measurement had a higher value as a lower value. When looking at the absolute values the mean for head circumference is $0.1 \mathrm{~cm}(S D=0.2)$, for crown rump length $0.4 \mathrm{~cm}(S D=$ $0.4 \mathrm{~cm})$ and for supine length $0.4(\mathrm{SD}=0.2)$. The minimum values are then, not surprisingly ' 0 ', the maximum values are $1.6 ; 2.0$ and $1.7 \mathrm{~cm}$ respectively. In regard to time, the SD diminishes, with the exception of the head circumference. This means that the measurements are more accurate when the infant is getting older, but head circumference remains difficult to measure accurately. The mean over the first 6 months of life is -0.1 for head circumference (SD = $0.27)$, crown rump length is $-0.1(S D=0.48)$ and supine length is $0.3(S D=0.85)$. For the following 6 months these values are $0.7(S D=0.14), 0.0(S D=0.28)$ and $0.1(\mathrm{SD}=0.59)$. In the first half of the second year these values are $1.2(\mathrm{SD}=$ $0.16), 0.0(\mathrm{SD}=0.29)$ and $-0.2(\mathrm{SD}=0.57)$ and for the second half of the second year of life the following differences were measured (in $\mathrm{cm}$ ): $1.6(\mathrm{SD}=0.15), 0.0$ $(\mathrm{SD}=0.11)$ and $0.0(\mathrm{SD}=0.1)$. This might be due to the fact that the older infant is less fussy and more cooperative about the whole process compared to a new born.

Finally a graphical representation of the difference in $\mathrm{cm}$ for head circumference, crown rump length and supine length, for age is given. 


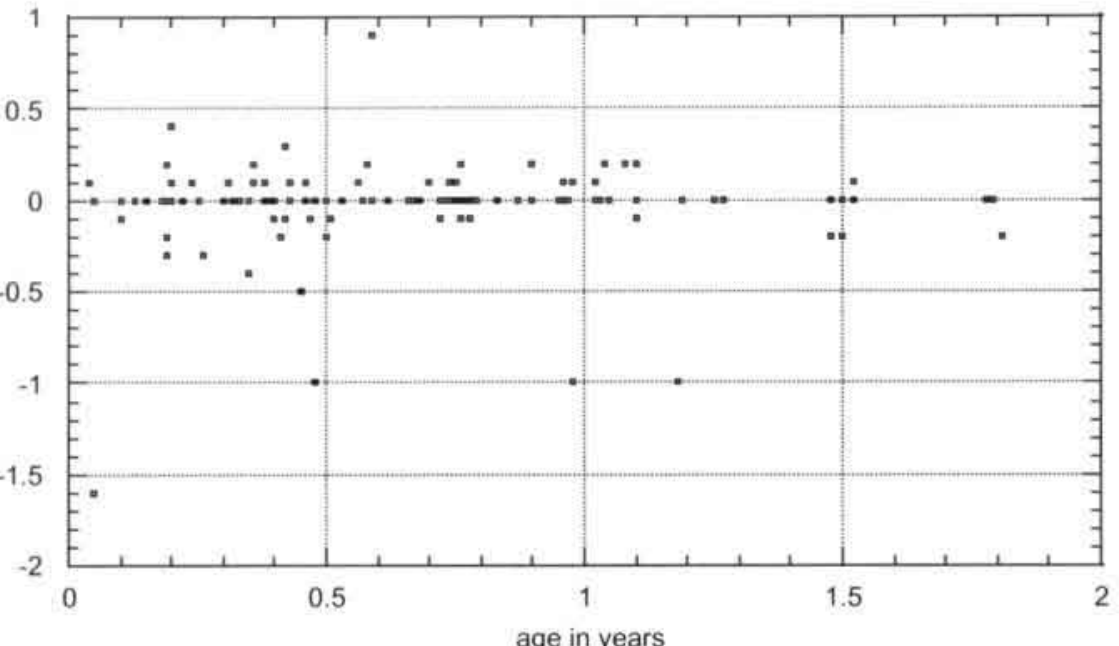

Figure 4.5: difference in $\mathrm{cm}$, between 2 consecutive measurements of the head circumference, to define the accuracy of the measurement

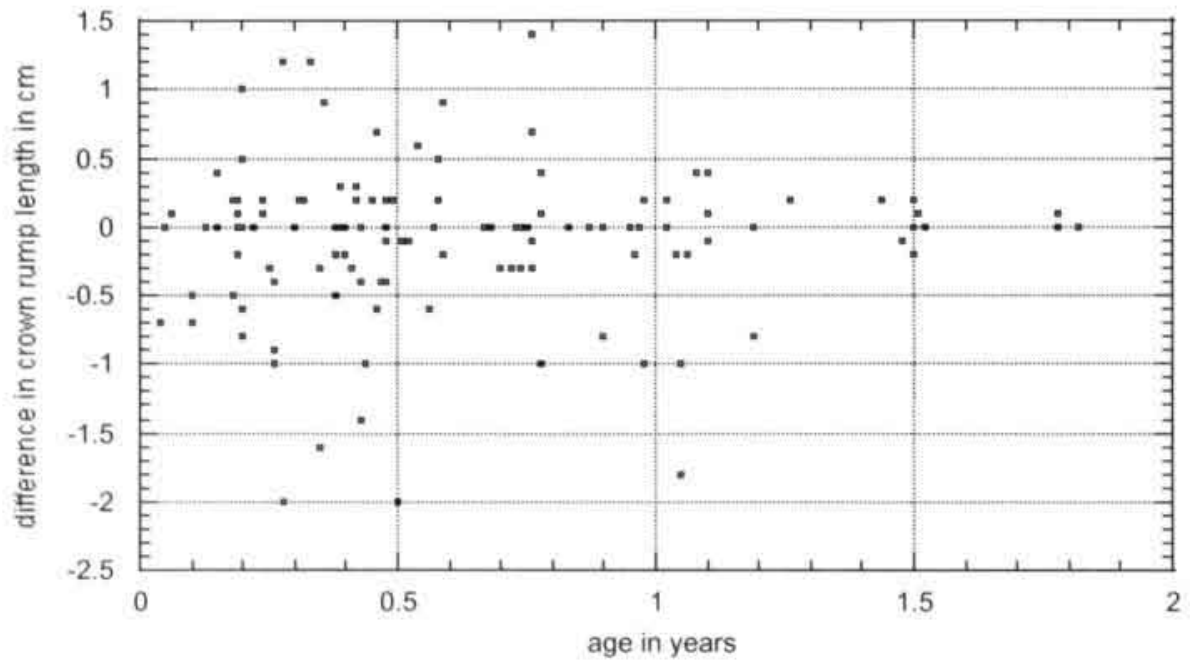

Figure 4.6: difference in $\mathrm{cm}$, between 2 consecutive measurements of the crown rump length, to define the accuracy of the measurement 


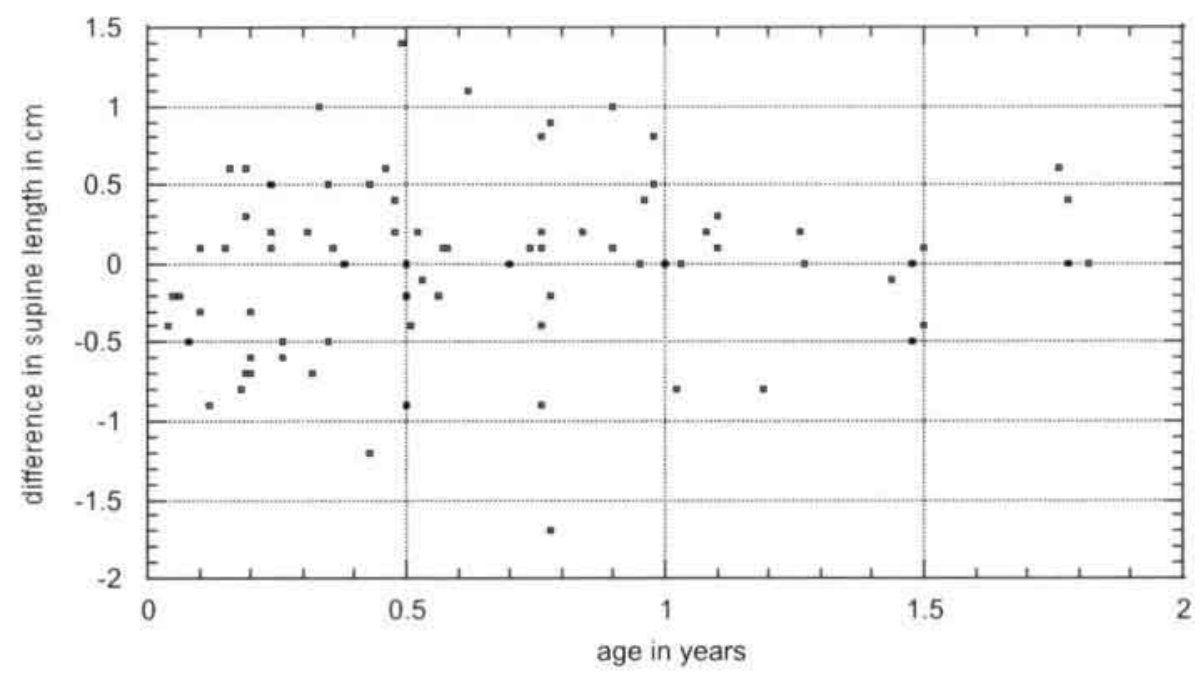

Figure 4.7: difference in $\mathrm{cm}$, between 2 consecutive measurements of the supine length, to define the accuracy of the measurement

\section{$\S 4.4$ Software}

The data was entered in the software program FilemakerPro. Calculations were made in Excel after the relevant data was converted from FilemakerPro into Excel. Simple statistical analyses were performed in SPSS while the more complex, multiregression analyses were performed in Stata. The graphs are made in Kaleidagraph.

\section{$\S 4.5$ Data management}

The anthropometric data were written down by the assistants on forms which were collected and entered manually by the investigator. When all data was entered, three checks were performed. All outliers were cross-checked with the paper files and corrected were necessary. First of all the z-scores and the SD was calculated for all data. A measurement was defined as an outlier if it exceeded three times the standard deviation. Furthermore a plot of all data was made to visualize the outliers. And finally for each infant four growth curves were plotted for the various anthropometric measurements. Outliers were defined as decreased angle of inclination of the curve, implying a decrease of growth. For head-circumference, supine length and crown-rump length this 
could not occur, but for weight a certain amount of decrease could exist without it being an error. After all outliers were checked and corrected where necessary the three checks were performed again as a final control. A final brief check was performed by Prof T. Cole and was graded as a good cleaned up data set.

\section{$\S 4.6$ Conclusion}

It is difficult to make cross study comparisons with other modern research projects for two reasons: First, the conditions under which the measurements were made have been inadequately described and cannot therefore be replicated by others [8]. Secondly, as Cameron pointed out, there is no commonly agreed terminology to express the error of height measurements. Looking at the data that have been collected, it can be concluded that the measurements have been performed quite accurately and the data are correct for the population and reproducible and adequate to use for further analysis. As the weight was determined by a scale that weighed the child 8 times, displaying the average value, no error of measurement was determined for this.

The questions of interest can now be answered:

The outliers are not extreme for head-circumference, supine length or crown rump length. The error of measurement is correlated to the age of the infant, with the exception of head circumference, which remains the same during the first two years of life. It means that with the increase of age, the measurements are both absolutely and relatively more accurate. One of the most important reasons for an improvement of the error or measurement might be that the measurements are easier to perform with an older and more flexible child and the infant is more cooperative to the procedure. Both the mean and median are (close to) 0 , determining that the error is equally distributed in both a positive and a negative error measurement. Unfortunately the error of measurement can not be expressed in a common standard deviation for all measurements. But for supine length and crown rump length that same standard deviation can be used: $0.55 \mathrm{~cm}$. The standard deviation for head circumference is about half of that: $0.27 \mathrm{~cm}$. But one has to take into account that the standard deviation diminishes with the increase of the age of the child. 


\section{References}

1. Kaplan, S.A., Clinical pediatric and adolescent endocrinology. 1982: W.B. Saunder technology.

2. Cortinovis, I., A. Bossi, and S. Milani, Longitudinal growth charts for weight, length and head-circumference of Italian children up to three years of age. Acta Med. Auxol, 1993. 25: p. 13-29.

3. Cameron, N., The methods of auxological antropometry, in Human growth: a comprehensive treatise, F. Falkner and J.M. Tanner, Editors. 1986, Plenum Press: New York \& London. p. 3-43.

4. Tanner, J.M., Foetus into Man: physical growth from conception to maturity. second ed. 1989, London: Castlemead publications. 280.

5. Hull, D. and D.I. Johnston, Essential Paediatrics. Third ed. 1993, Edinburgh: Churchill Livingstone. 365 .

6. Marshall, W.A., Human growth and its disorders. first ed. 1977, London: Academic press Inc. Ltd. 179.

7. Vanderschueren-Lodeweyckx, M., Growth Hormone Deficiency and Its Treatment: NovoNordisk. 87.

8. Voss, L.D., et al., The reliability of height measurement (The Wessex Growth Study). Archives of disease in childhood, 1990. 65: p. 1340-1344. 


\section{Chapter V \\ Growth Curves and Growth Charts}

Growth is the only evidence of life

- John Henry, Cardinal Newman- 


\section{$\S 5.1$ Introduction}

Growth data are used in several ways. Growth charts may indicate the general health and nutrition of a population. Growth charts of several generations can be compared and a secular trend might be noticed. A comparison between the charts of various or sub-populations can be made and a description of variations in human growth can be detected as Eveleth and Tanner [1] have done extensively in their book "The World-wide Variations in Human Growth." Another use for growth charts is to study the response to treatment of a child known to be ill. But the most commonly use for growth charts is for screening. Often the conclusion normal or abnormal growth is drawn for the evaluation of the growth of an individual child. There are arguments against this blunt approach based sometimes on just one single point on the curve. Firstly, one has to realize that the term 'normal' carries two distinct meanings. It can be seen as the 'norm', meaning the ideal or target. On the other hand it can be seen as 'typical' meaning commonly occurring. The value most commonly occurring is not necessary the norm as in the case of weight in some developing countries. While the mean weight is typical for that population, the target weight is at a higher level. The ideal situation is when the norm and typical are the same. Using a growth standard as a norm implies that it represents optimal growth, but a larger child is not necessarily a healthier child. Basically, a reference standard provides a reference, not a norm [2], so one can better speak of reference values than of standard values. Secondly, one point on the reference curve does not say anything about growth, because it is a dynamic process which can only be described by a series of measurements. One can compare this phenomenon with determining the speed of a car. Seeing just a photo of a car can't tell you anything about how fast it is driving. But by following the car for a certain period of time one can calculate its speed by the distance it has traveled in that certain period of time. Of course most of the paediatricians realize this and therefore will first collect several measurements of a child over a period of time. But still they usually draw conclusions of a longitudinal process by depicting the child's data on cross-sectional reference data. Longitudinal growth data are necessary to interpret the individual growth curve because they also give more information about the variation of the shape of the growth curve and the growth velocity. For each individual one estimates how much the deviation in relation to the norm can be accepted as normal. In fact not the position of each single measurement on the growth curve is important but the correlation between the various measurements - the shape of the child's curve - gives information on the growth process. 


\section{$\S 5.2$ Overview}

In 1885 Galton presented anthropometric percentiles to summarize the distribution of body measurements in human beings he had measured in his laboratory [3]. He compared the distribution of measurements for the two sexes by identifying the percentile for each sex where the distributions crossed, counting up for the men and down for the women. The 7 th percentile for men was the same as the 93rd percentile for women. This idea has been extended by Bowditch [4] by displaying percentiles of height on a chart, so they appeared as curves plotted against age. During the first half of the twentieth century, the use of growth charts expanded considerably as various sets of reference data for height and weight became available.

In the construction of reference charts one has to distinguish two processes: describing the growth curve and determining the distribution around the average value, or the centiles in the charts.

\section{$\S 5.2 .1$ Describing the human growth curve in structural and non- structural models}

Fitting the growth curve to a model can be applied to individuals or to a group of means related to age. Either way, the shape of the growth curve is very complex and a variety of models has been performed over the years. In the beginning this was done by hand, the most flexible way of 'fitting', but very biased and far from reproducible by others. One has to remember that smoothing involves steering a middle course between smoothness and goodness of fit, and therefore there is no best curve [2]. To develop a more objective way of curvefitting a spline or kernel smoothing procedure was introduced [5] [6]. Splines and kernels are basically a summation of simple curves, that provides smooth and flexible models, with limited support [7]. But still these are, like the handfitting, difficult to describe as a mathematical formula, but have to be presented as tables. So over the years many mathematical formulae have been develop to describe the human growth curve. Most of the time the whole growth process was divided into two groups; those applicable to the early part of life, when the growth velocity is dropping, and those formulas covering the whole of growth process including the pubertal growth spurt. The main drawback of describing the whole of the human growth curve is the considerably poor fits in particular parts of the curve or the numerous parameters necessary to establish a reasonable fit [8]. As this thesis is focused on the first two years of life, only the infancy models will be discussed.

There is a group of non-structural models, firstly introduced by Bock [9] to denote those models that do not postulate a particular form of the growth curve. They merely provide a good description, rather than an explanation, of the 
growth process. They mainly consist of polynomials of varying degrees, which provide a smoothing of individual serial growth data in order to suppress measurement error and short-term variation in growth rate (due to i.e. seasonal variation). Polynomials, at least in theory, can be made to fit curves of almost arbitrary shape [10]. The parameters are estimated by classical regression techniques by means of least squares. Their general form is:

$$
y=b_{0}+b_{1} t+b_{2} t^{2}+\ldots+b_{n} t^{n}
$$

where $y=$ size, $t=$ age and $b 0 \ldots$ bn, are the polynomial coefficients. Polynomials have the property that the means curve (this is the curve of the mean of all measurements at each age) is equivalent to the mean-constant curve (is the curve provided by the averages of the polynomial coefficients, obtained after fitting the function to each individual's serial data) [11]. This means that the mean-constant curve of polynomials suffers from the same limitations as the mean cross-sectional curve, in that it cannot adjust for the phase-difference effect in timing of the growth process, and that it will smooth out features which show a large inter-individual variability in the timing [12] [13]. One of the main drawbacks of the use of polynomials is that the number of parameters to be estimated is generally large and that there is no clear biological interpretation that can be given to them [8]. Furthermore they are not good at modelling curves that approach an asymptote, as the human growth curve does towards maturity. They need many terms to cope with this. But a comparable problem occurs with the velocity data shortly after birth when a period of rapid deceleration is followed by one of roughly constant growth rate [10].

Generally one can state that non-structural models are useful whenever interest lies in providing a smooth representation of the individual growth curve without imposing any priori functional form on the growth pattern [14].

Secondly, structural models have been developed. They are based on the idea that the growth pattern has a basic functional form to which a direct 'biological' interpretation can be attributed. An early model of infant growth was developed in 1937 by Jenss and Bayley [15]. It described the growth from birth till the age of 8 years as:

$$
y=a+b t-e^{(c+d t)}+\text { error }
$$

In 1943 Count developed the following formula, which fits the growth data from birth to 7 years of age [16]:

$$
y=a+b t+c \log (t)+\text { error }
$$

In both formulae $y$ stands for the measurements (i.e. height), $t$ is age, so $\log (t)$ is the natural logarithm of age, while a, b, c and d are parameters to be esti- 
mated. The Jenss formula consists of a linear component $(a+b t)$ in which parameter $\mathrm{b}$ determines childhood growth velocity. The exponential component $\left(\mathrm{e}^{\mathrm{c}+\mathrm{dt}}\right)$ determines the decreasing growth rate shortly after birth. As this formula contains 4 parameters it fits better than the Count-formula, especially during the first year of life. Count's model is linear in its parameters. Parameter b determines the velocity of pre-school growth, which typically becomes linear, while parameter c can be interpreted as the main component of rapid early childhood growth. To develop a better fit, the Count-formula has been used as a basis with slight changes by various mathematicians. The Count-formula has been expanded with a series of inverse age terms by Berkey and Reed [17] giving the following formula:

1st order

$$
y=a+b t+c \ln (t)+d / t
$$

2nd order

$$
y=a+b t+c \ln (t) d_{1} / t+d_{2} / t^{2}
$$

or the linear age was replaced with the square root of age, giving [18]:

$$
y=a+b \sqrt{t}+c \log (t)+\text { error. }
$$

The models by Berkey can accommodate one or more inflection points, allowing them to describe one or more periods of growth accelerations and thus fitting a wider variety of both normal and abnormal growth patterns in early childhood. However, if birth data is included then chronological age since birth can not be used (as $\ln (0)$ and $1 / 0$ are undefined) and an alternative age scale has to be chosen. The same problem occurs with Count's models. Berkey suggested the age transformation $t=($ months since birth +9$) / 9$ which assigns $t=0$ at conception and $t=1$ at birth [17]. The four-parameter model of Berkey $\{4 \& 5\}$ provided a much better fit than the Jenss model \{2\} [14].

Milani fitted linear growth functions with three constants and belonging to the following formula

$$
y(t)=a f_{s}(t)+b f_{b}(t)+c f_{c}(t)+\text { error }
$$

by ordinary least squares to individual growth records. He set $f(t)$ equal to $\ln (\mathrm{t}+1)$ (Count-formula) and $(\mathrm{t}+1)^{1 / 2},(\mathrm{t}+1)^{1 / 3},(\mathrm{t}+1)^{2}[19]$.

Karlberg developed the ICP-growth model for human growth, by means of non-linear least squares [20]. ICP stands for Infancy, Childhood and Puberty. For each of these different periods of growth he developed a specific formula. The formula that fitted the growth perfectly for the first three years of life was a 
simple quadratic. The infancy model was assumed to start during foetal life, a rapidly decelerating course, ceasing at 3 or 4 years of age:

$$
y=a+b(1-\exp (-c t))
$$

In this function $\mathrm{y}$ is attained body size for the relevant component at time $\mathrm{t}$ in years from birth.

In general it is found that lack of fit increases considerably for all functions when the length at birth was included in growth records. As a matter of fact it is merely impossible to describe the growth of an infant during its first weeks of life with a 3-constant formula. Using a second degree polynomial overestimates the length at the age of three months and underestimates the length at six months. The Count-formula as well as functions including square or cubic root, give lack of fit of a similar extent and generally of similar pattern [19].

\section{$\S 5.2 .2$ Constructing growth charts}

A growth reference is a dataset representing the distribution of a given anthropometric measurement as it changes with some covariant, commonly age, in the two sexes, based on a specified reference sample of children [2]. In an essay on auxology presented to J.M. Tanner on the occasion of his 75 th birthday, Cole described the construction of growth charts as a kind of a black art. It involves a subtle blend of art and science. Knowing the distribution centiles to the measurement at different ages the artist can draw them as smooth curves, so as to strike a balance between the appearance of the curves and their fidelity to the underlying distribution [21]. The methods of growth standards, i.e. converting reference data to smooth percentile curves, has changed enormously in recent years, with the advent of fast computers and improved statistical techniques. Originally the curves where drawn by eye, but recently there has been something of an explosion in the statistical and mathematical literature on the subject of macgyvering growth charts[2].

All these different approaches have their advantages and drawbacks. It is not the author of this thesis' intention to give an overview of all the proposed methods and discuss them, with their individual advantages and disadvantages. But one of the most important differences between the methods is whether they assume they are dealing with a normal distribution of their dataset or not. And if they are not dealing with a normal distribution how to cope with this problem. Any normal distributed anthropometric measurement, like height, can be converted to an SD (= standard deviation) score by subtracting from the mean height of reference children of the same age and sex, and dividing by the corresponding height SD (for the same age and sex). For instance; for height the formula would be: 
$\mathrm{SD}=$ (height of child - mean height for age and sex)/SD of height for age and sex An SD score is a normal distributed variable with mean zero and an SD of one. If the mean and SD increase smoothly with age, than the height corresponding to a particular SD score also increases smoothly. In a normally distribution, a SD score can be converted to a centile and vice versa [22]. Unfortunately not all anthropometric data are normally distributed. Weight, for instance, tend to skew with the right tail of the distribution being longer than the left. The same accounts for circumferences and skin folds. There are basically two different approaches to this problem: a parametric and a non-parametric method. The non-parametric is a direct method. This method makes no assumption about the shape of the distribution. To estimate the 25 th or 75 th percentile one arranges the, for example, 100 sample values in an ascending order and pick out the 25th value from the bottom and the top. Drawback of this method is that the centile estimates are imprecise (the worst the farther away from the median) and the centiles are very much influenced by extreme values, unless the sample is large. Using this method while the population has a normal distribution gives a large sampling error and has the same effect on precision as throwing away more than half the data [23]. Another way to approach the problem is to assume that weight has a normal distribution above and below the median at each age, but with a larger SD above than below [24]. A radically different method was proposed by Healy and co-workers [23]. This method is based on techniques for smoothing a scatter diagram as described by Cleveland [25] and involves two steps. First the measurements are sorted by age in an ascending order. The data are then grouped (typically in groups of $5-10 \%$ of the total number of measurements), in groups each of which overlaps the groups on either side by just one point; the first group has used points 1 to $\mathrm{k}$ of the data, the second group consists of data 2 to $k+1$, the third groups 3 to $k+2$ etc. The regression of each group is formed and their residuals are calculated. Centiles are derived from these by sorting and counting and their values are plotted against the median of the values. The points will be irregular and need to be smoothed to provide usable centile curves. The centiles have followed a smooth curve and the intervals between centiles at a fixed age should behave smoothly. So basically it involves smoothing the selected centiles non-parametrically and then fitting polynomial curves to them. The coefficients of the curves for each centile are related to each other in a way which forces the centile curves to be of smaller shape. The order of the basic polynomials can be chosen first, but a second degree polynomial will often be sufficient for short age-spans [23]. Although this is a very flexible method, their are two main drawbacks. Beside the fact that it is vulnerable, to a certain extent, to outlying values (like the majority of methods of this kind), it requires a very complex computer program to do the calculations. A more useful approach to deal with non-normal anthropometry is a power transformation of the data at each age to remove the skewness: Box-Cox transformation [26] [27]. This method has been modified to the LMSmethod [28], in which the L stands for lambda; the power transformation; the M for mu; the median and S for sigma; the coefficient of variation. The LMS 
method fits growth standards to all forms of anthropometry by making the assumption one is dealing with a skew distribution. Cole describes in his paper the method in the hope that it will encourage future investigators to use it [22]. The LMS-method has been used ever since for the construction of various growth charts i.e. the most recent NHS growth charts, Several existing data sets have been recalculated according to this method i.e. British, American NCHS and Dutch national height standards [29] [30]. As it is a logical, clear and an accepted method, this method has been used to make the charts for the Maastricht data set.

\section{§ 5.3 The LMS method}

As stated before, the LMS-method summarizes each standard with three smooth curves, one is the 50th centile, one represents the power needed to normalize the data and the coefficient of variation of the distribution at each age. With these curves any required centile can be drawn [22].

The application of the LMS method consists of two basic steps:

1. Skewness and power transformation

2. Fitting the LMS curves

\section{Step 1: Skewness and power transformation}

The power transformation reduces the asymmetry of the distribution. The best power transformation to use is the Box-Cox power [26]. The amount of asymmetry present depends on the coefficient of variation $(\mathrm{CV})$ of the distribution. Left skewness is removed with a power greater than one, while right skewness requires a power less than one. The best Box-Cox power can be identified as the one which gives the smallest coefficient of variation [28]. The power changes with age.

The next part is subdivided into four independent steps to calculate the best Box-Cox-power, mean and coefficient of variation in each of age groups and then letting them change smoothly with age.

\section{Defining the age groups}

First the data set was divided into distinct age groups with each consisting of at least 100 and should be as narrow as possible, especially in ages with a high growth rate as in the first months of life [22]. As the majority of infants in the sample were measured at distinct ages and the age groups were over 500 each, the original distribution was maintained. 


\section{Calculating $\mathrm{L}, \mathrm{M}$, and $\mathrm{S}$}

This stage involved the calculation of the power; $\mathrm{L}$, mean; $\mathrm{M}$, and the coefficient of variation; $S$ for each age group in turn [22]

First the mean and SD of the natural logarithms of the measurements were calculated. The antilog of the mean is the geometric mean of the measurement $(\mathrm{Mg})$. By analogy the SD is called the geometric CV or Sg. The mean and SD of the original measurements were calculated. This is the arithmetic mean (Ma) of the measurement. The SD was divided by $\mathrm{Mg}$ to give the arithmetic CV (Sa). The mean and SD of the reciprocals of the measurements were calculated. The reciprocal of the mean is the harmonic mean $(\mathrm{Mh})$ of the measurement. The SD was multiplied by $\mathrm{Mg}$ to give the harmonic $\mathrm{CV}$, (Sh). The values $\mathrm{Sa}, \mathrm{Sg}$ and $\mathrm{Sh}$ should be very similar and now they can be substituted into the equations:

$$
\begin{aligned}
& \mathrm{A}=\log (\mathrm{Sa} / \mathrm{Sh}) \\
& \mathrm{B}=\log \left(\mathrm{SaSh} / \mathrm{Sg}^{2}\right)
\end{aligned}
$$

where A and B should be very small. The estimate of the Box-Cox power $\mathrm{L}$ is then given by

$$
1=-A /(2 B)
$$

and its standard error is

$$
1 / \sqrt{ }(\mathrm{nB})
$$

where $\mathrm{n}$ is the number of measurements in the age group [28]

Next the generalized coefficient of variation $\mathrm{S}$ at this value of $\mathrm{L}$ was calculated

$$
\mathrm{S}=\mathrm{Sg} \exp (\mathrm{AL} / 4)
$$

This interpolates between the three coefficients of variation to find the minimum value, so that $\mathrm{S}$ is slightly smaller then $\mathrm{Sa}, \mathrm{Sg}$ and $\mathrm{Sh}$. The approximate standard error of $\mathrm{S}$ is then

$$
S=\sqrt{ }\left(\left(S^{2}+1 / 2\right) / n\right)
$$

Finally, the generalized mean $\mathrm{M}$ for power $\mathrm{L}$ is obtained by interpolating between $\mathrm{Ma}, \mathrm{Mg}$ and $\mathrm{Mh}$ to give

$$
\mathrm{M}=\mathrm{Mg}+(\mathrm{Ma}-\mathrm{Mh}) \mathrm{L} / 2+(\mathrm{Ma}-2 \mathrm{Mg}+\mathrm{Mh}) \mathrm{L}^{2} / 2,
$$


with standard error

$$
\mathrm{MS} / \sqrt{\mathrm{n}}
$$

Note that the standard errors of L, M and S are all inversely proportional to the square root of $n$, the number of children in the age group.

\section{Step 2: Fitting the LMS curves}

Drawing the $\mathrm{L}, \mathrm{M}$ and $\mathrm{S}$ curves

The next stage is to plot the values of L, M and S obtained from each group against the group mean ages, to give separate graphs for $\mathrm{L}, \mathrm{M}$ and $\mathrm{S}$. A smooth curve is drawn through each set of points, to give the L curve, the M curve and the $S$ curve, respectively. This curve fitting can be done, theoretically, by complicated statistical methods or by eye [22]. Here a polynomial equation was used.

Obtaining the centile curves

After the curve fitting, the centiles can be calculated from them. The 50 th centile is the median and is exactly equivalent to the $M$ curve. To calculate the other centiles the L and S curves are also necessary. From the SD scores the corresponding centiles can be calculated (see table 5.1). To ensure a smooth centile curve, the age groups for which each centile is calculated has to be closer together than the age group means. For each age and SD score, the L, M and S from the curves was read and substituted into the equation:

$$
\mathrm{C}=\mathrm{M}(1+\mathrm{LSZ})^{1 / 1}
$$

as to give the required centiles $C$. This gives a table of centiles at each age and all these values for each centile and each age were plotted. A smooth curve was drawn through these points as to give the centile curve.

\begin{tabular}{|l|c|c|c|c|c|c|c|c|}
\hline Centile & $\mathbf{1}$ & $\mathbf{2}$ & $\mathbf{2 . 5}$ & $\mathbf{3}$ & $\mathbf{5}$ & $\mathbf{1 0}$ & $\mathbf{2 5}$ & $\mathbf{5 0}$ \\
\hline SD & -2.326 & -2.054 & -1.960 & -1.881 & -1.645 & -1.282 & -0.674 & 0.000 \\
\hline
\end{tabular}

\begin{tabular}{|l|c|c|c|c|c|c|c|c|}
\hline Centile & $\mathbf{9 9}$ & $\mathbf{9 8}$ & $\mathbf{9 7 . 5}$ & $\mathbf{9 7}$ & $\mathbf{9 5}$ & $\mathbf{9 0}$ & $\mathbf{7 5}$ & $\mathbf{5 0}$ \\
\hline SD & 2.326 & 2.054 & 1.960 & 1.881 & 1.645 & 1.282 & 0.674 & 0.000 \\
\hline
\end{tabular}

Table 5.1 Values for the SD score corresponding to some commonly used centiles 


\section{$\S 5.4$ Choosing centiles or standard deviations?}

Different centiles have been used around the world over the years in growth charts as references. Although it is generally accepted that the centiles should be symmetrical above and below the median curve [31], there are basically three different sets of centiles being used over the years. In Europe for height and weight charts, the $3 \mathrm{rd}, 10$ th and 25 th centiles are used below the median and the 75th, 90th and 97th centile above the median. While in North America the 5th and 95th are generally used instead of the 3rd and 97th. The World Health organization prefers to use SD scores instead of centiles. They use $-3,-2$ and -1 SD score below the median and $+3,+2$ and +1 SD above the median [31]. There isn't a definite rule as to which is better. The differences are merely due to different requirements. While in Europe and North America the majority ( $94 \%$ and $90 \%$ respectively) lie between the two extreme centiles. The countries in which the WHO charts are used (mainly the developing countries), many children lie below the 1st centile, which makes a classification based on centiles useless. In practice there is no need for three different growth charts. So as to determine which centiles to chose, the main question that has to be answered is: in the case of a certain chosen centile as a cut off point for further investigation in a clinic, how many false positive referrals will there be. Then why not use one format world-wide, which integrates the different approaches of centiles and SD scores. The problem with determining the extreme centiles, though, used to be the accuracy. In a small data set, the extreme centiles are highly influenced by extreme values (i.e. measuring errors) from that data set. With a large sample and the improved statistical methods, a reliable 3 rd or even lower centiles can be calculated [23] [28]. Lately the American National Center for Health Statistics started to use the 3rd centile instead of the previous preferred 5 th centile.

Looking back on the referral dilemma, one has to realize that if the 5 th centile is used as the cut off point, $5 \%$ of normal children, without any medical problem might be referred, closely followed and/or medically evaluated. Using the 3rd centile, this will be done in only $3 \%$. So, it is important to find a cut off point that has a low false positive score, but still will extract those children with a medical problem from the population. Nowadays in Britain an integration of centiles and SD scores is used. The -2 SD scores is close to the 3rd centile, similarly the 10th and 25th centile are closely related to -1.33 SD score and -0.67 SD score respectively ( 9 th centile and 25 th to be more precise). This way the centiles curves are equally spaced; two thirds of a standard deviation apart. Although in this way the -1 SD score and -3 SD score curves as proposed by the WHO are not presented in the chart, the -1 SD is of little use anyway. The $-3 \mathrm{SD}$ could be retained, but to stay in the 'rhythm', the -2.667 SD score could be used instead. This would still be useful for usage in the developing countries. This way a chart with nine equally spaced centiles is constructed $(-2.67 \mathrm{SD},-2.00 \mathrm{SD}$, $-1.33 \mathrm{SD},-0.67 \mathrm{SD}, 0 \mathrm{SD},+0.67 \mathrm{SD},+1.33 \mathrm{SD},+2.00 \mathrm{SD},+2.67 \mathrm{SD})$ in which the 
skewness of the distribution can more easily be taken into account and be visualized in the reference chart. The advantage of these curves is that there is a region, between the two lowest centiles, in which the physician can determine to refer or wait. Another advantage of the use of the -2.776 SD curve is the fact that parents seem to be easier reassured that their child is growing normally as long as there is still a centile under their child's curve. It seems that this centile functions as a psychological safety net for worried parents. If the $-2.667 \mathrm{SD}$ score is used as the definitive referral border only 1 in 260 children will be a false positive referral in contrast to 1 in 44 when the -2 SD would have been used. Furthermore it enables physicians to calculate growth deviations, as described in paragraph 5.5, which makes the evaluation of a child's growth more objective. The approach for developing growth charts using SD-curves instead of centiles, has been promoted to use universally. Even at a recent meeting of the Dutch Association of Small People the use of SD's has been suggested too. By unifying the next generations of growth charts world-wide, it is possible to compare charts and improve the chart's clinical utility [31].

\section{$\S 5.5$ Conditional reference charts}

To evaluate an infant's growth the consecutive measurements of this infant have to be plotted on a growth chart. Growth charts consist of several curves presenting the various centiles and SD's. As stated earlier in this thesis it is wrong to expect children to grow along or parallel to one of these centiles. So, although a child at a certain age is, say on the 75th centile, it doesn't have to be on the 75th centile when measured again a couple of months later. Especially during infancy the growth process has a very whimsical course. The growth of a foetus is mostly influenced by maternal factors, i.e. mothers height besides smoking, alcohol use and/or smoking during pregnancy [32]. Size at birth is the individual end product of growth and development during foetal life, the period of the fastest growth and the highest vulnerability. The size reached at birth forms the basis for the future growth and development and, when related to gestational age, summarizes the overall foetal growth rate from conception to birth [33]. Besides that it is found that in general infants with genes determining for large size, but born to (too) small mothers move upwards through the centiles, while infants born large but with genes determining small size move downwards [32]. The upward shift, or catch-up growth is mostly completed within six months after birth, while the downward shift, or catch-down growth, takes up to 18 months to accomplish [34]. It is important to realize that these phenomena are all about averages. The mean question that rises is how much an infant is allowed to deviate from the centile it started from. In other words, how many centiles is an infant allowed to intersect before further investigation is necessary to exclude any pathology. 
To answer this question a statistical approach to the problem might bear the solution. The basic assumption that has to be made is that infants in general tend to become less extreme over a period of time, they tend to drift or regress towards the mean [35]. So what it comes down to is the following. Knowing nothing about an infant, one will assume that the weight of this infant will be average, that it is around the 50th centile. Knowing the history of this infant will change ones perspective on where an infant's position on the curve is. If, for instance, the infant's weight was on the 10th centile at an earlier point in time, it is now less likely for this infant to be on the 50th centile. Depending on how much an infant has drifted it's position can range from one extreme (10th centile) to another extreme (50th centile). Either possibility is very unlikely, so the actual position of this infant on the chart will presumably be somewhere in between. If the infant has remained on the same centile, there would have been a perfect correlation between the two measurements. This is called perfect tracking, which is almost impossible. There will always be a noticeable regression to the mean. But the important thing is to quantify the amount of regression between two points in time. This should not be mistaken with the velocity. Traditionally there have been two kinds of charts: distance and velocity charts. The first one depicts the total attained amount of weight (or length etc.) at a certain age. The second one reflects the gain of weight (or length etc.) between two ages. The last one implies that all children of a particular age have the same expected velocity, which is not true. Light infants tend to increase more weight than heavier infants do. The same applies, for instance, for small infants at birth. Individuals in the tail of the distribution on the first occasion are likely to be less extreme subsequently, so that those who start small grow faster and vice versa [2]. Therefore, it is more important to determine correlations between measurements at various ages, than to calculate the growth velocity alone. This can be done by developing conditional reference charts, they take the association between distance and velocity into account. These charts depict the correlations between distinct ages. To determine the correlation for any age intermediate to the measurement ages, they have to be interpolated from the known correlations, by means of a regression analysis, where the correlation is modelled as a function of the two ages of measurement. In this analysis, each pair of ages is converted to its mean on the one hand, and the time gap between ages on the other [35]. The need for a conditional chart rather then a velocity chart during puberty has been emphasized repeatedly by Tanner [36]. Unfortunately the need for conditional charts during infancy has been less recognized [37], although catch-up growth during this period is know to have a major effect on centile position [34]

To construct these conditional reference charts all data have to be converted to SD-scores first. This was done by using the data of the Netherlands third Nation- wide Survey [38]. This is done to correct any non-normal distribution. Let $r$ be the correlation coefficient between the SD-score of a measurement at the 
first point in time (SDS1) and the SD-score at a second point in time (SDS2). The predicted value of SDS2 is then given by

$$
\mathrm{SDS}_{2}=\mathrm{rSDS}{ }_{1}
$$

with a normal distribution

$$
\operatorname{SD} \sqrt{ }\left(1-r^{2}\right)
$$

A regression coefficient below 1 indicates appreciable regression to the mean. If $\mathrm{r}<1$, SDS2 is approaching one (the median) with the passing of time. The equation representing conditional increase or SDS increase is then as follows:

$$
\mathrm{SDS}_{\text {increase }}=\left(\mathrm{SDS}_{2}-\mathrm{r} \mathrm{SDS}_{1}\right) / \sqrt{ }\left(1-\mathrm{r}^{2}\right)
$$

and can be expressed as a centile. The correlation coefficient $r$ between SDS1 and SDS2 varies according to the two ages of measurement. But generally, the smaller the time gap between measurements and the greater the mean age, the higher the correlation [35]. Each of the calculated correlations $\mathrm{r}$ is transformed by means of Fisher's transformation [39]

$$
Z=1 / 2 \log _{e}((1+r) /(1-r))
$$

Let $\mathrm{n}$ be the sample size, then the correlation variances is given by $1 /(\mathrm{n}-3)$. The transformed correlation can be modelled as the dependent variable in a multiple regression equation involving sex, powers of the mean age and time interval, and interactions between them. The value $Z$ predicted from the regression equation for a particular pair of ages can then be converted back to a correlation using the formula:

$$
r=(\exp 2 Z-1) /(\exp 2 Z+1)
$$

and substituted into equation $\{9\}$.

This way a correlation matrix can be constructed for the distance SD score of either weight, supine length, crown-rump length or head-circumference at each of the various measurements. In this matrix the interdependent correlations between ages and SDS is given. Such a matrix will have the following structure. Let say, having measured a group of infants five times ( $\mathrm{t} 1 \ldots \mathrm{t} 5)$ in total 10 correlations coefficients $(\mathrm{r})$ can be calculated giving the following matrix: 


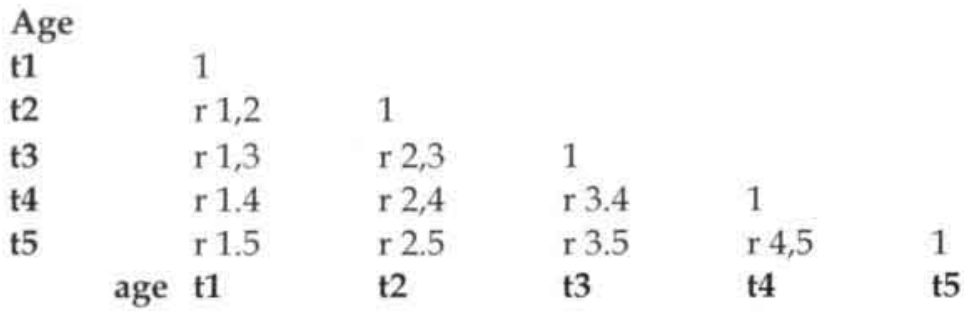

Table 5.2 Matrix for determining the correlation coefficients for 5 different points in time.

These kind of matrixes are important for clinical use. After all the main question to solve is determining how many centiles an infant is allowed to intersect before further investigation is necessary. It is not only the number of centiles an infant intersects that determines the likelihood of a growth disorder, but more important is which centiles this infant has crossed. Knowing an infant's position on the curve at the first measurement and again at a second occasion, can determine what percentage of infants have followed the same course in growth during that same period of time. By substituting the SDS1 and SDS2 in equation \{9\} with the observed SDS' and looking up the corresponding $\mathrm{r}$ for that age interval in the matrix the SDS increase can then be calculated. This SDS increase can then be converted into a centile which represents the percentage of infants who have followed the same growth pattern. By doing this it is possible to determine whether a certain deviating growth curve of an infant is either a sign of faltering growth or just regression to the mean. As long as the infants are being measured at ages close to those given in the matrix it is easy to calculate the SDS increase. Unfortunately not all infants are being measured at the same age, but by interpolating between the ages in the matrix, using a regression model of the transformed correlation as a function of the two measurement ages, this problem can be solved [35]. In chapter 7, where the correlation matrixes are presented, an example of the calculation will be given.

The next step is to display the conditional increase of SDS preferably in the same chart as the distance SDS. A way of doing this is by converting the distance centiles to horizontal lines, and letting the conditional centiles be symmetric curves that shrink towards the median with increasing age. In such a chart lines representing the same length (or weight/crown-rump-length/headcircumference) are used to plot the data of an infant. These particular lines representing the same value for a certain measurement, whether it be weight, length, crown-rump length or head-circumference are called isolines. To draw isolines, the measurement in the following formula is set to a certain value which is required and the appropriate values of $\mathrm{L}, \mathrm{M}$ and $\mathrm{S}$ for a series of ages are also substituted.

$$
\text { SDS }=\left((\text { Measurement } / M)^{L}-1\right) /(L \times S)
$$


This resulting series of SDS' plotted against age gives the isolines. The advantage of conditional charts is that it can be calculated over a longer period of time to reduce the effect of measurement error.

\section{$\S 5.6$ Conclusion}

Over the years different mathematical methods have been developed to describe construct growth charts. Various sets of reference curves are being used in the growth charts in various countries. The main difference is either the use of centiles or standard deviations. Even within the use of centiles differences occur as sometimes the $3^{\text {rd }}$ and $97^{\text {th }}$ centile lines are being used while at other times the $5^{\text {th }}$ and $95^{\text {th }}$ centiles are being used to define the limits of 'normal' growth. When using standard deviation, the +2.67 SD en $-2.67 \mathrm{SD}$ is mostly used for this purpose. All of them are based on the same fundamentals and have a similar purpose. The aim of the growth chart is to plot a child's growth data to assess the child's growth and to detect any possible growth disorders as soon as possible. The aim is to use a chart that lets you find all the children with a growth disorders, without having 'normal' small for age children being diagnosed as having a possible growth disorder. Hence a chart that has a high reliability by means of having a small chance of a false positive finding. Using the standard deviations has the following advantages compared to the use of centiles. First of all the false positive score is more beneficial, the skewness of the distribution, especially for weight, is better taken into account, and it enables the physician to evaluate the growth more objectively by means of calculating the possible growth deviation. Therefore the use of standard deviations is increasingly becoming the standard way of presenting reference growth charts. It is also important to realize that the growth of a child is a dynamic process and evaluation can only be done after various measurements, to see whether or not the shape of the growth curve of the child deviates from the reference growth chart. A conditional growth reference chart can be helpful for this assessment. Whatever type of growth standard is used, it is important to know the possible effects of using a standard which is inappropriate for the data [2]. 


\section{References}

1. Eveleth, P.B. and T. J.M., Worldwide variation in human growth. Second ed. 1990, Cambridge: Cambridge university Press. 397.

2. Cole, T.J., The use and construction of anthropometric growth reference standards, in Nutrition Research Reviews. 1993. p. 19-50.

3. Galton, F., Antropometric percentiles. Nature, 1885. 31: p. 223-225.

4. Bowditch, H.P., The growth of children, studied by Galton's method of percentile grades. 1891, boston: Wright \& Pooter.

5. Stützle, W., et al., Shape-invariant modelling of human growth. Annals of Human Biology, 1980. 7: p. 507-528.

6. Cole, T.J. and P.J. Green, Smoothing reference centile curves: the LMS method and penalized likelihood. Statistics in medicine, 1992. 11: p. 1305-1319.

7. Guo, S., et al., Kernel regression for smoothing percentile curves: reference data for calf and subscapular skinfold thickness in Mexican Americans. American journal of Clinical Nutrition, 1990. 51: p. 908S-916S.

8. Preece, M.A. and M.J. Baines, A new family of mathematical models describing the human growth curve. Annals of Human biology, 1978. 5: p. 1-24.

9. Bock, R.D. and D.M. Thissen, Statistical problems of fitting individual growth curves, in Human physical grouth and maturation, J. F.E., A.F. Roche, and C. Susanne, Editors. 1980, Plenum Press: New York and London. p. 265-290.

10. Healy, M.J.R. Growth curves and growth standards - the state of the art. in Perspectives in the science of growth and development. 1989: Smith-Gordon.

11. Merrell, M., The relationship of individual growth to average growth. Human Biology, 1931. 3: p. 37-70.

12. Marubini, E., Mathematical handling of long-term data, in Human Growth; Principles and prenatal growth, F. Falkner and J.M. Tanner, Editors. 1978, J.M. Bailière Tindal: London. p. 209-225.

13. Marubini, E., The fitting of longitudinal growth data of man, in Auxology: human growth in health and disorder, L. Gedda and L. Parisi, Editors. 1978, Academic Press: London, New York and San Fransisco.

14. Hauspie, R.C., Mathematical models for the study of individual growth patterns. Rev. Epidem. et sante publ, 1989. 37: p. 461-476.

15. Jenss, R.M. and N. Bayley, A mathematical method for studying the growth of a child. Human iology, 1937. 9: p. 556-563.

16. Count, E., Growth pattern of the human physique. Human Biology, 1943. 15: p. 1-32.

17. Berkey, C.S. and R.B. Reed, A model for describing normal and abnormal growth in early childhood. Human Biology, 1987. 59: p. 973-987.

18. Guo, S., A.F. Roche, and D.L. Yeung, Monthly growth status from a longitudinal study of Canadian infants. Canadian Journal of Public Health, 1990. 81: p. 215-221.

19. Milani, S., A. Bossi, and E. Marubini, Individual growth curves and longitudinal growth charts between 0 and 3 years. Acta paediartic. Scand. Suppl., 1989. 350: p. 95-104.

20. Karlberg, J., A biologically-oriented mathematical model (ICP) for Human Growth. Acta Paediatr. Scand. Suppl., 1989. 350: p. 70-94. 
21. Cole, T.J., Constructing growth charts smoothed across time and space, in Essays on Auxology: presented to James Mourilyan Tanner by former colleagues and Fellows, R. Hauspie, G. Lindgren, and F. Falkner, Editors. 1995, Castlemead Publications: Welwyn Garden City. p. 76-89.

22. Cole, T.J., The LMS method for constructing normalized growth standards. European Journal of Clinical Nutrition, 1990. 44: p. 45-60.

23. Healy, M.J.R.T., J. Rasbach, and M. Yang, Distribution-free estimation of age-related centiles. Ann. Human Biology, 1988. 15: p. 17-22.

24. Dibley, M.J., et al., Development of normalized curves for the international growth reference: historical and technical considerations. Am. J. Clin. Nutr., 1987. 46: p. 736-748.

25. Cleveland, W.S., Robust locally weighted regression ans smoothing scatterplots. Journal of the American Statistical Association, 1979. 79: p. 829-836.

26. Box, G.E.P. and D.R. Cox, An analysis of transformations. J.R. Statist. Soc B, 1964. 26: p. 211-252.

27. Hof van 't, J.M. and M.J. Roede, A method to construct age references for skewed skinfold data, using Box-Cox transformations to normality. Hum. Biol., 1985. 57: p. 131-139.

28. Cole, T.J., Fitting smoothed centile curves to reference data (with discussion). J.R. Statist Soc A, 1988. 151: p. 385-418.

29. Cole, T.J., The British, American NCHS and Dutch weight standards compared using the LMS method. Am. J. Hum. Biol., 1989. 1: p. 397-408.

30. Cole, T.J., Using the LMS method to measure skewness in the NCHS and Dutch National height Standards. Annals of Human Biology, 1989. 16(5): p. 407-419.

31. Cole, T.J. and March, Do growth charts centiles need a face lift? BMJ, 1994. 308: p. 641642.

32. Tanner, J.M., Foetus into Man: physical growth from conception to maturity. second ed. 1989, London: Castlemead publications. 280.

33. Karlberg, P. and A. Niklasson, Size at birth-evaluation strategies, in Essays on Auxology: presented to James Mourilyan Tanner by former colleagues and Fellows, R. Hauspie, G. Lindgren, and F. Falkner, Editors. 1995, Castlemead Publication: Welwyn Garden City. p. 153-163.

34. Smith, D.W., et al., Shifting linear growth during infancy; illustration of genetic factors in growth from fetal like through infancy. Journal of Paediatrics, 1976. 89: p. 225-230.

35. Cole, T.J., Conditional reference charts to asses weight gain in British children. Archives of Disease in Childhood, 1995. 73: p. 8-16.

36. Tanner, J.M., Growth at adolescence, with a general consideration of the effects of hereditary and environmental factors upon growth and maturation from birth to maturity. second edition ed. 1962, Oxford: Blackwell.

37. Wright, C.M., et al., What is a normal rate of weight in infancy? Acta Paediatrica, 1994.

38. Roede, M.J, and J.C. van Wieringen, Growth Diagrams 1980, Netherlands Third Nationwide Survey. Tijdschrift voor Sociale Gezondheidszorg, supplement, 1985. 63(supplement 1985): p. 1-34.

39. Kendall, M.G. and A. Stuart, The advanced theory of statistics. Vol. 2. 1973, London: Griffin. 


\section{Chapter VI \\ Influences on Infant Growth}

I guess growing isn't hard to do, just stand against the wall

Once I was just two feet high, today I'm six feet tall.

- John Denver - 


\section{\$6.1 Introduction}

Various external factors can influence the growth of humans. Trying to determine the various factors and their power in influencing growth can result in a distorted image. First of all it is important to understand the interpretation of a significant correlation. Significance is determined partly by the measurements, but also on the size of the sample. The outcome that something is significant for that sample size cannot be extrapolated to the total population this sample is part of. Statistics is not chemistry where during titration one has a fixed turning point irrespective of the volume.

Furthermore there might be a significant correlation from a statistical point of view, but there might not be a biological explanation or foundation for a causal correlation (yet?). It is however crucial not to look at the statistical results only from a mathematical point of view, but always keep the biology of human growth in mind when interpreting the data.

Finally, individual influences might not be as individual as they seem. There is a correlation between various factors that sometimes is obvious but some are unexpected. Therefore a mono-regression analysis does not give a realistic interpretation of the correlation, but a multi-variation regression analysis can remedy this problem. In paragraph 6.2 an overview of various intercorrelated influences is given. The multi variation analyses for the final results were based on these intercorrelations.

Paragraph 6.3 gives an overview of literature of the most important influences on growth that have been reported. Paragraph 6.4 gives the results of the multivariation analysis of the data from this Maastricht study.

\section{$\S 6.2$ Correlations}

In this paragraph an overview of various anthropometric measurements at birth are given and the significant or non-significant correlations. 


\begin{tabular}{|c|c|c|c|c|c|c|}
\hline & Birth $v$ & weight & $\begin{array}{r}\text { Supi } \\
\text { at }\end{array}$ & $\begin{array}{l}\text { length } \\
\text { rth }\end{array}$ & $\begin{array}{r}\text { circu } \\
\text { at }\end{array}$ & $\begin{array}{l}\text { d } \\
\text { erence } \\
\text { th }\end{array}$ \\
\hline & a & $\mathrm{n}$ & $a$ & $\mathrm{n}$ & a & $\mathrm{n}$ \\
\hline Sex & 0.103 & 960 & $0.000^{* \star}$ & 864 & $0.000^{* *}$ & 643 \\
\hline Supine length father & $0.000^{\star *}$ & 874 & $0.000^{\star \star}$ & 789 & $0.000^{\star *}$ & 591 \\
\hline Supine length mother & $0.000^{* \star}$ & 874 & $0.000^{\text {t*k }}$ & 789 & $0.000^{\star \star}$ & 591 \\
\hline Target height & $0.000^{* \star}$ & 874 & $0.000^{ \pm \star}$ & 789 & $0.000^{\star \star}$ & 391 \\
\hline Weight father & $0.021^{\star}$ & 449 & 0.052 & 446 & $0.042^{\star}$ & 359 \\
\hline Weight mother & $0.000^{* *}$ & 452 & $0.000^{*}$ & 449 & $0.010^{*}$ & 361 \\
\hline Education father & 0.052 & 450 & 0.052 & 447 & 0.624 & 360 \\
\hline Education mother & $0.000^{\star \star *}$ & 451 & $0.000^{* \star}$ & 448 & 0.019 & 360 \\
\hline Duration of pregnancy & $0.000^{* *}$ & 960 & $0.000^{*}$ & 864 & $0.000^{* \star}$ & 643 \\
\hline Alcohol consumption & 0.697 & 452 & 0.697 & 449 & 0.113 & 361 \\
\hline Order of birth & $0.005^{* \star}$ & 919 & $0.043^{*}$ & 824 & $0.008^{\star \star}$ & 611 \\
\hline Jaundice & 0.724 & 442 & 0.724 & 439 & 0.907 & 352 \\
\hline Smoking & $0.000^{\star \star}$ & 450 & $0.000^{\star \star}$ & 447 & $0.000^{* *}$ & 360 \\
\hline Breast feeding & 0.247 & 433 & $0.015^{\star}$ & 432 & 0.070 & 347 \\
\hline Birth weight & 1.000 & 960 & $0.000^{\text {*t* }}$ & 863 & $0.000^{* *}$ & 643 \\
\hline Supine length at birth & $0.000^{\star * *}$ & 862 & 1.000 & 864 & $0.000^{* *}$ & 633 \\
\hline Head circumference at birth & $0.000^{\star \star}$ & 643 & $0.000^{* \star}$ & 633 & 1.000 & 643 \\
\hline
\end{tabular}

**Correlation is significant at the 0.01 level (2-tailed).

*Correlation is significant at the 0.05 level (2-tailed).

Table 6.1 Overview of correlations

As can be seen in table 6.1, there is a correlation between the supine length, head circumference and weight at birth. In the graph shown hereafter, a matrix plot of these measurements is given. It is clear that the correlation between the supine length and weight at birth is more profound then either one with head circumference. 


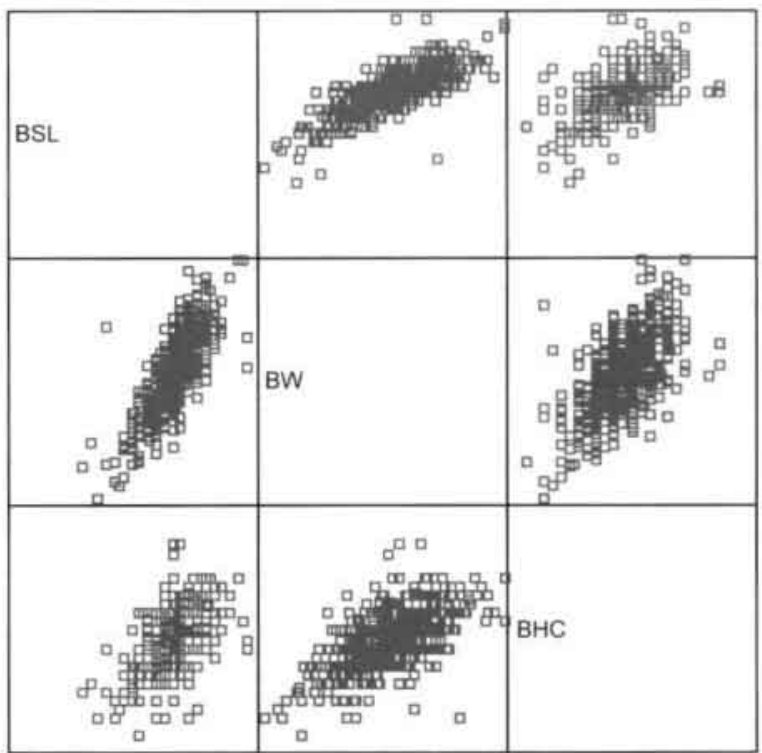

$B S L=$ supine length at birth; $B W=$ weight at birth; $B H C=$ head circumference at birth.

Figure 6.1 Birth anthropometry correlation matrix

\section{$\S 6.3$ Parental correlations}

In the chapter describing the sample, table 3.4 showed the distribution of the education of mother vs. the education of father. The correlation between the education of parents is significant $(\alpha=0.000)$

There is a significant correlation between the supine length of the fathers and mothers of the infants of our population as can be seen in table 6.2 and figure 6.2 Furthermore, a correlation between parental weight can be noted.

\begin{tabular}{|l|l|l|l|l|}
\hline & $\begin{array}{l}\text { Supine Length } \\
\text { Father }\end{array}$ & $\begin{array}{l}\text { Supine Length } \\
\text { Mother }\end{array}$ & $\begin{array}{l}\text { Weight } \\
\text { Father }\end{array}$ & $\begin{array}{l}\text { Weight } \\
\text { Mother }\end{array}$ \\
\hline Supine Length Father & 1.000 & $0.233^{\star \star}$ & $0.483^{\star \star}$ & 0.000 \\
\hline Supine Length Mother & $0.233^{\star *}$ & 1.000 & $0.095^{\star}$ & $0.308^{\star \star}$ \\
\hline Weight Father & $0.483^{\star *}$ & $0.095^{\star}$ & 1.000 & 0.090 \\
\hline Weight Mother & 0.000 & $0.308^{\star \star}$ & 0.090 & 1.000 \\
\hline
\end{tabular}

** Correlation is significant at the 0.01 level (2-tailed).

* Correlation is significant at the 0.05 level (2-tailed).

Table 6.2 Correlation of parental anthropometric data 


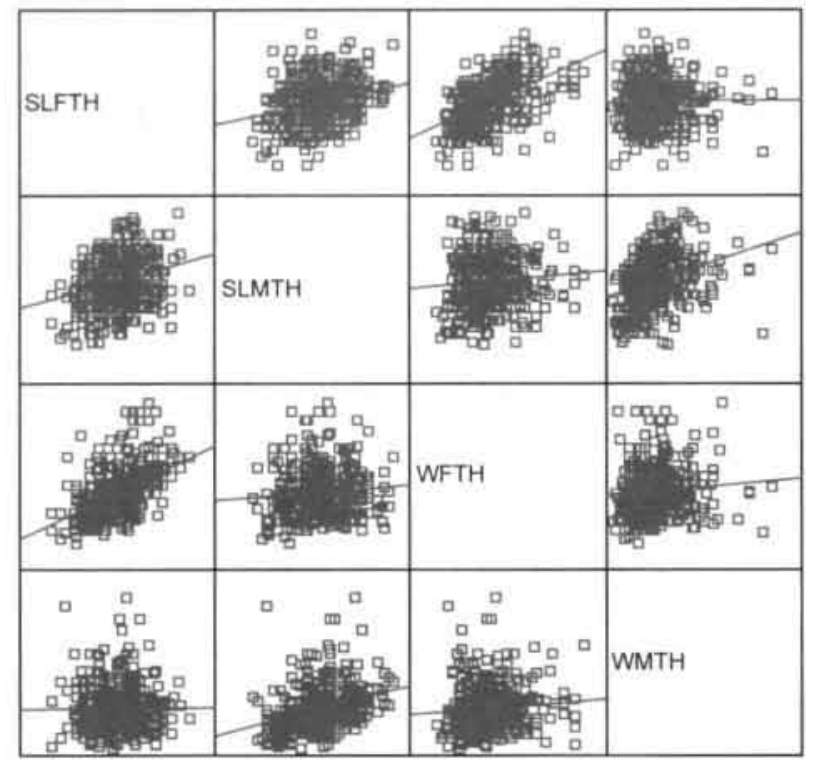

WMTH $=$ weight mother; WFTH = weight father; $S L M T H=$ supine length mother; SLFTH $=$ supine length father

Figure 6.2 Parental anthropometric data correlation matrix

It is not surprising that there is a correlation between parental height and the target height as is shown in figure 6.3. The two layers that are shown in the graph depict the target height for boys and for girls respectively.

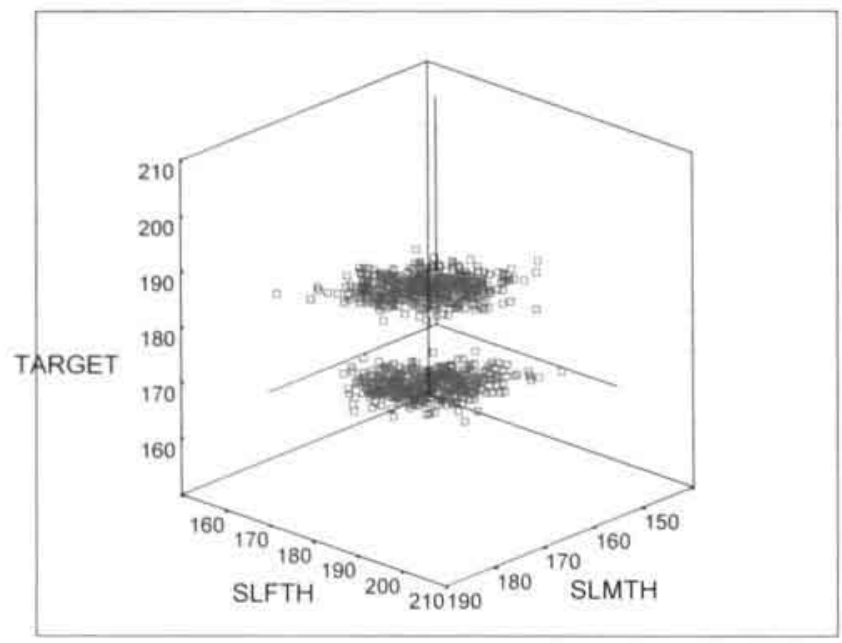

Target $=$ target height, SLFTH = supine length father: $S L M T H=$ supine length mother Figure 6.3 Correlation of parental and target height 
The following table shows that the level of education seems to be related to the supine length of the parents. The higher educated are taller. The reason why the supine length of father is correlated with the level of education of the mother is most likely due to the fact that taller women choose taller men. Taller men, do not always choose taller women, as can been seen in the table.

\begin{tabular}{|l|l|l|l|l|}
\hline & $\begin{array}{l}\text { Supine Length } \\
\text { Father }\end{array}$ & $\begin{array}{l}\text { Supine Length } \\
\text { Mother }\end{array}$ & Weight Father & $\begin{array}{l}\text { Weight } \\
\text { Mother }\end{array}$ \\
\hline Education Father & $0.202^{\star \star}$ & 0.400 & -0.72 & $-0.155^{\star}$ \\
\hline Education Mother & $0.280^{\star \star}$ & $0.158^{\star \star}$ & -0.01 & $-0.143^{\star}$ \\
\hline
\end{tabular}

** Correlation is significant at the 0.01 level (2-tailed).

*Correlation is significant at the 0.05 level (2-triled).

Table 6.3 Correlation of parental anthropometric data and education

There is still a significant correlation when taking both supine length and weight of the parent into account for the education of that parent.

\section{$\S 6.4$ Human milk for human babies?}

If nature has found it necessary to make the composition of milk so dynamic within the same species, how much more significant are likely to be the variations between species.' [1]

\section{$\S 6.4 .1$ Introduction}

In his publication "Emile" in 1762, Jean Jacques Rousseau advocated a 'return to nature', which included the recommendation of mothers breast-feeding their own infants. Artificial feeding devices, ranging from cow's horns to clay vessels, have been used for centuries, but were becoming more common in cities. As these devices were difficult to clean and the animal milk (or other liquids) fed to infants was not maintained under hygienic conditions, this resulted in intestinal infections for the infant. The higher social classes often 'farmed out' their infants to wet-nurses. Most of the time these nurses had several infants they had to feed, including their own, which meant that these infants received too little breast milk or furtively received artificial feeding [2]. Although breast feeding is usually assumed to have been universal in ancient times, there is evidence that women may always have been ready to adopt alternative methods of nursing their young, should means of doing so be available. An indication of this tendency is the need that some authorities seem to have had to issue directions in the connection. For example, the King of Sparta, issued a law in 350 B.C. requiring mother to breast feed their babies. Implements for artificially feeding babies have been found in archaeological sites in Egypt, Greece and Rome [3] [4]. 
In general paediatricians prefer to advise breastfeeding above formula feeding for the newborn infant [5]. This advice has been based on the outcome of various studies. Breast feeding has been associated for instance with increased visual acuity [6, 7], increased cognitive development [8-10] and increased intelligence in preterm infants [11] while formula feeding has been associated with increased risk of diabetes [12-14], increased risk of multiple sclerosis [15], increased incidence of otitis media [16-18], increased risk of sudden infant death $[17][9,19,20]$, increased risk of respiratory infections $[17,21,22]$, increased risk of urinary infections [23, 24], intestinal blood loss [25], increased risk of necrotising entercolitis [23, 26], increased risk of gastro-intestinal infections [21, 2729], increased risk of atopic disease (especially where there was a family history) $[24,30,31]$, increased risk of neonatal tetany [32], increased risk for nursing caries [33], increased serum lipid concentration, increased death rate due to ischemic heart diseases among adult men [13] and breastfeeding can be protective against the development of obesity. The $\mathrm{WHO}$ has given out guidelines concerning breastfeeding. They recommend to give infants up to age of 4 to 6 months, solely human milk. The introduction of any additional nutriments should not be started prior to this period. Habicht and Van Loon both found that, no matter the ethnic or socio-economic class in both the developed and developing nations, the growth of infants of normal birth weight is comparable during the first six months of life [34, 35]. Apparently breast-feeding tends to have more influence than environmental aspects, by supplying nutrients, immunity and psychological needs of the infants. Although after six months, human milk no longer meets the nutritional demands of the growing infant, the American Academy of Paediatrics has recommended that human milk feeding should continue for 6 to 12 months to benefit from the preventive effects on the infants health [25]. Up till the age of two years, children can continue to be breast fed in combination with solid and liquid nutriments [36]. Infants from developed countries or higher socio-economic classes may become significantly larger than infants from poorer environments due to the fact that the later group does not supply adequate supplementary feeding. These differences become greater and by childhood the differences may have become irreversible if nutrition or health status does not improve $[34,35]$. The incidence and duration of breast-feeding varies greatly between different geographical areas and over time [3]. The goal of The Healthy Children 2000 Act was that $50 \%$ of infants would still being breast-fed at 6 months [33]. Although the number of infants being nourished by breast feeding in developed countries has increased since the early 1970's [3, 37-39], the number of infants being breast-fed solely at the age of 4 to 6 months remains rather low ( 20 to $35 \%$ ) [40]. In the US the rate varies from $84 \%$ among women in Washington to $24 \%$ in low-income women in Georgia. In Europe differences are also noticeable; in Copenhagen $88 \%$ were breast feeding at 1 months, while only $32 \%$ of the women were in Sheffield [3]. In the Netherlands 70 to $75 \%$ of mothers will start breast feeding, but about half of these mothers combined this with formula feeding and ultimately will switch to solely formula feeding. It is very unusual for children to be breast-fed for 
more then 6 months [36]. There is a higher prevalence of breast feeding in the northern provinces of The Netherlands and in the major cities [41]. This does not correspond with findings from another research, conducted by Butler et al. They found that in rural areas more infants were being breast-fed and for a longer period than infants in urban areas [42]. Many studies indicate that the decisions on infant feeding are made early in pregnancy or even before conception and $75 \%$ have made a decision by the end of the pregnancy [33]. Women who were particularly concerned about their own body shape are less likely to breast-feed [43]. Furthermore, a lower incidence of breast feeding has been associated with lower education levels and lower socio-economic status [3, 33]. Women who are competitive and have a hard-driving work style, an impatient desire for speedy task completion and a high involvement in mastering the task at hand surprisingly, were more likely to breast feed their infants at the age of 3 months than women who do not have these characteristics. Other factors that promote breast-feeding were: hospital deliveries (especially university hospitals), rooming-in of infants with their mother in hospitals, first born infants, marital status of the mother, older age of the mother, skin-to-skin contact during the first hour of life, reassuring of the mother, growth monitoring, prenatal counselling and help during the early weeks after birth [3]. To promote breastfeeding in general, education has to be aimed at the whole population and not just the mothers $[3,44]$. The milk secreted the first five days of lactation, the so called colostrum, has a higher concentration of total protein, lactoferin and immunoglobulines (especially $\operatorname{Ig} \mathrm{A}$ ) and a lower concentration of fat and lactose. In some cultures colostrum is not fed to the baby as it is thought to be disadvantageous, but very little evidence is available [45]. Colostrum contains about $15 \mathrm{kcals} / 100 \mathrm{ml}$ less compared to formula feeding, which might explain why infants being breast-fed tend to lose more weight after birth [45]. The composition of transitional milk, which is secreted from approximately day 6 through day 15, lays between that of colostrums and mature milk. Even the mature milk changes throughout lactation. The question arises why the composition of the milk changes in time. These changes might merely reflect the maturation of the mammary gland function, but it is more likely and tempting to assume that these changes represent evolutionary adaptation of composition of the differing nutritional requirements of the infant. This hypothesis is confirmed by looking at the composition of the milk of the mother of premature infants. This milk appears to be more suitable for the premature infant as it consists of a higher protein concentration than 'term' milk, as is the IgA concentration, suggesting some extra protection against infections, especially gastrointestinal and respiratory $[1,46]$. This does not imply that all the known and yet unknown differences between human and artificial milk are of functional significance [1]. Although the nutrient content of milk might be insufficient under certain circumstances $[9,47]$ and the protection against infections may be minimal [48], breast feeding is probably the best option we have [1]. 
Full-term breast-fed infants are much more likely to develop hyperbilirubinemia than those infants who were fed formula milk. Thereby, the majority of infants who received treatment for hyperbilirubinemia were breast-fed $[17,40,49]$. But in his research Martinez found that the majority of infants with hyperbilirubinemia required no intervention at all and could safely be observed while breastfeeding continued.

One of the substances of human milk is long chain polysaturated fatty acids (LCP). This is not found in formula milk. LCP are derivates of linoleïc acid (LA) and alfa-linolenic acid (ALA), which are formed by alternating desaturation and elongation. It is assumed that contrary to adults, infants are not able to form adequate amounts of arachidonic acid (AA) and docosahexaenoic acid (DHA) from respectively LA and ALA. Therefore this needs to be taken in as a nutrient [50-52]. As LCP are important structural and functional components of membrane structural lipids, it is assumed that growth is dependent on the availability of significant amounts of LCP $[50,53]$.

Several studies have shown a positive relationship between AA and human growth, although it has to been taken into account that of lot of these studies have been performed with premature infants. AA does seem to promote weight gain, but it is not clear if there is a relationship with supine length and/or head circumference $[53,54][52]$.

\section{$\S$ 6.4.2 Growth of breast fed vs. bottle fed infants}

Besides the earlier mentioned effects of breast or formula feeding, many studies have been performed to describe the growth of infants according to the type of nutrition. Tanzer and co-workers compared three nutritional groups: totally breast-fed and formula-fed and combined breast and formula-fed from birth onwards. At the end of the six-month period of this study, the difference in height between the three groups amongst the boys and the girls was not found to be significant. But the difference in weight between the groups for both the girls and the boys was found to be significant at the end of the six month period as both the boys and girls who were breast-fed had gained more weight than those who were given formula. Unfortunately there was not a comparable group size for the three different nutritional groups as $41.5 \%$ were both breast and formula-fed, $48,5 \%$ was totally breast-fed and only $10 \%$ received formula [55]. There are various other studies that concluded that there is no difference in growth based on the feeding mode [18, 56-61]. However, the majority of studies show contradictory findings and have suggested that charts for weight and length based on breast-fed infants are needed. Over the years various studies concluded that growth of breast-fed infants in developed countries in both Europe and in America, deviate from the reference data used [16, 39, 62-65]. The differences are most obvious for weight and sometimes also for length. Head circumference never differed. This can be explained by the fact that 
growth of the head is less influenced by energy intake in comparison to weight and length. Growth of the head will only be limited in serious cases of deprivation [66] Several types of growth promoting factors have been found in human milk, which act like hormones. Among these are epidermal growth factors (EGF), insulin, somatomedin-C and transforming growth factors. These are peptides with very low concentrations but pronounced physiological activity. Some of these can affect mucosal cell growth or gastric $\mathrm{pH}$, and may consequently exert an effect on the absorption of nutrients [1], which may influence the growth of a child. The Darling study is a longitudinal study that followed infants from 0 to 18 months, who where either breast or formula fed (neither group was given solid foods before four months). The two cohorts were matched for parental, socio-economic status, education, ethnic group, anthropometrical characteristics, infant sex and birth weight. The most important findings concerning growth of this study were, first of all that growth in weight, but not length, of breast-fed infants from 3 to 12 months of age differs from the NCHS reference data and from that of formula-fed infants.
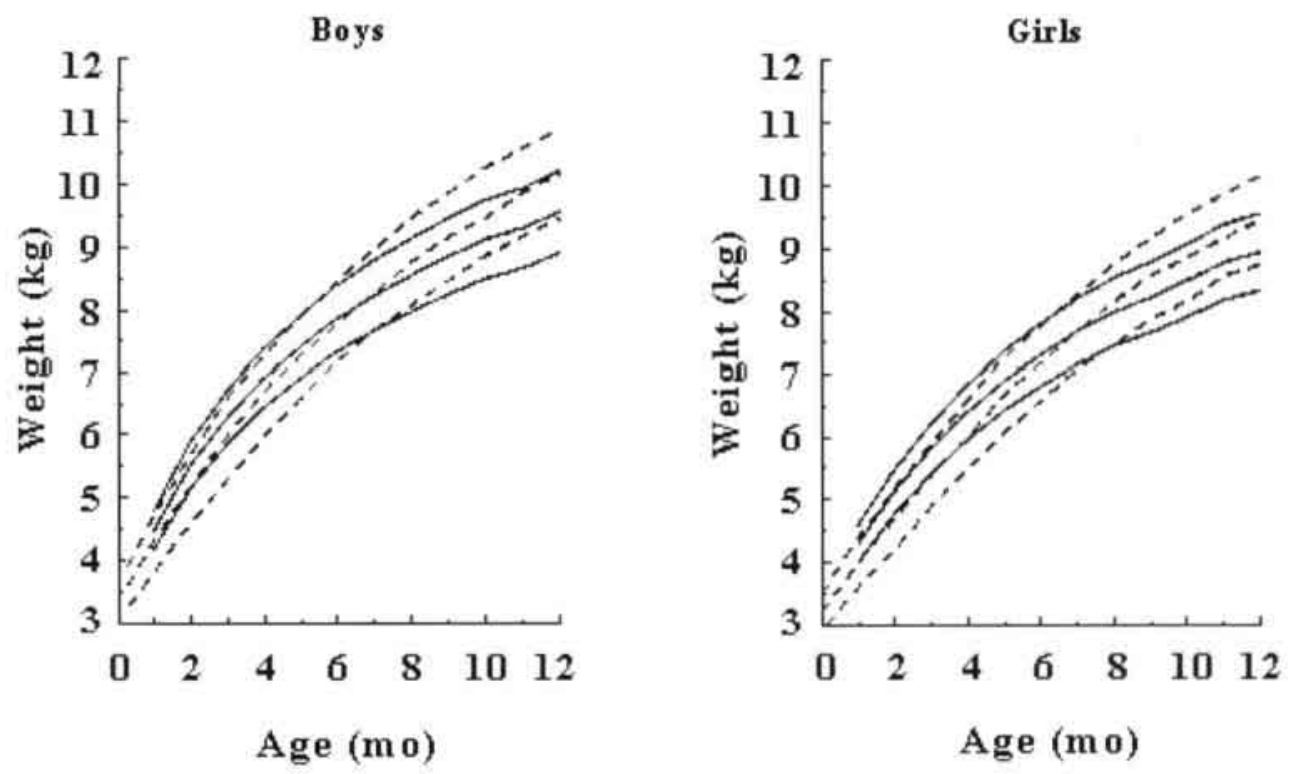

-Breast-fed set ---NCHS-WHO 

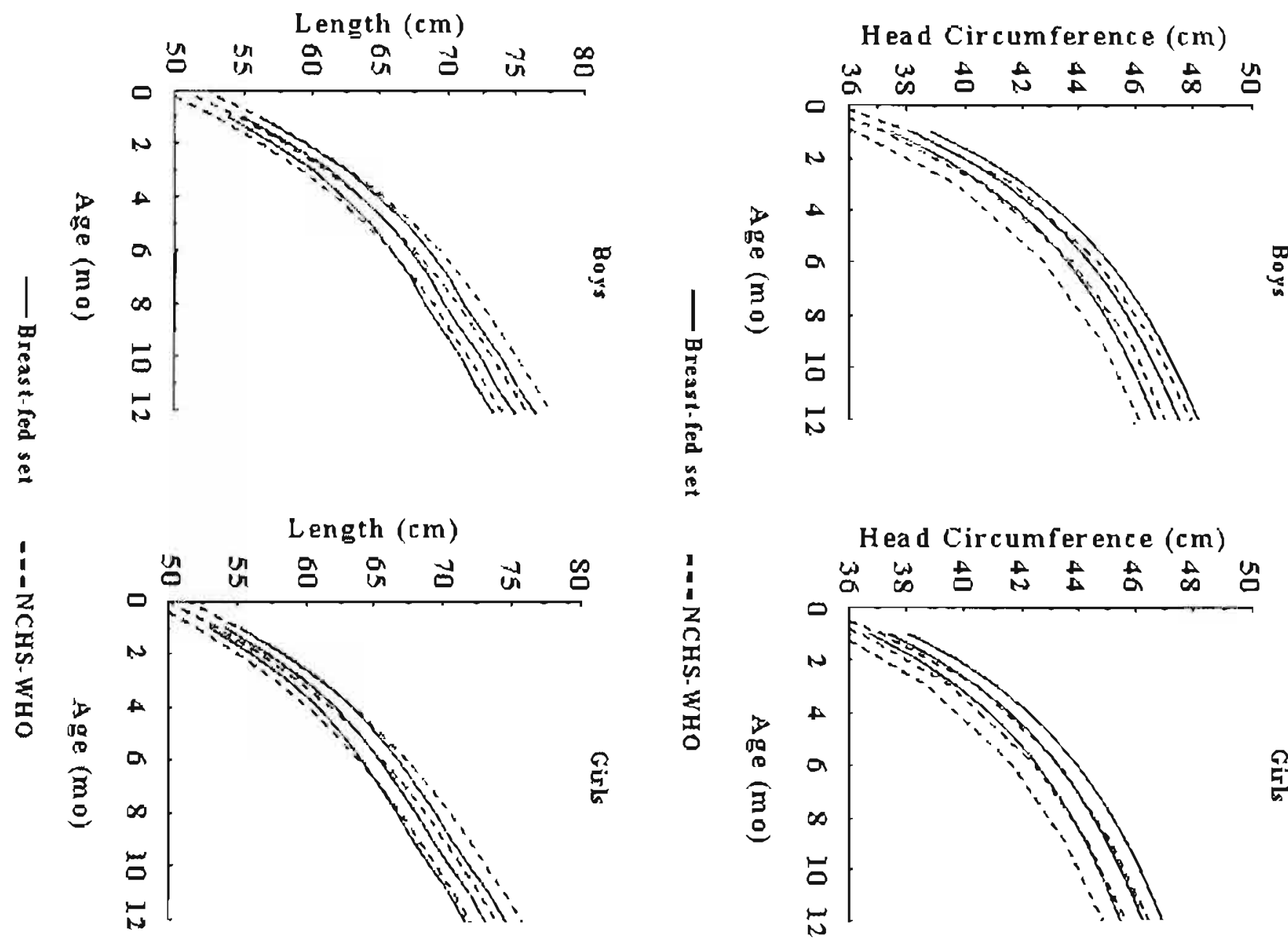

?ำ 

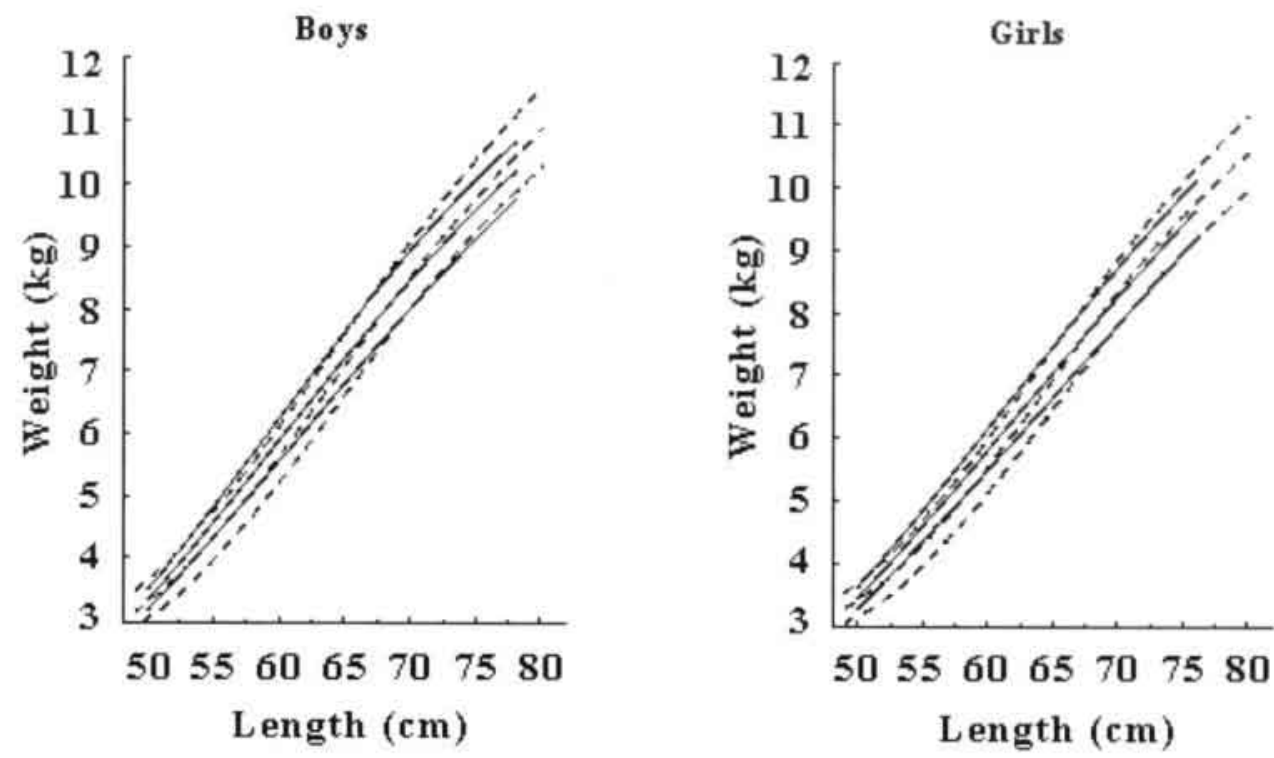

-Breast-fed set $\quad--$ NCHS-WHO

Figure 6.4 various anthropometric data comparing the WHO standard os the breast fed data set.

Between the age of 6 and 18 months formula-fed girls were significantly heavier than breast-fed girls at each month, while for boys this difference was noticed between the age of 6 and 19. When combining the sexes the weight gain between the formula-fed and breast-fed groups, was similar during the first 3 months. Thereafter, the breast-fed infants gained significantly less weight than formula-fed infants at 3 to 6,6 to 9 and 9 to 12 months. The difference in cumulative weight gain during the first year of life was $0.65 \mathrm{~kg}$ for both boys and girls. Breast-fed infants were leaner than formula-fed infants at 9 to 15 months. There was no significant difference in head-circumference between the breastfed and formula-fed group between the age of 6 and 18 months [65, 67-69]. Nelson et al. found in his research that the sex-related differences in body weight is greater than the difference related to the mode of feeding. Weight of formulafed boys was greater than the breast-fed boys, but weight of formula-fed girls was not significantly greater than the breast-fed girls. Length of formula-fed boys was significantly greater than breast-fed males, but again there was no significant difference for the girls. The significant difference for weight and length started at the age of 42 days till 112 days and 8 till 112 days respectively [70]. Similar findings were represented by De Bruin et al. They found no consistent differences in growth and body composition between breast and formula fed infants. However, when analysing the sexes separately, they noticed that the breast-fed girls had a lower weight gain between 2 and 4 months. For- 
mula-fed infants had higher weight gain resulting in higher amounts of total body fat and fat-free mass at 4 to 8 months of age [71]

Studies from North America (including Canada) Denmark, Sweden, Finland and the United Kingdom showed remarkable similarities in the growth pattern of breast-fed infants. They all showed that breast-fed babies grow faster for the first two to three months, and then tend to grow slower than the bottle-fed infants, resulting in a large decline in weight-for age $\mathrm{z}$ scores from 3 to 12 months when comparing to the NCHS data [21, 33, 65, 72-74]. Recent studies of breast-fed infants from upper- and middle-class families in Japan, Thailand and India have shown patterns of growth similar to the above dataset [65]. A review of 19 studies comparing growth of breast-fed and formula-fed infants in affluent populations showed in almost all cases that weight gain among breast-fed infants was less than in the formula-fed cohort. This was evident even in the first 3 to 4 months of life if the sample was large enough. The difference in attained weight at 12 months of age was on average about 600 to 650 gram. The findings for gain in length were less consistent as more than half of the studies showed no significant difference. As a result breast-fed infants tend to be leaner, on average, than formula-fed infants [75]. In the fourth national growth study performed cross-sectionally in The Netherlands, infants breast-fed (either partly of fully) in the first six months of life gained more weight than formulafed infants. This difference was more clear in girls then in boys. Boys gained more weight in the first two months of their lives when being breast-fed. After that their gain in weight lies behind the formula-fed group. In girls the gain in weight was also more marked in the first two months, but even thereafter their gain in weight remains higher [36]. Stuff et al. stated that the weight-for-length percentiles reflected the redistribution of weights and lengths respectively, for their study. Between the ages of 8 and 12 weeks, weight-for-length was at the $63 \mathrm{rd}$ percentile, and by 28 weeks it had stabilized to the $53 \mathrm{rd}$ percentile of the NCHS standards [76]. An Australian study conducted in 1988 monitored the growth in the first 3 months of life. It showed that breast-fed infants gained more weight during the first ten days, but thereafter the formula-fed infants caught up and ended up with a more significantly weight gain starting from day ten till day 90 (the end of the study period) [75]. Another Australian study showed that infants from both sexes who were being formula-fed from birth or breast-fed for less than three months, gained significantly more weight between birth and 12 months of age. Most of this weight had been acquired after three months of age. The greatest difference in weight gain occurred between those infants who were fed artificially from birth and those infants who were breastfed to 12 months of age. The boys and girls in the first group gained 750 gram and 560 gram more weight respectively compared to the latter group. The growth pattern in the first three months of life of both formula and breast-fed infants is rather comparable. From 3 months onward till the end of the first year of life the formula-fed infants gain more weight. This study also showed not only a significant relationship between infant-feeding practice and social group, 
at the ages of 6,9 and 12 months but also the relationship of weight to social group. It was indicated that growth differences among infants of differing social groups might be a result of differences in feeding practice as there is a higher prevalence and a longer duration of breast-feeding among mothers from higher social groups $[39,77]$ In developing countries the opposite conclusions can be drawn; the lower social classes are bound to breast-feed, as was illustrated by the fact that in his population Tanzer found an unemployment rate of zero in the bottle fed group [55]. The reference charts for 2 to 18 years old, used worldwide by the $\mathrm{WHO}$ are based on data from a representative cohort by the US National Center for Health Statistics (NCHS). The charts used for children up till the age of 2 years are based on data from the Fels Longitudinal Study, a study conducted in Ohio, USA between 1929 and 1975. The differences that have been pointed out repeatedly between the breast-fed infants and the general growth charts can be caused by the fact that the population of the Fels study was predominantly formula-fed $[65,67]$. The composition of formulamilk has altered over the years, with the modern formula milk more and more resembling mother milk [45]. Furthermore the population was relatively homogeneous with regard to ethnicity and socio-economic status [65] and measurements were performed too infrequently to adequately characterize the pattern of growth in early infancy [65]. Also, the technique used to develop the charts, by means of i.e. curve fitting, might be outdated [21, 75]

All in all the various studies and critics agreed on the fact that new growth charts (one for formula-fed and one for breast-fed infants) would be of value to prevent infants being diagnosed wrongly for growth retardation, or mothers being told that their milk production is insufficient even when their infants are obviously healthy in all other respects $[21,33,67,69,78,79]$. A deviation in weight does not justify supplementation [62]. The energy intake of breast-fed infants is lower than the intake of formula-fed infants, even after solid foods are introduced in equal amounts to both groups [68, 80, 81]. The energy intake of breast-fed infants is about $20 \%$ lower [76]. The difference in weight was most evident during the second 6 months of life. It has been implied that there is a self-regulating intake by the breast-fed infants, resulting in a relatively low energy intake $[76,82]$. All this does not result in deleterious consequences in terms of morbidity, activity level or behavioural development [83]. On the contrary; higher protein intake has been associated with a higher incidence in illness from 6 to 9 months [68]. All this implies that the growth pattern of breastfed infants is adequate [81] and might even be called normal. As was correctly formulated by Sheard in his article: "The difficult question that needs to be answered is whether or not the growth of breast-fed infants is delayed or is the growth in formula-fed infants accelerated" [84]. There is a lack of data showing whether there are any adverse long-term consequences of slower linear growth during infancy. It can, however, not be excluded that there might be negative effects [72]. For instance, there has been evidence that length at the end of the first year is a strong predictor of adult stature [85]. A decrease in linear growth during the first year of life is not likely to be caught up later during childhood 
$[34,86]$. Is bigger better, or is smaller better? Probably only better is better [87]. The WHO Expert Committee on 'Physical Status: The Use and Interpretation of Anthropology' concluded that one new growth chart for the first 2 years of life should be developed. This chart should be based on data of breast-fed infants from healthy populations. Growth of all infants should be plotted on this chart regardless of their feeding mode as it was suggested that growth of breast-fed infants is the biological norm [88]

\title{
$\S 6.5$ Infant growth after nicotine exposure
}

\author{
No foetus of a smoking mother remains unscathed
}

Zaren-

\section{$\S 6.5 .1$ Introduction}

Between 1957 and 1986 over 100 published studies, documenting over half a million births have reported differences between infants exposed to nicotine and those who haven't [89]. Smoking has been associated with several adverse outcomes of pregnancy. Besides low birth weight and premature births, the number of spontaneous abortions and peri-natal deaths (including SIDS) is higher and there is a reduction of most auxiological parameters [90]. It has been noted that neonatal mortality and long-term defects in both physical and mental development of the offspring of mother who have been smoking during pregnancy are also higher. There is also evidence of pathological placental events and a higher incidence of developing allergies [91, 92], zinc deficiency and increased levels of cadmium levels in the foetus [90]. There seems to be no difference in the influences between the black and white race, although white pregnant women seem to be more likely to smoke than African American pregnant women [93]. Even after 1986 research on growth and nicotine exposure continued. Not all studies confirm the findings of the others; some even can't find such a difference [94-104]. Some are even contradictory. In this paragraph the various studies and their findings are given, for what they are worth. As there are over 2000 substances in cigarette smoke, many of which are toxic; there are various pathways by which cigarette smoking can lead to decreased growth in infants [105-108]. The main agents that are suspected of harming the foetus are carbon monoxide and nicotine. The first passes through the placenta, simply by diffusion or maybe by a protein carrier [107]. Carbon monoxide diminishes the blood's capacity to transport oxygen and shifts the haemoglobin curve to the left, resulting in the tension of haematic oxygen and producing hypoxia in the foetus. The hypoxia is secondary to vasoconstriction of the placenta [108]. Nicotine increases carboxyhaemoglobin concentration and reduces placental haematic flow, thus causing reduced energy availability [109] [110]. The placental weight in women who smoked during pregnancy is significantly lower [90]. 


\section{$\S 6.5 .2$ Growth of infants after prenatal nicotine exposure}

The difference in birth weight varies in the literature between 100 and 358 gram and seems to be more profound in infants of older women [102, 111, 112]. There is an obvious positive dose-effect between the average number of cigarettes smoked by the mother and birth weight. Furthermore there is no difference in weight between infants born to women who never smoked during their lives and those who quit smoking only during pregnancy [102]. Neither is there a difference between passive smoking mothers and light smoking mothers [90]. It is shown that a reduction of smoking during pregnancy is associated with an increase in birth weight [105]. Smoking not only decreases the birth weight, but it has also a negative influence on birth length and head circumference. However, it is not clear whether the growth reduction caused by maternal smoking predominantly affects fat deposits, or if it may cause a general, symmetrical growth retardation with possible influences on brain development [106]. Garn et al stated that obesity in mothers counteracts the effect of smoking, but Laml et al found that smoking resulted in a back $\log$ in foetal growth in overweight mothers [105]. A smoking environment does not seem to effect the growth of an infant after birth [113]. The growth retardation caused by maternal smoking on intrauterine growth is not only a matter of reduced fat deposits, as is reflected in the skin folds or of smaller circumference of the abdomen, but it seems to be of a more general and serious type of growth retardation. Given a certain grade of retardation, the head growth seems to be more specifically affected. The infants of smoking mothers are at an increased risk of having a head circumference less then $32 \mathrm{~cm}$ and are also at an increased risk of having a head that is less then 2 SD below the given head circumference for the gestational age [91, $92,106,108]$. The association remains significant, but diminishes when adjusting for intrauterine growth. Infants of the mothers who stopped smoking in the second half of the pregnancy have the smallest fat deposition of all the newborns, although smoking was stopped during the period of maximum foetal growth accumulation [92]. It seems reasonable to assume that maternal smoking effects the brain development negatively [106]. Of course it is known that infants who are small for gestational age are at an increased risk for neurodevelopmental impairment than equally premature, appropriate for gestational age infants. The long-term effects on the subsequent cognitive and physical development of a child are less clearly understood [89]. The best predictor for the neurobehavioral outcome seems to be the head circumference at birth. One of the hypotheses for the small head circumference is the fact that there is a positive association between maternal smoking and premature closure of one or more of the cranial sutures, which has been reported by Kallen [106]. Therefore the small head circumference might not be the primary event, but is a representation of a secondary occurrence [106]. Another explanation might be that the later somatic differences in physical development are mediated by prenatal 
growth retardation [89]. Furthermore there is a positive correlation described in the literature between smoking habits and alcohol consumption. Alcohol abuse during pregnancy causes growth retardation in general and small head circumferences in specific. Therefore the alcohol consumption might bias the results. However there is no effect found of moderate alcohol consumption and the head circumference [106]. In the population of this research there was a significant correlation between smoking and alcohol use $(\alpha=0.000)$, but no participating mother was diagnosed as being alcohol abusive.

The outcome of the weight difference varies. It has been reported that the difference in weight at birth is caught up by the age of 6 months [102,113]. But if the difference is not overcome by that age, the difference might be due to other aspects than smoking during pregnancy, i.e. lower socio economic status [102]. Sexton and Fox [114-118] suggested that deficits of weight at birth in children of mothers who smoked during pregnancy may remain throughout life. The difference in weight was still present at the age of 3 years, but this difference was only significant when it was not corrected for other variables such as birth weight, socioeconomic backgrounds or length of gestation. So the difference noticed could be more due to these variables or a combination of them, than to smoking alone. The infants with a low ponderal index experience a great catchup growth and are better developed when evaluating at the age of 3 years, than the growth retarded infants with an appropriate ponderal index. [106]. Cross sectional data at birth showed that infants of smokers had lower weight and length, but similar ponderal index. This may suggest that the growth retardation is symmetrical. Analysis of longitudinal growth curves indicate that the growth retardation most likely took place during the second half of the pregnancy. In his follow-up study, Vik et al found that during the first 5 years of life, children of smokers showed a complete catch-up growth in weight, a partial catch-up in height, but showed no catch up growth in head-circumference. At the age of 5 years, children who have been exposed to smoking during pregnancy had a higher ponderal index and skin fold thickness. This may mean that these children, when compared with their peers who had not been exposed to smoking, were more obese [119]. To complete this overview it has to be mentioned that in a small sample in the United States of white, married and well educated mothers, the infant size described by weight, height and head circumference was not significant at 8 months of age, while the smoking habit was highly related to birth size [102]. In his article on light and passive smoking, Luciano et al reported that there was a significant reduction of lower fat mass, crown-heel, upper-arm and lower-arm lengths in infants exposed to smoking during pregnancy, but they found no significant difference in crown-rump length and all circumferences with the exception of the upper and lower limbs circumferences [90]. Lindsay et al found a decreased crown-heel and extremity lengths, particularly the lower extremities, but found no difference in skin fold or circumference measurements and an increase in fat-free mass in infants exposed to smoking and declares that smoking does not affect fat mass. The effect 
of smoking on fat-free mass appears to be long bone growth but not muscle mass [111]. The difference in length may be a result of preferential shunting of distal blood flow away from the lower extremities in addition to relative hypoxia induced by smoking or an increase in vascular reactivity resulting from nicotine [111].

Besides the fact that the weight of an infant is correlated with the number of cigarettes smoked by the mother, the weight of the mother itself is related to the average number of cigarettes she smokes daily. The lowest weight prior to pregnancy can be seen among women who smoke $6-10$ cigarettes per day, while women who smoke more than 25 cigarettes per day not only show the highest weight and body mass index prior to the pregnancy but also gain the most weight during the pregnancy [105]. This was not confirmed by the study of Lindsay [111]. Some reports have found smoking mothers to have a poorer quality of diet besides the fact that they eat less and that they have a lower pregnancy weight increase as their non-smoking peers [92]. But the results in the literature are conflicting. Epidemiological studies indicate that smokers weigh less than non-smokers despite a caloric consumption similar or higher than in non-smokers $[92,119]$. One of the explanations could be the fact that smoking influences the energy utilization and metabolism up to $10 \%$ [92]. Another hypothesis is that smoking might reduce the appetite or change the taste for food, thus resulting in under nutrition of the mother, lower pregnancy weight gain and restricted foetal growth. Compared to non-smokers, the infants of smokers had a lower-birth weight [92] Other studies have shown food intakes and pregnancy weight increase to be equal, even higher, among smoking mothers, compared to the non-smokers [92]. Conter et al found that the smoking habit was more common in the upper classes, whereas the percentage of heavy smokers was independent of the socioeconomic class [102]. In studies conducted in Finland and England it was found that smoking habits were associated with poorer socioeconomic factors [102]. This is in accordance with the findings in the population of this research. There we found that smoking was more common in the lower and middle socioeconomic class while the middle and higher educated mothers were less likely to smoke $(\alpha=0.000)$. Evidence regarding the association between maternal smoking during pregnancy and maternal weight gain is conflicting in the literature and varies with the measure of weight gain used [112].

\begin{tabular}{|l|c|c|c|c|}
\hline & $\begin{array}{c}\text { Education } \\
\text { Mother } \\
\text { Group I }\end{array}$ & $\begin{array}{c}\text { Education } \\
\text { Mother } \\
\text { Group II }\end{array}$ & $\begin{array}{c}\text { Education } \\
\text { Mother } \\
\text { Goup III }\end{array}$ & $\begin{array}{c}\text { Education } \\
\text { Mother } \\
\text { Group IV }\end{array}$ \\
\hline Non smoking & $0.9 \%$ & $16.7 \%$ & $30.7 \%$ & $23.1 \%$ \\
\hline Smoking & $0.7 \%$ & $14.2 \%$ & $10.4 \%$ & $3.3 \%$ \\
\hline
\end{tabular}

Table 6.4 Smoking habit of mother during pregnancy compared with education level of mother

In the population of this research the average number of cigarettes smoked per day by the mothers was not recorded, therefore this difference in maternal 
weight can not be noted. In fact there is not a significant correlation between smoking and maternal weight $(\alpha=0.545)$. However there is a positive correlation between maternal education and smoking $(\alpha=0.000)$ and between maternal education and maternal weight $(\alpha=0.002)$. So the correlation that has been described by Laml et al, can be due to the fact that lower educated mothers are more likely to smoke and are heavier.

The constructing of growth curves for children who have been exposed to smoke and those who haven't, reveals significant differences. The growth in weight, length and head-circumference between week 17 and 37 of pregnancy was lower in infants of smokers. The growth curve for length shows a partial, but continuing catch-up growth between birth and the age of 5 years. The curve for weight and height suggest a rapid catch-up growth between birth and 6 months, which may be followed by a slow but continuing catch-up growth until the age of 5 years. The growth curve for head circumference shows a similar intrauterine pattern as the curves for weight and length, but there is no evidence of catch-up growth between birth and 5 years of age [119]. These findings can not be confirmed (at least for the first two years of life) in the results of this research.

\section{$\S 6.6$ Smoking and breastfeeding.}

Repetitively researches find that the mothers who provide breast-feeding for a long time are the ones who do not smoke, were older, better educated and most likely financially better of [113]. In the population of this research this can be partly confirmed; the breast feeding mothers are not likely to smoke and are better educated. The husbands of breastfeeding mothers are also more likely to be better educated and less likely to smoke. As both parents are better educated, it is to be expected that this family has a better solid financial base. The age of the mother was not asked in the survey and therefore no conclusions about this correlation can be made for this population. On the other hand, the literature describes the bottle feeding mothers as being younger, more likely to smoke, not as well educated and less wealthy [113]. Young mothers are also likely to stop breastfeeding earlier compared to older mothers. And if the father smokes, the duration of the breastfeeding is also limited [120].

From a study conducted in Seattle (USA) it has been reported that infants who were breastfed by mothers who smoked gained more weight than either infants who were breastfed by mothers who did not smoke or infants who were bottlefed by mothers who smoked in the first year of life. This was also found in a Dutch trial conducted by Boshuizen. However this study did not find that long-term breastfeeding was associated with slower growth [113]. In a study conducted in Norway a decrease in smoking prevalence was observed between 1970 en 1991, from 38 to $26 \%$. Furthermore an increase of breastfeeding after 6 
months was observed. This increase went from 15 to $44 \%$ among smoking mothers and from 30 to $72 \%$ in non smoking mothers [120]. The composition of human milk from mothers who smoke differs from those who do not smoke, besides the fact that mothers who do not smoke are more likely to sustain breastfeeding for a longer time, compared to their smoking counterparts. When smoking mothers decrease the breastfeeding, the infants have signs of nicotine withdrawal, which is expressed in hunger or fussiness of the infant. This behaviour may lead not only to switch to solid foods quicker but also give more solid foods to please the infants mood. Alternatively, the withdrawal of nicotine might decrease energy expenditure, increasing the weight similar to the weight gain seen in adults who quit smoking. But strangely Boshuizen reports that there is no effect on growth observed from exposure to tobacco smoke after pregnancy. There was no effect of exposure to smoke of smokers in the household, or a direct effect of exposure to tobacco by-products through breast milk [113].

Maternal smoking not only has short term consequences on the infant, but more and more the direct or indirect long- term consequences are being noted. The exact outcome of the various anthropometric measurements are not consistent and not all described differences can be confirmed. But the fact remains that smoking does have an effect on the foetus. This effect is most likely not a positive one.

\section{$\S 6.7$ Parental influences?}

Maternal weight gain during pregnancy can be a predictor of infant birth weight in non-obese women. In non-obese women the birth weight of an infant is correlated to the increases as maternal weight during the pregnancy [112, 121]. The relationship between maternal weight gain and infant birth weight is attenuated by increasing maternal pre-pregnancy weight. Low rates of weight gain both early in pregnancy and later in pregnancy have been associated with increased risk of delivering a small for gestational age infant [122] [123]. This is confirmed by Zaren [92] who found in a regression analysis weight gain and pre-pregnancy weight to be the most important variable besides maternal smoking, height, weight and pregnancy weight gain, while the BMI was not significant.

\section{§6.8 Infant and childhood causes of adult diseases}

Various studies conducted by Barker et al. have shown correlations between infant/childhood growth and parameters and certain diseases in adulthood. Maternal hypertension increases the risk of hypertension in the children of this mother. There is also a negative correlation between birth weight and growth, 
and blood pressure in adults as there is for the lipid profile and glucose tolerance. Children originating from lower social classes have an increased risk of developing ischaemic heart-disease, especially when impaired growth and development occurred in early life. Low birth weight has also been associated with a deprived long function and lethal obstructive airway diseases. [13]

\section{§6.9 The growth of this population}

There was already a difference in weight at birth between the breast-fed and formula-fed group. This difference was also noticed in an Italian study [124]. Mothers who smoke are less likely to breast feed, and if so, are less successful in it. This has been observed in all socio-economic layers [3]. Three explanations have been suggested. First of all nicotine inhibits the production of prolactin, which results in reduced breast-milk production. Smoking among women has been associated with social factors, i.e. education, income and social support. Since 1990 smoking is more common among young adults with only elementary education. Finally smoking mothers might consider breast-feeding combined with smoking to be harmful and therefore are less likely to start or continue to breast-feed their infants [120].

Breast-fed babies seem to grow differently in comparison to formula-fed babies in terms of growth rate. Although formula-fed infants tend to be heavier at the end of the first year of their live, there is insufficient evidence to determine whether this will persist in later life [82]. Regarding the influence of long chain polysaturated fatty acids (LCP) on growth, and more specific the arachidonic acid (AA) concentration, it would be over-simplified to use this as a parameter. After all the AA concentration in the human milk was not measured and one would only jump to conclusions using assumptions. Still one can keep it in mind as one of the possible explanations for noticed differences.

\section{§6.9.1 Analysis of a longitudinal growth curve data set}

A set of infants was selected for the analysis of longitudinal growth. The condition to be part of this set was to have information regarding the parents and environment of the infant and that an adequate number of anthropometric data for at least the first 2 years of life was determined and entered into the database. In total 473 infants complied with these criteria. Not all anthropometric data was available, but out of the intended 17 measurements per infant, 4732 anthropometric measurements were available, an average of 10 per infant.

The growth curves of head circumference, length and weight, were analysed with respect to gender, breast feeding and parental parameters. The data are not homoscedastic: for length and weight, the variance increases with time. For head circumference, the variance is about the same at age zero and at age three 
years. The data of weight and length are log-transformed to obtain a more homogeneous variance, for head circumference this was not needed.

\section{$\S 6.9 .2$ Head circumference}

For head circumference, no significant differences were found in growth between the breast fed, partially breastfed and bottle fed infants. Neither was there an effect of breastfeeding difference between boy or girls. The head circumference of boys was about $6 \mathrm{~mm}$ larger at birth increasing to $1,2 \mathrm{~cm}$ at the age of 7 months, but then decreasing to $1 \mathrm{~cm}$ at 40 months.

The declining influence of mother's smoking was obvious and significant. Infants of smoking mothers have about $7 \mathrm{~mm}$ smaller head circumferences at birth, initially seem to catch up, but then a delay in growth is seen after 9 months of age.

Infants of taller mothers have a larger head at birth. Comparing mothers with a stature on the 80th percentile and the 20th percentile, the difference in head circumference for their children is about $3 \mathrm{~mm}$ at birth, decreasing at first but increasing after about 11 weeks to almost $5 \mathrm{~mm}$ at 40 months of age.

\section{$\S 6.9 .3$ Supine length}

For supine length, a more profound effect of breastfeeding is observed. In the first 9 months, growth is slower in breast fed infants. Initially the breast fed infants are $0.5 \%$ taller at birth. But when being breastfed they are either $0.5 \%$ smaller (when breast fed up to 3 months) or $1.0 \%$ smaller (when breast fed for more then 3 months). There was no difference seen between boys or girls in this matter. The difference in boys and girls was about $0.2 \%$ at birth, and almost stable until the age of 11 months, decreasing after this to $0.05 \%$ at 40 months.

Infants of smoking mothers started out about $2 \%$ smaller, but appeared to catch up as by the age of 10 months when no difference could be noted. Both taller mothers and taller father not only had taller babies (the difference between the parental height at the 20 th and the 80 th percentile, was about $1,3 \%$ ), but these babies seem to grow faster as well.

\section{$\S 6.9 .4$ Weight}

The effect of breast feeding on the weight increase of infants was significant. The breast feeding group was about $1 \%$ heavier at birth and grew slower compared to bottle fed infants till about the age of 7 months. At this point they were about $2 \%$ lighter. After that they seemed to catch up and by the time they 
reach the age of 40 months they are about $2 \%$ heavier. No difference was observed between boys or girls regarding breastfeeding.

The difference between boys and girls was pronounced; about $7 \%$ at birth, it then stabilized to decrease after the age of 7 months to approximately $3 \%$ by the age of 40 months.

Smoking was again significant as infants of smoking mothers were $6 \%$ lighter on average, they then caught up, but grew slower after the age of 11 months towards the end of the follow-up period. Both heavier mothers and heavier fathers have significantly heavier babies. The weight difference decreases to about 7 months and increases again after that. When comparing the parents of the 80th percentile for weight, with those on the 20th percentile, the difference in weight at birth is about $3 \%$ and diminishes to $1 \%$ (for mothers' weight) or $0 \%$ (for fathers' weight). It then increases to about $2.5 \%$ at the age of 40 months. When both parents are heavy, this effect adds up.

Moreover, growth is fast during the first weeks of life and slower later on. The analysis model assumed an autoregressive (ar1) error structure for the interdependence of the several measurements of the same child. To linearize the growth a transformation in time was necessary : Fc (days) $=\log (1+$ days $/ c)$, in which c optimized the linearity. The optimum was determined as the minimum residual variance in a linear regression analysis assuming no correlations.

\section{$\S 6.10$ Correlations regarding breastfeeding and smoking}

There is a significant correlation between the education of the mother and the fact that she will breast feed the infant. Higher educated mothers are more likely to breast feed their infant $(\alpha=0.000)$. As there is a positive correlation between the education of the parents, breastfeeding is also seen in families with higher educated fathers. There is also a significant correlation between breastfeeding and not smoking during the pregnancy $(\alpha=0.000)$ as there is a significant correlation between higher education and not smoking. Furthermore there is a significant correlation between non alcohol use during the pregnancy and breastfeeding the infant. In general it seems like the better educated mothers have a healthier approach towards pregnancy and are more likely to breastfeed their infant. The birth weight is however surprisingly not significantly different when comparing for breastfeeding vs bottle-feeding or regarding the occurrence of jaundice. There was no significance between breastfeeding and the sex of the child $(\alpha=0.322)$ either regarding medication use during the pregnancy ( $\alpha$ $=0.434)$ nor in regard to the order of birth or number of miscarriages $(\alpha=0.974$ and 0.902 respectively). Breastfed infants did not start to crawl at an earlier or later time then the bottle fed infants $(\alpha=0.254)$. Performing a simple monocorrelation the weight of the infant is the only anthropometric measurement 
that seems to be influenced by growth. The changes in weight are only significant at the age of 6,9 and 12 months $(\alpha=0.09,0.13$ and 0.30 respectively). By the age of 15 months, there is no longer a significant difference $(\alpha=0.345)$.

\section{$\S 6.11$ Conclusion}

This chapter describes correlations that are explainable or obvious. As stated earlier in this chapter, statistically more correlations can be found, but they might not have any (biological) implications (i.e. the correlation between weight of the father and smoking during pregnancy by the mother). Still, to complete this chapter a matrix with all correlations is given. The author of this thesis leaves it up to the discretion of the reader to interpret these data as useful or valuable. (see appendix C) 


\section{References}

1. Jain, S. and R.L. Bijlani, The significance of some significant features of breast milk. Ind J Physiol Pharmac, 1989. 33(2): p. 118-128.

2. Bogin, B., Evolutionary perspective on human growth. Annu Rev Anthropol, 1999. 28: p. 109-53.

3. Rogers, I.S., et al., The incidence and duration of breast feeding. early Human Development, 1997. 49: p. s45-s74.

4. Barker, D.J.P., et al., Growth in utero, blood pressure in childhood and adult life, and mortality from cardiovascular disease. British Medical Journal, 1989. 298: p. 564-567.

5. Anand, R.K., Recommendations on breastfeeding promotion among paediatricians. Int J Gynecol Obstet, 1990. 31(suppl 1): p. 51-55.

6. Makrides, M., et al., Erythrocyte docosahexaenoic acid correlates with the visual response of healthy infants. Pediatric research, 1993. 33: p. 425-427.

7. Uauy, R., et al., Effect of dietary omega-3 fatty acids on retinal function of very low birthweight neonates. Pediatric Research, 1990. 28: p. 485-492.

8. Rogan, W.J. and B.C. Gladen, Breast-feeding and cognitive development. Early Human Development, 1993. 31: p. 181-193.

9. Anon., Breast non necessarily best. Lancet, 1988. 1(8586): p. 624-626.

10. Morley, R., et al., Mother's choice to provide breast milk and developmental outcome. Arch Dis Child, 1988. 63(11): p. 1382-1385.

11. Lucas, A., et al., Breast milk and subsequent intelligence quotient in children born perterm. The Lancet, 1992. 339(feb 1): p. 261-264.

12. Virtanen, S. and A. Aro, Dietary factors in the aetology of diabetes. Ann Med, 1994. 26: p. $469-478$.

13. Barker, D.J.P., Fetal and infant origins of adult disease, 1992, London: Britisch Medical Journal. 343.

14. Mayer, E.J., et al., Reduced risk of IDDM among breast-fed children. The Colorado IDDM Registry. Diabetes, 1988. 37(12): p. 1625-32.

15. Pisacane, A., et al., Breast feeding and multiple sclerosis, Bmj, 1994. 308(6941): p. 1411-2.

16. Duncan, B., et al., Exclusive breastfeeding for at least 4 months protects against otitis media. Pediatrics, 1993, 91: p. 867-872.

17. Ford, K. and M. Labbok, Breast-feeding and Child Health in the United States. J. Biosoc Sci, 1993. 25: p. 187-194.

18. Saarinen, U.M., Prolonged breast feeding as prophylaxis for recurrent otitis media. Acta Paediatr, 1982(71): p. 567-571.

19. Mitchell, E.A., J.M. Thompson, and B. Borman, No association between fluoridation of water supplies and sudden infant death syndrome. N Z Med J, 1991. 104(924): p. 500-1.

20. Hoffman, H.J. and L.S. Hillman, Epidemiology of the sudden infant death syndrome: maternal, neonatal, and postneonatal risk factors. Clin Perinatol, 1992. 19(4): p. 717-37.

21. Victora, C.G., et al., The NCHS reference and the growth of breat-and bottle-fed infants. J. Nutr., 1998(128): p. 1134-1138.

22. Wright, C.M., et al., What is a normal rate of weight in infancy? Acta Paediatrica, 1994.

23. Contreras-Lemus, J., et al., Morbidity reduction in preterm newborns fed with milk of their own mothers. Bol Med Hosp Infant Mex, 1992. 49(10): p. 671-677.

24. Lucas, A., et al., Early diet in perterm babies and developmental status at 18 months. The Lancet, 1990. 335(june 23): p. 1477-1481. 
25. Murtaugh, M.A., Optimal breast-feeding duration. Journal of the american dietetic association, 1997. 97(november number 11): p. 1252-1254.

26. Marild, S., U. Jodal, and L.A. Hanson, Breastfeeding and urinary-tract infection. Lancet, 1990, 336(8720): p. 942.

27. Howie, P., et al., Protective effect of breast feeding against infection. BMJ, 1990, 6(300): p. 11-16.

28. Duffy, L., et al., The effects of infant feeding on rotavirus-induced gastroenteritis: a prospective study. Am J Public Health., 1986. 76(3): p. 259-263.

29. Duffy, L., et al., Modulation of rotavirus enteritis during breast-feeding. Implications on alterations in the intestinal bacterial florn. Am J Dis Child, 1986. 140(11): p. 1164-1168.

30. Burr, M., et al., Infant feeding, wheezing, and allergy: a prospective study. Arch Dis Child, 1993. 68(6): p. 724-728.

31. Burr, M., et al., Environmental factors and symptoms in infants at high risk of allergy. J Epidemiol Community Health, 1989. 43(2): p. 125-132.

32. Specker, B., et al., Low serum calcium and high parathyroid hormone levels in neonates fed' humanized' cow's milk-based formula. Am J Dis Child, 1991. 145(8): p. 941-945.

33. Rider, E., et al., Physical growth, infant nutrition, breastfeeding and general nutrition. Current Opinion in Pediatrics, 1996. 8: p. 293-97.

34. Habicht, J.-P., et al., Height and weight standards for preschool children. How relevant are ethnic differences in growth potential. Lancet, 1974. I: p. 611-615.

35. Loon van, H., et al., Local versus universal growth standards: the effect of using NCHS as universal reference. Annals of human biology, 1986. 13(4): p. 347-357.

36. Burgmeijer, R.J.F. Groei van borstgevoede kinderen. in De vierde landelijke groeistudie (1997); Presentatie nieuwe groeidiagrammen, 1998. Den Haag: Bohn Stafleu Van Loghum.

37. Hartmann, P., S. Rattigan, and C.G. Prosser, Studies on breast-feeding and reproduction in women. J. Food Nutr, 1982. 39: p. 46-50.

38. Coy, J.F., et al., Longitudinal growth study of Tasmanian children. The ten-year-olds. Med J Aust., 1980. 2(8): p. 424-426.

39. Hitchcock, N.E. and J.F. Coy, The growth of healthy Australian infants in relation to infant feeding and social group. The medical journal of Australia, 1989. 150(march 20): p. 306-311.

40. Oski, F.A., Infant Nutrition, physical growth, breast-feeding and general mutrition. Current Opinions in Pediatrics, 1994. 6: p. 361-364.

41. Burgmeijer, R.J.F. and J.C. Wieringen van, Secular changes of growth in The Netherlands. Secular changes in Europe, ed. B.É. Bodzsar and C. Susanne. 1998, Budapest: Eötvös Univ Press. 233-262.

42. Butler, N. and J. Golding, From Birth to Five, in A study of the health and behaviour of Britain's five year olds. 1986, Pergamon Press: Oxford.

43. Barnes, J., et al., Extreme attitudes to body shape, social and psychological factors and a reluctance to breast feed. Journal of the royal society of medicine, 1997. 90: p. 551-559.

44. Greaves, J.P. and L. Hendrata, Breastfeeding and growth monitoring. Int J Gynecol Obstet, 1990. 31(suppl 1): p. 121-123.

45. Rogers, I.S., et al., The growth and nutritional status of the breast-fed infant. Early Human development, 1997. 49: p. s157-s174.

46. Musoke, R.N., Breastfeeding promotion: feeding the low birth weight infant. Int J Gynecol Obstet, 1990. 31(suppl 1): p. 57-59.

47. Bijur, A. and M. Kumbhat, Vitamin-B composition of breast milk from mothers of preterm and term babies. Indian Pediatr., 1987. 24(1): p. 33-37. 
48. Bauchner, H., J.M. Leventhal, and E.D. Shapiro, Studies of breast-feeding and infections. How good is the evidence. JAMA, 1986. 256: p. 887-892.

49. Martinez, J.C., et al., Hyperbilirubinemia in the breast-fed newborn, a controlled trial of four interventions. Pediatrics, 1993. 91: p. 470-473.

50. Farquharson, J., et al., Infant cerebral cortex phospholipid fatty-acid composition and diet. The Lancet, 1992. 340(oct 3): p. 810-813.

51. Koletzko, B., Dietary Lipid supply in the neonatal period, Kinderpolikliniek der Ludwig-Maximilians-Universitat: Munchen, Germany.

52. Nettleton, J., Are n-3 fatty acids essential nutrients for fetal and infant development? J Am Diet Assoc., 1993. 93(1): p. 58-64.

53. Simopoulos, A., Omega-3 fatty acids in health and disense and in growth and development. Am J Clin Nutr., 1991. 54(3): p. 438-463.

54. Simopoulos, A., R. Kifer, and A. Wykes, Omega 3 fatty acids: research advances and support in the field since June 1985 (worldwide). World Rev Nutr Diet., 1991. 66: p. 5171.

55. Tanzer, F. and C. Gumuser, A study of the growth of 200 newborn babies for a period of 6 months according the type of nutrition. Annals of tropical paediatrics, 1989. 9: p. 54-58.

56. Motil, K.J., et al., Human milk protein does not limit growth of breast-fed infants. Journal of pedatric gastroenterology and nutrition, 1997. 24: p. 10-17.

57. Volz, V., L. Book, and H. Churella, Growth and plasma amino acid concentrations in term infants fed either whey-predominant formula or human milk. J Pediatr, 1983. 102(1): p. $27-31$.

58. Schmitt, L.H. and G.A. Harrison, Patterns in the within-population variability of stature and weight. Annals of Human Biology, 1988. 15: p. 353-364.

59. Gasser, T., et al., Velocity and acceleration of height growth using kernel estimation. Annals of human biology, 1984. 11(5): p. 397-411.

60. Jung, E. and D.M. Czajka-Narins, Birth weight doubling and tripling times: an updated look at the effects of birth weight, sex, race and type of feeding. Am J Clin Nutr., 1985. 42(2): p. 182-189.

61. Evans, T.J., Growth and milk intake of normal infants. Arch Dis Child, 1978. 53(9): p. 749-51.

62. Behague, D., Growth monitoring and the promotion of breastfeeding. Soc. Sci. Med, 1993. 37(12): p. $1565-1578$.

63. Dewey, K.G., et al., Growth of breast-fed infants deviates from current reference data: a pooled analysis of US, Canadian, and European data sets. WHO working group on infant growth. The American academy of pediatrics, 1995. 96: p. 495-503.

64. Chandra, R.K., Physical growth of exclusizely breast-fed infants. Nutr Res, 1982. 2(275).

65. Dewey, K.G., Cross-cultural patterns of growth and nutritional status of breast-fed infants. Am. J. Clin Nutr, 1998. 67: p. 10-17.

66. Tanner, J.M., The Regulation of Human Growth. Child Development, 1963. 34: p. 817 847.

67. Dewey, K.G., et al., Growth of breast-fed and formula-fed infants from 0 to 18 months: The DARLING study. Pediatrics, 1992. 89(6/june): p. 1035-1041.

68. Heinig, M.J., et al., Energy and protein intakes of breast-fed and formula-fed infants during the first year of life and their association with growth velocity: the DARLING Study. Am J Clin Nutr, 1993. 58: p. 152-161.

69. Dewey, K.G., et al., Infant growth and breast-feeding. Am J Clin Nutr, 1989. 50: p. 1116.

70. Nelson, S.E., et al., Gain in weight and length during early infancy. Early Human Development, 1989. 19: p. 223-239. 
71. Bruin de, N.C., et al., Energy utilization and growth in breast-fed and formula-fed infants measured prospectively during the first year of life. Am J Clin Nutr, 1998. 67: p. 885-896.

72. Nielsen, G.A., B.L. Thomson, and K.F. Michaelsen, Influence of breastfeeding and complementary food on growth between 5 and 10 months. Acta Paediatrica, 1998. 97: p, 911917.

73. Michaelsen, K.F., et al., Weight, length, head circumference and growth velocity in a longitudinal study of Danish infants. Dan Med Bull, 1994. 41: p. 577-585.

74. Brownlee, A., Growth monitoring and promotion: The behavioural issues. Behavioural issues in child survival programs. 1990, USAID: International Health and Development associates.

75. Dewey, K.G., Growth Characteristics of Breast-fed compared to Formula-fed infants. Biology of the Neonate, 1998. 74: p. 94-105.

76. Stuff, J.E. and B.L. Nichols, Nutrient intake and growth performance of older infants fed human milk. The journal of pediatrics, 1989. december: p. 959-967.

77. Fomon, S.J., et al., Growth and serum chemical values of normal breast-fed infants. Acta Paediatr. Scand, 1978. 273(suppl).

78. Basco, R.B. and mar, Choose standards for infant growth wisely. Arch pedaitr adolesc med, 1997. 151: p. 322.

79. Frongillo, E.A. and march, Infant growth differs by feeding mode. Arch pediatr adols med, 1997. 151: p. 322-323.

80. Butte, N.F. and C. Garza, Energy utilisation of human milk-fed and formula-fed infants. Am J Clinc Nutr, 1987. 45: p. 823.

81. Butte, N.F., et al., Human milk intake and growth in exclusively breast-fed infants. The Journal of Pediatrics, 1984. 104(2/February): p. 187-194.

82. Dewey, K.G., Growth patterns of breastfed infants and the current status of growth charts for infants. J.Hum Lact, 1988. 14(2): p. 89-92.

83. Dewey, K.G., et al., Maternal versus infant factors related to breast milk intake and residunl milk volume: the DARLING study. Pediatrics, 1991. 87(6): p. 829-837.

84. Sheard, N.F., Growth patterns in the first year of life: what is the norm? Nutrition Reviews, $1993.51(2):$ p. 52-54.

85. Tanner, J.M., et al., Aberdeen growth study I, The prediction of adult body measurements from measurements taken each year from birth to five years. Archives of disease in childhood, 1956. 31: p. 372-381.

86. Karlberg, P. and B. Kristiansson, [A revision of growth charts of infants is justified. The growth pattern, not weight or length, should be the basis]. Lakartidningen, 1988. 85(42): p. 3452-3.

87. Grummer-Strawn, L.N., Does prolonged breast-feeding impair child growth? A critical review. Pediatrics, 1993, 91 ; p. 766-771.

88. WHO Working group on infant growth, N.U., An evaluation of infant growth: A summery of analyses performed in preparation for th WHO Expert Committee on "Physical Status; The use and interpretation of anthropometry., in Doc WHO/NUT/94.8. 1994, WHO: Geneva.

89. Lassen, K. and T.P.S. Oei, Effects of maternal cigarette smoking during pregnancy on long-term physical and cognitive parameters of child development. Addictive Behaviours, 1998. 23(5): p. 635-653.

90. Luciano, A., et al., The influence of maternal passive and light active smoking on intrauterine growth and body composition of the newborn. European Journal of Clinical Nutrition, 1998. 52: p. 760-763.

91. Zaren, B., G. Lindmark, and P. Bergsjo, Hemoconcentration in smoking mothers is associated with impaired fetal growth. Acta Obstet Gynecol Scand., 1997. 76(10): p. 933-941. 
92. Zaren, B., S. Cnattingius, and G. Lindmark, Fetal growth impairment from smoking-is it influenced by maternal anthropometry? Acta Obstet Gynecol Scand Suppl., 1997. 165: p. 30-34.

93. Sprauve, M.E., et al., Racial patterns in the effects of tobacco use on fetal growth. Am J Obstet Gynecol, 1999. 181(1): p. S22-7.

94. Naye, R., Influence of maternal cigarette smoking during pregnancy on fetal and childhood growth. Obstet Gynecol, 1981. 57: p. 18-21.

95. Rantakallio, P., A follow up study up to the age 14 of children whose mothers smoked during pregnancy. Acta Paediatric Scand., 1983. 72: p. 747-753.

96. Fogelman, K.R. and O. Manor, Smoking in pregnancy and development into early adulthood. Br. Med. J., 1988. 297: p. 1233-1236.

97. Fox, N.L., M. Sexton, and R.J. Hebel, Prenatal exposure to tobacco. I. Effects on physical growth at age three. Int. J. Epidemiol., 1990. 19: p. 66-71.

98. Hardy, J.B. and E.D. Mellits, Does maternal smoking during pregnancy have a long term effect on the child? Lancet, 1972, ii: p. 1332-1336.

99. Barr, H.M., A.P. Streissguth, and D.C. Martin, Infant size at 8 months of age; relationship to maternal use of alcohol, nicotine and caffeine during pregnancy. pediactrics, 1984. 74: p. 336-341.

100. Day, N., et al., The effects of prenatal tobacco and marijuana use on offspring growth from birth through 3 years of age. Neurotoxicol. Teratol, 1992. 14: p. 407-414.

101. Schulte-Hobein, B., et al., Cigarette smoke exposure and development of infants throughout the first year of life: influence of passive smoking and nursing on nicotine levels in breast milk and infant's urine. Acta Paediatr., 1992. 81: p. 550-557.

102. Conter, V., et al., Weight growth in infants born to mothers who smoked during pregnancy. Br. Med. J., 1995. 310: p. 768-771.

103. Goldstein, H., Factors influencing the height of seven year old children-results from the national child development study. Human biology, 1971. 43: p. 92-111.

104. Wingerd, J. and S. E.J., Factors influencing length at birth and height at five years. Pediactrics, 1974. 53: p. 737-741.

105. Laml, T., et al., Impact of maternal anthropometry and smoking on neonatal birth weight. Gynecol Obstet Invest, 2000. 50(4): p. 231-6.

106. Kallen, K., Maternal smoking during pregnancy and infant head circumference at birth. Early Hum Dev, 2000. 58(3): p. 197-204.

107. Juchau, M.R. and M.J. Namkung, Studies on the biotransformation of naphthalene-1,2oxide in fetal and placental tissues of humans and monkeys. Drug Metab Dispos, 1974. 2(4): p. 380-5.

108. Zaren, B., G. Lindmark, and M. Gebre-Medhin, Maternal smoking and body composition of the newborn. Acta Paediatr, 1996, 85(2): p. 213-9.

109. Longo, L.D. and E.P. Hill, Carbon monoxide uptake and elimination in fetal and maternal sheep. Am J Physiol, 1977. 232(3): p. H324-30.

110. Pollack, R.N. and M.Y. Divon, Intrauterine growth retardation: definition, classification, and etiology. Clin Obstet Gynecol, 1992. 35(1): p. 99-107.

111. Lindsay, M.K., A.J. Thomas, and P.M. Catalano, The effect of smoking tobacco on neonatal body composition. Am J Obstet Gynecol, 1997. 177(5): p. 1124-1128.

112.Segal, M.R., et al., Maternal smoking during pregnancy and birth outcomes with weight gain adjustments via varying-coefficient models. Statistics in Medicine, 1997. 16: p. 1603 $-1616$.

113. Boshuizen, H.C., et al., Maternal smoking during lactation: relation to growth during the first year of life in a Dutch birth cohort. Am J. Epidemiology, 1998. 147(2): p. 117-126. 
114. Sexton, M., N.L. Fox, and J.R. Hebel, Prenatal exposure to tobacco: II. Effects on cognitive functioning at age three. Int J Epidemiol, 1990. 19(1): p. 72-7.

115. Fox, N.L., M. Sexton, and J.R. Hebel, Prenatal exposure to tobacco: I. Effects on physical growth at age three. Int J Epidemiol, 1990. 19(1): p. 66-71.

116. Fox, N.L., et al., The reliability of self-reports of smoking and alcohol consumption by pregnant women. Addict Behav, 1989. 14(2): p. 187-95.

117. Hebel, J.R., N.L. Fox, and M. Sexton, Dose-response of birth weight to various measures of maternal smoking during pregnancy. J Clin Epidemiol, 1988. 41(5): p. 483-9.

118. Fox, N.L., M.J. Sexton, and J.R. Hebel, Alcohol consumption among pregnant smokers: effects of a smoking cessation intervention program. Am J Public Health, 1987. 77(2): p. 211-3.

119. Vik, T., et al., Pre-and post-natal growth in children of women who smoked in pregnancy. Early Hum Dev, 1996. 45: p. 245-255.

120. Haug, K., et al., Secular trends in breastfeeding and parental smoking. Acta Paeditrica, 1998. 87: p. 1023-1027.

121. Subcommittee on nutritional status and weight gain during pregnancy, in National Academy Press. 1990, Institute of Medicine: Washington DC.

122. Abrahms, B. and V. Newman, Small-for-gestational-age birth; maternal predictors and comparison of risk factors of spontaneous preterm delivery in the same cohort. Americam Journal of Obstetrics and Gynecology, 1991. 164: p. 785-790.

123. Hediger, J.L., et al., Patterns of weight gain in adolescent pregnancy: effects on birth weight and preterm delivery. Obstetrics and Gynaecology, 1989. 74(6-12).

124. Chatenoud, L., et al., Prevalence of smoking among pregnant women is lower in Italy than England. Bmj, 1999. 318(7189): p. 1012. 


\section{Chapter VII \\ Correlations in Growth}

'Well,' said Pooh, 'if I plant a honeycomb outside my house, then it will grow up into a beehive.'

- A.A. Milne- 


\section{$\S 7.1$ Introduction}

In paragraph 5.5 in the chapter on graphs, a comprehensive description of the background and construction of the correlation matrix has been given. In this chapter the matrix is put into its practical implication. Matrix for weight and supine length were being developed separately for boys and girls. The matrixes were calculated from the $z$-scores. For the calculation of the $z$-score the normal reference values of the $4^{\text {th }}$ national growth study were used. As the increment of the growth of head is rather small, and the measurement error is about the same as the standard deviation, no matrix was constructed for the head circumference. Neither was there a matrix constructed for the crown rump length as there were no normal values available in the $4^{\text {th }}$ national growth study. Time intervals for the matrix were chosen at 3 months as this would be the most useful in the day to day practice.

\section{$\S 7.2$ The Matrixes}

The matrix has been calculated from the z-scores of weight and supine length using the Pearson Product-Moment Correlation. To achieve the values of weight or supine length for the exact ages of 3, 6, 9, 12, 15, 18, 21 and 24 months the $z$-scores were interpolated. The interpolation was not done linearly, but the shape of the individual growth curve was taken into account. All the graphical presentations of the correlations in the chapter are mirrored in the diagonal line from left top to right bottom. The graphs show all z-scores correlated with each other at various fixed time points.

Figure 7.1 gives a graphical representation of the inter correlations of weight at various ages. With the increase of age and a decrease in the period of the interval between the ages, the correlation is getting higher. This can be seen by a compressed and almost linear set of data points in the box of the $21-24$ month correlation (bottom right), compared to a less dense and rather oval set of data points in the box of the $3-24$ month correlation (top right). This is confirmed in the matrix in table 7.1 by a higher correlation, approaching the value of 1.000 (representing a linear correlation), with the increase of age and a decrease in the length of the interval time. This phenomenon appears both in weight and supine length as in boys and girls. 


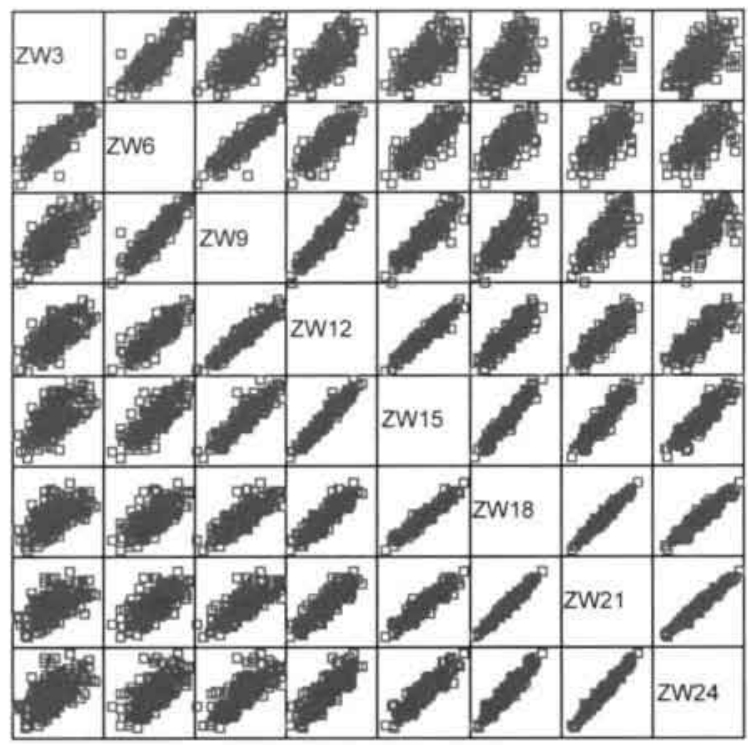

Figure 7.1 Graphical representation of the correlations of z-score for weight (ZW) in boys from $3-6-9-12-15-18-21$ or 24 months of age

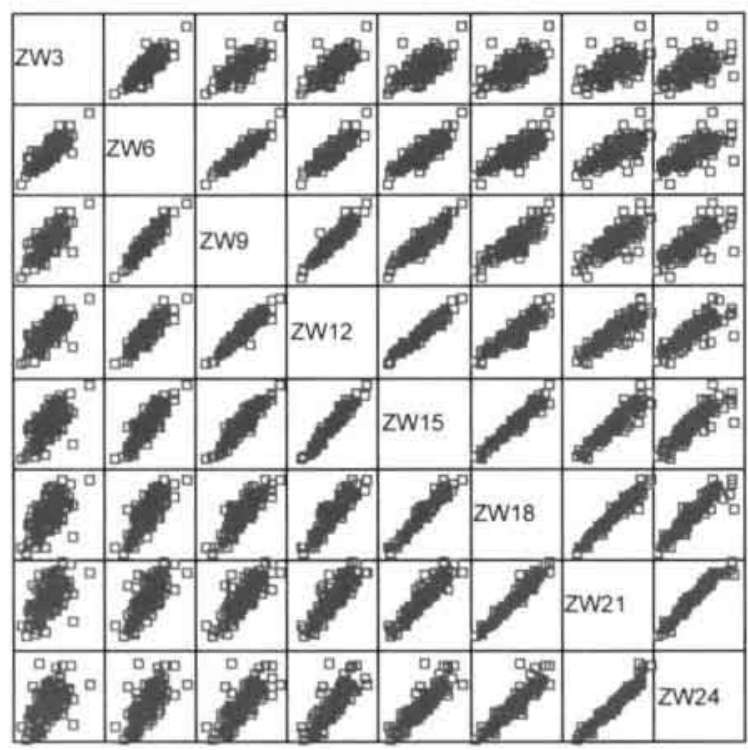

Figure 7.2 Graphical representation of the correlations of z-score for weight (ZW) in girls from $3-6-9-12-15-18-21$ or 24 months of age 


$\begin{array}{lcccccccc}\text { M3 } & 1.000 & & & & & & & \\ \text { M6 } & 0.846 & 1.000 & & & & & & \\ \text { M9 } & 0.761 & 0.912 & 1.000 & & & & & \\ \text { M12 } & 0.680 & 0.821 & 0.939 & 1.000 & & & & \\ \text { M15 } & 0.659 & 0.764 & 0.887 & 0.967 & 1.000 & & & \\ \text { M18 } & 0.605 & 0.693 & 0.816 & 0.910 & 0.974 & 1.000 & & \\ \text { M21 } & 0.563 & 0.636 & 0.762 & 0.866 & 0.942 & 0.987 & 1.000 & \\ \text { M24 } & 0.550 & 0.570 & 0.673 & 0.792 & 0.886 & 0.941 & 0.969 & 1.000 \\ & \text { M3 } & \text { M6 } & \text { M9 } & \text { M12 } & \text { M15 } & \text { M18 } & \text { M21 } & \text { M24 }\end{array}$

Table 7.1 Correlation of z-score for weight in boys from 3 to 24 months of age depicted in numbers

$\begin{array}{ccccccccc}\text { M3 } & 1.000 & & & & & & & \\ \text { M6 } & 0.857 & 1.000 & & & & & & \\ \text { M9 } & 0.777 & 0.903 & 1.000 & & & & & \\ \text { M12 } & 0.700 & 0.808 & 0.942 & 1.000 & & & & \\ \text { M15 } & 0.693 & 0.744 & 0.896 & 0.973 & 1.000 & & & \\ \text { M18 } & 0.607 & 0.671 & 0.809 & 0.927 & 0.972 & 1.000 & & \\ \text { M21 } & 0.552 & 0.602 & 0.758 & 0.867 & 0.898 & 0.984 & 1.000 & \\ \text { M24 } & 0.526 & 0.548 & 0.691 & 0.853 & 0.857 & 0.933 & 0.975 & 1.000 \\ & \text { M3 } & \text { M6 } & \text { M9 } & \text { M12 } & \text { M15 } & \text { M18 } & \text { M21 } & \text { M24 }\end{array}$

Table 7.2 Correlation of z-score for weight in girls from 3 to 24 months of age depicted in numbers correlation of $z$-score for weight in girls 


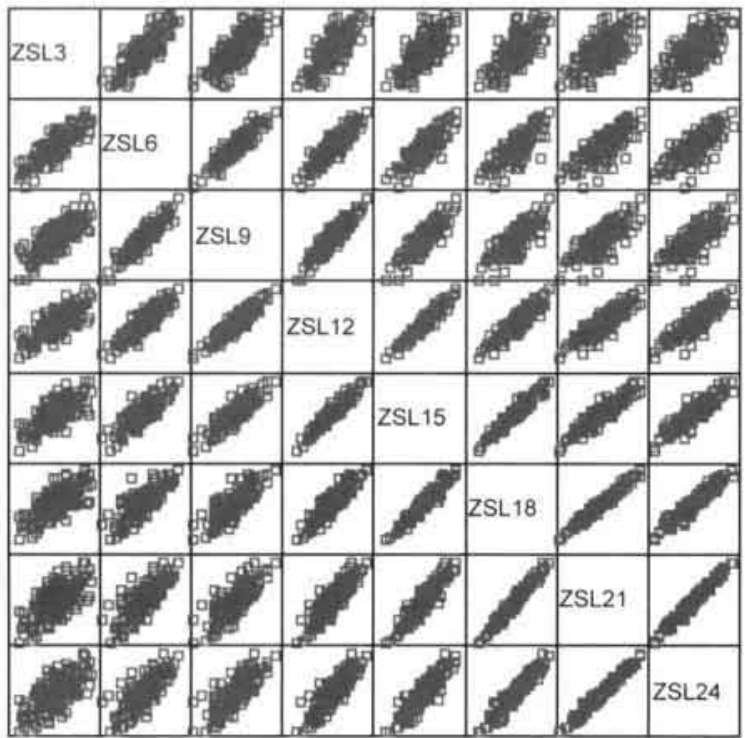

Figure 7.3 Graphical representation of the correlations of z-score for supine length (ZSL) in boys from 3-6-9-12-15-18-21 or 24 months of age

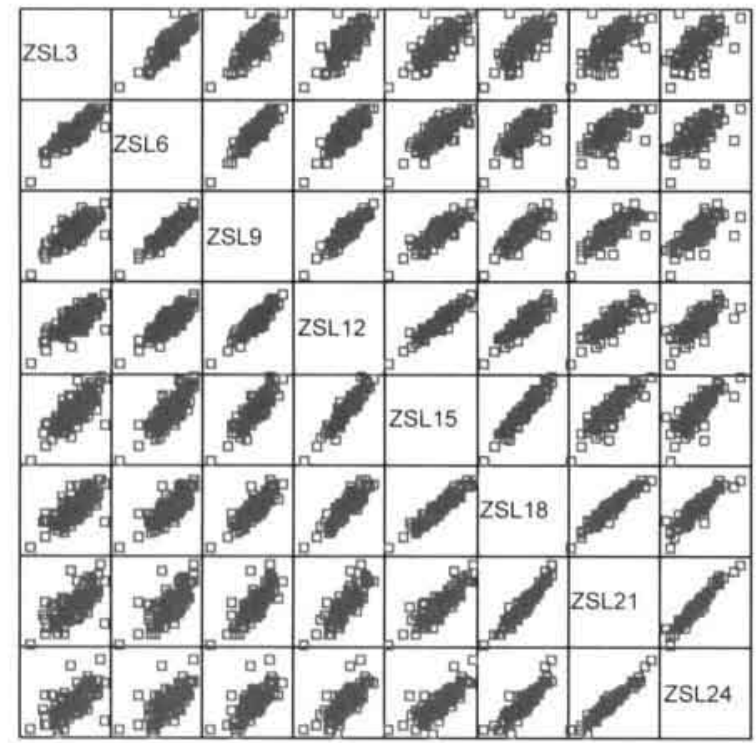

Figure 7.4 Graphical representation of the correlations of z-score for supine length (ZSL) in girls from $3-6-9-12-15-18-21$ or 24 months of age 


$\begin{array}{ccccccccc}\text { M3 } & 1.000 & & & & & & & \\ \text { M6 } & 0.841 & 1.000 & & & & & & \\ \text { M9 } & 0.773 & 0.907 & 1.000 & & & & & \\ \text { M12 } & 0.759 & 0.855 & 0.929 & 1.000 & & & & \\ \text { M15 } & 0.763 & 0.832 & 0.891 & 0.959 & 1.000 & & & \\ \text { M18 } & 0.713 & 0.763 & 0.837 & 0.904 & 0.966 & 1.000 & & \\ \text { M21 } & 0.676 & 0.716 & 0.798 & 0.862 & 0.924 & 0.979 & 1.000 & \\ \text { M24 } & 0.654 & 0.598 & 0.668 & 0.768 & 0.846 & 0.907 & 0.951 & 1.000 \\ & \text { M3 } & \text { M6 } & \text { M9 } & \text { M12 } & \text { M15 } & \text { M18 } & \text { M21 } & \text { M24 }\end{array}$

Table 7.3 Correlation of z-score for supine length in boys from 3 to 24 months of age depicted in numbers

$\begin{array}{ccccccccc}\text { M3 } & 1.000 & & & & & & & \\ \text { M6 } & 0.869 & 1.000 & & & & & & \\ \text { M9 } & 0.790 & 0.898 & 1.000 & & & & & \\ \text { M12 } & 0.710 & 0.835 & 0.917 & 1.000 & & & & \\ \text { M15 } & 0.739 & 0.813 & 0.881 & 0.958 & 1.000 & & & \\ \text { M18 } & 0.713 & 0.781 & 0.845 & 0.896 & 0.964 & 1.000 & & \\ \text { M21 } & 0.658 & 0.714 & 0.793 & 0.815 & 0.894 & 0.970 & 1.000 & \\ \text { M24 } & 0.625 & 0.551 & 0.600 & 0.575 & 0.583 & 0.725 & 0.835 & 1.000 \\ & \text { M3 } & \text { M6 } & \text { M9 } & \text { M12 } & \text { M15 } & \text { M18 } & \text { M21 } & \text { M24 }\end{array}$

Table 7.4 Correlation of z-score for supine length in girls from 3 to 24 months of age depicted in numbers

\section{$\S 7.3$ Conclusion}

Immediately below the diagonals in the tables measures the regression to the mean from one time point to the next. As can been seen in table 7.1 and 7.2 and depicted in graphs 7.1 and 7.2, the correlation for weight diminishes, not surprisingly, when the interval between two measurements increases. With increasing age the correlation in a 3 month interval is more profound. These findings apply for both boys and girls. When comparing the sexes it can be noticed that the correlation deviates. The correlation for weight in girls is less when compared to the boys toward the end of the second year of life. The correlations for supine length are shown in tables and graphs 7.3 and 7.4. One can notice that the correlations are more similar when comparing the sexes. Only towards the second year of life can a difference be noticed. These conclusions are not surprising when looking at the growth curves; supine length vs age and weight vs age, as they confirm these findings. Furthermore, the fact that the correlations for both weight and supine length are more profound with increasing age, confirms the phenomenon and general assumption that by the age of two years 
a child has "found it's position in the growth chart". Meaning that the child has settled on a certain centile / SD - isoline, and is assumed to follow this more or less during the course of its growing life. This is especially true for supine length. The best way to explain the use of the matrix is by means of an example. Between M3 and M6 the correlation for weight in girls is 0.857 . When the SDS at M3 is i.e. -2 , the amount of regression to the mean in the following 3 months is $2{ }^{*} 0.857=-1.714$. Equally, between M6 and M9, the same child is expected to move from -1.714 to $-1.55(-1.714 * 0.903)$. The amount of regression to the mean over a series of measurements every 3 months can be obtained by multiplying together the 8 correlations below the diagonal [1].

\section{§7.4 Discussion}

This chapter might be controversial, but only by putting ideas on display can controversial matters be altered, adjusted and perhaps eventually accepted.

First of all, the original matrix constructed by Time Cole didn't distinguish the girls from the boys, but was an unisex matrix [1,2]. If one wants to describe differences in correlations between boys and girls, a matrix for each needs to be created. One of the basic conditions for constructing a matrix is that the group needs to be reasonably large. This was still the case for our sample when forming the two groups. Furthermore weight is a more suitable parameter for the matrix than supine length. Generally speaking, the smaller the time gap between measurements and the greater the mean age, the higher the correlation will be [1]. The original matrix of Cole was on weight and combined both boys and girls into one matrix. As weight fluctuates more than supine length it is a more suitable parameter. In addition supine length is more difficult to measure in infancy than weight. Cole even stated that in general a correlation matrix for supine length is less successful and he discourages people constructing or using it. As this study had sufficient amount of data for both sexes, a matrix could be constructed for each of them separately. Finally one could discuss the interpolation controversy. Ideally measurements should be close to pre-specified nominal ages. As this was not always the case in this sample, interpolation seemed to be second best. The disadvantage of interpolation is that it might bias the correlation, as interpolation is a form of weighted average. Therefore the interpolated values are more precise, with less measurement error, than directly measured values. As a result, the correlations based on interpolated data are higher than they ought to be. By not using a linear interpolation and by calculating the $\mathrm{z}$-scores, this would diminish the effect, besides the fact that the purpose was to compare the boys with the girls. In both groups this effect would occur, so a comparison can still be made. [3]. Constructing matrixes for breast fed infants compare them with bottle fed infants was considered. To have sufficient data in both groups, the breast feeding group (and therefore also the bottle feeding group) the boys and girls needed to be pooled. But as has already been noted in earlier statistical analysis and was visualized in the growth curves, the differ- 
ences between the groups were marginal and therefore it was decided not to proceed with the construction of these matrixes. So although one can construct numerous of matrixes, most of them will not have a practical implication. The matrix for weight has its use and supine length only to a certain extent. 


\section{References}

1. Cole, T.J., Conditional reference charts to asses weight gain in British children. Archives of Disease in Childhood, 1995. 73: p. 8-16.

2. Cole, T.J., Constructing growth charts smoothed across time and space, in Essays on Auxology: presented to James Mourilyan Tanner by former collengues and Fellows, R. Hauspie, G. Lindgren, and F. Falkner, Editors. 1995, Castlemead Publications: Welwyn Garden City. p. 76-89.

3. Hauspie, R.C. and T.J. Cole, LMS, V.E.K.M. Walle van de, Editor. 1997: Geleen. 


\section{Chapter VIII Secular trends}

Simply the number of environmental factors on which secular changes in growth are thought to depend can make it obvious why it has taken so long until their influence became clear

-Villermé- 


\section{$\S 8.1$ Introduction}

Secular change or secular trend is the change of (anthropometric) measurements and development between generations of the same population. One can distinguish a positive and a negative secular trend, in which the negative one depicts a decline in weight and/or length between two generations. A positive trend describes an increase in attained height and/or weight between generations, or the advance occurrence of menarche in girls [1]. For example; menarche was seldom seen before the age of thirteen in the second half of the $18^{\text {th }}$ century in The Netherlands, but does now occur at approximately the $13^{\text {th }}$ birthday of a girl. Not only has the menarche advanced ( 4.5 months/decade in the first half of the $20^{\text {th }}$ century) the standard deviation has increased as well. The $10^{\text {th }}$ centile remains about the same in that period, but the $90^{\text {th }}$ has decreased remarkably, meaning that the decrease in the age of menarche can be explained by a decrease in the number of girls who mature late. There is also a shortening of the growth period, as is reflected in the age of menarche. Milestones in the process of growth and development are reached at an earlier age. A shorter period of growth does not clarify the increase in adult height. On the contrary, it might even suggest a limited attained adult height. But as the age of the adolescent growth spurt, peak height velocity and menarche, are earlier, the growth curve will shift to the left on the time axis, producing differences in attained height at all ages during growth. The changes are largest in periods of rapid growth, exactly what adolescence is all about [1]. A positive secular trend can be to due favourable environmental conditions such as the progression of living conditions, resulting from improvement of nutrition and hygiene, mass immunization and the reduction of family size [2] [3]. As quoted earlier: Growth is a mirror of conditions in society [4]. Therefore the study of secular changes is an important tool to evaluate a population's changing nutritional, hygienic and health status [5].

Secular changes in growth have been described for nearly two centuries for various populations and countries and it seems that the extent of the secular changes varies per country, region, generation and century [6-9]. In The Netherlands a continuing positive secular trend has been noticed between 1955 and 1997, although the rate has slowed down in the last 17 years compared to the first years of that period [2]. Between 1880 and 1980 the secular changes seen in Europe and North America for height was about $1.5 \mathrm{~cm} /$ decade in childhood, $2.5 \mathrm{~cm} /$ decade in adolescent and about $1 \mathrm{~cm} /$ decade in adulthood. This change is mainly due to an increase in leg length [1]. The secular increase in body weight between 1830 and 1980 was $0.7 \mathrm{~kg} /$ decade in boys at the age of 18 years and $0.6 \mathrm{~kg} /$ decade in girls in Belgium [10]. Secular changes have been remarkable in Japan where an increase in stature is seen of $8 \mathrm{~cm} /$ decade at the age of 14 years between 1950 and 1960. Japanese boys had a similar increase in height, when compared with their European peers between 1980 and 1990, so there is 
still an increase but it has diminished [1]. Secular trend rate varies not only per decade but also per country and per population and within more or less the same time period (1975 - 1995) a rate between 0.3 to $3.0 \mathrm{~cm} /$ decade can be seen. The smallest increase was observed in Sweden while the largest increase was found in women in Czech Republic and men in Japan [1]. In his article, Burgmeijer et al gives an overview of the mean z-scores of height of prepubertal boys and girls in the period $1860-1994$ related to the reference data of the $3^{\text {rd }}$ National Growth Survey of 1980 . In the first half of the $20^{\text {th }}$ century impressive differences have been found in height according to socio-economic status. The children from the lower socio-economic layers of the Dutch society in 1905 and 1916 showed z-scores equal to the $40-50$ years earlier ones, whereas children of the highest socio-economic layers showed clear signs of a positive secular growth and were only slightly shorter when compared to their peers in the 1980 group. In one century and a quarter, height at 6.5 years of age has increased by 16 to $20 \mathrm{~cm}$ in both boys and girls. In 1865 the 4 year long pre-pubertal longitudinal growth ranged from 19 to $20 \mathrm{~cm}$ in boys and between 16 and $18 \mathrm{~cm}$ in girls. Gradually this longitudinal increment has grown to almost $23 \mathrm{~cm}$ in both sexes by 1980 . When compared to the 1980 data, the $z$-score in 1862 for height was -4.1 for prepubertal boys and girls and -3.3 and -4.7 for pubertal boys and girls respectively from labour families, while the boys and girls from higher socio economic families had $z$-scores of $-2.7,-3.7$ for boys and -2.5 and -2.7 for girls. The $z$-score for height gradually approached 0 over the years and when comparing data from 1994-1995 with the 1980 data the $z$-scores reached values of +0.1 and +0.2 [3]. Children of better of families seem to have less of a secular trend than the overall population, almost certainly because they are already taller and are closer to the natural attainable height. The continuation of acceleration in growth and maturation has to be regarded as an indicator of an approach to 'optimal health' [11].

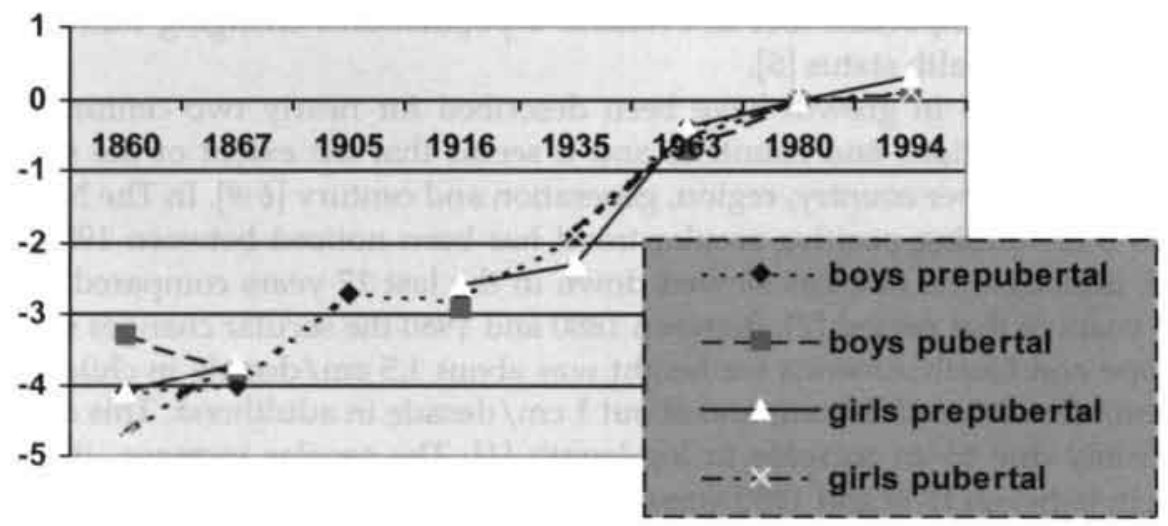

Figure 8.1: z-scores for height vs historical year

The rate at which secular changes occurred has diminished, especially in the last 17 years, but it does not seem to have come to a hold yet [2]. After adjusting for sex and age, the mean adult height was found to have increased from 171.3 
$\mathrm{cm}$ in 1980 to 173.1 in 1995 . This means that an average of $1 \mathrm{~mm}$ per year is accounted for by means of the secular trend [3]. Assuming that the living conditions of the middle and lower socio economic groups keep improving, a further increase of mean height may be expected, and more individuals may attain a height of $200 \mathrm{~cm}$ or over. And although the positive change in mean stature has slowed down, the population in the Netherlands belongs now to the tallest ones in the industrialized world [3].

To complete this paragraph besides length and weight, secular trends are being noticed for leg length, sitting height, skeletal age, dental development, head shape and most other skeletal dimensions. But so as not only to focus on the anthropological measurements, a secular trend has also been noticed for blood haemoglobin and chemistry [1].

\section{$\S 8.2$ Secular trend in this population}

Secular changes in growth are the result of the combined effect of changes in overall body size at almost all ages after birth and changes in the period of time needed for the completion of growth [5]. Although the secular trend is most obvious in adolescents or in young adults, almost all of the secular increase in adult height is established shortly after birth and almost entirely realized during childhood [12]. Therefore the data of this research can be used to evaluate a possible secular trend. As the $4^{\text {th }}$ National Growth Survey took place around and about the same period as this investigation, the data of the $3^{\text {rd }}$ national Growth Survey need to be used to detect any differences. Only length, weight and head circumference were determined in the $3^{\text {rd }}$ national Growth Survey, so therefore these were the anthropometric data used for the comparison. 


\section{Girls head circumference}

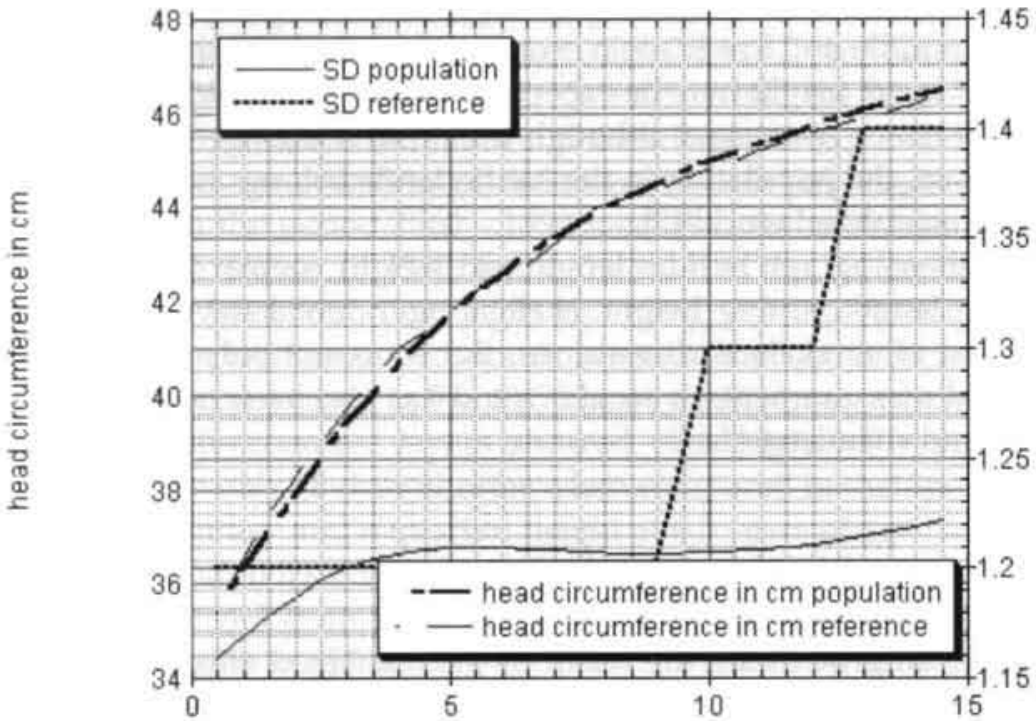

age in months

\section{Boys head circumference}

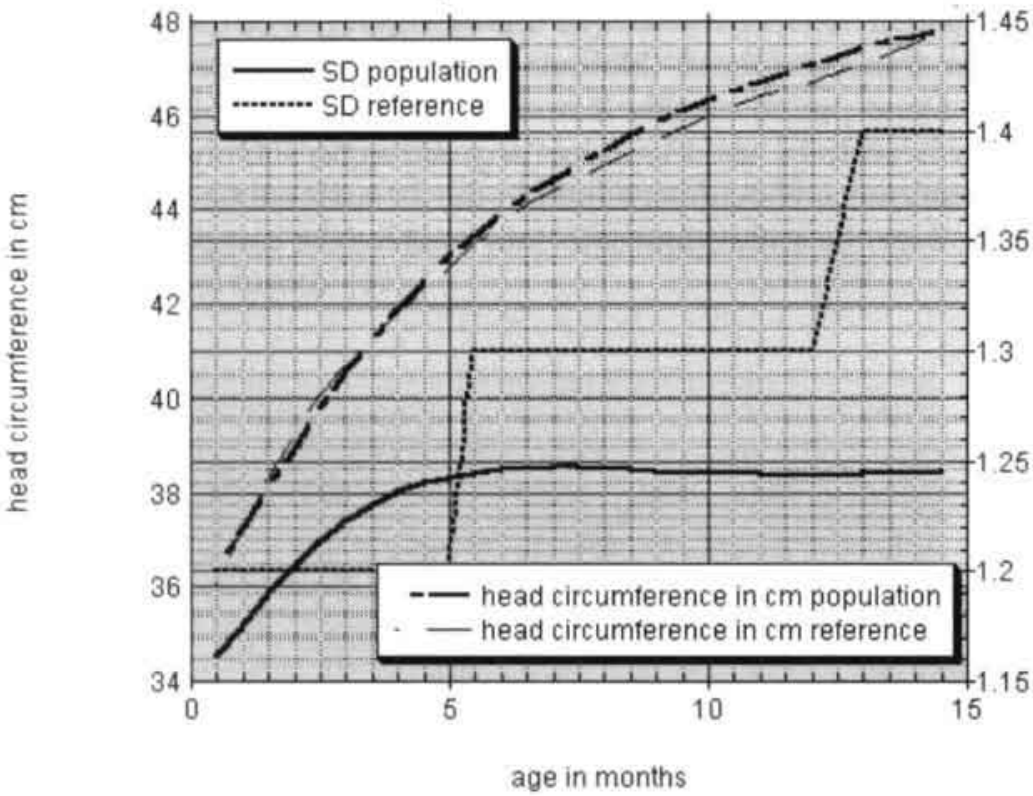

Figure 8.2 and 8.3 show the p50 (reference value on the left site) and SD (reference values on right side) for age us head circumference for both girls and boys. There isn't a significant difference in supine length between the Maastricht population and the Dutch reference of 1980. The SD curve of the Dutch reference is not a smooth line, due to the given reference values. The difference in SD score is mainly due to a different mathematical approach. 


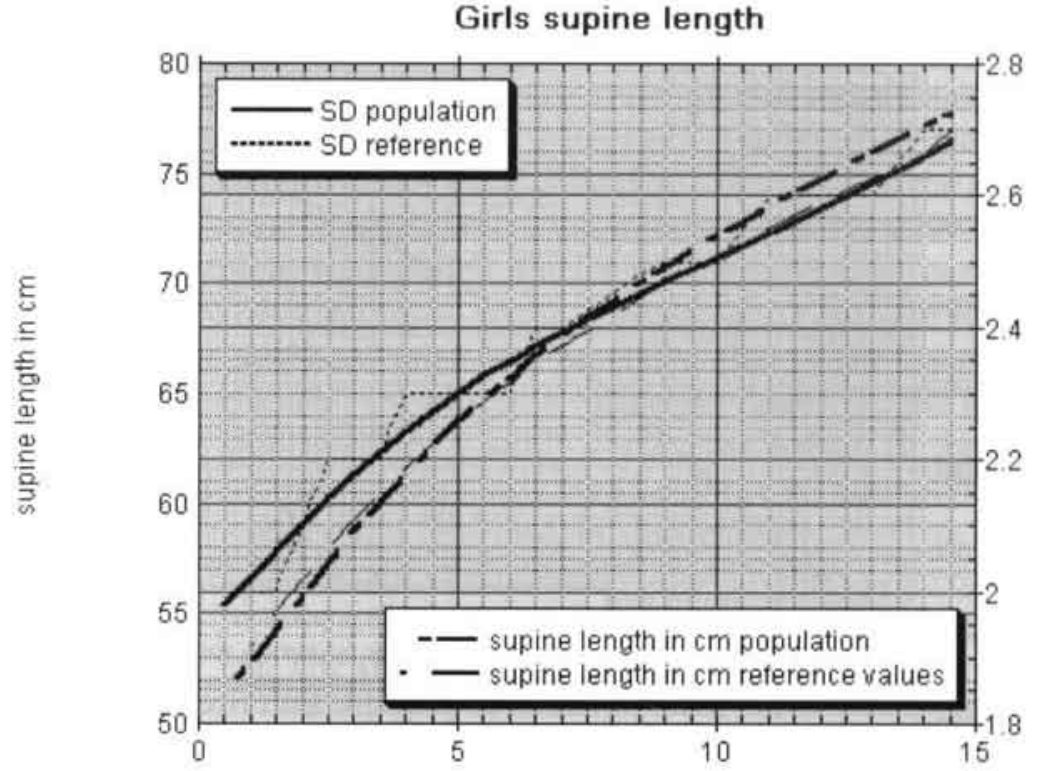

age in months

\section{Boys supine length}

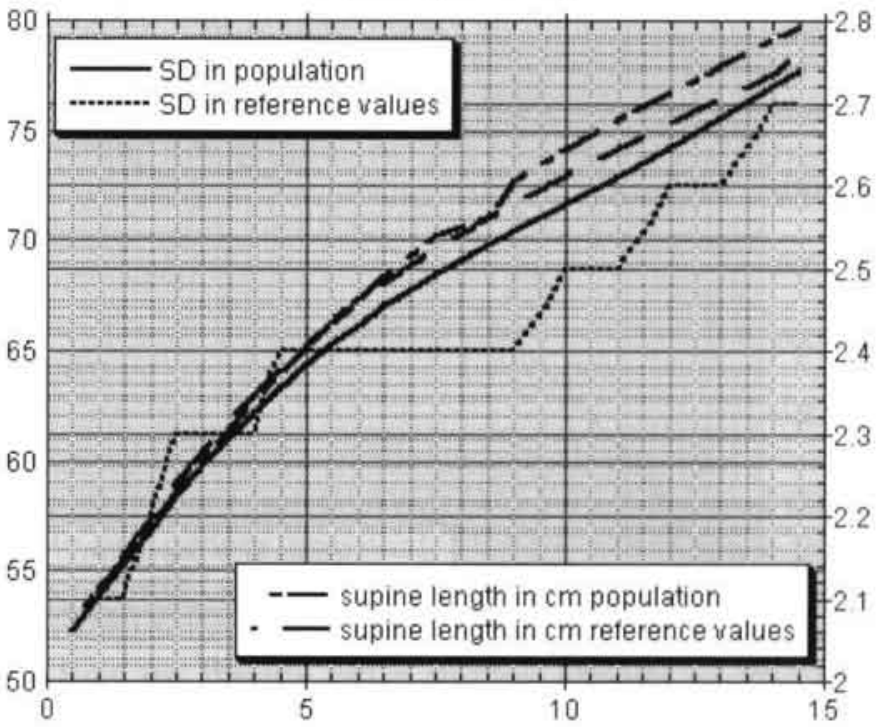

age in months

Figure 8.4 and 8.5 show the p50 (reference value on the left site) and SD (reference values on right side) for age vs supine length for both girls and boys. There isn't a significant difference in supine length between the Mastricht population and the Dutch reference of 1980. The SD curve of the Dutch reference is not a smooth line, due to the given reference values. (Horizontal lines follow the grid lines) 

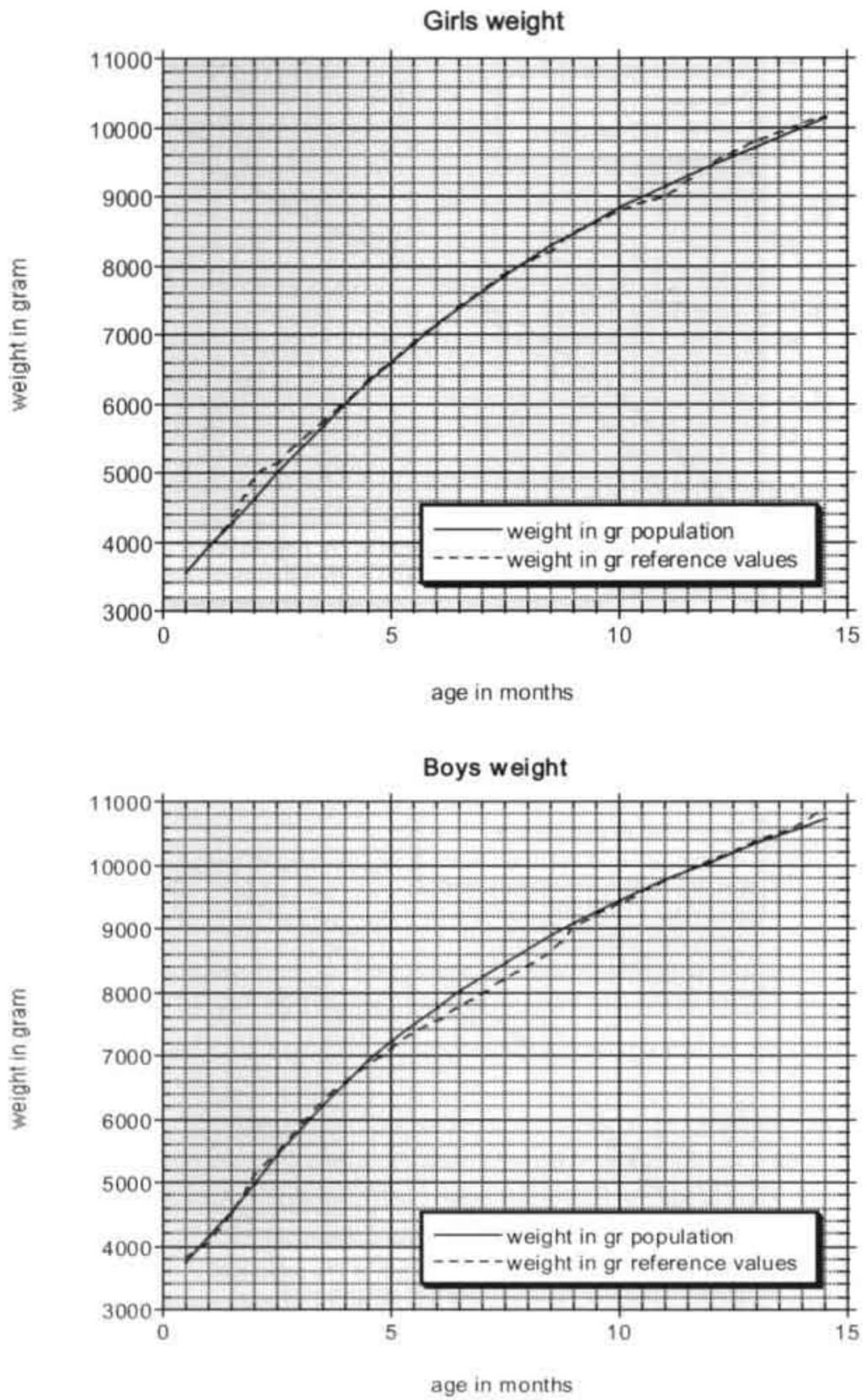

Figure 8.6 and 8.7 show the p50 for age vs. weight for both girls and boys. As can be noticed, there is not an obvious difference between the Maastricht population and the Dutch population of 1980 . The SD is not depicted due to the skewness of the distribution of weight. 
Height differences according to region, education level of parents and family size have remained and can not be held responsible for any differences in height in time [2]. A regional difference in length and weight has been detected and described, both in the $3^{\text {rd }}$ and $4^{\text {th }}$ National Growth Survey [13]. In 1980 children in the northern provinces were taller than their peers in the southern provinces. These differences were about $1 \mathrm{~cm}$ at infancy and reached about $2 \mathrm{~cm}$ in adolescents. As might be expected, the lengths in the middle-eastern and western regions were between those of the northern and southern regions. Weight for height in the southern provinces exceeded that of the northern ones for both sexes. Unfortunately no absolute reference values for the southern provinces have been published. In a study conducted locally in the north of The Netherlands: The Oosterwolde study by Gerver, a secular trend was noticed between the data collected in 1980 and the data collected in 1989. An increase in both height and sitting height was noticed [14]. As has been mentioned in other literature, the difference in height in secular trend is mainly due to an increase in leg length $[1,14]$. The reason for the regional difference is given in chapter one. When interpreting the graphs and acknowledging the $1 \mathrm{~cm}$ difference for infants, it can be concluded that between 1980 and 1994 a secular trend can be noticed by the end of the first year of life.

The question remains how and when a population has reached an optimum body dimension [1]. And is the optimum body dimension, actually the optimum body dimension? Our genetic blueprint for stature is not known (yet?), so what is optimum and what is best depends on various factors. For as far as we can see are the environmental influences the most important influences that keep us from attaining our 'natural' height; our fenotype. But from what can be seen from the various data, including this investigation, we have not yet reached our genetic potential.

\section{$\S 8.3$ Conclusion}

Generations still seem to be getting taller than their previous counterparts. With the improvement of hygiene, medical care and better nutrition we are more and more living up to our genetic potential. There is a difference in secular trend between socio economic layers of society, in the sense that the higher socio economic families show less of a secular trend compared to the lower ones, probably as the first are already taller and are already near to the natural attainable height. The increase in final attained height is mostly due to an increase in the length of legs and is not seen in the crown rump length. This increase is not seen in the first two years of life, but is established later, most likely during puberty.

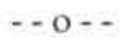




\section{References}

1. R. C. Hauspie, M. Vercauteren, C. Susanne, Acta Paediatr. 423, 20 (1997).

2. A. M. Frederiks et al., Pediatric Research 47, 316 (2000).

3. R. J. F. Burgmeijer, J. C. Wieringen van, Secular changes of growth in The Netherlands. B. É. Bodzsar, C. Susanne, Eds., Secular changes in Europe (Eötvös Univ Press, Budapest, 1998), pp. 233-262.

4. J. M. Tanner, A history of the study of human growth (Cambridge University Press, Cambridge, 1981), pp.

5. R. C. Hauspie, M. Vercauteren, C. Susanne, Horm Res 45, 8 (1996).

6. R. C. Hauspie, M. Vercauteren, paper presented at the De Vierde Landelijke Groeistudie (1997); Presentatie nieuwe groeidiagrammen, Den Haag, 11 juni 19981998.

7. R. D. Hoppa, T. N. Garie, Annals of Human Biology 25, 553 (1998).

8. G. Biering, Acta Paediatr Scand, Suppl 319, 74 (1985).

9. D. F. Roberts, Acta medica auxologica 24, 167 (1992).

10. M. Vercauteren, R. C. Hauspie, C. Susanne, in Secular trend in Europe C. Susanne, B. É. Bodzsar, Eds. (Eötvös Loránd University Press, Budapest, 1997).

11. J. C. Wieringen van, in Human growth F. Falkner, J. M. Tanner, Eds. (Plenum Press, New York, 1986), vol. 3, pp. 307-331.

12. M. Rosenberg, Ann Hum Biology 15, 275 (1988).

13. M. J. Roede, J. C. van Wieringen, Tijdschrift voor Sociale Gezondheidszorg, supplement 63, 1 (1985).

14. W. J. Gerver, R. Bruin de, N. M. Drayer, Acta Paediatr. 83, 812 (1994). 


\section{Chapter IX \\ Findings}

From principles is derived probability, but truth or certainty is obtained only from facts

- Nathaniel Hawthorne- 


\section{§9.1 Presentation in 2 Dimensions}

The Appendix consists of a collection of the various growth curves that have been generated from the data of this research is given. Appendix A presents a collection of the growth curves for the various parameters. Whether or not the parameters have a significant influence on the growth of infants is described in chapter 6 .

The following curves can be found for head circumference, weight, supine length, subischial leg length and crown rump length:

- alcohol consumption of the mother during pregnancy

- (duration of) breastfeeding

- onset of the delivery

- education level of the father

- education level of the mother

- jaundice of the infant

- presentation

- medication intake of the mother during pregnancy

- $\quad$ kind of delivery

- order of birth (various group classifications)

- sex

- smoking of the mother during pregnancy

Appendix B consists of the growth charts. The charts can be used in the clinic or healthcare centres. For the practical use of the charts both charts with percentiles (p3, p10, p25, p50, p75, p90 and p97) and standard deviations (-2.67 SD, $2.00 \mathrm{SD},-1.33 \mathrm{SD},-0.67 \mathrm{SD}$, mean, +0.67 SD, +1.33 SD, +2.00 SD, +2.67 SD) are given, followed by percentile graphs in which all the data are plotted. Furthermore a table with the percentile values for biological age and the standard deviation scores for chronological age are given, followed by a table with the $\mathrm{L}, \mathrm{M}$ and $\mathrm{S}$ scores and the standard deviation for the various biological ages. The edf score used for the construction of the curve is given in the index of the chart. Finally an overview graph is given as a verification with the means vs biological age calculated from the rough data, the LMS data and from increments respectively, as are the SD scores from the LMS data and increments.

The following charts are presented:

- supine length vs. age

- weight vs. age

- head circumference vs. age

- crown rump length vs. age 
- subischial leg length vs. age

- weight vs. supine length

- subischial leg length vs. supine length

- head circumference vs. crown rump length

This list could have been supplemented with numerous comparison charts, but the goal was to present charts with a practical implication in the day to day use of physicians in the clinic or at health care centres. The practical use of these charts and the interpretation of an infant's plotted growth data is described in chapter 4 .

\section{§9.2 Presentation in 3 Dimensions}

Another way to present the dataset, that will also tell more about the internal correlations and can give a better insight on the proportions is by plotting the data in a 3-D graph, correlating the various anthropometric data with each other.

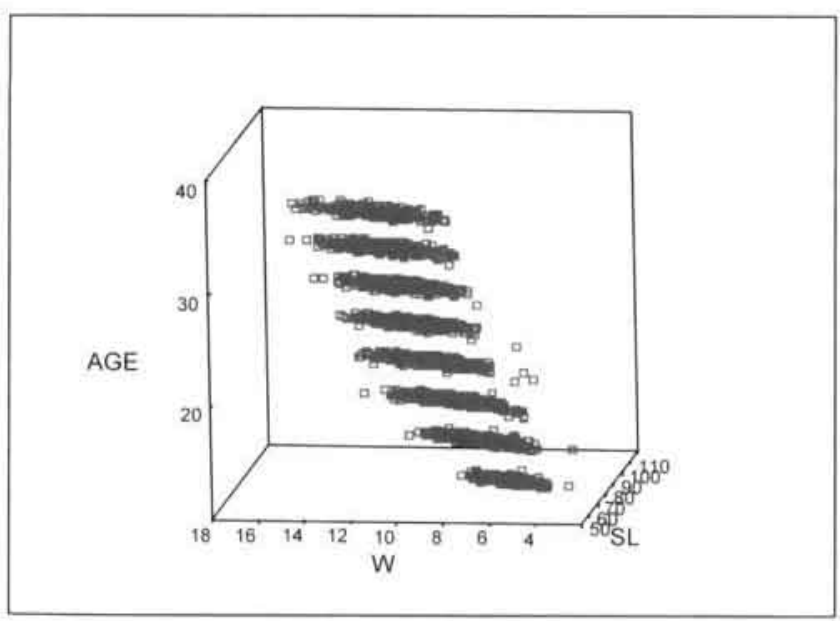

Figure 9.13-Dimensional presentation of the data of Maastricht of weight in $\mathrm{kg}(\mathrm{w})$ vs supine length in $\mathrm{cm}$ (sl) vs age in months (a) 


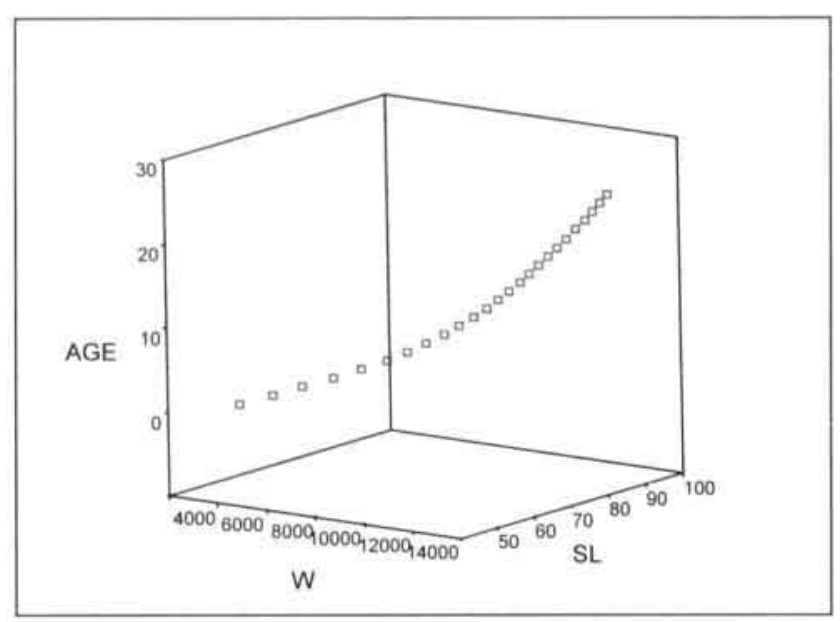

Figure 9.2 3-Dimensional presentation of P50 values of weight in gram $(w)$ vs supine length in $\mathrm{cm}$ (sl) os age in months (a)

Figures 9.1 and 9.2 give a representation of the weight vs. supine length vs. age. In figure 9.1 all the data of the Maastricht infants are being plotted. As the measurements were taken at predefined ages, the graph shows the layers at these specific ages. It also shows that with the increase of age there is a increase in the distribution of the weight and supine length of the infants. Figure 9.2 shows the P50 value of the weight vs. supine length vs. age.

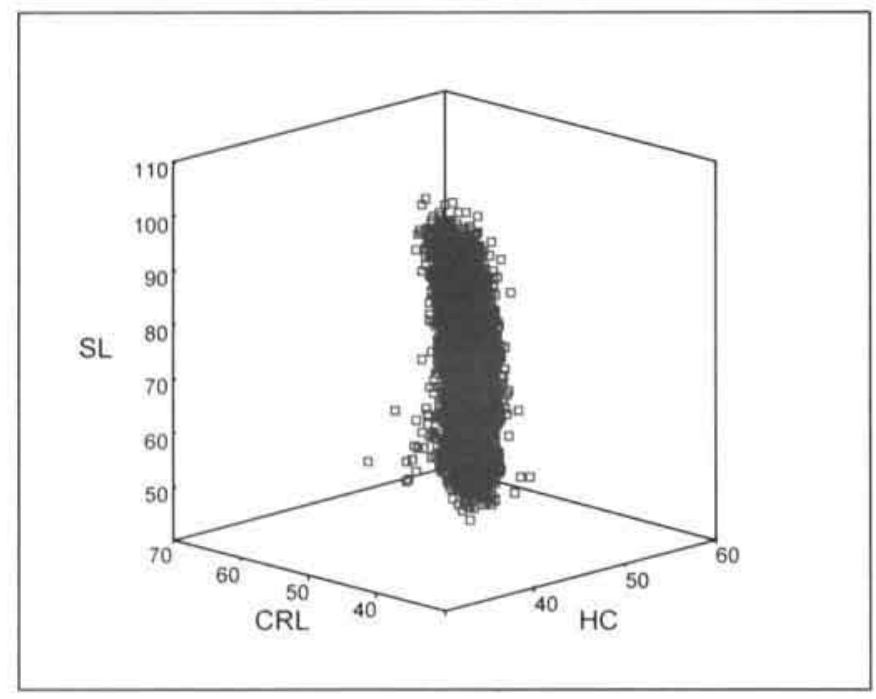

Figure 9.3 3-Dimensional presentation of the data of Maastricht of crown rump length in $\mathrm{cm}(\mathrm{crl})$ vs he circumference in $\mathrm{cm}(\mathrm{hc})$ vs supine length in $\mathrm{cm}(\mathrm{sl})$ 


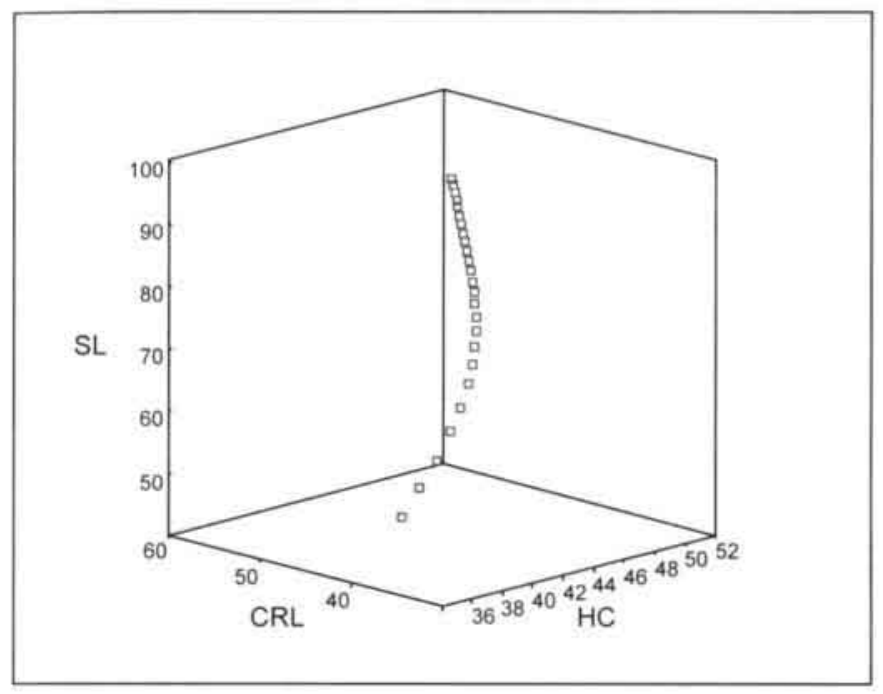

Figure 9.4 3-Dimensional presentation of P50 values of crown rump length in cm (crl) vs head circumference in $\mathrm{cm}$ (hc) vs supine length in $\mathrm{cm}$ (sl)

Figures 9.3 and 9.4 give a representation of the crown rump length vs. head circumference vs. supine length. It shows that with an increase of supine length, the head circumference doesn't continue to grow at the same rate, but seems to slow down, which is a normal phenomenon $[1,2][3]$. There seems to be a linear correlation between the supine length and crown rump length, which again is a normal phenomenon and is seen in more growth studies focused on the first two years $[1,2][3]$. 


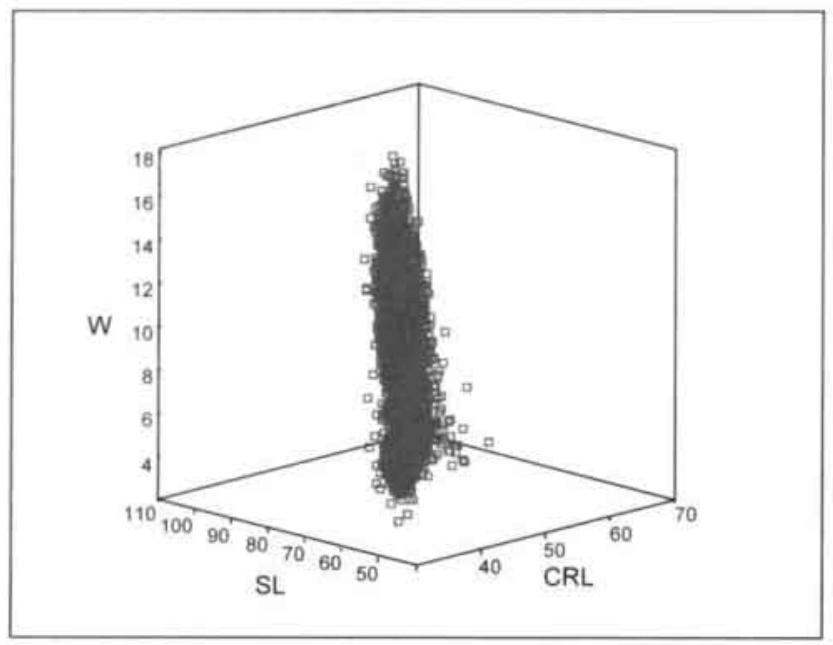

Figure 9.5 3-Dimensional presentation of the data of Maastricht of weight in $\mathrm{kg}(\mathrm{w})$ vs supine length in $\mathrm{cm}(\mathrm{sl})$ vs crown rump length in $\mathrm{cm}$ (crl)

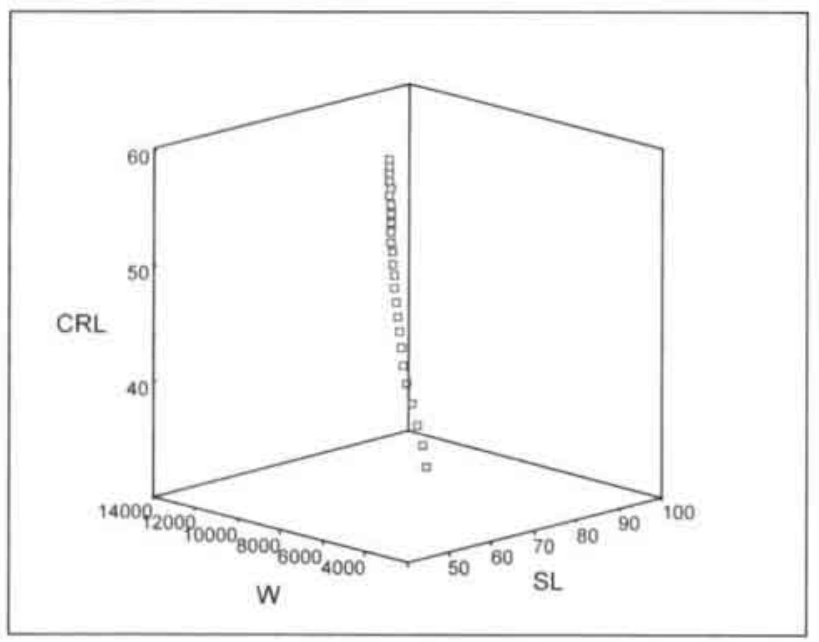

Figure 9.6 3-Dimensional presentation of P50 values of weight in $\mathrm{kg}(\mathrm{w})$ vs supine length in $\mathrm{cm}$ (sl) vs crown rump length in $\mathrm{cm}(\mathrm{crl})$

Figures 9.5 and 9.6 give a representation of weight vs supine length and crown rump length. These three parameters are highly linear correlated as can be seen in both graphs, which is not surprising. With the increase of supine length, both weight and crown rump length will increase as well, as is confirmed in the literature [1, 2] [3].

The linear correlations between supine length, weight and crown rump length vs the deviation of the growth of head circumference over a period of time is 
also shown in figure 9.7. Note that the supine length, head circumference and crown rump length value is given on the left $\mathrm{x}$-axis while the weight in grams is given on the right $\mathrm{x}$-axis.

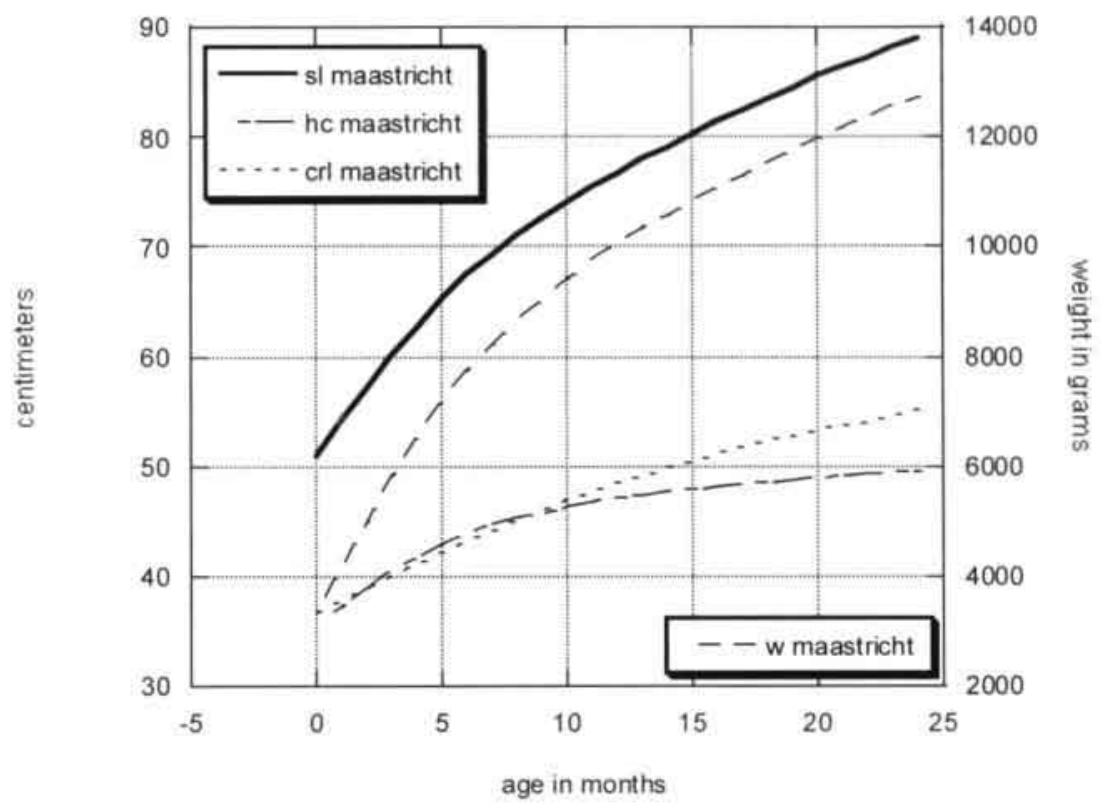

Figure 9.7 The P50 values on the left hand of supine length (sl), head circumference (hc), crown rump length (crl) and on the right hand weight $(w)$ vs age

\section{\$9.3 Conclusion}

There is a linear correlation between the supine length, crown rump length and weight as is confirmed both in the 2-D and 3-D presentations, while the head circumference decrease in its growth velocity over a period of time. The presentation of the curves in a 2-D mode is very clear and practical for day to day use. To get a better grip on the changes of the body proportions, a 3-D presentation is more suitable. The major drawback of a 3-D presentation on paper is the restricted view in depth, which would give a better feeling. Therefore the graphs are included in the software and the graphs can be turned around in all directions giving a better total overview. 


\section{References}

1. Cole, T.J., J.V. Freeman, and M.A. Preece, British 1990 growth reference centiles for weight, height, body mass index and head circumference fitted by maximum penalized likelihood. Statistics in Medicine, 1998. 17(407-429).

2. Hauspie, R.C., et al., Body length, body weight and head circumference in Belgian boys and girls aged 1 - 36 months: sex difference and effect of socioeconomic status. Acta Medica Auxologica, 1992. 24(3): p. 149-159.

3. Brandt, I., Perzentilkurven fur das Längenwachstum bei Früh- und Reif gebornen inden ersten fünf Jahren. Der Kinderarzt, 1980. 11: p. 43-51. 


\section{Chapter X \\ Comparison of growth studies}

With all there is,

Why settle for

Just a piece of sky

-Yentl- 


\section{$\S 10.1$ Introduction}

After the presentation of the various growth charts, it is now time to make a comparison with other published growth charts. A choice of various studies has been used for the comparison. The choice was based on studies that would be comparable to this population by means of age group, generation, race, nutrient intake and anthropometric measurements taken.

First of all the dataset was compared to the national growth study of Van Wieringen [1], as this was the standard around the time of the conduct of this study. Another Dutch growth chart that was used for comparison came from the Paediatric Morphometrics book [2], as this study was partly based on the same geographical population and the crown rump length was measured. A Spanish study conducted in Zaragoza was chosen as it was a longitudinal study partly performed around and about the same time as this study [3-6]. The Swiss study from Prader was chosen as this study is thorough and internationally famous and well accepted [7]. This applies as well for the Tanner study [8]. After a comparison on anthropometry without any reference to Mr Tanner would be incomplete. A German study was used as this is geographically close to The Netherlands [9]. And finally, maintain to an European distribution for the comparison a Danish study was selected [10]. It was a conscience choice not to use Asian and/or American data for comparison, as the racial and geographical differences are too big and any conclusion drawn would not have any medical or scientific implication. This chapter is not intended to validate the growth charts presented in this thesis, but is merely mend to illustrate geographical, generational and/or mathematical differences.

\section{$\S 10.2$ Comparisons}

In this paragraph graphs are presented in which the P50 or the median of various growth studies is depicted. The P50 based on the Maastricht data, the data of this trial, is bold. Only the graphs of the boys have been printed, as the graphs were rather similar and the findings were equal for both boys and girls. First of all a graph with the comparison of supine length for boys is given. 


\section{$\S 10.1$ Introduction}

After the presentation of the various growth charts, it is now time to make a comparison with other published growth charts. A choice of various studies has been used for the comparison. The choice was based on studies that would be comparable to this population by means of age group, generation, race, nutrient intake and anthropometric measurements taken.

First of all the dataset was compared to the national growth study of Van Wieringen [1], as this was the standard around the time of the conduct of this study. Another Dutch growth chart that was used for comparison came from the Paediatric Morphometrics book [2], as this study was partly based on the same geographical population and the crown rump length was measured. A Spanish study conducted in Zaragoza was chosen as it was a longitudinal study partly performed around and about the same time as this study [3-6]. The Swiss study from Prader was chosen as this study is thorough and internationally famous and well accepted [7]. This applies as well for the Tanner study [8]. After a comparison on anthropometry without any reference to Mr Tanner would be incomplete. A German study was used as this is geographically close to The Netherlands [9]. And finally, maintain to an European distribution for the comparison a Danish study was selected [10]. It was a conscience choice not to use Asian and/or American data for comparison, as the racial and geographical differences are too big and any conclusion drawn would not have any medical or scientific implication. This chapter is not intended to validate the growth charts presented in this thesis, but is merely mend to illustrate geographical, generational and/or mathematical differences.

\section{$\S 10.2$ Comparisons}

In this paragraph graphs are presented in which the P50 or the median of various growth studies is depicted. The P50 based on the Maastricht data, the data of this trial, is bold. Only the graphs of the boys have been printed, as the graphs were rather similar and the findings were equal for both boys and girls. First of all a graph with the comparison of supine length for boys is given. 


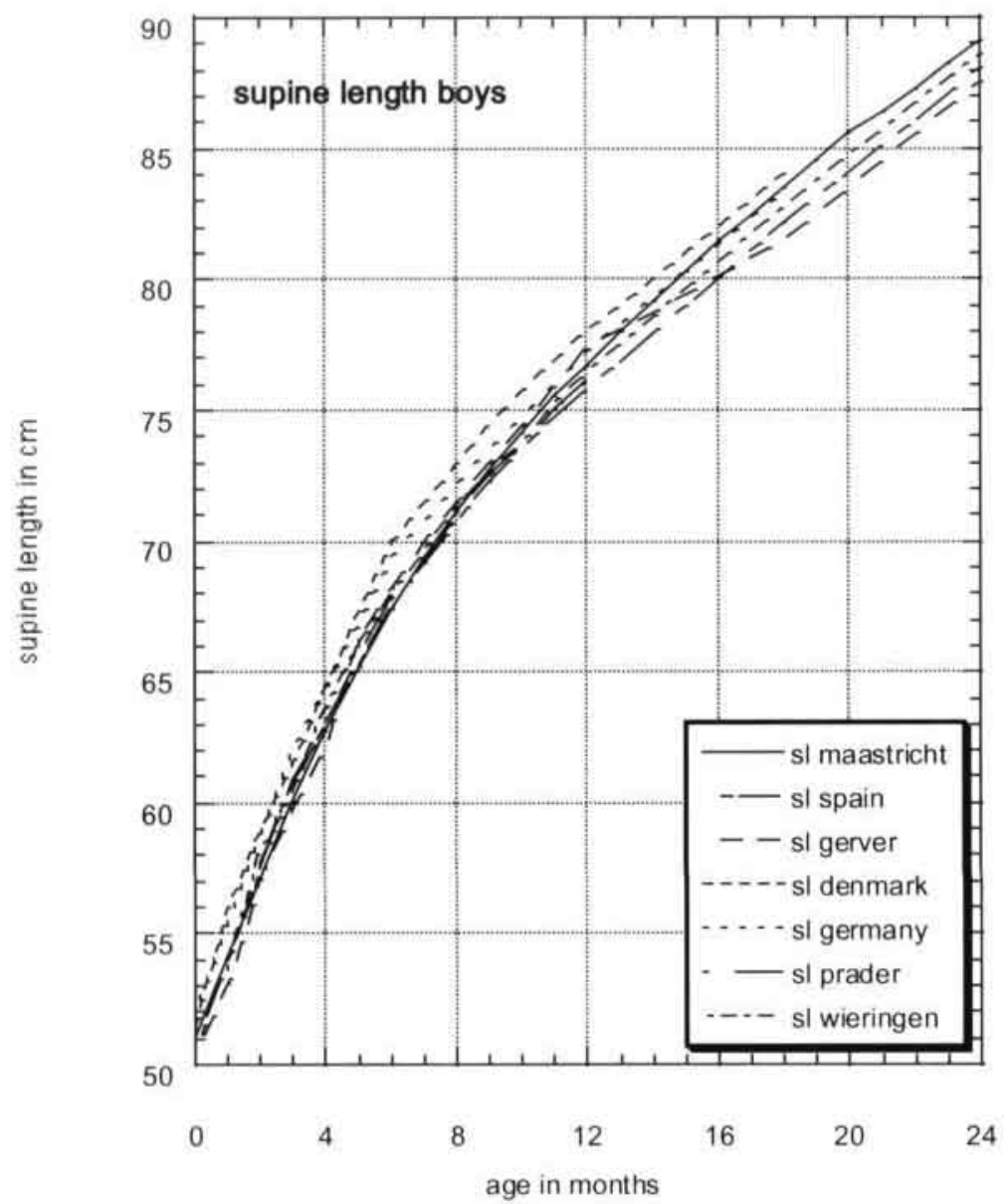

Figure 10.1 Comparison of various supine length curves (sl) for boys with the curve of this research (SL Maastricht)

The curve of the Denmark study stands out in the graph. This might be due to the fact that this curve is the median instead of the P50 curve as in the other studies. Furthermore the curve of the Maastricht sample lies above the other curves toward the end of the second year of life. No reasonable explanation can be given for that, other than perhaps the fact that the curve from this thesis is based on longitudinal data. The bending of the 'Gerver' curve as can been seen in figure 10.1 at the age of 12 months suggests a period of less growth. But the explanation for this lies in the fact that 2 separate curves were constructed; for the first year of life, and from 1.5 years till the age of 18 years. Combining these separate curves results in a not smooth and a rather artificial connecting point. This phenomenon can also be seen in the following graphs. One other explanation might be that up till the first birthday, infants are being measured laying down but after that they are being measured standing up. Measuring infants laying down has the advantage that the infant can be measured more accurately 
as has been described in chapter four. When measuring a child while standing, it is more difficult to measure accurately and children seem to 'shrink' a bit based on their growth charts. This hypothesis would only explain the bending in the supine length and crown rump length curves, but not the head circumference or weight.

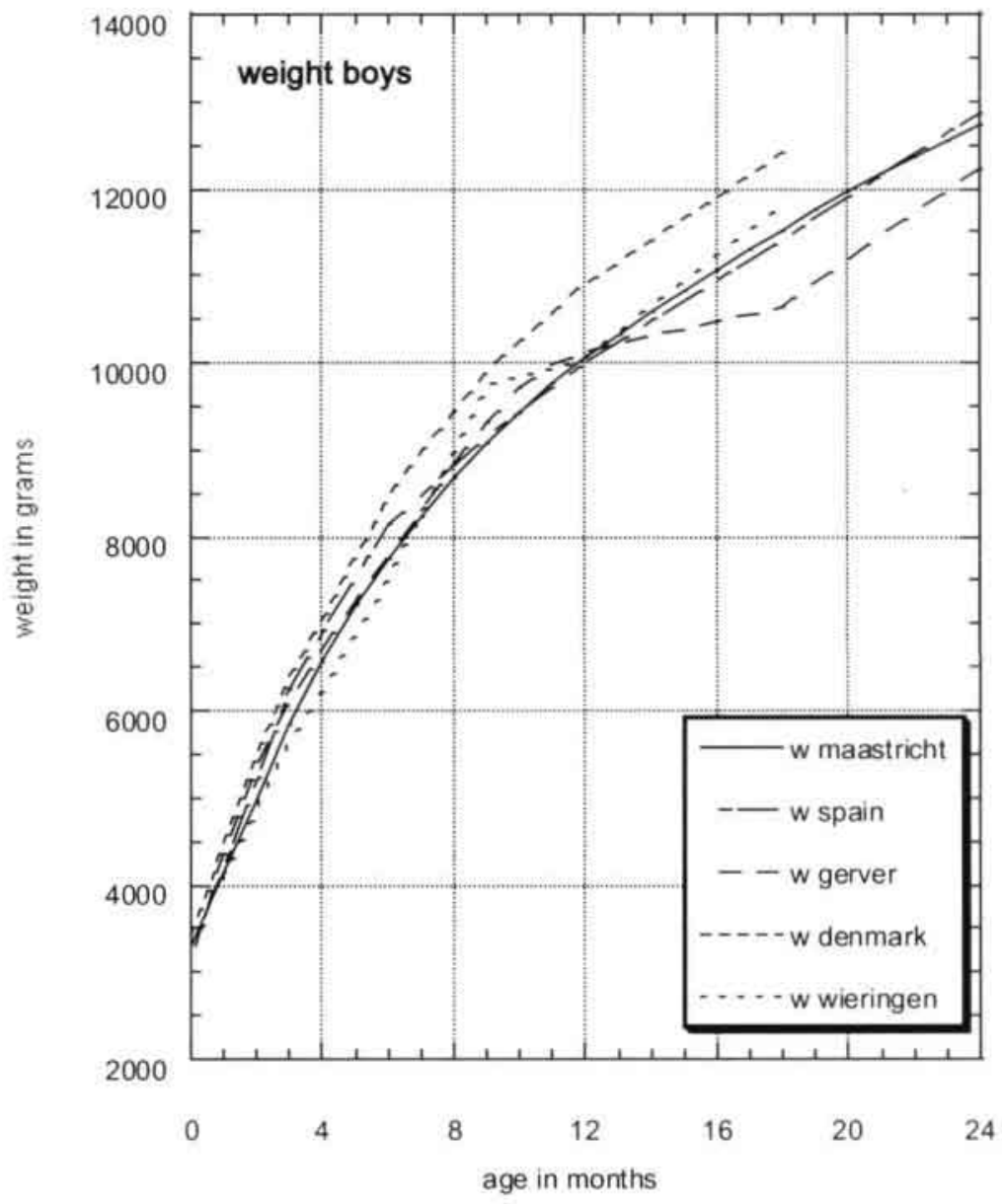

Figure 10.2 Comparison of various weight curves (w)for boys with the curve of this research (W Maastricht)

In figure 10.2 regarding weight, the same phenomenon as has been described for supine length can be noticed. The Denmark curve lays above the rest. The curve from the Maastricht data is more or less comparable to the other curves for approximately the first 18 months of life. The Gerver curve shows again the bending of the curve after 12 months in figure 10.2, again caused by the forced combining of two separate curves. As the Denmark curve lays clearly above the other curves after 18 months, this would suggest Danish toddlers are heavier 
then other European toddlers. However this can not be confirmed in the literature.

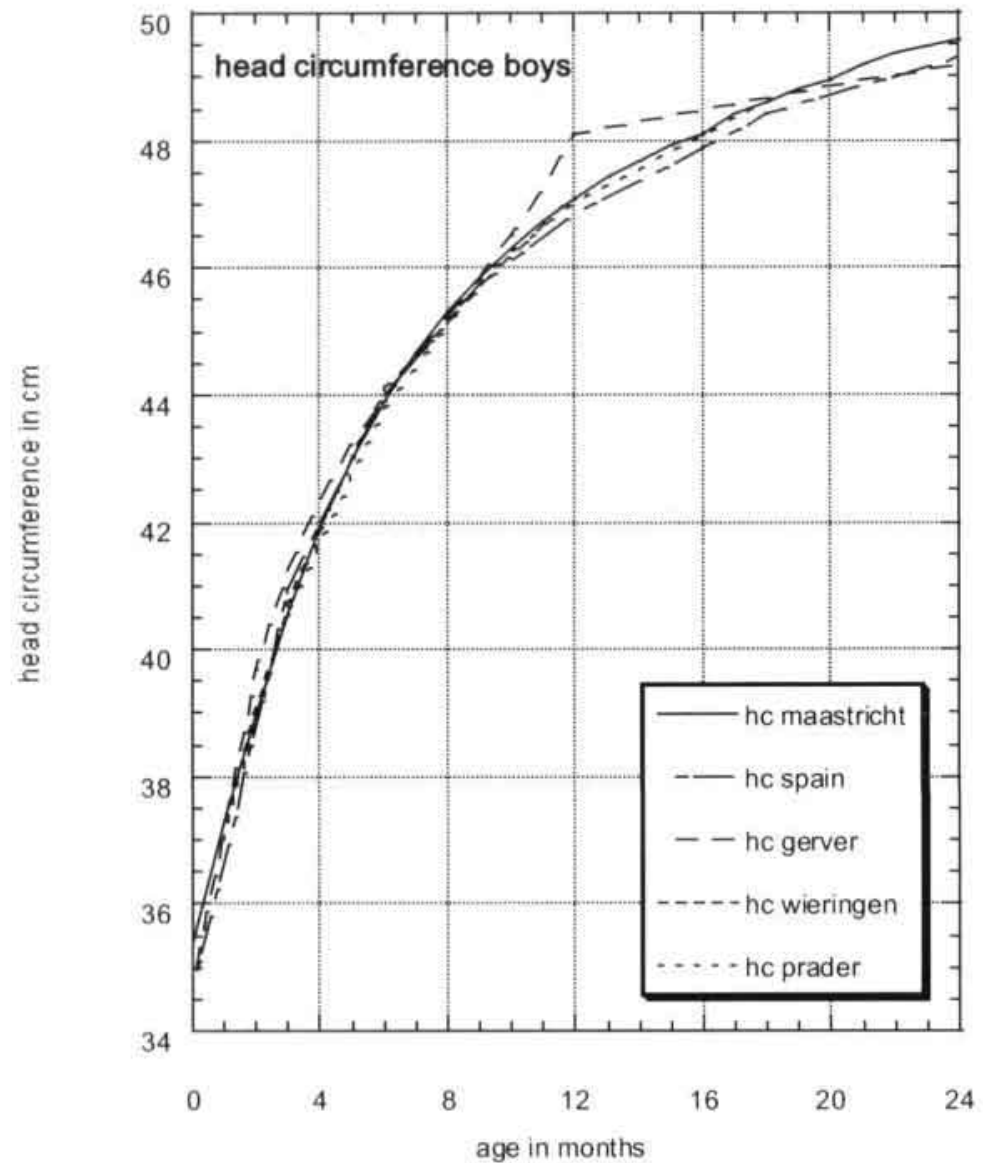

Figure 10.3 Comparison of various head circumference curves (hc) for boys with the curve of this research (HC Manstricht)

No additional comments need to be made for the head circumference comparison besides the bending of the Gerver curve at the age of 12 months as described with the two previous graphs. 


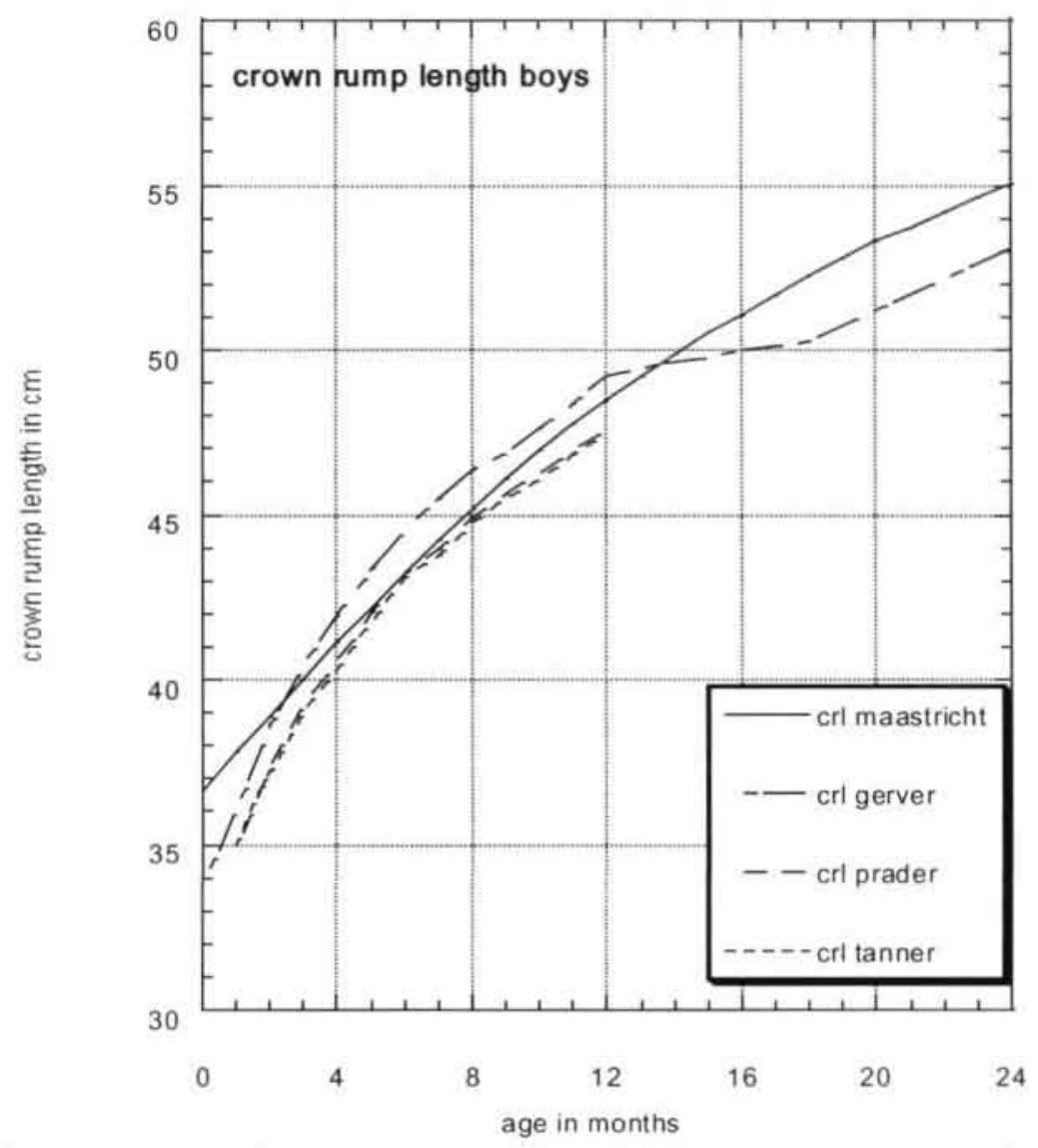

Figure 10.4 Comparison of various crown rump length curves (crl) for boys with the curve of this research (CRL Maastricht)

It is striking to notice that the Maastricht curve for crown rump length starts of at a higher value and the P50 line is less curved compared to the other curves. This can be explained, most likely, by means of different mathematical methods for the construction of the curves. For the construction for the Maastricht curve the smoothing was more substantial compared to the others as the weighing for the data at the various ages was equal for the various ages.

\section{$\S 10.3$ Conclusion}

Various comparisons have been made and minimal and more profound differences have been noticed. The differences can be explained by various reasons. First of all there is geographical difference between Northern and Southern regions within Europe. The Southern people tend to be smaller in comparison to the Northern. Furthermore a difference between generations can cause a 
difference as is described in chapter seven on secular trends. The bending that is seen in the curves from the Gerver studies is mostly due to an inaccuracy caused by the forced mathematical construction of combining two separate curves from 0-12 months and 12 - 24 months. The majority of studies are crosssectional, while this thesis is about a longitudinal research. Graphs based on cross-sectional studies smooth out differences in the actual growth curve. This is not so much the case in graphs based on longitudinal data. The differences in shape of the curves can also be explained by the differences in the construction of the charts. Different mathematical methods will give slightly different graphs. This was also the reason why only the $50^{\text {th }}$ percentile or the median was chosen for the comparison. The SD could also have been taken into account, but as some mathematical methods take the skewed distribution into account and others don't, a comparison would not be justified. In general it can be concluded that the graphs as they are presented in this thesis have their own niche and use. 


\section{References}

1. Roede, M.J. and J.C. van Wieringen, Growth Diagrams 1980, Netherlands Third Nationwide Survey. Tijdschrift voor Sociale Gezondheidszorg, supplement, 1985. 63(supplement 1985): p. 1-34.

2. Gerver, W.J. and d.R. Bruin, Paediatric Morphometrics. 1st ed. 1996, Utrecht: Wetenschappelijke uitgeverij Bunge. 262.

3. Longás, A.F., Estándares longitudinales normales del crecimiento de los niño aragoneses. 1994, Centro Andreas Prader: Zaragoza.

4. Longás, A.F., Centro de Estudio Longitudinal del crecimiento y desarrollo 'Andrea Prader'; datos de 0 a 12 anos. 1996, Andrea Prader center: Zaragoza.

5. Longás, A.F., Eständares longitudinales normales del crecimiento de los ñinos aragonesis. 1994, Centr "Andrea Prader": Zaragoza.

6. Longás, A.F., Estándares longitudinales normales de madureación intelectual de los ninos aragoneses, V.E.K.M. Walle van de, Editor. 1995, Andrea Prader: Zaragoza. p. normal values.

7. Prader, A. and H. Budliger, Body measurements, growth velocity and bone age of healthy children up to 12 years of age (longitudinal growth study Zurich). Helvetica Paediatrica Acta, 1977. Supple(37): p. 5-44.

8. Tanner, J.M., R.H. Whitehouse, and M. Takaishi, Standards from birth to maturity for height, weight, height velocity and weight velocity; British children, 1965. Archieves of Disease in Childhood, 1966. 41: p. 454-471:613-635.

9. Brandt, I., Perzentilkurven fur das Längenwachstum bei Früh- und Reif gebornen inden ersten fünf Jahren. Der Kinderarzt, 1980. 11: p. 43-51.

10. Andersen, E., et al., Hojde og vaegt hos danske born. Ugeskrift vor Laeger, 1982. 144: p. 1760-1765. 


\section{Chapter XI \\ Conclusions}

Kijk niet om, kijk niet om Kijk alleen maar naar de verte naar de mooie horizon

- Youp van 't Hek- 


\section{Conclusion}

The original aim of the study, to evaluate the various individual influences on growth, was found to be unrealistic. During the course of the analysis of the data, it was found that the influences were not separate, independent factors, but they were correlated again among each other. Anyone who claims that only breast feeding, only smoking or only the educational level of the parents is of influence on the growth of the infant, has omitted crucial information and has not presented the true picture on growth, but merely a simplification of the reality. Mothers who breast feed are most of the time the same mothers that do not smoke and are better educated. The question if the children of these mothers tend to be larger due to either the fact they didn't smoke, they were better educated or the infant was breast fed, can only be answered by 'all of the above'. Better educated women seem to be more conscious about the health of the infant and themselves. Breastfeeding is part of that concept for these women and so is refraining from smoking. By not smoking during the pregnancy, a woman gives her child a better start after birth. On top of that, breastfeeding has a positive influence on the immunity, amongst other things, and therefore these infants are less ill and have the opportunity to develop better towards their potential.

An analysis of the measurement techniques and the accuracy of the measurements showed that with the increase of age, the measurements were getting more accurate, with the exception of the head-circumference measurements, which remained difficult to measure in the first two years of life. In general it was concluded that the measurements in this research were performed accurately and were reproducible. Comparisons with other growth studies were made and, of course, differences were found. Reasons for these differences were explained by geographical, generational, racial and mathematical differences.

Differences that occur over generations and between populations can be explained by various factors. Of course there is a genetical difference between populations. But this does not explain differences between generations. But one thing that was not found in the literature is the fact that as a result of a difference between generations in feeding habits differences in growth might occur. For instance, if the prevalence of smoking decreases and the prevalence of breast feeding increases, as has been found in some populations [1], it is not surprising that the next generation will be taller.

One of the main reasons for physicians to use growth charts is to evaluate the growth of a child. The growth and development of a child reflects the child's health and therefore it can be used as a guidance to discover health problems or see the results of a treatment. It is a combined (inter)action of genes, environment and hormones. Prior to birth, the growth is mostly influenced by maternal 
and placental factors, while after birth paternal and environmental factors, i.e. physical and socio-cultural influences, play a role. An adverse environment during early life increases the risk of developing cardiovascular disease in adults. Birth weight and growth in the first year of life have a predictability for certain adult diseases. So the growth of a child in the first year is crucial. It lays the basis for the rest of it's life. If a backlog arrear or exist in growth these need to be caught up before the $2^{\text {nd }}$ birthday. Various investigators have confirmed that after that time there is no catching up for this backlog. When using the growth charts as an indicator, the interpretation of the growth curves is crucial. It seems that there is not always a common interpretation of the growth curves. A couple of practicalities arise to guarantee a correct reading and interpretation. Only then the growth of the child can be evaluated correctly. First of all the correct age of the child has to be used. Therefore the biological age is the best to use in the first two years. One also has to ascertain that the curves are based on the same niche as the child whose growth is depicted in the graph. This means that the charts need to be based on i.e. the same generation and ethnic background. The graphs are constructed with either centiles or SD - lines to depict averages and extremes of normal growth. Both have their advantages and disadvantages, but currently the SD lines are more commonly used to evaluate growth. By using these the false negative errors are less compared to when using centile lines. In addition it is a common misunderstanding that children have 'to follow the centile curves' printed on the charts. The centiles or SD lines are references based on averages and are not a true presentation of the actual growth process. The majority of healthy children will have their fluctuating growth curve lie between the upper and lower reference line. Growth can not be assessed by one single measurement. As growth is a dynamic process, at least two different anthropometric measurements at two different time points need to be made. Especially during the first two years of life a combination of supine length, weight and head circumference will give an idea on the growth process. Crown rump length can give additional information when one wants to look at the proportional growth. Secondly a child tends to grow according to 'regression to the mean'. Meaning that a child tends to grow towards the average and doesn't intend to grow into extreme sizes. Furthermore a child's growth varies during the various age periods and the seasons; it grows faster in the summer than in the winter. Therefore the growth curve of a child will not be a smooth line, with a predefined angle of inclination, reflecting a constant growth. It will have definite ups and not so much of ups, but rather 'flat' periods with no inclination. The weight curve can even show a negative inclination at some point. The growth potential of a child is also determined by the parental height. The various parts of the body don't grow with an equal speed at various ages. Therefore not only the ages need to be taken into account. But also the interdependent correlations between head circumference, crown rump length, supine length and weight need to be accessed as well. 
One could state that this thesis isn't complete as velocity curves were not presented. It was a conscience choice not to do so. In daily practice velocity curves have little or no use. The velocity depends on the length of the period in which the measurements were taken and is always an average. Not only the length of the period is of influence on the velocity calculation, it is known that depending on the season (winter vs summer), the velocity of growth of children differs. The use of a correlation matrix, is much more relevant as one is using the $\mathrm{z}$ scores instead of the actual number of centimetres. The matrix determines the regression to the mean by correlations between two time points. The smaller the time gap between measurements and the greater the mean age, the higher the correlation will be. The final drawback to calculating the velocity between two time points is that if the length of the period is rather small, the error of measurement at either point can add up and give a too high or too low value to the velocity.

The most important question that needs to be answered is the question "What is 'normal'?" The literature wasn't able to give an unequivocal definition. It seems that normal depends on geography, race, nutrition, education etc. The statement of Tanner many years ago, that the growth of the children is a mirror of the wellbeing of a society on its whole, reflects this matter. It might even be more accurate to use only the growth chart derived from breast feeding children, as it might be stated that breast-feeding is 'normal' and therefore this growth charts reflects the true growth process.

The question arises when one has to be concerned with looking solely at the growth curve of a child. When taken into account all the conditions mentioned earlier there isn't one way to interpret the growth curve. But it is most important to have similar growth patterns for the various anthropometric measurements; to have the growth curve stay within the reference lines and see a respectable increase in growth over a certain period of time. The use of the correlation matrix can be a supplementary method to determine any deviation of the growth of a child. 


\section{References}

1. Haug, K., et al., Secular trends in breastfeeding and parental smoking. Acta Paeditrica, 1998. 87: p. 1023-1027. 


\section{Abstract}

Ik weet niet of ik wakker bleef, Of wanneer ik deze woorden schreef, Ik weet alleen maar dat ik leef Dat lijkt mij wel genoeg - Boudewijn de Groot- 


\section{Abstract}

This thesis presents a variety of information regarding the growth of human infants in the first two years of their life. The presentation is far from complete. With the collected data an infinite number of graphs, tables and correlations could have been presented. A choice was made to go for pragmatic, medically relevant rather than obscure information. A lot of correlations could have been made that would be significant from a statistical point of view. But these correlations might not have any biological explanation or implication at all.

The thesis starts with a historical overview of what is studied, known and published on growth. It is followed with a description of the process of growing during the various stages of life. In total 1234 children participated in this study. They were followed for over 2 years in their growth in which they were measured approximately 10 times at different ages. The supine length, weight, crown rump length and head circumference were measured, while information regarding (exposure to) various external parameters were collected. The external parameters can be divided into parental related issues (i.e. parental height and parental education), perinatal issues (i.e. medicine intake and smoking of mother during pregnancy, birth order, delivery) and infant related issues (i.e. feeding). A description of the population, based on these parameters is portrayed in chapter 3. Chapter 4 describes the measuring techniques used and their accuracy and reproducibility. It then continues with Chapter 5 in which the various methods that have been developed to create growth charts from growth data is given. An inventory of the various mathematical models is given. In this thesis the LMS method was used as it is currently the most widely used and accepted method, especially for constructing longitudinal growth data. This allowed for a better comparison of the charts constructed in this thesis with other charts in the literature as is done in chapter 10. In chapters 6 and 9 the growth curves and charts for each of the various separate parameters is depicted. Differences and similarities can be observed in the appendix, in which all the various growth charts are presented, some with all the original measurements plotted in them. The use of a correlation matrix, as has been described in chapter 7, is relevant as one is using the z-scores instead of the absolute value. The matrix determines the regression to the mean by correlating two different time points. The use of the correlation matrix enables the user to determine the likelihood of a certain growth pattern of a certain child is normal or a deviation from what is the norm. As there is still a the secular trend

observed, chapter 8 shines a light on this phenomenon in general and more specific on the secular trend in the population the children of this trial belong to. 
The conclusions derived from this thesis are various. The main observations are that there isn't one single parameter that is responsible for a certain noticed difference is in growth. Various parameters are linked and therefore a difference noticed can only be explained by the combination of the various parameters. I.e. mothers who breast feed are most of the time the same mothers that do not smoke and are better educated. The question if the children of these mothers tend to be larger due to either the fact they didn't smoke, they were better educated or the infant was breast fed, can only be answered by 'all of the above'. There is room for different growth charts, depending on geography, socio-economic background but also i.e. on breast feeding vs bottle feeding. It might even be more accurate to use only the growth chart derived from breast feeding children of non-smoking mothers, as it might be stated that breastfeeding is 'normal' and therefore this growth chart reflects the true growth process of a child. Finally when evaluating the growth of child, one should not focus on one single measure, but rather take a combination of various parameters and points in time into account. As in the first year of life there is a strong linear correlation between head circumference and crown rump length, a deviation from this correlation should elicit for further analysis. It's the proportional growth and the dynamics of the growth process that should be looked at and interpreted.

\section{Samenvatting}

Dit proefschrift geeft een beschrijving van de groei van kinderen in hun eerste twee levensjaren. De presentatie van de gegevens is verre van compleet. Met de data die verzameld is tijdens het onderzoek zou een bijna oneindig aantal grafieken, tabellen en correlaties kunnen worden gepresenteerd. Er is echter een keuze gemaakt op basis van praktisch en medisch relevant dan te kiezen voor het obscure. Vele correlaties kunnen vanuit een statistisch oogpunt significant zijn hetgeen niet betekent dat er een biologische correlatie dan wel een verklaring voor gegeven kan worden.

Het proefschrift begint met een historisch overzicht van studies over groei, gevolgd door een beschrijving van het groeiproces tijdens de diverse periodes van het leven. In het totaal hebben 1234 kinderen deelgenomen aan het onderzoek die over een periode van ruim 2 jaar bijna 10 keer zijn gemeten. De lichaamslengte, zithoogte, hoofdomtrek en het gewicht werden gemeten. Daarnaast werd er informatie verzameld van diverse invloeden en parameters rondom het kind. Deze kunnen onderverdeeld worden in ouder gerelateerde parameters (bv lengte en opleiding van de respectievelijke ouders), parameters rondom de zwangerschap en geboorte (bv roken en medicatie gebruik van moeder tijdens de zwangerschap, rangorde en bevalling) en kind gerelateerd parameters (bv voeding). Een beschrijving van de populatie op basis van deze gegevens is gegeven in hoofdstuk 3 . Hoofdstuk 4 beschrijft de techniek van het 
meten van de kinderen en de betrouwbaarheid van deze metingen. Er zijn diverse mathematische methoden om groei te beschrijven en groeicurven te construeren. Een overzicht van deze methoden wordt gegeven in hoofdstuk 5 . In dit proefschrift is gekozen om de LMS methode te gebruiken voor het construeren van de groeicurven gezien het feit dat deze methode heden ten dagen algemeen geaccepteerd is en gebruikt wordt, met name als het gaat om het bewerken van longitudinale data. Dit maakte het mogelijk om de curven van dit onderzoek te vergelijken met curven uit andere onderzoeken zoals gepresenteerd in hoofdstuk 10. In hoofdstukken 6 en 9 worden diverse groeicurven gepresenteerd voor de diverse parameters. In de appendix worden de verschillende curven gepresenteerd als referentiecurven, waarbij bij sommigen de originele meetpunten geplot zijn. Uit dit overzicht blijkt dat er overeenkomsten en verschillen zijn tussen de diverse parameters en dat er ruimte is voor specifieke groeicurven. Het gebruik van een correlatie matrix, zoals gepresenteerd in hoofdstuk 7, is relevant door het gebruik van de z-score in plaats van de absolute waarde. Hierdoor kan de 'regression to the mean' worden bepaald aan de hand van de correlatie tussen twee verschillende tijdstippen. Dit maakt het mogelijk om bij een kind te bepalen of het groeipatroon tussen twee tijdstippen normaal is of afwijkt van normaal. Aangezien er nog steeds sprake is van verschillen tussen generaties: de seculare trend, wordt in hoofdstuk 8 dieper ingegaan op dit fenomeen en de trend in de populatie waartoe de onderzoekspopulatie behoort.

Er worden diverse conclusies getrokken in het onderzoek. De belangrijkste observatie is dat er niet één afzonderlijke parameter van invloed is op de groei van een kind. Diverse parameters zijn met elkaar gecorreleerd en een verschil dat wordt gemeten kan dan ook alleen maar verklaard worden door de invloeden van de diverse parameters. Om een voorbeeld te geven; moeders die borstvoeding geven, bleken meestal ook de niet rokende moeders te zijn die tevens meestal een hogere opleiding bleken te hebben genoten. De vraag of deze kinderen langer zijn door de borstvoeding dan wel vanwege het feit dat hun moeder niet rookte of beter opgeleid was, kan alleen maar beantwoord worden met 'ja' op alle opties. Er is dus ruimte voor verschillende groeicurven afhankelijk van geografische verschillen, voeding, sociaal economische achtergrond etc. Alhoewel ook gesteld kan worden dat bijvoorbeeld niet roken en borstvoeding natuurlijk is en dat daarom deze groeicurve de norm zou moeten zijn. Tenslotte, om de groei van een kind te evalueren mag er niet gekeken worden naar eén meting op één tijdstip. Er zijn significante correlaties tussen de diversen antropometrische maten van kinderen. $\mathrm{Zo}_{0}$ is in het eerste levensjaar de hoofdomtrek en de zithoogte nagenoeg van de zelfde waarde. Bij een kind waar dit niet zo is, dient nader onderzoek gedaan te worden op pathologie uit te sluiten.

Het gaat om de proportionele groei en de dynamiek van het proces van groeien dat geëvalueerd dient te worden. 


\section{Appendix A \\ Comparison Charts}

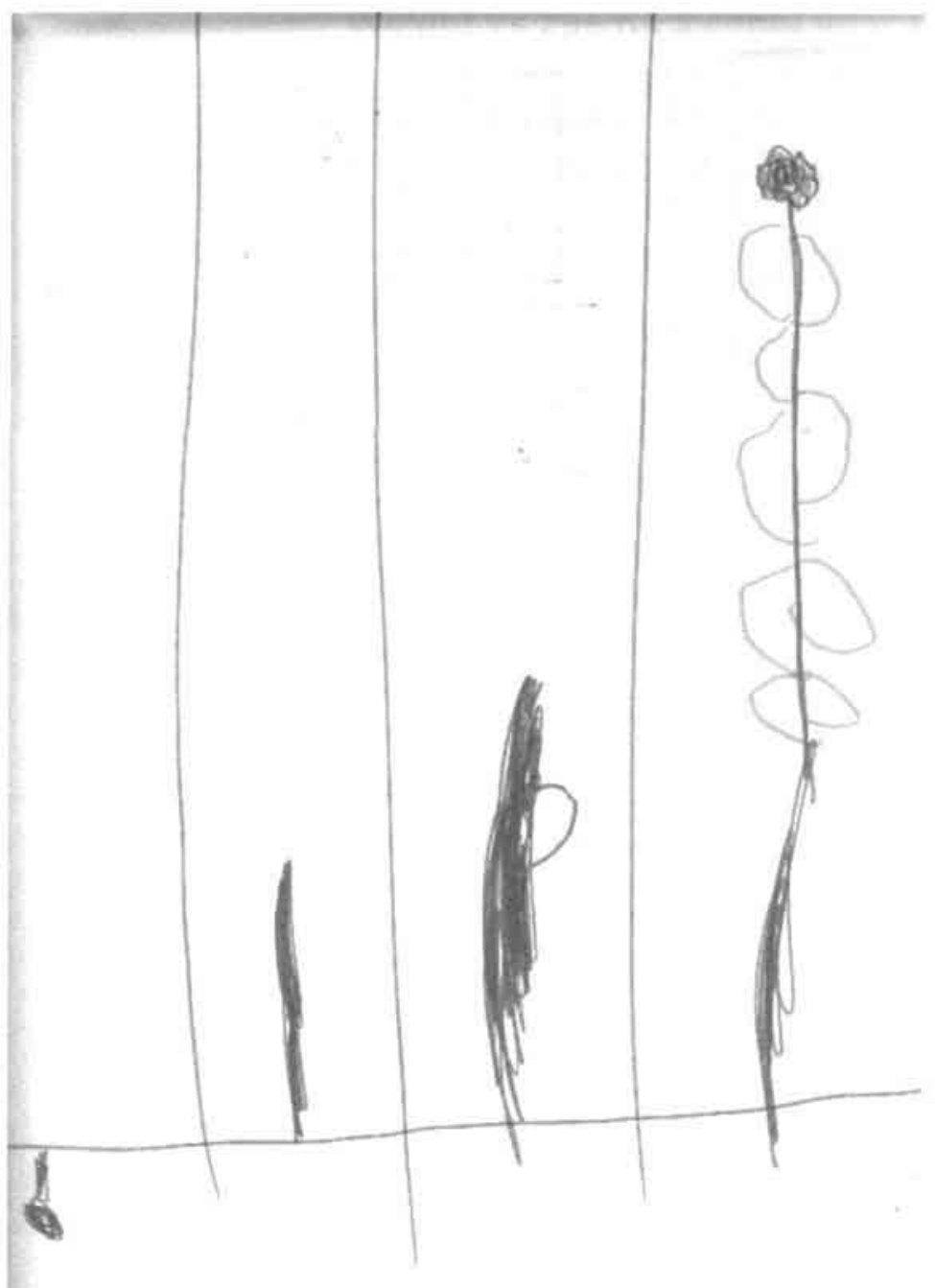

Groei

Job van de Walle 


\section{Alcohol intake}

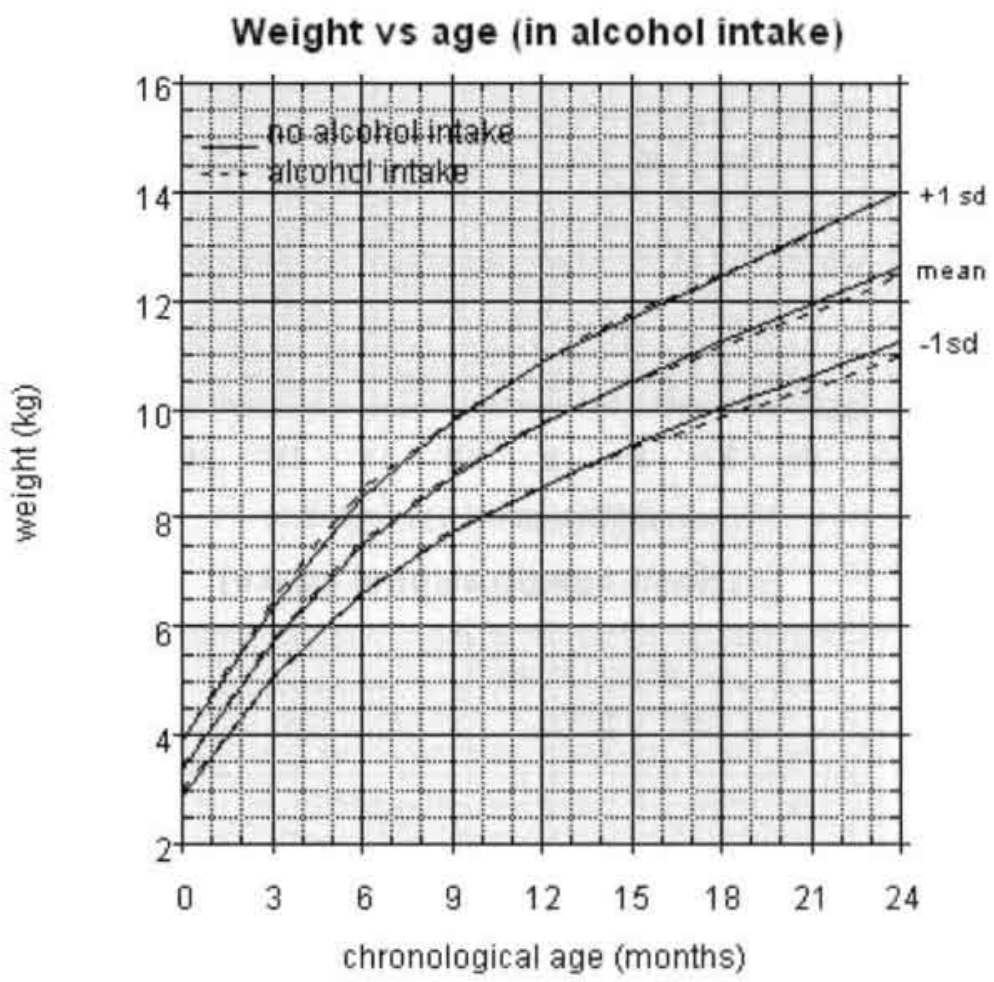


Crl vs age (in alcohol intake)

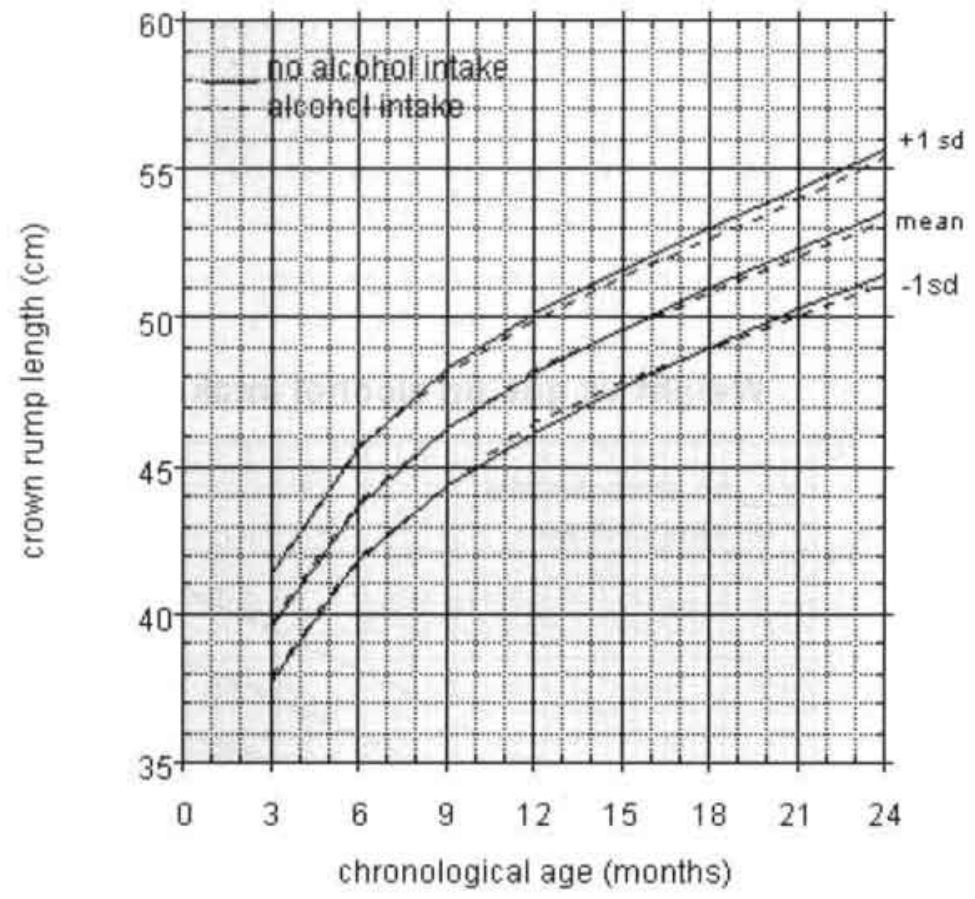

$\mathrm{Hc}$ vs age (in alcohol intake)

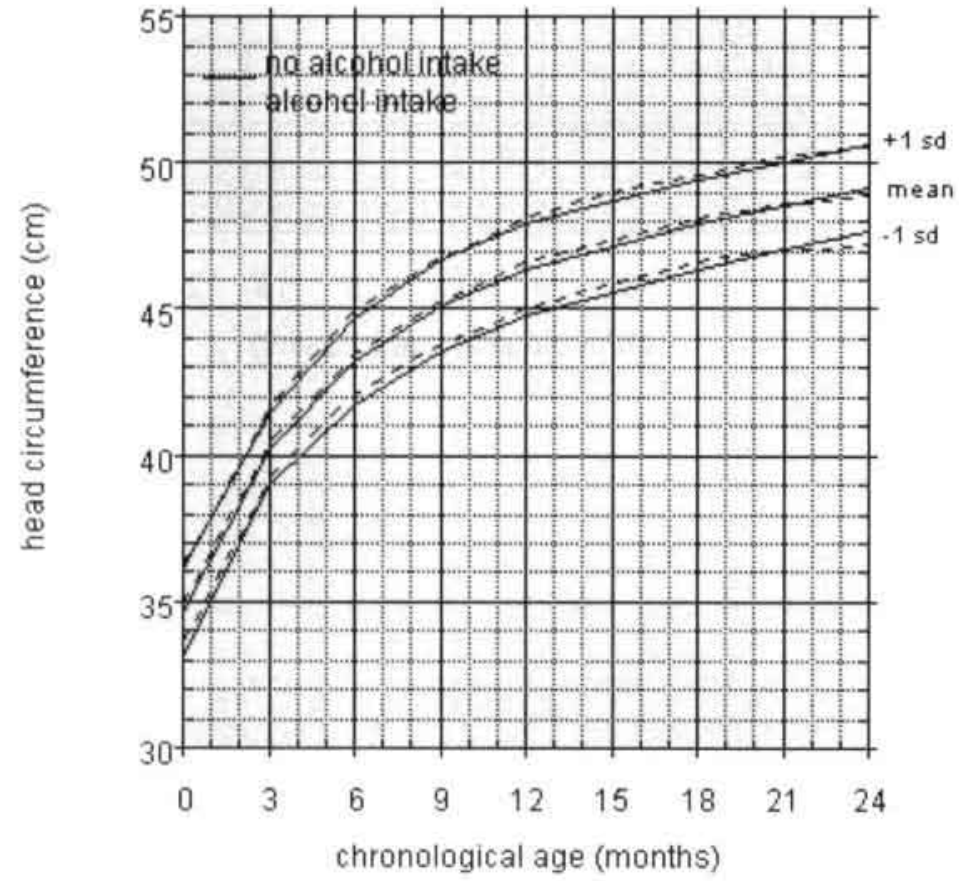




\section{SIl vs age (in alcohol intake)}

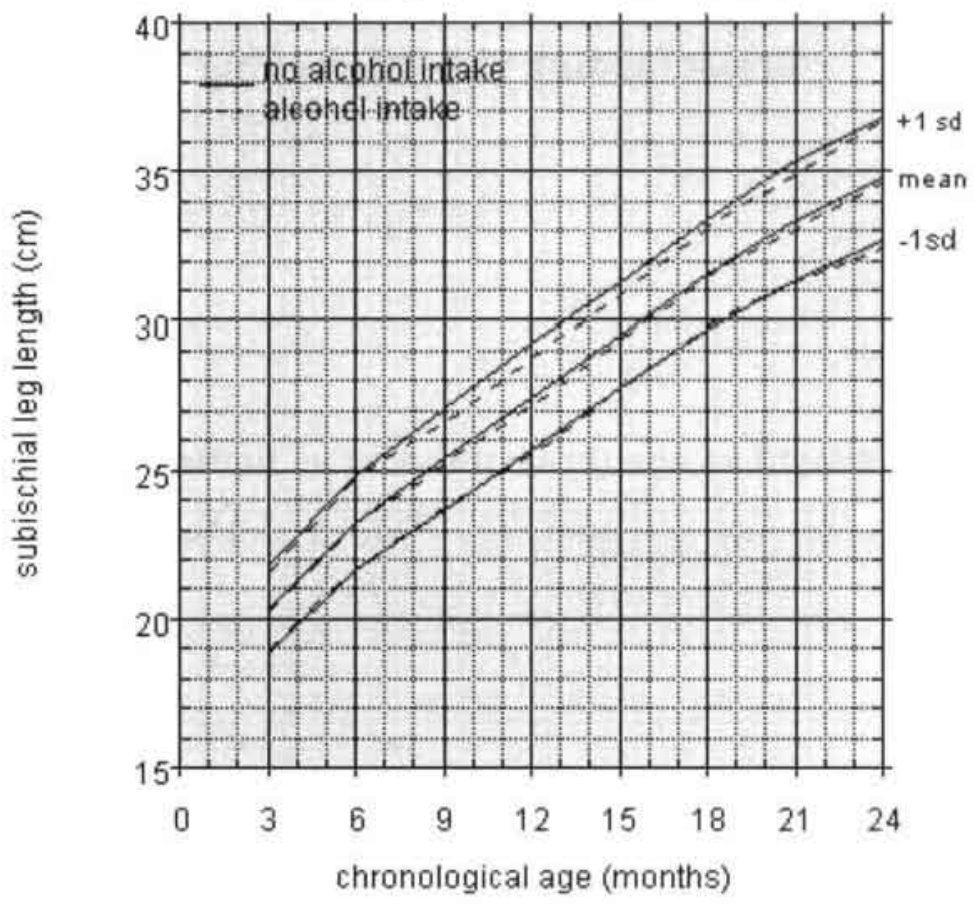

\section{SI vs age (in alcohol intake)}

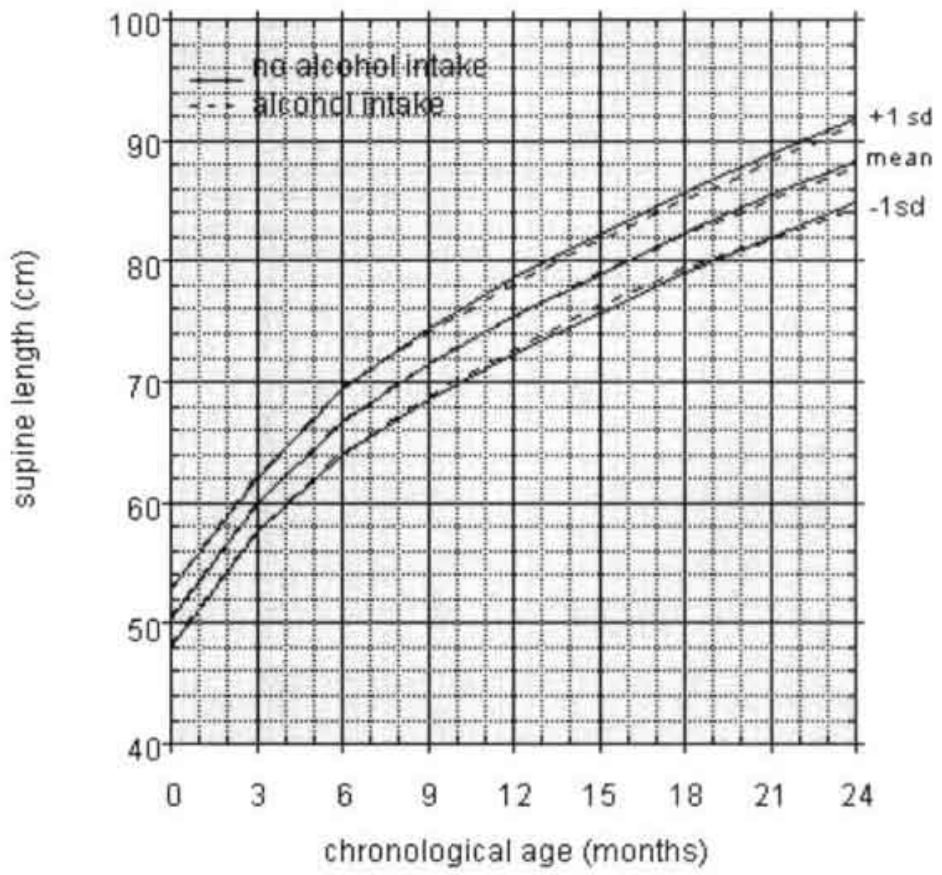




\section{Breast feeding vs bottlefeeding}

Weight vs age (breastfeeding vs bottlefeeding)

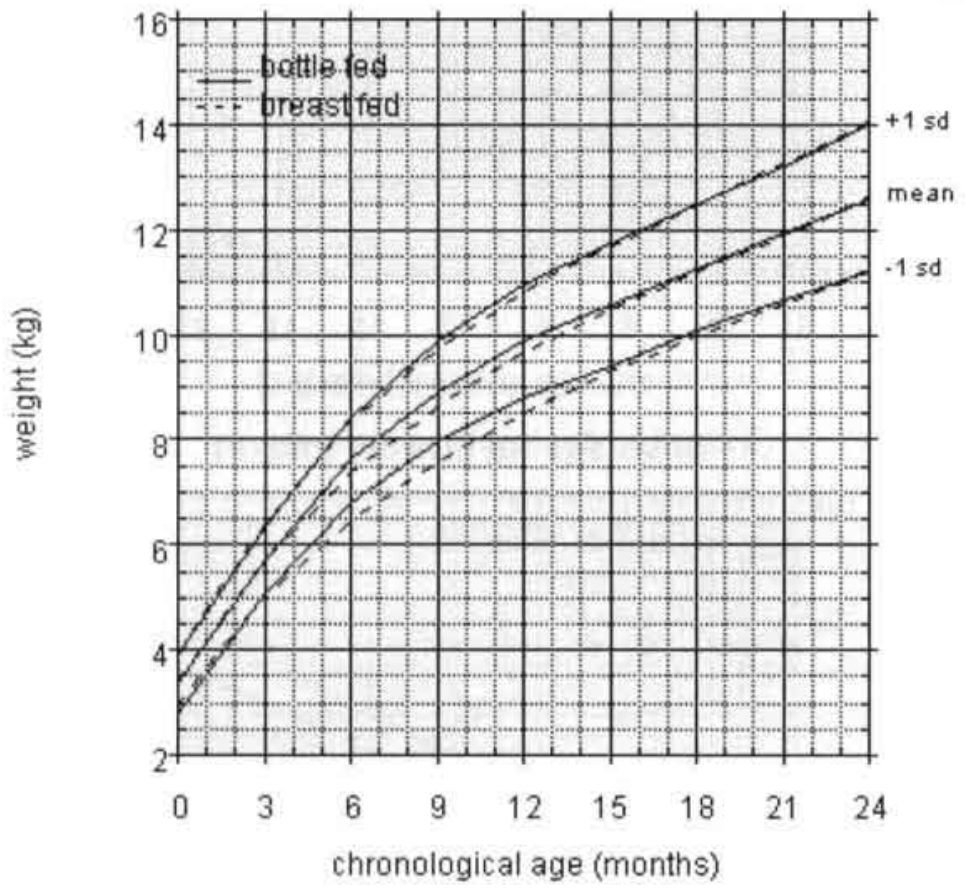


Crl vs age (breastfeeding vs bottlefeeding)

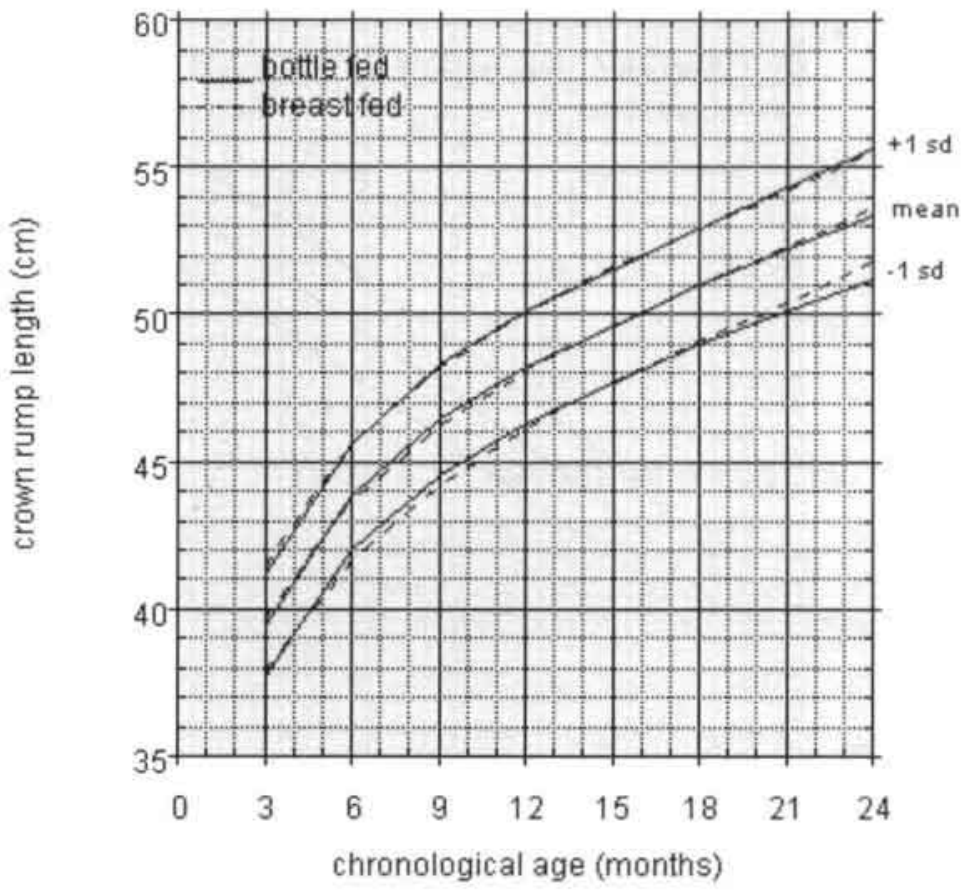

$\mathrm{Hc}$ vs age (breastfeeding vs bottlefeeding)

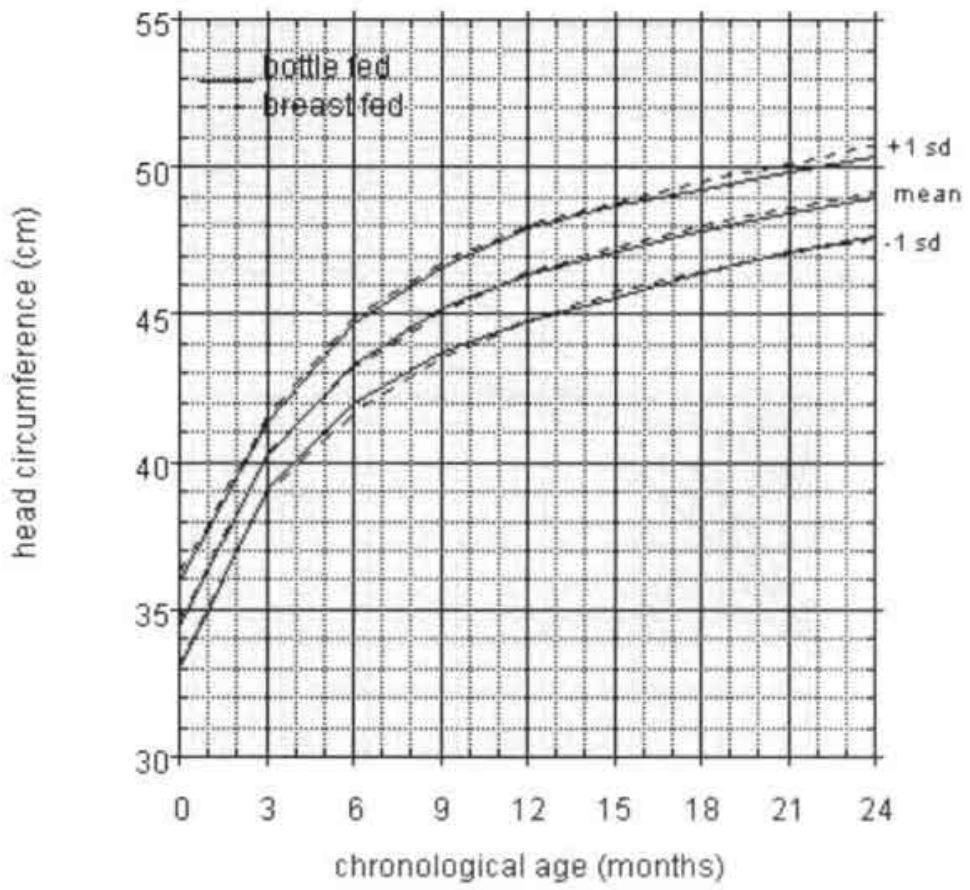


SII vs age (breastfeeding vs bottlefeeding)

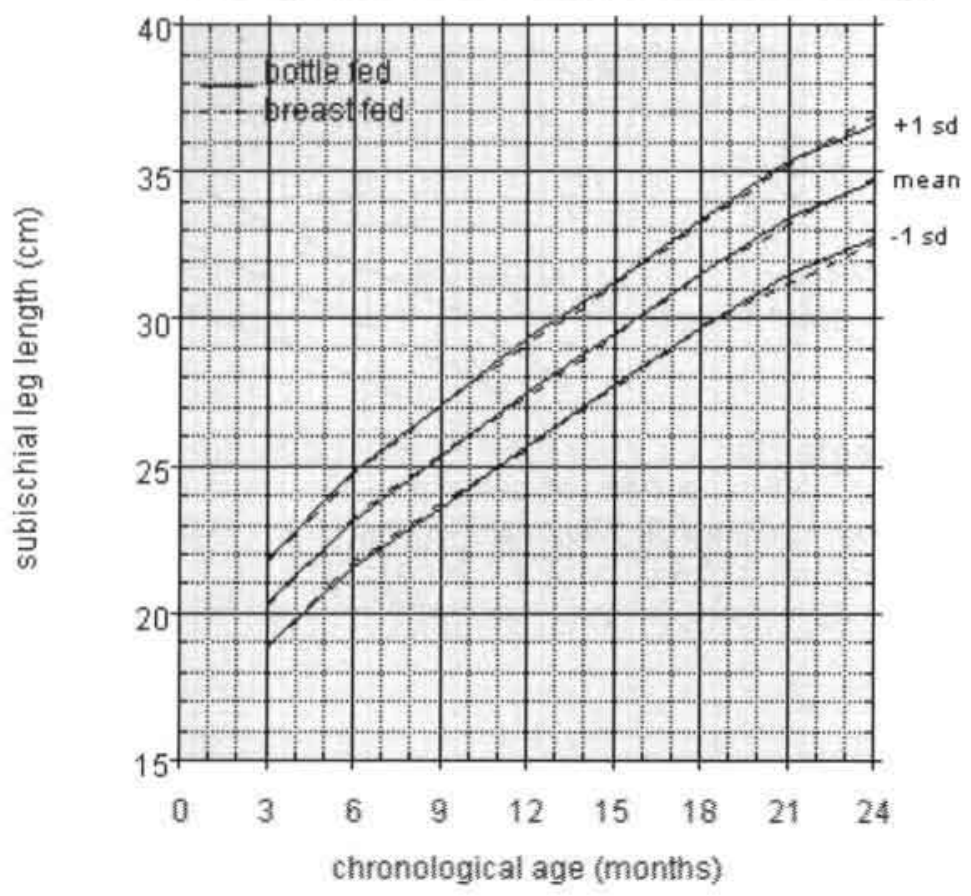

SI vs age (breastfeeding vs bottlefeeding)

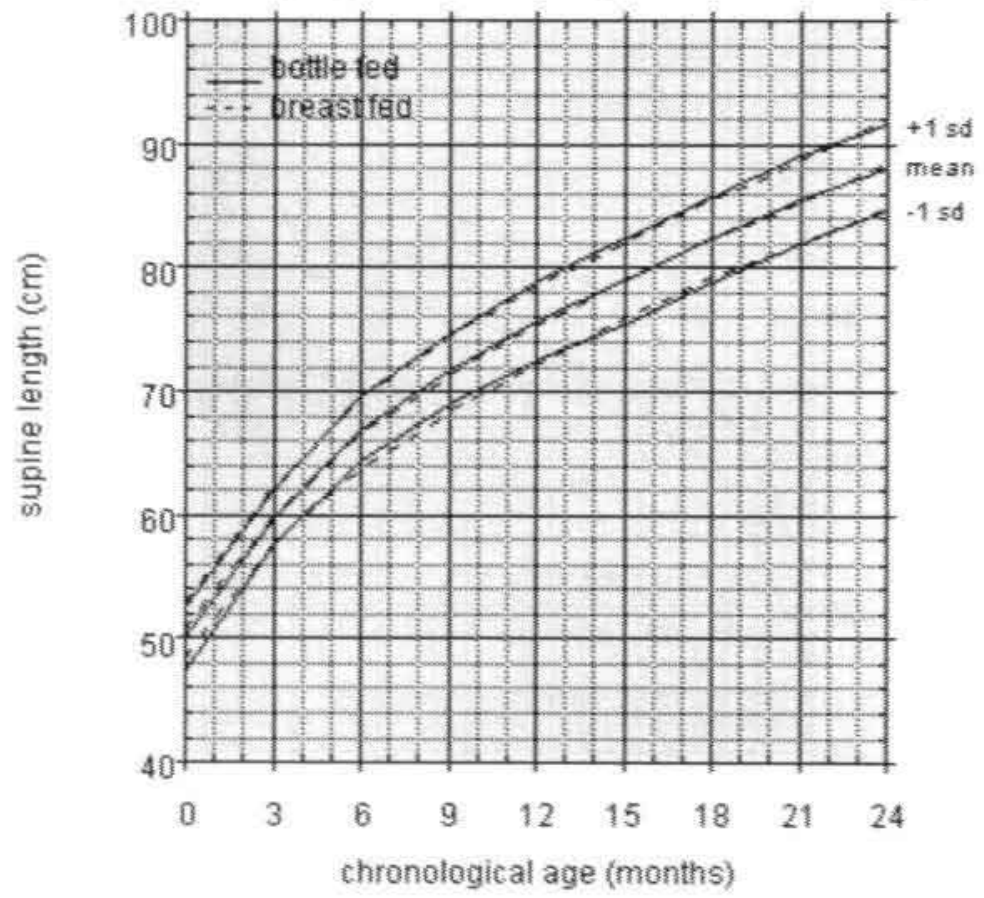




\section{Delivery}

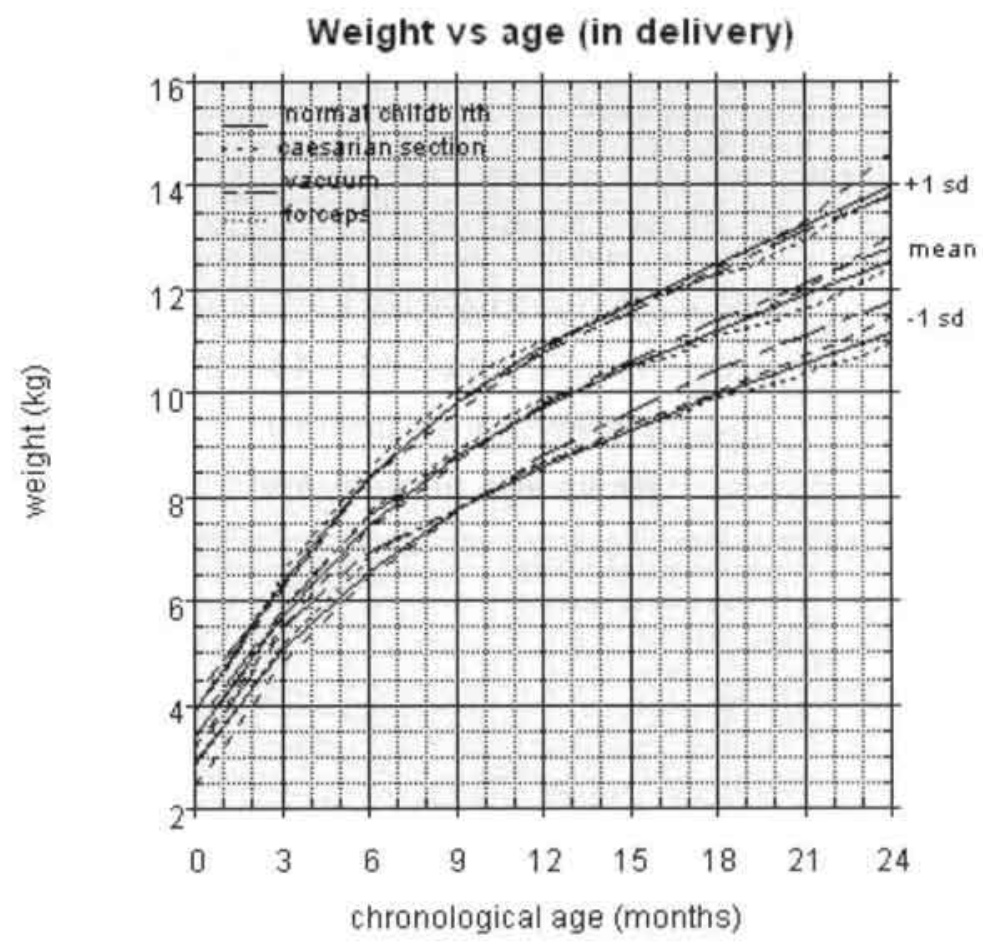




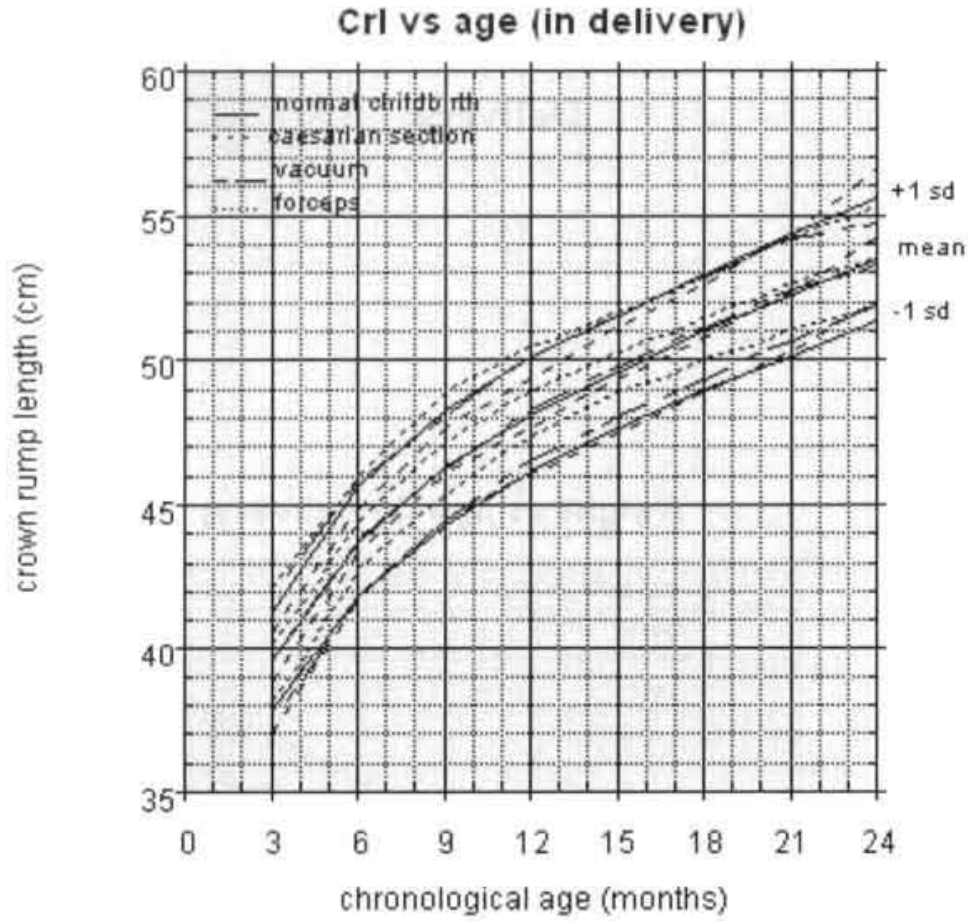

$\mathrm{Hc}$ vs age (in delivery)

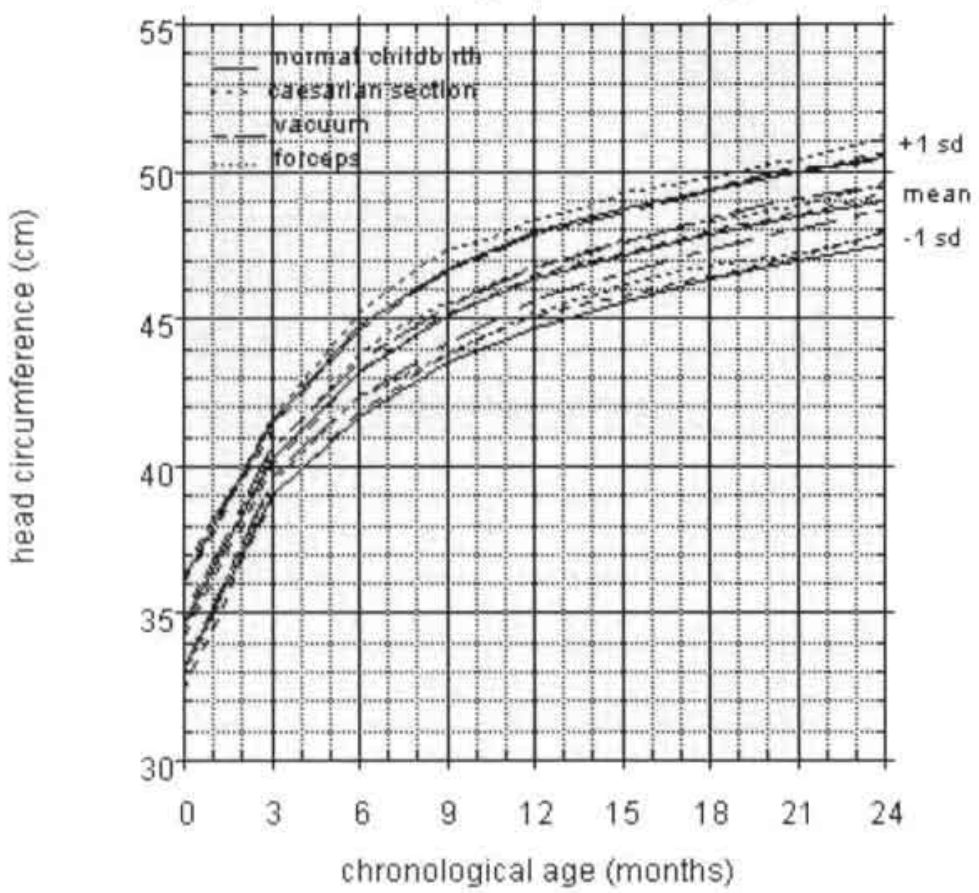




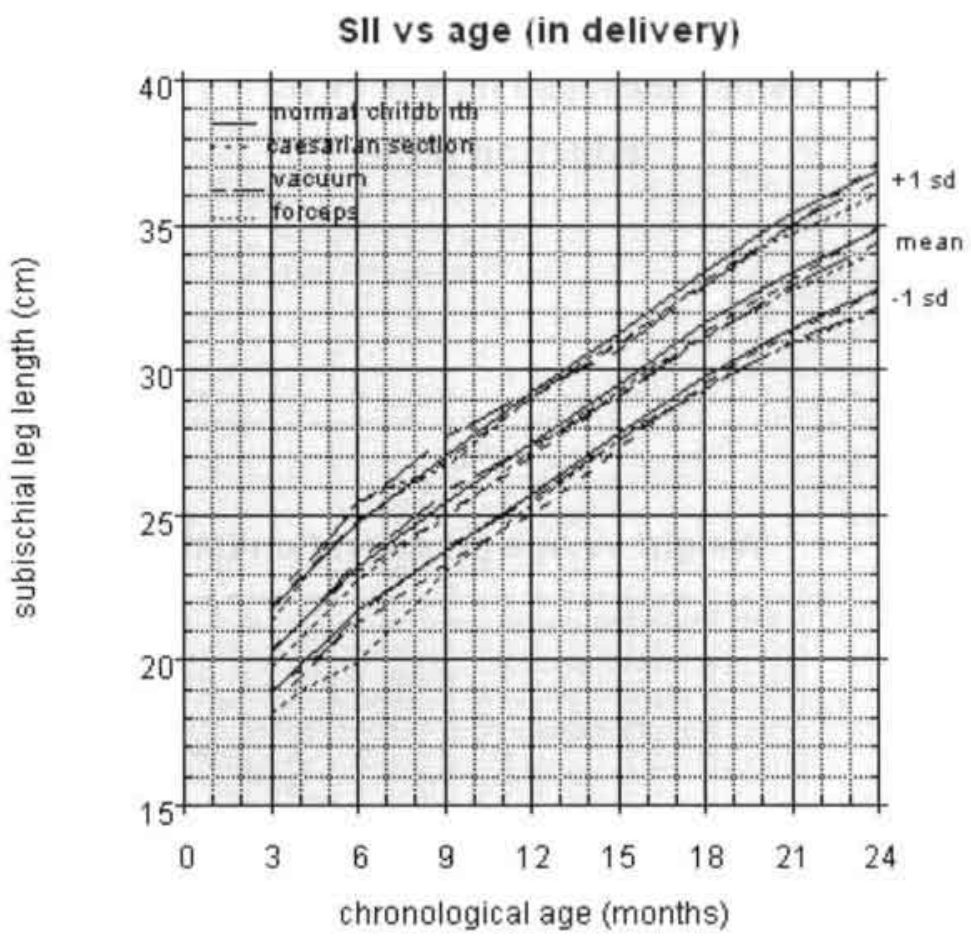

\section{SI vs age (in delivery)}

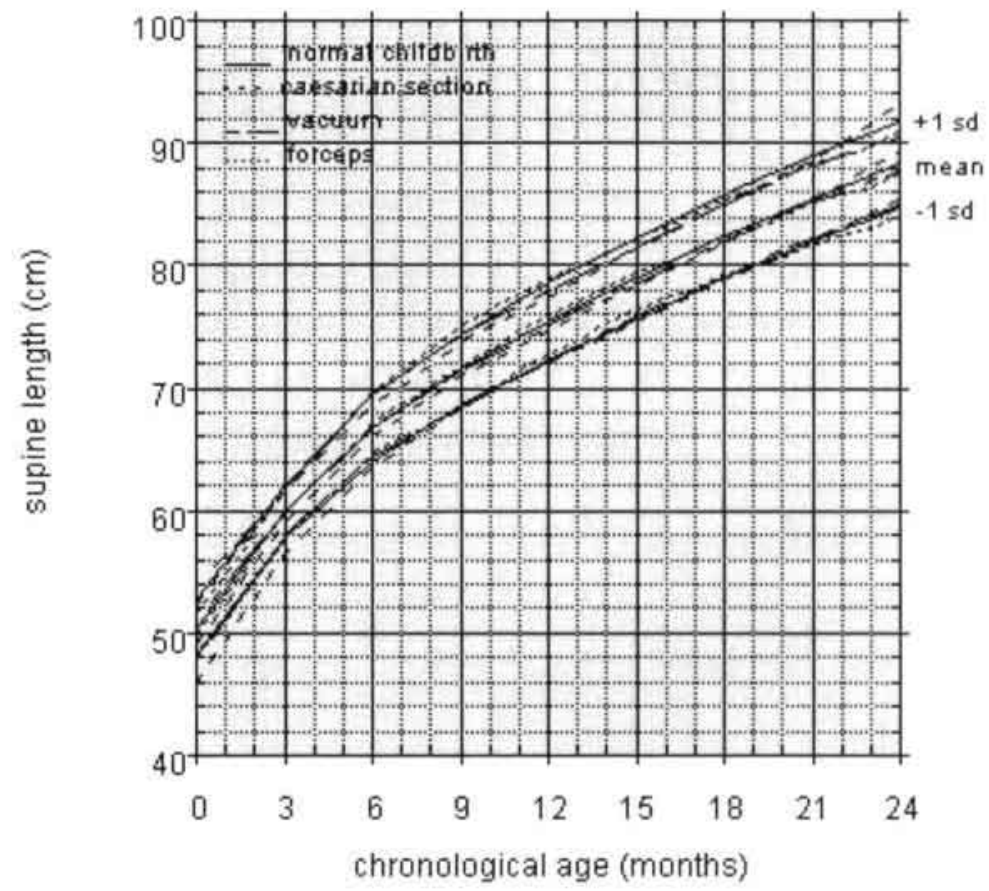




\section{Eduction father}

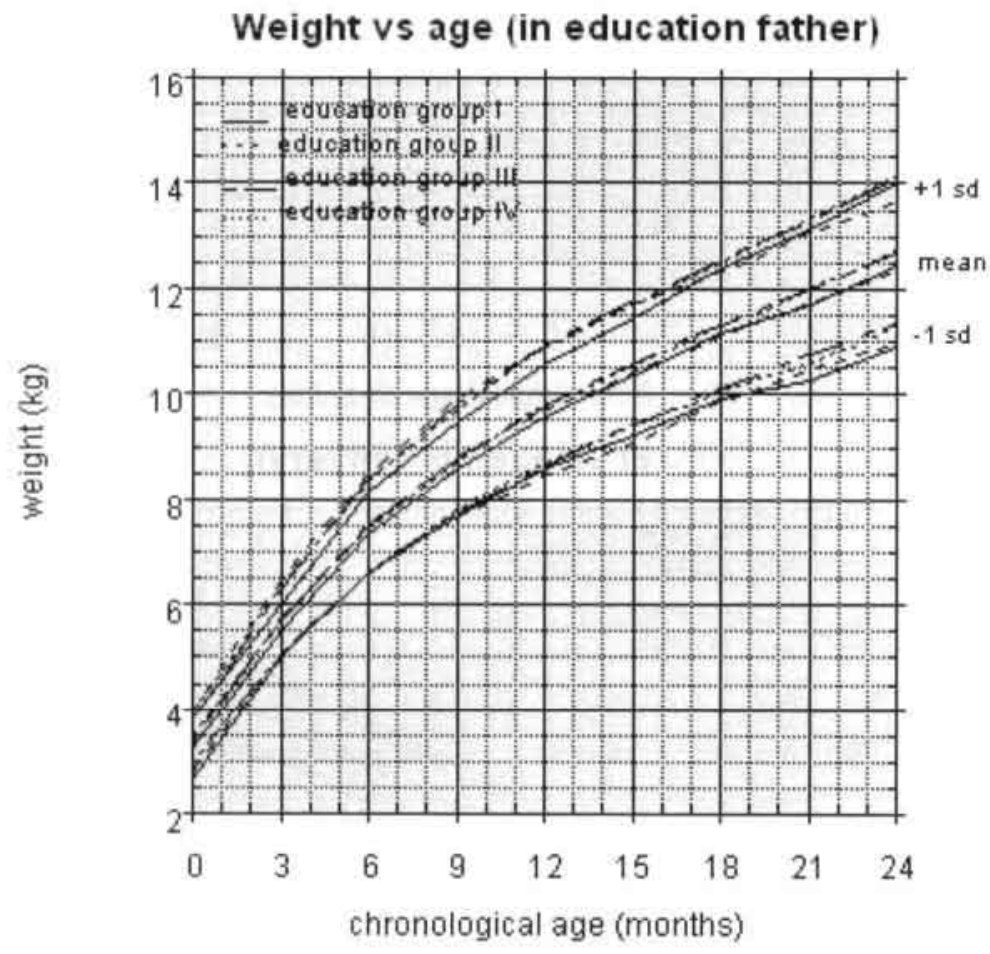




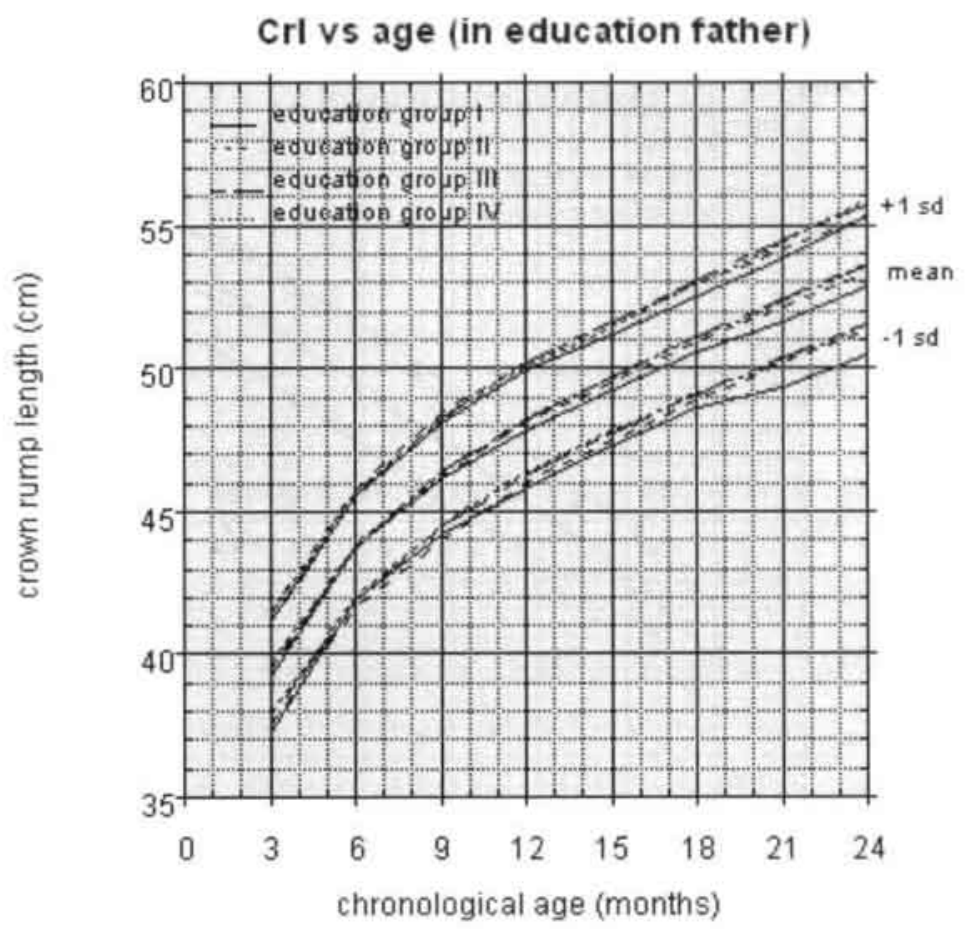

$\mathrm{Hc}$ vs age (in education father)

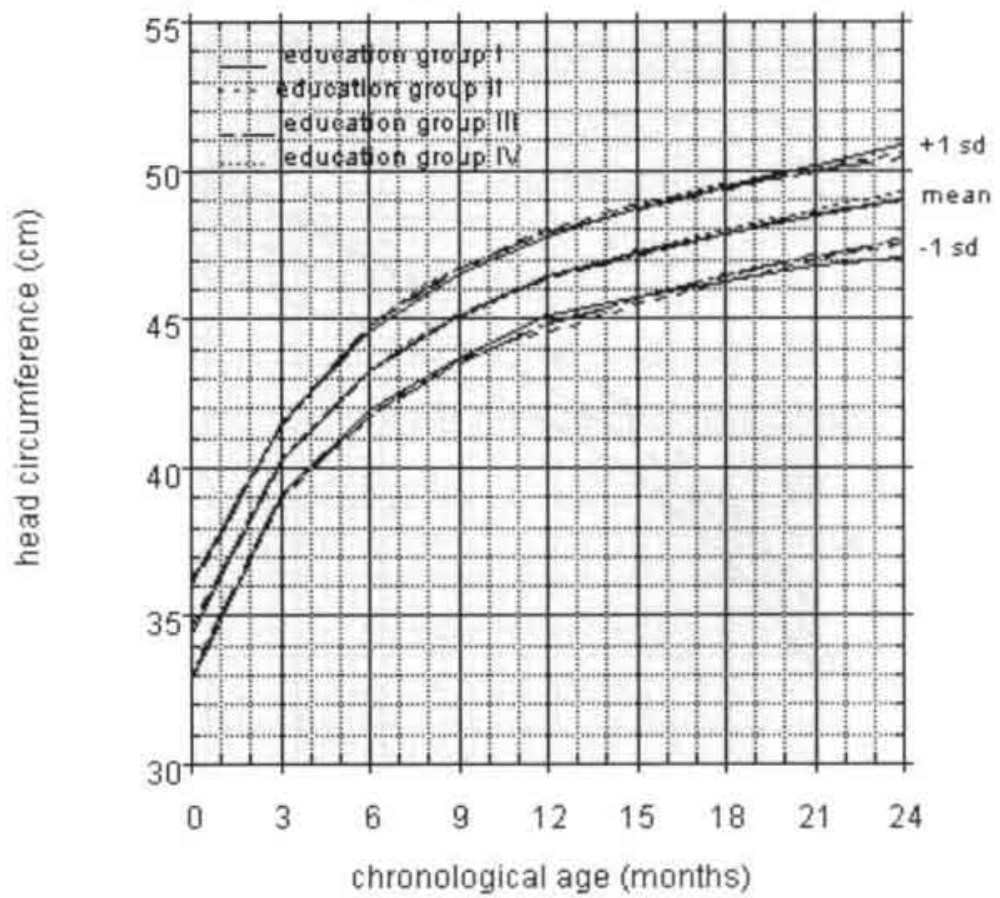




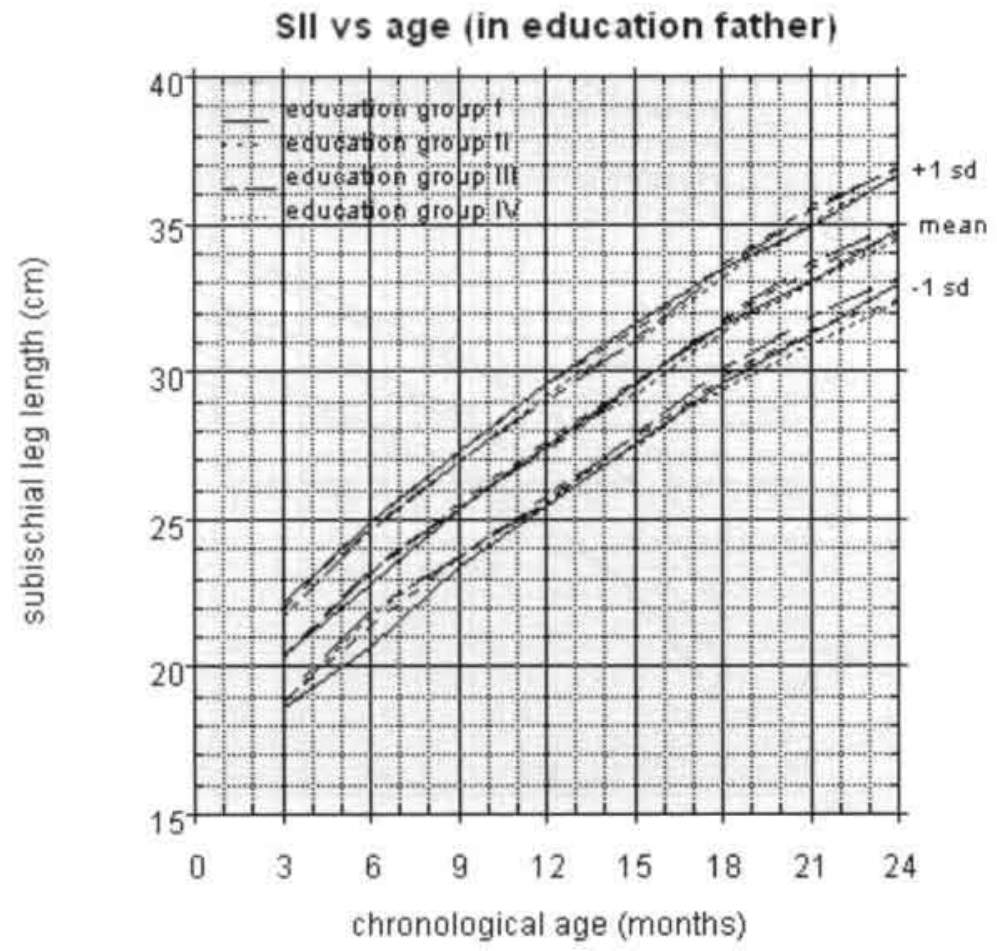

SI vs age (in education father)

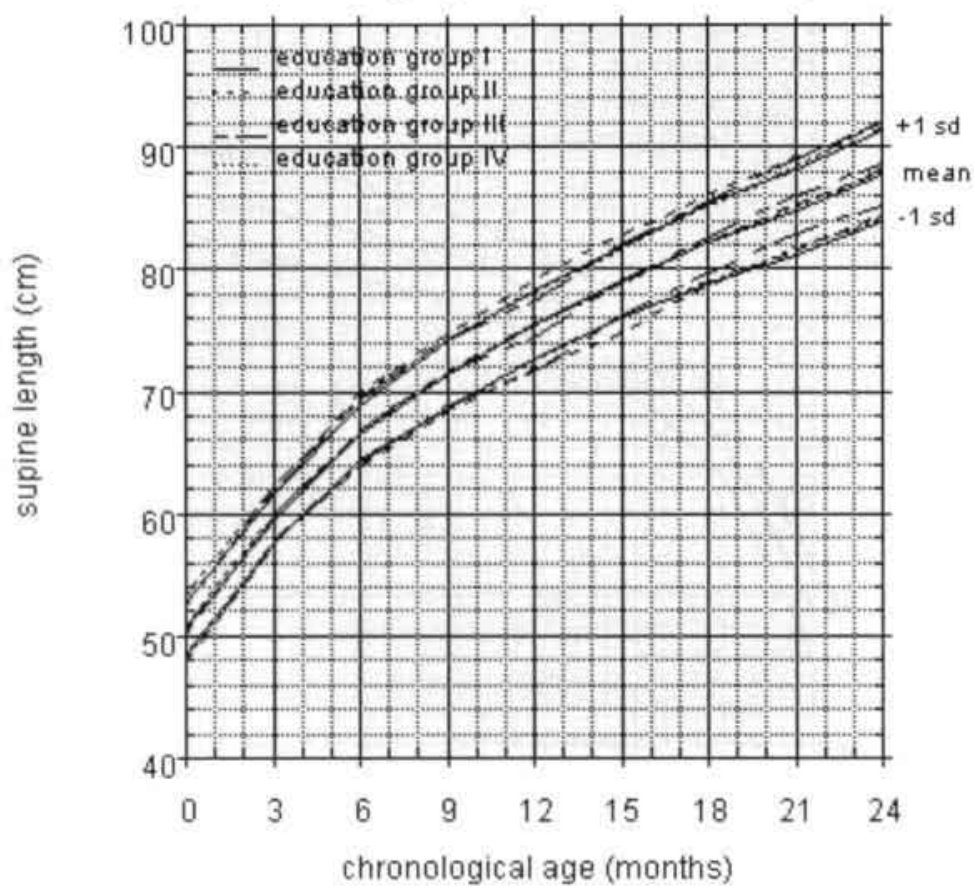




\section{Education Mother}

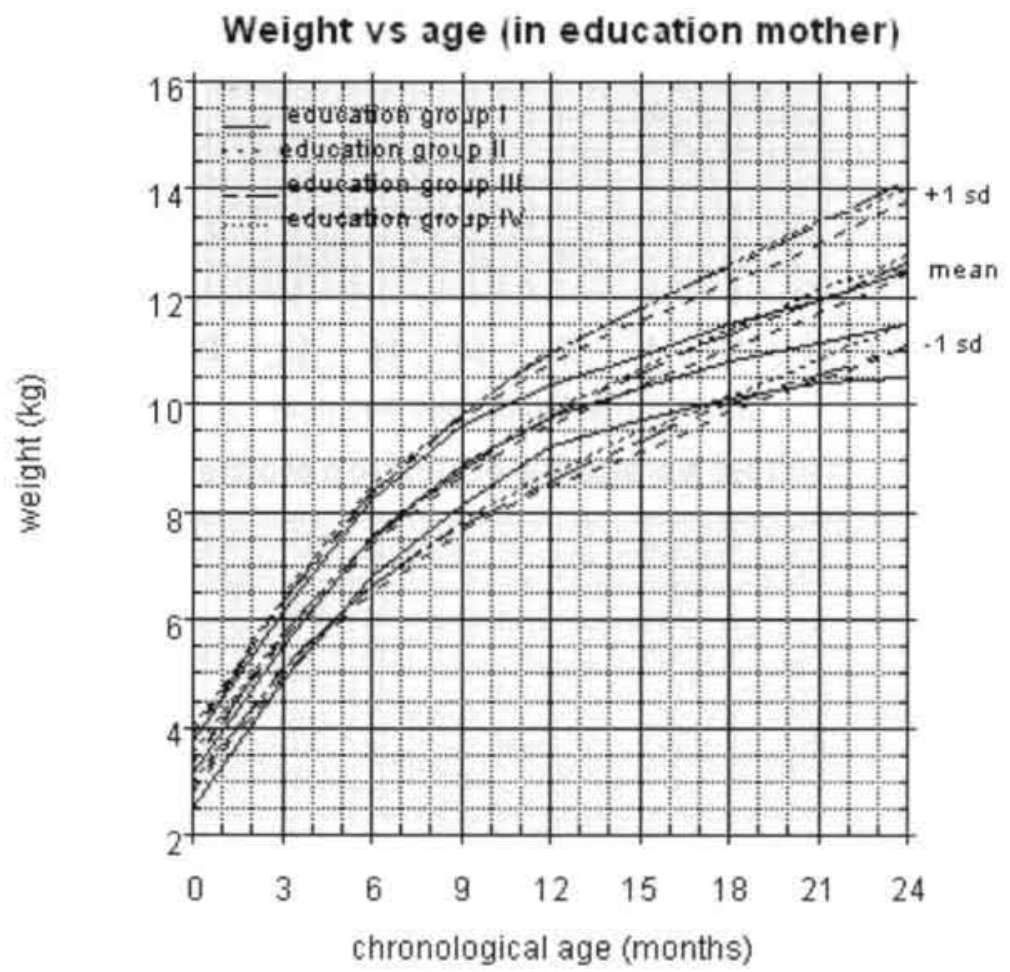


Crl vs age (in education mother)

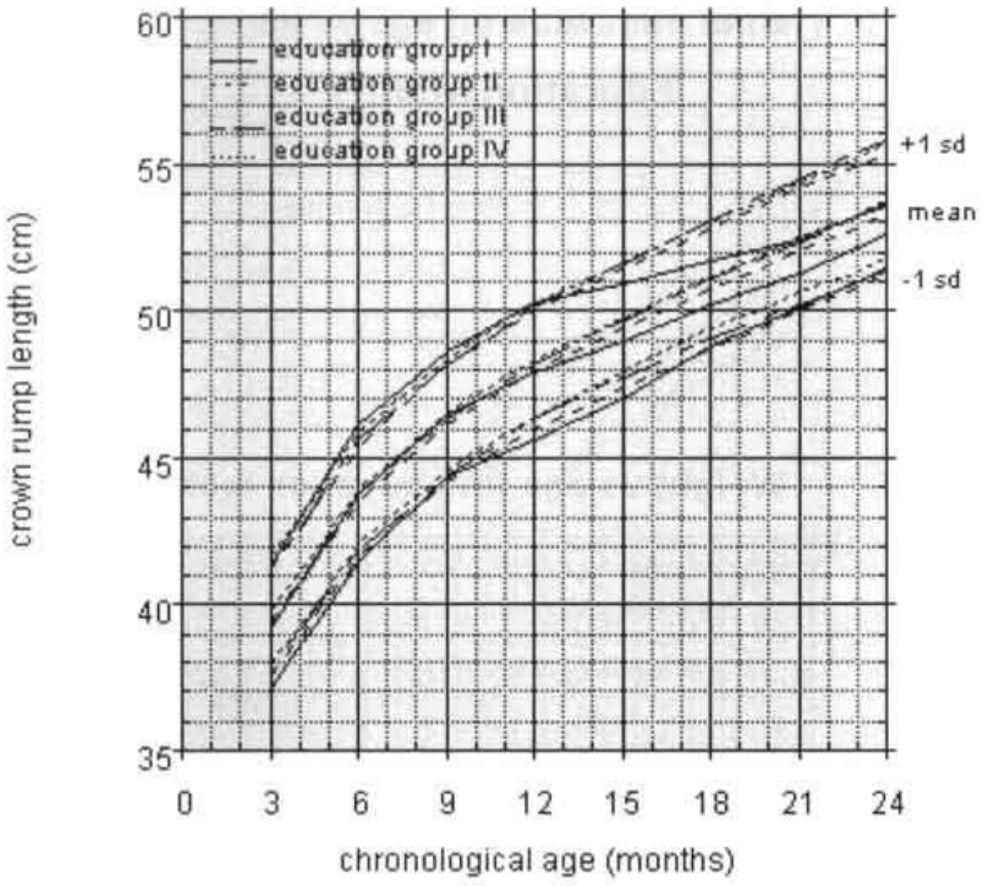

$\mathrm{Hc}$ vs age (in education mother)

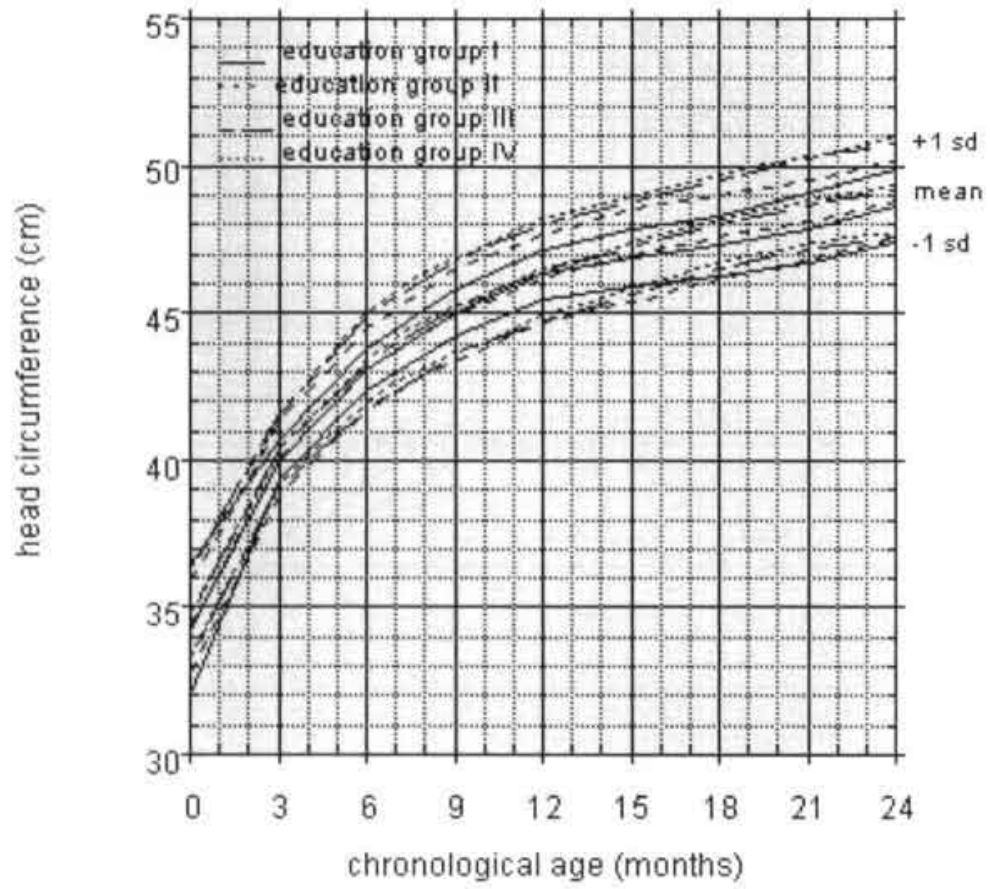




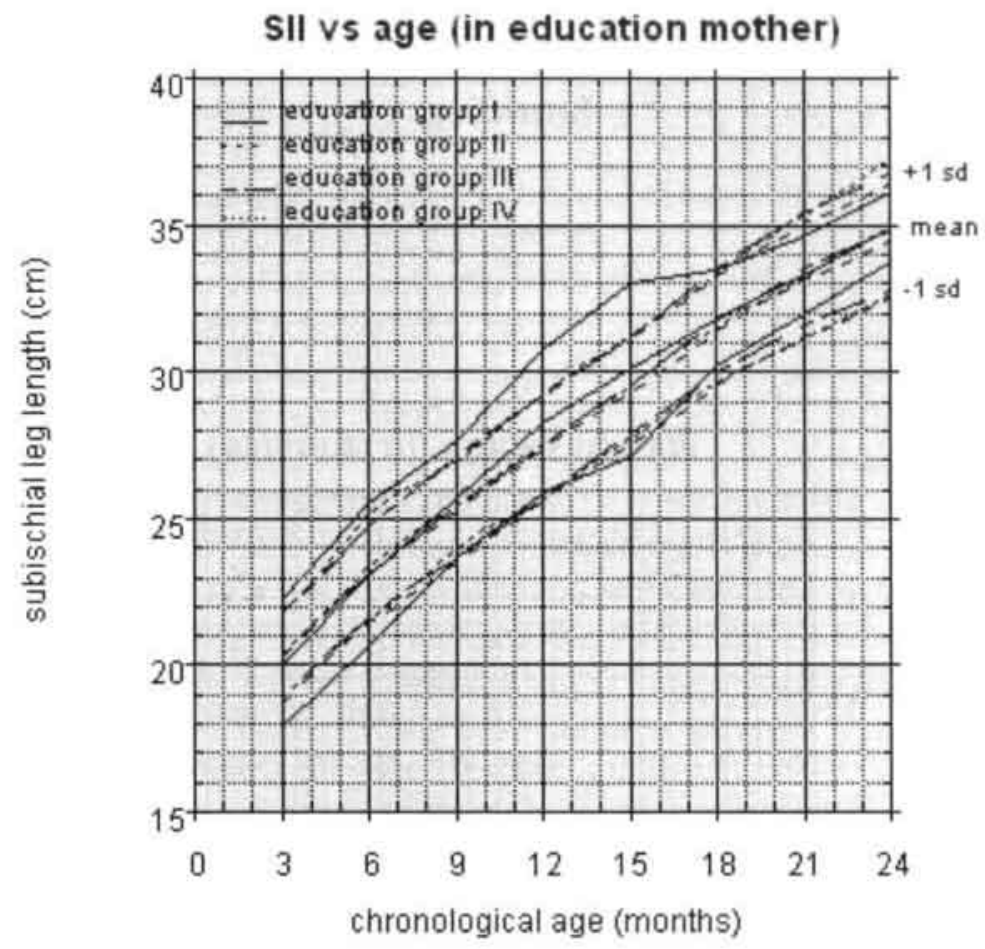

SI vs age (in education mother)

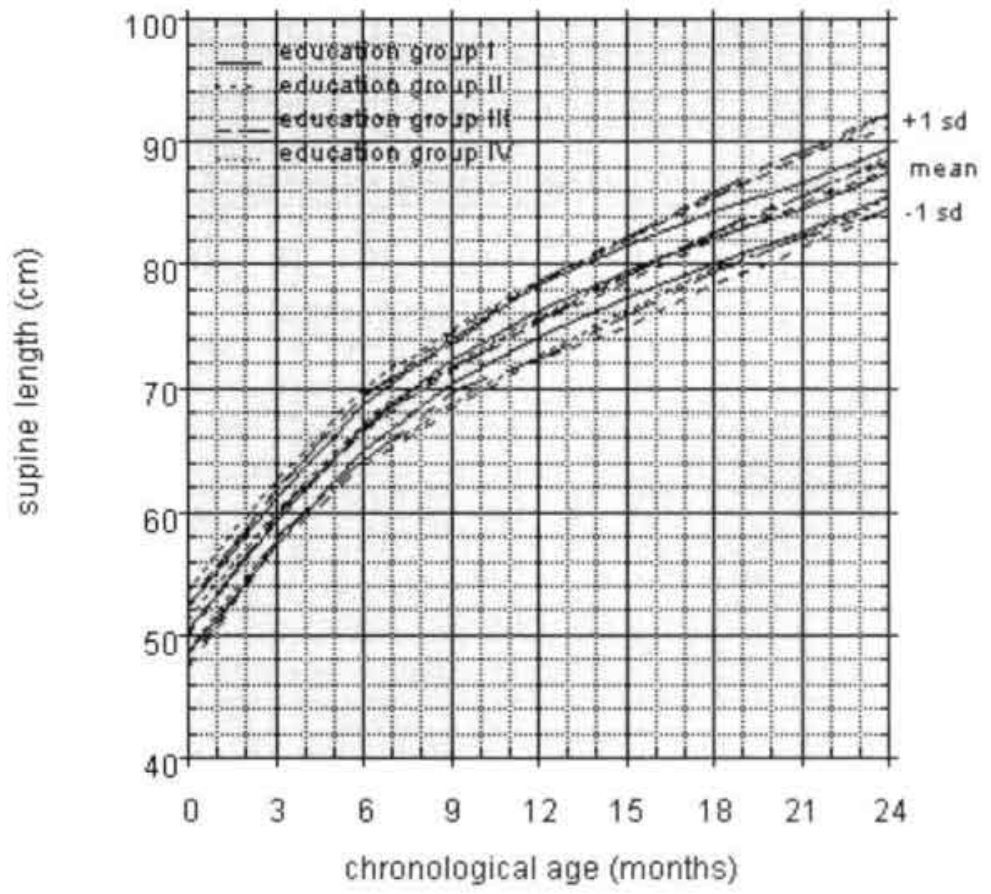




\section{Jaundice}

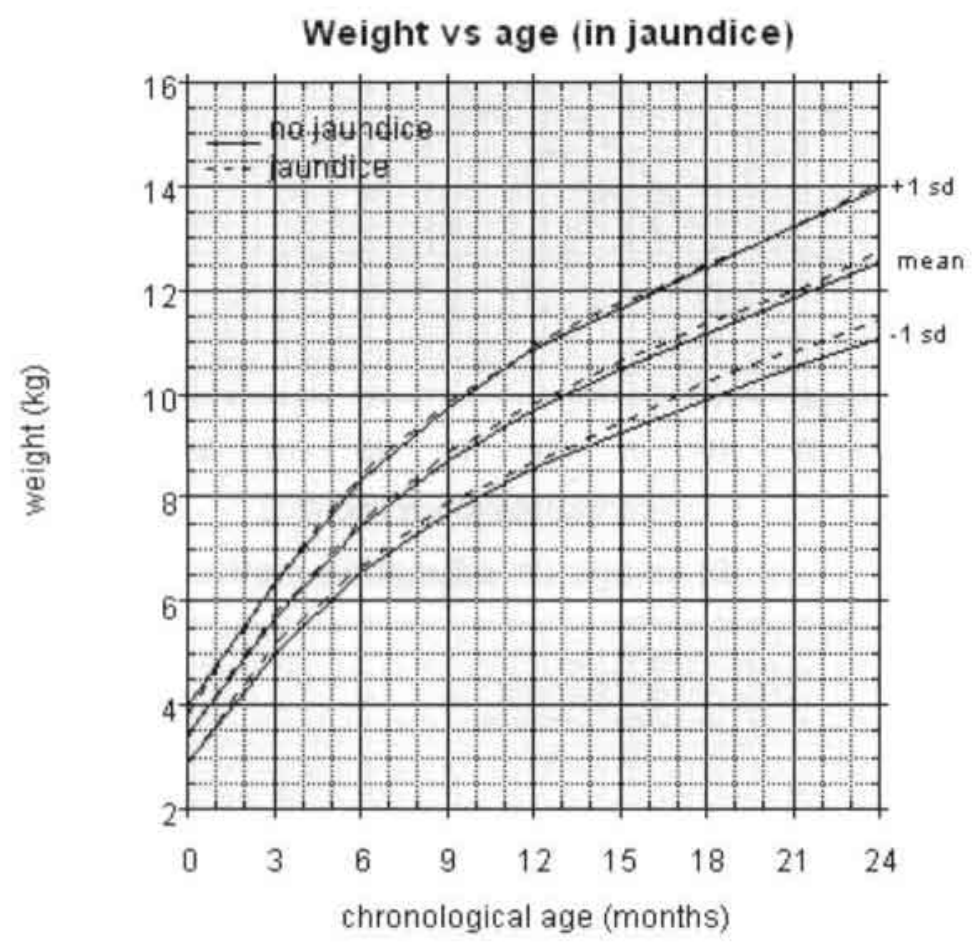


Crl vs age (in jaundice)

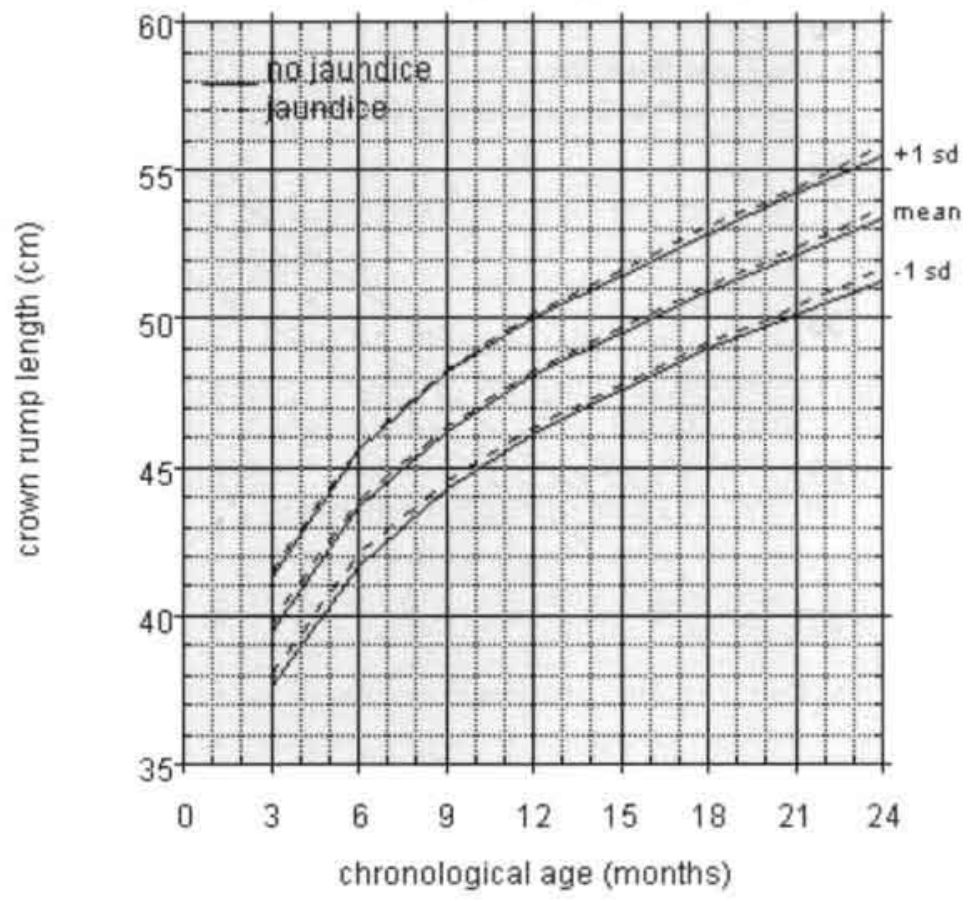

Hc vs age (in jaundice)

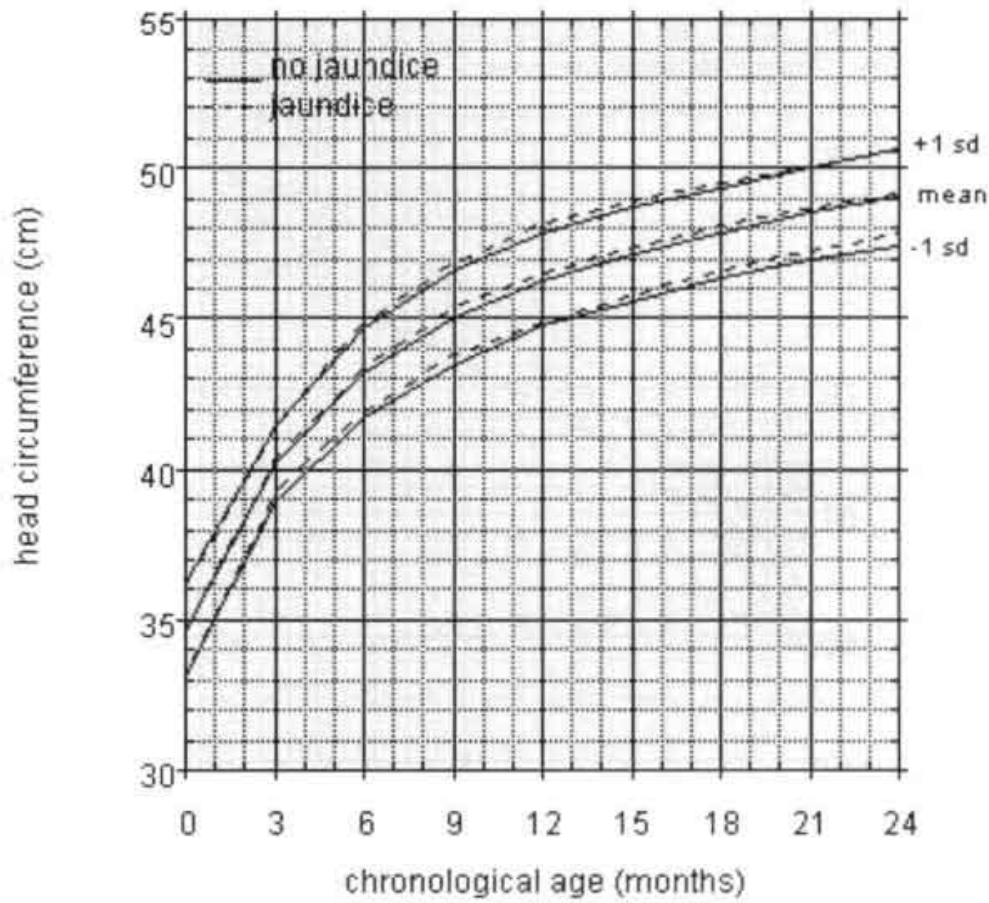




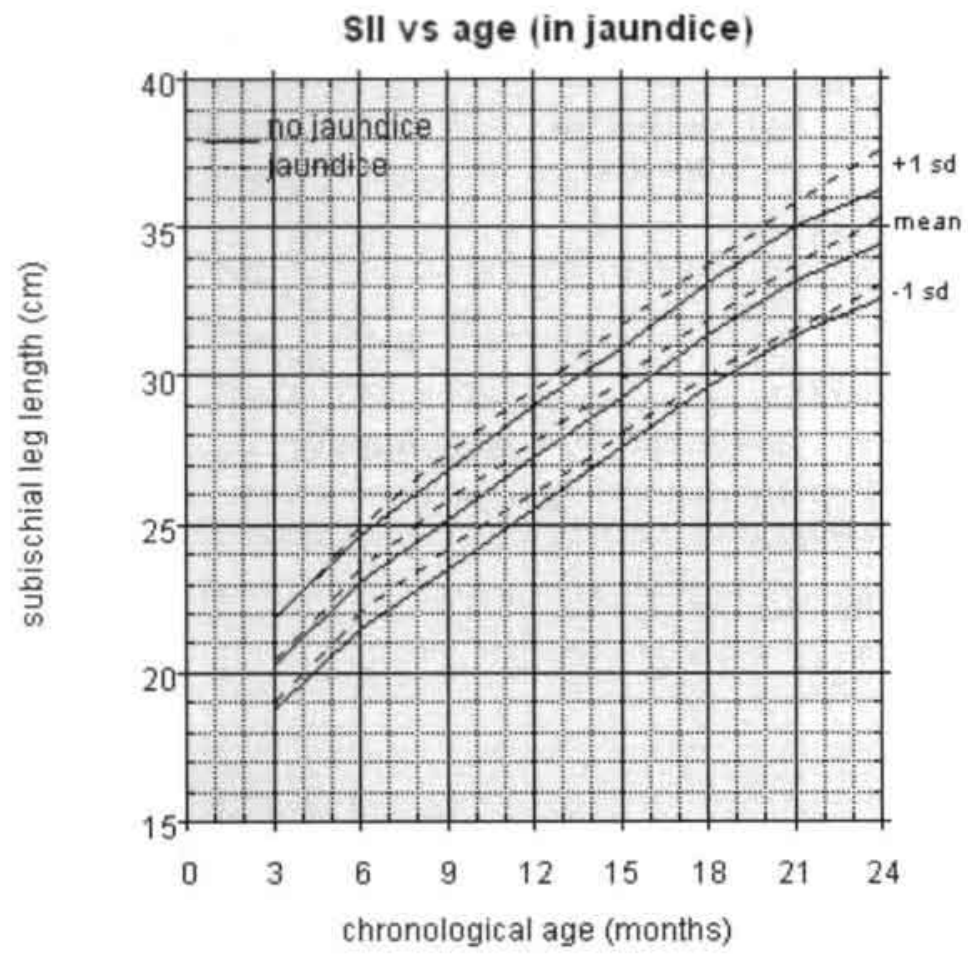

SI vs age (in jaundice)

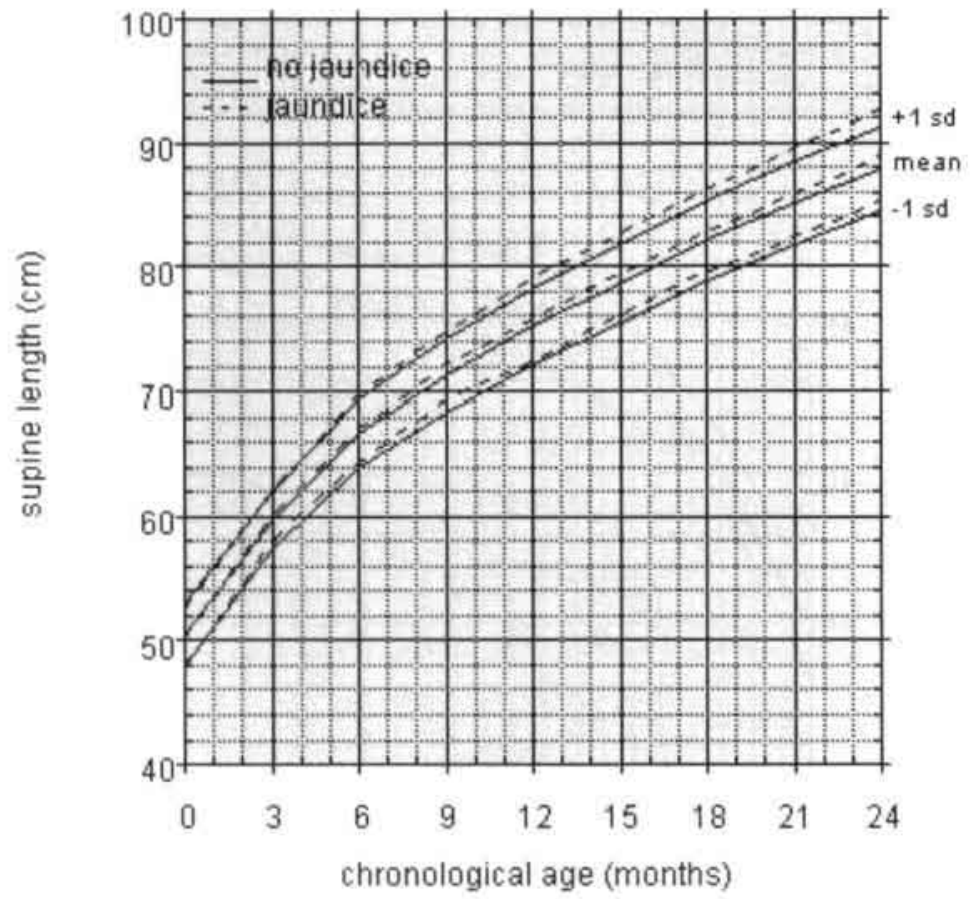




\section{Presentation}

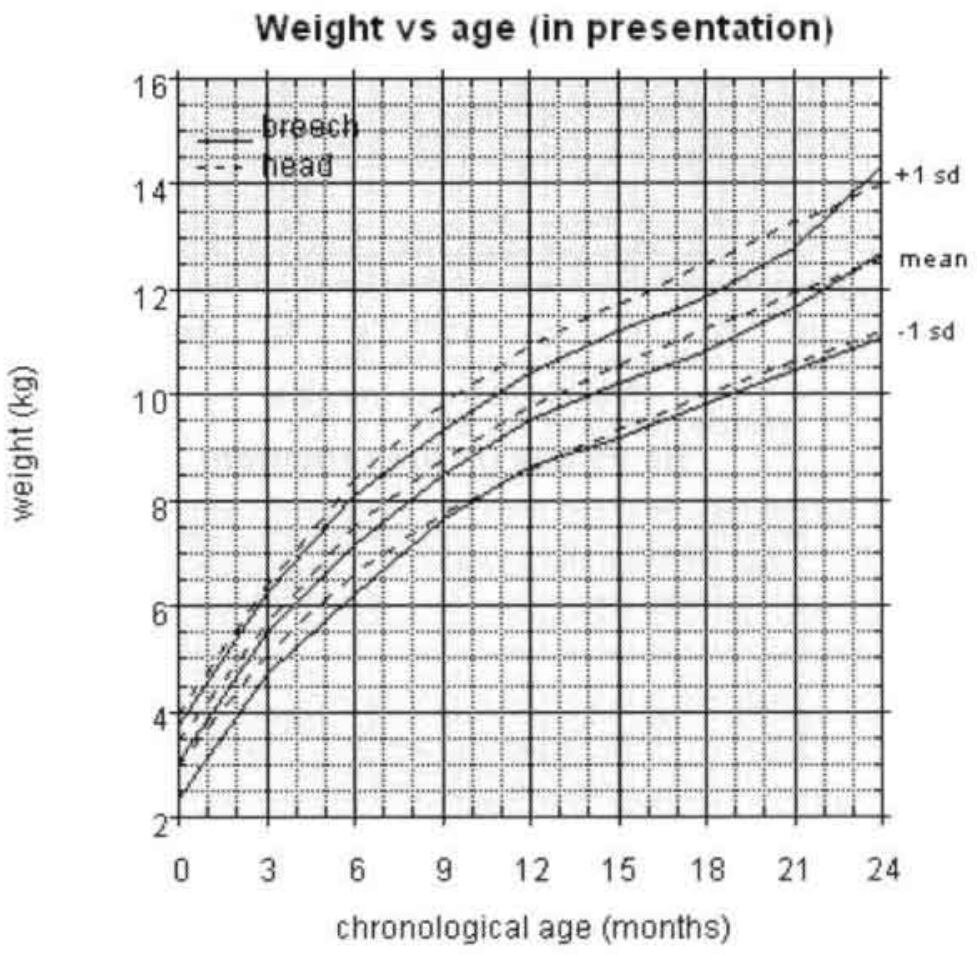




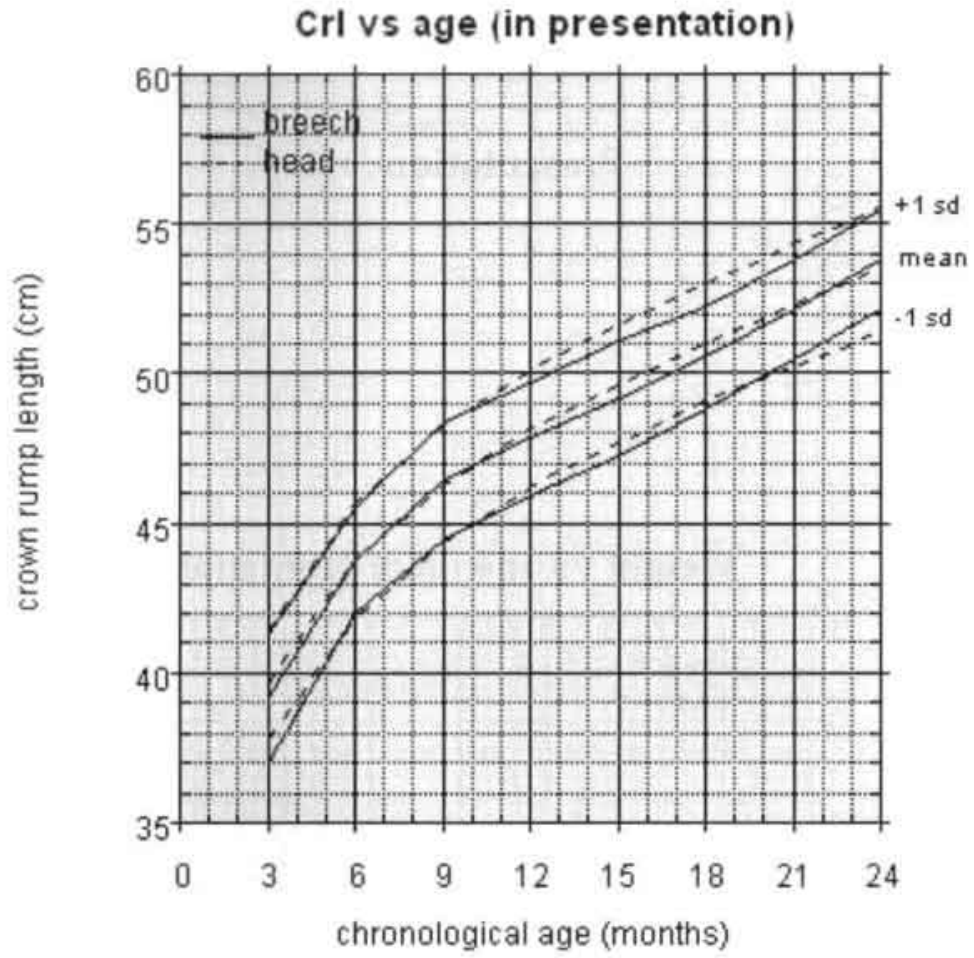

$\mathrm{Hc}$ vs age (in presentation)

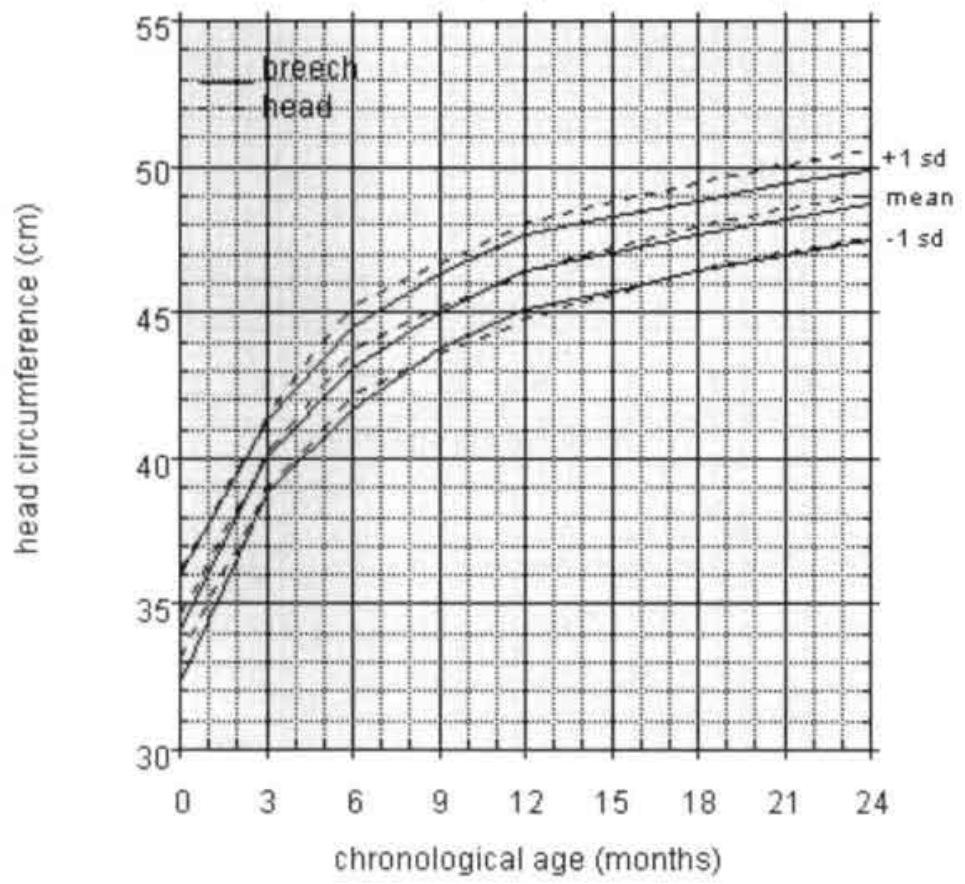




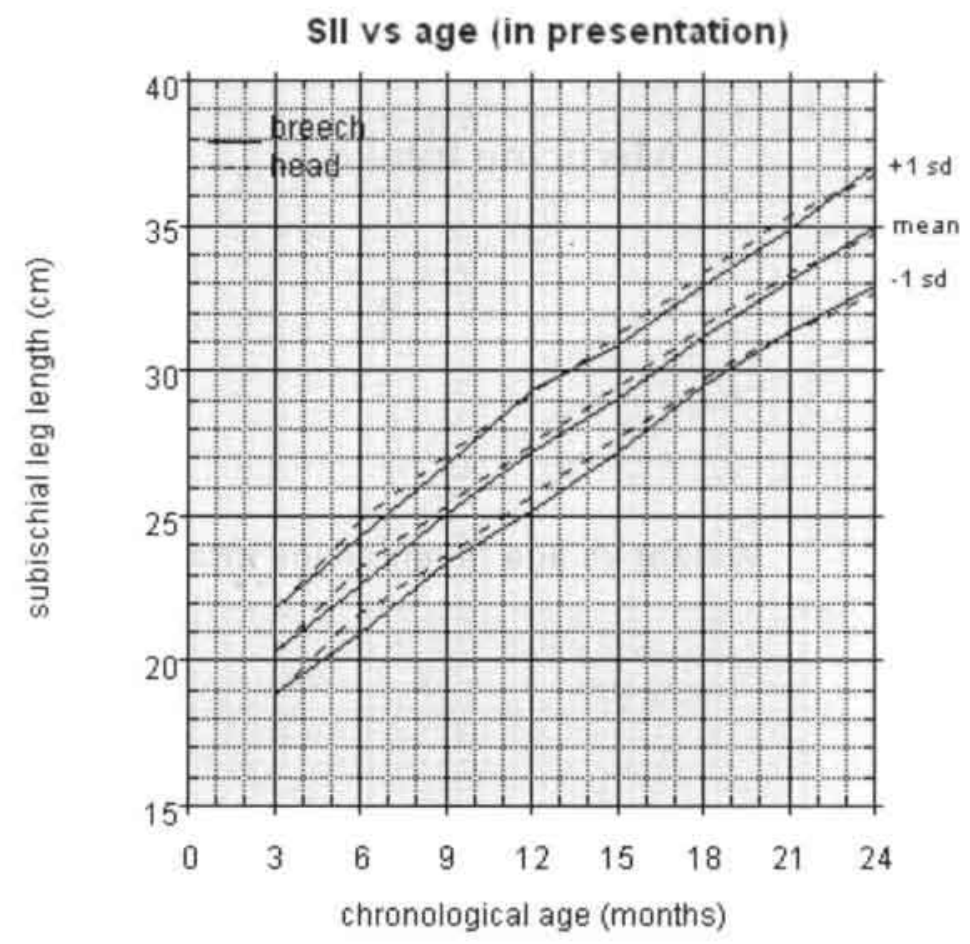

SI vs age (in presentation)

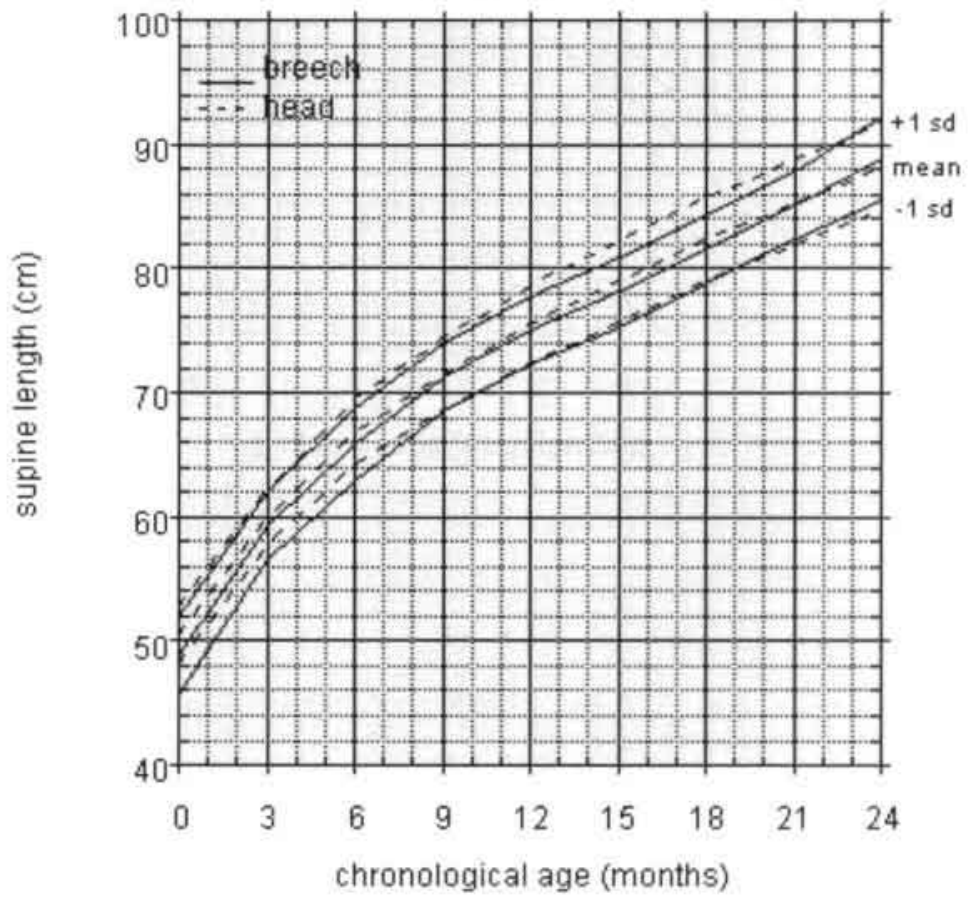


Medicine intake

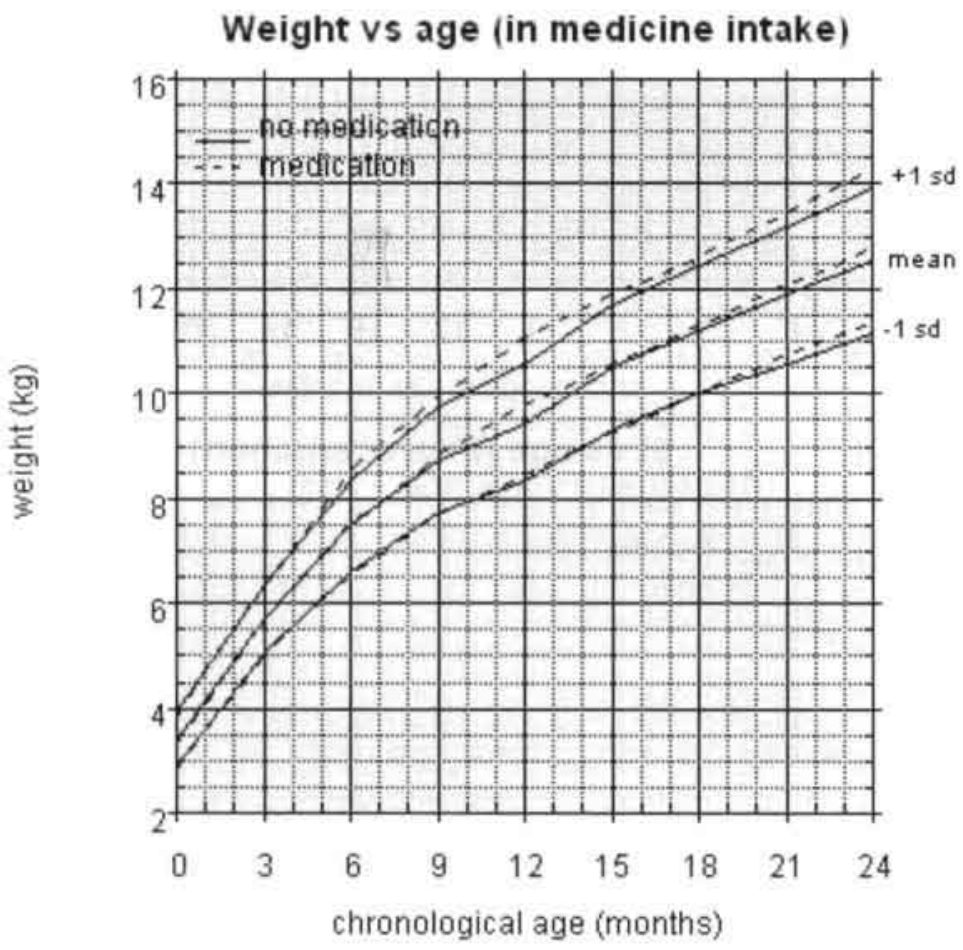




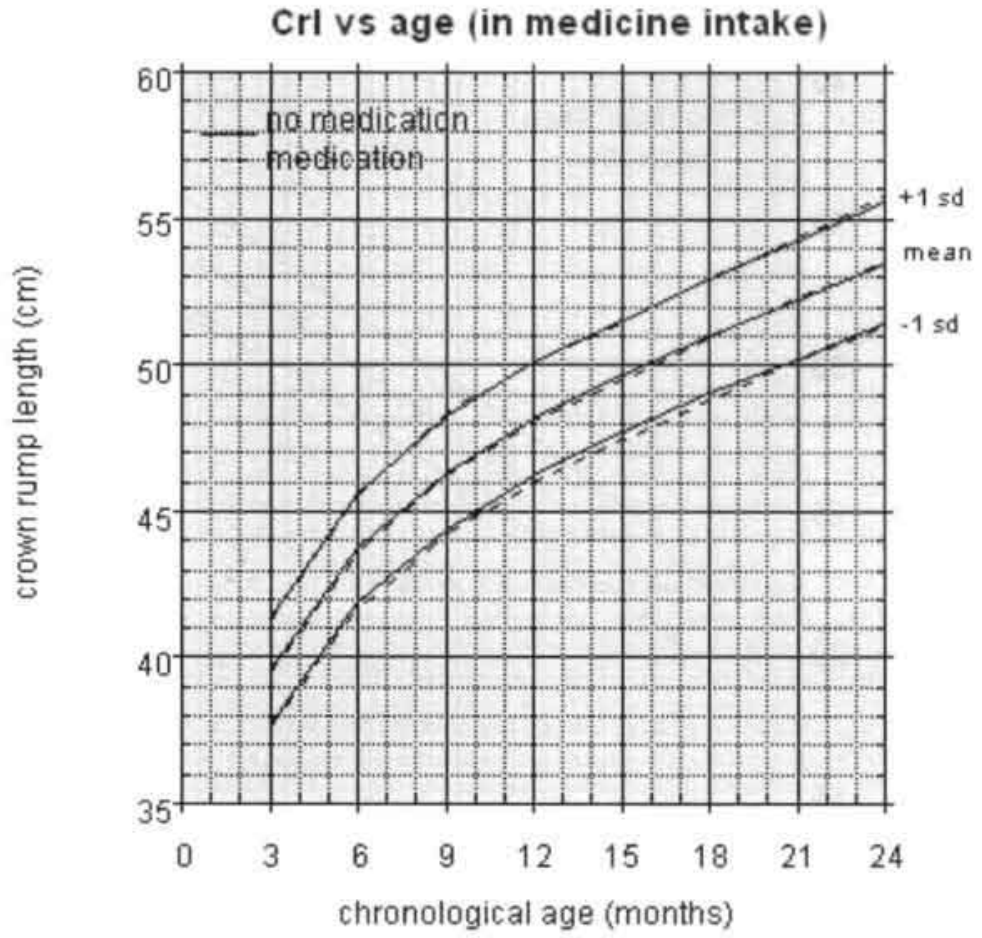

$\mathrm{Hc}$ vs age (in medicine intake)

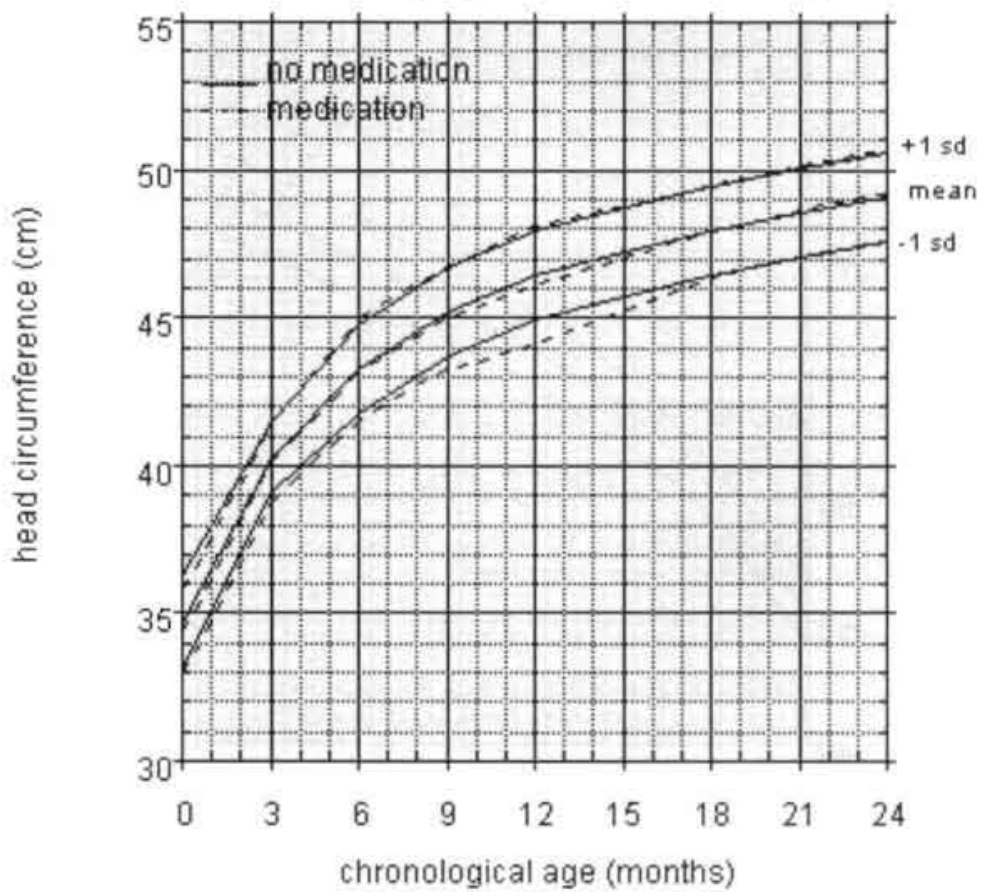




\section{SII vs age (in medicine intake)}

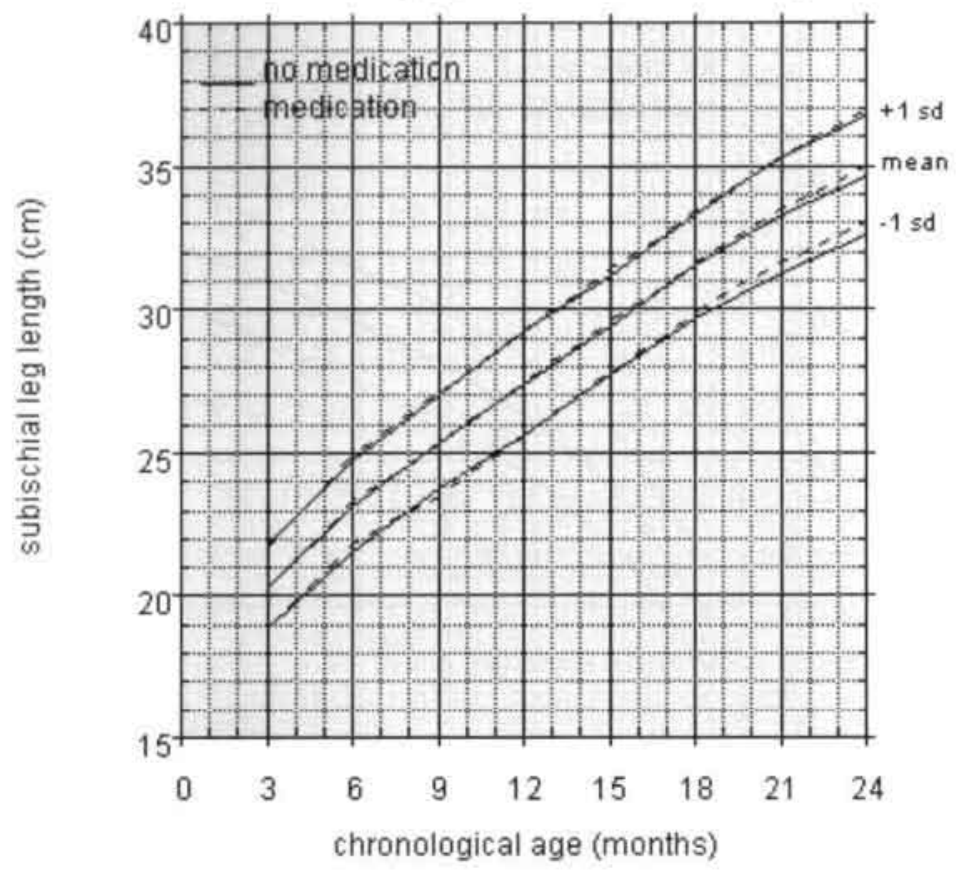

sI vs age (in medicine intake)

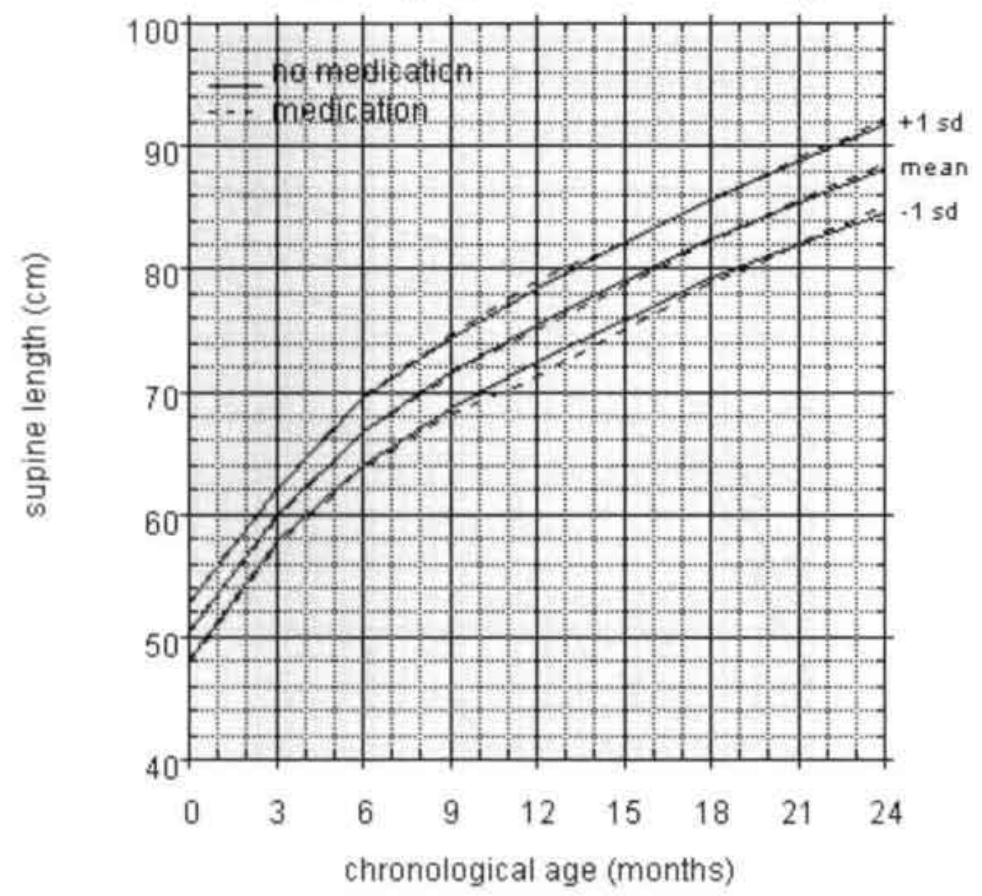




\section{Birth}

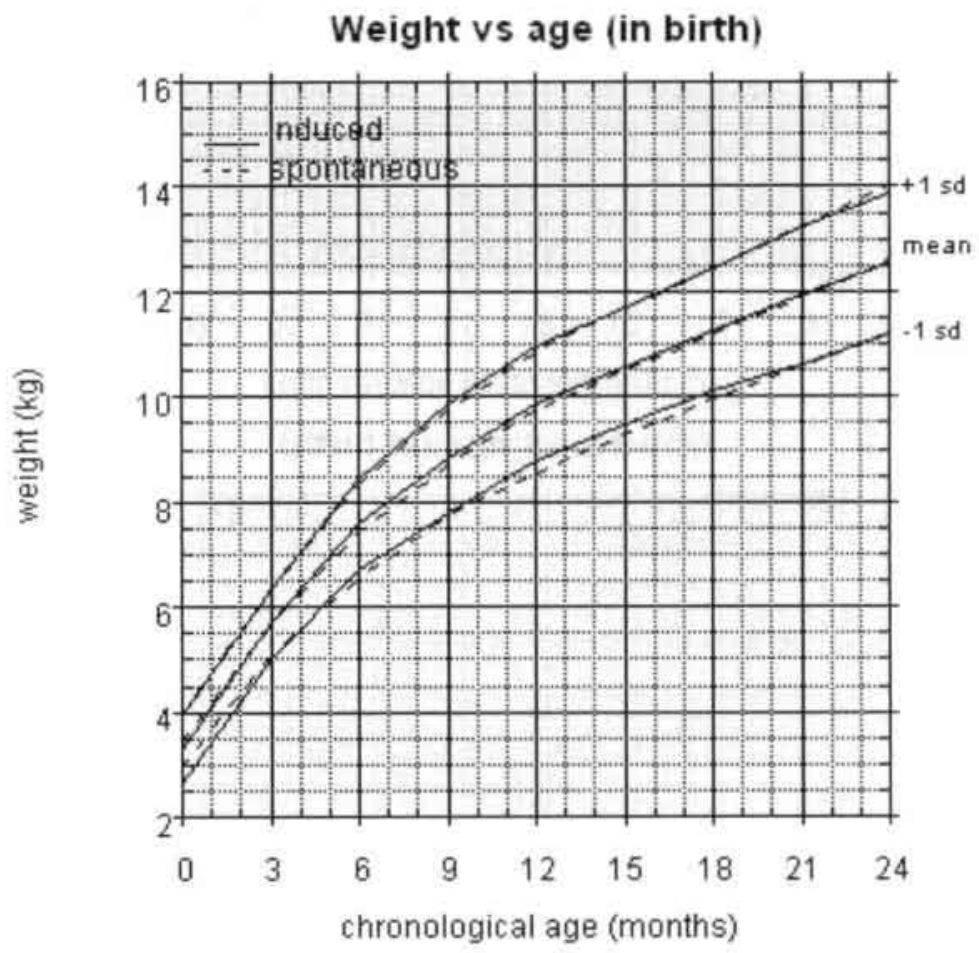




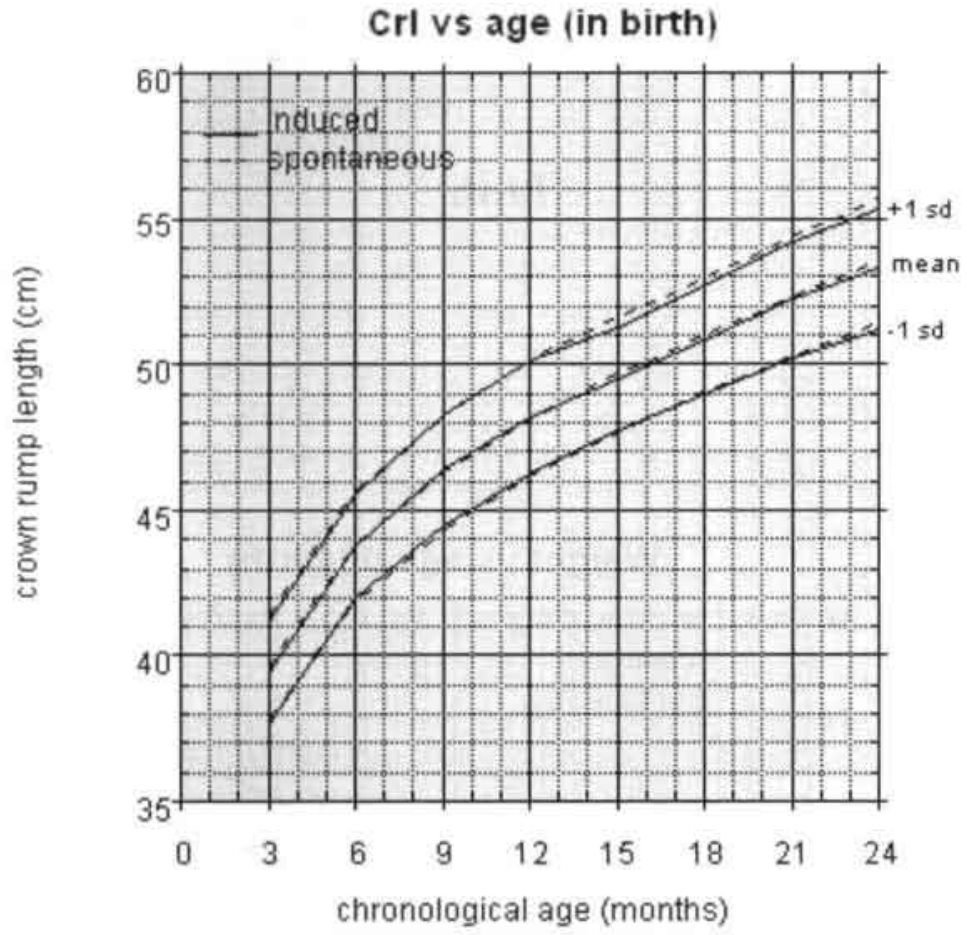

$\mathrm{Hc}$ vs age (in birth)

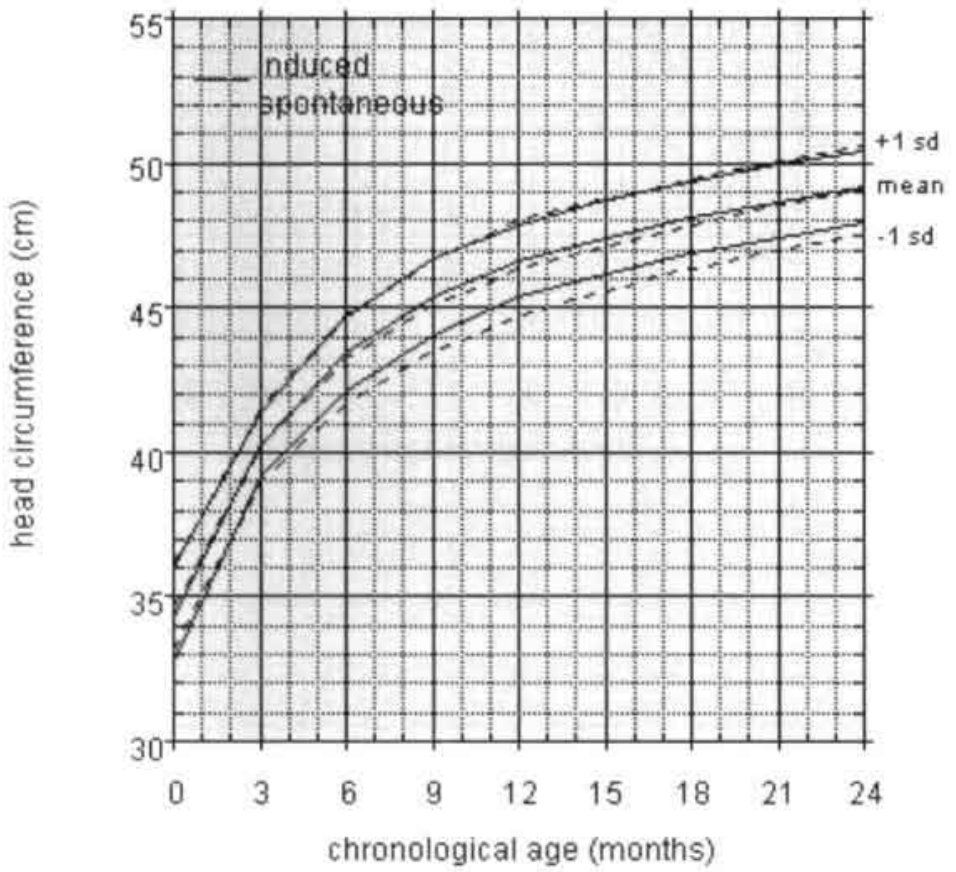




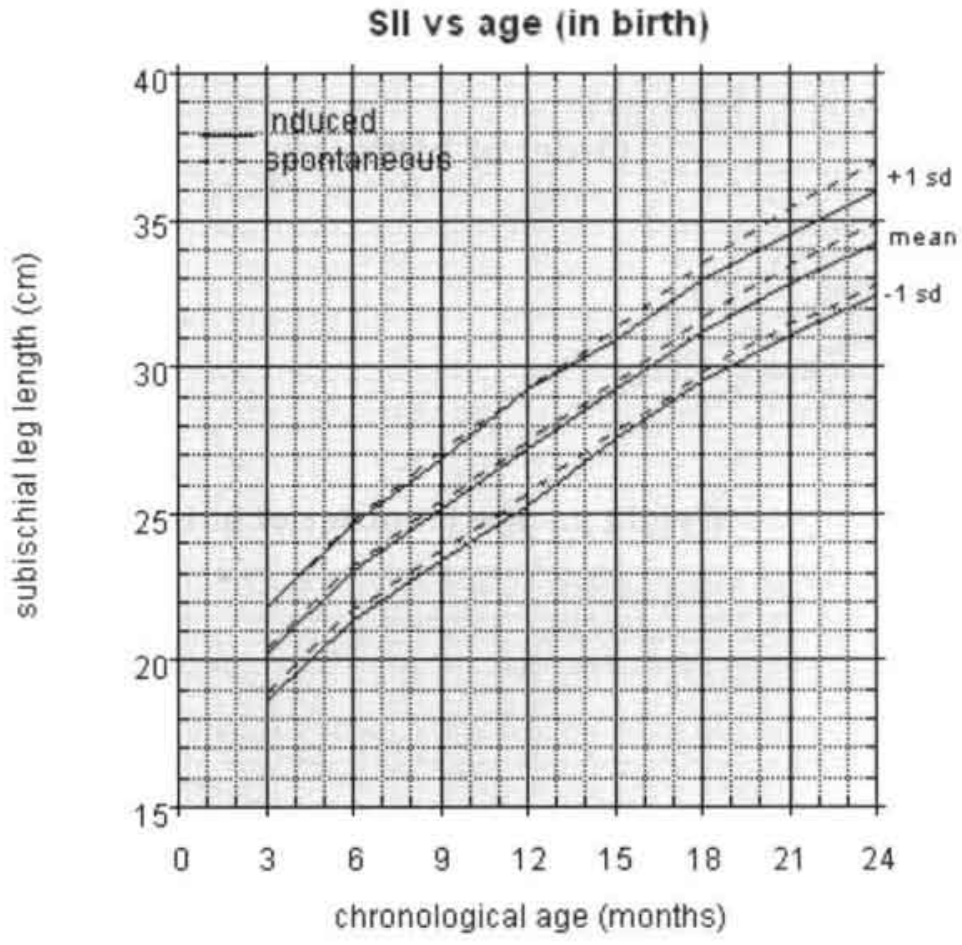

SI vs age (in birth)

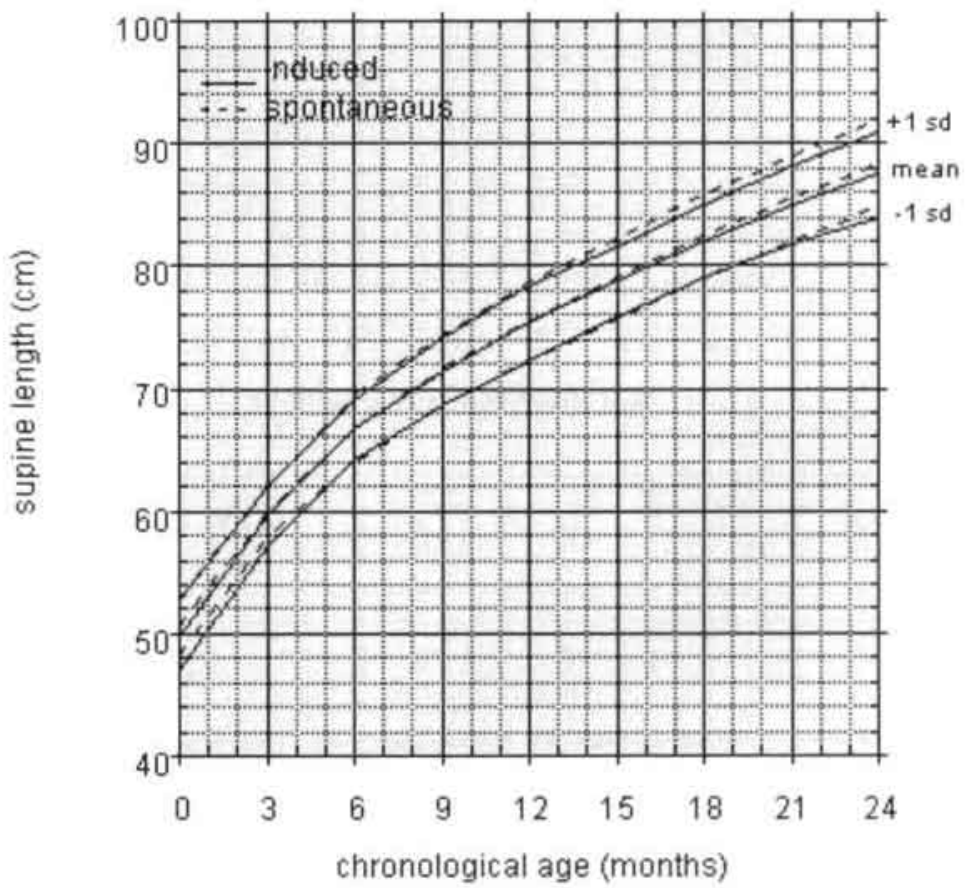




\section{Order of birth}

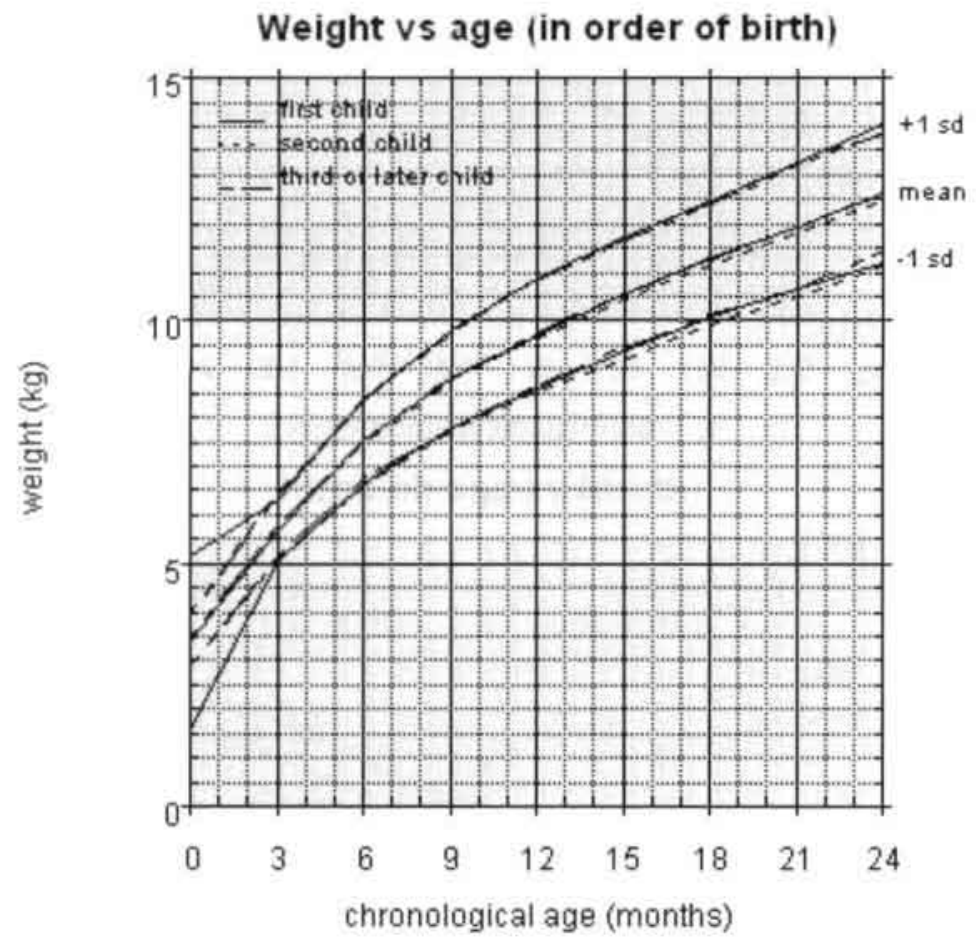




\section{Crl vs age (in order of birth)}

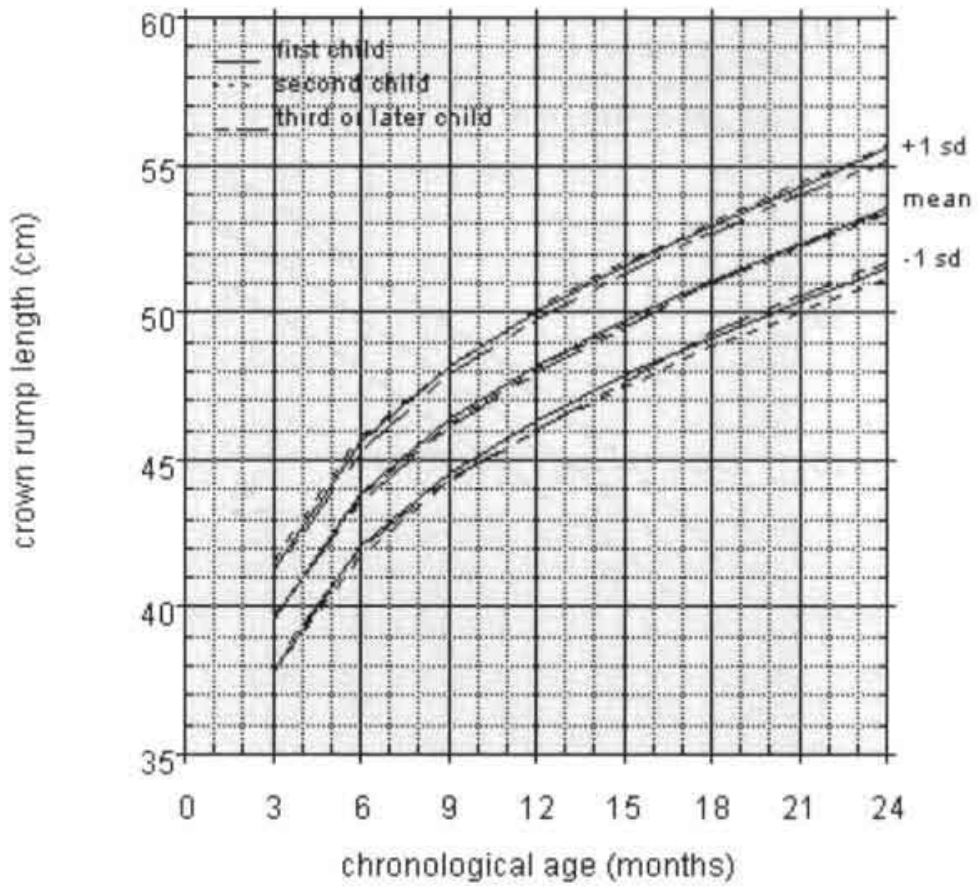

$\mathrm{Hc}$ vs age (in order of birth)

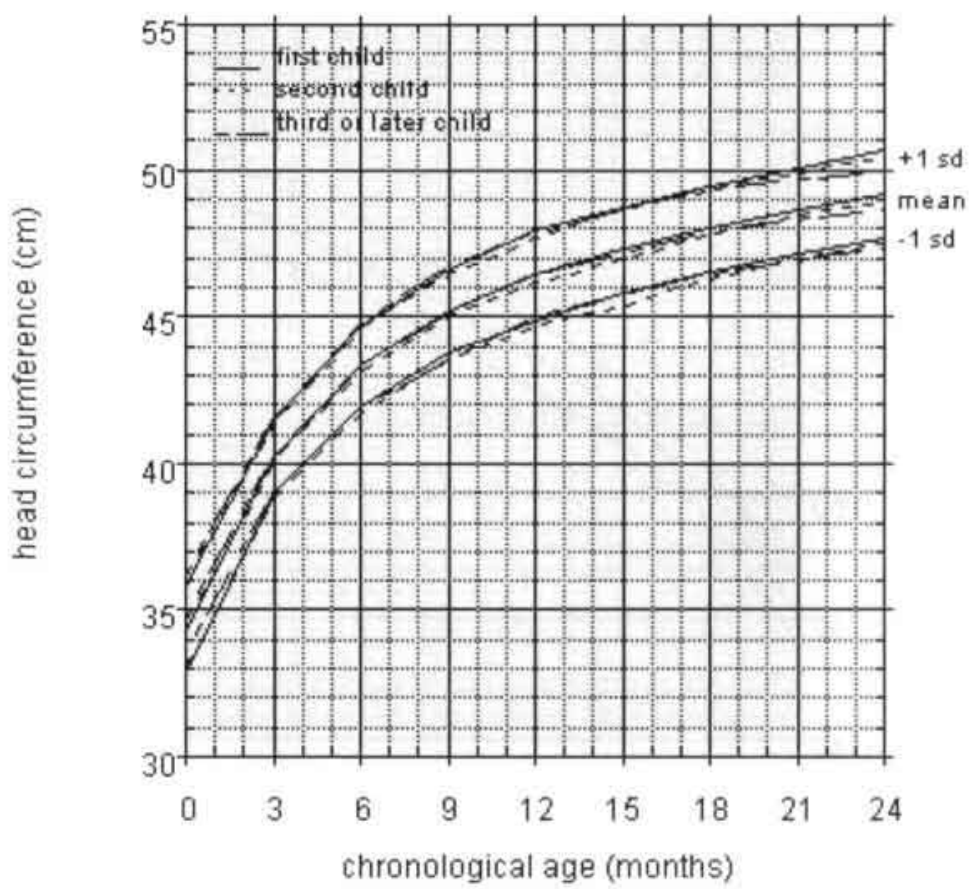


SIl vs age (in order of birth)

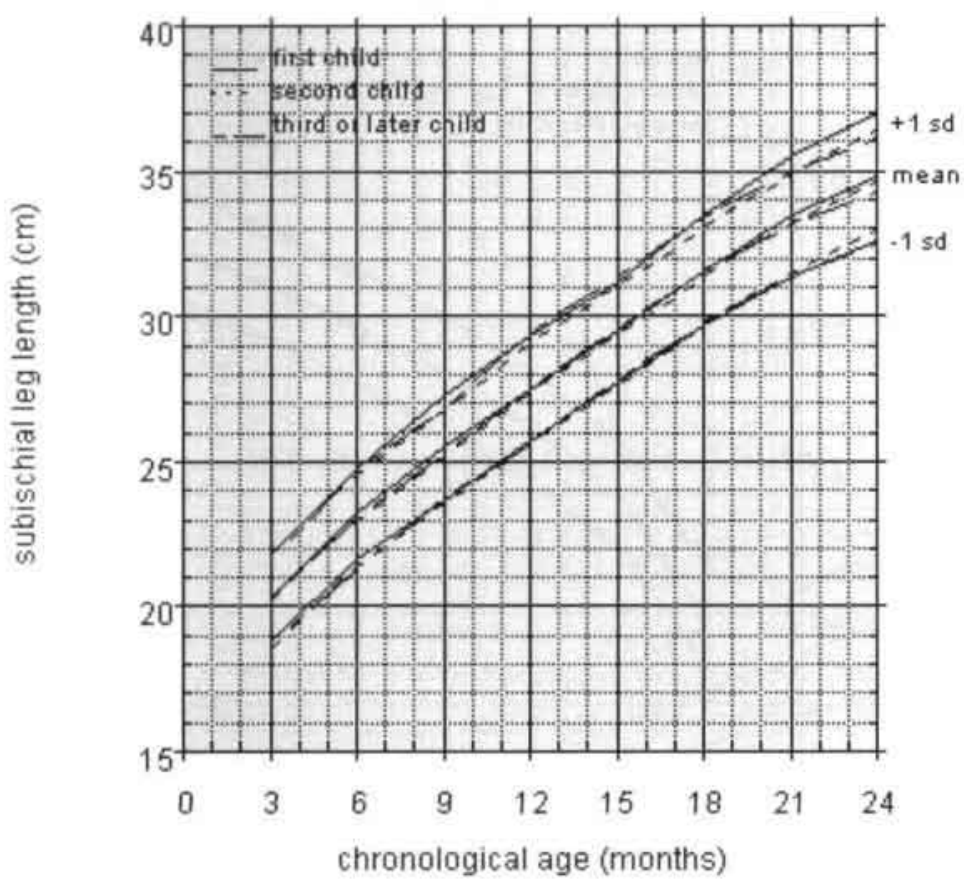

SI vs age (in order of birth)

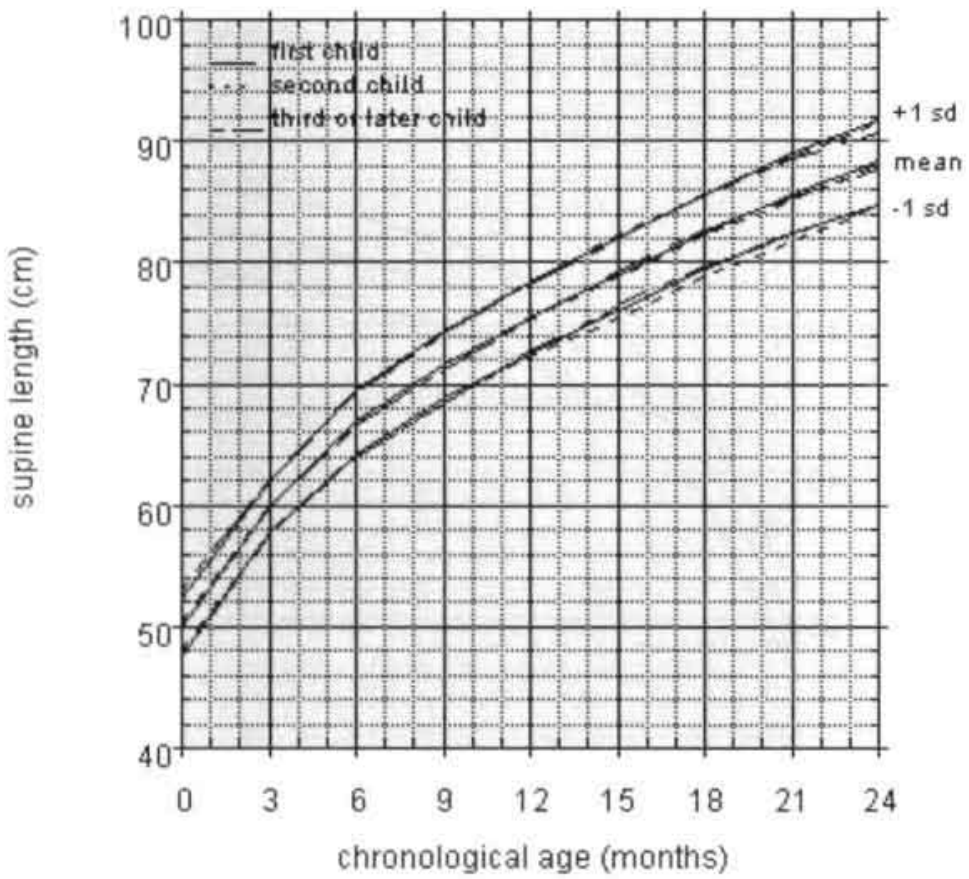


Sex

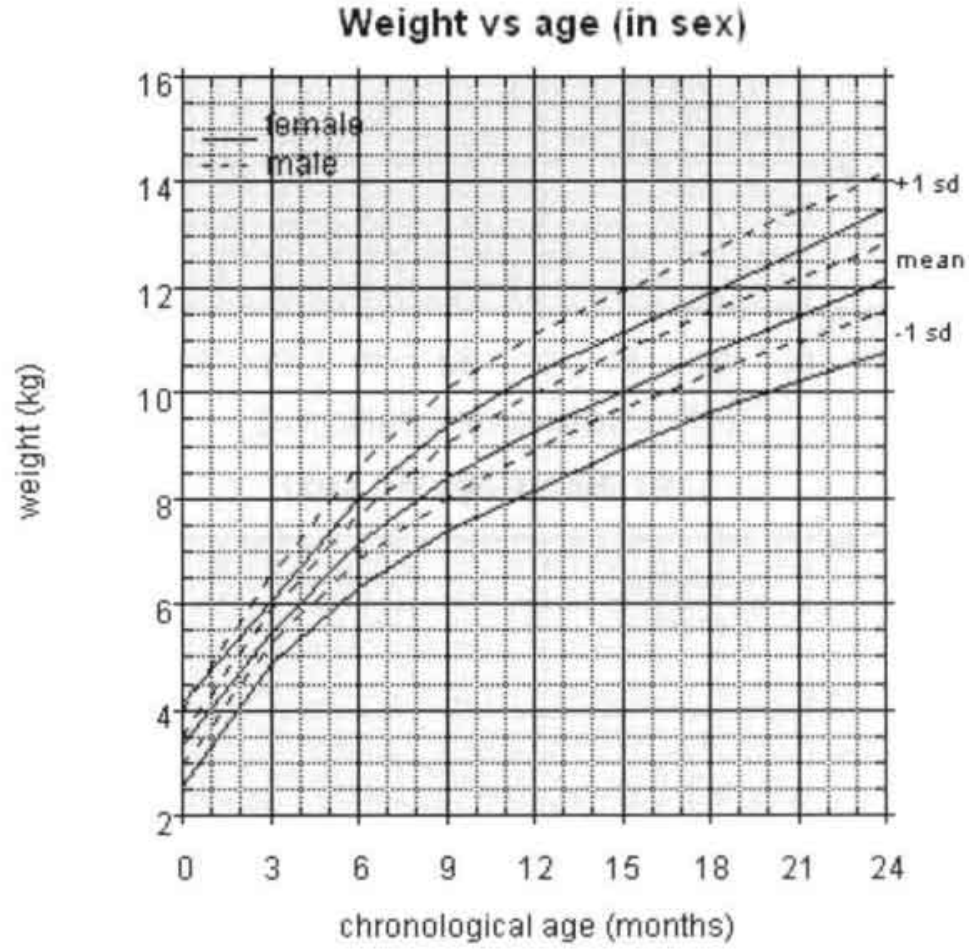



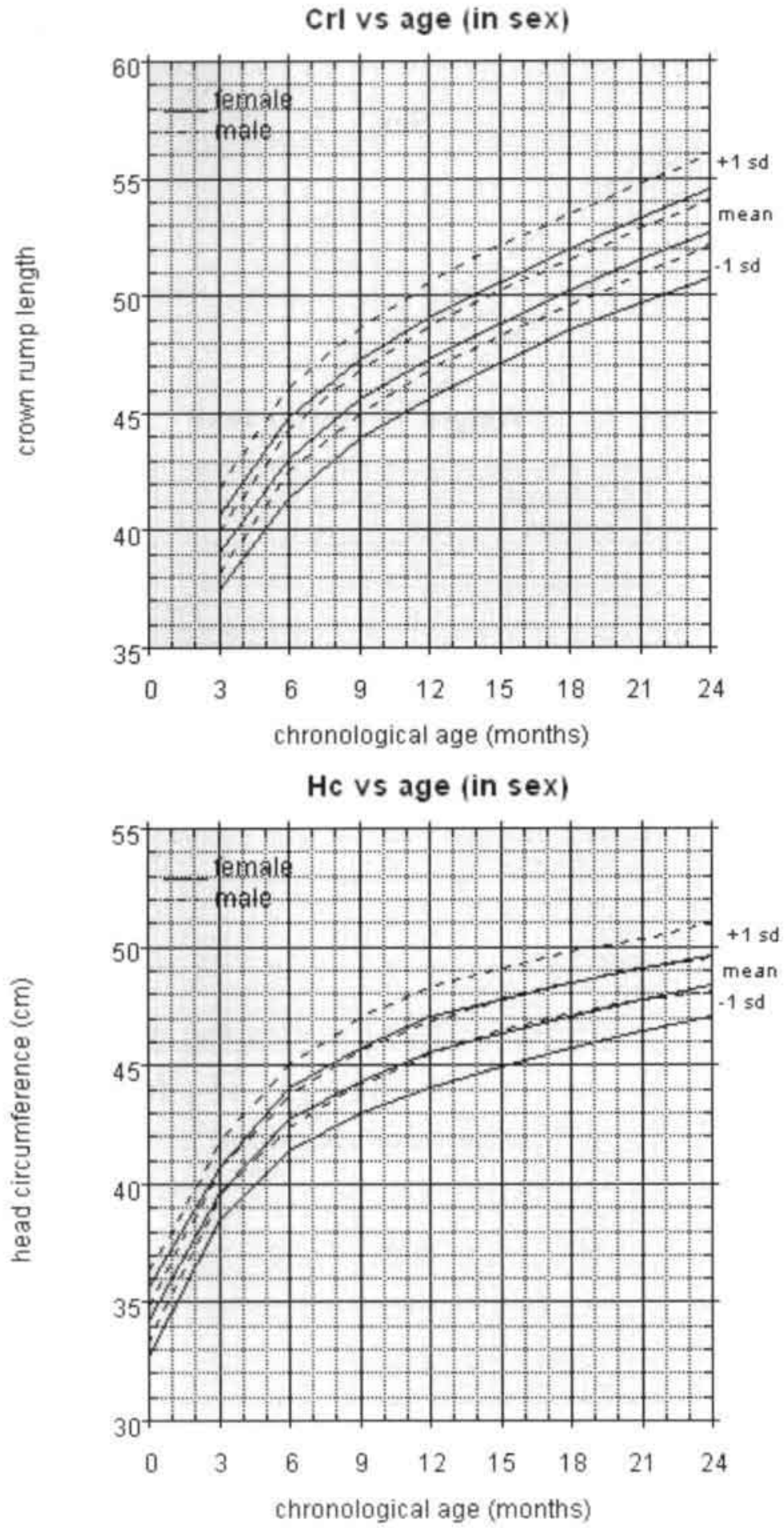


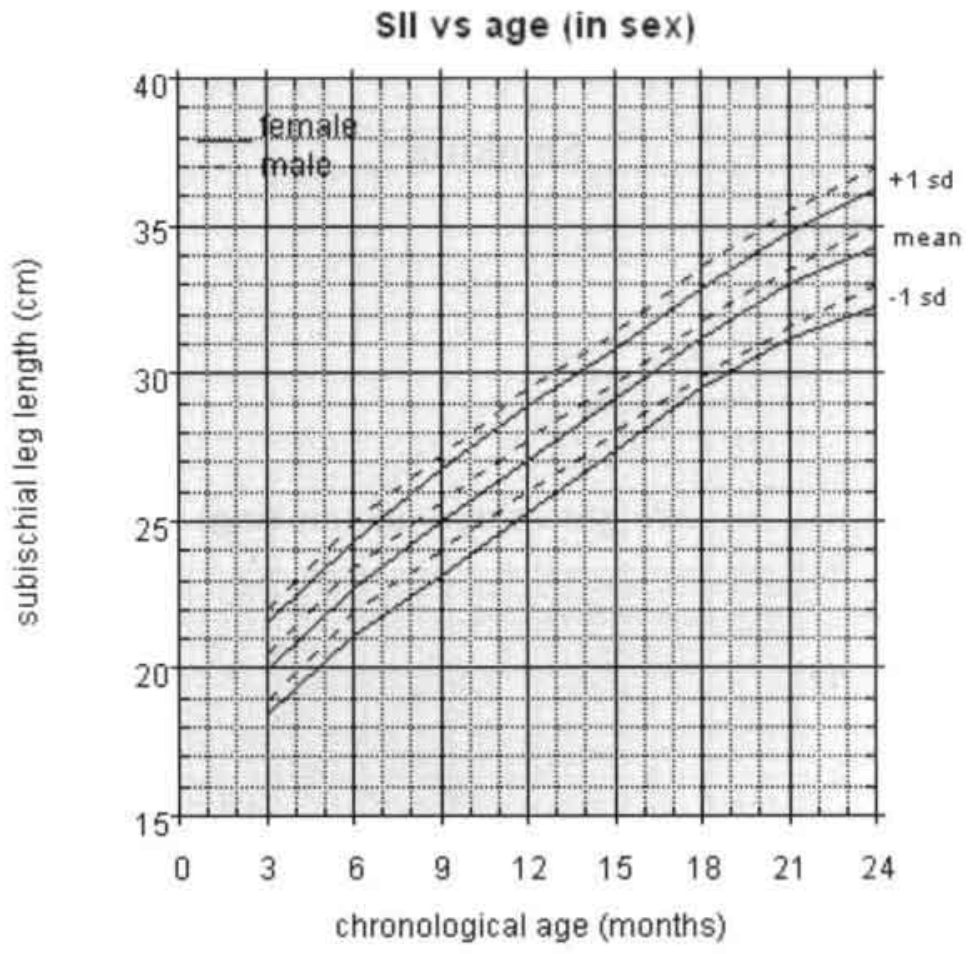

SI vs age (in sex)

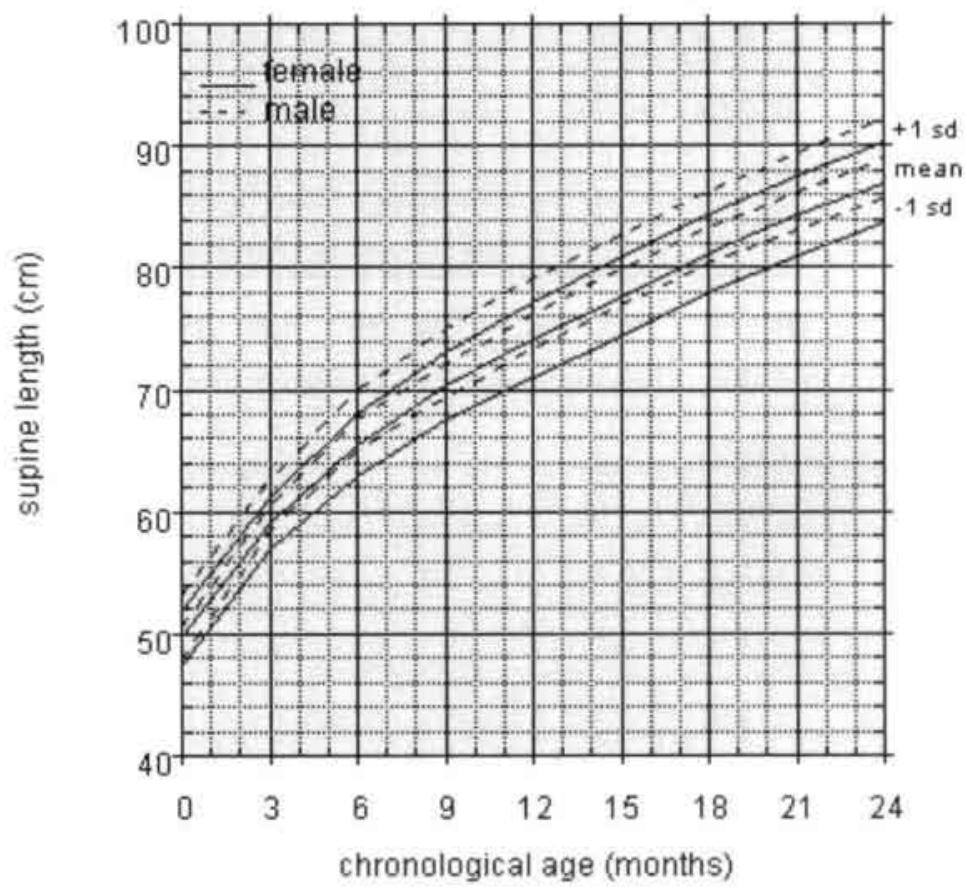




\section{Smoking}

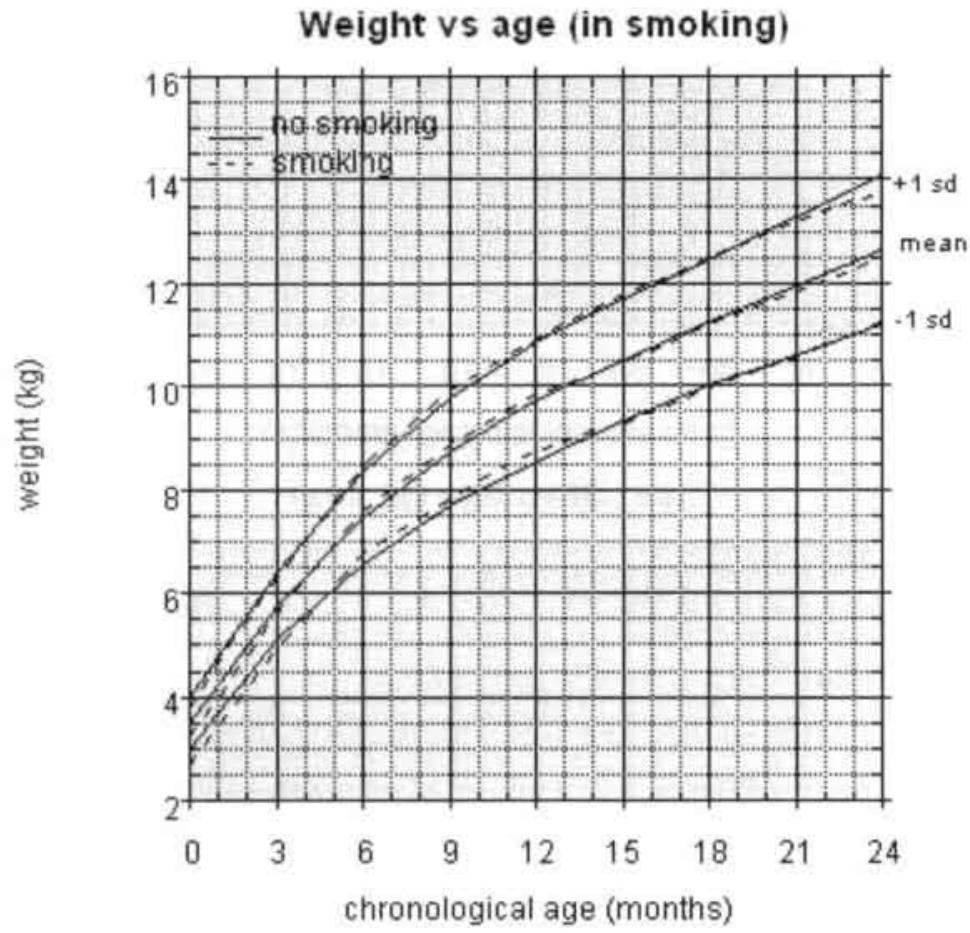


Crl vs age (in smoking)

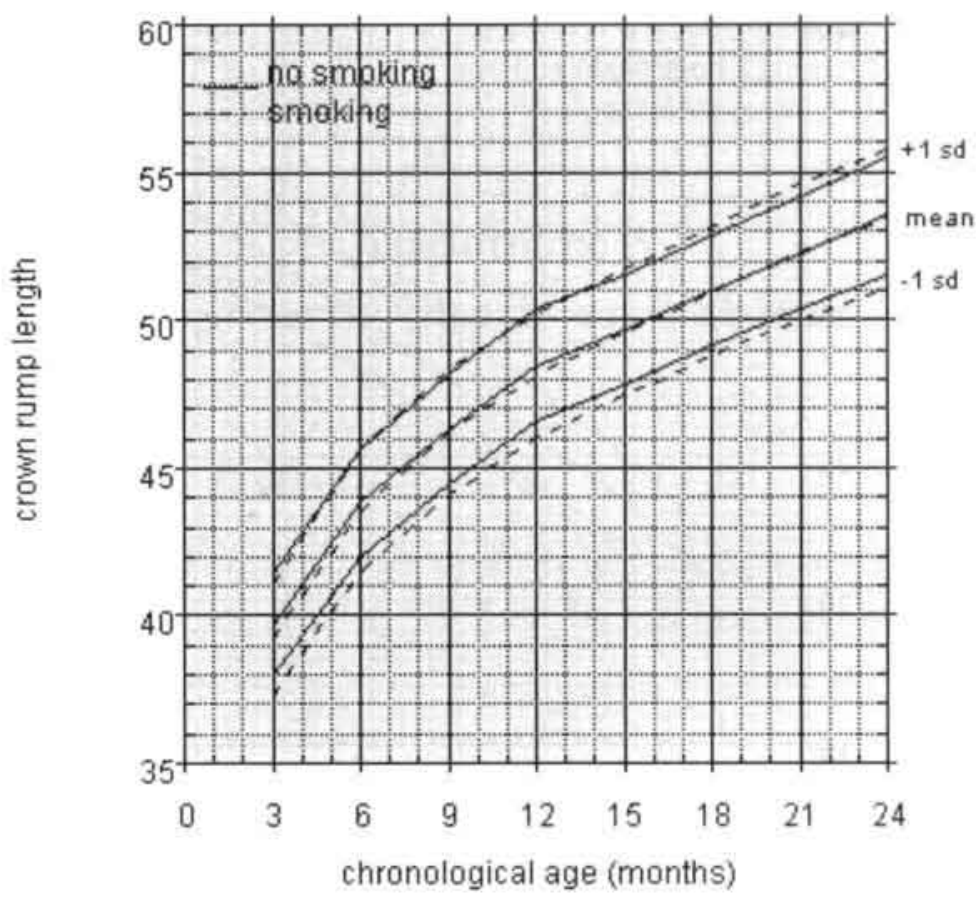

$\mathrm{Hc}$ vs age (in smoking)

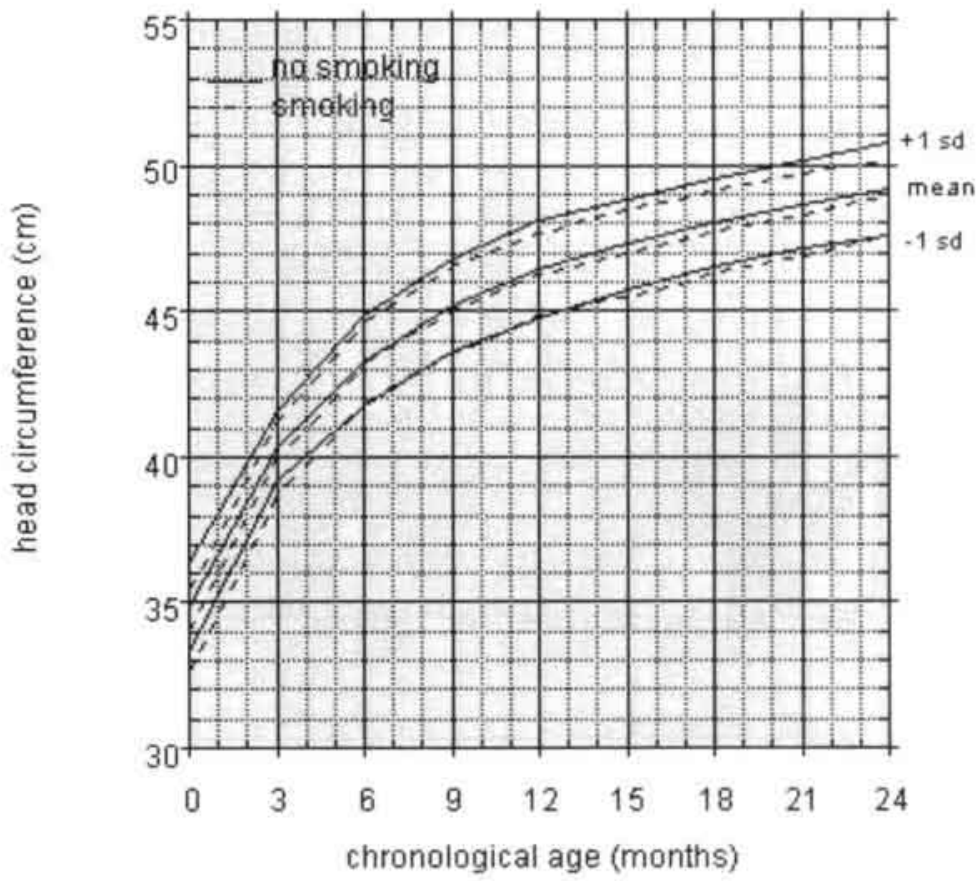



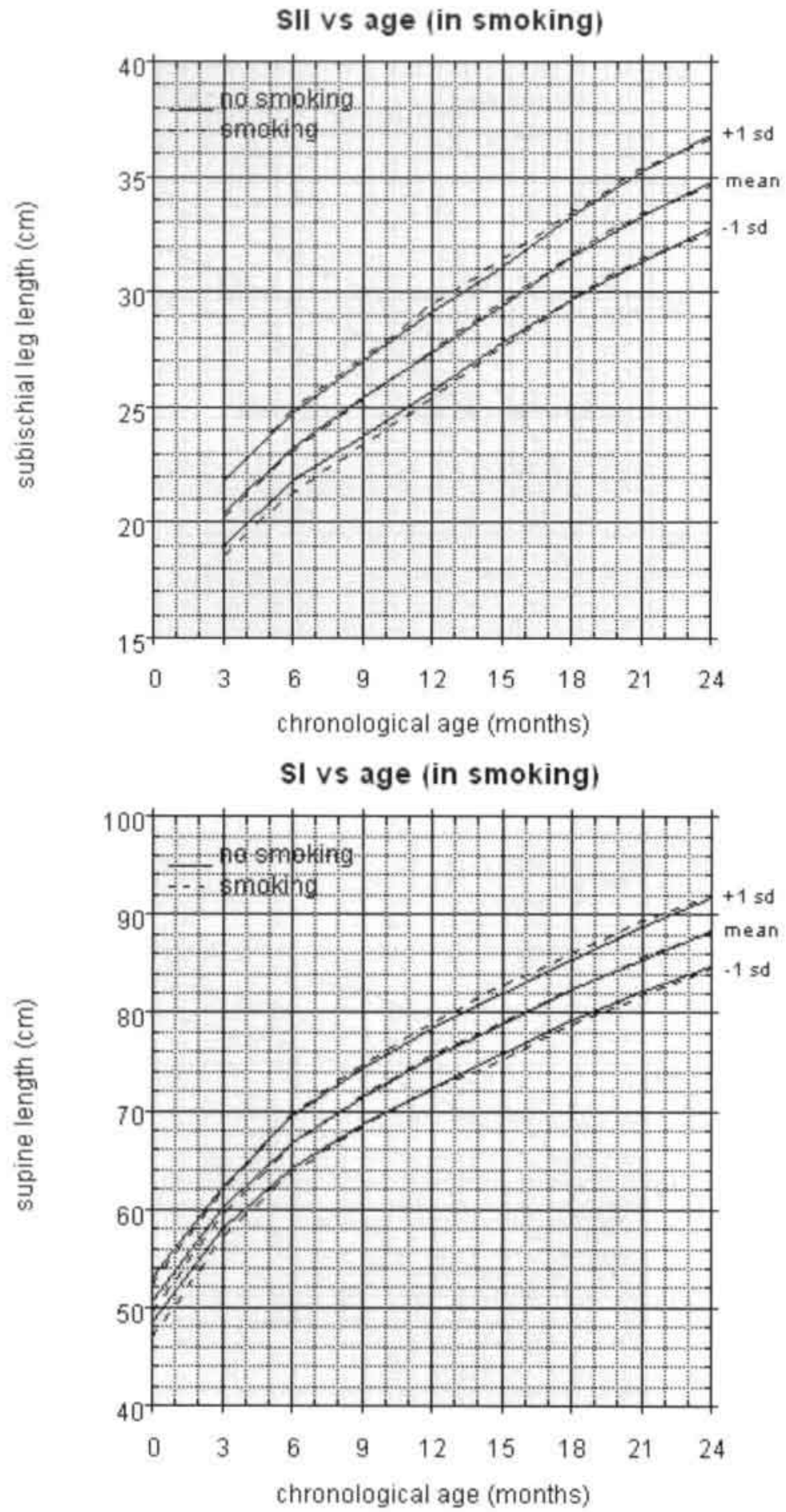


\section{Appendix B Growth Charts en Tables}

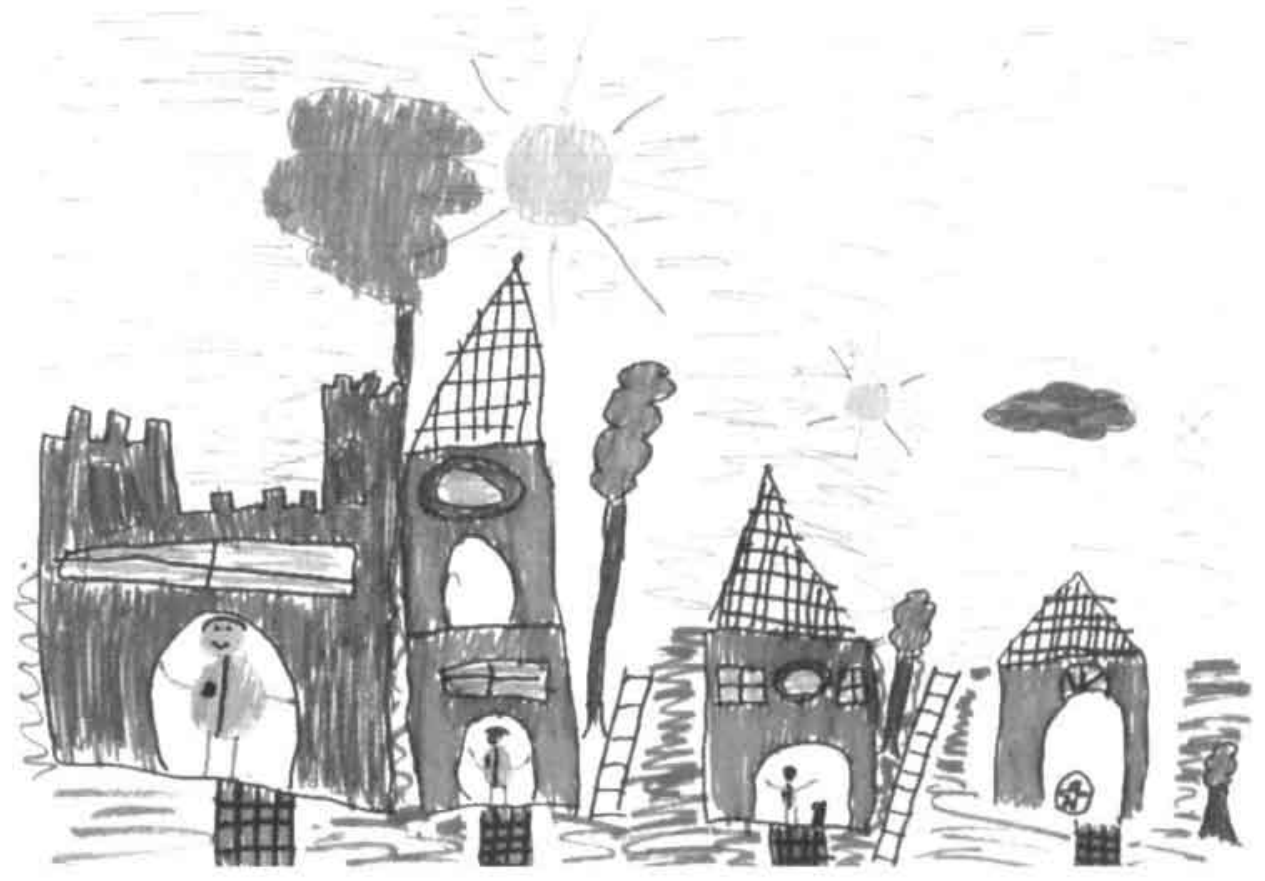

Groei

Cedric van de Walle 
Appendix B 


\section{Supine length vs age}

\begin{tabular}{|c|c|c|c|}
\hline Boys & \multicolumn{3}{|c|}{ Supine length vs age } \\
\hline Edf: 35 3 3 (3.01 4.98 2.99) & N: 6059 & Nc: 1658 \\
\hline Range & Expected & Observed & Difference \\
\hline < P3 & 181.8 & 175 & -6.8 \\
\hline P3-P10 & 424.1 & 377 & -47.1 \\
\hline P10 - P25 & 908.9 & 884 & -24.9 \\
\hline P25 - P 50 & 1514.7 & 1607 & 92.3 \\
\hline P50 - P75 & 1514.7 & 1599 & 84.3 \\
\hline P75 - P90 & 908.9 & 830 & -78.9 \\
\hline P90 - P97 & 424.1 & 394 & -30.1 \\
\hline > P97 & 181.8 & 193 & 11.2 \\
\hline
\end{tabular}

\begin{tabular}{|c|c|c|c|}
\hline Girls & \multicolumn{4}{|c|}{ Supine length vs age } \\
\hline Edf: 2 6 3 (2.00 6.03 3.01) & N:5178 & Nc: 1517 \\
\hline Range & Expected & Observed & Difference \\
\hline <P3 & 155.3 & 161 & 5.7 \\
\hline P3-P10 & 362.5 & 319 & -43.5 \\
\hline P10 - P25 & 776.7 & 774 & -2.7 \\
\hline P25 - P 50 & 1294.5 & 1317 & 22.5 \\
\hline P50 - P75 & 1294.5 & 1329 & 34.5 \\
\hline P75 - P90 & 776.7 & 794 & 17.3 \\
\hline P90 - P97 & 362.5 & 358 & -4.5 \\
\hline > P97 & 155.3 & 126 & -29.3 \\
\hline
\end{tabular}




\section{Comparison supine length boys}

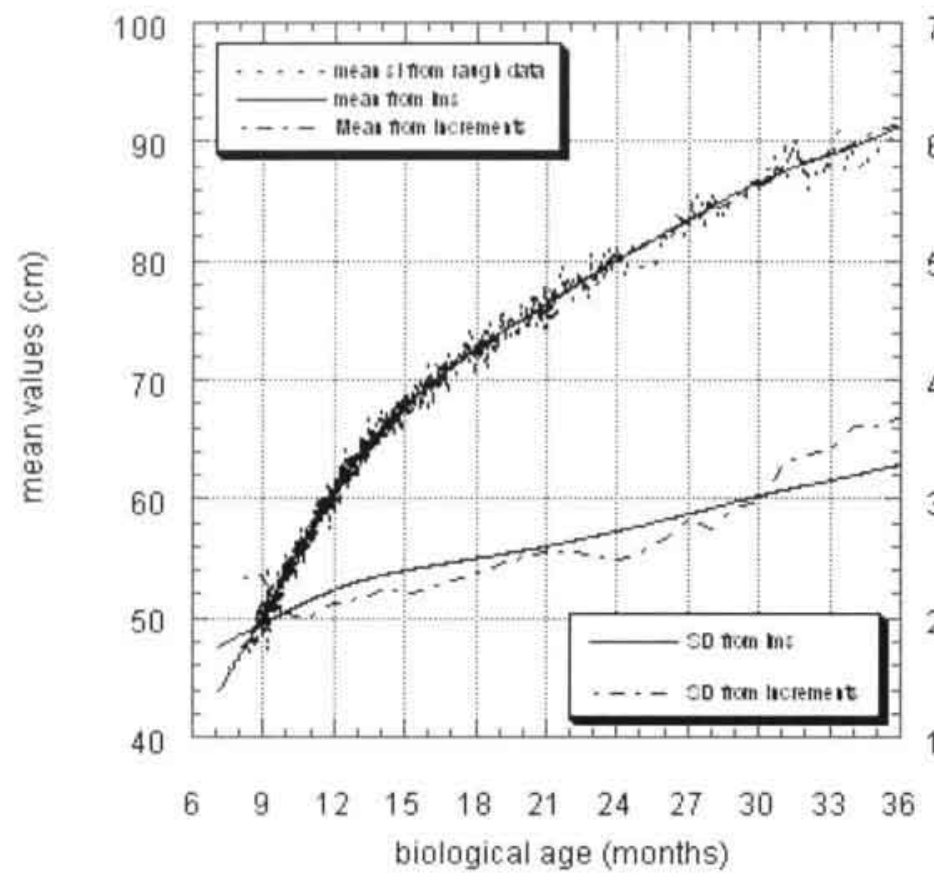

Comparison supine length girls

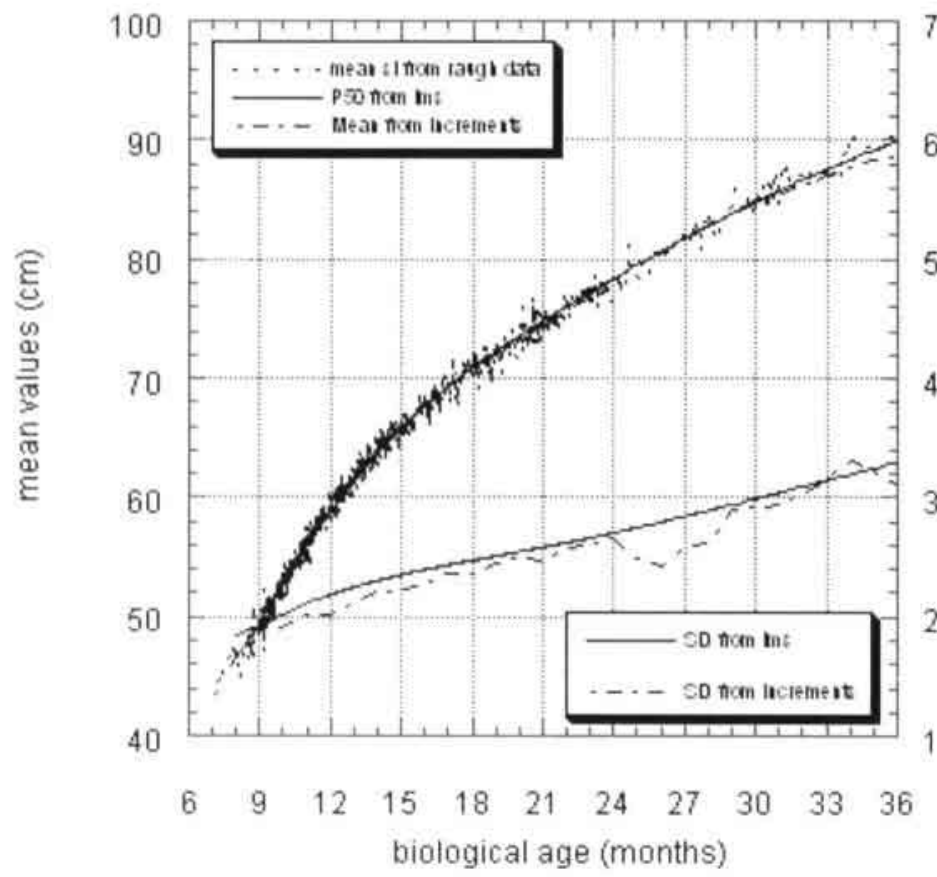




\section{Boys supine length vs age; edf 353}

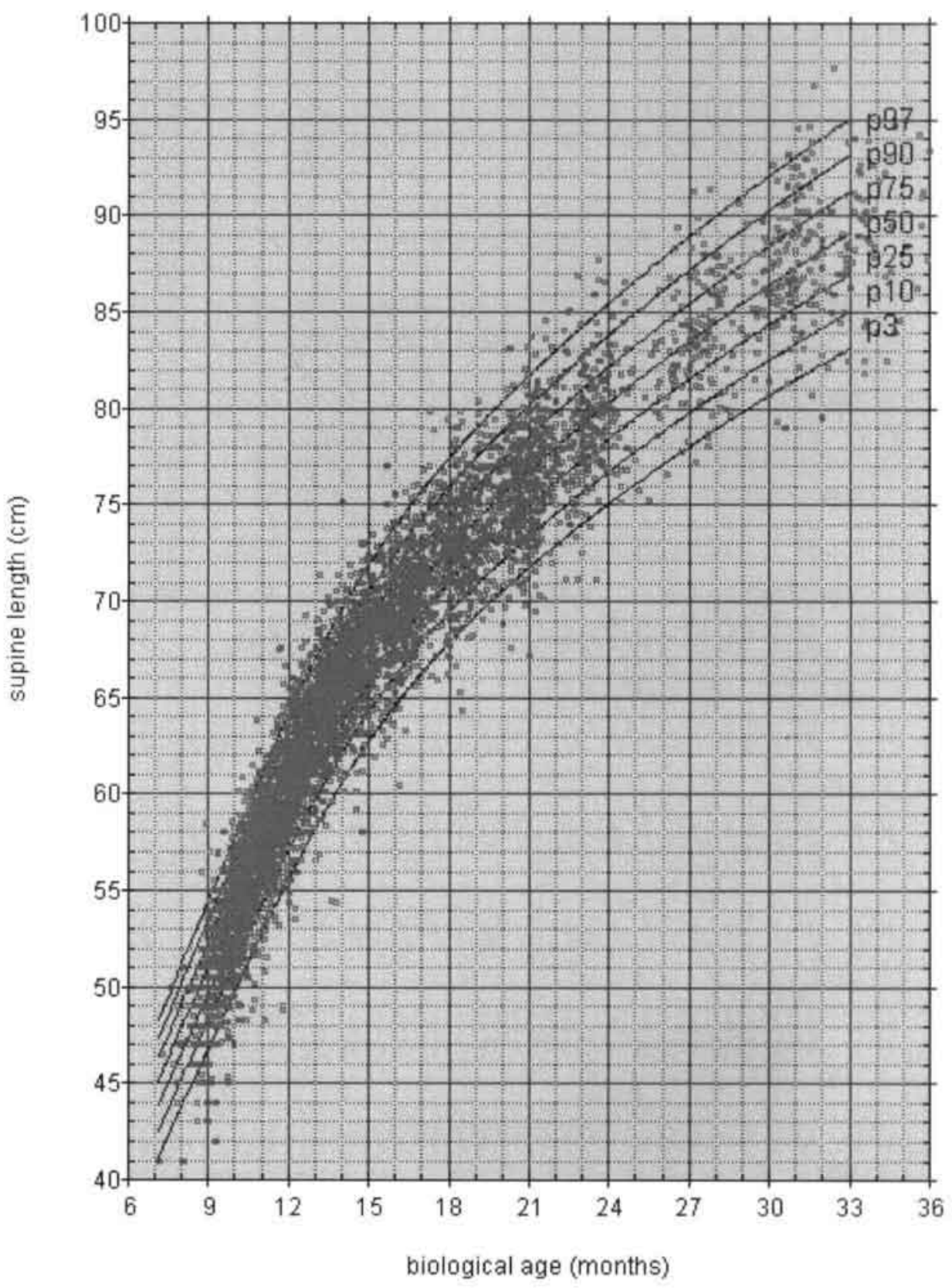




\section{Boys supine length vs age; edf 353}

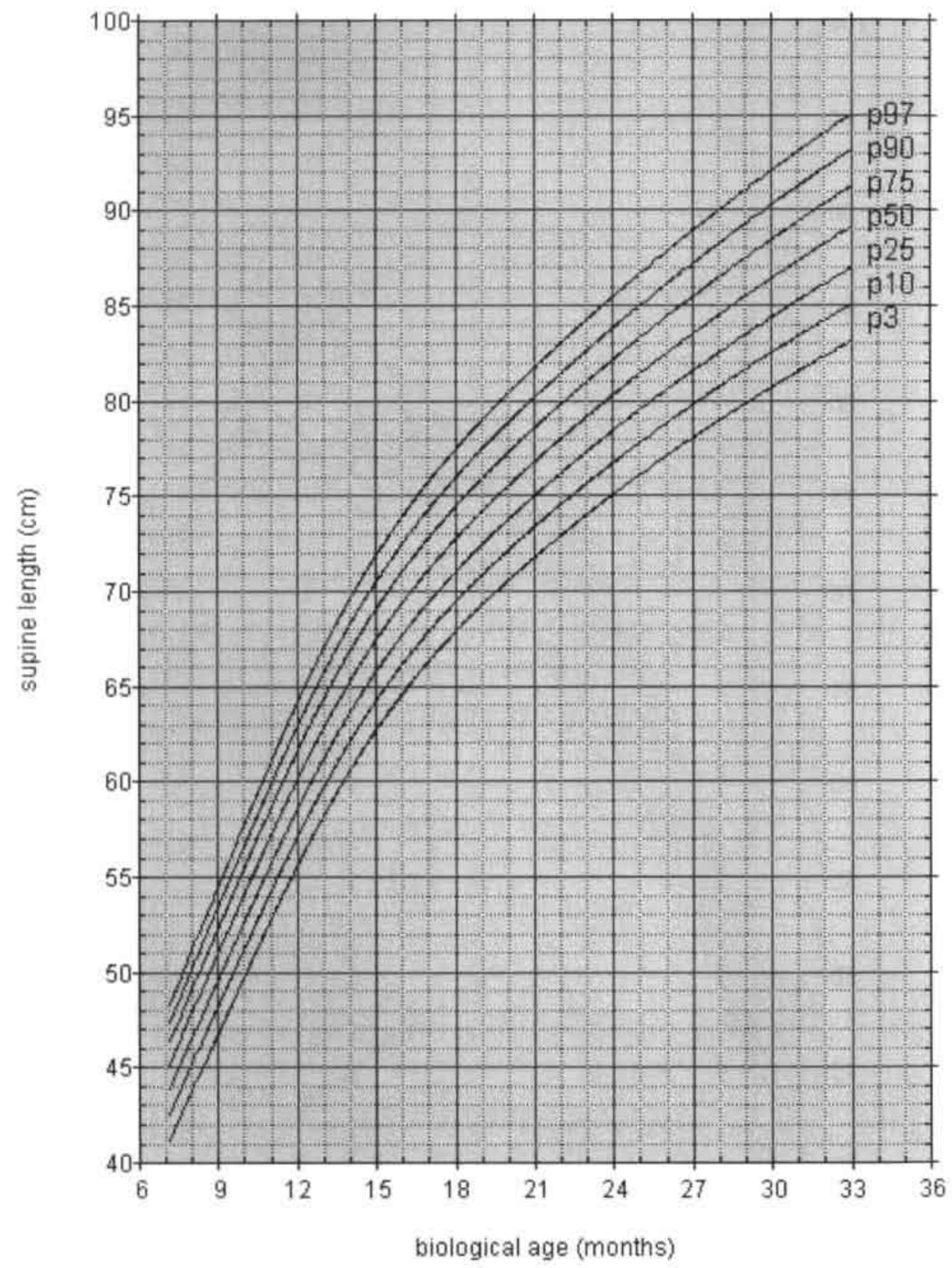


Boys supine length vs age; edf 353

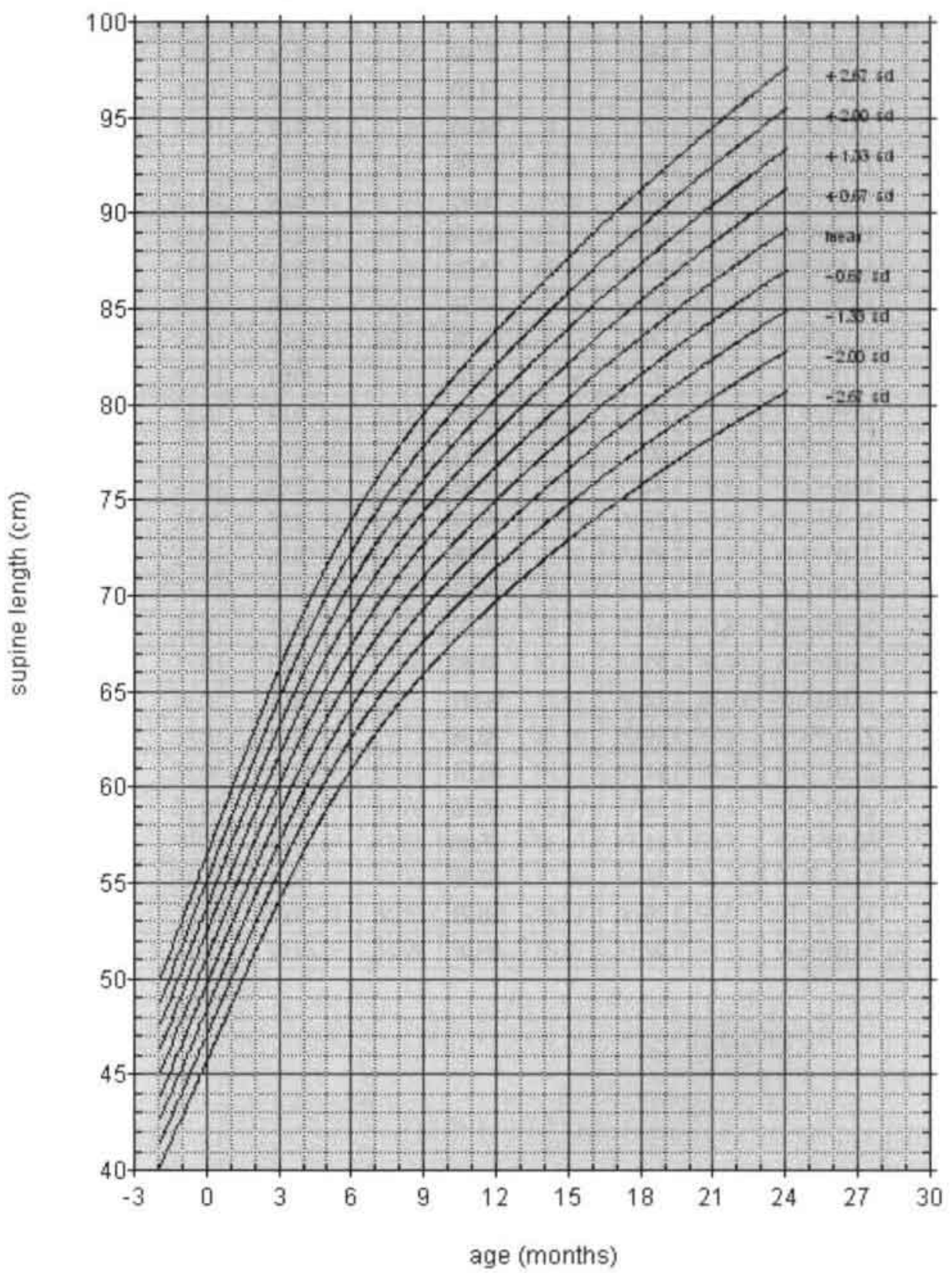




\begin{tabular}{|c|c|c|c|c|}
\hline \multicolumn{5}{|c|}{ Boys supine length LMS values ( edf 35 3) } \\
\hline biological age & L & M & S & SD \\
\hline 8.00 & 4.05 & 47.62 & 0.04 & 1.91 \\
\hline 9.00 & 3.66 & 51.03 & 0.04 & 2.02 \\
\hline 10.00 & 3.31 & 54.15 & 0.04 & 2.10 \\
\hline 11.00 & 2.99 & 57.06 & 0.04 & 2.18 \\
\hline 12.00 & 2.67 & 60.03 & 0.04 & 2.26 \\
\hline 13.00 & 2.39 & 62.70 & 0.04 & 2.33 \\
\hline 14.00 & 2.14 & 65.20 & 0.04 & 2.38 \\
\hline 15.00 & 1.93 & 67.36 & 0.04 & 2.43 \\
\hline 16.00 & 1.76 & 69.35 & 0.04 & 2.47 \\
\hline 17.00 & 1.62 & 71.08 & 0.04 & 2.51 \\
\hline 18.00 & 1.50 & 72.69 & 0.04 & 2.55 \\
\hline 19.00 & 1.40 & 74.11 & 0.04 & 2.58 \\
\hline 20.00 & 1.32 & 75.48 & 0.04 & 2.61 \\
\hline 21.00 & 1.26 & 76.74 & 0.03 & 2.65 \\
\hline 22.00 & 1.21 & 77.98 & 0.03 & 2.68 \\
\hline 23.00 & 1.17 & 79.13 & 0.03 & 2.72 \\
\hline 24.00 & 1.14 & 80.28 & 0.03 & 2.76 \\
\hline 25.00 & 1.12 & 81.40 & 0.03 & 2.80 \\
\hline 26.00 & 1.11 & 82.41 & 0.04 & 2.84 \\
\hline 27.00 & 1.10 & 83.46 & 0.04 & 2.89 \\
\hline 28.00 & 1.11 & 84.51 & 0.04 & 2.94 \\
\hline 29.00 & 1.12 & 85.60 & 0.04 & 2.99 \\
\hline 30.00 & 1.14 & 86.40 & 0.04 & 3.03 \\
\hline 31.00 & 1.16 & 87.30 & 0.04 & 3.07 \\
\hline 32.00 & 1.19 & 88.21 & 0.04 & 3.12 \\
\hline 33.00 & 1.22 & 89.07 & 0.04 & 3.16 \\
\hline & & & & \\
\hline
\end{tabular}




\begin{tabular}{|c|c|c|c|c|c|c|c|c|c|}
\hline \multicolumn{10}{|c|}{ Boys supine length (in cm) vs age (in months) } \\
\hline age & -2.76 SD & -2.00 SD & -1.33 SD & -0.67 SD & 0SD & +0.67 SD & +1.33 SD & +2.00 SD & +2.67 SD \\
\hline-1.00 & 42.51 & 43.79 & 45.07 & 46.34 & 47.62 & 48.90 & 50.17 & 51.45 & 52.73 \\
\hline 0.00 & 45.65 & 47.00 & 48.35 & 49.68 & 51.03 & 52.38 & 53.71 & 55.06 & 56.41 \\
\hline 1.00 & 48.53 & 49.94 & 51.35 & 52.74 & 54.15 & 55.56 & 56.95 & 58.36 & 59.77 \\
\hline 2.00 & 51.23 & 52.69 & 54.16 & 55.60 & 57.06 & 58.52 & 59.96 & 61.43 & 62.89 \\
\hline 3.00 & 54.00 & 55.51 & 57.02 & 58.52 & 60.03 & 61.54 & 63.04 & 64.55 & 66.06 \\
\hline 4.00 & 56.49 & 58.05 & 59.61 & 61.14 & 62.70 & 64.26 & 65.79 & 67.35 & 68.91 \\
\hline 5.00 & 58.84 & 60.43 & 62.03 & 63.60 & 65.20 & 66.80 & 68.37 & 69.97 & 71.57 \\
\hline 6.00 & 60.87 & 62.50 & 64.13 & 65.73 & 67.36 & 68.99 & 70.59 & 72.22 & 73.85 \\
\hline 7.00 & 62.74 & 64.40 & 66.06 & 67.69 & 69.35 & 71.01 & 72.64 & 74.30 & 75.96 \\
\hline 8.00 & 64.38 & 66.06 & 67.74 & 69.40 & 71.08 & 72.76 & 74.42 & 76.10 & 77.78 \\
\hline 9.00 & 65.90 & 67.60 & 69.31 & 70.99 & 72.69 & 74.40 & 76.08 & 77.78 & 79.49 \\
\hline 10.00 & 67.23 & 68.95 & 70.68 & 72.38 & 74.11 & 75.84 & 77.54 & 79.27 & 80.99 \\
\hline 11.00 & 68.51 & 70.26 & 72.01 & 73.73 & 75.48 & 77.23 & 78.95 & 80.70 & 82.45 \\
\hline 12.00 & 69.68 & 71.45 & 73.22 & 74.97 & 76.74 & 78.51 & 80.26 & 82.03 & 83.81 \\
\hline 13.00 & 70.82 & 72.61 & 74.41 & 76.18 & 77.98 & 79.78 & 81.55 & 83.35 & 85.14 \\
\hline 14.00 & 71.87 & 73.69 & 75.51 & 77.31 & 79.13 & 80.95 & 82.75 & 84.57 & 86.39 \\
\hline 15.00 & 72.91 & 74.76 & 76.61 & 78.43 & 80.28 & 82.13 & 83.95 & 85.80 & 87.65 \\
\hline 16.00 & 73.92 & 75.79 & 77.67 & 79.52 & 81.40 & 83.28 & 85.13 & 87.01 & 88.88 \\
\hline 17.00 & 74.82 & 76.72 & 78.63 & 80.51 & 82.41 & 84.32 & 86.19 & 88.10 & 90.00 \\
\hline 18.00 & 75.75 & 77.68 & 79.62 & 81.52 & 83.46 & 85.40 & 87.30 & 89.24 & 91.17 \\
\hline 19.00 & 76.67 & 78.64 & 80.61 & 82.54 & 84.51 & 86.48 & 88.42 & 90.38 & 92.35 \\
\hline 20.00 & 77.62 & 79.62 & 81.63 & 83.60 & 85.60 & 87.60 & 89.57 & 91.58 & 93.58 \\
\hline 21.00 & 78.32 & 80.35 & 82.37 & 84.37 & 86.40 & 88.43 & 90.43 & 92.45 & 94.48 \\
\hline 22.00 & 79.10 & 81.15 & 83.21 & 85.24 & 87.30 & 89.36 & 91.39 & 93.45 & 95.51 \\
\hline 23.00 & 79.88 & 81.97 & 84.06 & 86.12 & 88.21 & 90.30 & 92.36 & 94.45 & 96.54 \\
\hline 24.00 & 80.62 & 82.74 & 84.86 & 86.95 & 89.07 & 91.19 & 93.28 & 95.40 & 97.52 \\
\hline
\end{tabular}




\begin{tabular}{|c|c|c|c|c|c|c|c|c|c|}
\hline \multicolumn{10}{|c|}{ Boys supine length (in cm) vs age (in months } \\
\hline age & -2.76 SD & -2.00 SD & -1.33 SD & -0.67 SD & 0SD & +0.67 SD & +1.33 SD & +2.00 SD & +2.67 SD \\
\hline-1.00 & 42.51 & 43.79 & 45.07 & 46.34 & 47.62 & 48.90 & 50.17 & 51.45 & 52.73 \\
\hline 0.00 & 45.65 & 47.00 & 48.35 & 49.68 & 51.03 & 52.38 & 53.71 & 55.06 & 56.41 \\
\hline 1.00 & 48.53 & 49.94 & 51.35 & 52.74 & 54.15 & 55.56 & 56.95 & 58.36 & 59.77 \\
\hline 2.00 & 51.23 & 52.69 & 54.16 & 55.60 & 57.06 & 58.52 & 59.96 & 61.43 & 62.89 \\
\hline 3.00 & 54.00 & 55.51 & 57.02 & 58.52 & 60.03 & 61.54 & 63.04 & 64.55 & 66.06 \\
\hline 4.00 & 56.49 & 58.05 & 59.61 & 61.14 & 62.70 & 64.26 & 65.79 & 67.35 & 68.91 \\
\hline 5.00 & 58.84 & 60.43 & 62.03 & 63.60 & 65.20 & 66.80 & 68.37 & 69.97 & 71.57 \\
\hline 6.00 & 60.87 & 62.50 & 64.13 & 65.73 & 67.36 & 68.99 & 70.59 & 72.22 & 73.85 \\
\hline 7.00 & 62.74 & 64.40 & 66.06 & 67.69 & 69.35 & 71.01 & 72.64 & 74.30 & 75.96 \\
\hline 8.00 & 64.38 & 66.06 & 67.74 & 69.40 & 71.08 & 72.76 & 74.42 & 76.10 & 77.78 \\
\hline 9.00 & 65.90 & 67.60 & 69.31 & 70.99 & 72.69 & 74.40 & 76.08 & 77.78 & 79.49 \\
\hline 10.00 & 67.23 & 68.95 & 70.68 & 72.38 & 74.11 & 75.84 & 77.54 & 79.27 & 80.99 \\
\hline 11.00 & 68.51 & 70.26 & 72.01 & 73.73 & 75.48 & 77.23 & 78.95 & 80.70 & 82.45 \\
\hline 12.00 & 69.68 & 71.45 & 73.22 & 74.97 & 76.74 & 78.51 & 80.26 & 82.03 & 83.81 \\
\hline 13.00 & 70.82 & 72.61 & 74.41 & 76.18 & 77.98 & 79.78 & 81.55 & 83.35 & 85.14 \\
\hline 14.00 & 71.87 & 73.69 & 75.51 & 77.31 & 79.13 & 80.95 & 82.75 & 84.57 & 86.39 \\
\hline 15.00 & 72.91 & 74.76 & 76.61 & 78.43 & 80.28 & 82.13 & 83.95 & 85.80 & 87.65 \\
\hline 16.00 & 73.92 & 75.79 & 77.67 & 79.52 & 81.40 & 83.28 & 85.13 & 87.01 & 88.88 \\
\hline 17.00 & 74.82 & 76.72 & 78.63 & 80.51 & 82.41 & 84.32 & 86.19 & 88.10 & 90.00 \\
\hline 18.00 & 75.75 & 77.68 & 79.62 & 81.52 & 83.46 & 85.40 & 87.30 & 89.24 & 91.17 \\
\hline 19.00 & 76.67 & 78.64 & 80.61 & 82.54 & 84.51 & 86.48 & 88.42 & 90.38 & 92.35 \\
\hline 20.00 & 77.62 & 79.62 & 81.63 & 83.60 & 85.60 & 87.60 & 89.57 & 91.58 & 93.58 \\
\hline 21.00 & 78.32 & 80.35 & 82.37 & 84.37 & 86.40 & 88.43 & 90.43 & 92.45 & 94.48 \\
\hline 22.00 & 79.10 & 81.15 & 83.21 & 85.24 & 87.30 & 89.36 & 91.39 & 93.45 & 95.51 \\
\hline 23.00 & 79.88 & 81.97 & 84.06 & 86.12 & 88.21 & 90.30 & 92.36 & 94.45 & 96.54 \\
\hline 24.00 & 80.62 & 82.74 & 84.86 & 86.95 & 89.07 & 91.19 & 93.28 & 95.40 & 97.52 \\
\hline
\end{tabular}




\section{Girls supine length vs age; edf 263}

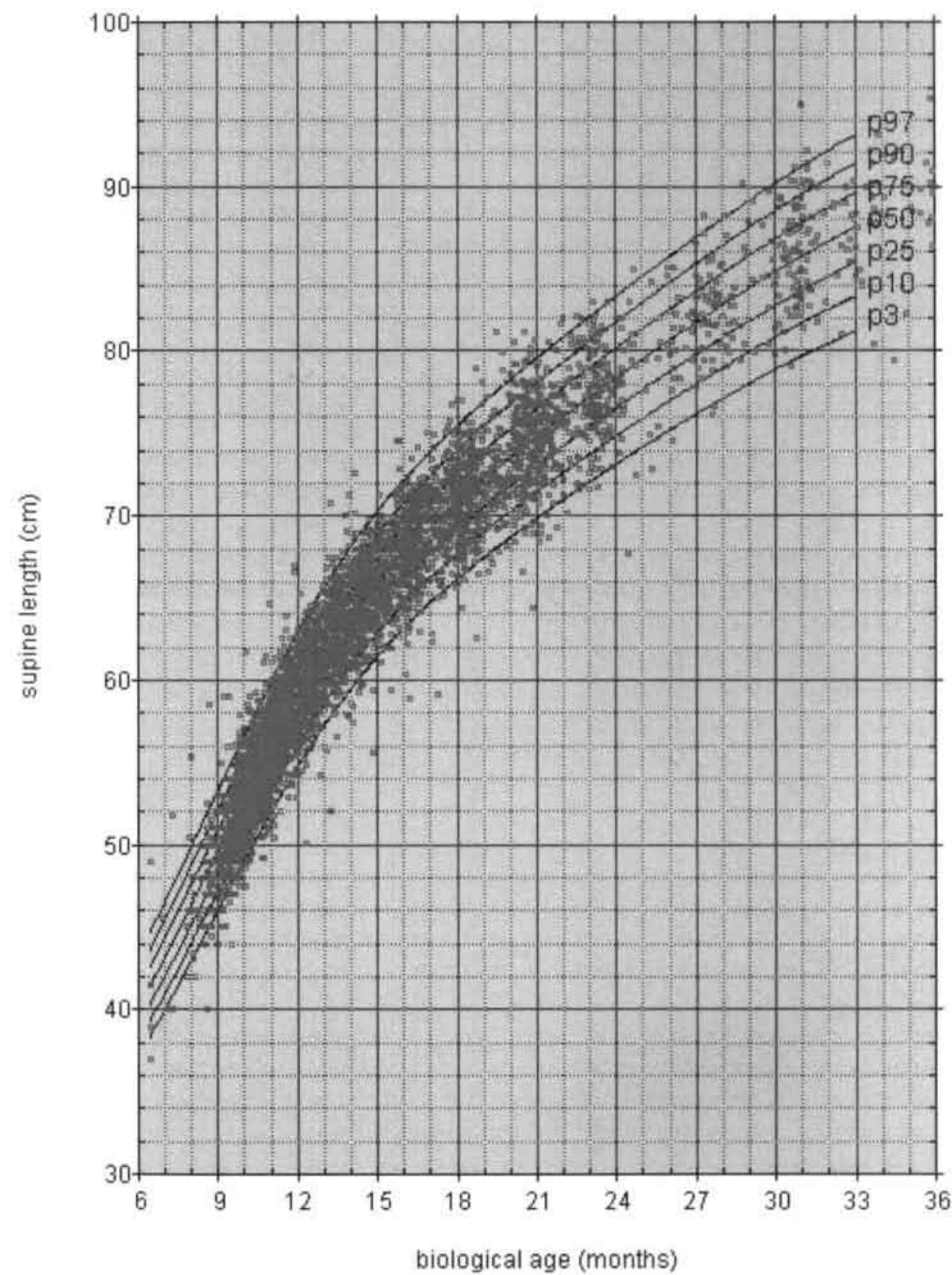


Girls supine length vs age: edf 263

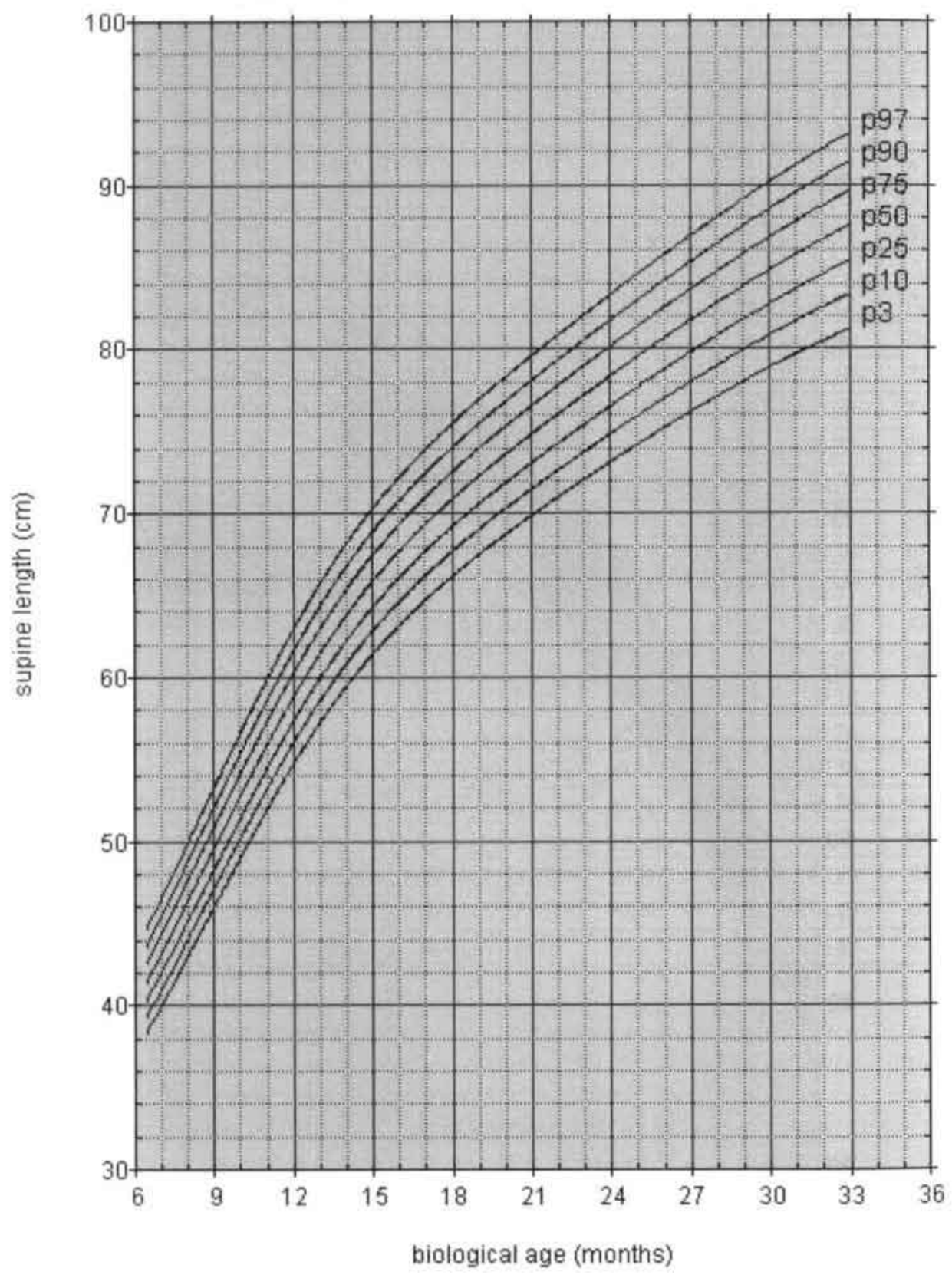


Girls supine length vs age; edf 263

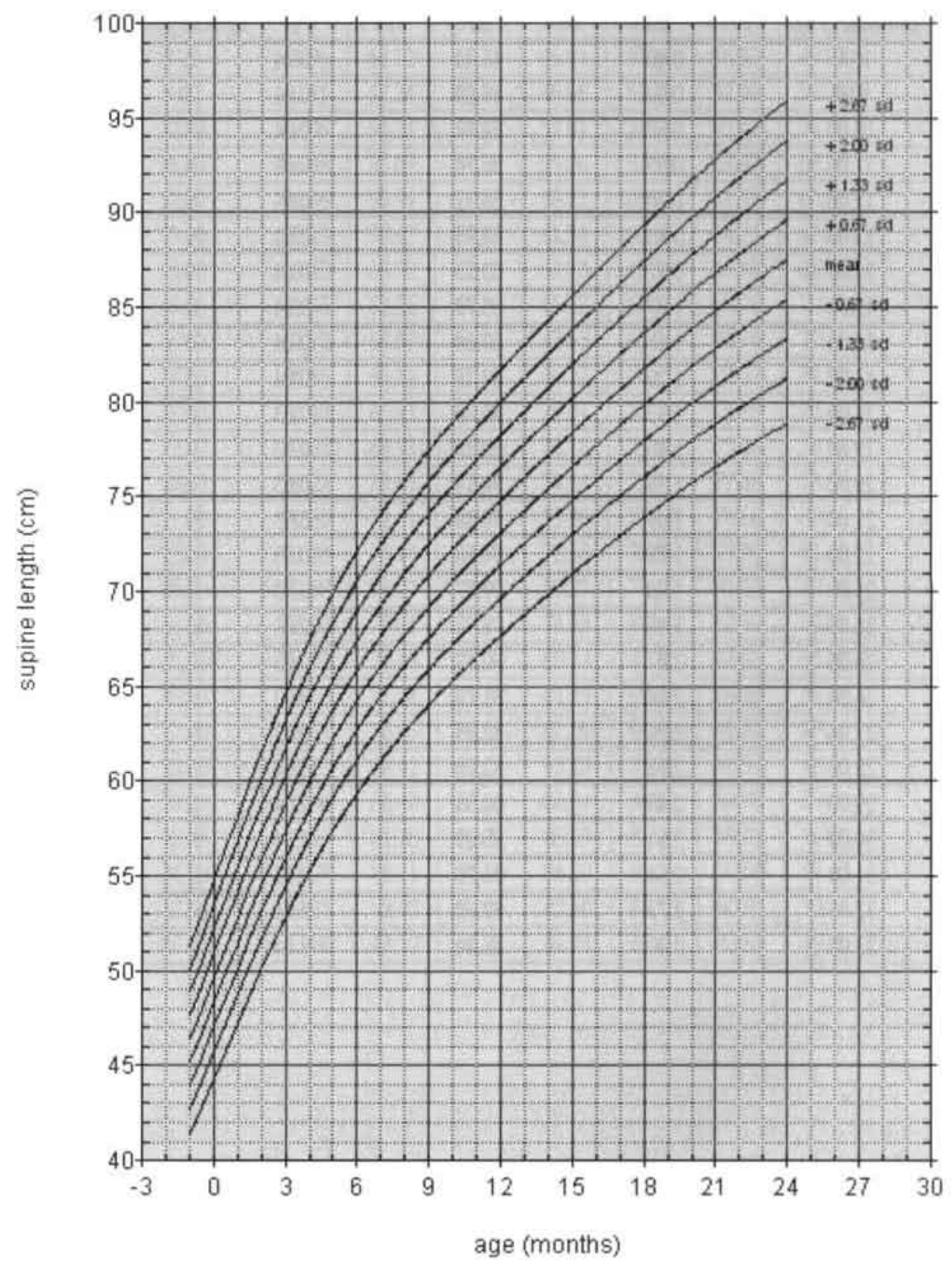




\begin{tabular}{|c|c|c|c|c|}
\hline \multicolumn{5}{|c|}{ Girls supine length LMS values (edf 263) } \\
\hline biological age & L & M & S & SD \\
\hline 8.00 & 0.40 & 46.44 & 0.04 & 1.84 \\
\hline 9.00 & 0.50 & 49.68 & 0.04 & 1.93 \\
\hline 10.00 & 0.59 & 52.81 & 0.04 & 2.02 \\
\hline 11.00 & 0.69 & 55.76 & 0.04 & 2.10 \\
\hline 12.00 & 0.78 & 58.72 & 0.04 & 2.18 \\
\hline 13.00 & 0.88 & 61.33 & 0.04 & 2.24 \\
\hline 14.00 & 0.97 & 63.73 & 0.04 & 2.30 \\
\hline 15.00 & 1.07 & 65.77 & 0.04 & 2.35 \\
\hline 16.00 & 1.16 & 67.64 & 0.04 & 2.39 \\
\hline 17.00 & 1.26 & 69.27 & 0.04 & 2.43 \\
\hline 18.00 & 1.35 & 70.80 & 0.03 & 2.47 \\
\hline 19.00 & 1.45 & 72.18 & 0.03 & 2.51 \\
\hline 20.00 & 1.59 & 74.14 & 0.03 & 2.56 \\
\hline 21.00 & 1.69 & 75.40 & 0.03 & 2.60 \\
\hline 22.00 & 1.78 & 76.58 & 0.03 & 2.64 \\
\hline 23.00 & 1.88 & 77.77 & 0.03 & 2.68 \\
\hline 24.00 & 1.98 & 78.98 & 0.03 & 2.73 \\
\hline 25.00 & 2.07 & 80.13 & 0.03 & 2.78 \\
\hline 26.00 & 2.16 & 81.15 & 0.03 & 2.82 \\
\hline 27.00 & 2.26 & 82.25 & 0.03 & 2.87 \\
\hline 28.00 & 2.35 & 83.28 & 0.04 & 2.92 \\
\hline 29.00 & 2.45 & 84.34 & 0.04 & 2.97 \\
\hline 30.00 & 2.54 & 85.29 & 0.04 & 3.02 \\
\hline 31.00 & 2.64 & 86.20 & 0.04 & 3.07 \\
\hline 32.00 & 2.73 & 87.10 & 0.04 & 3.12 \\
\hline 33.00 & 0.40 & 46.44 & 0.04 & 1.84 \\
\hline & & & & \\
\hline
\end{tabular}




\begin{tabular}{|c|c|c|c|c|c|c|c|}
\hline \multicolumn{7}{|c|}{ Girls supine length (in cm) vs biological age (in months) } \\
\hline biological age & P3 & P10 & P25 & P50 & P75 & P90 & P97 \\
\hline 8.00 & 43.06 & 44.12 & 45.21 & 46.44 & 47.69 & 48.83 & 49.97 \\
\hline 9.00 & 46.11 & 47.24 & 48.39 & 49.68 & 51.00 & 52.19 & 53.38 \\
\hline 10.00 & 49.06 & 50.24 & 51.45 & 52.81 & 54.18 & 55.42 & 56.66 \\
\hline 11.00 & 51.85 & 53.09 & 54.35 & 55.76 & 57.18 & 58.47 & 59.75 \\
\hline 12.00 & 54.66 & 55.94 & 57.25 & 58.72 & 60.19 & 61.52 & 62.85 \\
\hline 13.00 & 57.13 & 58.47 & 59.82 & 61.33 & 62.85 & 64.21 & 65.57 \\
\hline 14.00 & 59.40 & 60.78 & 62.18 & 63.73 & 65.28 & 66.68 & 68.06 \\
\hline 15.00 & 61.35 & 62.76 & 64.19 & 65.77 & 67.36 & 68.78 & 70.18 \\
\hline 16.00 & 63.12 & 64.57 & 66.03 & 67.65 & 69.26 & 70.70 & 72.12 \\
\hline 17.00 & 64.66 & 66.14 & 67.63 & 69.27 & 70.91 & 72.37 & 73.81 \\
\hline 18.00 & 66.10 & 67.61 & 69.13 & 70.81 & 72.46 & 73.95 & 75.40 \\
\hline 19.00 & 67.39 & 68.93 & 70.48 & 72.18 & 73.86 & 75.36 & 76.83 \\
\hline 20.00 & 69.23 & 70.81 & 72.40 & 74.14 & 75.86 & 77.38 & 78.87 \\
\hline 21.00 & 70.39 & 72.01 & 73.63 & 75.40 & 77.14 & 78.68 & 80.19 \\
\hline 22.00 & 71.48 & 73.14 & 74.78 & 76.58 & 78.35 & 79.91 & 81.43 \\
\hline 23.00 & 72.58 & 74.27 & 75.95 & 77.77 & 79.57 & 81.15 & 82.68 \\
\hline 24.00 & 73.68 & 75.41 & 77.12 & 78.98 & 80.80 & 82.41 & 83.96 \\
\hline 25.00 & 74.72 & 76.49 & 78.24 & 80.13 & 81.98 & 83.61 & 85.18 \\
\hline 26.00 & 75.63 & 77.44 & 79.22 & 81.15 & 83.03 & 84.67 & 86.26 \\
\hline 27.00 & 76.61 & 78.46 & 80.28 & 82.25 & 84.15 & 85.82 & 87.43 \\
\hline 28.00 & 77.53 & 79.42 & 81.28 & 83.28 & 85.22 & 86.91 & 88.54 \\
\hline 29.00 & 78.46 & 80.40 & 82.30 & 84.34 & 86.31 & 88.03 & 89.68 \\
\hline 30.00 & 79.29 & 81.28 & 83.22 & 85.29 & 87.29 & 89.03 & 90.70 \\
\hline 31.00 & 80.08 & 82.11 & 84.09 & 86.20 & 88.23 & 90.00 & 91.68 \\
\hline 32.00 & 80.85 & 82.93 & 84.95 & 87.10 & 89.16 & 90.95 & 92.66 \\
\hline 33.00 & 43.06 & 44.12 & 45.21 & 46.44 & 47.69 & 48.83 & 49.97 \\
\hline
\end{tabular}


Appendix B

\begin{tabular}{|c|c|c|c|c|c|c|c|c|c|}
\hline \multicolumn{10}{|c|}{ Girls supine length (in cm) vs age (in months) } \\
\hline age & -2.76 SD & -2.00 SD & -1.33 SD & -0.67 SD & 0 SD & +0.67 SD & +1.33 SD & +2.00 SD & +2.67 SD \\
\hline-1.00 & 41.37 & 42.76 & 44.00 & 45.21 & 46.44 & 47.67 & 48.88 & 50.12 & 51.51 \\
\hline 0.00 & 44.34 & 45.81 & 47.11 & 48.38 & 49.68 & 50.98 & 52.25 & 53.55 & 55.02 \\
\hline 1.00 & 47.23 & 48.77 & 50.12 & 51.46 & 52.81 & 54.16 & 55.50 & 56.85 & 58.39 \\
\hline 2.00 & 49.96 & 51.56 & 52.97 & 54.35 & 55.76 & 57.17 & 58.55 & 59.96 & 61.56 \\
\hline 3.00 & 52.71 & 54.36 & 55.82 & 57.26 & 58.72 & 60.18 & 61.62 & 63.08 & 64.73 \\
\hline 4.00 & 55.14 & 56.84 & 58.35 & 59.83 & 61.33 & 62.83 & 64.31 & 65.82 & 67.52 \\
\hline 5.00 & 57.38 & 59.13 & 60.67 & 62.19 & 63.73 & 65.27 & 66.79 & 68.33 & 70.08 \\
\hline 6.00 & 59.29 & 61.07 & 62.65 & 64.20 & 65.77 & 67.34 & 68.89 & 70.47 & 72.25 \\
\hline 7.00 & 61.04 & 62.85 & 64.46 & 66.04 & 67.64 & 69.24 & 70.82 & 72.43 & 74.24 \\
\hline 8.00 & 62.56 & 64.41 & 66.04 & 67.64 & 69.27 & 70.90 & 72.50 & 74.13 & 75.98 \\
\hline 9.00 & 63.98 & 65.86 & 67.51 & 69.15 & 70.80 & 72.45 & 74.09 & 75.74 & 77.62 \\
\hline 10.00 & 65.26 & 67.17 & 68.85 & 70.50 & 72.18 & 73.86 & 75.51 & 77.19 & 79.10 \\
\hline 11.00 & 67.07 & 69.02 & 70.73 & 72.42 & 74.14 & 75.86 & 77.55 & 79.26 & 81.21 \\
\hline 12.00 & 68.22 & 70.20 & 71.94 & 73.66 & 75.40 & 77.14 & 78.86 & 80.60 & 82.58 \\
\hline 13.00 & 69.29 & 71.30 & 73.07 & 74.81 & 76.58 & 78.35 & 80.09 & 81.86 & 83.87 \\
\hline 14.00 & 70.36 & 72.40 & 74.20 & 75.97 & 77.77 & 79.57 & 81.34 & 83.14 & 85.18 \\
\hline 15.00 & 71.45 & 73.52 & 75.35 & 77.15 & 78.98 & 80.81 & 82.61 & 84.44 & 86.51 \\
\hline 16.00 & 72.47 & 74.58 & 76.44 & 78.27 & 80.13 & 81.99 & 83.82 & 85.68 & 87.79 \\
\hline 17.00 & 73.37 & 75.51 & 77.40 & 79.26 & 81.15 & 83.04 & 84.90 & 86.79 & 88.93 \\
\hline 18.00 & 74.33 & 76.51 & 78.44 & 80.33 & 82.25 & 84.17 & 86.06 & 87.99 & 90.17 \\
\hline 19.00 & 75.23 & 77.45 & 79.40 & 81.33 & 83.28 & 85.23 & 87.16 & 89.11 & 91.33 \\
\hline 20.00 & 76.15 & 78.40 & 80.39 & 82.35 & 84.34 & 86.33 & 88.29 & 90.28 & 92.53 \\
\hline 21.00 & 76.96 & 79.25 & 81.28 & 83.27 & 85.29 & 87.31 & 89.30 & 91.33 & 93.62 \\
\hline 22.00 & 77.73 & 80.06 & 82.12 & 84.14 & 86.20 & 88.26 & 90.28 & 92.34 & 94.67 \\
\hline 23.00 & 78.49 & 80.86 & 82.95 & 85.01 & 87.10 & 89.19 & 91.25 & 93.34 & 95.71 \\
\hline 24.00 & 41.37 & 42.76 & 44.00 & 45.21 & 46.44 & 47.67 & 48.88 & 50.12 & 51.51 \\
\hline
\end{tabular}




\section{Weight vs age}

\begin{tabular}{|c|c|c|c|}
\hline Boys & \multicolumn{4}{|c|}{ Weight vs age } \\
\hline Edf: 4 9 3 $(4.018 .993 .00)$ & N: 5270 & Nc: 1526 \\
\hline Range & Expected & Observed & Difference \\
\hline <P3 & 185.8 & 194 & 8.2 \\
\hline P3-P10 & 433.4 & 400 & -33.4 \\
\hline P10-P25 & 928.8 & 889 & -39.8 \\
\hline P25-P 50 & 1548.0 & 1600 & 52.0 \\
\hline P50-P75 & 1548.0 & 1626 & 78.0 \\
\hline P75-P90 & 928.8 & 877 & -51.8 \\
\hline P90-P97 & 433.4 & 406 & -27.4 \\
\hline >P97 & 185.8 & 200 & 14.2 \\
\hline
\end{tabular}

\begin{tabular}{|c|c|c|c|}
\hline Girls & \multicolumn{3}{|c|}{ Weight vs age } \\
\hline Edf: 1 4 4 (1.00 4.00 4.01) & $\mathrm{N}: 5270$ & Nc: 1526 \\
\hline Range & Expected & Observed & Difference \\
\hline <P3 & 151.7 & 160 & 8.3 \\
\hline P3-P10 & 354.1 & 325 & 29.1 \\
\hline P10-P25 & 758.7 & 747 & -11.7 \\
\hline P25-P50 & 1264.5 & 1274 & 9.5 \\
\hline P50-P75 & 1264.5 & 1316 & 51.5 \\
\hline P75-P90 & 758.7 & 767 & 8.3 \\
\hline P90-P97 & 354.1 & 322 & -32.1 \\
\hline >P97 & 151.7 & 147 & -4.7 \\
\hline
\end{tabular}




\section{Comparison weight boys}

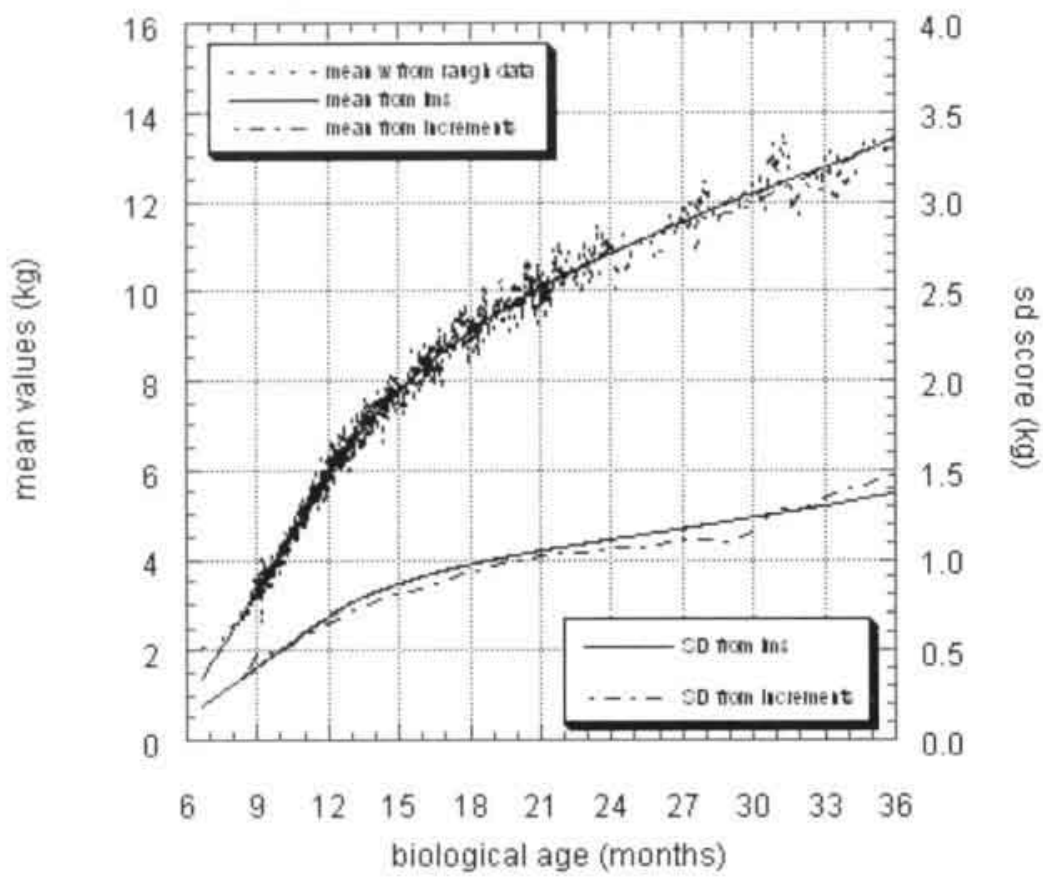

Comparison weight girls

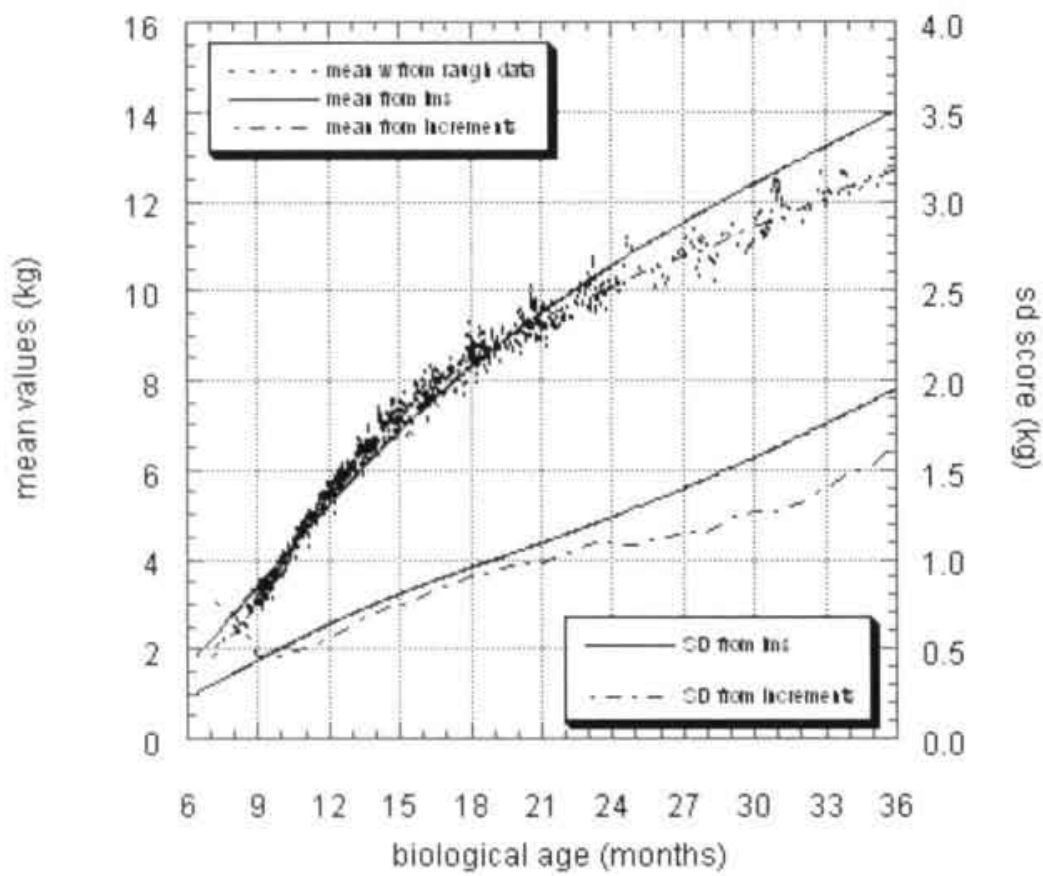


Boys weight vs age; edf 493

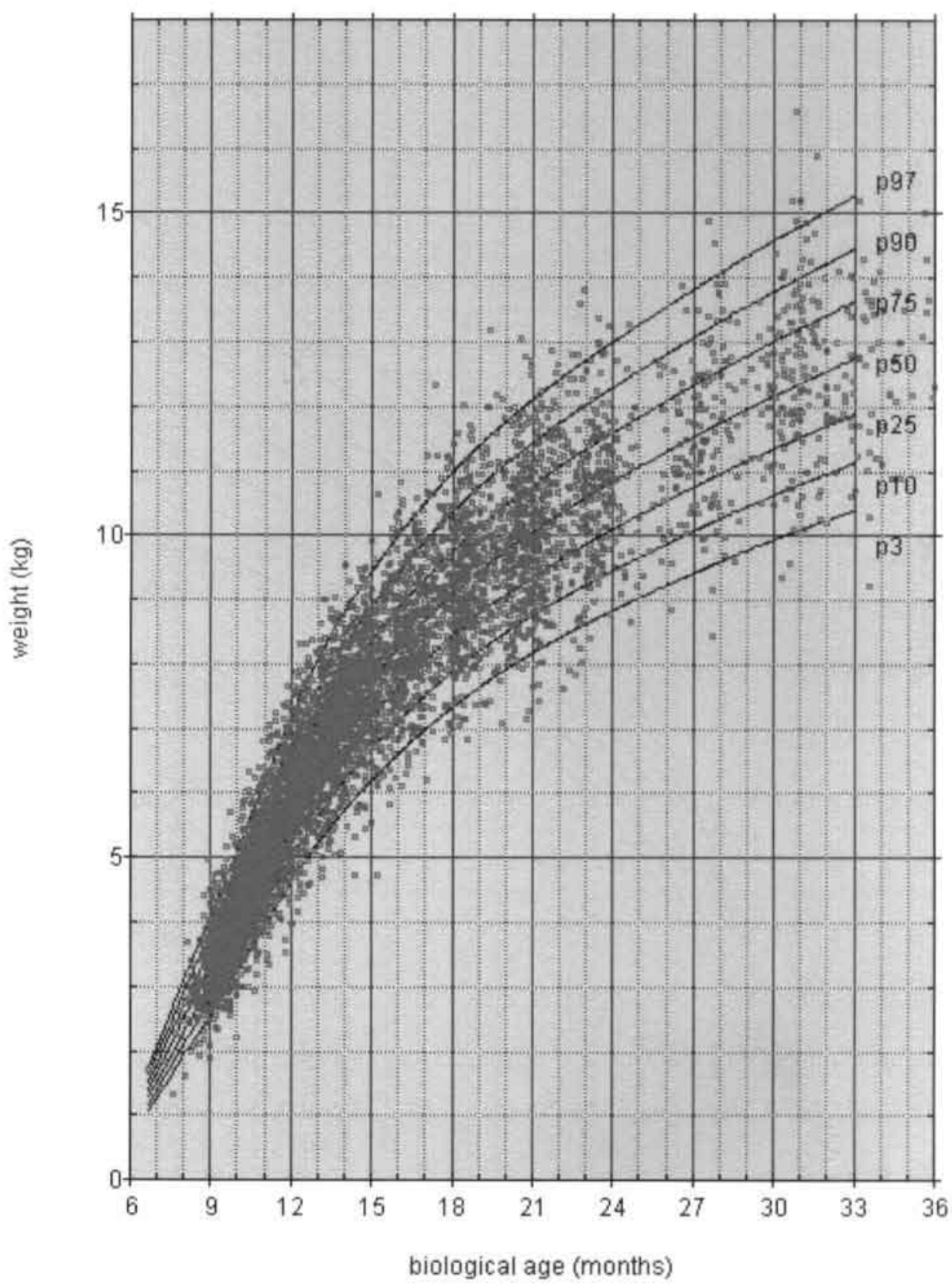




\section{Boys weight vs age; edf 493}

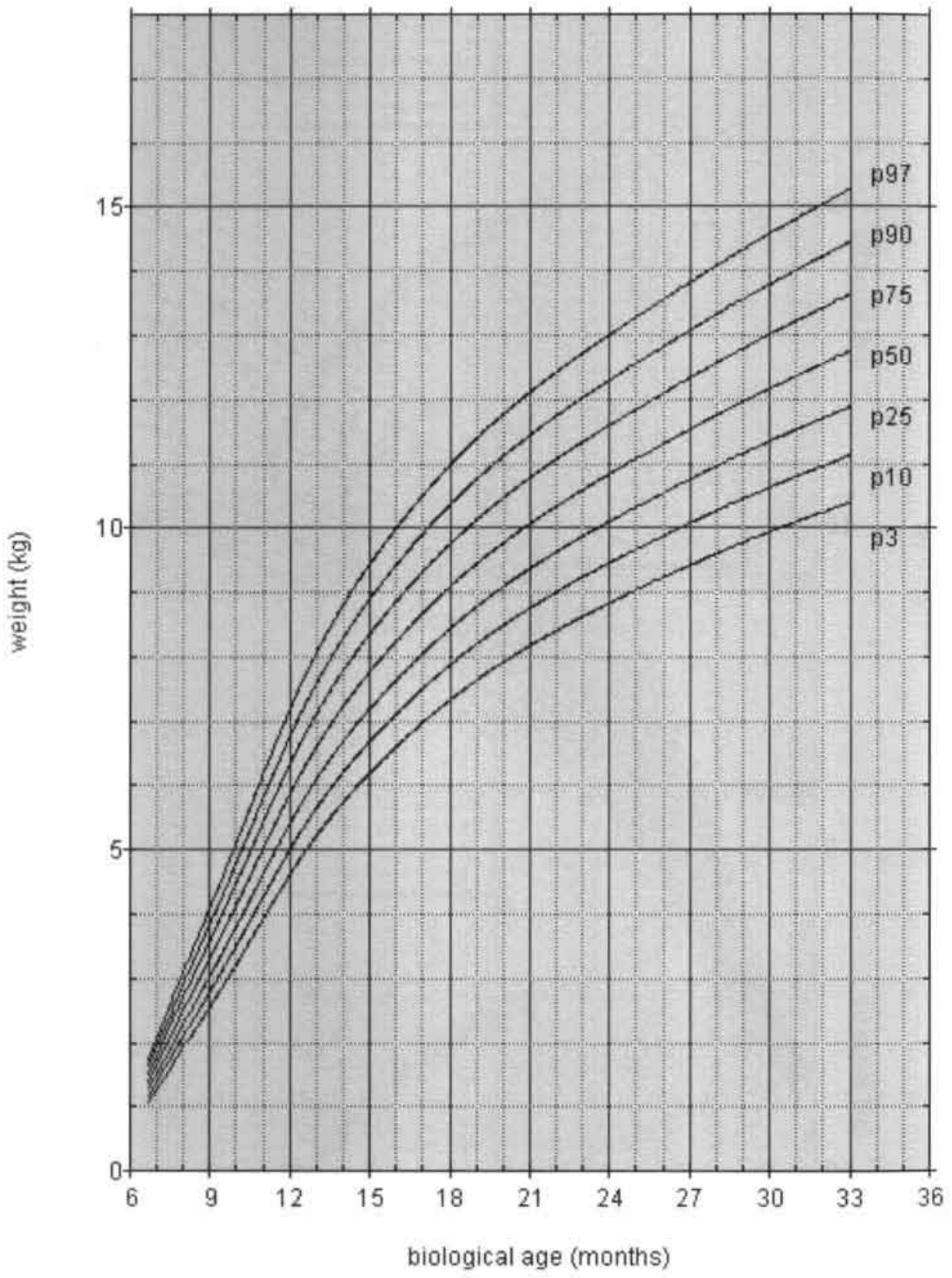




\begin{tabular}{|c|c|c|c|c|}
\hline \multicolumn{5}{|c|}{ Boys weight LMS values (edf 4 93) } \\
\hline biological age & L & M & S & SD \\
\hline 8.00 & 0.87 & 2.57 & 0.13 & 0.32 \\
\hline 9.00 & 0.84 & 3.31 & 0.12 & 0.41 \\
\hline 10.00 & 0.81 & 4.15 & 0.12 & 0.50 \\
\hline 11.00 & 0.79 & 4.98 & 0.12 & 0.59 \\
\hline 12.00 & 0.76 & 5.84 & 0.12 & 0.68 \\
\hline 13.00 & 0.74 & 6.57 & 0.12 & 0.76 \\
\hline 14.00 & 0.73 & 7.21 & 0.11 & 0.82 \\
\hline 15.00 & 0.71 & 7.75 & 0.11 & 0.86 \\
\hline 16.00 & 0.68 & 8.23 & 0.11 & 0.90 \\
\hline 17.00 & 0.66 & 8.67 & 0.11 & 0.94 \\
\hline 18.00 & 0.64 & 9.07 & 0.11 & 0.97 \\
\hline 19.00 & 0.62 & 9.43 & 0.11 & 1.00 \\
\hline 20.00 & 0.61 & 9.76 & 0.10 & 1.03 \\
\hline 21.00 & 0.60 & 10.05 & 0.10 & 1.05 \\
\hline 22.00 & 0.60 & 10.33 & 0.10 & 1.07 \\
\hline 23.00 & 0.59 & 10.59 & 0.10 & 1.09 \\
\hline 24.00 & 0.59 & 10.83 & 0.10 & 1.11 \\
\hline 25.00 & 0.59 & 11.07 & 0.10 & 1.13 \\
\hline 26.00 & 0.59 & 11.29 & 0.10 & 1.15 \\
\hline 27.00 & 0.59 & 11.52 & 0.10 & 1.17 \\
\hline 28.00 & 0.59 & 11.76 & 0.10 & 1.19 \\
\hline 29.00 & 0.59 & 11.95 & 0.10 & 1.21 \\
\hline 30.00 & 0.60 & 12.16 & 0.10 & 1.23 \\
\hline 31.00 & 0.60 & 12.36 & 0.10 & 1.25 \\
\hline 32.00 & 0.61 & 12.55 & 0.10 & 1.28 \\
\hline 33.00 & 0.61 & 12.74 & 0.10 & 1.30 \\
\hline & & & & \\
\hline
\end{tabular}




\begin{tabular}{|c|c|c|c|c|c|c|c|}
\hline \multicolumn{7}{|c|}{ Boys weight (in kg) vs biological age (in months) } \\
\hline biological age & P3 & P10 & P25 & P50 & P75 & P90 & P97 \\
\hline 8.00 & 2.16 & 2.36 & 2.57 & 2.79 & 2.99 & 3.19 & 2.16 \\
\hline 9.00 & 2.79 & 3.03 & 3.31 & 3.59 & 3.84 & 4.09 & 2.79 \\
\hline 10.00 & 3.51 & 3.81 & 4.15 & 4.49 & 4.80 & 5.12 & 3.51 \\
\hline 11.00 & 4.23 & 4.58 & 4.98 & 5.38 & 5.75 & 6.12 & 4.23 \\
\hline 12.00 & 4.98 & 5.38 & 5.84 & 6.30 & 6.73 & 7.15 & 4.98 \\
\hline 13.00 & 5.62 & 6.06 & 6.57 & 7.08 & 7.56 & 8.03 & 5.62 \\
\hline 14.00 & 6.19 & 6.67 & 7.21 & 7.77 & 8.28 & 8.79 & 6.19 \\
\hline 15.00 & 6.66 & 7.17 & 7.75 & 8.33 & 8.87 & 9.42 & 6.66 \\
\hline 16.00 & 7.10 & 7.63 & 8.23 & 8.85 & 9.42 & 9.99 & 7.10 \\
\hline 17.00 & 7.49 & 8.04 & 8.67 & 9.31 & 9.90 & 10.49 & 7.49 \\
\hline 18.00 & 7.86 & 8.43 & 9.07 & 9.74 & 10.35 & 10.97 & 7.86 \\
\hline 19.00 & 8.18 & 8.76 & 9.43 & 10.11 & 10.74 & 11.38 & 8.18 \\
\hline 20.00 & 8.48 & 9.08 & 9.76 & 10.46 & 11.11 & 11.76 & 8.48 \\
\hline 21.00 & 8.75 & 9.36 & 10.05 & 10.77 & 11.43 & 12.10 & 8.75 \\
\hline 22.00 & 9.00 & 9.62 & 10.33 & 11.06 & 11.74 & 12.42 & 9.00 \\
\hline 23.00 & 9.23 & 9.86 & 10.59 & 11.33 & 12.02 & 12.72 & 9.23 \\
\hline 24.00 & 9.45 & 10.10 & 10.84 & 11.59 & 12.29 & 13.00 & 9.45 \\
\hline 25.00 & 9.67 & 10.32 & 11.07 & 11.85 & 12.56 & 13.28 & 9.67 \\
\hline 26.00 & 9.86 & 10.53 & 11.29 & 12.08 & 12.80 & 13.54 & 9.86 \\
\hline 27.00 & 10.06 & 10.75 & 11.52 & 12.32 & 13.06 & 13.81 & 10.06 \\
\hline 28.00 & 10.27 & 10.96 & 11.76 & 12.57 & 13.32 & 14.08 & 10.27 \\
\hline 29.00 & 10.44 & 11.15 & 11.95 & 12.78 & 13.54 & 14.32 & 10.44 \\
\hline 30.00 & 10.63 & 11.34 & 12.17 & 13.01 & 13.79 & 14.57 & 10.63 \\
\hline 31.00 & 10.79 & 11.52 & 12.36 & 13.22 & 14.01 & 14.80 & 10.79 \\
\hline 32.00 & 10.96 & 11.70 & 12.55 & 13.42 & 14.23 & 15.04 & 10.96 \\
\hline 33.00 & 11.12 & 11.88 & 12.74 & 13.63 & 14.44 & 15.27 & 11.12 \\
\hline & & & & & & & \\
\hline
\end{tabular}


Boys weight (in $\mathrm{kg}$ ) vs age (in months)

\begin{tabular}{|c|c|c|c|c|c|c|c|c|c|}
\hline age & $-2.76 \mathrm{SD}$ & $-2.00 \mathrm{SD}$ & $-1.33 \mathrm{SD}$ & $-0.67 \mathrm{SD}$ & $0 \mathrm{SD}$ & $+0.67 \mathrm{SD}$ & $+1.33 \mathrm{SD}$ & $+2.00 \mathrm{SD}$ & $+2.67 \mathrm{SD}$ \\
\hline-1.00 & 1.70 & 1.92 & 2.14 & 2.35 & 2.57 & 2.79 & 3.00 & 3.22 & 3.44 \\
\hline 0.00 & 2.22 & 2.49 & 2.77 & 3.04 & 3.31 & 3.58 & 3.85 & 4.13 & 4.40 \\
\hline 1.00 & 2.80 & 3.14 & 3.48 & 3.81 & 4.15 & 4.49 & 4.82 & 5.16 & 5.50 \\
\hline 2.00 & 3.39 & 3.79 & 4.19 & 4.58 & 4.98 & 5.38 & 5.77 & 6.17 & 6.57 \\
\hline 3.00 & 4.01 & 4.47 & 4.93 & 5.38 & 5.84 & 6.30 & 6.75 & 7.21 & 7.67 \\
\hline 4.00 & 4.55 & 5.06 & 5.56 & 6.06 & 6.57 & 7.08 & 7.58 & 8.08 & 8.59 \\
\hline 5.00 & 5.03 & 5.58 & 6.12 & 6.66 & 7.21 & 7.76 & 8.30 & 8.84 & 9.39 \\
\hline 6.00 & 5.45 & 6.02 & 6.60 & 7.17 & 7.75 & 8.33 & 8.90 & 9.48 & 10.05 \\
\hline 7.00 & 5.82 & 6.42 & 7.03 & 7.62 & 8.23 & 8.84 & 9.43 & 10.04 & 10.64 \\
\hline 8.00 & 6.16 & 6.79 & 7.42 & 8.04 & 8.67 & 9.30 & 9.92 & 10.55 & 11.18 \\
\hline 9.00 & 6.48 & 7.13 & 7.78 & 8.42 & 9.07 & 9.72 & 10.36 & 11.01 & 11.66 \\
\hline 10.00 & 6.76 & 7.43 & 8.10 & 8.76 & 9.43 & 10.10 & 10.76 & 11.43 & 12.10 \\
\hline 11.00 & 7.02 & 7.71 & 8.40 & 9.07 & 9.76 & 10.45 & 11.12 & 11.81 & 12.50 \\
\hline 12.00 & 7.25 & 7.96 & 8.66 & 9.35 & 10.05 & 10.75 & 11.44 & 12.14 & 12.85 \\
\hline 13.00 & 7.48 & 8.19 & 8.91 & 9.61 & 10.33 & 11.05 & 11.75 & 12.47 & 13.18 \\
\hline 14.00 & 7.68 & 8.41 & 9.14 & 9.86 & 10.59 & 11.32 & 12.04 & 12.77 & 13.50 \\
\hline 15.00 & 7.87 & 8.61 & 9.36 & 10.09 & 10.83 & 11.57 & 12.31 & 13.05 & 13.79 \\
\hline 16.00 & 8.05 & 8.81 & 9.57 & 10.31 & 11.07 & 11.83 & 12.57 & 13.33 & 14.09 \\
\hline 17.00 & 8.22 & 8.99 & 9.76 & 10.52 & 11.29 & 12.06 & 12.82 & 13.59 & 14.36 \\
\hline 18.00 & 8.40 & 9.18 & 9.96 & 10.74 & 11.52 & 12.30 & 13.08 & 13.86 & 14.64 \\
\hline 19.00 & 8.58 & 9.38 & 10.18 & 10.96 & 11.76 & 12.56 & 13.35 & 14.14 & 14.94 \\
\hline 20.00 & 8.71 & 9.53 & 10.34 & 11.14 & 11.95 & 12.76 & 13.56 & 14.37 & 15.19 \\
\hline 21.00 & 8.87 & 9.69 & 10.52 & 11.33 & 12.16 & 12.99 & 13.80 & 14.63 & 15.45 \\
\hline 22.00 & 9.01 & 9.85 & 10.69 & 11.52 & 12.36 & 13.20 & 14.03 & 14.87 & 15.71 \\
\hline 23.00 & 9.15 & 10.00 & 10.85 & 11.70 & 12.55 & 13.40 & 14.25 & 15.10 & 15.95 \\
\hline 24.00 & 9.28 & 10.15 & 11.02 & 11.87 & 12.74 & 13.61 & 14.46 & 15.33 & 16.20 \\
\hline
\end{tabular}


Girls weight vs age; edf 144

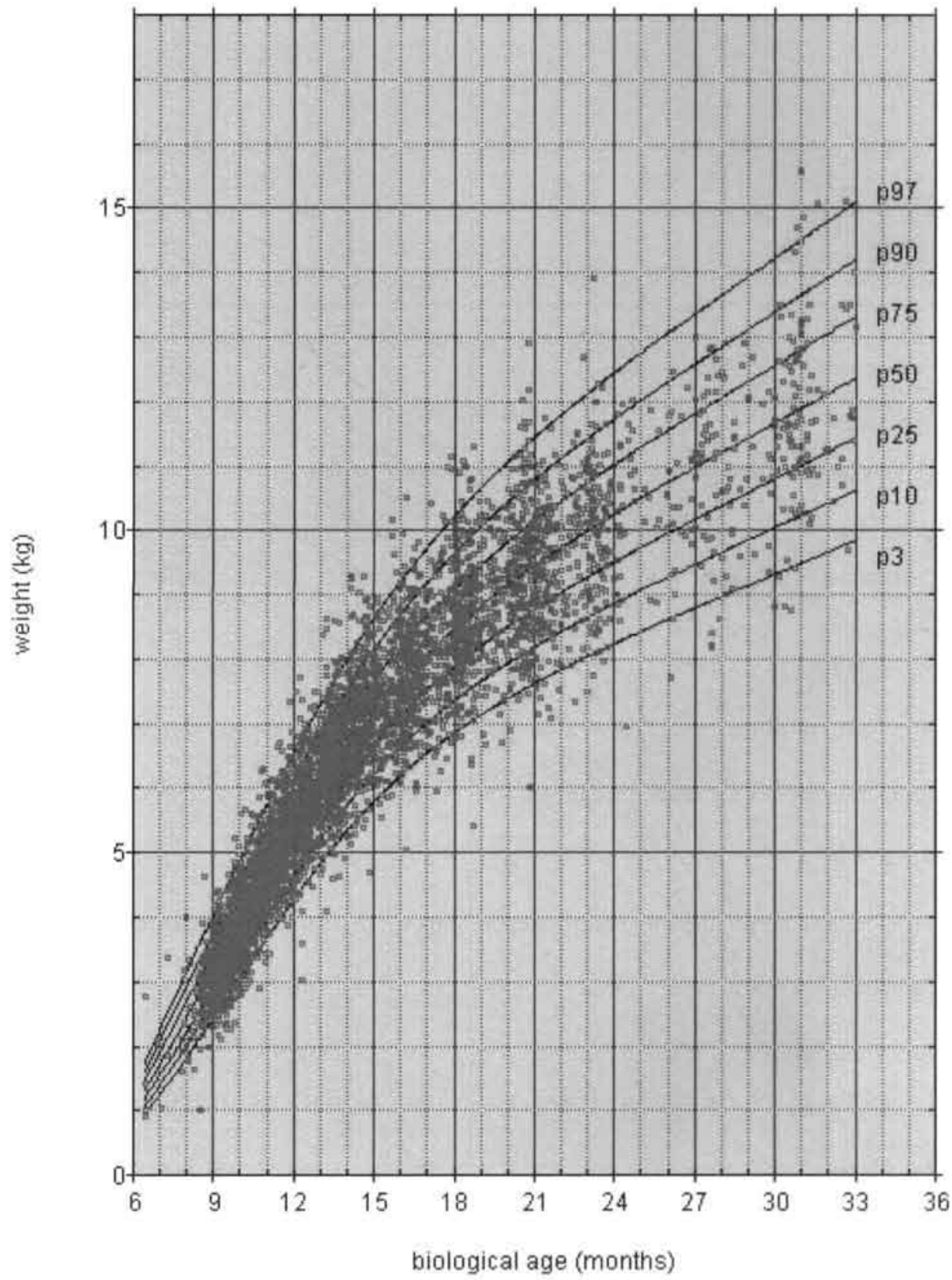


Girls weight vs age: edf 144

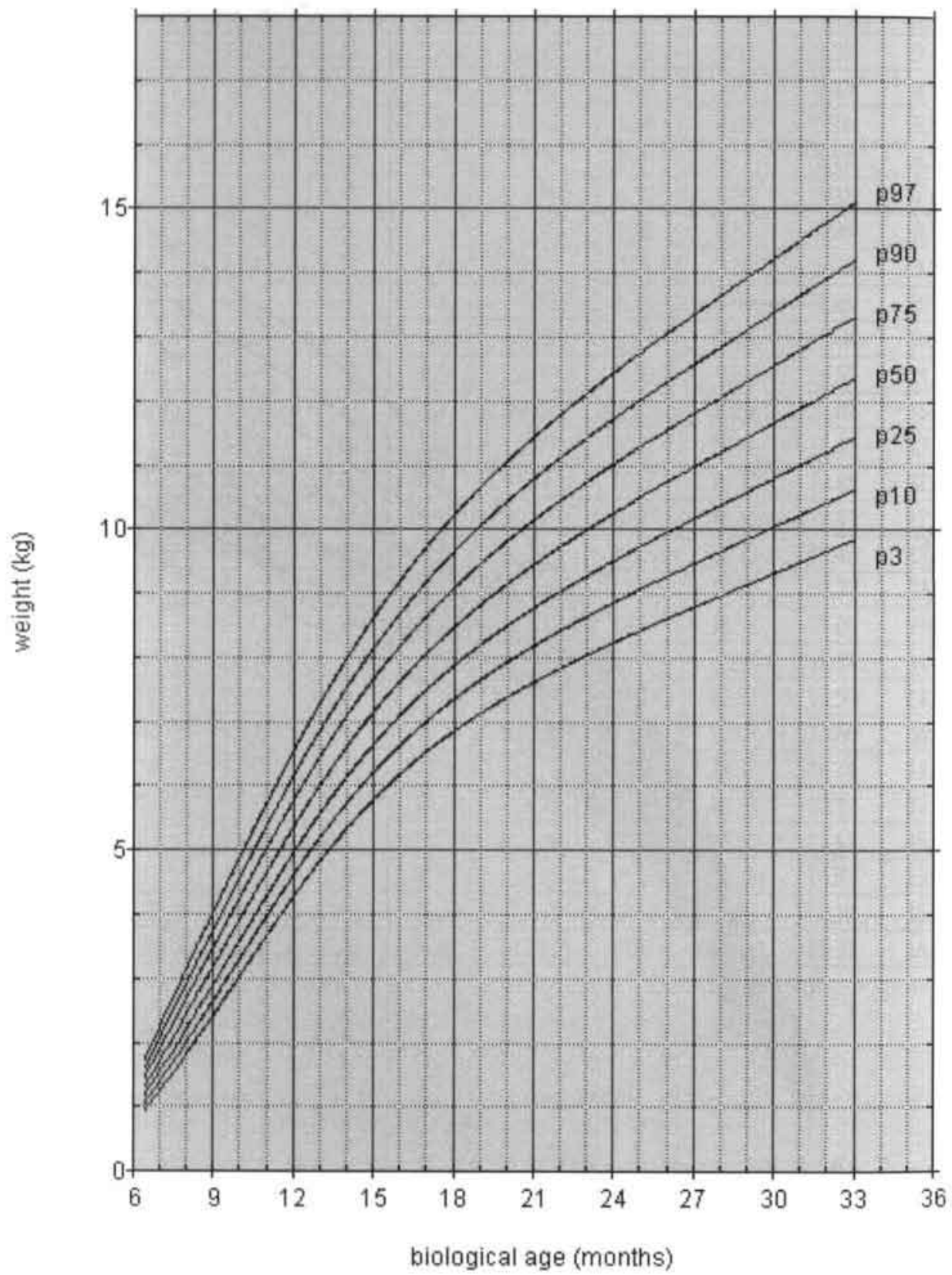


Growth Charts en Tables

Girls weight vs age; edf 144

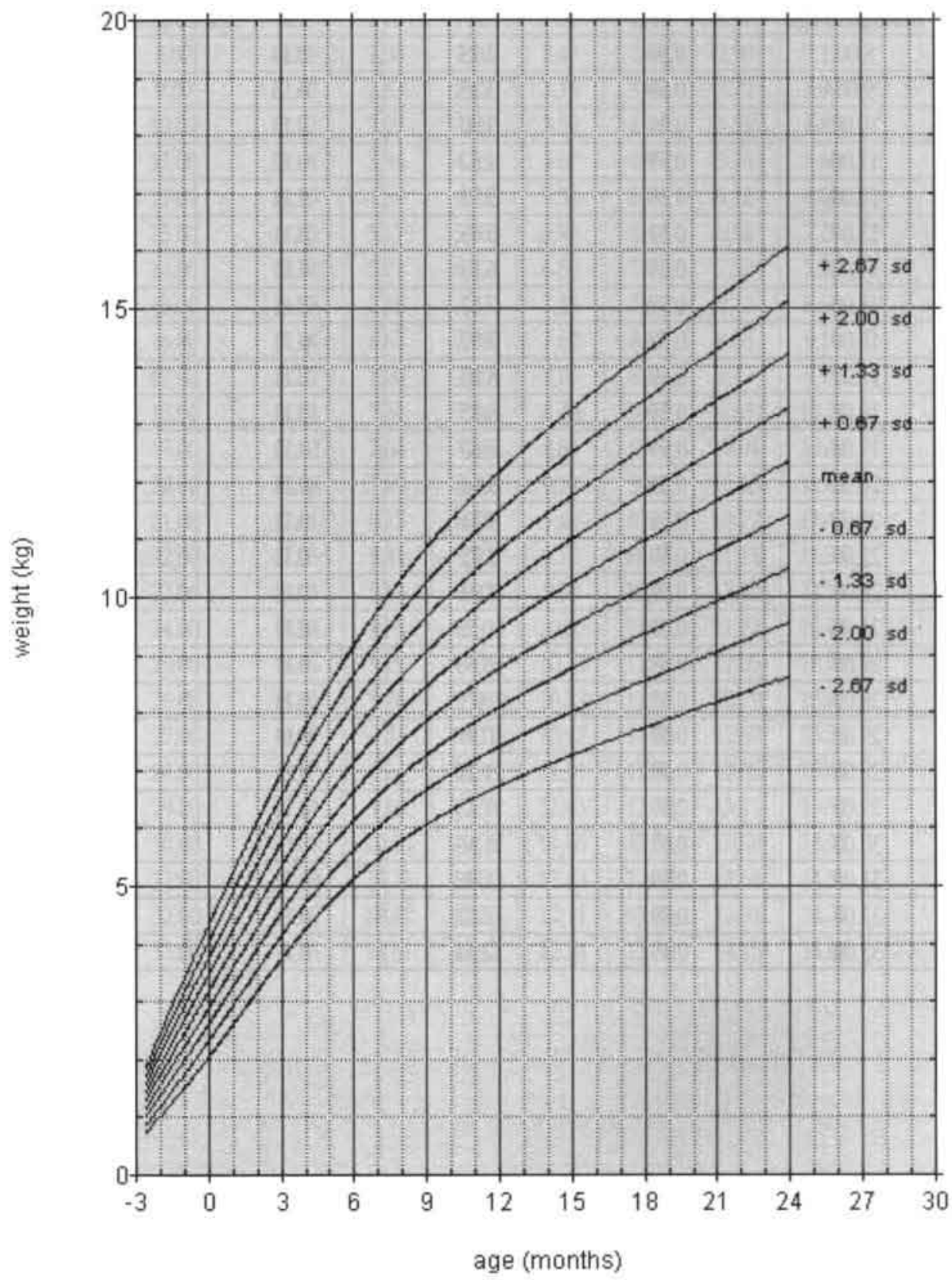




\begin{tabular}{|c|c|c|c|c|}
\hline \multicolumn{5}{|c|}{ Girls weight LMS values (edf 144) } \\
\hline biological age & L & M & S & SD \\
\hline 8.00 & 0.59 & 2.43 & 0.14 & 0.35 \\
\hline 9.00 & 0.59 & 3.15 & 0.13 & 0.43 \\
\hline 10.00 & 0.59 & 3.90 & 0.13 & 0.49 \\
\hline 11.00 & 0.59 & 4.62 & 0.12 & 0.55 \\
\hline 12.00 & 0.59 & 5.33 & 0.11 & 0.60 \\
\hline 13.00 & 0.59 & 5.98 & 0.11 & 0.65 \\
\hline 14.00 & 0.59 & 6.59 & 0.11 & 0.71 \\
\hline 15.00 & 0.59 & 7.13 & 0.11 & 0.75 \\
\hline 16.00 & 0.59 & 7.62 & 0.11 & 0.80 \\
\hline 17.00 & 0.59 & 8.05 & 0.11 & 0.85 \\
\hline 18.00 & 0.59 & 8.45 & 0.11 & 0.89 \\
\hline 19.00 & 0.59 & 8.80 & 0.11 & 0.94 \\
\hline 20.00 & 0.59 & 9.14 & 0.11 & 0.98 \\
\hline 21.00 & 0.59 & 9.44 & 0.11 & 1.02 \\
\hline 22.00 & 0.59 & 9.72 & 0.11 & 1.05 \\
\hline 23.00 & 0.59 & 9.99 & 0.11 & 1.09 \\
\hline 24.00 & 0.59 & 10.25 & 0.11 & 1.12 \\
\hline 25.00 & 0.59 & 10.53 & 0.11 & 1.16 \\
\hline 26.00 & 0.59 & 10.73 & 0.11 & 1.18 \\
\hline 27.00 & 0.59 & 10.97 & 0.11 & 1.21 \\
\hline 28.00 & 0.59 & 11.21 & 0.11 & 1.24 \\
\hline 29.00 & 0.59 & 11.43 & 0.11 & 1.27 \\
\hline 30.00 & 0.59 & 11.66 & 0.11 & 1.30 \\
\hline 31.00 & 0.59 & 11.88 & 0.11 & 1.33 \\
\hline 32.00 & 0.59 & 12.11 & 0.11 & 1.36 \\
\hline 33.00 & 0.59 & 12.34 & 0.11 & 1.40 \\
\hline
\end{tabular}




\begin{tabular}{|c|c|c|c|c|c|c|c|}
\hline \multicolumn{7}{|c|}{ Girls weight (in kg) vs biological age (in months) } \\
\hline biological age & P3 & P10 & P25 & P50 & P75 & P90 & P97 \\
\hline 8.00 & 1.81 & 2.00 & 2.20 & 2.43 & 2.68 & 2.90 & 3.13 \\
\hline 9.00 & 2.40 & 2.63 & 2.87 & 3.15 & 3.45 & 3.72 & 3.99 \\
\hline 10.00 & 3.02 & 3.29 & 3.58 & 3.90 & 4.24 & 4.55 & 4.87 \\
\hline 11.00 & 3.64 & 3.94 & 4.25 & 4.62 & 4.99 & 5.34 & 5.69 \\
\hline 12.00 & 4.25 & 4.58 & 4.93 & 5.33 & 5.74 & 6.12 & 6.51 \\
\hline 13.00 & 4.80 & 5.17 & 5.55 & 5.98 & 6.43 & 6.84 & 7.26 \\
\hline 14.00 & 5.32 & 5.71 & 6.12 & 6.59 & 7.07 & 7.52 & 7.97 \\
\hline 15.00 & 5.77 & 6.19 & 6.63 & 7.13 & 7.64 & 8.12 & 8.60 \\
\hline 16.00 & 6.18 & 6.62 & 7.09 & 7.62 & 8.17 & 8.68 & 9.19 \\
\hline 17.00 & 6.52 & 7.00 & 7.49 & 8.05 & 8.63 & 9.17 & 9.71 \\
\hline 18.00 & 6.84 & 7.34 & 7.86 & 8.45 & 9.07 & 9.63 & 10.20 \\
\hline 19.00 & 7.12 & 7.64 & 8.18 & 8.81 & 9.45 & 10.04 & 10.64 \\
\hline 20.00 & 7.38 & 7.92 & 8.49 & 9.14 & 9.81 & 10.43 & 11.05 \\
\hline 21.00 & 7.61 & 8.17 & 8.76 & 9.44 & 10.13 & 10.77 & 11.42 \\
\hline 22.00 & 7.83 & 8.41 & 9.02 & 9.72 & 10.44 & 11.11 & 11.78 \\
\hline 23.00 & 8.03 & 8.64 & 9.27 & 9.99 & 10.73 & 11.42 & 12.11 \\
\hline 24.00 & 8.23 & 8.86 & 9.50 & 10.25 & 11.01 & 11.72 & 12.44 \\
\hline 25.00 & 8.45 & 9.09 & 9.76 & 10.53 & 11.32 & 12.05 & 12.79 \\
\hline 26.00 & 8.61 & 9.26 & 9.95 & 10.73 & 11.54 & 12.29 & 13.05 \\
\hline 27.00 & 8.79 & 9.46 & 10.17 & 10.97 & 11.80 & 12.57 & 13.35 \\
\hline 28.00 & 8.97 & 9.66 & 10.38 & 11.21 & 12.06 & 12.85 & 13.65 \\
\hline 29.00 & 9.14 & 9.84 & 10.58 & 11.43 & 12.30 & 13.11 & 13.92 \\
\hline 30.00 & 9.31 & 10.04 & 10.79 & 11.66 & 12.55 & 13.38 & 14.22 \\
\hline 31.00 & 9.49 & 10.23 & 11.00 & 11.88 & 12.80 & 13.64 & 14.50 \\
\hline 32.00 & 9.66 & 10.41 & 11.20 & 12.11 & 13.04 & 13.91 & 14.78 \\
\hline 33.00 & 9.83 & 10.61 & 11.42 & 12.34 & 13.30 & 14.18 & 15.08 \\
\hline & & & & & & & \\
\hline
\end{tabular}


Girls weight (in kg) vs age (in months)

\begin{tabular}{|c|c|c|c|c|c|c|c|c|c|}
\hline age & $-2.76 \mathrm{SD}$ & $-2.00 \mathrm{SD}$ & $-1.33 \mathrm{SD}$ & $-0.67 \mathrm{SD}$ & 0 SD & $+0.67 \mathrm{SD}$ & $+1.33 \mathrm{SD}$ & $+2.00 \mathrm{SD}$ & $+2.67 \mathrm{SD}$ \\
\hline-1.00 & 1.49 & 1.73 & 1.96 & 2.19 & 2.43 & 2.67 & 2.90 & 3.13 & 3.37 \\
\hline 0.00 & 2.02 & 2.30 & 2.58 & 2.87 & 3.15 & 3.43 & 3.72 & 4.00 & 4.28 \\
\hline 1.00 & 2.59 & 2.92 & 3.25 & 3.57 & 3.90 & 4.23 & 4.55 & 4.88 & 5.21 \\
\hline 2.00 & 3.16 & 3.53 & 3.89 & 4.25 & 4.62 & 4.99 & 5.35 & 5.71 & 6.08 \\
\hline 3.00 & 3.73 & 4.13 & 4.53 & 4.93 & 5.33 & 5.73 & 6.13 & 6.53 & 6.93 \\
\hline 4.00 & 4.24 & 4.67 & 5.11 & 5.54 & 5.98 & 6.42 & 6.85 & 7.29 & 7.72 \\
\hline 5.00 & 4.71 & 5.18 & 5.65 & 6.12 & 6.59 & 7.06 & 7.53 & 8.00 & 8.47 \\
\hline 6.00 & 5.12 & 5.62 & 6.13 & 6.63 & 7.13 & 7.63 & 8.13 & 8.64 & 9.14 \\
\hline 7.00 & 5.48 & 6.02 & 6.55 & 7.08 & 7.62 & 8.16 & 8.69 & 9.22 & 9.76 \\
\hline 8.00 & 5.79 & 6.35 & 6.92 & 7.48 & 8.05 & 8.62 & 9.18 & 9.75 & 10.31 \\
\hline 9.00 & 6.06 & 6.66 & 7.26 & 7.85 & 8.45 & 9.05 & 9.64 & 10.24 & 10.84 \\
\hline 10.00 & 6.30 & 6.93 & 7.56 & 8.17 & 8.80 & 9.43 & 10.05 & 10.67 & 11.30 \\
\hline 11.00 & 6.53 & 7.19 & 7.84 & 8.49 & 9.14 & 9.79 & 10.44 & 11.09 & 11.75 \\
\hline 12.00 & 6.73 & 7.41 & 8.09 & 8.76 & 9.44 & 10.12 & 10.79 & 11.47 & 12.15 \\
\hline 13.00 & 6.91 & 7.62 & 8.32 & 9.02 & 9.72 & 10.42 & 11.12 & 11.82 & 12.53 \\
\hline 14.00 & 7.09 & 7.82 & 8.55 & 9.26 & 9.99 & 10.72 & 11.43 & 12.16 & 12.89 \\
\hline 15.00 & 7.26 & 8.01 & 8.76 & 9.50 & 10.25 & 11.00 & 11.74 & 12.49 & 13.24 \\
\hline 16.00 & 7.45 & 8.22 & 8.99 & 9.76 & 10.53 & 11.30 & 12.07 & 12.84 & 13.61 \\
\hline 17.00 & 7.57 & 8.37 & 9.16 & 9.94 & 10.73 & 11.52 & 12.30 & 13.09 & 13.89 \\
\hline 18.00 & 7.73 & 8.54 & 9.36 & 10.16 & 10.97 & 11.78 & 12.58 & 13.40 & 14.21 \\
\hline 19.00 & 7.89 & 8.72 & 9.56 & 10.38 & 11.21 & 12.04 & 12.87 & 13.70 & 14.53 \\
\hline 20.00 & 8.03 & 8.88 & 9.74 & 10.58 & 11.43 & 12.28 & 13.12 & 13.98 & 14.83 \\
\hline 21.00 & 8.18 & 9.05 & 9.93 & 10.79 & 11.66 & 12.53 & 13.39 & 14.27 & 15.14 \\
\hline 22.00 & 8.32 & 9.21 & 10.11 & 10.99 & 11.88 & 12.77 & 13.65 & 14.55 & 15.44 \\
\hline 23.00 & 8.47 & 9.38 & 10.30 & 11.20 & 12.11 & 13.02 & 13.92 & 14.84 & 15.75 \\
\hline 24.00 & 8.62 & 9.55 & 10.49 & 11.41 & 12.34 & 13.28 & 14.20 & 15.13 & 16.07 \\
\hline & & & & & & & & & \\
\hline
\end{tabular}




\section{Head circumference vs age}

\begin{tabular}{|c|c|c|c|}
\hline Boys & \multicolumn{4}{|c|}{ Head circumference vs age } \\
\hline Edf: 373 3 & $(3.006 .99$ 3.00) & N: 5271 & Nc: 1605 \\
\hline Range & Expected & Observed & Difference \\
\hline <P3 & 171.6 & 163 & -8.6 \\
\hline P3-P10 & 400.5 & 395 & -5.5 \\
\hline P10 - P25 & 858.2 & 892 & 33.8 \\
\hline P25 - P 50 & 1430.2 & 1401 & -29.2 \\
\hline P50 - P75 & 1430.2 & 1465 & 34.8 \\
\hline P75 - P90 & 858.2 & 823 & -35.2 \\
\hline P90 - P97 & 400.5 & 406 & 5.5 \\
\hline > P97 & 171.6 & 176 & 4.4 \\
\hline
\end{tabular}

\begin{tabular}{|c|c|c|c|}
\hline Girls & \multicolumn{4}{|c|}{ Head circumference vs age } \\
\hline Edf: 273 (2.00 7.01 3.00) & $\mathrm{N}: 4910$ & Nc: 1469 \\
\hline Range & Expected & Observed & Difference \\
\hline < P3 & 147.3 & 130 & -17.3 \\
\hline P3-P10 & 343.7 & 307 & -36.7 \\
\hline P10 - P25 & 736.5 & 730 & -6.5 \\
\hline P25 - P 50 & 1227.5 & 1315 & 87.5 \\
\hline P50 - P75 & 1227.5 & 1293 & 65.5 \\
\hline P75 - P90 & 736.5 & 690 & -46.5 \\
\hline P90 - P97 & 343.7 & 289 & -54.7 \\
\hline > P97 & 147.3 & 156 & 8.7 \\
\hline
\end{tabular}




\section{Comparison head-circumference boys}
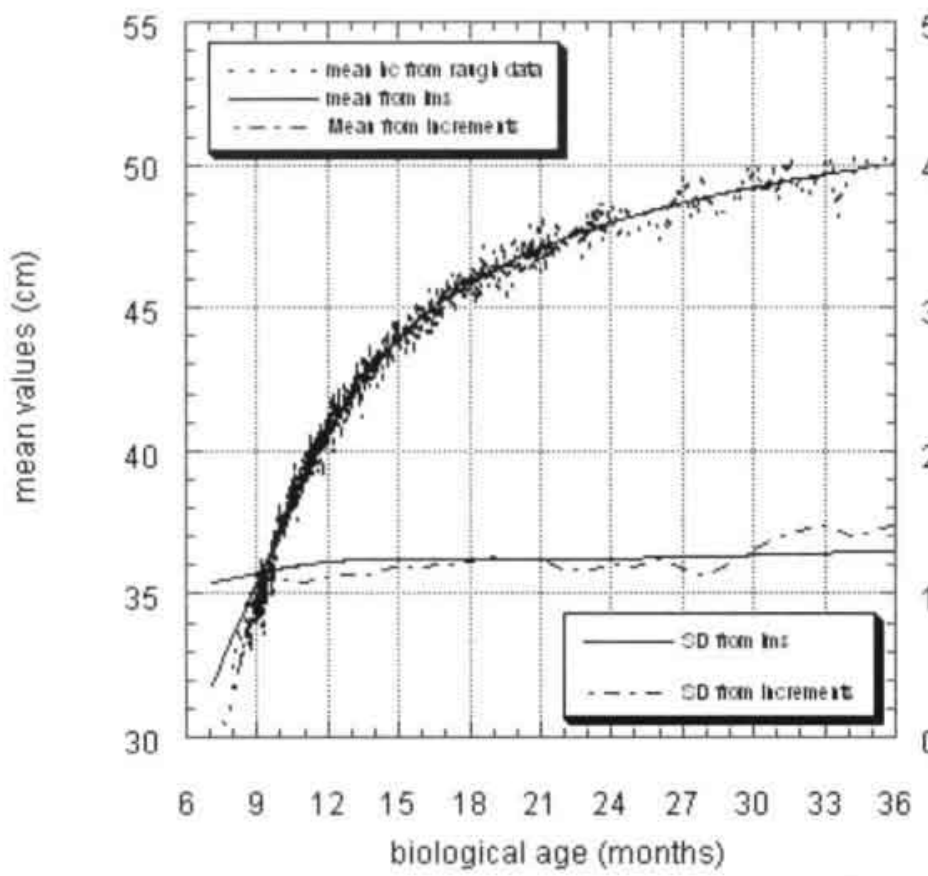

Comparison head-circumference girls

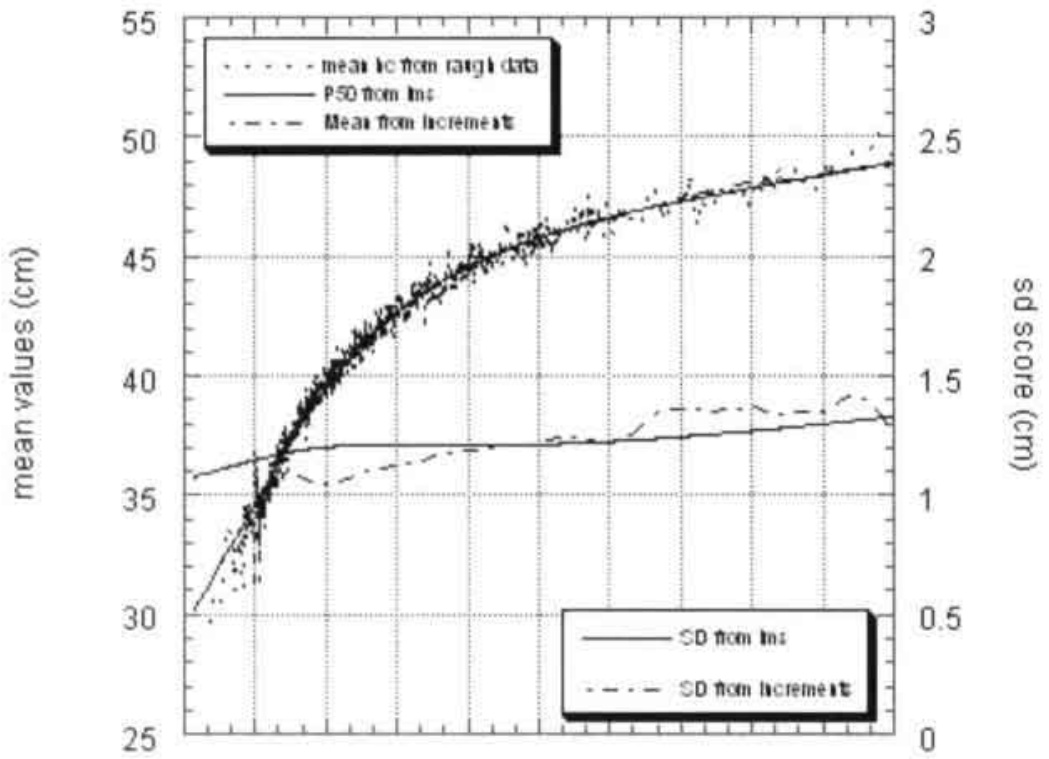
69
1215

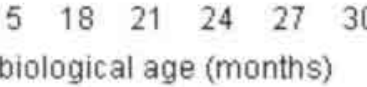
3336 


\section{Boys head-circumference vs age; edf 373}

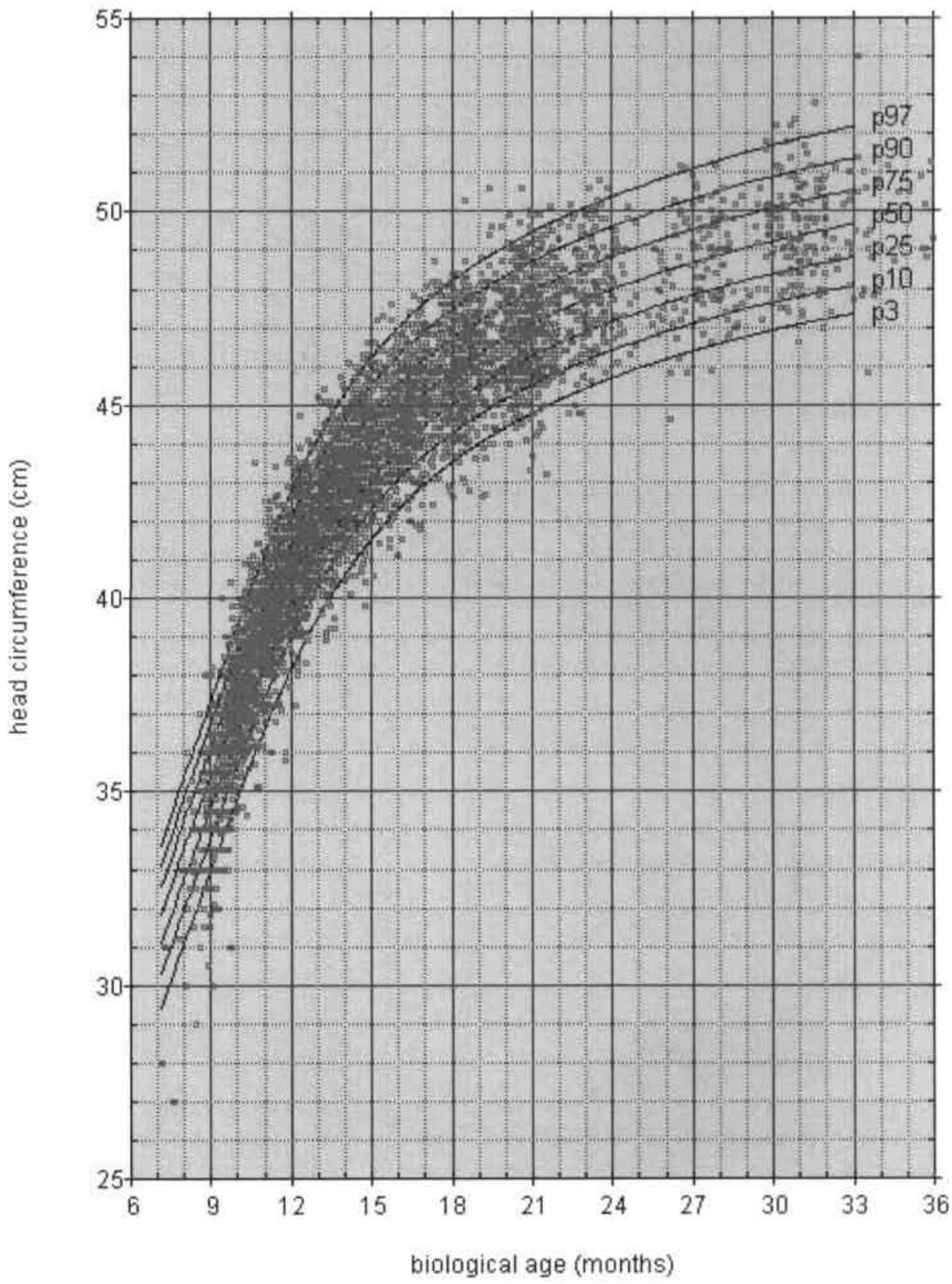


Boys head-circumference vs age; edf 373

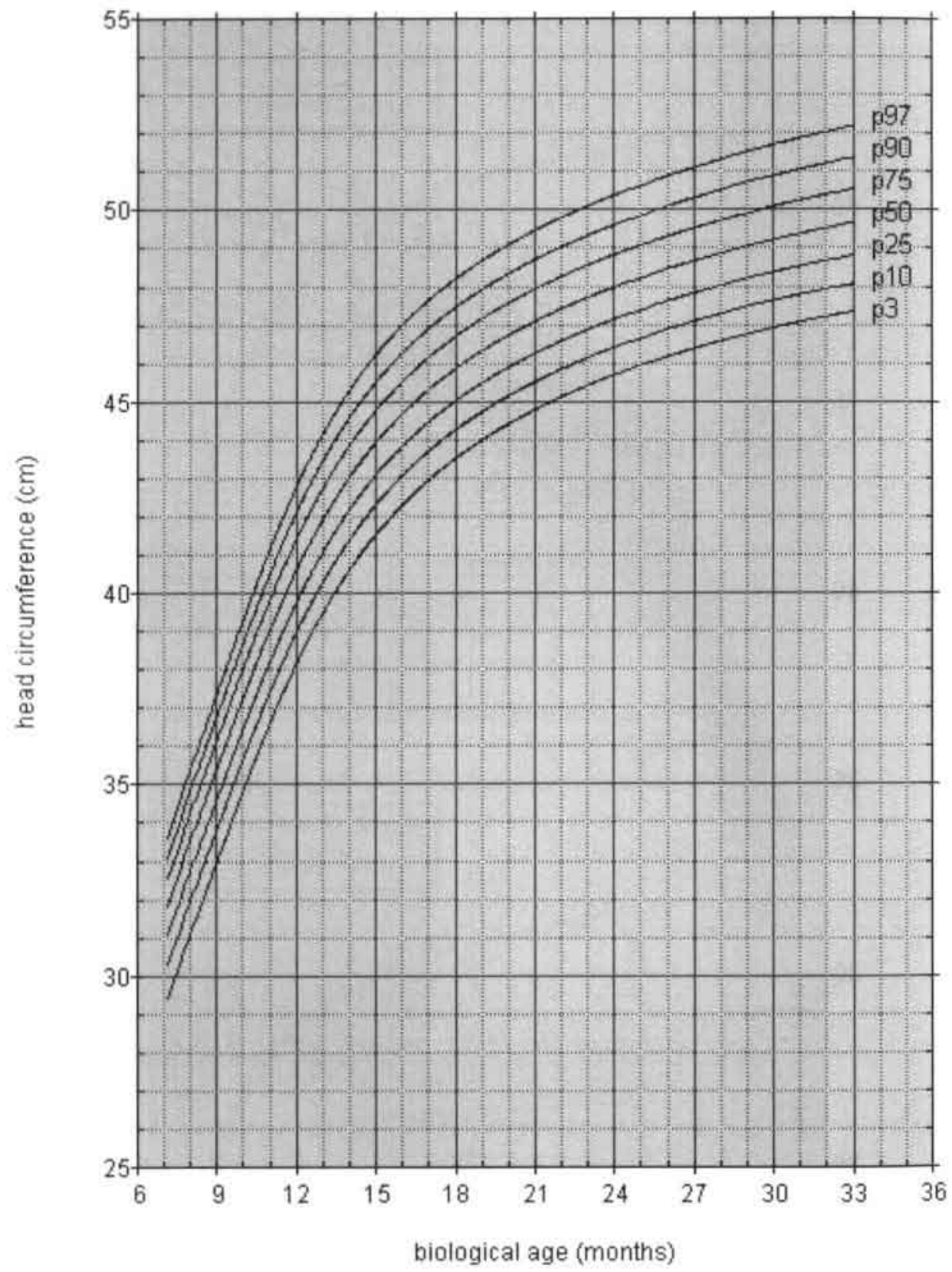




\section{Boys head-circumference vs age; edf 373}

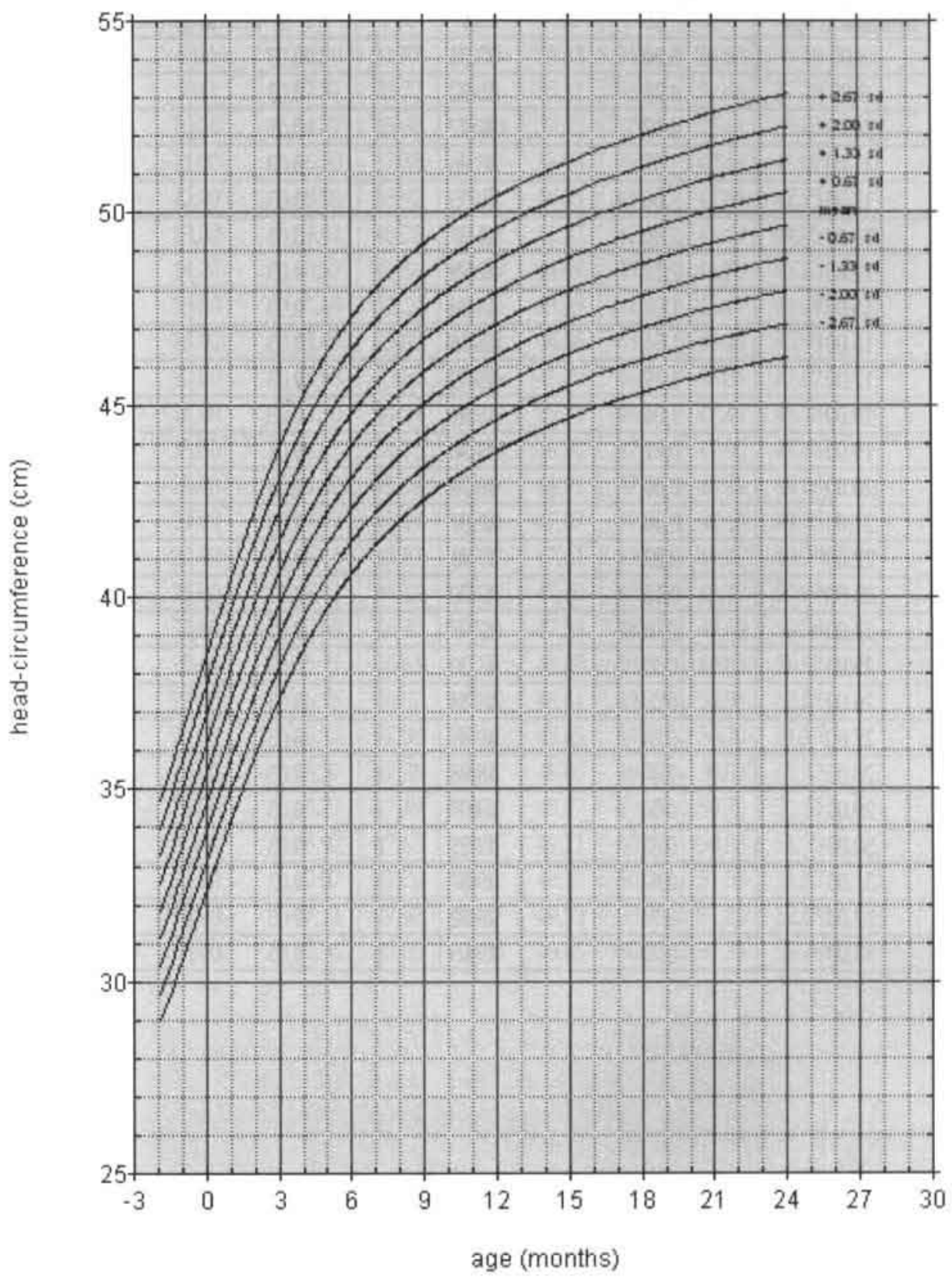




\begin{tabular}{|c|c|c|c|c|}
\hline \multicolumn{5}{|c|}{ Boys head circumference LMS values (edf 373) } \\
\hline biological age & L & M & S & SD \\
\hline 8.00 & 5.34 & 33.33 & 0.03 & 1.11 \\
\hline 9.00 & 4.71 & 35.32 & 0.03 & 1.14 \\
\hline 10.00 & 4.12 & 37.22 & 0.03 & 1.18 \\
\hline 11.00 & 3.57 & 38.96 & 0.03 & 1.20 \\
\hline 12.00 & 3.06 & 40.55 & 0.03 & 1.22 \\
\hline 13.00 & 2.62 & 41.87 & 0.03 & 1.24 \\
\hline 14.00 & 2.22 & 42.99 & 0.03 & 1.24 \\
\hline 15.00 & 1.88 & 43.89 & 0.03 & 1.25 \\
\hline 16.00 & 1.56 & 44.66 & 0.03 & 1.25 \\
\hline 17.00 & 1.29 & 45.29 & 0.03 & 1.25 \\
\hline 18.00 & 1.04 & 45.84 & 0.03 & 1.25 \\
\hline 19.00 & 0.82 & 46.30 & 0.03 & 1.25 \\
\hline 20.00 & 0.61 & 46.72 & 0.03 & 1.25 \\
\hline 21.00 & 0.44 & 47.07 & 0.03 & 1.24 \\
\hline 22.00 & 0.27 & 47.41 & 0.03 & 1.25 \\
\hline 23.00 & 0.13 & 47.70 & 0.03 & 1.25 \\
\hline 24.00 & -0.01 & 47.97 & 0.03 & 1.25 \\
\hline 25.00 & -0.12 & 48.20 & 0.03 & 1.25 \\
\hline 26.00 & -0.24 & 48.44 & 0.03 & 1.25 \\
\hline 27.00 & -0.34 & 48.65 & 0.03 & 1.26 \\
\hline 28.00 & -0.44 & 48.86 & 0.03 & 1.26 \\
\hline 29.00 & -0.54 & 49.07 & 0.03 & 1.27 \\
\hline 30.00 & -0.61 & 49.21 & 0.03 & 1.27 \\
\hline 31.00 & -0.67 & 49.37 & 0.03 & 1.27 \\
\hline 32.00 & -0.74 & 49.52 & 0.03 & 1.28 \\
\hline 33.00 & -0.79 & 49.65 & 0.03 & 1.29 \\
\hline & & & & \\
\hline
\end{tabular}




\begin{tabular}{|c|c|c|c|c|c|c|c|}
\hline \multicolumn{6}{|c|}{ Boys head circumference (in cm) vs biological age (in months) } \\
\hline biological age & P3 & P10 & P25 & P50 & P75 & P90 & P97 \\
\hline 8.00 & 30.90 & 31.77 & 32.55 & 33.33 & 34.04 & 34.63 & 35.18 \\
\hline 9.00 & 32.87 & 33.72 & 34.51 & 35.32 & 36.06 & 36.68 & 37.26 \\
\hline 10.00 & 34.77 & 35.60 & 36.40 & 37.22 & 37.98 & 38.64 & 39.25 \\
\hline 11.00 & 36.50 & 37.33 & 38.12 & 38.96 & 39.75 & 40.43 & 41.07 \\
\hline 12.00 & 38.10 & 38.92 & 39.71 & 40.55 & 41.36 & 42.06 & 42.73 \\
\hline 13.00 & 39.43 & 40.23 & 41.02 & 41.87 & 42.69 & 43.40 & 44.09 \\
\hline 14.00 & 40.57 & 41.36 & 42.15 & 42.99 & 43.82 & 44.55 & 45.26 \\
\hline 15.00 & 41.49 & 42.27 & 43.05 & 43.89 & 44.73 & 45.47 & 46.19 \\
\hline 16.00 & 42.28 & 43.05 & 43.82 & 44.66 & 45.50 & 46.25 & 46.98 \\
\hline 17.00 & 42.93 & 43.68 & 44.45 & 45.29 & 46.13 & 46.88 & 47.62 \\
\hline 18.00 & 43.50 & 44.24 & 45.00 & 45.84 & 46.68 & 47.44 & 48.18 \\
\hline 19.00 & 43.97 & 44.71 & 45.46 & 46.30 & 47.14 & 47.90 & 48.65 \\
\hline 20.00 & 44.40 & 45.13 & 45.88 & 46.72 & 47.56 & 48.32 & 49.08 \\
\hline 21.00 & 44.77 & 45.49 & 46.24 & 47.07 & 47.92 & 48.68 & 49.45 \\
\hline 22.00 & 45.11 & 45.83 & 46.57 & 47.41 & 48.25 & 49.02 & 49.79 \\
\hline 23.00 & 45.41 & 46.13 & 46.87 & 47.70 & 48.55 & 49.32 & 50.09 \\
\hline 24.00 & 45.69 & 46.40 & 47.14 & 47.98 & 48.82 & 49.60 & 50.38 \\
\hline 25.00 & 45.91 & 46.63 & 47.37 & 48.20 & 49.05 & 49.83 & 50.62 \\
\hline 26.00 & 46.15 & 46.87 & 47.60 & 48.44 & 49.29 & 50.08 & 50.87 \\
\hline 27.00 & 46.37 & 47.08 & 47.82 & 48.65 & 49.51 & 50.30 & 51.10 \\
\hline 28.00 & 46.57 & 47.28 & 48.02 & 48.86 & 49.72 & 50.52 & 51.32 \\
\hline 29.00 & 46.77 & 47.49 & 48.23 & 49.07 & 49.93 & 50.73 & 51.54 \\
\hline 30.00 & 46.92 & 47.63 & 48.37 & 49.21 & 50.08 & 50.88 & 51.70 \\
\hline 31.00 & 47.07 & 47.78 & 48.52 & 49.37 & 50.24 & 51.05 & 51.87 \\
\hline 32.00 & 47.21 & 47.92 & 48.67 & 49.52 & 50.39 & 51.21 & 52.03 \\
\hline 33.00 & 47.34 & 48.05 & 48.80 & 49.65 & 50.53 & 51.35 & 52.18 \\
\hline & & & & & & \\
\hline
\end{tabular}




\section{Boys head circumference (in $\mathrm{cm}$ ) vs age (in months)}

\begin{tabular}{|c|c|c|c|c|c|c|c|c|c|}
\hline age & -2.76 SD & -200 SD & -1.33 SD & -0.67 SD & 0SD & +0.67 SD & +1.33 SD & +2.00 SD & +2.67 SD \\
\hline-1.00 & 30.38 & 31.12 & 31.86 & 32.59 & 33.33 & 34.07 & 34.80 & 35.54 & 36.28 \\
\hline 0.00 & 32.27 & 33.04 & 33.80 & 34.56 & 35.32 & 36.09 & 36.84 & 37.60 & 38.37 \\
\hline 1.00 & 34.08 & 34.87 & 35.66 & 36.43 & 37.22 & 38.01 & 38.78 & 39.57 & 40.36 \\
\hline 2.00 & 35.75 & 36.56 & 37.36 & 38.16 & 38.96 & 39.77 & 40.56 & 41.36 & 42.17 \\
\hline 3.00 & 37.29 & 38.10 & 38.92 & 39.73 & 40.55 & 41.37 & 42.18 & 43.00 & 43.82 \\
\hline 4.00 & 38.57 & 39.40 & 40.23 & 41.04 & 41.87 & 42.70 & 43.51 & 44.34 & 45.17 \\
\hline 5.00 & 39.67 & 40.50 & 41.34 & 42.16 & 42.99 & 43.82 & 44.64 & 45.48 & 46.31 \\
\hline 6.00 & 40.56 & 41.40 & 42.23 & 43.06 & 43.89 & 44.73 & 45.55 & 46.38 & 47.22 \\
\hline 7.00 & 41.33 & 42.16 & 43.00 & 43.82 & 44.66 & 45.50 & 46.32 & 47.16 & 47.99 \\
\hline 8.00 & 41.96 & 42.80 & 43.63 & 44.46 & 45.29 & 46.13 & 46.95 & 47.78 & 48.62 \\
\hline 9.00 & 42.51 & 43.35 & 44.18 & 45.01 & 45.84 & 46.68 & 47.50 & 48.33 & 49.17 \\
\hline 10.00 & 42.98 & 43.81 & 44.64 & 45.47 & 46.30 & 47.13 & 47.96 & 48.79 & 49.62 \\
\hline 11.00 & 43.40 & 44.23 & 45.06 & 45.89 & 46.72 & 47.55 & 48.38 & 49.21 & 50.04 \\
\hline 12.00 & 43.75 & 44.58 & 45.42 & 46.24 & 47.07 & 47.90 & 48.73 & 49.56 & 50.39 \\
\hline 13.00 & 44.09 & 44.92 & 45.75 & 46.58 & 47.41 & 48.24 & 49.07 & 49.90 & 50.73 \\
\hline 14.00 & 44.37 & 45.21 & 46.04 & 46.87 & 47.70 & 48.54 & 49.36 & 50.19 & 51.03 \\
\hline 15.00 & 44.64 & 45.48 & 46.31 & 47.14 & 47.97 & 48.81 & 49.63 & 50.46 & 51.30 \\
\hline 16.00 & 44.87 & 45.70 & 46.54 & 47.36 & 48.20 & 49.04 & 49.86 & 50.70 & 51.54 \\
\hline 17.00 & 45.10 & 45.94 & 46.78 & 47.60 & 48.44 & 49.28 & 50.11 & 50.94 & 51.78 \\
\hline 18.00 & 45.30 & 46.14 & 46.98 & 47.81 & 48.65 & 49.49 & 50.32 & 51.16 & 52.00 \\
\hline 19.00 & 45.50 & 46.34 & 47.18 & 48.02 & 48.86 & 49.70 & 50.54 & 51.38 & 52.22 \\
\hline 20.00 & 45.69 & 46.54 & 47.39 & 48.22 & 49.07 & 49.92 & 50.75 & 51.60 & 52.45 \\
\hline 21.00 & 45.82 & 46.67 & 47.52 & 48.36 & 49.21 & 50.06 & 50.90 & 51.75 & 52.60 \\
\hline 22.00 & 45.97 & 46.82 & 47.68 & 48.52 & 49.37 & 50.22 & 51.06 & 51.92 & 52.77 \\
\hline 23.00 & 46.10 & 46.96 & 47.82 & 48.66 & 49.52 & 50.38 & 51.22 & 52.08 & 52.94 \\
\hline 24.00 & 46.22 & 47.08 & 47.94 & 48.79 & 49.65 & 50.51 & 51.36 & 52.22 & 53.08 \\
\hline
\end{tabular}


Girls head circumference vs age; edf 273

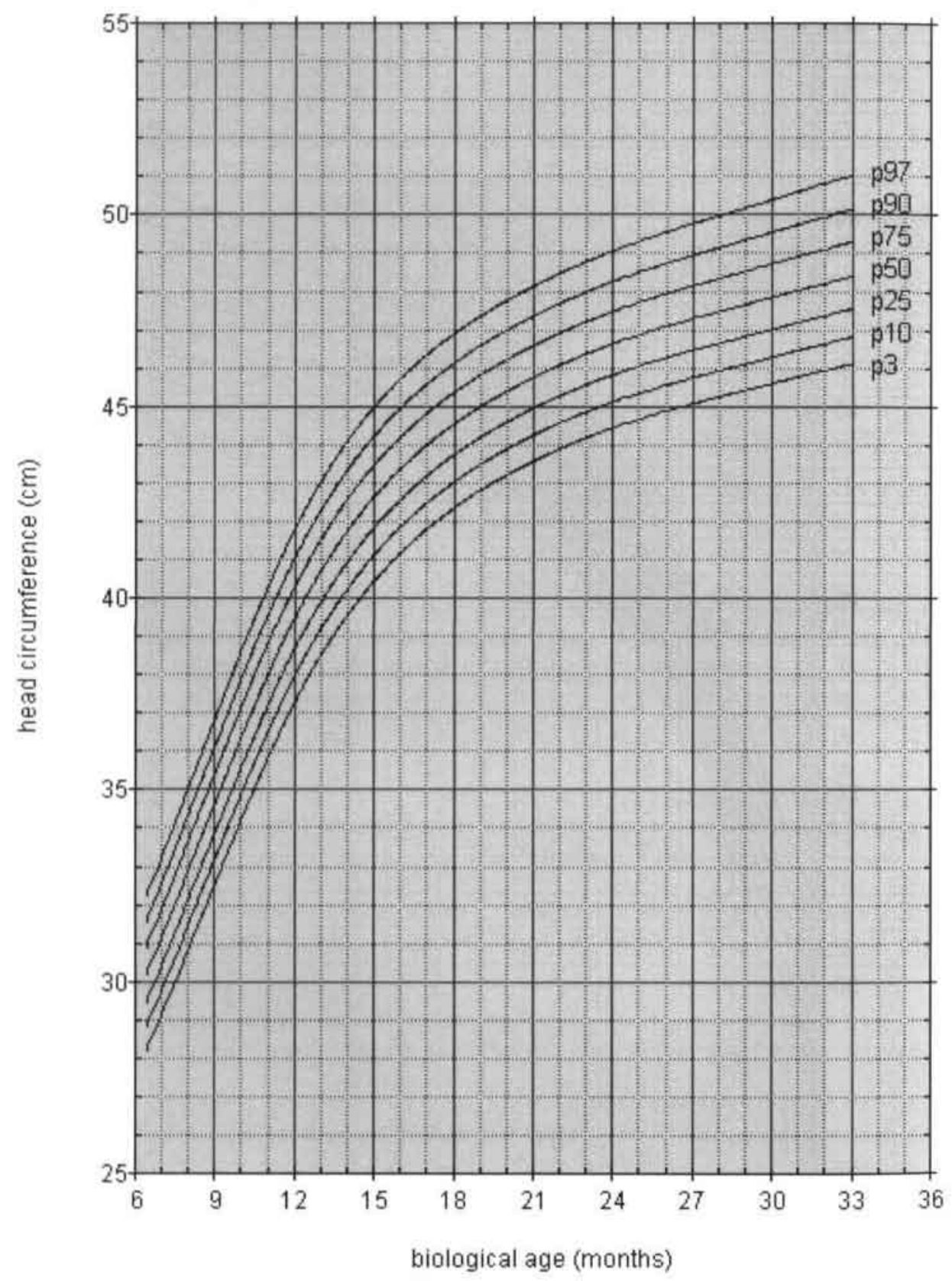


Appendix B

\begin{tabular}{|c|c|c|c|c|}
\hline \multicolumn{5}{|c|}{ Girls head circumference LMS values (edf 273) } \\
\hline biological age & L & M & S & SD \\
\hline 8.00 & 0.41 & 32.85 & 0.03 & 1.12 \\
\hline 9.00 & 0.32 & 34.67 & 0.03 & 1.15 \\
\hline 10.00 & 0.24 & 36.36 & 0.03 & 1.17 \\
\hline 11.00 & 0.15 & 37.93 & 0.03 & 1.19 \\
\hline 12.00 & 0.06 & 39.42 & 0.03 & 1.20 \\
\hline 13.00 & -0.02 & 40.66 & 0.03 & 1.21 \\
\hline 14.00 & -0.11 & 41.74 & 0.03 & 1.21 \\
\hline 15.00 & -0.20 & 42.61 & 0.03 & 1.21 \\
\hline 16.00 & -0.29 & 43.36 & 0.03 & 1.21 \\
\hline 17.00 & -0.38 & 43.97 & 0.03 & 1.21 \\
\hline 18.00 & -0.46 & 44.52 & 0.03 & 1.21 \\
\hline 19.00 & -0.55 & 44.97 & 0.03 & 1.21 \\
\hline 20.00 & -0.64 & 45.39 & 0.03 & 1.21 \\
\hline 21.00 & -0.73 & 45.74 & 0.03 & 1.21 \\
\hline 22.00 & -0.82 & 46.07 & 0.03 & 1.22 \\
\hline 23.00 & -0.90 & 46.36 & 0.03 & 1.22 \\
\hline 24.00 & -1.00 & 46.65 & 0.03 & 1.23 \\
\hline 25.00 & -1.09 & 46.90 & 0.03 & 1.23 \\
\hline 26.00 & -1.17 & 47.08 & 0.03 & 1.24 \\
\hline 27.00 & -1.26 & 47.28 & 0.03 & 1.24 \\
\hline 28.00 & -1.35 & 47.48 & 0.03 & 1.25 \\
\hline 29.00 & -1.43 & 47.66 & 0.03 & 1.26 \\
\hline 30.00 & -1.52 & 47.85 & 0.03 & 1.27 \\
\hline 31.00 & -1.60 & 48.03 & 0.03 & 1.28 \\
\hline 32.00 & -1.69 & 48.21 & 0.03 & 1.29 \\
\hline 33.00 & -1.78 & 48.39 & 0.03 & 1.30 \\
\hline & & & & \\
\hline
\end{tabular}




\begin{tabular}{|c|c|c|c|c|c|c|c|}
\hline \multicolumn{6}{|c|}{ Girls head circumference (in cm) vs biological age (in months) } \\
\hline biological age & P3 & P10 & P25 & P50 & P75 & P90 & P97 \\
\hline 8.00 & 30.78 & 31.43 & 32.10 & 32.85 & 33.61 & 34.30 & 35.00 \\
\hline 9.00 & 32.56 & 33.22 & 33.90 & 34.67 & 35.45 & 36.16 & 36.87 \\
\hline 10.00 & 34.21 & 34.89 & 35.58 & 36.36 & 37.16 & 37.89 & 38.62 \\
\hline 11.00 & 35.75 & 36.43 & 37.13 & 37.93 & 38.74 & 39.48 & 40.22 \\
\hline 12.00 & 37.22 & 37.91 & 38.62 & 39.42 & 40.24 & 40.98 & 41.74 \\
\hline 13.00 & 38.45 & 39.14 & 39.85 & 40.66 & 41.48 & 42.24 & 42.99 \\
\hline 14.00 & 39.53 & 40.22 & 40.93 & 41.74 & 42.56 & 43.32 & 44.08 \\
\hline 15.00 & 40.40 & 41.09 & 41.80 & 42.61 & 43.43 & 44.19 & 44.96 \\
\hline 16.00 & 41.16 & 41.85 & 42.55 & 43.36 & 44.18 & 44.94 & 45.71 \\
\hline 17.00 & 41.78 & 42.46 & 43.17 & 43.97 & 44.80 & 45.56 & 46.33 \\
\hline 18.00 & 42.33 & 43.01 & 43.72 & 44.52 & 45.34 & 46.11 & 46.88 \\
\hline 19.00 & 42.79 & 43.47 & 44.17 & 44.97 & 45.80 & 46.56 & 47.34 \\
\hline 20.00 & 43.20 & 43.88 & 44.58 & 45.39 & 46.21 & 46.98 & 47.76 \\
\hline 21.00 & 43.56 & 44.23 & 44.94 & 45.74 & 46.57 & 47.34 & 48.12 \\
\hline 22.00 & 43.89 & 44.56 & 45.27 & 46.07 & 46.91 & 47.68 & 48.47 \\
\hline 23.00 & 44.17 & 44.85 & 45.56 & 46.36 & 47.20 & 47.98 & 48.77 \\
\hline 24.00 & 44.45 & 45.13 & 45.84 & 46.65 & 47.49 & 48.27 & 49.07 \\
\hline 25.00 & 44.70 & 45.37 & 46.08 & 46.90 & 47.74 & 48.53 & 49.34 \\
\hline 26.00 & 44.87 & 45.55 & 46.26 & 47.08 & 47.93 & 48.72 & 49.54 \\
\hline 27.00 & 45.07 & 45.75 & 46.46 & 47.28 & 48.14 & 48.94 & 49.76 \\
\hline 28.00 & 45.25 & 45.94 & 46.65 & 47.48 & 48.34 & 49.15 & 49.98 \\
\hline 29.00 & 45.43 & 46.11 & 46.83 & 47.66 & 48.53 & 49.35 & 50.19 \\
\hline 30.00 & 45.60 & 46.29 & 47.01 & 47.85 & 48.72 & 49.55 & 50.39 \\
\hline 31.00 & 45.77 & 46.46 & 47.19 & 48.03 & 48.91 & 49.74 & 50.60 \\
\hline 32.00 & 45.94 & 46.63 & 47.36 & 48.21 & 49.10 & 49.94 & 50.81 \\
\hline 33.00 & 46.11 & 46.80 & 47.54 & 48.39 & 49.29 & 50.14 & 51.02 \\
\hline & & & & & & \\
\hline
\end{tabular}




\section{Girls head circumference (in $\mathrm{cm}$ ) vs age (in months)}

\begin{tabular}{|c|c|c|c|c|c|c|c|c|c|}
\hline age & $-2.76 \mathrm{SD}$ & $-2.00 \mathrm{SD}$ & $-1.33 \mathrm{SD}$ & $-0.67 \mathrm{SD}$ & $0 \mathrm{SD}$ & $+0.67 \mathrm{SD}$ & $+1.33 \mathrm{SD}$ & $+2.00 \mathrm{SD}$ & $+2.67 \mathrm{SD}$ \\
\hline-1.00 & 29.86 & 30.61 & 31.36 & 32.10 & 32.85 & 33.60 & 34.34 & 35.09 & 35.84 \\
\hline 0.00 & 31.61 & 32.38 & 33.14 & 33.90 & 34.67 & 35.44 & 36.20 & 36.96 & 37.73 \\
\hline 1.00 & 33.24 & 34.02 & 34.80 & 35.58 & 36.36 & 37.14 & 37.92 & 38.70 & 39.48 \\
\hline 2.00 & 34.76 & 35.56 & 36.35 & 37.14 & 37.93 & 38.73 & 39.51 & 40.30 & 41.10 \\
\hline 3.00 & 36.22 & 37.02 & 37.82 & 38.62 & 39.42 & 40.22 & 41.02 & 41.82 & 42.62 \\
\hline 4.00 & 37.44 & 38.25 & 39.06 & 39.85 & 40.66 & 41.47 & 42.27 & 43.07 & 43.88 \\
\hline 5.00 & 38.51 & 39.32 & 40.13 & 40.93 & 41.74 & 42.55 & 43.35 & 44.16 & 44.97 \\
\hline 6.00 & 39.38 & 40.19 & 41.00 & 41.80 & 42.61 & 43.42 & 44.22 & 45.03 & 45.84 \\
\hline 7.00 & 40.13 & 40.94 & 41.75 & 42.55 & 43.36 & 44.17 & 44.97 & 45.78 & 46.59 \\
\hline 8.00 & 40.75 & 41.55 & 42.36 & 43.16 & 43.97 & 44.78 & 45.58 & 46.39 & 47.20 \\
\hline 9.00 & 41.30 & 42.11 & 42.92 & 43.71 & 44.52 & 45.33 & 46.13 & 46.93 & 47.74 \\
\hline 10.00 & 41.75 & 42.55 & 43.36 & 44.16 & 44.97 & 45.78 & 46.58 & 47.39 & 48.20 \\
\hline 11.00 & 42.16 & 42.97 & 43.78 & 44.58 & 45.39 & 46.20 & 47.00 & 47.81 & 48.62 \\
\hline 12.00 & 42.51 & 43.32 & 44.13 & 44.93 & 45.74 & 46.55 & 47.35 & 48.16 & 48.97 \\
\hline 13.00 & 42.83 & 43.64 & 44.45 & 45.26 & 46.07 & 46.88 & 47.69 & 48.50 & 49.31 \\
\hline 14.00 & 43.11 & 43.92 & 44.74 & 45.54 & 46.36 & 47.18 & 47.98 & 48.80 & 49.62 \\
\hline 15.00 & 43.38 & 44.20 & 45.02 & 45.83 & 46.65 & 47.47 & 48.28 & 49.10 & 49.92 \\
\hline 16.00 & 43.61 & 44.44 & 45.26 & 46.08 & 46.90 & 47.73 & 48.54 & 49.36 & 50.19 \\
\hline 17.00 & 43.78 & 44.61 & 45.44 & 46.25 & 47.08 & 47.91 & 48.73 & 49.55 & 50.38 \\
\hline 18.00 & 43.96 & 44.79 & 45.63 & 46.45 & 47.28 & 48.11 & 48.94 & 49.77 & 50.60 \\
\hline 19.00 & 44.14 & 44.98 & 45.82 & 46.64 & 47.48 & 48.32 & 49.15 & 49.98 & 50.82 \\
\hline 20.10 & 44.30 & 45.14 & 45.98 & 46.82 & 47.66 & 48.50 & 49.34 & 50.18 & 51.02 \\
\hline 21.00 & 44.46 & 45.31 & 46.16 & 47.00 & 47.85 & 48.70 & 49.54 & 50.39 & 51.24 \\
\hline 22.00 & 44.62 & 45.48 & 46.33 & 47.17 & 48.03 & 48.89 & 49.73 & 50.58 & 51.44 \\
\hline 23.00 & 44.77 & 45.64 & 46.50 & 47.35 & 48.21 & 49.07 & 49.92 & 50.78 & 51.65 \\
\hline 24.00 & 44.93 & 45.80 & 46.67 & 47.52 & 48.39 & 49.26 & 50.12 & 50.98 & 51.85 \\
\hline & & & & & & & & & \\
\hline 130 & & & \\
\hline
\end{tabular}




\section{Crown rump length vs age}

\begin{tabular}{|c|c|c|c|}
\hline Boys & \multicolumn{4}{|c|}{ Crown nump length vs age } \\
\hline Edf: 2 3 3 $(2.002 .942 .95)$ & $\mathrm{N}: 5066$ & Nc: 1533 \\
\hline Range & Expected & Observed & Difference \\
\hline <P3 & 152.0 & 146 & -6.0 \\
\hline P3-P10 & 354.6 & 362 & 7.4 \\
\hline P10-P25 & 759.9 & 763 & 3.1 \\
\hline P25-P 50 & 1266.5 & 1289 & 22.5 \\
\hline P50-P75 & 1266.5 & 1254 & -12.5 \\
\hline P75-P90 & 759.9 & 734 & -25.9 \\
\hline P90-P97 & 354.6 & 354 & -0.6 \\
\hline$>$ P97 & 152.0 & 164 & 12.0 \\
\hline
\end{tabular}

\begin{tabular}{|c|c|c|c|}
\hline Girls & \multicolumn{4}{|c|}{ Crown nump length vs age } \\
\hline Edf:3 6 3 $(2.996 .013 .01)$ & N: 4208 & Nc: 1373 \\
\hline Range & Expected & Observed & Difference \\
\hline <P3 & 126.2 & 126 & -0.2 \\
\hline P3-P10 & 294.6 & 280 & -14.6 \\
\hline P10-P25 & 631.2 & 620 & -11.2 \\
\hline P25-P 50 & 1052.0 & 1073 & 21.0 \\
\hline P50-P75 & 1052.0 & 1083 & 31.0 \\
\hline P75-P90 & 631.2 & 593 & -38.2 \\
\hline P90-P97 & 294.6 & 305 & 10.4 \\
\hline$>$ P97 & 126.2 & 127 & 0.8 \\
\hline
\end{tabular}


Comparison crown rump length boys

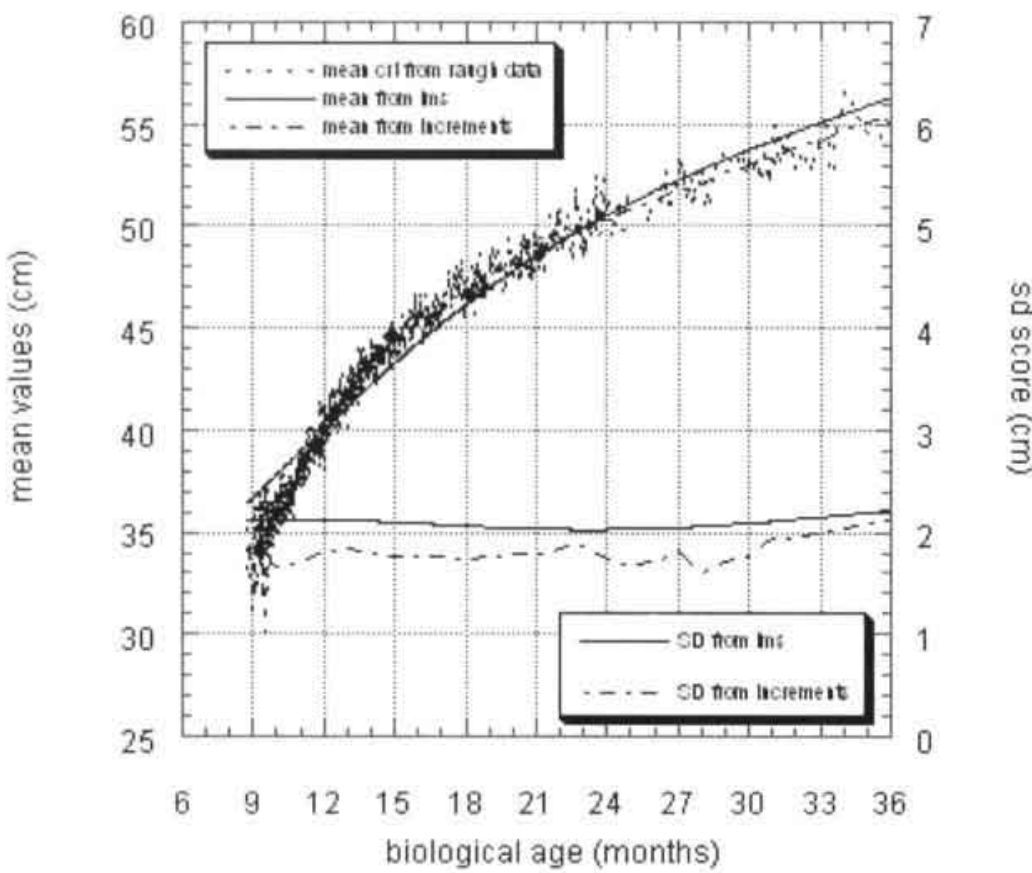

Comparison crown rump length girls

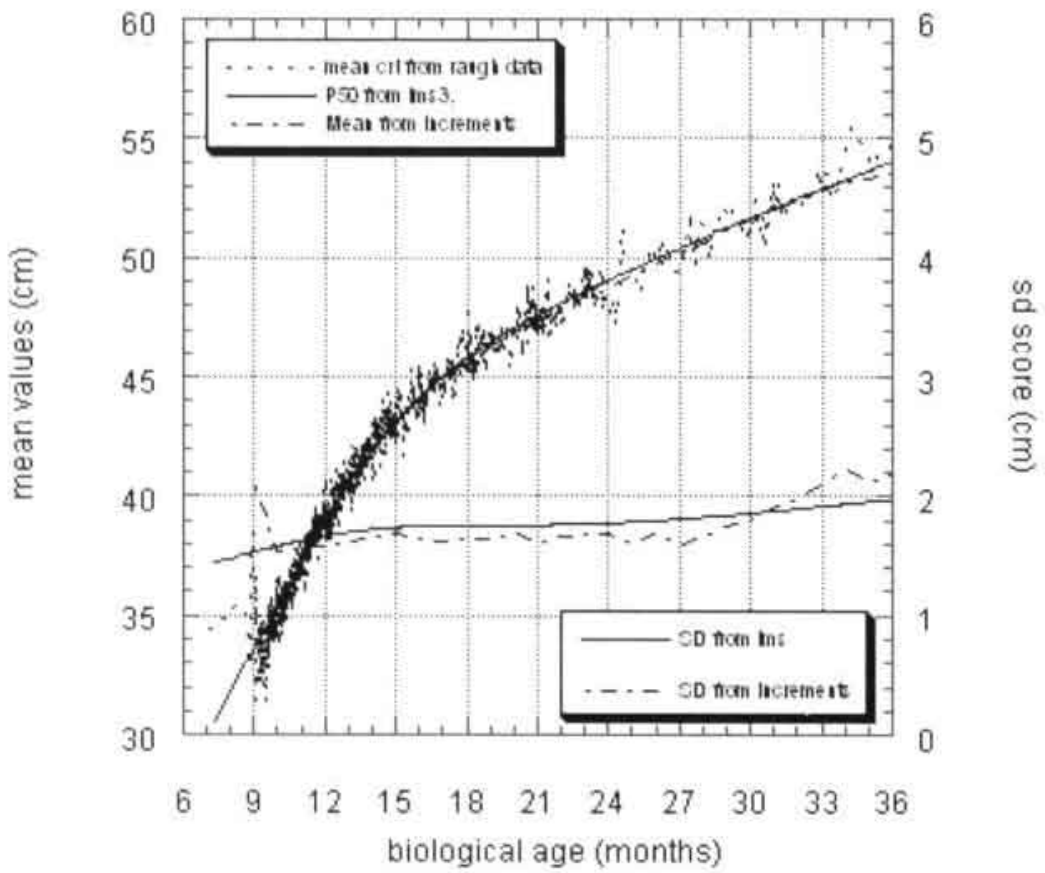




\section{Boys crown rump length vs age; edf 233}

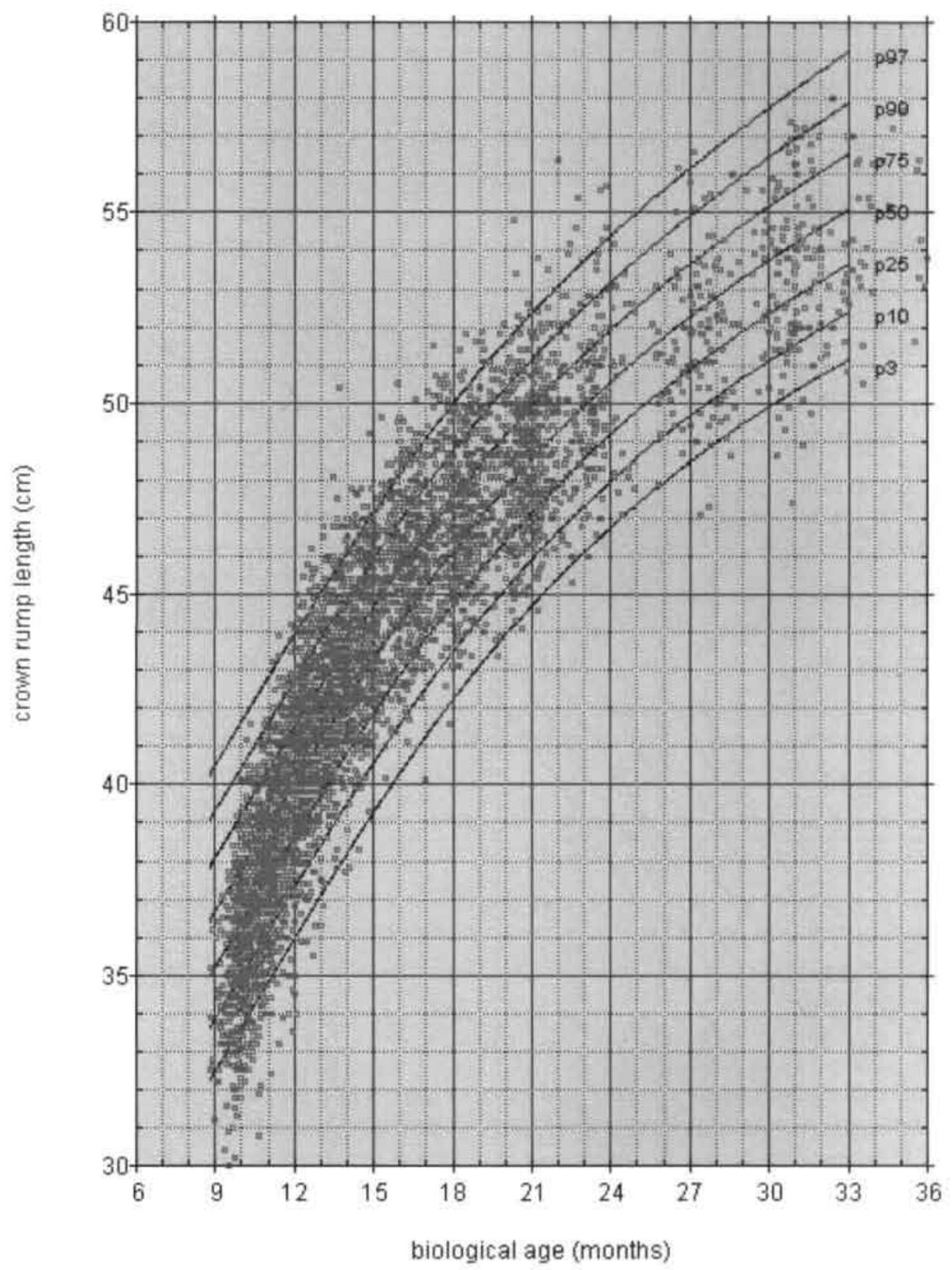




\section{Boys crown rump length vs age; edf 233}

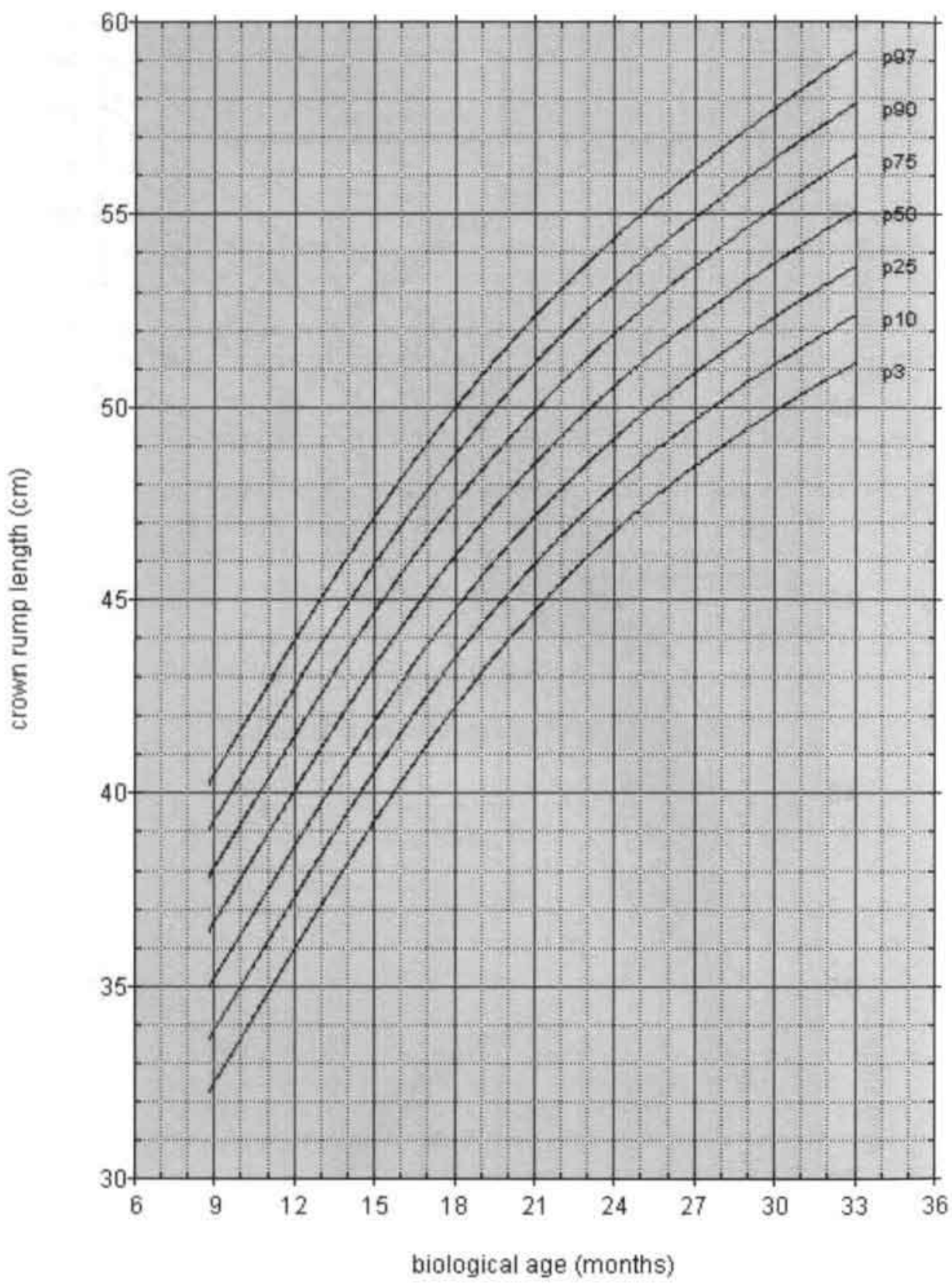




\section{Boys crown rump length vs age; edf 233}

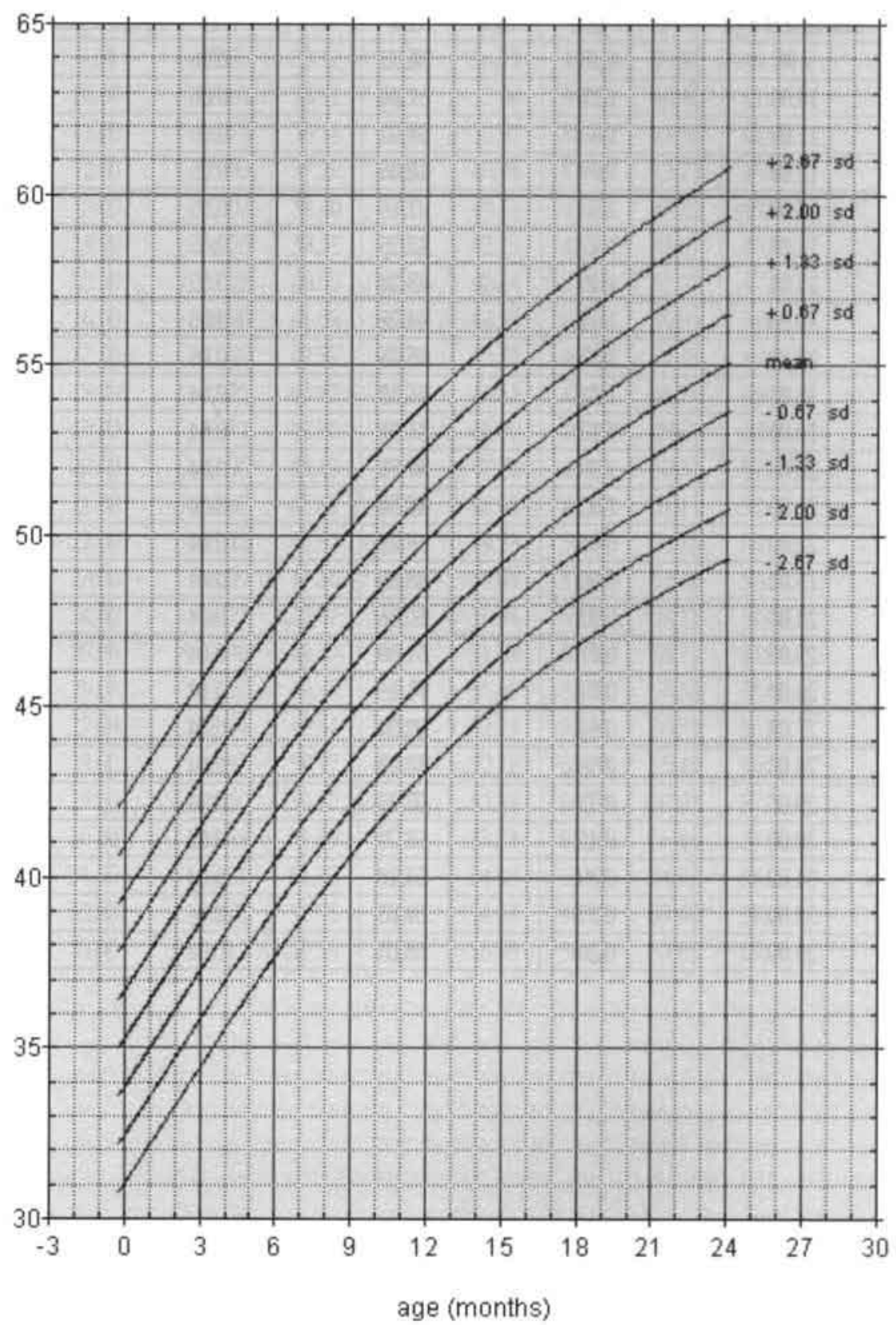




\begin{tabular}{|c|c|c|c|c|}
\hline \multicolumn{5}{|c|}{ Boys crown rump length LMS values (edf 233) } \\
\hline biological age & L & M & S & SD \\
\hline 9.00 & 1.78 & 36.72 & 0.06 & 2.12 \\
\hline 10.00 & 1.72 & 37.80 & 0.06 & 2.12 \\
\hline 11.00 & 1.66 & 38.92 & 0.05 & 2.12 \\
\hline 12.00 & 1.59 & 40.06 & 0.05 & 2.12 \\
\hline 13.00 & 1.53 & 41.16 & 0.05 & 2.11 \\
\hline 14.00 & 1.47 & 42.25 & 0.05 & 2.11 \\
\hline 15.00 & 1.40 & 43.28 & 0.05 & 2.10 \\
\hline 16.00 & 1.34 & 44.28 & 0.05 & 2.09 \\
\hline 17.00 & 1.27 & 45.25 & 0.05 & 2.07 \\
\hline 18.00 & 1.21 & 46.13 & 0.04 & 2.06 \\
\hline 19.00 & 1.15 & 46.99 & 0.04 & 2.05 \\
\hline 20.00 & 1.09 & 47.76 & 0.04 & 2.04 \\
\hline 21.00 & 1.02 & 48.50 & 0.04 & 2.03 \\
\hline 22.00 & 0.96 & 49.23 & 0.04 & 2.03 \\
\hline 23.00 & 0.90 & 49.89 & 0.04 & 2.03 \\
\hline 24.00 & 0.83 & 50.56 & 0.04 & 2.03 \\
\hline 25.00 & 0.77 & 51.09 & 0.04 & 2.03 \\
\hline 26.00 & 0.71 & 51.69 & 0.04 & 2.04 \\
\hline 27.00 & 0.64 & 52.24 & 0.04 & 2.05 \\
\hline 28.00 & 0.58 & 52.78 & 0.04 & 2.06 \\
\hline 29.00 & 0.51 & 53.33 & 0.04 & 2.07 \\
\hline 30.00 & 0.45 & 53.73 & 0.04 & 2.09 \\
\hline 31.00 & 0.39 & 54.18 & 0.04 & 2.11 \\
\hline 32.00 & 0.32 & 54.63 & 0.04 & 2.13 \\
\hline 33.00 & 0.26 & 55.05 & 0.04 & 2.15 \\
\hline
\end{tabular}




\begin{tabular}{|c|c|c|c|c|c|c|c|}
\hline \multicolumn{6}{|c|}{ Boys crown rump length (in cm) v biological age (in months) } \\
\hline biological age & P3 & P10 & P25 & P50 & P75 & P90 & P97 \\
\hline 9.00 & 32.55 & 33.92 & 35.27 & 36.72 & 38.13 & 39.37 & 40.56 \\
\hline 10.00 & 33.64 & 35.01 & 36.35 & 37.80 & 39.22 & 40.46 & 41.66 \\
\hline 11.00 & 34.78 & 36.14 & 37.47 & 38.92 & 40.34 & 41.58 & 42.79 \\
\hline 12.00 & 35.95 & 37.29 & 38.62 & 40.06 & 41.48 & 42.73 & 43.94 \\
\hline 13.00 & 37.07 & 38.40 & 39.72 & 41.16 & 42.57 & 43.82 & 45.04 \\
\hline 14.00 & 38.20 & 39.51 & 40.82 & 42.25 & 43.66 & 44.91 & 46.13 \\
\hline 15.00 & 39.25 & 40.55 & 41.85 & 43.28 & 44.68 & 45.93 & 47.15 \\
\hline 16.00 & 40.30 & 41.58 & 42.87 & 44.29 & 45.69 & 46.93 & 48.15 \\
\hline 17.00 & 41.30 & 42.57 & 43.84 & 45.25 & 46.64 & 47.89 & 49.11 \\
\hline 18.00 & 42.22 & 43.47 & 44.74 & 46.13 & 47.52 & 48.76 & 49.98 \\
\hline 19.00 & 43.11 & 44.36 & 45.61 & 46.99 & 48.37 & 49.61 & 50.83 \\
\hline 20.00 & 43.90 & 45.13 & 46.38 & 47.76 & 49.13 & 50.37 & 51.58 \\
\hline 21.00 & 44.67 & 45.89 & 47.13 & 48.50 & 49.87 & 51.11 & 52.32 \\
\hline 22.00 & 45.42 & 46.63 & 47.86 & 49.23 & 50.60 & 51.83 & 53.05 \\
\hline 23.00 & 46.09 & 47.30 & 48.52 & 49.89 & 51.26 & 52.49 & 53.72 \\
\hline 24.00 & 46.77 & 47.97 & 49.19 & 50.56 & 51.93 & 53.17 & 54.39 \\
\hline 25.00 & 47.30 & 48.50 & 49.72 & 51.09 & 52.46 & 53.71 & 54.94 \\
\hline 26.00 & 47.90 & 49.10 & 50.32 & 51.69 & 53.07 & 54.32 & 55.56 \\
\hline 27.00 & 48.44 & 49.64 & 50.87 & 52.24 & 53.63 & 54.89 & 56.14 \\
\hline 28.00 & 48.97 & 50.17 & 51.40 & 52.78 & 54.18 & 55.45 & 56.71 \\
\hline 29.00 & 49.50 & 50.70 & 51.94 & 53.33 & 54.74 & 56.02 & 57.30 \\
\hline 30.00 & 49.88 & 51.09 & 52.33 & 53.73 & 55.15 & 56.44 & 57.74 \\
\hline 31.00 & 50.31 & 51.52 & 52.77 & 54.18 & 55.61 & 56.92 & 58.23 \\
\hline 32.00 & 50.73 & 51.95 & 53.21 & 54.63 & 56.08 & 57.40 & 58.73 \\
\hline 33.00 & 51.12 & 52.35 & 53.62 & 55.05 & 56.51 & 57.85 & 59.20 \\
\hline & & & & & & & \\
\hline
\end{tabular}




\begin{tabular}{|c|c|c|c|c|c|c|c|c|c|}
\hline \multicolumn{10}{|c|}{ Boys crown rump length (in cm) vs age (in months) } \\
\hline age & -2.76 SD & -2.00 SD & -1.33 SD & -0.67 SD & 0 SD & +0.67 SD & +1.33 SD & +2.00 SD & +2.67 SD \\
\hline 0.00 & 31.06 & 32.48 & 33.90 & 35.30 & 36.72 & 38.14 & 39.54 & 40.96 & 42.38 \\
\hline 1.00 & 32.13 & 33.55 & 34.98 & 36.38 & 37.80 & 39.22 & 40.62 & 42.05 & 43.47 \\
\hline 2.00 & 33.25 & 34.67 & 36.10 & 37.50 & 38.92 & 40.34 & 41.74 & 43.17 & 44.59 \\
\hline 3.00 & 34.40 & 35.82 & 37.24 & 38.64 & 40.06 & 41.48 & 42.88 & 44.30 & 45.72 \\
\hline 4.00 & 35.52 & 36.93 & 38.35 & 39.74 & 41.16 & 42.58 & 43.97 & 45.39 & 46.80 \\
\hline 5.00 & 36.62 & 38.04 & 39.45 & 40.84 & 42.25 & 43.66 & 45.05 & 46.46 & 47.88 \\
\hline 6.00 & 37.68 & 39.09 & 40.49 & 41.88 & 43.28 & 44.69 & 46.07 & 47.47 & 48.88 \\
\hline 7.00 & 38.71 & 40.11 & 41.51 & 42.88 & 44.28 & 45.68 & 47.05 & 48.45 & 49.85 \\
\hline 8.00 & 39.71 & 41.10 & 42.49 & 43.86 & 45.25 & 46.64 & 48.01 & 49.40 & 50.79 \\
\hline 9.00 & 40.62 & 42.01 & 43.39 & 44.75 & 46.13 & 47.51 & 48.87 & 50.25 & 51.64 \\
\hline 10.00 & 41.51 & 42.89 & 44.26 & 45.62 & 46.99 & 48.36 & 49.72 & 51.09 & 52.47 \\
\hline 11.00 & 42.31 & 43.68 & 45.05 & 46.39 & 47.76 & 49.13 & 50.48 & 51.84 & 53.21 \\
\hline 12.00 & 43.07 & 44.43 & 45.80 & 47.14 & 48.50 & 49.86 & 51.21 & 52.57 & 53.93 \\
\hline 13.00 & 43.81 & 45.17 & 46.53 & 47.87 & 49.23 & 50.59 & 51.93 & 53.29 & 54.65 \\
\hline 14.00 & 44.48 & 45.84 & 47.19 & 48.53 & 49.89 & 51.25 & 52.59 & 53.94 & 55.30 \\
\hline 15.00 & 45.15 & 46.50 & 47.86 & 49.20 & 50.56 & 51.92 & 53.26 & 54.62 & 55.98 \\
\hline 16.00 & 45.67 & 47.03 & 48.39 & 49.73 & 51.09 & 52.45 & 53.79 & 55.15 & 56.51 \\
\hline 17.00 & 46.25 & 47.62 & 48.98 & 50.33 & 51.69 & 53.06 & 54.40 & 55.76 & 57.13 \\
\hline 18.00 & 46.78 & 48.15 & 49.52 & 50.87 & 52.24 & 53.61 & 54.96 & 56.33 & 57.70 \\
\hline 19.00 & 47.28 & 48.66 & 50.04 & 51.40 & 52.78 & 54.16 & 55.52 & 56.90 & 58.28 \\
\hline 20.00 & 47.79 & 49.18 & 50.57 & 51.94 & 53.33 & 54.72 & 56.09 & 57.48 & 58.87 \\
\hline 21.00 & 48.16 & 49.55 & 50.95 & 52.33 & 53.73 & 55.13 & 56.51 & 57.91 & 59.31 \\
\hline 22.00 & 48.56 & 49.97 & 51.38 & 52.77 & 54.18 & 55.59 & 56.98 & 58.39 & 59.80 \\
\hline 23.00 & 48.95 & 50.38 & 51.80 & 53.21 & 54.63 & 56.05 & 57.46 & 58.88 & 60.31 \\
\hline 24.00 & 49.32 & 50.76 & 52.20 & 53.61 & 55.05 & 56.49 & 57.90 & 59.34 & 60.78 \\
\hline
\end{tabular}




\section{Girls crown rump length vs age; edf 363}

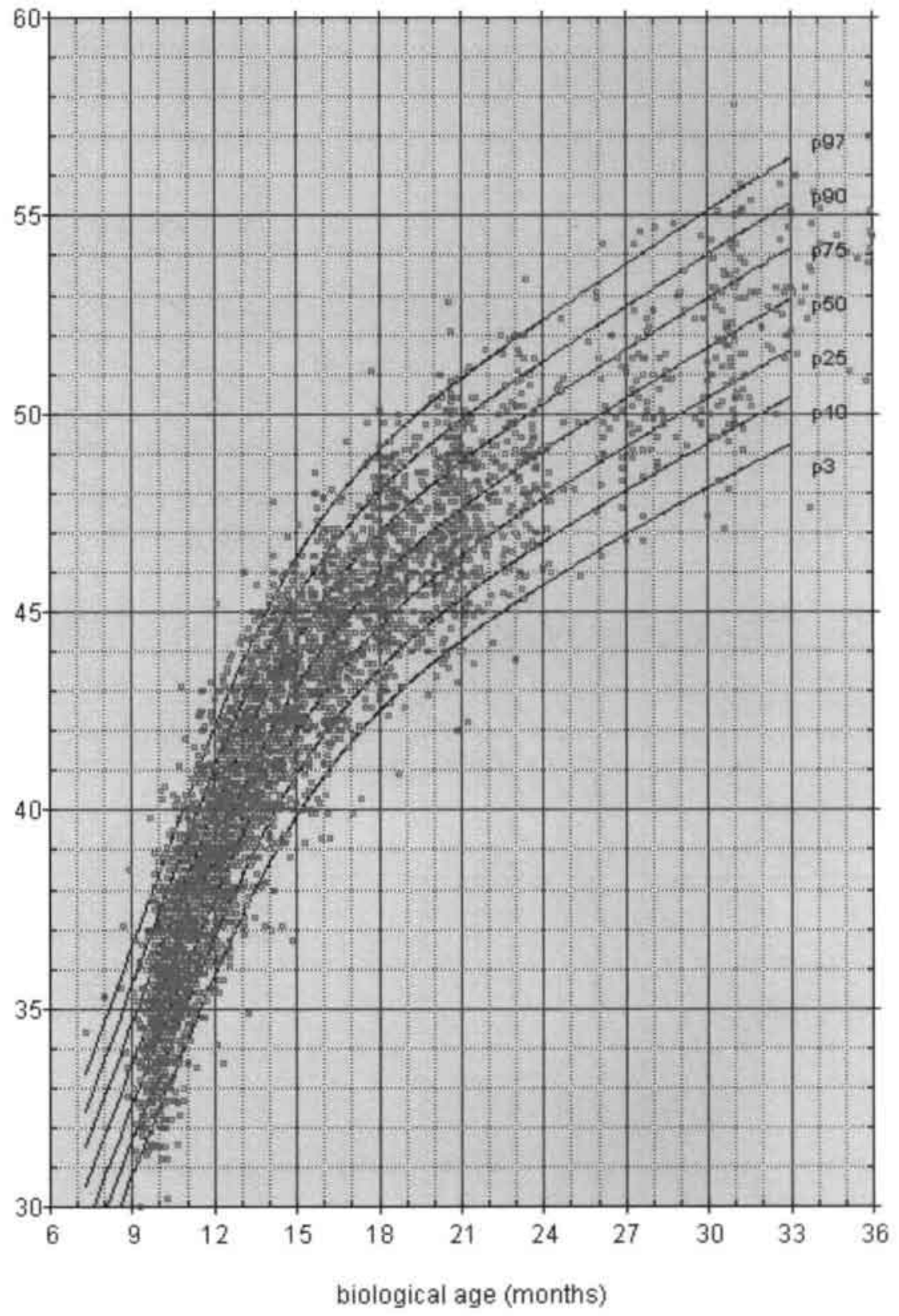


Appendix B

Girls crown rump length vs age: edf 363

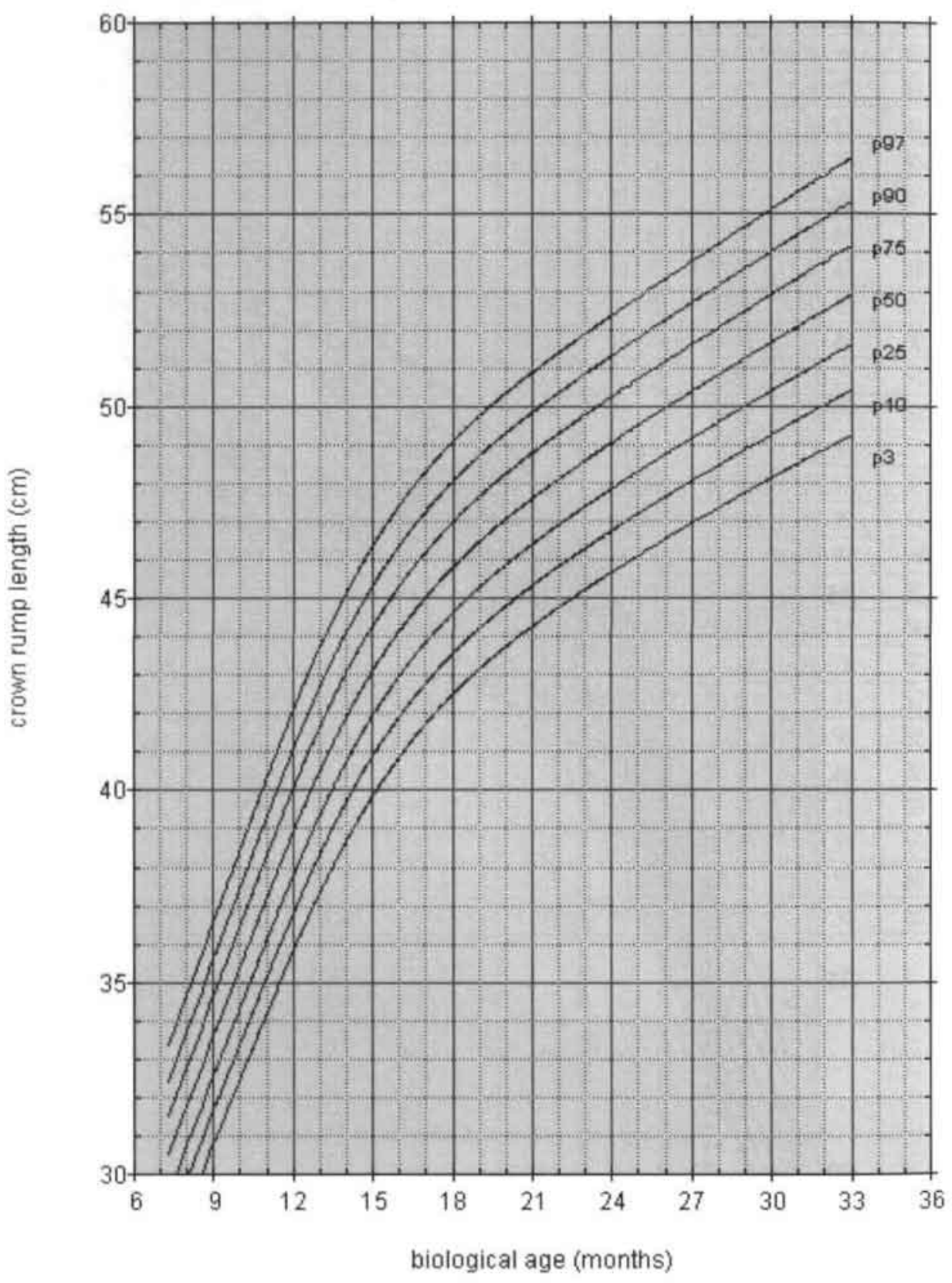


Girls crown rump length vs age; edf 363

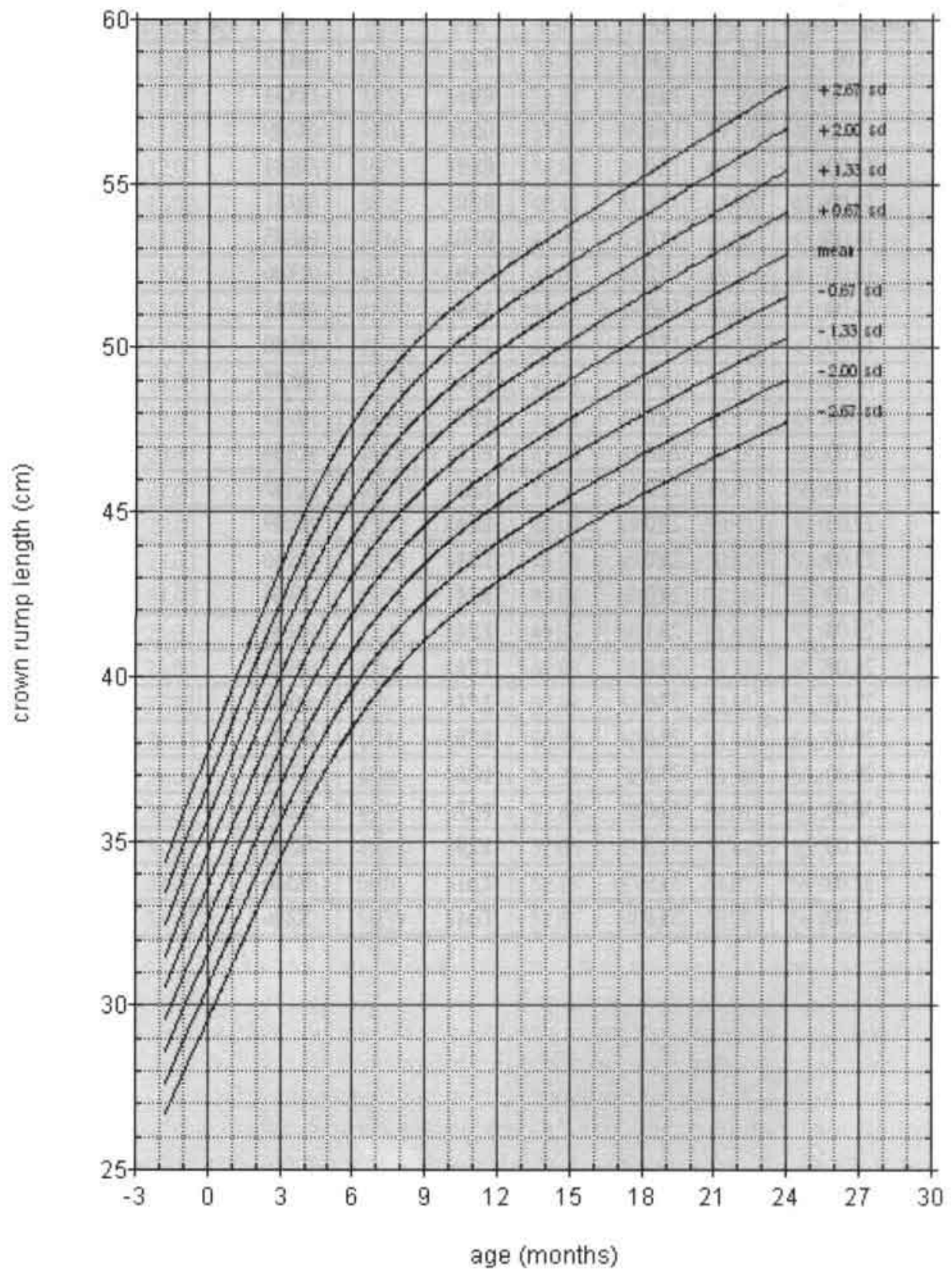




\begin{tabular}{|c|c|c|c|c|}
\hline \multicolumn{5}{|c|}{ Girls crown rump length LMS values (edf 36 3) } \\
\hline biological age & L & M & S & SD \\
\hline 9.00 & 9.1 & 0.34 & 33.75 & 0.05 \\
\hline 10.00 & 10.0 & 0.45 & 35.34 & 0.04 \\
\hline 11.00 & 11.0 & 0.57 & 37.09 & 0.04 \\
\hline 12.00 & 12.0 & 0.69 & 38.84 & 0.04 \\
\hline 13.00 & 13.0 & 0.80 & 40.41 & 0.04 \\
\hline 14.00 & 14.0 & 0.90 & 41.85 & 0.04 \\
\hline 15.00 & 15.0 & 0.99 & 43.06 & 0.04 \\
\hline 16.00 & 16.0 & 1.06 & 44.12 & 0.04 \\
\hline 17.00 & 17.0 & 1.12 & 45.00 & 0.04 \\
\hline 18.00 & 18.0 & 1.16 & 45.78 & 0.04 \\
\hline 19.00 & 19.0 & 1.19 & 46.43 & 0.04 \\
\hline 20.00 & 20.0 & 1.21 & 47.04 & 0.04 \\
\hline 21.00 & 21.0 & 1.23 & 47.57 & 0.04 \\
\hline 22.00 & 22.0 & 1.24 & 48.09 & 0.04 \\
\hline 23.00 & 23.0 & 1.24 & 48.56 & 0.04 \\
\hline 24.00 & 24.0 & 1.24 & 49.04 & 0.04 \\
\hline 25.00 & 25.1 & 1.24 & 49.56 & 0.04 \\
\hline 26.00 & 26.0 & 1.24 & 49.93 & 0.04 \\
\hline 27.00 & 27.0 & 1.24 & 50.38 & 0.04 \\
\hline 28.00 & 28.0 & 1.25 & 50.81 & 0.04 \\
\hline 29.00 & 29.0 & 1.26 & 51.23 & 0.04 \\
\hline 30.00 & 30.0 & 1.27 & 51.65 & 0.04 \\
\hline 31.00 & 31.0 & 1.29 & 52.05 & 0.04 \\
\hline 32.00 & 31.9 & 1.31 & 52.46 & 0.04 \\
\hline 33.00 & 33.0 & 1.34 & 52.86 & 0.04 \\
\hline
\end{tabular}




\begin{tabular}{|c|c|c|c|c|c|c|c|}
\hline \multicolumn{7}{|c|}{ Girls crown rump length (in cm) vs biological age (in months) } \\
\hline biological age & P3 & P10 & P25 & P50 & P75 & P90 & P97 \\
\hline 9.00 & 30.95 & 31.82 & 32.73 & 33.75 & 34.80 & 35.76 & 36.73 \\
\hline 10.00 & 32.44 & 33.35 & 34.28 & 35.34 & 36.41 & 37.39 & 38.38 \\
\hline 11.00 & 34.09 & 35.04 & 36.00 & 37.09 & 38.19 & 39.20 & 40.20 \\
\hline 12.00 & 35.75 & 36.73 & 37.73 & 38.84 & 39.97 & 40.99 & 42.01 \\
\hline 13.00 & 37.25 & 38.25 & 39.27 & 40.41 & 41.56 & 42.60 & 43.62 \\
\hline 14.00 & 38.63 & 39.65 & 40.69 & 41.85 & 43.01 & 44.06 & 45.10 \\
\hline 15.00 & 39.79 & 40.83 & 41.89 & 43.06 & 44.23 & 45.28 & 46.32 \\
\hline 16.00 & 40.83 & 41.88 & 42.94 & 44.12 & 45.29 & 46.35 & 47.39 \\
\hline 17.00 & 41.69 & 42.75 & 43.81 & 45.00 & 46.17 & 47.23 & 48.27 \\
\hline 18.00 & 42.46 & 43.52 & 44.59 & 45.78 & 46.96 & 48.01 & 49.06 \\
\hline 19.00 & 43.11 & 44.18 & 45.25 & 46.44 & 47.62 & 48.67 & 49.71 \\
\hline 20.00 & 43.71 & 44.78 & 45.85 & 47.04 & 48.22 & 49.28 & 50.32 \\
\hline 21.00 & 44.24 & 45.31 & 46.38 & 47.57 & 48.75 & 49.81 & 50.85 \\
\hline 22.00 & 44.75 & 45.82 & 46.90 & 48.09 & 49.27 & 50.33 & 51.37 \\
\hline 23.00 & 45.21 & 46.29 & 47.37 & 48.56 & 49.75 & 50.82 & 51.86 \\
\hline 24.00 & 45.67 & 46.75 & 47.84 & 49.04 & 50.23 & 51.30 & 52.35 \\
\hline 25.00 & 46.17 & 47.25 & 48.35 & 49.56 & 50.76 & 51.83 & 52.89 \\
\hline 26.00 & 46.53 & 47.62 & 48.72 & 49.93 & 51.14 & 52.22 & 53.28 \\
\hline 27.00 & 46.94 & 48.04 & 49.15 & 50.38 & 51.59 & 52.68 & 53.75 \\
\hline 28.00 & 47.35 & 48.46 & 49.58 & 50.81 & 52.04 & 53.14 & 54.22 \\
\hline 29.00 & 47.74 & 48.86 & 49.99 & 51.23 & 52.47 & 53.58 & 54.67 \\
\hline 30.00 & 48.12 & 49.25 & 50.39 & 51.65 & 52.90 & 54.01 & 55.11 \\
\hline 31.00 & 48.49 & 49.63 & 50.78 & 52.05 & 53.32 & 54.44 & 55.55 \\
\hline 32.00 & 48.85 & 50.01 & 51.17 & 52.46 & 53.73 & 54.87 & 55.99 \\
\hline 33.00 & 49.22 & 50.39 & 51.57 & 52.86 & 54.15 & 55.30 & 56.43 \\
\hline
\end{tabular}


Appendix B

\begin{tabular}{|c|c|c|c|c|c|c|c|c|c|}
\hline \multicolumn{8}{|c|}{ Girls crown rump length (in cm) vs age (in months) } \\
\hline age & -2.76 SD & -2.00 SD & -1.33 SD & -0.67 SD & 0 SD & +0.67 SD & +1.33 SD & +2.00 SD & +2.67 SD \\
\hline 0.00 & 29.65 & 30.68 & 31.71 & 32.72 & 33.75 & 34.78 & 35.79 & 36.82 & 37.85 \\
\hline 1.00 & 31.12 & 32.18 & 33.24 & 34.28 & 35.34 & 36.40 & 37.44 & 38.50 & 39.56 \\
\hline 2.00 & 32.76 & 33.84 & 34.93 & 36.00 & 37.09 & 38.18 & 39.25 & 40.34 & 41.42 \\
\hline 3.00 & 34.40 & 35.51 & 36.63 & 37.73 & 38.84 & 39.95 & 41.05 & 42.17 & 43.28 \\
\hline 4.00 & 35.88 & 37.02 & 38.16 & 39.27 & 40.41 & 41.55 & 42.66 & 43.80 & 44.94 \\
\hline 5.00 & 37.26 & 38.41 & 39.56 & 40.70 & 41.85 & 43.00 & 44.14 & 45.29 & 46.44 \\
\hline 6.00 & 38.43 & 39.59 & 40.75 & 41.90 & 43.06 & 44.22 & 45.37 & 46.53 & 47.69 \\
\hline 7.00 & 39.46 & 40.63 & 41.80 & 42.95 & 44.12 & 45.29 & 46.44 & 47.61 & 48.78 \\
\hline 8.00 & 40.33 & 41.50 & 42.67 & 43.83 & 45.00 & 46.17 & 47.33 & 48.50 & 49.67 \\
\hline 9.00 & 41.10 & 42.28 & 43.45 & 44.61 & 45.78 & 46.95 & 48.11 & 49.28 & 50.46 \\
\hline 10.00 & 41.75 & 42.92 & 44.10 & 45.26 & 46.43 & 47.61 & 48.76 & 49.94 & 51.11 \\
\hline 11.00 & 42.35 & 43.53 & 44.71 & 45.86 & 47.04 & 48.22 & 49.37 & 50.55 & 51.73 \\
\hline 12.00 & 42.88 & 44.06 & 45.23 & 46.39 & 47.57 & 48.75 & 49.91 & 51.08 & 52.26 \\
\hline 13.00 & 43.39 & 44.57 & 45.75 & 46.91 & 48.09 & 49.27 & 50.43 & 51.61 & 52.79 \\
\hline 14.00 & 43.84 & 45.03 & 46.21 & 47.38 & 48.56 & 49.74 & 50.91 & 52.09 & 53.28 \\
\hline 15.00 & 44.30 & 45.49 & 46.68 & 47.85 & 49.04 & 50.23 & 51.40 & 52.59 & 53.78 \\
\hline 16.00 & 44.79 & 45.99 & 47.19 & 48.36 & 49.56 & 50.76 & 51.94 & 53.13 & 54.33 \\
\hline 17.00 & 45.14 & 46.34 & 47.54 & 48.73 & 49.93 & 51.13 & 52.32 & 53.52 & 54.73 \\
\hline 18.00 & 45.55 & 46.76 & 47.97 & 49.17 & 50.38 & 51.59 & 52.79 & 54.00 & 55.21 \\
\hline 19.00 & 45.94 & 47.16 & 48.38 & 49.59 & 50.81 & 52.03 & 53.24 & 54.46 & 55.68 \\
\hline 20.00 & 46.32 & 47.55 & 48.78 & 50.00 & 51.23 & 52.46 & 53.68 & 54.91 & 56.15 \\
\hline 21.00 & 46.69 & 47.93 & 49.18 & 50.41 & 51.65 & 52.90 & 54.12 & 55.37 & 56.61 \\
\hline 22.00 & 47.04 & 48.30 & 49.55 & 50.79 & 52.05 & 53.31 & 54.55 & 55.80 & 57.06 \\
\hline 23.00 & 47.40 & 48.67 & 49.94 & 51.19 & 52.46 & 53.73 & 54.98 & 56.25 & 57.52 \\
\hline 24.00 & 47.74 & 49.03 & 50.31 & 51.58 & 52.86 & 54.14 & 55.41 & 56.69 & 57.98 \\
\hline
\end{tabular}




\section{Subischial leg length}

\begin{tabular}{|c|c|c|c|}
\hline Boys & \multicolumn{4}{|c|}{ Subischial leg length vs age } \\
\hline Edf: 5 4 5 (5.01 3.99 4.99) & N: 5055 & Nc: 1530 \\
\hline Range & Expected & Observed & Difference \\
\hline <P3 & 151.6 & 157 & 5.4 \\
\hline P3-P10 & 353.9 & 357 & 3.1 \\
\hline P10-P25 & 758.3 & 770 & 11.7 \\
\hline P25-P 50 & 1263.7 & 1230 & -33.7 \\
\hline P50-P75 & 1263.7 & 1263 & -0.7 \\
\hline P75-P90 & 758.3 & 798 & 39.7 \\
\hline P90-P97 & 353.9 & 348 & -5.9 \\
\hline >P97 & 151.6 & 132 & -19.6 \\
\hline
\end{tabular}

\begin{tabular}{|c|c|c|c|}
\hline Girls & \multicolumn{4}{|c|}{ Subischial leg length vs age } \\
\hline Edf: 6 6 6 (6.01 5.99 5.99) & N:4198 & Nc: 1370 \\
\hline Range & Expected & Observed & Difference \\
\hline <P3 & 125.9 & 132 & 6.1 \\
\hline P3-P10 & 293.9 & 291 & -2.9 \\
\hline P10-P25 & 629.7 & 633 & 3.3 \\
\hline P25-P50 & 1049.5 & 1044 & -5.5 \\
\hline P50-P75 & 1049.5 & 1076 & 26.5 \\
\hline P75-P90 & 629.7 & 633 & 3.3 \\
\hline P90-P97 & 293.9 & 279 & -14.9 \\
\hline$>$ P97 & 125.9 & 120 & -5.9 \\
\hline
\end{tabular}




\section{Comparison subischial leg length boys}

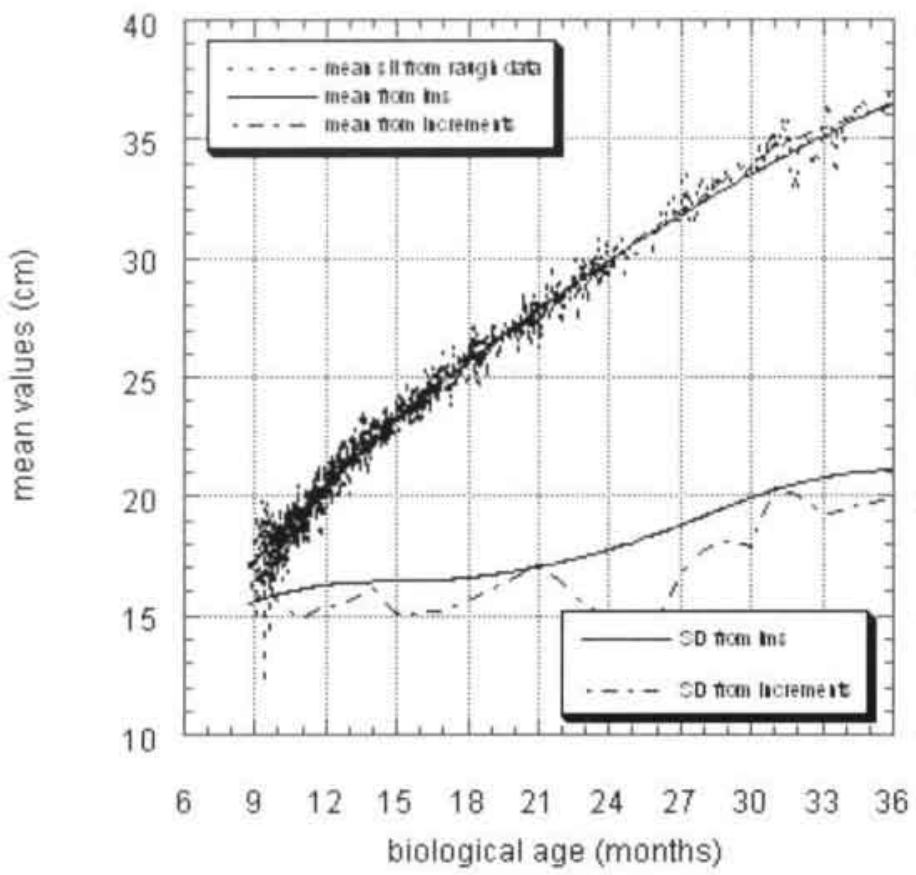

Comparison subischial leg length girls

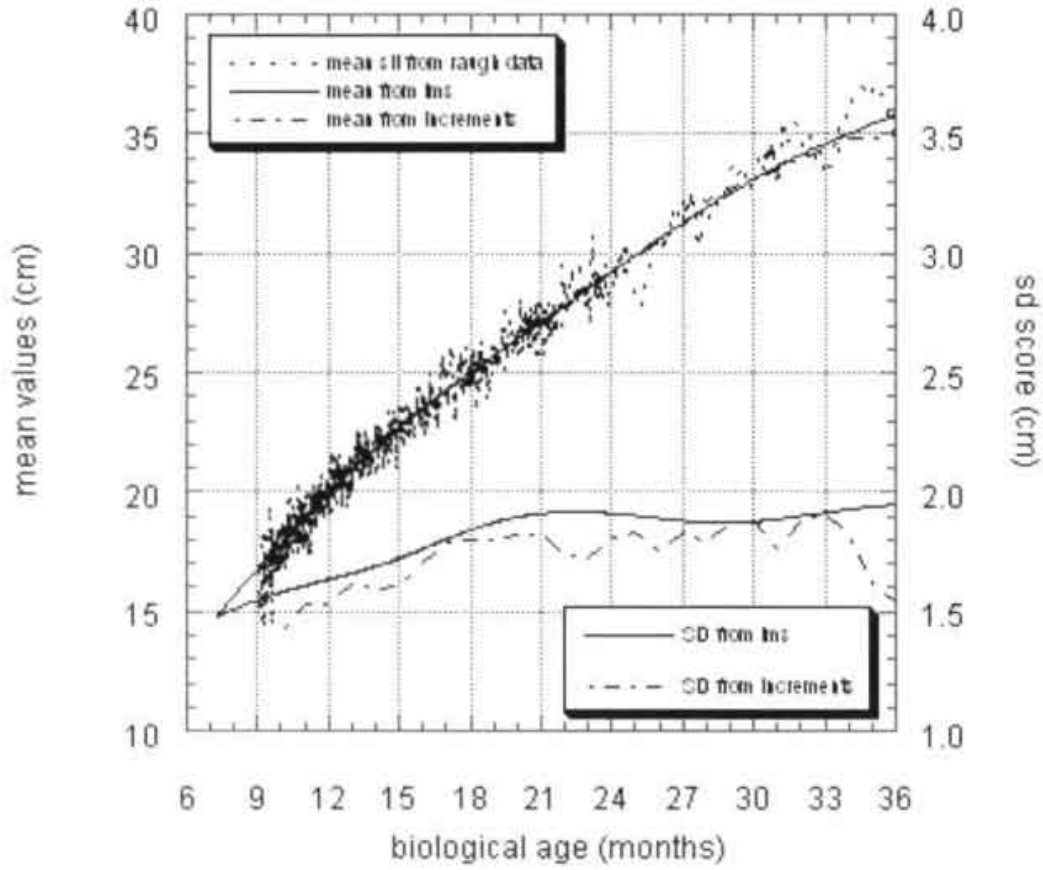




\section{Boys subischial leg length vs age; edf 545}

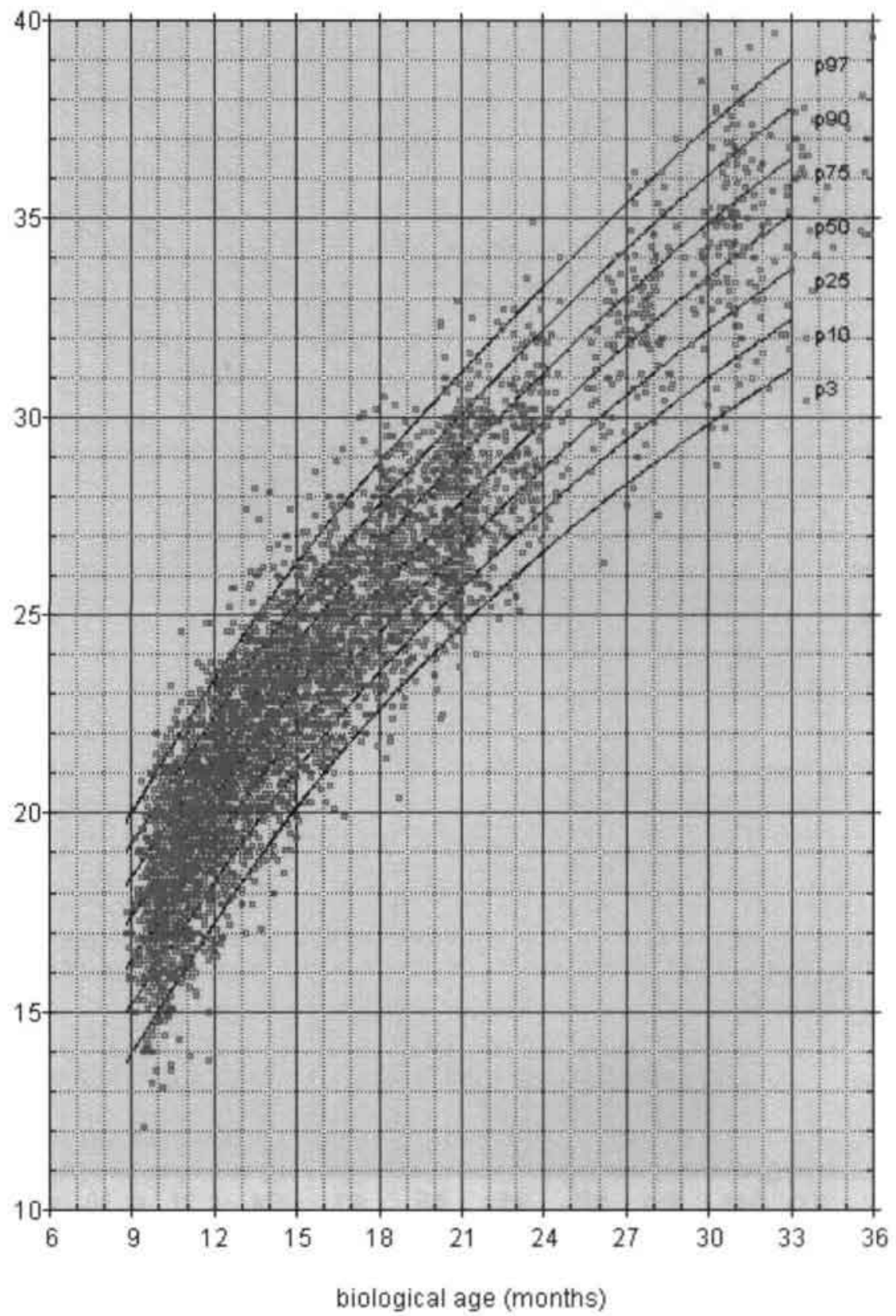




\section{Boys subischial leg length vs age; edf 545}

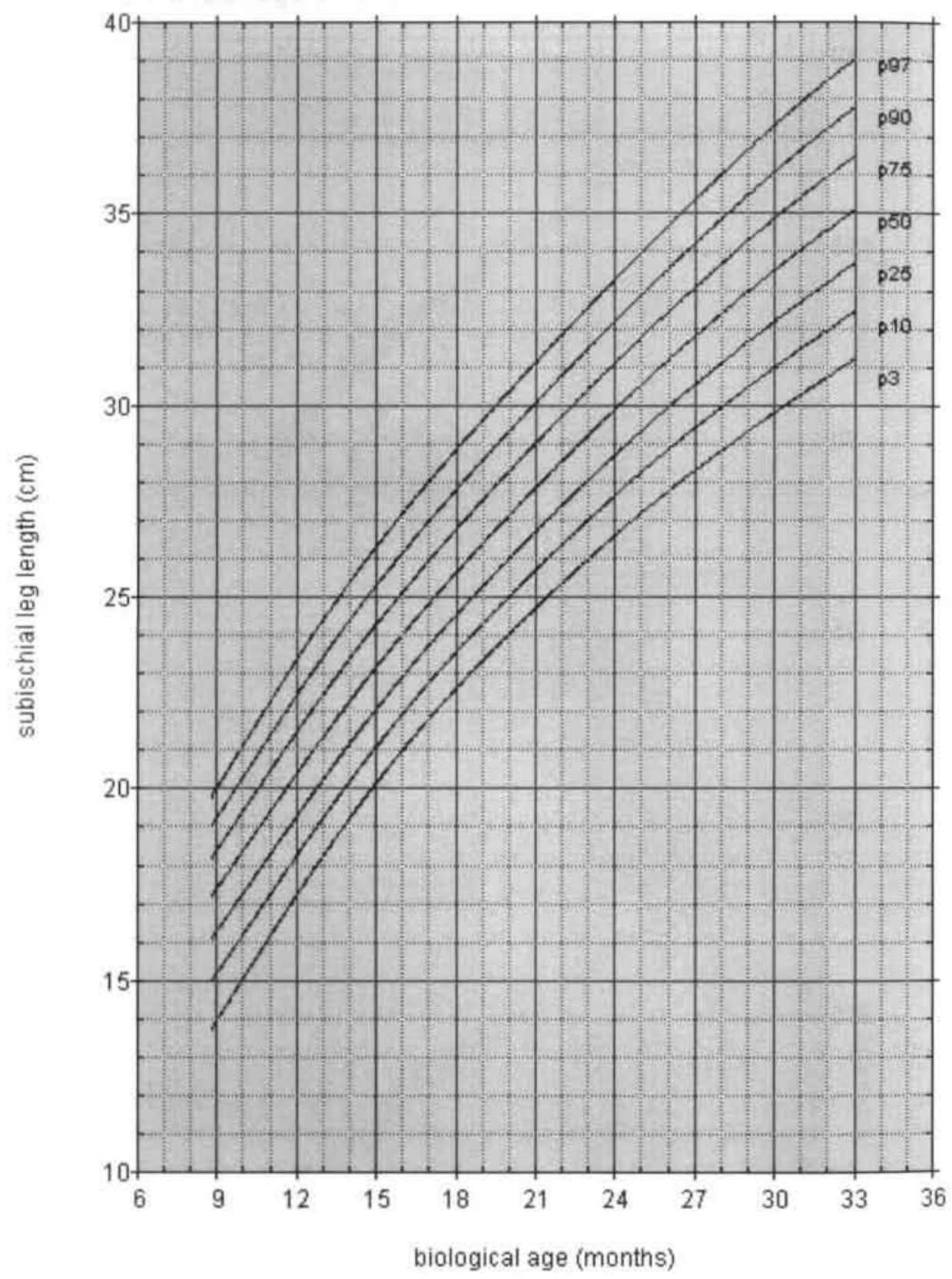




\begin{tabular}{|c|c|c|c|c|}
\hline \multicolumn{5}{|c|}{ Boys subischial leg length LMS values ( edf 5 45) } \\
\hline biological age & L & M & S & SD \\
\hline 9.00 & 2.54 & 17.38 & 0.09 & 1.56 \\
\hline 10.00 & 2.15 & 18.40 & 0.09 & 1.59 \\
\hline 11.00 & 1.79 & 19.35 & 0.08 & 1.61 \\
\hline 12.00 & 1.42 & 20.35 & 0.08 & 1.63 \\
\hline 13.00 & 1.10 & 21.30 & 0.08 & 1.64 \\
\hline 14.00 & 0.85 & 22.25 & 0.07 & 1.64 \\
\hline 15.00 & 0.69 & 23.13 & 0.07 & 1.64 \\
\hline 16.00 & 0.59 & 24.00 & 0.07 & 1.65 \\
\hline 17.00 & 0.55 & 24.81 & 0.07 & 1.65 \\
\hline 18.00 & 0.55 & 25.61 & 0.06 & 1.66 \\
\hline 19.00 & 0.58 & 26.36 & 0.06 & 1.67 \\
\hline 20.00 & 0.61 & 27.11 & 0.06 & 1.69 \\
\hline 21.00 & 0.65 & 27.82 & 0.06 & 1.70 \\
\hline 22.00 & 0.68 & 28.53 & 0.06 & 1.73 \\
\hline 23.00 & 0.72 & 29.21 & 0.06 & 1.75 \\
\hline 24.00 & 0.75 & 29.89 & 0.06 & 1.78 \\
\hline 25.00 & 0.78 & 30.48 & 0.06 & 1.80 \\
\hline 26.00 & 0.82 & 31.27 & 0.06 & 1.85 \\
\hline 27.00 & 0.84 & 31.77 & 0.06 & 1.88 \\
\hline 28.00 & 0.85 & 32.40 & 0.06 & 1.92 \\
\hline 29.00 & 0.85 & 33.04 & 0.06 & 1.96 \\
\hline 30.00 & 0.85 & 33.51 & 0.06 & 1.99 \\
\hline 31.00 & 0.85 & 34.04 & 0.06 & 2.03 \\
\hline 32.00 & 0.87 & 34.57 & 0.06 & 2.06 \\
\hline 33.00 & 0.90 & 35.07 & 0.06 & 2.08 \\
\hline
\end{tabular}




\begin{tabular}{|c|c|c|c|c|c|c|c|}
\hline \multicolumn{7}{|c|}{ Boys subischial leg length (in cm) vs biological age (in months) } \\
\hline biological age & P3 & P10 & P25 & P50 & P75 & P90 & P97 \\
\hline 9.00 & 13.94 & 15.17 & 16.28 & 17.38 & 18.39 & 19.23 & 20.00 \\
\hline 10.00 & 15.06 & 16.21 & 17.29 & 18.40 & 19.44 & 20.32 & 21.15 \\
\hline 11.00 & 16.10 & 17.19 & 18.24 & 19.35 & 20.41 & 21.33 & 22.21 \\
\hline 12.00 & 17.18 & 18.22 & 19.24 & 20.35 & 21.44 & 22.40 & 23.33 \\
\hline 13.00 & 18.20 & 19.19 & 20.19 & 21.30 & 22.40 & 23.39 & 24.36 \\
\hline 14.00 & 19.19 & 20.16 & 21.14 & 22.25 & 23.36 & 24.37 & 25.37 \\
\hline 15.00 & 20.10 & 21.05 & 22.03 & 23.13 & 24.25 & 25.26 & 26.28 \\
\hline 16.00 & 20.98 & 21.93 & 22.90 & 24.00 & 25.12 & 26.15 & 27.18 \\
\hline 17.00 & 21.79 & 22.73 & 23.71 & 24.81 & 25.93 & 26.96 & 28.00 \\
\hline 18.00 & 22.58 & 23.52 & 24.50 & 25.61 & 26.74 & 27.78 & 28.82 \\
\hline 19.00 & 23.30 & 24.26 & 25.24 & 26.36 & 27.50 & 28.54 & 29.58 \\
\hline 20.00 & 24.01 & 24.99 & 25.99 & 27.11 & 28.26 & 29.31 & 30.35 \\
\hline 21.00 & 24.68 & 25.67 & 26.68 & 27.82 & 28.98 & 30.03 & 31.09 \\
\hline 22.00 & 25.35 & 26.35 & 27.38 & 28.53 & 29.71 & 30.77 & 31.84 \\
\hline 23.00 & 25.97 & 26.99 & 28.04 & 29.21 & 30.39 & 31.47 & 32.55 \\
\hline 24.00 & 26.59 & 27.63 & 28.70 & 29.89 & 31.09 & 32.18 & 33.27 \\
\hline 25.00 & 27.13 & 28.19 & 29.27 & 30.48 & 31.71 & 32.82 & 33.92 \\
\hline 26.00 & 27.83 & 28.92 & 30.03 & 31.27 & 32.52 & 33.65 & 34.78 \\
\hline 27.00 & 28.28 & 29.38 & 30.51 & 31.77 & 33.05 & 34.20 & 35.34 \\
\hline 28.00 & 28.82 & 29.96 & 31.11 & 32.40 & 33.70 & 34.87 & 36.04 \\
\hline 29.00 & 29.38 & 30.54 & 31.72 & 33.04 & 34.37 & 35.57 & 36.76 \\
\hline 30.00 & 29.80 & 30.98 & 32.17 & 33.51 & 34.86 & 36.08 & 37.29 \\
\hline 31.00 & 30.27 & 31.46 & 32.68 & 34.04 & 35.41 & 36.65 & 37.88 \\
\hline 32.00 & 30.74 & 31.95 & 33.19 & 34.57 & 35.96 & 37.22 & 38.47 \\
\hline 33.00 & 31.19 & 32.42 & 33.67 & 35.07 & 36.47 & 37.74 & 39.00 \\
\hline & & & & & & & \\
\hline
\end{tabular}


Appendix B

\begin{tabular}{|c|c|c|c|c|c|c|c|c|c|}
\hline \multicolumn{10}{|c|}{ Boys subischial leg length (in cm) vs age (in months) } \\
\hline age & -2.76 SD & -2.00 SD & -1.33 SD & -0.67 SD & 0 SD & +0.67 SD & +1.33 SD & +2.00 SD & +2.67 SD \\
\hline 0.00 & 13.22 & 14.26 & 15.31 & 16.34 & 17.38 & 18.43 & 19.46 & 20.50 & 21.55 \\
\hline 1.00 & 14.16 & 15.22 & 16.29 & 17.34 & 18.40 & 19.47 & 20.52 & 21.58 & 22.65 \\
\hline 2.00 & 15.05 & 16.13 & 17.21 & 18.27 & 19.35 & 20.43 & 21.49 & 22.57 & 23.65 \\
\hline 3.00 & 16.00 & 17.09 & 18.19 & 19.26 & 20.35 & 21.44 & 22.52 & 23.61 & 24.70 \\
\hline 4.00 & 16.93 & 18.02 & 19.12 & 20.20 & 21.30 & 22.40 & 23.48 & 24.58 & 25.67 \\
\hline 5.00 & 17.86 & 18.96 & 20.07 & 21.15 & 22.25 & 23.35 & 24.44 & 25.54 & 26.64 \\
\hline 6.00 & 18.74 & 19.84 & 20.94 & 22.03 & 23.13 & 24.23 & 25.32 & 26.42 & 27.52 \\
\hline 7.00 & 19.61 & 20.71 & 21.81 & 22.90 & 24.00 & 25.10 & 26.19 & 27.29 & 28.40 \\
\hline 8.00 & 20.40 & 21.51 & 22.62 & 23.71 & 24.81 & 25.92 & 27.00 & 28.11 & 29.22 \\
\hline 9.00 & 21.18 & 22.29 & 23.40 & 24.50 & 25.61 & 26.72 & 27.82 & 28.93 & 30.04 \\
\hline 10.00 & 21.90 & 23.02 & 24.14 & 25.24 & 26.36 & 27.48 & 28.58 & 29.70 & 30.82 \\
\hline 11.00 & 22.61 & 23.74 & 24.87 & 25.98 & 27.11 & 28.24 & 29.35 & 30.48 & 31.61 \\
\hline 12.00 & 23.27 & 24.41 & 25.55 & 26.68 & 27.82 & 28.96 & 30.09 & 31.23 & 32.37 \\
\hline 13.00 & 23.92 & 25.08 & 26.24 & 27.37 & 28.53 & 29.69 & 30.82 & 31.98 & 33.14 \\
\hline 14.00 & 24.54 & 25.71 & 26.89 & 28.04 & 29.21 & 30.38 & 31.54 & 32.71 & 33.88 \\
\hline 15.00 & 25.15 & 26.34 & 27.53 & 28.70 & 29.89 & 31.08 & 32.25 & 33.44 & 34.63 \\
\hline 16.00 & 25.66 & 26.87 & 28.08 & 29.27 & 30.48 & 31.69 & 32.88 & 34.09 & 35.30 \\
\hline 17.00 & 26.34 & 27.58 & 28.81 & 30.03 & 31.27 & 32.51 & 33.73 & 34.96 & 36.20 \\
\hline 18.00 & 26.76 & 28.02 & 29.27 & 30.51 & 31.77 & 33.03 & 34.27 & 35.52 & 36.78 \\
\hline 19.00 & 27.28 & 28.56 & 29.85 & 31.12 & 32.40 & 33.69 & 34.95 & 36.24 & 37.52 \\
\hline 20.00 & 27.80 & 29.12 & 30.43 & 31.73 & 33.04 & 34.35 & 35.65 & 36.96 & 38.28 \\
\hline 21.00 & 28.19 & 29.52 & 30.86 & 32.18 & 33.51 & 34.85 & 36.16 & 37.50 & 38.83 \\
\hline 22.00 & 28.63 & 29.99 & 31.35 & 32.68 & 34.04 & 35.40 & 36.74 & 38.09 & 39.45 \\
\hline 23.00 & 29.08 & 30.46 & 31.84 & 33.19 & 17.38 & 35.95 & 37.30 & 38.68 & 40.06 \\
\hline 24.00 & 29.52 & 30.92 & 32.31 & 33.68 & 18.40 & 36.46 & 37.83 & 39.22 & 40.62 \\
\hline & & & & & & & & & \\
\hline
\end{tabular}


Girls subischial leg length vs age; edf 666

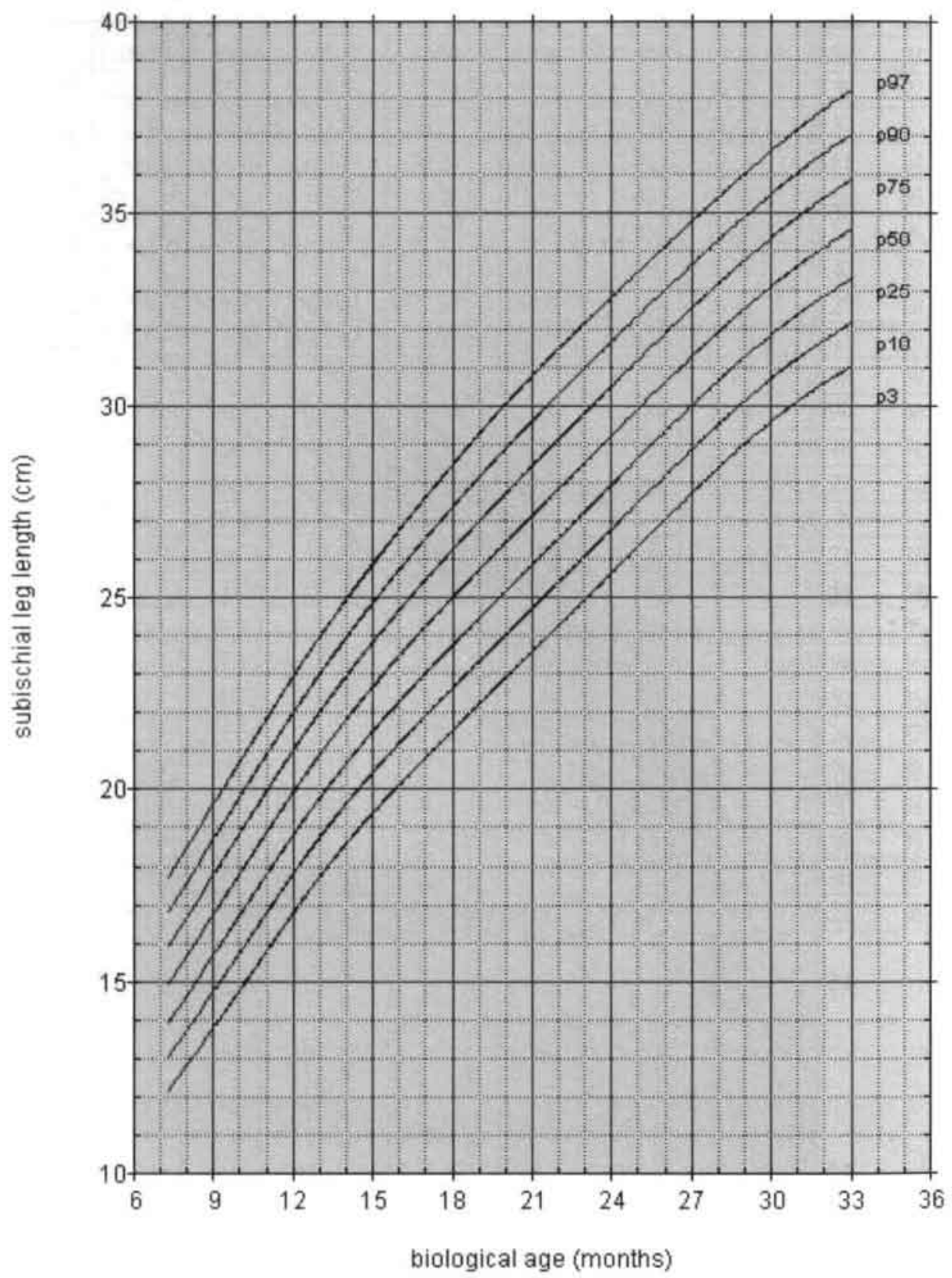


Girls subischial leg length vs age; edf 666

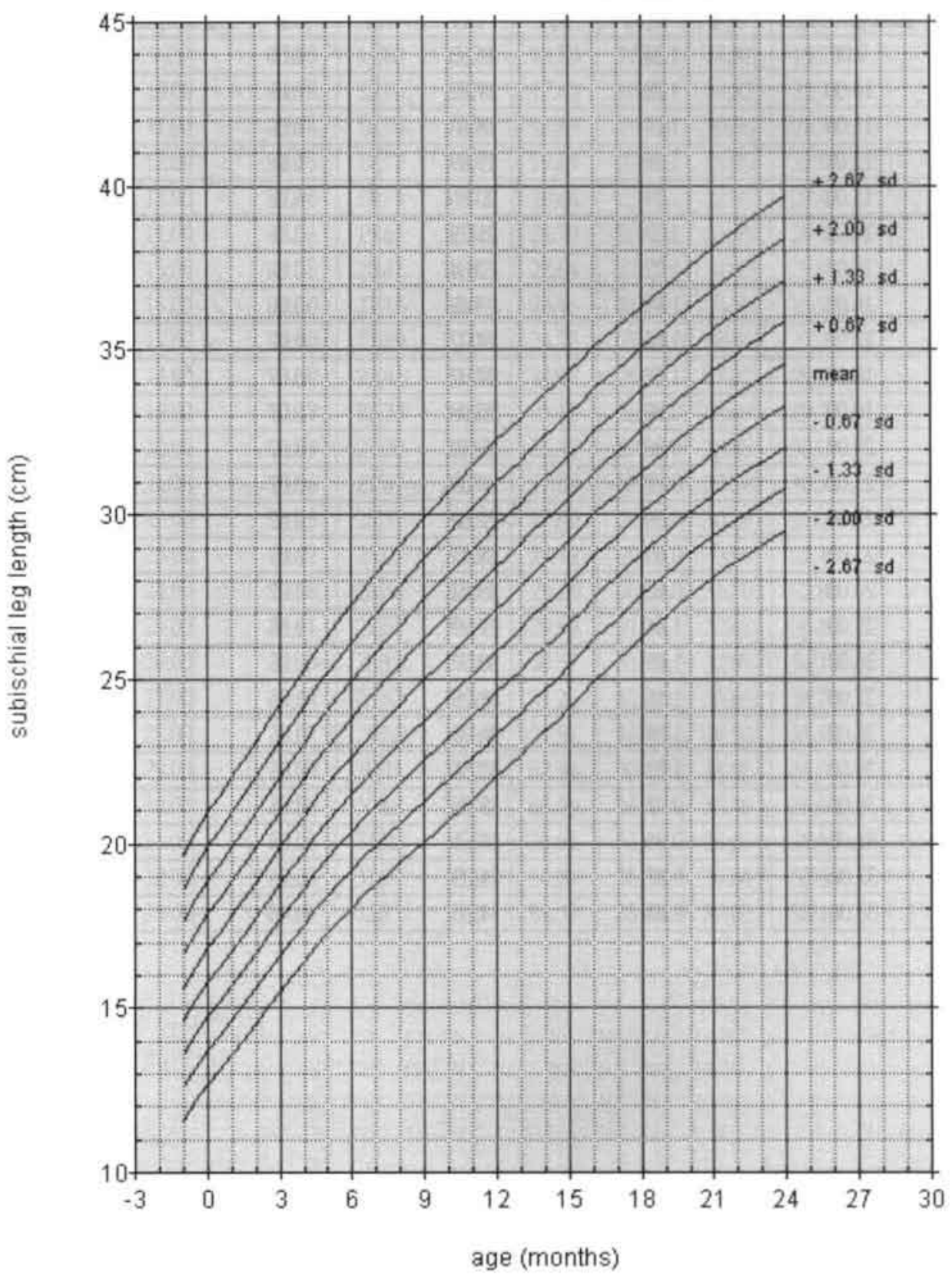




\begin{tabular}{|c|c|c|c|c|}
\hline \multicolumn{5}{|c|}{ Girls subischial leg length LMS values (edf 666) } \\
\hline biological age & $\mathrm{L}$ & $\mathrm{M}$ & $\mathrm{S}$ & $\mathrm{SD}$ \\
\hline 9.00 & 1.14 & 16.83 & 0.09 & 1.55 \\
\hline 10.00 & 1.23 & 17.82 & 0.09 & 1.58 \\
\hline 11.00 & 1.27 & 18.83 & 0.09 & 1.61 \\
\hline 12.00 & 1.26 & 19.89 & 0.08 & 1.63 \\
\hline 13.00 & 1.24 & 20.86 & 0.08 & 1.66 \\
\hline 14.00 & 1.23 & 21.79 & 0.08 & 1.69 \\
\hline 15.00 & 1.22 & 22.64 & 0.08 & 1.72 \\
\hline 16.00 & 1.19 & 23.46 & 0.08 & 1.76 \\
\hline 17.00 & 1.13 & 24.22 & 0.07 & 1.80 \\
\hline 18.00 & 1.03 & 24.97 & 0.07 & 1.84 \\
\hline 19.00 & 0.89 & 25.68 & 0.07 & 1.87 \\
\hline 20.00 & 0.80 & 26.40 & 0.07 & 1.90 \\
\hline 21.00 & 0.77 & 27.09 & 0.07 & 1.91 \\
\hline 22.00 & 0.79 & 27.80 & 0.07 & 1.92 \\
\hline 23.00 & 0.85 & 28.49 & 0.07 & 1.92 \\
\hline 24.00 & 0.95 & 29.24 & 0.07 & 1.91 \\
\hline 25.00 & 1.04 & 29.99 & 0.06 & 1.90 \\
\hline 26.00 & 1.09 & 30.57 & 0.06 & 1.89 \\
\hline 27.00 & 1.10 & 31.25 & 0.06 & 1.88 \\
\hline 28.00 & 1.08 & 31.91 & 0.06 & 1.87 \\
\hline 29.00 & 1.03 & 32.51 & 0.06 & 1.87 \\
\hline 30.00 & 0.97 & 33.08 & 0.06 & 1.88 \\
\hline 31.00 & 0.91 & 33.61 & 0.06 & 1.89 \\
\hline 32.00 & 0.87 & 34.09 & 0.06 & 1.90 \\
\hline 33.00 & 0.83 & 34.55 & 0.06 & 1.91 \\
\hline
\end{tabular}




\begin{tabular}{|c|c|c|c|c|c|c|c|}
\hline \multicolumn{6}{|c|}{ Girls subischial leg length (in cm) vs biological age (in months) } \\
\hline biological age & P3 & P10 & P25 & P50 & P75 & P90 & P97 \\
\hline 9.00 & 13.88 & 14.83 & 15.78 & 16.83 & 17.88 & 18.81 & 19.72 \\
\hline 10.00 & 14.78 & 15.76 & 16.74 & 17.82 & 18.88 & 19.82 & 20.74 \\
\hline 11.00 & 15.74 & 16.74 & 17.74 & 18.83 & 19.91 & 20.86 & 21.79 \\
\hline 12.00 & 16.75 & 17.77 & 18.78 & 19.89 & 20.98 & 21.95 & 22.90 \\
\hline 13.00 & 17.68 & 18.71 & 19.73 & 20.86 & 21.97 & 22.96 & 23.93 \\
\hline 14.00 & 18.56 & 19.61 & 20.65 & 21.79 & 22.92 & 23.93 & 24.92 \\
\hline 15.00 & 19.35 & 20.41 & 21.47 & 22.64 & 23.79 & 24.82 & 25.82 \\
\hline 16.00 & 20.10 & 21.18 & 22.27 & 23.46 & 24.64 & 25.70 & 26.73 \\
\hline 17.00 & 20.80 & 21.89 & 23.00 & 24.22 & 25.43 & 26.51 & 27.58 \\
\hline 18.00 & 21.50 & 22.61 & 23.73 & 24.97 & 26.21 & 27.32 & 28.42 \\
\hline 19.00 & 22.19 & 23.29 & 24.42 & 25.68 & 26.94 & 28.09 & 29.22 \\
\hline 20.00 & 22.89 & 24.00 & 25.13 & 26.40 & 27.69 & 28.85 & 30.01 \\
\hline 21.00 & 23.56 & 24.67 & 25.81 & 27.09 & 28.39 & 29.56 & 30.74 \\
\hline 22.00 & 24.25 & 25.37 & 26.52 & 27.80 & 29.10 & 30.28 & 31.46 \\
\hline 23.00 & 24.92 & 26.05 & 27.20 & 28.49 & 29.79 & 30.96 & 32.13 \\
\hline 24.00 & 25.66 & 26.80 & 27.95 & 29.24 & 30.53 & 31.70 & 32.85 \\
\hline 25.00 & 26.41 & 27.55 & 28.71 & 29.99 & 31.27 & 32.42 & 33.56 \\
\hline 26.00 & 27.00 & 28.14 & 29.29 & 30.57 & 31.85 & 32.99 & 34.11 \\
\hline 27.00 & 27.69 & 28.83 & 29.98 & 31.25 & 32.52 & 33.65 & 34.77 \\
\hline 28.00 & 28.37 & 29.50 & 30.64 & 31.91 & 33.17 & 34.30 & 35.42 \\
\hline 29.00 & 28.99 & 30.11 & 31.25 & 32.51 & 33.78 & 34.91 & 36.03 \\
\hline 30.00 & 29.56 & 30.68 & 31.82 & 33.08 & 34.35 & 35.49 & 36.62 \\
\hline 31.00 & 30.08 & 31.20 & 32.34 & 33.61 & 34.88 & 36.03 & 37.17 \\
\hline 32.00 & 30.55 & 31.67 & 32.81 & 34.09 & 35.38 & 36.54 & 37.69 \\
\hline 33.00 & 30.99 & 32.11 & 33.27 & 34.55 & 35.85 & 37.02 & 38.18 \\
\hline
\end{tabular}


Appendix B

\begin{tabular}{|c|c|c|c|c|c|c|c|c|c|}
\hline \multicolumn{8}{|c|}{ Girls subischial leg length (in cm) vs age (in months) } \\
\hline age & -2.76 SD & -2.00 SD & -1.33 SD & -0.67 SD & 0 SD & +0.67 SD & +1.33 SD & +2.00 SD & +2.67 SD \\
\hline 0.00 & 12.69 & 13.73 & 14.77 & 15.79 & 16.83 & 17.87 & 18.89 & 19.93 & 20.97 \\
\hline 1.00 & 13.60 & 14.66 & 15.72 & 16.76 & 17.82 & 18.88 & 19.92 & 20.98 & 22.04 \\
\hline 2.00 & 14.54 & 15.62 & 16.69 & 17.75 & 18.83 & 19.91 & 20.97 & 22.04 & 23.12 \\
\hline 3.00 & 15.53 & 16.63 & 17.72 & 18.80 & 19.89 & 20.98 & 22.06 & 23.15 & 24.25 \\
\hline 4.00 & 16.43 & 17.54 & 18.66 & 19.75 & 20.86 & 21.97 & 23.07 & 24.18 & 25.29 \\
\hline 5.00 & 17.29 & 18.42 & 19.55 & 20.66 & 21.79 & 22.92 & 24.03 & 25.16 & 26.29 \\
\hline 6.00 & 18.05 & 19.20 & 20.35 & 21.49 & 22.64 & 23.79 & 24.93 & 26.08 & 27.23 \\
\hline 7.00 & 18.76 & 19.94 & 21.12 & 22.28 & 23.46 & 24.64 & 25.80 & 26.98 & 28.16 \\
\hline 8.00 & 19.41 & 20.62 & 21.83 & 23.01 & 24.22 & 25.43 & 26.62 & 27.82 & 29.03 \\
\hline 9.00 & 20.06 & 21.29 & 22.52 & 23.74 & 24.97 & 26.20 & 27.42 & 28.65 & 29.88 \\
\hline 10.00 & 20.68 & 21.94 & 23.19 & 24.43 & 25.68 & 26.93 & 28.17 & 29.42 & 30.68 \\
\hline 11.00 & 21.34 & 22.61 & 23.88 & 25.13 & 26.40 & 27.67 & 28.92 & 30.19 & 31.46 \\
\hline 12.00 & 21.99 & 23.27 & 24.55 & 25.81 & 27.09 & 28.37 & 29.63 & 30.91 & 32.19 \\
\hline 13.00 & 22.68 & 23.97 & 25.25 & 26.52 & 27.80 & 29.08 & 30.35 & 31.63 & 32.92 \\
\hline 14.00 & 23.37 & 24.66 & 25.94 & 27.21 & 28.49 & 29.77 & 31.04 & 32.32 & 33.61 \\
\hline 15.00 & 24.14 & 25.42 & 26.70 & 27.96 & 29.24 & 30.52 & 31.78 & 33.06 & 34.34 \\
\hline 16.00 & 24.92 & 26.19 & 27.46 & 28.72 & 29.99 & 31.26 & 32.52 & 33.79 & 35.06 \\
\hline 17.00 & 25.52 & 26.79 & 28.06 & 29.30 & 30.57 & 31.84 & 33.09 & 34.35 & 35.62 \\
\hline 18.00 & 26.23 & 27.49 & 28.75 & 29.99 & 31.25 & 32.51 & 33.75 & 35.01 & 36.27 \\
\hline 19.00 & 26.91 & 28.16 & 29.42 & 30.65 & 31.91 & 33.17 & 34.40 & 35.66 & 36.91 \\
\hline 20.00 & 27.51 & 28.77 & 30.02 & 31.26 & 32.51 & 33.76 & 35.00 & 36.25 & 37.51 \\
\hline 21.00 & 28.07 & 29.33 & 30.58 & 31.82 & 33.08 & 34.34 & 35.58 & 36.83 & 38.09 \\
\hline 22.00 & 28.57 & 29.84 & 31.10 & 32.35 & 33.61 & 34.87 & 36.12 & 37.38 & 38.65 \\
\hline 23.00 & 29.02 & 30.29 & 31.56 & 32.82 & 34.09 & 35.36 & 36.62 & 37.89 & 39.16 \\
\hline 24.00 & 29.44 & 30.72 & 32.00 & 33.27 & 34.55 & 35.83 & 37.10 & 38.38 & 39.66 \\
\hline
\end{tabular}


Weight vs supine length

\begin{tabular}{|c|c|c|c|}
\hline Boys & \multicolumn{3}{|c|}{ Weight vs supine length } \\
\hline Edf: 7 7 7 (7.00 7.04 7.00) & N:6047 & Nc: 547 \\
\hline Range & Expected & Observed & Difference \\
\hline <P3 & 181.4 & 191 & 9.6 \\
\hline P3-P10 & 423.3 & 407 & -16.3 \\
\hline P10-P25 & 907.1 & 863 & -44.1 \\
\hline P25-P50 & 1511.8 & 1556 & 44.2 \\
\hline P50-P75 & 1511.8 & 1555 & 43.2 \\
\hline P75-P90 & 907.1 & 829 & -78.1 \\
\hline P90-P97 & 423.3 & 467 & 43.7 \\
\hline >P97 & 181.4 & 179 & -2.4 \\
\hline
\end{tabular}

\begin{tabular}{|c|c|c|c|}
\hline Girls & \multicolumn{3}{|c|}{ Weight vs supine length } \\
\hline Edf: 1 77 (1.00 7.01 7.00) & N:5158 & Nc: 501 \\
\hline Range & Expected & Observed & Difference \\
\hline <P3 & 154.7 & 128 & -26.7 \\
\hline P3-P10 & 361.1 & 384 & 22.9 \\
\hline P10-P25 & 773.7 & 787 & 13.3 \\
\hline P25-P 50 & 1289.5 & 1276 & -13.5 \\
\hline P50-P75 & 1289.5 & 1337 & 47.5 \\
\hline P75-P90 & 773.7 & 734 & -39.7 \\
\hline P90-P97 & 361.1 & 344 & -17.1 \\
\hline >P97 & 154.7 & 168 & 13.3 \\
\hline
\end{tabular}


Boys weight vs supine length; edf 777

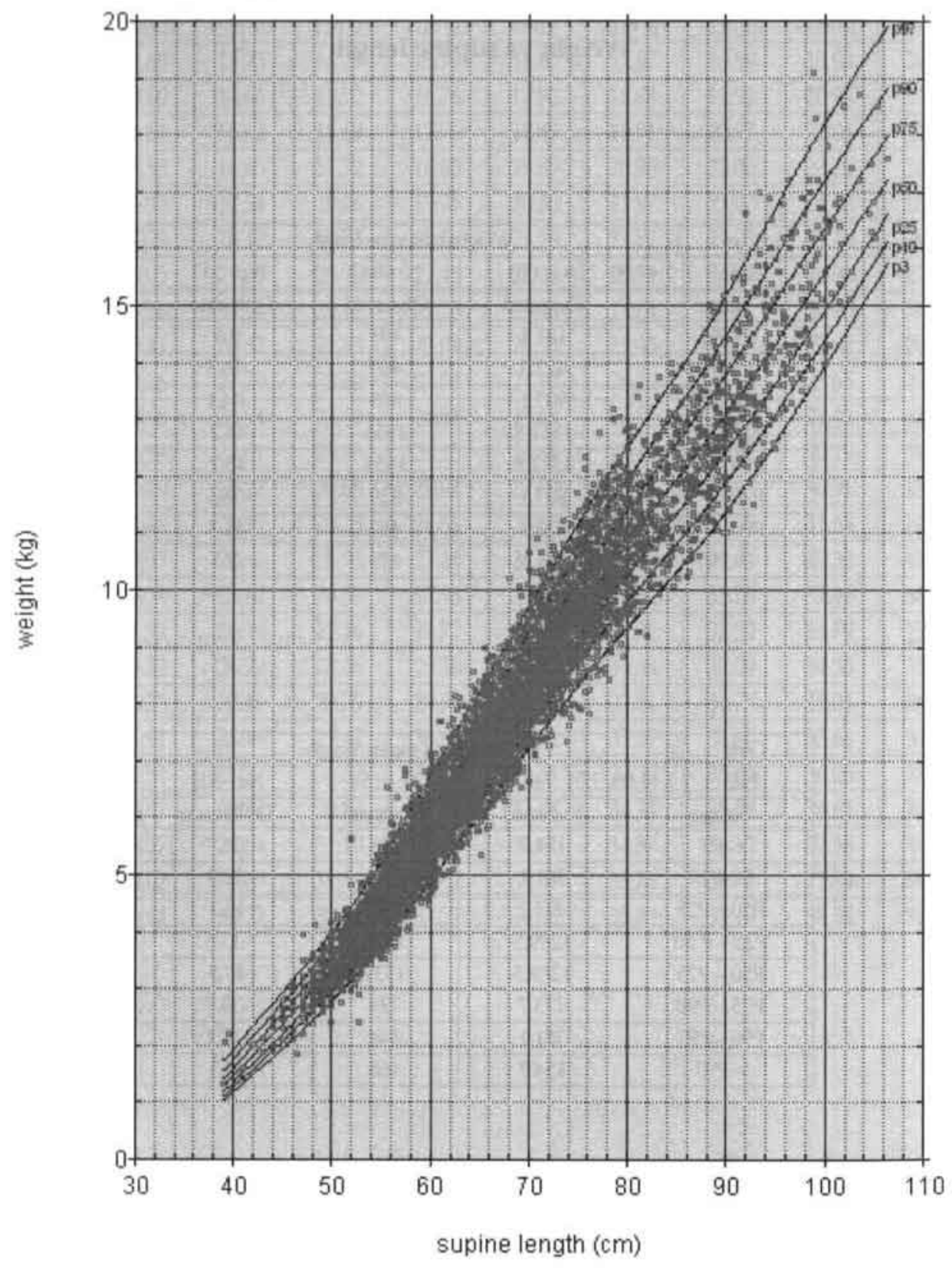


Boys weight vs supine length; edf 777

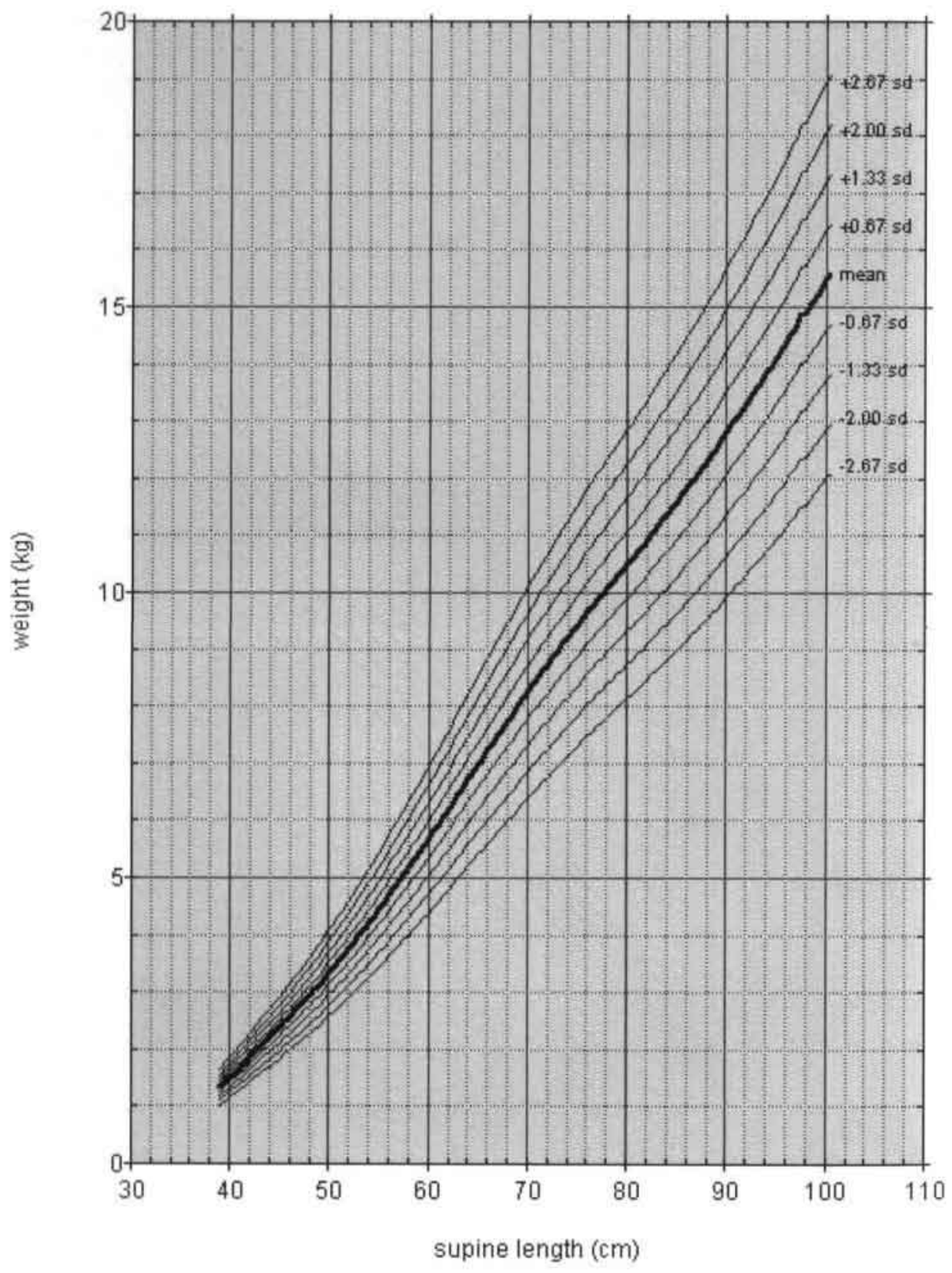


Boys weight vs supine length LMS values (edf 777)

\begin{tabular}{|c|c|c|c|c|}
\multicolumn{5}{|c|}{ Boys weight vs supine length LMS values(edf 777) } \\
\hline Supine length & L & M & S & SD \\
\hline 39.00 & -1.32 & 1.29 & 0.13 & 0.17 \\
\hline 41.00 & -0.90 & 1.66 & 0.12 & 0.20 \\
\hline 42.00 & -0.69 & 1.84 & 0.12 & 0.22 \\
\hline 43.00 & -0.50 & 2.02 & 0.12 & 0.23 \\
\hline 44.00 & -0.32 & 2.20 & 0.11 & 0.25 \\
\hline 45.00 & -0.16 & 2.39 & 0.11 & 0.26 \\
\hline 46.00 & -0.02 & 2.57 & 0.11 & 0.27 \\
\hline 47.00 & 0.10 & 2.76 & 0.10 & 0.29 \\
\hline 48.00 & 0.19 & 2.95 & 0.10 & 0.30 \\
\hline 49.00 & 0.27 & 3.15 & 0.10 & 0.31 \\
\hline 50.00 & 0.32 & 3.35 & 0.10 & 0.32 \\
\hline 51.00 & 0.34 & 3.55 & 0.09 & 0.33 \\
\hline 52.00 & 0.34 & 3.76 & 0.09 & 0.34 \\
\hline 53.00 & 0.31 & 3.98 & 0.09 & 0.36 \\
\hline 54.00 & 0.23 & 4.21 & 0.09 & 0.38 \\
\hline 55.00 & 0.14 & 4.44 & 0.09 & 0.39 \\
\hline 56.00 & 0.04 & 4.69 & 0.09 & 0.41 \\
\hline 57.00 & -0.06 & 4.94 & 0.09 & 0.43 \\
\hline 58.00 & -0.13 & 5.20 & 0.09 & 0.45 \\
\hline 59.00 & -0.19 & 5.46 & 0.09 & 0.47 \\
\hline 60.00 & -0.24 & 5.72 & 0.08 & 0.49 \\
\hline 61.00 & -0.28 & 5.98 & 0.08 & 0.50 \\
\hline 62.00 & -0.30 & 6.25 & 0.08 & 0.52 \\
\hline 63.00 & -0.31 & 6.51 & 0.08 & 0.54 \\
\hline 64.00 & -0.31 & 6.77 & 0.08 & 0.55 \\
\hline 65.00 & -0.30 & 7.03 & 0.08 & 0.57 \\
\hline 66.00 & -0.30 & 7.29 & 0.08 & 0.59 \\
\hline 67.00 & -0.30 & 7.55 & 0.08 & 0.61 \\
\hline 68.00 & -0.31 & 7.82 & 0.08 & 0.63 \\
\hline 69.00 & -0.32 & 8.08 & 0.08 & 0.64 \\
\hline 70.00 & -0.33 & 8.35 & 0.08 & 0.66 \\
\hline 71.00 & -0.31 & 8.61 & 0.08 & 0.68 \\
\hline 72.00 & -0.28 & 8.87 & 0.08 & 0.70 \\
\hline 73.00 & -0.22 & 9.13 & 0.08 & 0.72 \\
\hline 74.00 & -0.16 & 9.39 & 0.08 & 0.74 \\
\hline 75.00 & -0.11 & 9.64 & 0.08 & 0.76 \\
\hline 76.00 & -0.07 & 9.89 & 0.08 & 0.78 \\
\hline 77.00 & -0.03 & 10.13 & 0.08 & 0.79 \\
\hline 78.00 & 0.01 & 10.37 & 0.08 & 0.81 \\
\hline & & & & \\
\hline
\end{tabular}


Appendix B

\begin{tabular}{|c|c|c|c|c|}
\hline \multicolumn{5}{|c|}{ Boys weight vs supine length LMS values (edf 777) } \\
\hline Supine length & L & M & S & SD \\
\hline 79.00 & 0.04 & 10.60 & 0.08 & 0.83 \\
\hline 80.00 & 0.08 & 10.83 & 0.08 & 0.84 \\
\hline 81.00 & 0.12 & 11.06 & 0.08 & 0.86 \\
\hline 82.00 & 0.15 & 11.28 & 0.08 & 0.87 \\
\hline 83.00 & 0.17 & 11.51 & 0.08 & 0.89 \\
\hline 84.00 & 0.18 & 11.73 & 0.08 & 0.91 \\
\hline 85.00 & 0.17 & 11.95 & 0.08 & 0.92 \\
\hline 86.00 & 0.13 & 12.18 & 0.08 & 0.94 \\
\hline 87.00 & 0.06 & 12.41 & 0.08 & 0.96 \\
\hline 88.00 & -0.04 & 12.63 & 0.08 & 0.97 \\
\hline 89.00 & -0.16 & 12.87 & 0.08 & 0.99 \\
\hline 90.00 & -0.30 & 13.10 & 0.08 & 1.00 \\
\hline 91.00 & -0.47 & 13.34 & 0.08 & 1.02 \\
\hline 92.00 & -0.67 & 13.58 & 0.08 & 1.03 \\
\hline 93.00 & -0.88 & 13.82 & 0.08 & 1.05 \\
\hline 94.00 & -1.10 & 14.07 & 0.08 & 1.06 \\
\hline 95.00 & -1.33 & 14.32 & 0.07 & 1.06 \\
\hline 96.00 & -1.57 & 14.57 & 0.07 & 1.07 \\
\hline 97.00 & -1.81 & 14.82 & 0.07 & 1.07 \\
\hline 98.00 & -2.05 & 15.07 & 0.07 & 1.07 \\
\hline 99.00 & -2.29 & 15.33 & 0.07 & 1.07 \\
\hline 100.00 & -2.53 & 15.58 & 0.07 & 1.07 \\
\hline 101.00 & -2.76 & 15.83 & 0.07 & 1.06 \\
\hline & & & & \\
\hline
\end{tabular}




\begin{tabular}{|c|c|c|c|c|c|c|c|}
\hline \multicolumn{7}{|c|}{ Boys weight (in kg) vs supine length (in cm) } \\
\hline Supine length & P3 & P10 & P25 & P50 & P75 & P90 & P97 \\
\hline 39.00 & 1.05 & 1.11 & 1.19 & 1.29 & 1.42 & 1.56 & 1.73 \\
\hline 41.00 & 1.34 & 1.43 & 1.53 & 1.66 & 1.80 & 1.96 & 2.14 \\
\hline 42.00 & 1.49 & 1.59 & 1.70 & 1.84 & 2.00 & 2.16 & 2.34 \\
\hline 43.00 & 1.64 & 1.75 & 1.87 & 2.02 & 2.19 & 2.36 & 2.54 \\
\hline 44.00 & 1.79 & 1.91 & 2.04 & 2.20 & 2.38 & 2.55 & 2.74 \\
\hline 45.00 & 1.95 & 2.08 & 2.22 & 2.39 & 2.57 & 2.75 & 2.94 \\
\hline 46.00 & 2.11 & 2.24 & 2.39 & 2.57 & 2.76 & 2.95 & 3.14 \\
\hline 47.00 & 2.27 & 2.42 & 2.57 & 2.76 & 2.96 & 3.15 & 3.35 \\
\hline 48.00 & 2.44 & 2.59 & 2.76 & 2.95 & 3.16 & 3.35 & 3.56 \\
\hline 49.00 & 2.61 & 2.77 & 2.95 & 3.15 & 3.36 & 3.56 & 3.77 \\
\hline 50.00 & 2.78 & 2.95 & 3.14 & 3.35 & 3.57 & 3.77 & 3.98 \\
\hline 51.00 & 2.96 & 3.14 & 3.33 & 3.55 & 3.78 & 3.99 & 4.21 \\
\hline 52.00 & 3.15 & 3.34 & 3.53 & 3.76 & 4.00 & 4.22 & 4.45 \\
\hline 53.00 & 3.34 & 3.54 & 3.74 & 3.98 & 4.23 & 4.46 & 4.70 \\
\hline 54.00 & 3.55 & 3.75 & 3.96 & 4.21 & 4.47 & 4.71 & 4.96 \\
\hline 55.00 & 3.76 & 3.97 & 4.19 & 4.45 & 4.72 & 4.97 & 5.24 \\
\hline 56.00 & 3.97 & 4.19 & 4.42 & 4.69 & 4.98 & 5.25 & 5.53 \\
\hline 57.00 & 4.20 & 4.42 & 4.66 & 4.94 & 5.24 & 5.53 & 5.83 \\
\hline 58.00 & 4.43 & 4.66 & 4.91 & 5.20 & 5.51 & 5.82 & 6.13 \\
\hline 59.00 & 4.66 & 4.90 & 5.16 & 5.46 & 5.79 & 6.10 & 6.43 \\
\hline 60.00 & 4.89 & 5.14 & 5.41 & 5.72 & 6.06 & 6.39 & 6.73 \\
\hline 61.00 & 5.13 & 5.38 & 5.66 & 5.98 & 6.34 & 6.67 & 7.03 \\
\hline 62.00 & 5.36 & 5.63 & 5.91 & 6.25 & 6.61 & 6.96 & 7.33 \\
\hline 63.00 & 5.59 & 5.87 & 6.16 & 6.51 & 6.88 & 7.24 & 7.62 \\
\hline 64.00 & 5.82 & 6.10 & 6.41 & 6.77 & 7.15 & 7.53 & 7.92 \\
\hline 65.00 & 6.05 & 6.34 & 6.66 & 7.03 & 7.43 & 7.81 & 8.22 \\
\hline 66.00 & 6.28 & 6.58 & 6.91 & 7.29 & 7.70 & 8.10 & 8.52 \\
\hline 67.00 & 6.51 & 6.82 & 7.16 & 7.55 & 7.98 & 8.39 & 8.82 \\
\hline 68.00 & 6.75 & 7.07 & 7.41 & 7.82 & 8.25 & 8.68 & 9.12 \\
\hline 69.00 & 6.98 & 7.31 & 7.66 & 8.08 & 8.53 & 8.97 & 9.42 \\
\hline 70.00 & 7.21 & 7.55 & 7.92 & 8.35 & 8.81 & 9.26 & 9.73 \\
\hline 71.00 & 7.45 & 7.79 & 8.17 & 8.61 & 9.09 & 9.55 & 10.03 \\
\hline 72.00 & 7.68 & 8.03 & 8.42 & 8.87 & 9.36 & 9.83 & 10.32 \\
\hline 73.00 & 7.90 & 8.27 & 8.67 & 9.13 & 9.63 & 10.11 & 10.61 \\
\hline 74.00 & 8.12 & 8.50 & 8.91 & 9.39 & 9.90 & 10.39 & 10.90 \\
\hline 75.00 & 8.33 & 8.73 & 9.15 & 9.64 & 10.17 & 10.67 & 11.19 \\
\hline 76.00 & 8.54 & 8.95 & 9.38 & 9.89 & 10.43 & 10.94 & 11.47 \\
\hline 77.00 & 8.75 & 9.17 & 9.61 & 10.13 & 10.68 & 11.20 & 11.74 \\
\hline 78.00 & 8.95 & 9.38 & 9.84 & 10.37 & 10.93 & 11.46 & 12.01 \\
\hline & & & & & & & \\
\hline
\end{tabular}




\begin{tabular}{|c|c|c|c|c|c|c|c|}
\hline \multicolumn{7}{|c|}{ Boys weight (in kg) vs supine length ( in cm) } \\
\hline Supine length & P3 & P10 & P25 & P50 & P75 & P90 & P97 \\
\hline 79.00 & 9.15 & 9.59 & 10.06 & 10.60 & 11.18 & 11.72 & 12.28 \\
\hline 80.00 & 9.35 & 9.80 & 10.28 & 10.83 & 11.42 & 11.97 & 12.53 \\
\hline 81.00 & 9.54 & 10.01 & 10.49 & 11.06 & 11.65 & 12.21 & 12.78 \\
\hline 82.00 & 9.74 & 10.21 & 10.71 & 11.28 & 11.89 & 12.45 & 13.03 \\
\hline 83.00 & 9.93 & 10.41 & 10.92 & 11.51 & 12.12 & 12.70 & 13.28 \\
\hline 84.00 & 10.13 & 10.62 & 11.13 & 11.73 & 12.35 & 12.94 & 13.54 \\
\hline 85.00 & 10.32 & 10.82 & 11.35 & 11.95 & 12.59 & 13.19 & 13.80 \\
\hline 86.00 & 10.52 & 11.03 & 11.56 & 12.18 & 12.83 & 13.43 & 14.06 \\
\hline 87.00 & 10.73 & 11.24 & 11.78 & 12.41 & 13.07 & 13.69 & 14.33 \\
\hline 88.00 & 10.94 & 11.45 & 12.00 & 12.63 & 13.31 & 13.95 & 14.61 \\
\hline 89.00 & 11.15 & 11.67 & 12.22 & 12.87 & 13.55 & 14.21 & 14.89 \\
\hline 90.00 & 11.38 & 11.89 & 12.45 & 13.10 & 13.80 & 14.47 & 15.18 \\
\hline 91.00 & 11.61 & 12.12 & 12.68 & 13.34 & 14.05 & 14.75 & 15.48 \\
\hline 92.00 & 11.85 & 12.36 & 12.91 & 13.58 & 14.31 & 15.02 & 15.78 \\
\hline 93.00 & 12.09 & 12.60 & 13.15 & 13.82 & 14.56 & 15.30 & 16.09 \\
\hline 94.00 & 12.34 & 12.84 & 13.39 & 14.07 & 14.82 & 15.57 & 16.40 \\
\hline 95.00 & 12.60 & 13.09 & 13.64 & 14.32 & 15.08 & 15.85 & 16.71 \\
\hline 96.00 & 12.86 & 13.34 & 13.89 & 14.57 & 15.34 & 16.13 & 17.02 \\
\hline 97.00 & 13.12 & 13.60 & 14.14 & 14.82 & 15.60 & 16.40 & 17.32 \\
\hline 98.00 & 13.39 & 13.86 & 14.40 & 15.07 & 15.85 & 16.67 & 17.62 \\
\hline 99.00 & 13.66 & 14.13 & 14.66 & 15.33 & 16.11 & 16.94 & 17.92 \\
\hline 100.00 & 13.94 & 14.39 & 14.91 & 15.58 & 16.36 & 17.20 & 18.21 \\
\hline 101.00 & 14.21 & 14.66 & 15.18 & 15.84 & 16.62 & 17.47 & 18.49 \\
\hline & & & & & & & \\
\hline
\end{tabular}




\section{Boys weight (in $\mathrm{kg}$ ) vs supine length (in $\mathrm{cm}$ )}

\begin{tabular}{|c|c|c|c|c|c|c|c|c|c|}
\hline $\begin{array}{l}\text { Supine } \\
\text { length }\end{array}$ & $-2.76 \mathrm{SD}$ & $-2.00 \mathrm{SD}$ & $-1.33 \mathrm{SD}$ & $-0.67 \mathrm{SD}$ & $0 \mathrm{SD}$ & $+0.67 \mathrm{SD}$ & $+1.33 \mathrm{SD}$ & $+2.00 \mathrm{SD}$ & $+2.67 \mathrm{SD}$ \\
\hline 39.00 & 0.84 & 0.96 & 1.07 & 1.18 & 1.29 & 1.40 & 1.51 & 1.62 & 1.74 \\
\hline 41.00 & 1.12 & 1.25 & 1.39 & 1.52 & 1.66 & 1.80 & 1.93 & 2.07 & 2.20 \\
\hline 42.00 & 1.26 & 1.40 & 1.55 & 1.69 & 1.84 & 1.99 & 2.13 & 2.28 & 2.42 \\
\hline 43.00 & 1.40 & 1.55 & 1.71 & 1.86 & 2.02 & 2.18 & 2.33 & 2.49 & 2.64 \\
\hline 44.00 & 1.54 & 1.70 & 1.87 & 2.03 & 2.20 & 2.37 & 2.53 & 2.70 & 2.86 \\
\hline 45.00 & 1.69 & 1.87 & 2.04 & 2.22 & 2.39 & 2.56 & 2.74 & 2.91 & 3.09 \\
\hline 46.00 & 1.84 & 2.02 & 2.21 & 2.39 & 2.57 & 2.75 & 2.93 & 3.12 & 3.30 \\
\hline 47.00 & 2.00 & 2.19 & 2.38 & 2.57 & 2.76 & 2.95 & 3.14 & 3.33 & 3.52 \\
\hline 48.00 & 2.16 & 2.36 & 2.56 & 2.75 & 2.95 & 3.15 & 3.35 & 3.54 & 3.74 \\
\hline 49.00 & 2.33 & 2.53 & 2.74 & 2.94 & 3.15 & 3.36 & 3.56 & 3.77 & 3.97 \\
\hline 50.00 & 2.50 & 2.71 & 2.93 & 3.14 & 3.35 & 3.56 & 3.77 & 3.99 & 4.20 \\
\hline 51.00 & 2.67 & 2.89 & 3.11 & 3.33 & 3.55 & 3.77 & 3.99 & 4.21 & 4.43 \\
\hline 52.00 & 2.84 & 3.07 & 3.30 & 3.53 & 3.76 & 3.99 & 4.22 & 4.45 & 4.68 \\
\hline 53.00 & 3.02 & 3.26 & 3.50 & 3.74 & 3.98 & 4.22 & 4.46 & 4.70 & 4.94 \\
\hline 54.00 & 3.21 & 3.46 & 3.71 & 3.96 & 4.21 & 4.46 & 4.71 & 4.96 & 5.21 \\
\hline 55.00 & 3.39 & 3.65 & 3.92 & 4.18 & 4.44 & 4.70 & 4.96 & 5.23 & 5.49 \\
\hline 56.00 & 3.59 & 3.87 & 4.14 & 4.41 & 4.69 & 4.97 & 5.24 & 5.51 & 5.79 \\
\hline 57.00 & 3.79 & 4.08 & 4.37 & 4.65 & 4.94 & 5.23 & 5.51 & 5.80 & 6.09 \\
\hline 58.00 & 4.00 & 4.30 & 4.60 & 4.90 & 5.20 & 5.50 & 5.80 & 6.10 & 6.40 \\
\hline 59.00 & 4.21 & 4.53 & 4.84 & 5.15 & 5.46 & 5.77 & 6.08 & 6.39 & 6.71 \\
\hline 60.00 & 4.43 & 4.75 & 5.07 & 5.40 & 5.72 & 6.05 & 6.37 & 6.69 & 7.01 \\
\hline 61.00 & 4.64 & 4.98 & 5.31 & 5.64 & 5.98 & 6.32 & 6.65 & 6.98 & 7.32 \\
\hline 62.00 & 4.87 & 5.21 & 5.56 & 5.90 & 6.25 & 6.60 & 6.94 & 7.29 & 7.63 \\
\hline 63.00 & 5.08 & 5.44 & 5.80 & 6.15 & 6.51 & 6.87 & 7.22 & 7.58 & 7.94 \\
\hline 64.00 & 5.30 & 5.67 & 6.04 & 6.40 & 6.77 & 7.14 & 7.50 & 7.87 & 8.24 \\
\hline 65.00 & 5.51 & 5.89 & 6.27 & 6.65 & 7.03 & 7.41 & 7.79 & 8.17 & 8.55 \\
\hline 66.00 & 5.72 & 6.11 & 6.51 & 6.90 & 7.29 & 7.68 & 8.07 & 8.47 & 8.86 \\
\hline 67.00 & 5.93 & 6.34 & 6.74 & 7.14 & 7.55 & 7.96 & 8.36 & 8.76 & 9.17 \\
\hline 68.00 & 6.15 & 6.57 & 6.99 & 7.40 & 7.82 & 8.24 & 8.65 & 9.07 & 9.49 \\
\hline 69.00 & 6.36 & 6.79 & 7,22 & 7.65 & 8.08 & 8.51 & 8.94 & 9.37 & 9.80 \\
\hline 70.00 & 6.58 & 7.02 & 7.47 & 7.91 & 8.35 & 8.79 & 9.23 & 9.68 & 10.12 \\
\hline 71.00 & 6.79 & 7.25 & 7.70 & 8.15 & 8.61 & 9.07 & 9.52 & 9.97 & 10.43 \\
\hline 72.00 & 7.00 & 7.47 & 7.94 & 8.40 & 8.87 & 9.34 & 9.80 & 10.27 & 10.74 \\
\hline 73.00 & 7.22 & 7.70 & 8.18 & 8.65 & 9.13 & 9.61 & 10.08 & 10.56 & 11.04 \\
\hline 74.00 & 7.42 & 7.92 & 8.41 & 8.90 & 9.39 & 9.88 & 10.37 & 10.86 & 11.36 \\
\hline 75.00 & 7.62 & 8.13 & 8.63 & 9.13 & 9.64 & 10.15 & 10.65 & 11.15 & 11.66 \\
\hline 76.00 & 7.82 & 8.34 & 8.86 & 9.37 & 9.89 & 10.41 & 10.92 & 11.44 & 11.96 \\
\hline 77.00 & 8.01 & 8.54 & 9.07 & 9.60 & 10.13 & 10.66 & 11.19 & 11.72 & 12.25 \\
\hline 78.00 & 8.20 & 8.75 & 9.29 & 9.83 & 10.37 & 10.91 & 11.45 & 11.99 & 12.54 \\
\hline
\end{tabular}


Appendix B

\begin{tabular}{|c|c|c|c|c|c|c|c|c|c|}
\hline \multicolumn{8}{|c|}{ Boys weight (in kg) vs supine length (in cm) } \\
\hline $\begin{array}{c}\text { Supine } \\
\text { length }\end{array}$ & -2.76 SD & -2.00 SD & -1.33 SD & -0.67 SD & 0 SD & +0.67 SD & +1.33 SD & +2.00 SD & +2.67 SD \\
\hline 79.00 & 8.39 & 8.94 & 9.50 & 10.05 & 10.60 & 11.16 & 11.70 & 12.26 & 12.81 \\
\hline 80.00 & 8.58 & 9.14 & 9.71 & 10.27 & 10.83 & 11.40 & 11.95 & 12.52 & 13.08 \\
\hline 81.00 & 8.77 & 9.34 & 9.92 & 10.48 & 11.06 & 11.64 & 12.20 & 12.78 & 13.35 \\
\hline 82.00 & 8.95 & 9.53 & 10.12 & 10.69 & 11.28 & 11.87 & 12.44 & 13.03 & 13.61 \\
\hline 83.00 & 9.13 & 9.73 & 10.33 & 10.91 & 11.51 & 12.11 & 12.69 & 13.29 & 13.89 \\
\hline 84.00 & 9.31 & 9.92 & 10.53 & 11.12 & 11.73 & 12.34 & 12.94 & 13.54 & 14.15 \\
\hline 85.00 & 9.49 & 10.11 & 10.72 & 11.33 & 11.95 & 12.57 & 13.18 & 13.79 & 14.41 \\
\hline 86.00 & 9.68 & 10.30 & 10.93 & 11.55 & 12.18 & 12.81 & 13.43 & 14.06 & 14.68 \\
\hline 87.00 & 9.86 & 10.50 & 11.14 & 11.77 & 12.41 & 13.05 & 13.68 & 14.32 & 14.96 \\
\hline 88.00 & 10.04 & 10.69 & 11.34 & 11.98 & 12.63 & 13.28 & 13.92 & 14.57 & 15.22 \\
\hline 89.00 & 10.23 & 10.89 & 11.56 & 12.21 & 12.87 & 13.53 & 14.18 & 14.85 & 15.51 \\
\hline 90.00 & 10.42 & 11.09 & 11.77 & 12.43 & 13.10 & 13.77 & 14.44 & 15.11 & 15.78 \\
\hline 91.00 & 10.62 & 11.30 & 11.99 & 12.66 & 13.34 & 14.02 & 14.70 & 15.38 & 16.06 \\
\hline 92.00 & 10.82 & 11.51 & 12.21 & 12.89 & 13.58 & 14.27 & 14.95 & 15.65 & 16.34 \\
\hline 93.00 & 11.03 & 11.73 & 12.43 & 13.12 & 13.82 & 14.52 & 15.21 & 15.91 & 16.61 \\
\hline 94.00 & 11.25 & 11.96 & 12.67 & 13.36 & 14.07 & 14.78 & 15.47 & 16.18 & 16.89 \\
\hline 95.00 & 11.48 & 12.19 & 12.91 & 13.61 & 14.32 & 15.03 & 15.73 & 16.45 & 17.16 \\
\hline 96.00 & 11.72 & 12.43 & 13.15 & 13.85 & 14.57 & 15.29 & 15.99 & 16.71 & 17.42 \\
\hline 97.00 & 11.96 & 12.68 & 13.40 & 14.10 & 14.82 & 15.54 & 16.24 & 16.96 & 17.68 \\
\hline 98.00 & 12.21 & 12.93 & 13.64 & 14.35 & 15.07 & 15.79 & 16.50 & 17.21 & 17.93 \\
\hline 99.00 & 12.47 & 13.19 & 13.91 & 14.61 & 15.33 & 16.05 & 16.75 & 17.47 & 18.19 \\
\hline 100.00 & 12.73 & 13.45 & 14.16 & 14.87 & 15.58 & 16.29 & 17.00 & 17.71 & 18.43 \\
\hline 101.00 & 13.00 & 13.71 & 14.42 & 15.12 & 15.83 & 16.54 & 17.24 & 17.95 & 18.66 \\
\hline
\end{tabular}




\section{Girls weight vs supine length; edf 177}

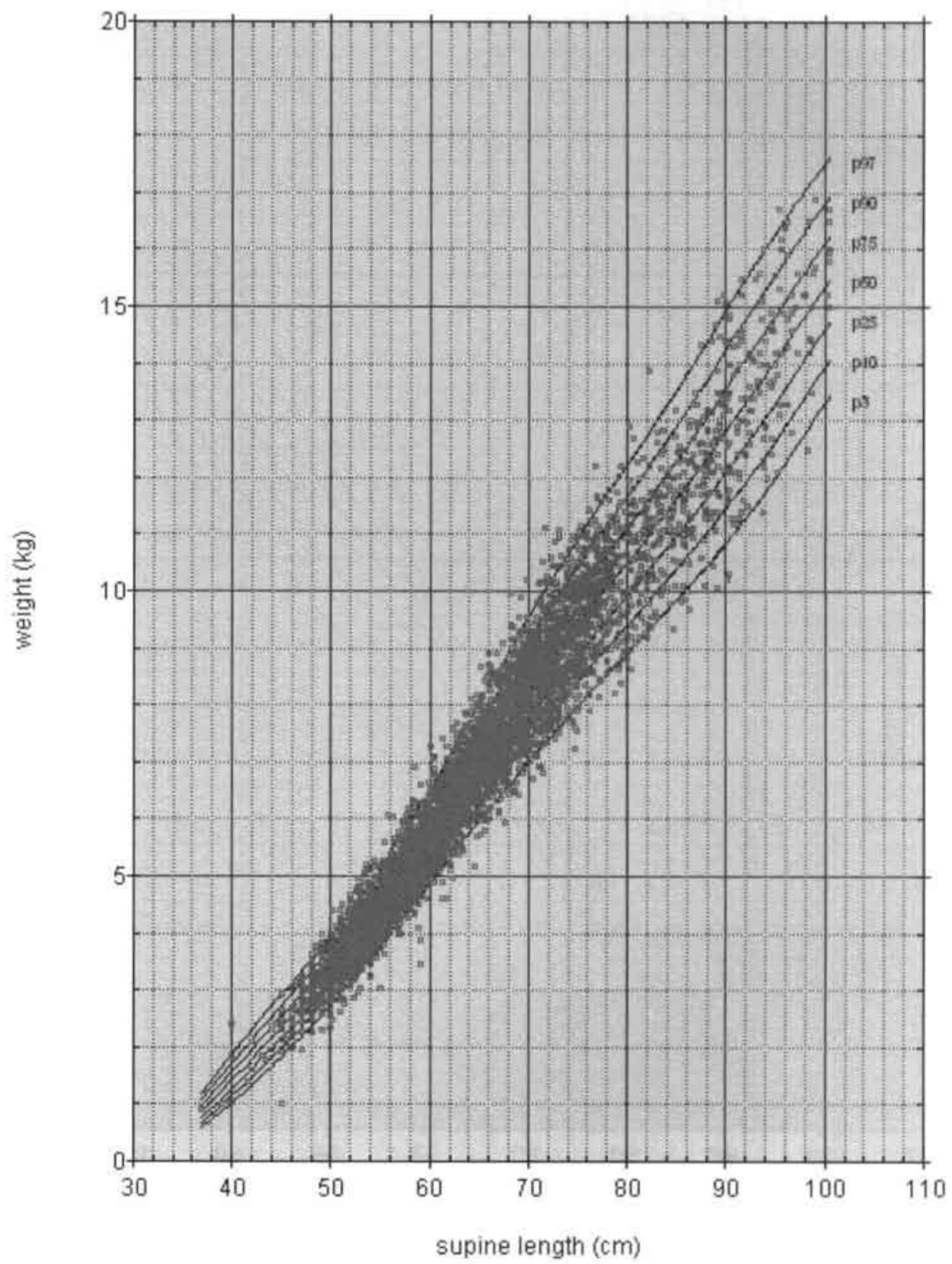


Girls weight vs supine length; edf 177

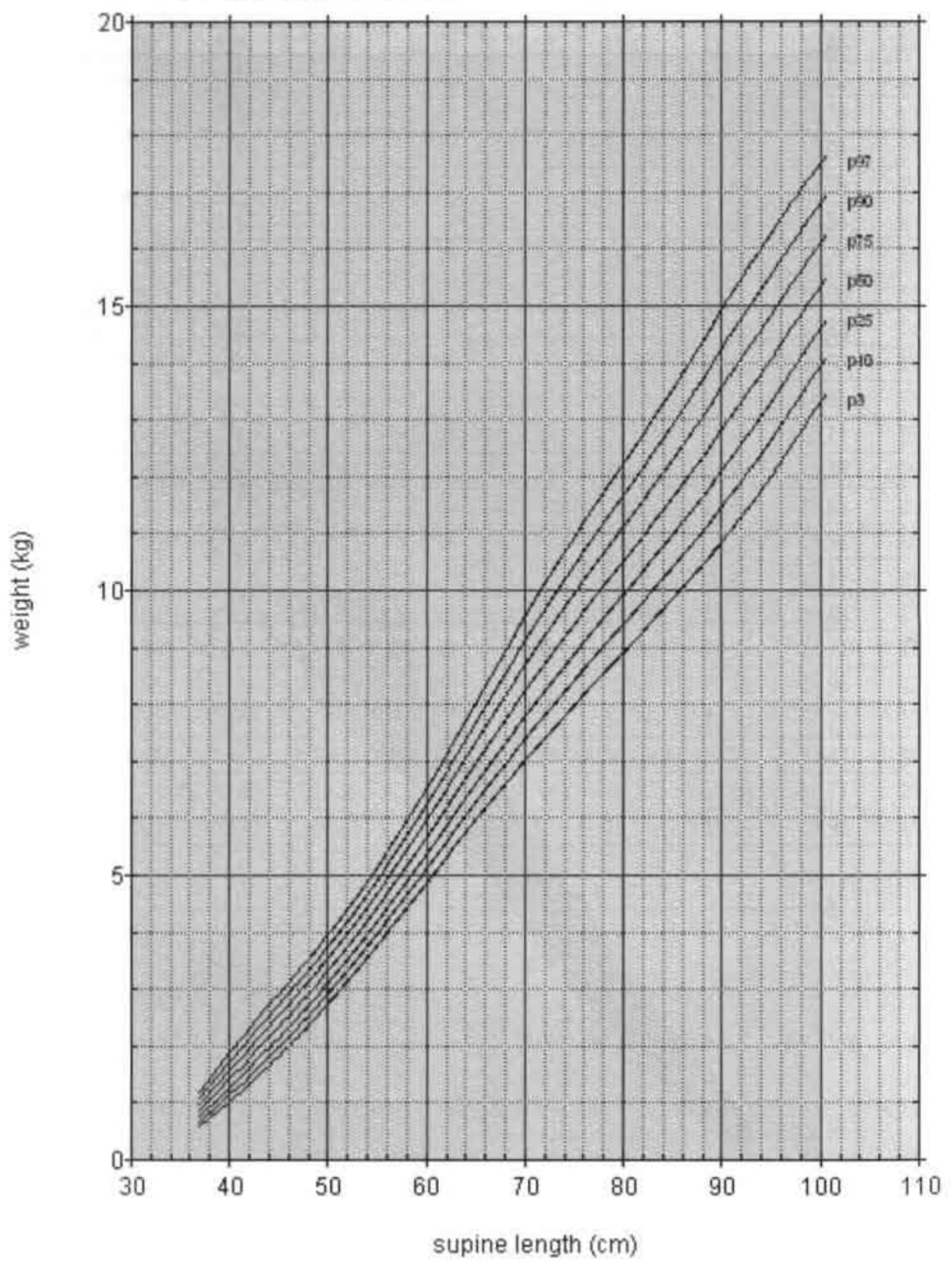




\section{Girls weight vs supine length; edf 177}

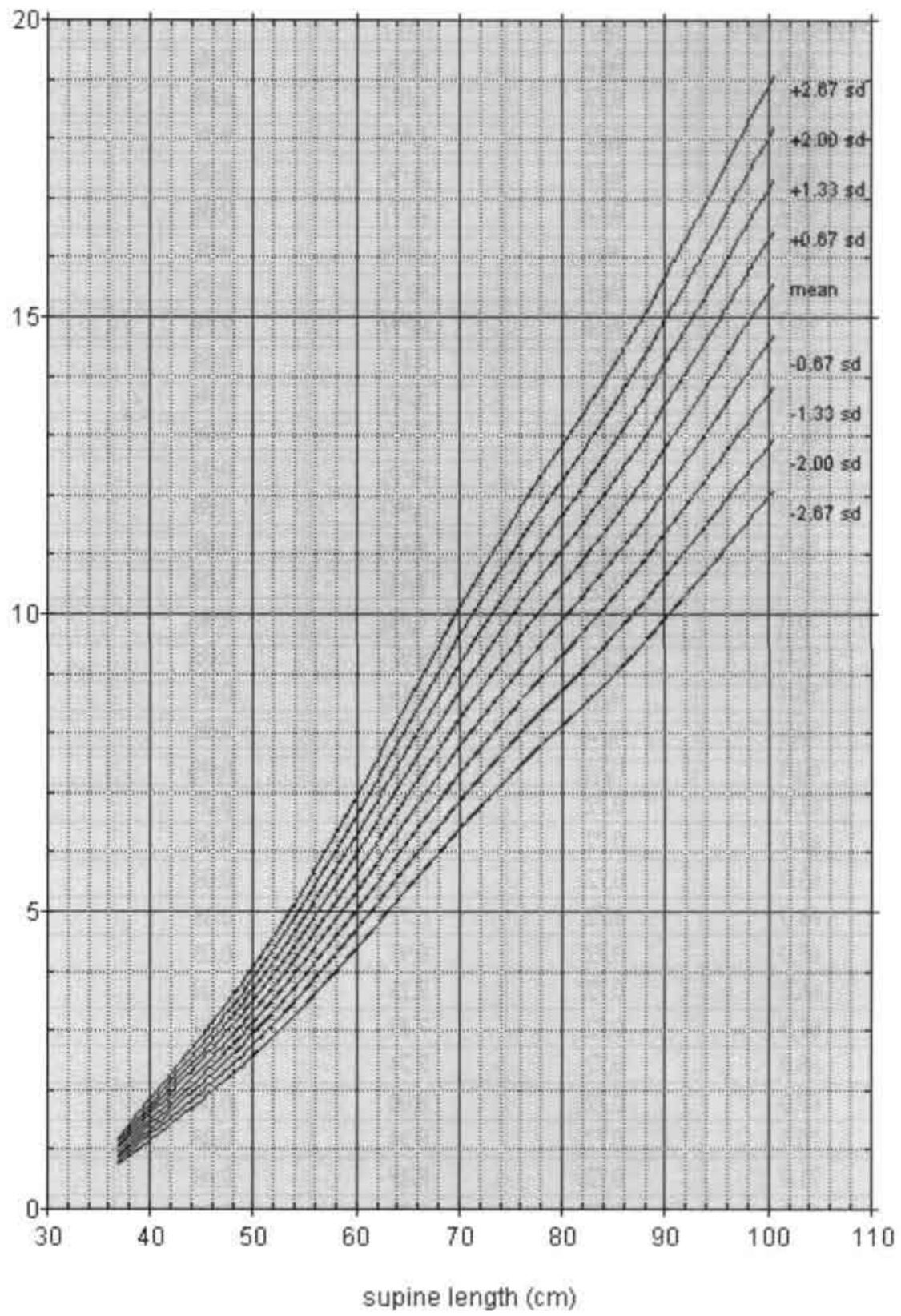




\begin{tabular}{|c|c|c|c|c|}
\hline \multicolumn{5}{|c|}{ Girls weight vs supine length LMS values ( edf 177) } \\
\hline Supine length & L & M & $\mathrm{S}$ & SD \\
\hline 39.0 & 0.72 & 1.33 & 0.08 & 0.11 \\
\hline 40.0 & 0.72 & 1.51 & 0.08 & 0.13 \\
\hline 42.0 & 0.72 & 1.85 & 0.08 & 0.16 \\
\hline 44.0 & 0.72 & 2.19 & 0.08 & 0.19 \\
\hline 45.0 & 0.72 & 2.37 & 0.08 & 0.20 \\
\hline 46.0 & 0.72 & 2.56 & 0.08 & 0.22 \\
\hline 47.0 & 0.72 & 2.75 & 0.08 & 0.23 \\
\hline 48.0 & 0.72 & 2.94 & 0.08 & 0.25 \\
\hline 49.0 & 0.72 & 3.13 & 0.08 & 0.26 \\
\hline 50.0 & 0.72 & 3.33 & 0.08 & 0.28 \\
\hline 51.0 & 0.72 & 3.53 & 0.08 & 0.30 \\
\hline 52.0 & 0.72 & 3.75 & 0.08 & 0.32 \\
\hline 53.0 & 0.72 & 3.98 & 0.08 & 0.33 \\
\hline 54.0 & 0.72 & 4.21 & 0.08 & 0.35 \\
\hline 55.0 & 0.72 & 4.44 & 0.08 & 0.37 \\
\hline 56.0 & 0.72 & 4.68 & 0.08 & 0.39 \\
\hline 57.0 & 0.72 & 4.92 & 0.08 & 0.41 \\
\hline 58.0 & 0.72 & 5.16 & 0.08 & 0.43 \\
\hline 59.0 & 0.72 & 5.41 & 0.08 & 0.46 \\
\hline 60.0 & 0.72 & 5.66 & 0.08 & 0.48 \\
\hline 61.0 & 0.72 & 5.92 & 0.08 & 0.50 \\
\hline 62.0 & 0.72 & 6.18 & 0.08 & 0.52 \\
\hline 63.0 & 0.72 & 6.44 & 0.08 & 0.54 \\
\hline 64.0 & 0.72 & 6.71 & 0.08 & 0.56 \\
\hline 65.0 & 0.72 & 6.97 & 0.08 & 0.59 \\
\hline 66.0 & 0.72 & 7.23 & 0.08 & 0.61 \\
\hline 67.0 & 0.72 & 7.49 & 0.08 & 0.63 \\
\hline 68.0 & 0.72 & 7.74 & 0.08 & 0.65 \\
\hline 69.0 & 0.72 & 8.00 & 0.08 & 0.67 \\
\hline 70.0 & 0.72 & 8.24 & 0.08 & 0.69 \\
\hline 71.0 & 0.72 & 8.49 & 0.08 & 0.71 \\
\hline 72.0 & 0.72 & 8.72 & 0.08 & 0.73 \\
\hline 73.0 & 0.72 & 8.96 & 0.08 & 0.75 \\
\hline 74.0 & 0.72 & 9.19 & 0.08 & 0.77 \\
\hline 75.0 & 0.72 & 9.42 & 0.08 & 0.79 \\
\hline 76.0 & 0.72 & 9.65 & 0.08 & 0.81 \\
\hline 77.0 & 0.72 & 9.87 & 0.08 & 0.83 \\
\hline 78.0 & 0.72 & 10.08 & 0.08 & 0.85 \\
\hline 79.0 & 0.72 & 10.29 & 0.08 & 0.87 \\
\hline
\end{tabular}




\begin{tabular}{|c|c|c|c|c|}
\hline \multicolumn{5}{|c|}{ Girls weight vs supine length LMS values (edf 177) } \\
\hline Supine length & L & M & S & SD \\
\hline 80.0 & 0.72 & 10.50 & 0.08 & 0.88 \\
\hline 81.0 & 0.72 & 10.71 & 0.08 & 0.90 \\
\hline 82.0 & 0.72 & 10.92 & 0.08 & 0.92 \\
\hline 83.0 & 0.72 & 11.14 & 0.08 & 0.94 \\
\hline 84.0 & 0.72 & 11.36 & 0.08 & 0.96 \\
\hline 85.0 & 0.72 & 11.59 & 0.08 & 0.97 \\
\hline 86.0 & 0.72 & 11.84 & 0.08 & 1.00 \\
\hline 87.0 & 0.72 & 12.06 & 0.08 & 1.01 \\
\hline 88.0 & 0.72 & 12.30 & 0.08 & 1.03 \\
\hline 89.0 & 0.72 & 12.55 & 0.08 & 1.06 \\
\hline 90.0 & 0.72 & 12.80 & 0.08 & 1.08 \\
\hline 91.0 & 0.72 & 13.06 & 0.08 & 1.10 \\
\hline 92.0 & 0.72 & 13.29 & 0.08 & 1.12 \\
\hline 93.0 & 0.72 & 13.58 & 0.08 & 1.14 \\
\hline 94.0 & 0.72 & 13.84 & 0.08 & 1.16 \\
\hline 95.0 & 0.72 & 14.11 & 0.08 & 1.19 \\
\hline 96.0 & 0.72 & 14.37 & 0.08 & 1.21 \\
\hline 97.0 & 0.72 & 14.66 & 0.08 & 1.23 \\
\hline 98.0 & 0.72 & 14.90 & 0.08 & 1.25 \\
\hline 99.0 & 0.72 & 15.19 & 0.08 & 1.28 \\
\hline 100.0 & 0.72 & 15.49 & 0.08 & 1.30 \\
\hline
\end{tabular}




\begin{tabular}{|c|c|c|c|c|c|c|c|}
\hline \multicolumn{7}{|c|}{ Girls weight (in kg) vs supine length (in cm) } \\
\hline Supine length & P3 & P10 & P25 & P50 & P75 & P90 & P97 \\
\hline 39.0 & 1.13 & 1.19 & 1.26 & 1.33 & 1.41 & 1.48 & 1.55 \\
\hline 40.0 & 1.27 & 1.35 & 1.42 & 1.51 & 1.59 & 1.67 & 1.75 \\
\hline 42.0 & 1.56 & 1.65 & 1.74 & 1.85 & 1.95 & 2.05 & 2.15 \\
\hline 44.0 & 1.86 & 1.96 & 2.07 & 2.20 & 2.32 & 2.44 & 2.55 \\
\hline 45.0 & 2.01 & 2.12 & 2.24 & 2.37 & 2.51 & 2.63 & 2.76 \\
\hline 46.0 & 2.16 & 2.29 & 2.41 & 2.56 & 2.71 & 2.84 & 2.97 \\
\hline 47.0 & 2.32 & 2.46 & 2.59 & 2.75 & 2.90 & 3.05 & 3.19 \\
\hline 48.0 & 2.48 & 2.63 & 2.77 & 2.94 & 3.10 & 3.26 & 3.41 \\
\hline 49.0 & 2.65 & 2.80 & 2.95 & 3.13 & 3.31 & 3.47 & 3.63 \\
\hline 50.0 & 2.81 & 2.97 & 3.14 & 3.33 & 3.52 & 3.69 & 3.86 \\
\hline 51.0 & 2.99 & 3.16 & 3.34 & 3.53 & 3.74 & 3.92 & 4.11 \\
\hline 52.0 & 3.17 & 3.35 & 3.54 & 3.75 & 3.97 & 4.16 & 4.36 \\
\hline 53.0 & 3.36 & 3.55 & 3.75 & 3.98 & 4.20 & 4.41 & 4.62 \\
\hline 54.0 & 3.56 & 3.76 & 3.97 & 4.21 & 4.45 & 4.67 & 4.89 \\
\hline 55.0 & 3.75 & 3.97 & 4.19 & 4.44 & 4.69 & 4.93 & 5.16 \\
\hline 56.0 & 3.96 & 4.18 & 4.42 & 4.68 & 4.95 & 5.19 & 5.44 \\
\hline 57.0 & 4.16 & 4.40 & 4.64 & 4.92 & 5.20 & 5.46 & 5.72 \\
\hline 58.0 & 4.37 & 4.62 & 4.87 & 5.16 & 5.46 & 5.73 & 6.00 \\
\hline 59.0 & 4.58 & 4.84 & 5.11 & 5.41 & 5.72 & 6.00 & 6.29 \\
\hline 60.0 & 4.79 & 5.06 & 5.34 & 5.66 & 5.99 & 6.28 & 6.58 \\
\hline 61.0 & 5.00 & 5.29 & 5.59 & 5.92 & 6.26 & 6.57 & 6.88 \\
\hline 62.0 & 5.22 & 5.52 & 5.83 & 6.18 & 6.53 & 6.85 & 7.18 \\
\hline 63.0 & 5.45 & 5.76 & 6.08 & 6.44 & 6.81 & 7.15 & 7.48 \\
\hline 64.0 & 5.67 & 6.00 & 6.33 & 6.71 & 7.09 & 7.44 & 7.79 \\
\hline 65.0 & 5.89 & 6.23 & 6.58 & 6.97 & 7.37 & 7.73 & 8.10 \\
\hline 66.0 & 6.11 & 6.46 & 6.82 & 7.23 & 7.65 & 8.02 & 8.40 \\
\hline 67.0 & 6.33 & 6.69 & 7.07 & 7.49 & 7.92 & 8.31 & 8.70 \\
\hline 68.0 & 6.55 & 6.92 & 7.31 & 7.74 & 8.19 & 8.59 & 9.00 \\
\hline 69.0 & 6.76 & 7.15 & 7.55 & 8.00 & 8.45 & 8.87 & 9.29 \\
\hline 70.0 & 6.97 & 7.37 & 7.78 & 8.24 & 8.71 & 9.14 & 9.57 \\
\hline 71.0 & 7.17 & 7.59 & 8.01 & 8.49 & 8.97 & 9.41 & 9.86 \\
\hline 72.0 & 7.38 & 7.80 & 8.23 & 8.73 & 9.22 & 9.68 & 10.13 \\
\hline 73.0 & 7.58 & 8.01 & 8.46 & 8.96 & 9.47 & 9.94 & 10.41 \\
\hline 74.0 & 7.77 & 8.22 & 8.68 & 9.19 & 9.72 & 10.20 & 10.68 \\
\hline 75.0 & 7.97 & 8.42 & 8.89 & 9.42 & 9.96 & 10.45 & 10.95 \\
\hline 76.0 & 8.16 & 8.62 & 9.11 & 9.65 & 10.20 & 10.70 & 11.21 \\
\hline 77.0 & 8.34 & 8.82 & 9.31 & 9.87 & 10.43 & 10.95 & 11.46 \\
\hline 78.0 & 8.52 & 9.01 & 9.52 & 10.08 & 10.66 & 11.19 & 11.71 \\
\hline 79.0 & 8.70 & 9.20 & 9.71 & 10.29 & 10.88 & 11.42 & 11.96 \\
\hline & & & & & & & \\
\hline
\end{tabular}




\begin{tabular}{|c|c|c|c|c|c|c|c|}
\hline \multicolumn{7}{|c|}{ Girls weight (in kg) vs supine length (in cm) } \\
\hline Supine length & P3 & P10 & P25 & P50 & P75 & P90 & P97 \\
\hline 80.0 & 8.88 & 9.39 & 9.91 & 10.50 & 11.10 & 11.65 & 12.20 \\
\hline 81.0 & 9.06 & 9.58 & 10.11 & 10.71 & 11.32 & 11.88 & 12.44 \\
\hline 82.0 & 9.24 & 9.76 & 10.31 & 10.92 & 11.55 & 12.12 & 12.69 \\
\hline 83.0 & 9.42 & 9.96 & 10.51 & 11.14 & 11.78 & 12.36 & 12.94 \\
\hline 84.0 & 9.60 & 10.15 & 10.72 & 11.36 & 12.01 & 12.60 & 13.20 \\
\hline 85.0 & 9.80 & 10.36 & 10.94 & 11.59 & 12.25 & 12.85 & 13.46 \\
\hline 86.0 & 10.01 & 10.59 & 11.18 & 11.84 & 12.52 & 13.14 & 13.76 \\
\hline 87.0 & 10.19 & 10.78 & 11.38 & 12.06 & 12.75 & 13.38 & 14.01 \\
\hline 88.0 & 10.40 & 11.00 & 11.61 & 12.30 & 13.01 & 13.65 & 14.29 \\
\hline 89.0 & 10.61 & 11.22 & 11.85 & 12.55 & 13.27 & 13.92 & 14.58 \\
\hline 90.0 & 10.83 & 11.45 & 12.08 & 12.80 & 13.54 & 14.20 & 14.87 \\
\hline 91.0 & 11.04 & 11.67 & 12.33 & 13.06 & 13.81 & 14.49 & 15.17 \\
\hline 92.0 & 11.24 & 11.88 & 12.54 & 13.29 & 14.05 & 14.75 & 15.44 \\
\hline 93.0 & 11.48 & 12.14 & 12.82 & 13.58 & 14.36 & 15.06 & 15.77 \\
\hline 94.0 & 11.70 & 12.37 & 13.06 & 13.84 & 14.63 & 15.36 & 16.08 \\
\hline 95.0 & 11.93 & 12.61 & 13.31 & 14.11 & 14.91 & 15.65 & 16.38 \\
\hline 96.0 & 12.15 & 12.85 & 13.56 & 14.37 & 15.19 & 15.94 & 16.69 \\
\hline 97.0 & 12.40 & 13.11 & 13.84 & 14.66 & 15.50 & 16.27 & 17.03 \\
\hline 98.0 & 12.60 & 13.32 & 14.06 & 14.90 & 15.75 & 16.53 & 17.31 \\
\hline 99.0 & 12.85 & 13.58 & 14.34 & 15.19 & 16.06 & 16.86 & 17.65 \\
\hline 100.0 & 13.09 & 13.84 & 14.62 & 15.49 & 16.37 & 17.18 & 17.99 \\
\hline
\end{tabular}


Girls weight (in $\mathrm{kg}$ ) vs supine length (in $\mathrm{cm}$ )

\begin{tabular}{|c|c|c|c|c|c|c|c|c|c|}
\hline $\begin{array}{l}\text { Supine } \\
\text { length }\end{array}$ & $-2.76 \mathrm{SD}$ & $-2.00 \mathrm{SD}$ & $-1.33 \mathrm{SD}$ & $-0.67 \mathrm{SD}$ & $0 \mathrm{SD}$ & $+0.67 \mathrm{SD}$ & $+1.33 \mathrm{SD}$ & $+2.00 \mathrm{SD}$ & $+2.67 \mathrm{SD}$ \\
\hline 39.0 & 1.03 & 1.11 & 1.18 & 1.26 & 1.33 & 1.41 & 1.48 & 1.55 & 1.63 \\
\hline 40.0 & 1.17 & 1.26 & 1.34 & 1.42 & 1.51 & 1.60 & 1.68 & 1.76 & 1.85 \\
\hline 42.0 & 1.44 & 1.54 & 1.64 & 1.75 & 1.85 & 1.95 & 2.06 & 2.16 & 2.26 \\
\hline 44.0 & 1.70 & 1.82 & 1.94 & 2.07 & 2.19 & 2.31 & 2.44 & 2.56 & 2.68 \\
\hline 45.0 & 1.84 & 1.97 & 2.10 & 2.24 & 2.37 & 2.50 & 2.64 & 2.77 & 2.90 \\
\hline 46.0 & 1.99 & 2.13 & 2.27 & 2.42 & 2.56 & 2.70 & 2.85 & 2.99 & 3.13 \\
\hline 47.0 & 2.13 & 2.29 & 2.44 & 2.60 & 2.75 & 2.90 & 3.06 & 3.21 & 3.37 \\
\hline 48.0 & 2.28 & 2.45 & 2.61 & 2.77 & 2.94 & 3.11 & 3.27 & 3.43 & 3.60 \\
\hline 49.0 & 2.43 & 2.60 & 2.78 & 2.95 & 3.13 & 3.31 & 3.48 & 3.66 & 3.83 \\
\hline 50.0 & 2.58 & 2.77 & 2.96 & 3.14 & 3.33 & 3.52 & 3.70 & 3.89 & 4.08 \\
\hline 51.0 & 2.74 & 2.94 & 3.14 & 3.33 & 3.53 & 3.73 & 3.93 & 4.12 & 4.32 \\
\hline 52.0 & 2.91 & 3.12 & 3.33 & 3.54 & 3.75 & 3.96 & 4.17 & 4.38 & 4.59 \\
\hline 53.0 & 3.09 & 3.31 & 3.54 & 3.76 & 3.98 & 4.20 & 4.42 & 4.65 & 4.87 \\
\hline 54.0 & 3.26 & 3.50 & 3.74 & 3.97 & 4.21 & 4.45 & 4.68 & 4.92 & 5.16 \\
\hline 55.0 & 3.44 & 3.69 & 3.94 & 4.19 & 4.44 & 4.69 & 4.94 & 5.19 & 5.44 \\
\hline 56.0 & 3.63 & 3.89 & 4.16 & 4.42 & 4.68 & 4.94 & 5.20 & 5.47 & 5.73 \\
\hline 57.0 & 3.81 & 4.09 & 4.37 & 4.64 & 4.92 & 5.20 & 5.47 & 5.75 & 6.03 \\
\hline 58.0 & 4.00 & 4.29 & 4.58 & 4.87 & 5.16 & 5.45 & 5.74 & 6.03 & 6.32 \\
\hline 59.0 & 4.20 & 4.50 & 4.80 & 5.11 & 5.41 & 5.71 & 6.02 & 6.32 & 6.62 \\
\hline 60.0 & 4.39 & 4.71 & 5.03 & 5.34 & 5.66 & 5.98 & 6.29 & 6.61 & 6.93 \\
\hline 61.0 & 4.59 & 4.92 & 5.26 & 5.59 & 5.92 & 6.25 & 6.58 & 6.92 & 7.25 \\
\hline 62.0 & 4.79 & 5.14 & 5.49 & 5.83 & 6.18 & 6.53 & 6.87 & 7.22 & 7.57 \\
\hline 63.0 & 4.99 & 5.36 & 5.72 & 6.08 & 6.44 & 6.80 & 7.16 & 7.52 & 7.89 \\
\hline 64.0 & 5.20 & 5.58 & 5.96 & 6.33 & 6.71 & 7.09 & 7.46 & 7.84 & 8.22 \\
\hline 65.0 & 5.41 & 5.80 & 6.19 & 6.58 & 6.97 & 7.36 & 7.75 & 8.14 & 8.53 \\
\hline 66.0 & 5.61 & 6.01 & 6.42 & 6.82 & 7.23 & 7.64 & 8.04 & 8.45 & 8.85 \\
\hline 67.0 & 5.81 & 6.23 & 6.65 & 7.07 & 7.49 & 7.91 & 8.33 & 8.75 & 9.17 \\
\hline 68.0 & 6.00 & 6.44 & 6.87 & 7.30 & 7.74 & 8.18 & 8.61 & 9.04 & 9.48 \\
\hline 69.0 & 6.21 & 6.66 & 7.11 & 7.55 & 8.00 & 8.45 & 8.89 & 9.34 & 9.79 \\
\hline 70.0 & 6.39 & 6.85 & 7.32 & 7.78 & 8.24 & 8.70 & 9.16 & 9.63 & 10.09 \\
\hline 71.0 & 6.59 & 7.06 & 7.54 & 8.01 & 8.49 & 8.97 & 9.44 & 9.92 & 10.39 \\
\hline 72.0 & 6.76 & 7.25 & 7.74 & 8.23 & 8.72 & 9.21 & 9.70 & 10.19 & 10.68 \\
\hline 73.0 & 6.95 & 7.45 & 7.96 & 8.46 & 8.96 & 9.46 & 9.96 & 10.47 & 10.97 \\
\hline 74.0 & 7.13 & 7.64 & 8.16 & 8.67 & 9.19 & 9.71 & 10.22 & 10.74 & 11.25 \\
\hline 75,0 & 7.31 & 7.84 & 8.37 & 8.89 & 9.42 & 9.95 & 10.47 & 11.00 & 11.54 \\
\hline 76.0 & 7.48 & 8.03 & 8.57 & 9.11 & 9.65 & 10.19 & 10.73 & 11.27 & 11.82 \\
\hline 77.0 & 7.65 & 8.21 & 8.77 & 9.31 & 9.87 & 10.43 & 10.97 & 11.53 & 12.09 \\
\hline 78.0 & 7.82 & 8.38 & 8.95 & 9.51 & 10.08 & 10.65 & 11.21 & 11.78 & 12.34 \\
\hline 79.0 & 7.98 & 8.56 & 9.14 & 9.71 & 10.29 & 10.87 & 11.44 & 12.02 & 12.60 \\
\hline
\end{tabular}


Growth Charts en Tables

\begin{tabular}{|c|c|c|c|c|c|c|c|c|c|}
\hline \multicolumn{10}{|c|}{ Girls weight (in kg) vs supine length (in cm) } \\
\hline $\begin{array}{c}\text { Supine } \\
\text { length }\end{array}$ & -2.76 SD & -2.00 SD & -1.33 SD & -0.67 SD & 0 SD & +0.67 SD & +1.33 SD & +2.00 SD & +2.67 SD \\
\hline 80.0 & 8.14 & 8.73 & 9.33 & 9.91 & 10.50 & 11.09 & 11.67 & 12.27 & 12.86 \\
\hline 81.0 & 8.30 & 8.91 & 9.51 & 10.11 & 10.71 & 11.31 & 11.91 & 12.51 & 13.12 \\
\hline 82.0 & 8.47 & 9.08 & 9.70 & 10.31 & 10.92 & 11.54 & 12.14 & 12.76 & 13.37 \\
\hline 83.0 & 8.64 & 9.27 & 9.89 & 10.51 & 11.14 & 11.77 & 12.39 & 13.01 & 13.64 \\
\hline 84.0 & 8.81 & 9.45 & 10.09 & 10.72 & 11.36 & 12.00 & 12.63 & 13.27 & 13.91 \\
\hline 85.0 & 8.99 & 9.64 & 10.30 & 10.94 & 11.59 & 12.24 & 12.89 & 13.54 & 14.19 \\
\hline 86.0 & 9.18 & 9.85 & 10.52 & 11.17 & 11.84 & 12.51 & 13.17 & 13.83 & 14.50 \\
\hline 87.0 & 9.35 & 10.03 & 10.71 & 11.38 & 12.06 & 12.74 & 13.41 & 14.09 & 14.77 \\
\hline 88.0 & 9.54 & 10.23 & 10.93 & 11.61 & 12.30 & 12.99 & 13.68 & 14.37 & 15.06 \\
\hline 89.0 & 9.73 & 10.44 & 11.15 & 11.84 & 12.55 & 13.26 & 13.95 & 14.66 & 15.37 \\
\hline 90.0 & 9.92 & 10.65 & 11.37 & 12.08 & 12.80 & 13.52 & 14.23 & 14.95 & 15.68 \\
\hline 91.0 & 10.13 & 10.86 & 11.60 & 12.32 & 13.06 & 13.80 & 14.52 & 15.26 & 15.99 \\
\hline 92.0 & 10.31 & 11.05 & 11.80 & 12.54 & 13.29 & 14.04 & 14.78 & 15.53 & 16.28 \\
\hline 93.0 & 10.53 & 11.30 & 12.06 & 12.82 & 13.58 & 14.35 & 15.10 & 15.86 & 16.63 \\
\hline 94.0 & 10.73 & 11.51 & 12.29 & 13.06 & 13.84 & 14.62 & 15.39 & 16.17 & 16.95 \\
\hline 95.0 & 10.94 & 11.74 & 12.53 & 13.32 & 14.11 & 14.91 & 15.69 & 16.48 & 17.28 \\
\hline 96.0 & 11.15 & 11.95 & 12.76 & 13.56 & 14.37 & 15.18 & 15.98 & 16.79 & 17.60 \\
\hline 97.0 & 11.37 & 12.19 & 13.02 & 13.83 & 14.66 & 15.49 & 16.30 & 17.13 & 17.95 \\
\hline 98.0 & 11.55 & 12.39 & 13.23 & 14.06 & 14.90 & 15.74 & 16.57 & 17.41 & 18.25 \\
\hline 99.0 & 11.78 & 12.63 & 13.49 & 14.33 & 15.19 & 16.05 & 16.89 & 17.75 & 18.60 \\
\hline 100.0 & 12.01 & 12.89 & 13.76 & 14.62 & 15.49 & 16.36 & 17.22 & 18.09 & 18.97 \\
\hline
\end{tabular}


Subischial leg length vs supine length

\begin{tabular}{|c|c|c|c|}
\hline Boys & \multicolumn{3}{|c|}{ Subischial leg length vs supine length } \\
\hline Edf: 34 3 3 (3.00 4.00 3.02) & N: 5055 & Nc: 527 \\
\hline Range & Expected & Observed & Difference \\
\hline <P3 & 151.6 & 180 & 28.4 \\
\hline P3-P10 & 353.9 & 337 & -16.9 \\
\hline P10-P25 & 758.3 & 681 & -77.3 \\
\hline P25-P50 & 1263.7 & 1304 & 40.3 \\
\hline P50-P75 & 1263.7 & 1318 & 54.3 \\
\hline P75-P90 & 758.3 & 773 & 14.7 \\
\hline P90-P97 & 353.9 & 315 & -38.9 \\
\hline >P97 & 151.6 & 147 & -4.6 \\
\hline
\end{tabular}

\begin{tabular}{|c|c|c|c|}
\hline Girls & \multicolumn{3}{|c|}{ Subischial leg length vs supine length } \\
\hline Edf: 3 3 3 $(2.893 .093 .14)$ & $\mathrm{N}: 4198$ & Nc: 487 \\
\hline Range & Expected & Observed & Difference \\
\hline <P3 & 125.9 & 134 & 8.1 \\
\hline P3-P10 & 293.9 & 301 & 7.1 \\
\hline P10-P25 & 629.7 & 576 & -53.7 \\
\hline P25-P50 & 1049.5 & 1084 & 34.5 \\
\hline P50-P75 & 1049.5 & 1071 & 21.5 \\
\hline P75-P90 & 629.7 & 639 & 9.3 \\
\hline P90-P97 & 293.9 & 269 & -24.9 \\
\hline >P97 & 125.9 & 124 & -1.9 \\
\hline
\end{tabular}


Boys subischial leg length vs supine length; edf 343

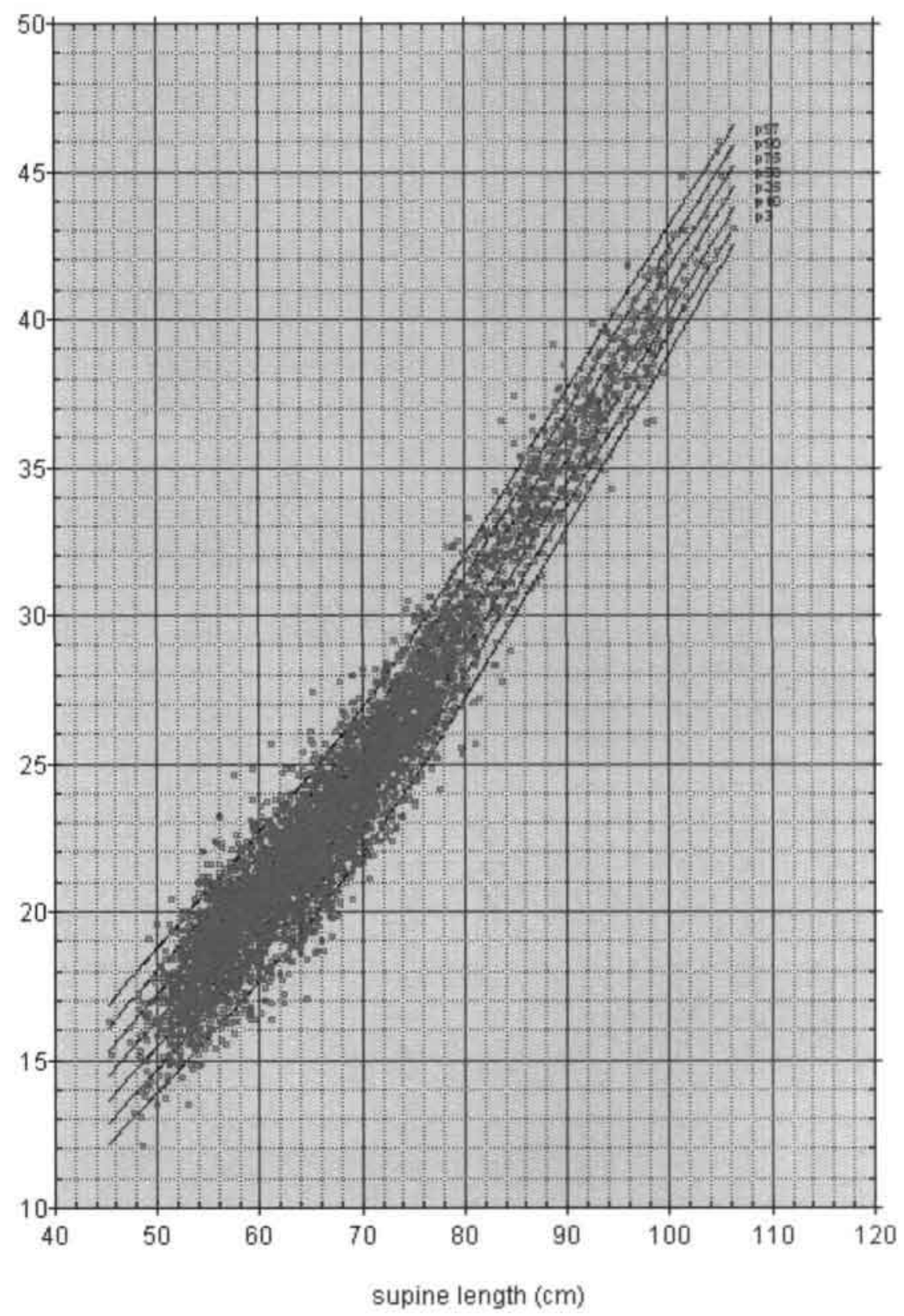


Boys subischial leg length vs supine length; edf 343

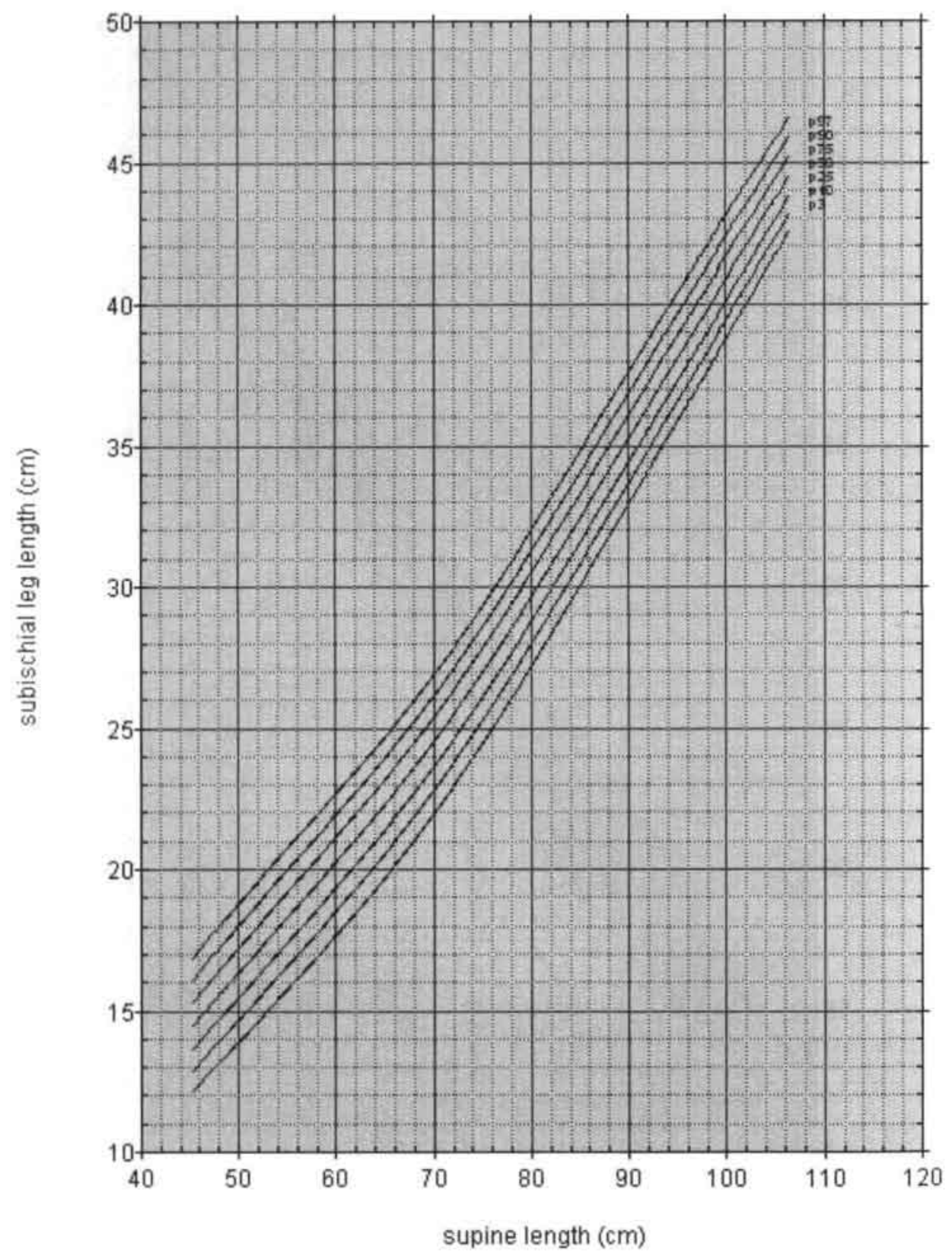


Boys subischial leg length vs supine length; edf 343

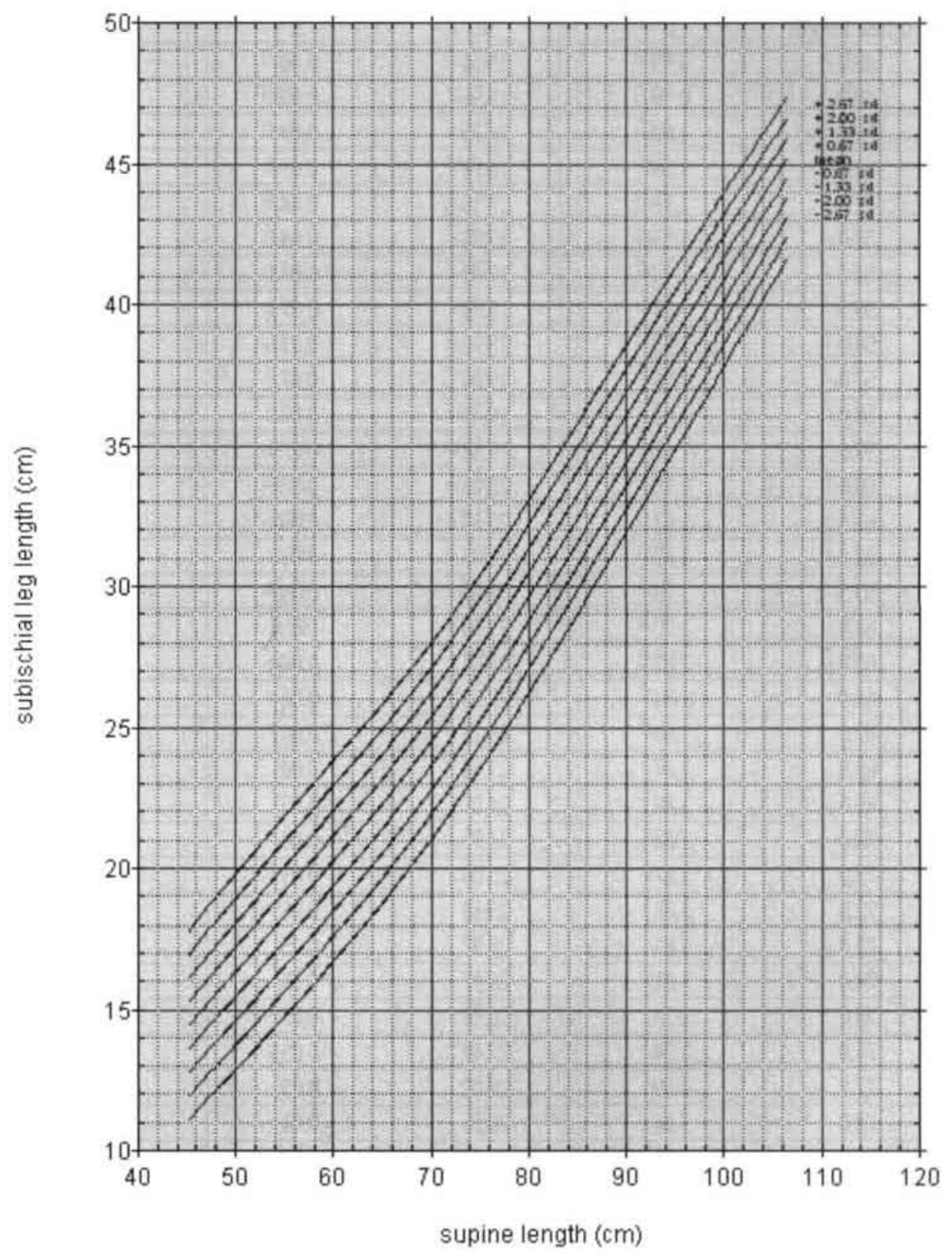




\begin{tabular}{|c|c|c|c|c|}
\hline \multicolumn{5}{|c|}{ Boys subischial leg length vs supine length LMS values ( edf 343 ) } \\
\hline Supine length & L & M & $\mathrm{S}$ & $\mathrm{SD}$ \\
\hline 48.0 & 0.95 & 15.64 & 0.08 & 1.28 \\
\hline 49.0 & 0.98 & 15.96 & 0.08 & 1.29 \\
\hline 50.0 & 1.02 & 16.35 & 0.08 & 1.30 \\
\hline 51.0 & 1.06 & 16.74 & 0.08 & 1.31 \\
\hline 52.0 & 1.11 & 17.13 & 0.08 & 1.31 \\
\hline 53.0 & 1.15 & 17.53 & 0.08 & 1.32 \\
\hline 54.0 & 1.20 & 17.92 & 0.07 & 1.33 \\
\hline 55.0 & 1.25 & 18.31 & 0.07 & 1.33 \\
\hline 56.0 & 1.30 & 18.70 & 0.07 & 1.33 \\
\hline 57.0 & 1.36 & 19.09 & 0.07 & 1.33 \\
\hline 58.0 & 1.42 & 19.49 & 0.07 & 1.33 \\
\hline 59.0 & 1.48 & 19.88 & 0.07 & 1.33 \\
\hline 60.0 & 1.55 & 20.28 & 0.07 & 1.33 \\
\hline 61.0 & 1.61 & 20.67 & 0.06 & 1.33 \\
\hline 62.0 & 1.67 & 21.08 & 0.06 & 1.33 \\
\hline 63.5 & 1.74 & 21.69 & 0.06 & 1.33 \\
\hline 64.0 & 1.77 & 21.90 & 0.06 & 1.32 \\
\hline 65.0 & 1.81 & 22.31 & 0.06 & 1.32 \\
\hline 66.0 & 1.84 & 22.74 & 0.06 & 1.32 \\
\hline 67.0 & 1.86 & 23.17 & 0.06 & 1.31 \\
\hline 68.0 & 1.87 & 23.61 & 0.06 & 1.31 \\
\hline 69.0 & 1.88 & 24.07 & 0.05 & 1.31 \\
\hline 70.0 & 1.88 & 24.53 & 0.05 & 1.30 \\
\hline 71.0 & 1.87 & 25.00 & 0.05 & 1.30 \\
\hline 72.0 & 1.86 & 25.48 & 0.05 & 1.30 \\
\hline 73.0 & 1.84 & 25.97 & 0.05 & 1.29 \\
\hline 74.0 & 1.81 & 26.47 & 0.05 & 1.29 \\
\hline 75.0 & 1.78 & 26.98 & 0.05 & 1.29 \\
\hline 76,0 & 1.74 & 27.49 & 0.05 & 1.29 \\
\hline 77.0 & 1.69 & 28.02 & 0.05 & 1.29 \\
\hline 78.0 & 1.64 & 28.56 & 0.04 & 1.28 \\
\hline 79.0 & 1.58 & 29.10 & 0.04 & 1.28 \\
\hline 80.0 & 1.51 & 29.64 & 0.04 & 1.28 \\
\hline 81.0 & 1.44 & 30.20 & 0.04 & 1.28 \\
\hline 82.0 & 1.36 & 30.75 & 0.04 & 1.28 \\
\hline 83.0 & 1.28 & 31.31 & 0.04 & 1.27 \\
\hline 84.0 & 1.20 & 31.87 & 0.04 & 1.27 \\
\hline 85.0 & 1.12 & 32.44 & 0.04 & 1.27 \\
\hline 86.0 & 1.03 & 33.00 & 0.04 & 1.26 \\
\hline
\end{tabular}




\begin{tabular}{|c|c|c|c|c|}
\hline \multicolumn{5}{|c|}{ Boys subischial leg length vs supine length LMS values (edf 343) } \\
\hline Supine length & L & M & S & SD \\
\hline 87.0 & 0.95 & 33.57 & 0.04 & 1.26 \\
\hline 88.0 & 0.86 & 34.14 & 0.04 & 1.26 \\
\hline 89.0 & 0.78 & 34.70 & 0.04 & 1.25 \\
\hline 90.0 & 0.69 & 35.27 & 0.04 & 1.24 \\
\hline 91.0 & 0.61 & 35.83 & 0.03 & 1.24 \\
\hline 92.0 & 0.53 & 36.39 & 0.03 & 1.23 \\
\hline 93.0 & 0.44 & 36.96 & 0.03 & 1.22 \\
\hline 94.0 & 0.36 & 37.52 & 0.03 & 1.21 \\
\hline 95.0 & 0.28 & 38.08 & 0.03 & 1.21 \\
\hline 96.0 & 0.19 & 38.64 & 0.03 & 1.20 \\
\hline 97.0 & 0.11 & 39.21 & 0.03 & 1.19 \\
\hline 98.0 & 0.03 & 39.77 & 0.03 & 1.18 \\
\hline 99.0 & -0.06 & 40.33 & 0.03 & 1.17 \\
\hline 100.0 & -0.14 & 40.89 & 0.03 & 1.15 \\
\hline 101.0 & -0.23 & 41.45 & 0.03 & 1.14 \\
\hline 102.0 & -0.30 & 41.90 & 0.03 & 1.13 \\
\hline 103.5 & -0.45 & 42.91 & 0.03 & 1.11 \\
\hline 104.5 & -0.54 & 43.47 & 0.03 & 1.09 \\
\hline 105.0 & -0.57 & 43.70 & 0.02 & 1.09 \\
\hline
\end{tabular}




\begin{tabular}{|c|c|c|c|c|c|c|c|}
\hline \multicolumn{8}{|c|}{ Boys subischial leg length (in $\mathrm{cm}$ ) vs supine length (in $\mathrm{cm}$ ) } \\
\hline Supine length & P3 & P10 & P25 & P50 & $\mathrm{P} 75$ & $\mathrm{P} 90$ & P97 \\
\hline 48.0 & 13.24 & 14.00 & 14.78 & 15.64 & 16.51 & 17.29 & 18.06 \\
\hline 49.0 & 13.53 & 14.31 & 15.09 & 15.96 & 16.83 & 17.61 & 18.39 \\
\hline 50.0 & 13.90 & 14.68 & 15.47 & 16.35 & 17.23 & 18.01 & 18.79 \\
\hline 51.0 & 14.27 & 15.06 & 15.86 & 16.74 & 17.62 & 18.41 & 19.19 \\
\hline 52.0 & 14.64 & 15.44 & 16.24 & 17.13 & 18.02 & 18.81 & 19.59 \\
\hline 53.0 & 15.01 & 15.82 & 16.63 & 17.53 & 18.41 & 19.21 & 19.98 \\
\hline 54.0 & 15.39 & 16.20 & 17.02 & 17.92 & 18.81 & 19.60 & 20.38 \\
\hline 55.0 & 15.76 & 16.59 & 17.41 & 18.31 & 19.20 & 19.99 & 20.77 \\
\hline 56.0 & 16.14 & 16.97 & 17.80 & 18.70 & 19.59 & 20.39 & 21.16 \\
\hline 57.0 & 16.52 & 17.36 & 18.19 & 19.09 & 19.99 & 20.78 & 21.55 \\
\hline 58.0 & 16.90 & 17.74 & 18.58 & 19.49 & 20.38 & 21.17 & 21.93 \\
\hline 59.0 & 17.29 & 18.13 & 18.97 & 19.88 & 20.77 & 21.56 & 22.32 \\
\hline 60.0 & 17.68 & 18.53 & 19.37 & 20.28 & 21.17 & 21.95 & 22.71 \\
\hline 61.0 & 18.07 & 18.92 & 19.77 & 20.68 & 21.56 & 22.34 & 23.09 \\
\hline 62.0 & 18.47 & 19.33 & 20.17 & 21.08 & 21.96 & 22.74 & 23.49 \\
\hline 63.5 & 19.08 & 19.94 & 20.78 & 21.69 & 22.57 & 23.34 & 24.08 \\
\hline 64.0 & 19.29 & 20.15 & 20.99 & 21.90 & 22.78 & 23.55 & 24.29 \\
\hline 65.0 & 19.71 & 20.57 & 21.41 & 22.31 & 23.19 & 23.96 & 24.70 \\
\hline 66.0 & 20.14 & 21.00 & 21.84 & 22.74 & 23.61 & 24.38 & 25.11 \\
\hline 67.0 & 20.58 & 21.44 & 22.27 & 23.17 & 24.04 & 24.81 & 25.54 \\
\hline 68.0 & 21.03 & 21.88 & 22.72 & 23.62 & 24.48 & 25.24 & 25.97 \\
\hline 69.0 & 21.49 & 22.34 & 23.17 & 24.07 & 24.93 & 25.69 & 26.42 \\
\hline 70.0 & 21.96 & 22.81 & 23.63 & 24.53 & 25.39 & 26.15 & 26.88 \\
\hline 71.0 & 22.44 & 23.28 & 24.11 & 25.00 & 25.86 & 26.62 & 27.34 \\
\hline 72.0 & 22.93 & 23.77 & 24.59 & 25.48 & 26.34 & 27.09 & 27.82 \\
\hline 73.0 & 23.43 & 24.26 & 25.08 & 25.97 & 26.83 & 27.58 & 28.31 \\
\hline 74.0 & 23.94 & 24.77 & 25.59 & 26.47 & 27.33 & 28.08 & 28.81 \\
\hline 75.0 & 24.46 & 25.28 & 26.10 & 26.98 & 27.84 & 28.59 & 29.32 \\
\hline 76.0 & 24.99 & 25.81 & 26.62 & 27.50 & 28.35 & 29.11 & 29.84 \\
\hline 77.0 & 25.53 & 26.34 & 27.15 & 28.02 & 28.88 & 29.64 & 30.37 \\
\hline 78.0 & 26.07 & 26.88 & 27.68 & 28.56 & 29.41 & 30.17 & 30.91 \\
\hline 79.0 & 26.62 & 27.43 & 28.22 & 29.10 & 29.95 & 30.71 & 31.45 \\
\hline 80.0 & 27.18 & 27.98 & 28.77 & 29.64 & 30.50 & 31.26 & 32.00 \\
\hline 81.0 & 27.75 & 28.54 & 29.33 & 30.20 & 31.05 & 31.82 & 32.56 \\
\hline 82.0 & 28.32 & 29.10 & 29.89 & 30.75 & 31.61 & 32.37 & 33.12 \\
\hline 83.0 & 28.89 & 29.67 & 30.45 & 31.31 & 32.17 & 32.93 & 33.68 \\
\hline 84.0 & 29.47 & 30.24 & 31.02 & 31.87 & 32.73 & 33.50 & 34.25 \\
\hline 85.0 & 30.04 & 30.81 & 31.58 & 32.44 & 33.29 & 34.06 & 34.81 \\
\hline 86.0 & 30.62 & 31.38 & 32.15 & 33.00 & 33.86 & 34.62 & 35.38 \\
\hline
\end{tabular}




\begin{tabular}{|c|c|c|c|c|c|c|c|}
\hline \multicolumn{7}{|c|}{ Boys subischial leg length (in cm) vs supine length (in cm) } \\
\hline Supine length & P3 & P10 & P25 & P50 & P75 & P90 & P97 \\
\hline 87.0 & 31.21 & 31.96 & 32.72 & 33.57 & 34.42 & 35.19 & 35.94 \\
\hline 88.0 & 31.79 & 32.53 & 33.29 & 34.14 & 34.98 & 35.75 & 36.51 \\
\hline 89.0 & 32.37 & 33.11 & 33.86 & 34.70 & 35.55 & 36.31 & 37.07 \\
\hline 90.0 & 32.95 & 33.68 & 34.43 & 35.27 & 36.11 & 36.87 & 37.63 \\
\hline 91.0 & 33.53 & 34.26 & 35.00 & 35.83 & 36.67 & 37.43 & 38.19 \\
\hline 92.0 & 34.12 & 34.83 & 35.57 & 36.39 & 37.23 & 37.99 & 38.74 \\
\hline 93.0 & 34.70 & 35.41 & 36.14 & 36.96 & 37.79 & 38.54 & 39.30 \\
\hline 94.0 & 35.28 & 35.98 & 36.71 & 37.52 & 38.35 & 39.10 & 39.85 \\
\hline 95.0 & 35.86 & 36.56 & 37.28 & 38.08 & 38.90 & 39.65 & 40.40 \\
\hline 96.0 & 36.45 & 37.13 & 37.84 & 38.64 & 39.46 & 40.20 & 40.95 \\
\hline 97.0 & 37.03 & 37.71 & 38.41 & 39.21 & 40.01 & 40.75 & 41.50 \\
\hline 98.0 & 37.61 & 38.29 & 38.98 & 39.77 & 40.57 & 41.30 & 42.04 \\
\hline 99.0 & 38.20 & 38.86 & 39.55 & 40.33 & 41.12 & 41.85 & 42.59 \\
\hline 100.0 & 38.78 & 39.44 & 40.12 & 40.89 & 41.68 & 42.40 & 43.13 \\
\hline 101.0 & 39.37 & 40.02 & 40.69 & 41.45 & 42.23 & 42.95 & 43.67 \\
\hline 102.0 & 39.84 & 40.48 & 41.15 & 41.90 & 42.67 & 43.39 & 44.10 \\
\hline 103.5 & 40.90 & 41.53 & 42.17 & 42.91 & 43.67 & 44.37 & 45.07 \\
\hline 104.5 & 41.49 & 42.11 & 42.75 & 43.47 & 44.22 & 44.91 & 45.61 \\
\hline 105.0 & 41.73 & 42.34 & 42.97 & 43.70 & 44.44 & 45.13 & 45.82 \\
\hline
\end{tabular}


Boys subischial leg length (in $\mathrm{cm}$ ) vs supine length (in $\mathrm{cm}$ )

\begin{tabular}{|c|c|c|c|c|c|c|c|c|c|}
\hline $\begin{array}{l}\text { Supine } \\
\text { length }\end{array}$ & $-2.76 \mathrm{SD}$ & $-200 \mathrm{SD}$ & -1.33 SD & $-0.67 \mathrm{SD}$ & $0 \mathrm{SD}$ & $+0.67 \mathrm{SD}$ & $+1.33 \mathrm{SD}$ & $+2.00 \mathrm{SD}$ & $+2.67 \mathrm{SD}$ \\
\hline 48.0 & 12.22 & 13.08 & 13.94 & 14.78 & 15.64 & 16.50 & 17.35 & 18.20 & 19.06 \\
\hline 49.0 & 12.52 & 13.38 & 14.24 & 15.10 & 15.96 & 16.82 & 17.68 & 18.54 & 19.40 \\
\hline 50.0 & 12.88 & 13.75 & 14.62 & 15.48 & 16.35 & 17.22 & 18.08 & 18.95 & 19.82 \\
\hline 51.0 & 13.25 & 14.13 & 15.00 & 15.86 & 16.74 & 17.62 & 18.48 & 19.35 & 20.23 \\
\hline 52.0 & 13.62 & 14.50 & 15.38 & 16.25 & 17.13 & 18.01 & 18.88 & 19.76 & 20.64 \\
\hline 53.0 & 14.01 & 14.89 & 15.77 & 16.65 & 17.53 & 18.41 & 19.29 & 20.17 & 21.05 \\
\hline 54.0 & 14.38 & 15.27 & 16.16 & 17.03 & 17.92 & 18.81 & 19.68 & 20.57 & 21.46 \\
\hline 55.0 & 14.76 & 15.65 & 16.54 & 17.42 & 18.31 & 19.20 & 20.08 & 20.97 & 21.86 \\
\hline 56.0 & 15.15 & 16.04 & 16.93 & 17.81 & 18.70 & 19.59 & 20.47 & 21.36 & 22.25 \\
\hline 57.0 & 15.53 & 16.42 & 17.32 & 18.20 & 19.09 & 19.98 & 20.86 & 21.76 & 22.65 \\
\hline 58.0 & 15.93 & 16.82 & 17.72 & 18.60 & 19.49 & 20.38 & 21.26 & 22.16 & 23.05 \\
\hline 59.0 & 16.32 & 17.21 & 18.11 & 18.99 & 19.88 & 20.77 & 21.65 & 22.55 & 23.44 \\
\hline 60.0 & 16.72 & 17.61 & 18.51 & 19.39 & 20.28 & 21.17 & 22.05 & 22.95 & 23.84 \\
\hline 61.0 & 17.12 & 18.01 & 18.90 & 19.78 & 20.67 & 21.56 & 22.44 & 23.33 & 24.22 \\
\hline 62.0 & 17.53 & 18.42 & 19.31 & 20.19 & 21.08 & 21.97 & 22.85 & 23.74 & 24.63 \\
\hline 63.5 & 18.15 & 19.04 & 19.93 & 20.80 & 21.69 & 22.58 & 23.45 & 24.34 & 25.23 \\
\hline 64.0 & 18.37 & 19.25 & 20.14 & 21.01 & 21.90 & 22.79 & 23.66 & 24.55 & 25.43 \\
\hline 65.0 & 18.79 & 19.67 & 20.55 & 21.43 & 22.31 & 23.19 & 24.07 & 24.95 & 25.83 \\
\hline 66.0 & 19.23 & 20.11 & 20.99 & 21.86 & 22.74 & 23.62 & 24.49 & 25.37 & 26.25 \\
\hline 67.0 & 19.67 & 20.55 & 21.43 & 22.29 & 23.17 & 24.05 & 24.92 & 25.79 & 26.67 \\
\hline 68.0 & 20.12 & 20.99 & 21.87 & 22.73 & 23.61 & 24.49 & 25.35 & 26.23 & 27.11 \\
\hline 69.0 & 20.59 & 21.46 & 22.33 & 23.20 & 24.07 & 24.94 & 25.81 & 26.68 & 27.55 \\
\hline 70.0 & 21.06 & 21.93 & 22.80 & 23.66 & 24.53 & 25.40 & 26.26 & 27.13 & 28.00 \\
\hline 71.0 & 21.53 & 22.40 & 23.27 & 24.13 & 25.00 & 25.87 & 26.73 & 27.60 & 28.47 \\
\hline 72.0 & 22.02 & 22.89 & 23.76 & 24.61 & 25.48 & 26.35 & 27.20 & 28.07 & 28.94 \\
\hline 73.0 & 22.52 & 23.38 & 24.25 & 25.10 & 25.97 & 26.84 & 27.69 & 28.56 & 29.42 \\
\hline 74.0 & 23.03 & 23.89 & 24.75 & 25.61 & 26.47 & 27.33 & 28.19 & 29.05 & 29.91 \\
\hline 75.0 & 23.54 & 24.40 & 25.27 & 26.12 & 26.98 & 27.84 & 28.69 & 29.56 & 30.42 \\
\hline 76.0 & 24.05 & 24.92 & 25.78 & 26.63 & 27.49 & 28.35 & 29.20 & 30.06 & 30.93 \\
\hline 77.0 & 24.59 & 25.45 & 26.31 & 27.16 & 28.02 & 28.88 & 29.73 & 30.59 & 31.45 \\
\hline 78.0 & 25.13 & 25.99 & 26.85 & 27.70 & 28.56 & 29.42 & 30.27 & 31.13 & 31.99 \\
\hline 79.0 & 25.68 & 26.54 & 27.40 & 28.24 & 29.10 & 29.96 & 30.81 & 31.66 & 32.52 \\
\hline 80.0 & 26.22 & 27.08 & 27.94 & 28.78 & 29.64 & 30.50 & 31.34 & 32.20 & 33.06 \\
\hline 81.0 & 26.79 & 27.64 & 28.50 & 29.34 & 30.20 & 31.06 & 31.90 & 32.76 & 33.61 \\
\hline 82.0 & 27.34 & 28.20 & 29.05 & 29.90 & 30.75 & 31.61 & 32.45 & 33.30 & 34.16 \\
\hline 83.0 & 27.91 & 28.76 & 29.62 & 30.46 & 31.31 & 32.16 & 33,00 & 33.86 & 34.71 \\
\hline 84.0 & 28.48 & 29.33 & 30.18 & 31.02 & 31.87 & 32.72 & 33.56 & 34.41 & 35.26 \\
\hline 85.0 & 29.05 & 29.90 & 30.75 & 31.59 & 32.44 & 33.29 & 34.13 & 34.98 & 35.83 \\
\hline 86.0 & 29.63 & 30.47 & 31.32 & 32.15 & 33.00 & 33.85 & 34.68 & 35.53 & 36.38 \\
\hline
\end{tabular}


Boys subischial leg length (in $\mathrm{cm}$ ) vs supine length (in $\mathrm{cm}$ )

\begin{tabular}{|c|c|c|c|c|c|c|c|c|c|}
\hline $\begin{array}{c}\text { Supine } \\
\text { length }\end{array}$ & -2.76 SD & -2.00 SD & -1.33 SD & -0.67 SD & 0SD & +0.67 SD & +1.33 SD & +2.00 SD & +2.67 SD \\
\hline 87.0 & 30.21 & 31.05 & 31.89 & 32.73 & 33.57 & 34.41 & 35.25 & 36.09 & 36.93 \\
\hline 88.0 & 30.79 & 31.63 & 32.47 & 33.30 & 34.14 & 34.98 & 35.81 & 36.65 & 37.49 \\
\hline 89.0 & 31.37 & 32.20 & 33.04 & 33.86 & 34.70 & 35.54 & 36.36 & 37.20 & 38.04 \\
\hline 90.0 & 31.95 & 32.78 & 33.62 & 34.44 & 35.27 & 36.10 & 36.92 & 37.76 & 38.59 \\
\hline 91.0 & 32.53 & 33.36 & 34.19 & 35.00 & 35.83 & 36.66 & 37.48 & 38.30 & 39.13 \\
\hline 92.0 & 33.11 & 33.93 & 34.75 & 35.57 & 36.39 & 37.21 & 38.03 & 38.85 & 39.67 \\
\hline 93.0 & 33.70 & 34.52 & 35.34 & 36.14 & 36.96 & 37.78 & 38.59 & 39.40 & 40.22 \\
\hline 94.0 & 34.28 & 35.09 & 35.91 & 36.71 & 37.52 & 38.33 & 39.14 & 39.95 & 40.76 \\
\hline 95.0 & 34.86 & 35.67 & 36.48 & 37.27 & 38.08 & 38.89 & 39.68 & 40.49 & 41.30 \\
\hline 96.0 & 35.44 & 36.25 & 37.05 & 37.84 & 38.64 & 39.44 & 40.23 & 41.03 & 41.84 \\
\hline 97.0 & 36.04 & 36.84 & 37.63 & 38.42 & 39.21 & 40.01 & 40.79 & 41.58 & 42.38 \\
\hline 98.0 & 36.63 & 37.42 & 38.21 & 38.98 & 39.77 & 40.56 & 41.34 & 42.12 & 42.91 \\
\hline 99.0 & 37.22 & 38.00 & 38.78 & 39.55 & 40.33 & 41.11 & 41.88 & 42.66 & 43.44 \\
\hline 100.0 & 37.81 & 38.58 & 39.36 & 40.12 & 40.89 & 41.66 & 42.43 & 43.20 & 43.97 \\
\hline 101.0 & 38.40 & 39.17 & 39.93 & 40.69 & 41.45 & 42.22 & 42.97 & 43.73 & 44.50 \\
\hline 102.0 & 38.88 & 39.64 & 40.39 & 41.14 & 41.90 & 42.66 & 43.41 & 44.16 & 44.92 \\
\hline 103.5 & 39.95 & 40.69 & 41.44 & 42.17 & 42.91 & 43.65 & 44.38 & 45.13 & 45.87 \\
\hline 104.5 & 40.55 & 41.28 & 42.02 & 42.74 & 43.47 & 44.20 & 44.92 & 45.66 & 46.39 \\
\hline 105.0 & 40.80 & 41.53 & 42.25 & 42.97 & 43.70 & 44.43 & 45.15 & 45.87 & 46.60 \\
\hline
\end{tabular}


Girls subischial leg length vs supine length; edf 333

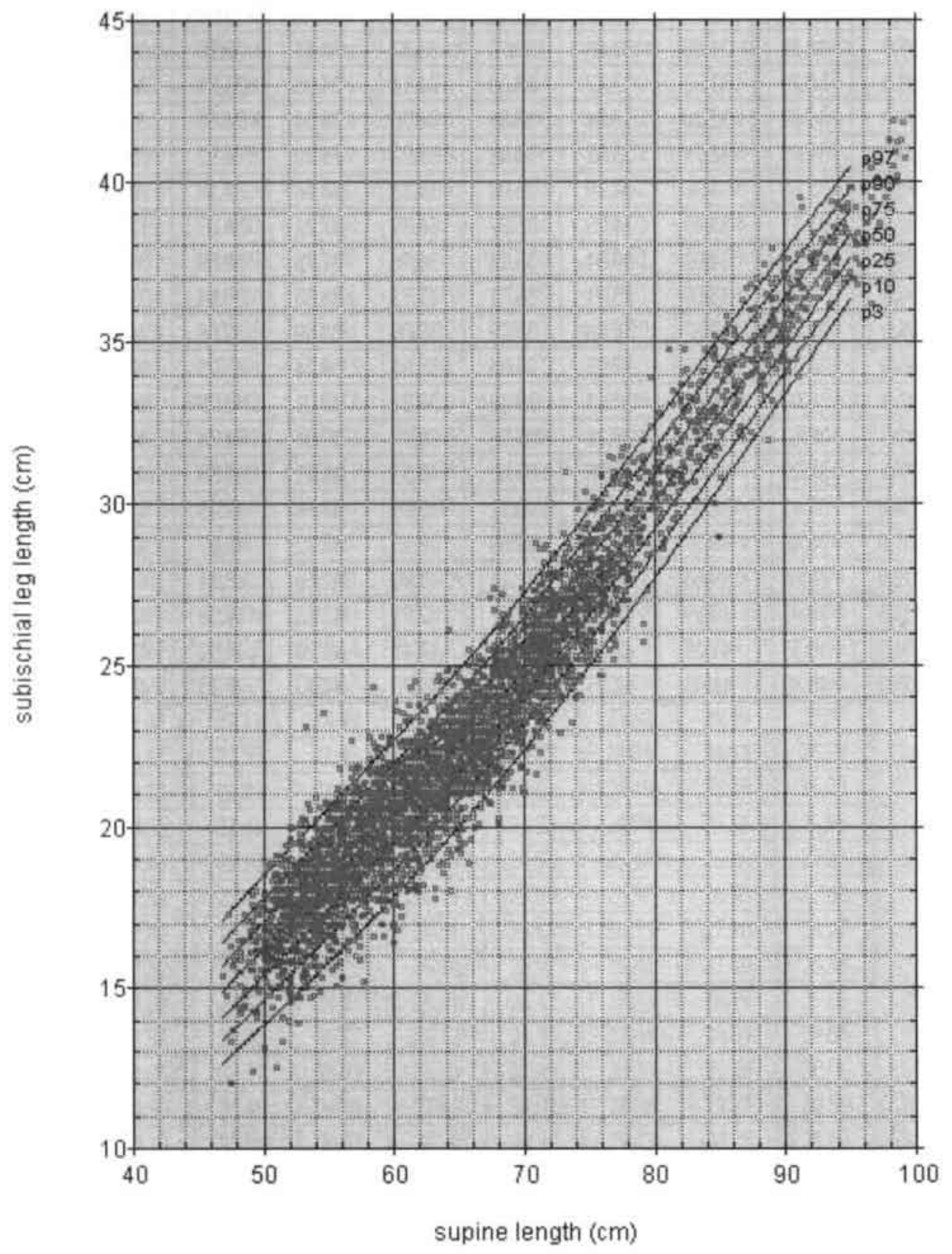


Girls subischial leg length vs supine length; edf 333

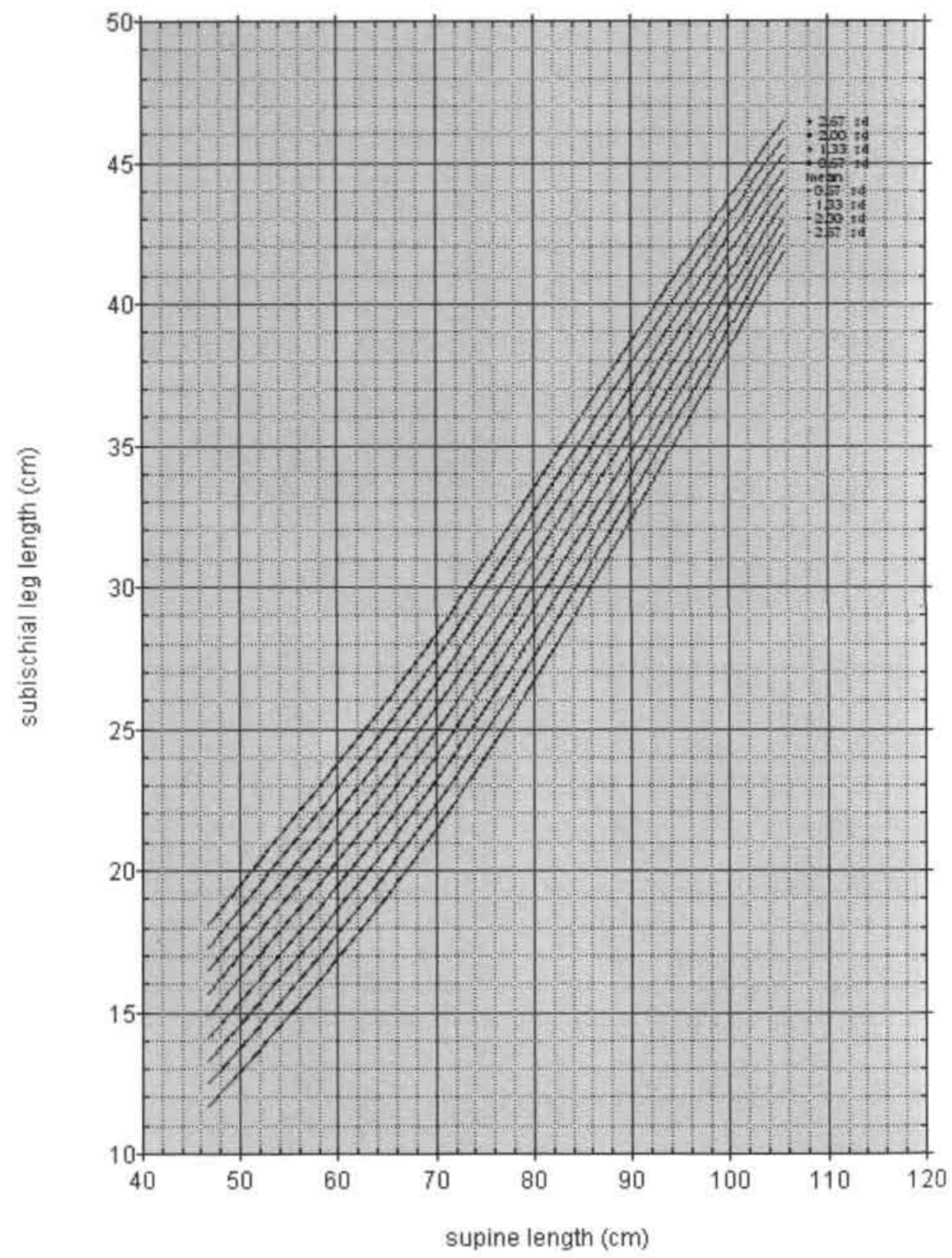




\begin{tabular}{|c|c|c|c|c|}
\hline \multicolumn{5}{|c|}{ Girls subischial leg length vs supine length LMS values (edf 333) } \\
\hline Supine length & L & M & S & SD \\
\hline 48.0 & 1.26 & 15.44 & 0.08 & 1.21 \\
\hline 49.0 & 1.29 & 15.81 & 0.08 & 1.22 \\
\hline 50.0 & 1.33 & 16.22 & 0.08 & 1.23 \\
\hline 51.0 & 1.36 & 16.63 & 0.07 & 1.24 \\
\hline 52.0 & 1.40 & 17.05 & 0.07 & 1.25 \\
\hline 53.0 & 1.44 & 17.46 & 0.07 & 1.26 \\
\hline 54.0 & 1.49 & 17.87 & 0.07 & 1.26 \\
\hline 55.0 & 1.54 & 18.28 & 0.07 & 1.27 \\
\hline 56.0 & 1.59 & 18.70 & 0.07 & 1.27 \\
\hline 57.0 & 1.64 & 19.11 & 0.07 & 1.28 \\
\hline 58.0 & 1.69 & 19.53 & 0.07 & 1.28 \\
\hline 59.0 & 1.74 & 19.95 & 0.06 & 1.28 \\
\hline 60.0 & 1.79 & 20.37 & 0.06 & 1.28 \\
\hline 61.0 & 1.83 & 20.80 & 0.06 & 1.28 \\
\hline 62.0 & 1.86 & 21.23 & 0.06 & 1.29 \\
\hline 63.0 & 1.89 & 21.67 & 0.06 & 1.29 \\
\hline 64.0 & 1.90 & 22.11 & 0.06 & 1.29 \\
\hline 65.0 & 1.90 & 22.56 & 0.06 & 1.29 \\
\hline 66.0 & 1.89 & 23.01 & 0.06 & 1.29 \\
\hline 67.0 & 1.87 & 23.47 & 0.05 & 1.29 \\
\hline 68.0 & 1.83 & 23.94 & 0.05 & 1.29 \\
\hline 69.0 & 1.79 & 24.42 & 0.05 & 1.29 \\
\hline 70.0 & 1.74 & 24.90 & 0.05 & 1.29 \\
\hline 71.0 & 1.67 & 25.39 & 0.05 & 1.29 \\
\hline 72.0 & 1.61 & 25.89 & 0.05 & 1.29 \\
\hline 73.0 & 1.53 & 26.40 & 0.05 & 1.28 \\
\hline 74.0 & 1.45 & 26.91 & 0.05 & 1.28 \\
\hline 75.0 & 1.37 & 27.42 & 0.05 & 1.28 \\
\hline 76.0 & 1.29 & 27.94 & 0.05 & 1.28 \\
\hline 77.0 & 1.20 & 28.47 & 0.04 & 1.28 \\
\hline 78.0 & 1.11 & 29.00 & 0.04 & 1.28 \\
\hline 79.0 & 1.03 & 29.54 & 0.04 & 1.27 \\
\hline 80.0 & 0.95 & 30.07 & 0.04 & 1.27 \\
\hline 81.0 & 0.86 & 30.61 & 0.04 & 1.26 \\
\hline 82.0 & 0.78 & 31.16 & 0.04 & 1.26 \\
\hline 83.0 & 0.70 & 31.76 & 0.04 & 1.25 \\
\hline 84.0 & 0.62 & 32.30 & 0.04 & 1.24 \\
\hline 85.0 & 0.56 & 32.80 & 0.04 & 1.23 \\
\hline 86.0 & 0.48 & 33.40 & 0.04 & 1.22 \\
\hline & & & & \\
\hline
\end{tabular}


Appendix B

\begin{tabular}{|c|c|c|c|c|}
\hline \multicolumn{5}{|c|}{ Girls subischial leg length vs supine length LMS values (edf 333) } \\
\hline Supine length & L & M & S & SD \\
\hline 87.0 & 0.42 & 33.90 & 0.04 & 1.21 \\
\hline 88.0 & 0.36 & 34.45 & 0.03 & 1.20 \\
\hline 89.0 & 0.30 & 35.00 & 0.03 & 1.19 \\
\hline 90.0 & 0.24 & 35.55 & 0.03 & 1.17 \\
\hline 91.0 & 0.18 & 36.10 & 0.03 & 1.16 \\
\hline 92.0 & 0.13 & 36.60 & 0.03 & 1.14 \\
\hline 93.0 & 0.07 & 37.21 & 0.03 & 1.13 \\
\hline 94.0 & 0.02 & 37.76 & 0.03 & 1.11 \\
\hline 95.0 & -0.03 & 38.32 & 0.03 & 1.09 \\
\hline
\end{tabular}




\begin{tabular}{|c|c|c|c|c|c|c|c|}
\hline \multicolumn{8}{|c|}{ Girls subischial leg length (in $\mathrm{cm}$ ) vs supine length (in $\mathrm{cm}$ ) } \\
\hline Supine length & P3 & P10 & $\mathrm{P} 25$ & P50 & $\mathrm{P} 75$ & $\mathrm{P} 90$ & P97 \\
\hline 48.0 & 12.89 & 13.63 & 14.38 & 15.19 & 16.00 & 16.72 & 17.42 \\
\hline 49.0 & 13.27 & 14.03 & 14.78 & 15.61 & 16.42 & 17.14 & 17.85 \\
\hline 50.0 & 13.66 & 14.42 & 15.18 & 16.02 & 16.84 & 17.57 & 18.28 \\
\hline 51.0 & 14.04 & 14.82 & 15.59 & 16.43 & 17.26 & 17.99 & 18.70 \\
\hline 52.0 & 14.43 & 15.21 & 15.99 & 16.84 & 17.67 & 18.41 & 19.13 \\
\hline 53.0 & 14.82 & 15.61 & 16.40 & 17.25 & 18.09 & 18.83 & 19.55 \\
\hline 54.0 & 15.21 & 16.01 & 16.81 & 17.67 & 18.51 & 19.25 & 19.97 \\
\hline 55.0 & 15.61 & 16.42 & 17.21 & 18.08 & 18.92 & 19.67 & 20.39 \\
\hline 56.0 & 16.01 & 16.82 & 17.62 & 18.49 & 19.34 & 20.08 & 20.80 \\
\hline 57.0 & 16.40 & 17.23 & 18.03 & 18.91 & 19.75 & 20.50 & 21.22 \\
\hline 58.0 & 16.81 & 17.63 & 18.45 & 19.32 & 20.17 & 20.92 & 21.63 \\
\hline 59.0 & 17.21 & 18.05 & 18.86 & 19.74 & 20.59 & 21.34 & 22.05 \\
\hline 60.0 & 17.63 & 18.46 & 19.28 & 20.16 & 21.01 & 21.76 & 22.47 \\
\hline 61.0 & 18.04 & 18.88 & 19,70 & 20.59 & 21.44 & 22.18 & 22.90 \\
\hline 62.0 & 18.47 & 19.31 & 20.13 & 21.01 & 21.87 & 22.61 & 23.32 \\
\hline 63.5 & 18.90 & 19.74 & 20.56 & 21.45 & 22.30 & 23.04 & 23.76 \\
\hline 64.0 & 19.11 & 19.96 & 20.78 & 21.67 & 22.52 & 23.26 & 23.97 \\
\hline 65.0 & 19.56 & 20.40 & 21.22 & 22.11 & 22.96 & 23.70 & 24.42 \\
\hline 66.0 & 20.01 & 20.85 & 21.67 & 22.56 & 23.41 & 24.15 & 24.87 \\
\hline 67.0 & 20.47 & 21.31 & 22.13 & 23.01 & 23.86 & 24.61 & 25.33 \\
\hline 68.0 & 20.94 & 21.77 & 22.59 & 23.47 & 24.33 & 25.07 & 25.79 \\
\hline 69.0 & 21.41 & 22.24 & 23.06 & 23.94 & 24.80 & 25.54 & 26.27 \\
\hline 70.0 & 21.90 & 22.72 & 23.54 & 24.42 & 25.27 & 26.02 & 26.75 \\
\hline 71.0 & 22.39 & 23.21 & 24.02 & 24.90 & 25.76 & 26.51 & 27.24 \\
\hline 72.0 & 22.89 & 23.71 & 24.52 & 25.39 & 26.25 & 27.01 & 27.74 \\
\hline 73.0 & 23.40 & 24.21 & 25.02 & 25.89 & 26.75 & 27.51 & 28.24 \\
\hline 74.0 & 23.92 & 24.72 & 25.52 & 26.40 & 27.25 & 28.02 & 28.76 \\
\hline 75.0 & 24.44 & 25.24 & 26.03 & 26.91 & 27.77 & 28.53 & 29.27 \\
\hline 76.0 & 24.97 & 25.76 & 26.55 & 27.42 & 28.28 & 29.05 & 29.80 \\
\hline 77.0 & 25.50 & 26.29 & 27.08 & 27.94 & 28.80 & 29.57 & 30.33 \\
\hline 78.0 & 26.04 & 26.82 & 27.61 & 28.47 & 29.33 & 30.10 & 30.86 \\
\hline 79.0 & 26.59 & 27.36 & 28.14 & 29.00 & 29.86 & 30.63 & 31.39 \\
\hline 80.0 & 27.14 & 27.90 & 28.68 & 29.54 & 30.39 & 31.17 & 31.93 \\
\hline 81.0 & 27.69 & 28.45 & 29.22 & 30.07 & 30.93 & 31.70 & 32.47 \\
\hline 82.0 & 28.25 & 29.00 & 29.76 & 30.61 & 31.47 & 32.24 & 33.00 \\
\hline 83.0 & 28.81 & 29.56 & 30.31 & 31.16 & 32.01 & 32.78 & 33.54 \\
\hline 84.0 & 29.43 & 30.17 & 30.92 & 31.76 & 32.60 & 33.37 & 34.13 \\
\hline 85.0 & 30.00 & 30.73 & 31.47 & 32.30 & 33.15 & 33.91 & 34.67 \\
\hline 86.0 & 30.52 & 31.23 & 31.97 & 32.80 & 33.63 & 34.39 & 35.15 \\
\hline
\end{tabular}




\begin{tabular}{|c|c|c|c|c|c|c|c|}
\hline \multicolumn{7}{|c|}{ Girls subischial leg length (in cm) vs supine length (in cm) } \\
\hline Supine length & P3 & P10 & P25 & P50 & P75 & P90 & P97 \\
\hline 87.0 & 31.15 & 31.86 & 32.58 & 33.40 & 34.23 & 34.99 & 35.74 \\
\hline 88.0 & 31.66 & 32.37 & 33.09 & 33.90 & 34.72 & 35.47 & 36.22 \\
\hline 89.0 & 32.24 & 32.93 & 33.65 & 34.45 & 35.26 & 36.01 & 36.75 \\
\hline 90.0 & 32.82 & 33.50 & 34.21 & 35.00 & 35.81 & 36.54 & 37.28 \\
\hline 91.0 & 33.40 & 34.07 & 34.77 & 35.55 & 36.35 & 37.08 & 37.81 \\
\hline 92.0 & 33.98 & 34.65 & 35.33 & 36.11 & 36.89 & 37.61 & 38.34 \\
\hline 93.0 & 34.51 & 35.16 & 35.84 & 36.60 & 37.38 & 38.09 & 38.81 \\
\hline 94.0 & 35.15 & 35.79 & 36.46 & 37.21 & 37.98 & 38.68 & 39.38 \\
\hline 95.0 & 35.73 & 36.37 & 37.02 & 37.76 & 38.52 & 39.21 & 39.91 \\
\hline 96.0 & 36.32 & 36.95 & 37.59 & 38.32 & 39.06 & 39.74 & 40.43 \\
\hline 97.0 & 13.12 & 13.87 & 14.62 & 15.44 & 16.25 & 16.97 & 17.68 \\
\hline 97.5 & 13.27 & 14.03 & 14.78 & 15.61 & 16.42 & 17.14 & 17.85 \\
\hline 98.0 & 13.46 & 14.22 & 14.98 & 15.81 & 16.63 & 17.35 & 18.06 \\
\hline 99.0 & 13.85 & 14.62 & 15.39 & 16.22 & 17.05 & 17.78 & 18.49 \\
\hline 100.0 & 14.24 & 15.02 & 15.79 & 16.64 & 17.46 & 18.20 & 18.91 \\
\hline 101.0 & 14.63 & 15.41 & 16.20 & 17.05 & 17.88 & 18.62 & 19.34 \\
\hline 102.0 & 15.02 & 15.81 & 16.60 & 17.46 & 18.30 & 19.04 & 19.76 \\
\hline 103.5 & 15.41 & 16.21 & 17.01 & 17.87 & 18.71 & 19.46 & 20.18 \\
\hline 104.5 & 15.61 & 16.42 & 17.21 & 18.08 & 18.92 & 19.67 & 20.39 \\
\hline 105.0 & 15.81 & 16.62 & 17.42 & 18.28 & 19.13 & 19.87 & 20.59 \\
\hline
\end{tabular}


Girls subischial leg length (in $\mathrm{cm}$ ) vs supine length (in $\mathrm{cm}$ )

\begin{tabular}{|c|c|c|c|c|c|c|c|c|c|}
\hline $\begin{array}{l}\text { Supine } \\
\text { length }\end{array}$ & $-2.76 \mathrm{SD}$ & $-2.00 \mathrm{SD}$ & $-1.33 \mathrm{SD}$ & $-0.67 \mathrm{SD}$ & $0 \mathrm{SD}$ & $+0.67 \mathrm{SD}$ & $+1.33 \mathrm{SD}$ & $+2.00 \mathrm{SD}$ & $+2.67 \mathrm{SD}$ \\
\hline 48.0 & 11.98 & 12.78 & 13.59 & 14.38 & 15.19 & 16.00 & 16.79 & 17.60 & 18.40 \\
\hline 49.0 & 12.37 & 13.18 & 13.99 & 14.80 & 15.61 & 16.42 & 17.23 & 18.04 & 18.85 \\
\hline 50.0 & 12.75 & 13.57 & 14.39 & 15.20 & 16.02 & 16.84 & 17.65 & 18.47 & 19.29 \\
\hline 51.0 & 13.13 & 13.96 & 14.79 & 15.60 & 16.43 & 17.26 & 18.07 & 18.90 & 19.73 \\
\hline 52.0 & 13.52 & 14.35 & 15.18 & 16.01 & 16.84 & 17.67 & 18.50 & 19.33 & 20.16 \\
\hline 53.0 & 13.90 & 14.74 & 15.58 & 16.41 & 17.25 & 18.09 & 18.92 & 19.76 & 20.60 \\
\hline 54.0 & 14.30 & 15.14 & 15.98 & 16.82 & 17.66 & 18.50 & 19.34 & 20.18 & 21.02 \\
\hline 55.0 & 14.70 & 15.55 & 16.40 & 17.23 & 18.08 & 18.93 & 19.76 & 20.61 & 21.46 \\
\hline 56.0 & 15.10 & 15.95 & 16.80 & 17.64 & 18.49 & 19.34 & 20.18 & 21.03 & 21.88 \\
\hline 57.0 & 15.51 & 16.36 & 17.21 & 18.06 & 18.91 & 19.76 & 20.61 & 21.46 & 22.31 \\
\hline 58.0 & 15.91 & 16.76 & 17.62 & 18.46 & 19.32 & 20.18 & 21.02 & 21.88 & 22.73 \\
\hline 59.0 & 16.32 & 17.18 & 18.04 & 18.88 & 19.74 & 20.60 & 21.44 & 22.30 & 23.16 \\
\hline 60.0 & 16.73 & 17.59 & 18.45 & 19.30 & 20.16 & 21.02 & 21.87 & 22.73 & 23.59 \\
\hline 61.0 & 17.15 & 18.01 & 18.87 & 19.72 & 20.58 & 21.44 & 22.29 & 23.15 & 24.01 \\
\hline 62.0 & 17.58 & 18.44 & 19.30 & 20.15 & 21.01 & 21.87 & 22.72 & 23.58 & 24.44 \\
\hline 63.5 & 18.02 & 18.88 & 19.74 & 20.59 & 21.45 & 22.31 & 23.16 & 24.02 & 24.88 \\
\hline 64.0 & 18.24 & 19.10 & 19.96 & 20.81 & 21.67 & 22.53 & 23.38 & 24.24 & 25.10 \\
\hline 65.0 & 18.68 & 19.54 & 20.40 & 21.25 & 22.11 & 22.97 & 23.82 & 24.68 & 25.54 \\
\hline 66.0 & 19.13 & 19.99 & 20.85 & 21.70 & 22.56 & 23.42 & 24.27 & 25.13 & 25.99 \\
\hline 67.0 & 19.58 & 20.44 & 21.30 & 22.15 & 23.01 & 23.87 & 24.72 & 25.58 & 26.44 \\
\hline 68.0 & 20.04 & 20.90 & 21.76 & 22.61 & 23.47 & 24.33 & 25.18 & 26.04 & 26.90 \\
\hline 69.0 & 20.51 & 21.37 & 22.23 & 23.08 & 23.94 & 24.80 & 25.65 & 26.51 & 27.37 \\
\hline 70.0 & 20.99 & 21.85 & 22.71 & 23.56 & 24.42 & 25.28 & 26.13 & 26.99 & 27.85 \\
\hline 71.0 & 21.47 & 22.33 & 23.19 & 24.04 & 24.90 & 25.76 & 26.61 & 27.47 & 28.33 \\
\hline 72.0 & 21.96 & 22.82 & 23.68 & 24.53 & 25.39 & 26.25 & 27.10 & 27.96 & 28.82 \\
\hline 73.0 & 22.46 & 23.32 & 24.18 & 25.03 & 25.89 & 26.75 & 27.60 & 28.46 & 29.32 \\
\hline 74.0 & 22.97 & 23.83 & 24.69 & 25.54 & 26.40 & 27.26 & 28.11 & 28.97 & 29.83 \\
\hline 75.0 & 23.48 & 24.34 & 25.20 & 26.05 & 26.91 & 27.77 & 28.62 & 29.48 & 30.34 \\
\hline 76.0 & 23.99 & 24.85 & 25.71 & 26.56 & 27.42 & 28.28 & 29.13 & 29.99 & 30.85 \\
\hline 77.0 & 24.52 & 25.38 & 26.24 & 27.08 & 27.94 & 28.80 & 29.64 & 30.50 & 31.36 \\
\hline 78.0 & 25.06 & 25.91 & 26.77 & 27.61 & 28.47 & 29.33 & 30.17 & 31.03 & 31.89 \\
\hline 79.0 & 25.59 & 26.45 & 27.30 & 28.14 & 29.00 & 29.86 & 30.70 & 31.55 & 32.41 \\
\hline 80.0 & 26.14 & 26.99 & 27.85 & 28.69 & 29.54 & 30.39 & 31.23 & 32.09 & 32.94 \\
\hline 81.0 & 26.68 & 27.53 & 28.38 & 29.22 & 30.07 & 30.92 & 31.76 & 32.61 & 33.46 \\
\hline 82.0 & 27.24 & 28.08 & 28.93 & 29.76 & 30.61 & 31.46 & 32.29 & 33.14 & 33.99 \\
\hline 83.0 & 27.80 & 28.64 & 29.49 & 30.32 & 31.16 & 32.00 & 32.83 & 33.68 & 34.52 \\
\hline 84.0 & 28.42 & 29.26 & 30.10 & 30.92 & 31.76 & 32.60 & 33.42 & 34.26 & 35.10 \\
\hline 85.0 & 28.99 & 29.82 & 30.65 & 31.47 & 32.30 & 33.13 & 33.95 & 34.78 & 35.61 \\
\hline 86.0 & 29.51 & 30.33 & 31.16 & 31.97 & 32.80 & 33.63 & 34.44 & 35.27 & 36.09 \\
\hline
\end{tabular}


Appendix B

\begin{tabular}{|c|c|c|c|c|c|c|c|c|c|}
\hline \multicolumn{8}{|c|}{ Girls supine length (in cm) vs subischial leg length (in cm) } \\
\hline $\begin{array}{c}\text { Supine } \\
\text { length }\end{array}$ & -2.76 SD & -2.00 SD & -1.33 SD & -0.67 SD & 0 SD & +0.67 SD & +1.33 SD & +2.00 SD & +2.67 SD \\
\hline 87.0 & 30.14 & 30.96 & 31.78 & 32.58 & 33.40 & 34.22 & 35.03 & 35.84 & 36.66 \\
\hline 88.0 & 30.66 & 31.48 & 32.29 & 33.09 & 33.90 & 34.71 & 35.51 & 36.32 & 37.14 \\
\hline 89.0 & 31.25 & 32.05 & 32.86 & 33.65 & 34.45 & 35.25 & 36.05 & 36.85 & 37.65 \\
\hline 90.0 & 31.83 & 32.63 & 33.42 & 34.21 & 35.00 & 35.80 & 36.58 & 37.37 & 38.17 \\
\hline 91.0 & 32.42 & 33.21 & 33.99 & 34.77 & 35.55 & 36.34 & 37.11 & 37.89 & 38.68 \\
\hline 92.0 & 33.01 & 33.79 & 34.56 & 35.33 & 36.10 & 36.88 & 37.64 & 38.41 & 39.19 \\
\hline 93.0 & 33.55 & 34.31 & 35.08 & 35.83 & 36.60 & 37.37 & 38.12 & 38.89 & 39.65 \\
\hline 94.0 & 34.21 & 34.96 & 35.71 & 36.46 & 37.21 & 37.96 & 38.71 & 39.46 & 40.21 \\
\hline 95.0 & 34.80 & 35.54 & 36.29 & 37.02 & 37.76 & 38.50 & 39.23 & 39.98 & 40.72 \\
\hline 96.0 & 35.41 & 36.14 & 36.87 & 37.59 & 38.32 & 39.05 & 39.77 & 40.50 & 41.23 \\
\hline 97.0 & 12.21 & 13.02 & 13.83 & 14.63 & 15.44 & 16.25 & 17.05 & 17.86 & 18.67 \\
\hline 98.0 & 12.55 & 13.37 & 14.19 & 14.99 & 15.81 & 16.63 & 17.43 & 18.25 & 19.07 \\
\hline 99.0 & 12.93 & 13.76 & 14.58 & 15.40 & 16.22 & 17.05 & 17.86 & 18.68 & 19.51 \\
\hline 100.0 & 13.32 & 14.15 & 14.98 & 15.80 & 16.63 & 17.46 & 18.28 & 19.11 & 19.94 \\
\hline 101.0 & 13.72 & 14.55 & 15.39 & 16.21 & 17.05 & 17.89 & 18.71 & 19.55 & 20.39 \\
\hline 102.0 & 14.10 & 14.95 & 15.79 & 16.62 & 17.46 & 18.30 & 19.13 & 19.97 & 20.82 \\
\hline 103.5 & 14.50 & 15.34 & 16.19 & 17.02 & 17.87 & 18.72 & 19.55 & 20.40 & 21.24 \\
\hline 104.5 & 14.70 & 15.55 & 16.40 & 17.23 & 18.08 & 18.93 & 19.76 & 20.61 & 21.46 \\
\hline 105.0 & 14.89 & 15.74 & 16.59 & 17.43 & 18.28 & 19.13 & 19.97 & 20.82 & 21.67 \\
\hline
\end{tabular}


Head circumference vs crown rump length

\begin{tabular}{|c|c|c|c|}
\hline Boys & \multicolumn{4}{|c|}{ Head circumference vs crown rump length } \\
\hline Edf: 333 3 3.02 2.97 2.97) & N: 4966 & Nc: 306 \\
\hline Range & Expected & Observed & Difference \\
\hline <P3 & 149.0 & 139 & -10.0 \\
\hline P3-P10 & 347.6 & 355 & 7.4 \\
\hline P10 - P25 & 744.9 & 755 & 10.1 \\
\hline P25 - P 50 & 1241.5 & 1227 & -14.5 \\
\hline P50 - P75 & 1241.5 & 1259 & 17.5 \\
\hline P75 - P90 & 744.9 & 739 & -5.9 \\
\hline P90 - P97 & 347.6 & 345 & -2.6 \\
\hline > P97 & 149.0 & 147 & -2.0 \\
\hline
\end{tabular}

\begin{tabular}{|c|c|c|c|}
\hline Girls & \multicolumn{4}{|c|}{ Head circumference vs crown rump length } \\
\hline Edf: $3223(3.002 .993 .00)$ & N: 4129 & Nc: 283 \\
\hline Range & Expected & Observed & Difference \\
\hline < P3 & 123.9 & 118 & -5.9 \\
\hline P3-P10 & 289.0 & 304 & 15.0 \\
\hline P10 - P25 & 619.4 & 580 & -39.4 \\
\hline P25 - P50 & 1032.3 & 1051 & 18.7 \\
\hline P50 - P75 & 1032.3 & 1088 & 55.7 \\
\hline P75 - P90 & 619.4 & 585 & -34.4 \\
\hline P90 - P97 & 289.0 & 276 & -13.0 \\
\hline > P97 & 123.9 & 127 & 3.1 \\
\hline
\end{tabular}


Boys head circumference vs crown rump length; edf 333

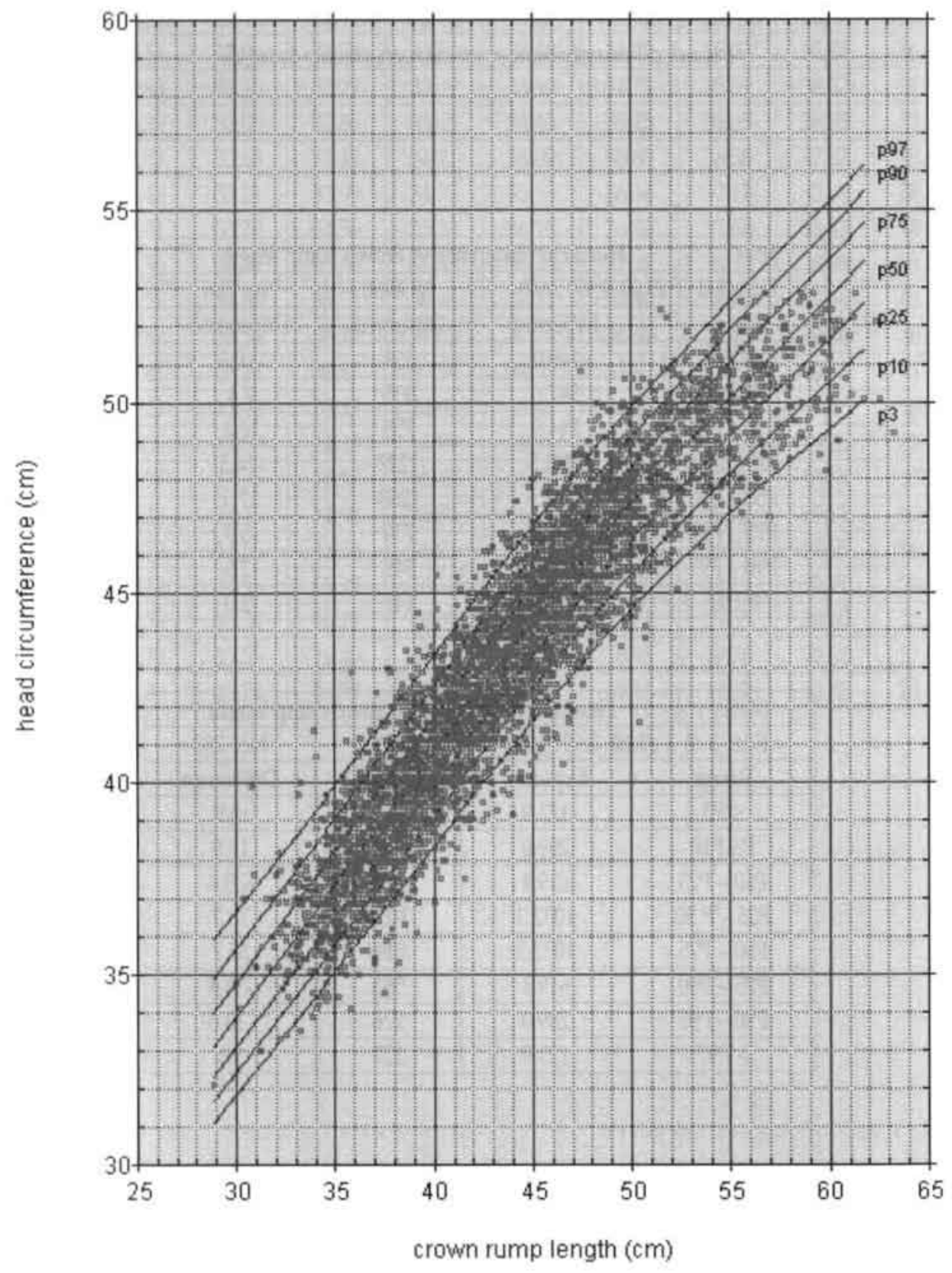


Boys head circumference vs crown rump length; edf 333

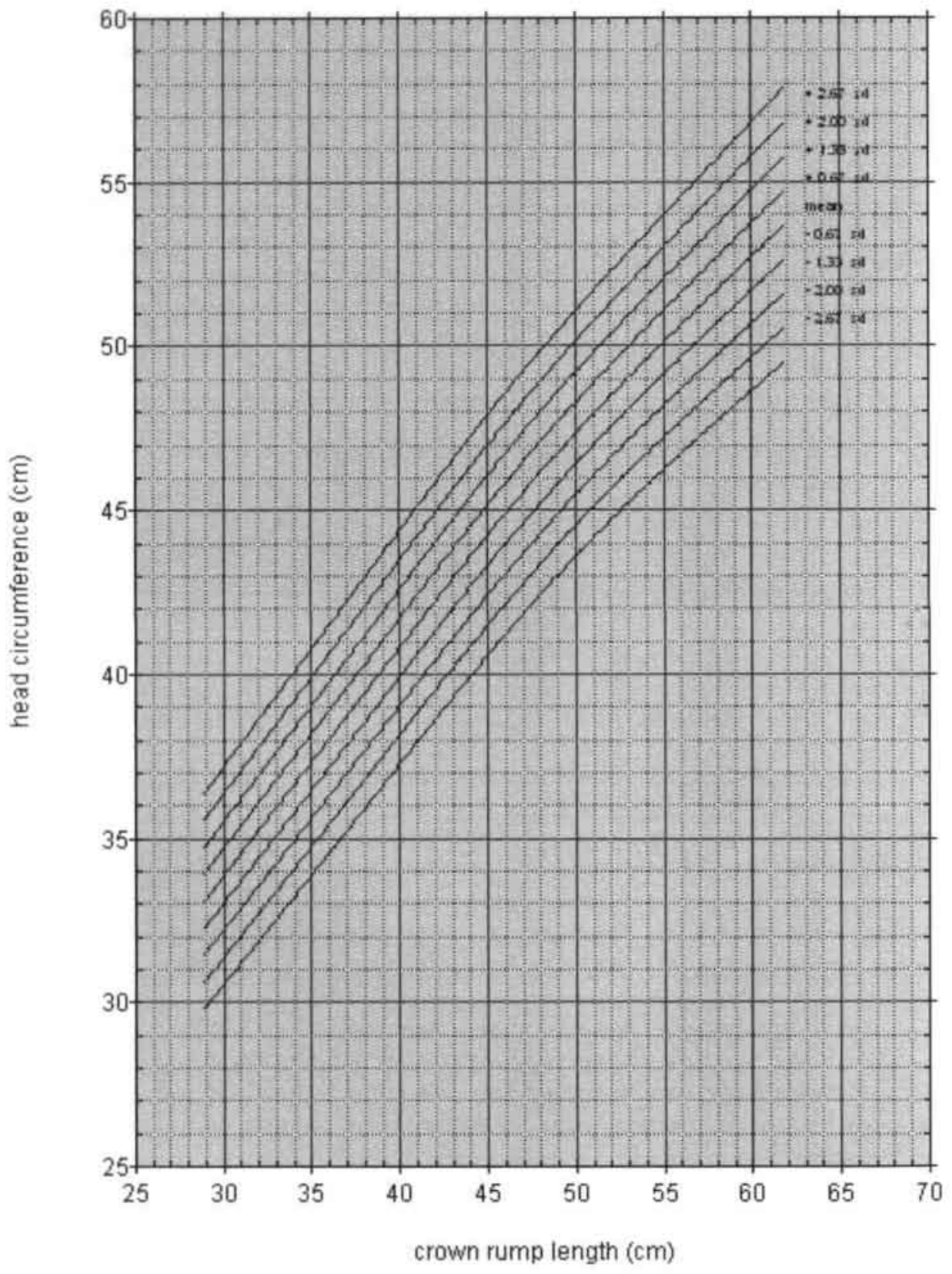




\begin{tabular}{|c|c|c|c|c|}
\hline \multicolumn{5}{|c|}{ Boys head circumference length vs crown rump LMS values ( edf 333 ) } \\
\hline $\begin{array}{l}\text { Crown rump } \\
\text { length }\end{array}$ & L & M & $\mathrm{S}$ & SD \\
\hline 30.0 & -3.30 & 33.87 & 0.04 & 1.24 \\
\hline 31.0 & -2.82 & 34.57 & 0.04 & 1.25 \\
\hline 32.0 & -2.35 & 35.26 & 0.04 & 1.26 \\
\hline 33.0 & -1.88 & 35.95 & 0.04 & 1.27 \\
\hline 34.0 & -1.42 & 36.65 & 0.03 & 1.28 \\
\hline 35.0 & -0.98 & 37.34 & 0.03 & 1.29 \\
\hline 36.0 & -0.57 & 38.04 & 0.03 & 1.30 \\
\hline 37.0 & -0.20 & 38.73 & 0.03 & 1.31 \\
\hline 38.0 & 0.15 & 39.43 & 0.03 & 1.32 \\
\hline 39.0 & 0.45 & 40.13 & 0.03 & 1.32 \\
\hline 40.0 & 0.73 & 40.83 & 0.03 & 1.33 \\
\hline 41.0 & 0.98 & 41.53 & 0.03 & 1.34 \\
\hline 42.0 & 1.21 & 42.22 & 0.03 & 1.35 \\
\hline 43.0 & 1.41 & 42.90 & 0.03 & 1.36 \\
\hline 44.0 & 1.61 & 43.58 & 0.03 & 1.36 \\
\hline 45.0 & 1.79 & 44.24 & 0.03 & 1.37 \\
\hline 46.0 & 1.97 & 44.89 & 0.03 & 1.38 \\
\hline 47.0 & 2.15 & 45.53 & 0.03 & 1.38 \\
\hline 48.0 & 2.35 & 46.15 & 0.03 & 1.39 \\
\hline 49.0 & 2.57 & 46.75 & 0.03 & 1.40 \\
\hline 50.0 & 2.81 & 47.34 & 0.03 & 1.40 \\
\hline 51.0 & 3.08 & 47.92 & 0.03 & 1.41 \\
\hline 52.0 & 3.38 & 48.48 & 0.03 & 1.42 \\
\hline 53.0 & 3.70 & 49.03 & 0.03 & 1.43 \\
\hline 54.0 & 4.05 & 49.57 & 0.03 & 1.44 \\
\hline 55.0 & 4.41 & 50.11 & 0.03 & 1.45 \\
\hline 56.0 & 4.80 & 50.64 & 0.03 & 1.46 \\
\hline 57.0 & 5.20 & 51.16 & 0.03 & 1.48 \\
\hline 58.0 & 5.61 & 51.69 & 0.03 & 1.50 \\
\hline 59.0 & 6.04 & 52.21 & 0.03 & 1.51 \\
\hline 60.0 & 6.47 & 52.73 & 0.03 & 1.53 \\
\hline 61.0 & 6.92 & 53.25 & 0.03 & 1.55 \\
\hline
\end{tabular}




\begin{tabular}{|c|c|c|c|c|c|c|c|}
\hline \multicolumn{8}{|c|}{ Boys head circumference (in $\mathrm{cm}$ ) vs crown rump length (in $\mathrm{cm}$ ) } \\
\hline $\begin{array}{c}\text { Crown rump } \\
\text { length }\end{array}$ & P3 & P10 & $\mathrm{P} 25$ & P50 & P75 & $\mathrm{P} 90$ & P97 \\
\hline 30.0 & 31.83 & 32.42 & 33.08 & 33.87 & 34.76 & 35.65 & 36.63 \\
\hline 31.0 & 32.47 & 33.09 & 33.76 & 34.57 & 35.45 & 36.33 & 37.29 \\
\hline 32.0 & 33.12 & 33.75 & 34.44 & 35.26 & 36.15 & 37.02 & 37.94 \\
\hline 33.0 & 33.76 & 34.42 & 35.12 & 35.95 & 36.84 & 37.70 & 38.60 \\
\hline 34.0 & 34.41 & 35.09 & 35.80 & 36.65 & 37.54 & 38.38 & 39.27 \\
\hline 35.0 & 35.06 & 35.76 & 36.49 & 37.34 & 38.23 & 39.07 & 39.94 \\
\hline 36.0 & 35.71 & 36.43 & 37.18 & 38.04 & 38.93 & 39.76 & 40.61 \\
\hline 37.0 & 36.36 & 37.10 & 37.86 & 38.73 & 39.63 & 40.45 & 41.29 \\
\hline 38.0 & 37.02 & 37.78 & 38.55 & 39.43 & 40.33 & 41.15 & 41.98 \\
\hline 39.0 & 37.68 & 38.45 & 39.24 & 40.13 & 41.03 & 41.85 & 42.67 \\
\hline 40.0 & 38.35 & 39.13 & 39.94 & 40.83 & 41.73 & 42.55 & 43.36 \\
\hline 41.0 & 39.01 & 39.81 & 40.62 & 41.53 & 42.43 & 43.24 & 44.05 \\
\hline 42.0 & 39.67 & 40.48 & 41.31 & 42.22 & 43.13 & 43.94 & 44.74 \\
\hline 43.0 & 40.32 & 41.15 & 41.99 & 42.90 & 43.81 & 44.63 & 45.42 \\
\hline 44.0 & 40,97 & 41.81 & 42.65 & 43.58 & 44.49 & 45.30 & 46.10 \\
\hline 45.0 & 41.60 & 42.46 & 43.31 & 44.24 & 45.16 & 45.97 & 46.76 \\
\hline 46.0 & 42.23 & 43.09 & 43.95 & 44.89 & 45.81 & 46.63 & 47.41 \\
\hline 47.0 & 42.84 & 43.71 & 44.58 & 45.53 & 46.45 & 47.26 & 48.05 \\
\hline 48.0 & 43.43 & 44.32 & 45,20 & 46.15 & 47.07 & 47.89 & 48.67 \\
\hline 49.0 & 44.00 & 44.91 & 45.80 & 46.75 & 47.68 & 48.49 & 49.27 \\
\hline 50.0 & 44.56 & 45.48 & 46.38 & 47.34 & 48.27 & 49.08 & 49.86 \\
\hline 51.0 & 45.10 & 46.04 & 46.95 & 47.92 & 48.85 & 49.66 & 50.43 \\
\hline 52.0 & 45.62 & 46.58 & 47.50 & 48.48 & 49.41 & 50.22 & 50.99 \\
\hline 53.0 & 46.12 & 47.10 & 48.04 & 49.03 & 49.97 & 50.77 & 51.54 \\
\hline 54.0 & 46.61 & 47.62 & 48.58 & 49.57 & 50.52 & 51.32 & 52.08 \\
\hline 55.0 & 47.09 & 48.12 & 49.10 & 50.11 & 51.06 & 51.86 & 52.61 \\
\hline 56.0 & 47.55 & 48.62 & 49.61 & 50.64 & 51.59 & 52.40 & 53.15 \\
\hline 57.0 & 48.00 & 49.10 & 50.12 & 51.16 & 52.12 & 52.93 & 53.67 \\
\hline 58.0 & 48.44 & 49.58 & 50.63 & 51.69 & 52.65 & 53.46 & 54.20 \\
\hline 59.0 & 48.87 & 50.06 & 51.13 & 52.21 & 53.18 & 53.99 & 54.73 \\
\hline 60.0 & 49.29 & 50.53 & 51.64 & 52.73 & 53.71 & 54.52 & 55.25 \\
\hline 61.0 & 49.71 & 51.00 & 52.14 & 53.25 & 54.24 & 55.05 & 55.78 \\
\hline
\end{tabular}


Boys head circumference (in $\mathrm{cm}$ ) vs crown rump length (in $\mathrm{cm}$ )

\begin{tabular}{|c|c|c|c|c|c|c|c|c|c|}
\hline $\begin{array}{l}\text { Crown } \\
\text { rump } \\
\text { length }\end{array}$ & $-2.76 \mathrm{SD}$ & $-2.00 \mathrm{SD}$ & $-1.33 \mathrm{SD}$ & $-0.67 \mathrm{SD}$ & $0 \mathrm{SD}$ & $+0.67 \mathrm{SD}$ & $+1.33 \mathrm{SD}$ & $+2.00 \mathrm{SD}$ & $+2.67 \mathrm{SD}$ \\
\hline 30.0 & 30.55 & 31.38 & 32.22 & 33.04 & 33.87 & 34.70 & 35.53 & 36.36 & 37.19 \\
\hline 31.0 & 31.22 & 32.06 & 32.90 & 33.73 & 34.57 & 35.41 & 36.24 & 37.08 & 37.92 \\
\hline 32.0 & 31.89 & 32.73 & 33.58 & 34.41 & 35.26 & 36.11 & 36.94 & 37.79 & 38.64 \\
\hline 33.0 & 32.55 & 33.40 & 34.26 & 35.10 & 35.95 & 36.80 & 37.64 & 38.50 & 39.35 \\
\hline 34.0 & 33.23 & 34.09 & 34.95 & 35.79 & 36.65 & 37.51 & 38.36 & 39.21 & 40.07 \\
\hline 35.0 & 33.89 & 34.76 & 35.62 & 36.48 & 37.34 & 38.21 & 39.06 & 39.92 & 40.79 \\
\hline 36.0 & 34.57 & 35.44 & 36.31 & 37.17 & 38.04 & 38.91 & 39.77 & 40.64 & 41.51 \\
\hline 37.0 & 35.24 & 36.11 & 36.99 & 37.85 & 38.73 & 39.61 & 40.47 & 41.35 & 42.22 \\
\hline 38.0 & 35.92 & 36.80 & 37.68 & 38.55 & 39.43 & 40.31 & 41.18 & 42.06 & 42.94 \\
\hline 39.0 & 36.60 & 37.48 & 38.37 & 39.24 & 40.13 & 41.02 & 41.89 & 42.78 & 43.67 \\
\hline 40.0 & 37.27 & 38.17 & 39.06 & 39.94 & 40.83 & 41.72 & 42.60 & 43.49 & 44.39 \\
\hline 41.0 & 37.95 & 38.85 & 39.75 & 40.63 & 41.53 & 42.43 & 43.31 & 44.21 & 45.11 \\
\hline 42.0 & 38.62 & 39.53 & 40.43 & 41.32 & 42.22 & 43.12 & 44.01 & 44.91 & 45.82 \\
\hline 43.0 & 39.28 & 40.19 & 41.10 & 41.99 & 42.90 & 43.81 & 44.70 & 45.61 & 46.52 \\
\hline 44.0 & 39.94 & 40.85 & 41.77 & 42.67 & 43.58 & 44.49 & 45.39 & 46.31 & 47.22 \\
\hline 45.0 & 40.58 & 41.50 & 42.42 & 43.32 & 44.24 & 45.16 & 46.06 & 46.98 & 47.90 \\
\hline 46.0 & 41.21 & 42.14 & 43.06 & 43.97 & 44.89 & 45.81 & 46.72 & 47.64 & 48.57 \\
\hline 47.0 & 41.84 & 42.76 & 43.69 & 44.60 & 45.53 & 46.46 & 47.37 & 48.30 & 49.22 \\
\hline 48.0 & 42.44 & 43.37 & 44.30 & 45.22 & 46.15 & 47.08 & 48.00 & 48.93 & 49.86 \\
\hline 49.0 & 43.02 & 43.96 & 44.89 & 45.82 & 46.75 & 47.69 & 48.61 & 49.54 & 50.48 \\
\hline 50.0 & 43.60 & 44.54 & 45.48 & 46.40 & 47.34 & 48.28 & 49.21 & 50.14 & 51.08 \\
\hline 51.0 & 44.16 & 45.10 & 46.05 & 46.98 & 47.92 & 48.86 & 49.79 & 50.74 & 51.68 \\
\hline 52.0 & 44.70 & 45.65 & 46.60 & 47.53 & 48.48 & 49.43 & 50.37 & 51.31 & 52.26 \\
\hline 53.0 & 45.22 & 46.18 & 47.13 & 48.08 & 49.03 & 49.99 & 50.93 & 51.88 & 52.84 \\
\hline 54.0 & 45.73 & 46.70 & 47.66 & 48.61 & 49.57 & 50.53 & 51.48 & 52.44 & 53.41 \\
\hline 55.0 & 46.24 & 47.21 & 48.18 & 49.14 & 50.11 & 51.08 & 52.04 & 53.01 & 53.98 \\
\hline 56.0 & 46.73 & 47.71 & 48.69 & 49.66 & 50.64 & 51.62 & 52.59 & 53.57 & 54.55 \\
\hline 57.0 & 47.21 & 48.20 & 49.19 & 50.17 & 51.16 & 52.15 & 53.13 & 54.12 & 55.11 \\
\hline 58.0 & 47.70 & 48.70 & 49.70 & 50.69 & 51.69 & 52.69 & 53.68 & 54.68 & 55.68 \\
\hline 59.0 & 48.17 & 49.18 & 50.20 & 51.20 & 52.21 & 53.22 & 54.22 & 55.24 & 56.25 \\
\hline 60.0 & 48.64 & 49.67 & 50.69 & 51.70 & 52.73 & 53.76 & 54.77 & 55.79 & 56.82 \\
\hline 61.0 & 49.11 & 50.15 & 51.19 & 52.21 & 53.25 & 54.29 & 55.31 & 56.35 & 57.39 \\
\hline
\end{tabular}


Appendix B

Girls head circumference vs crown rump length; edf 323

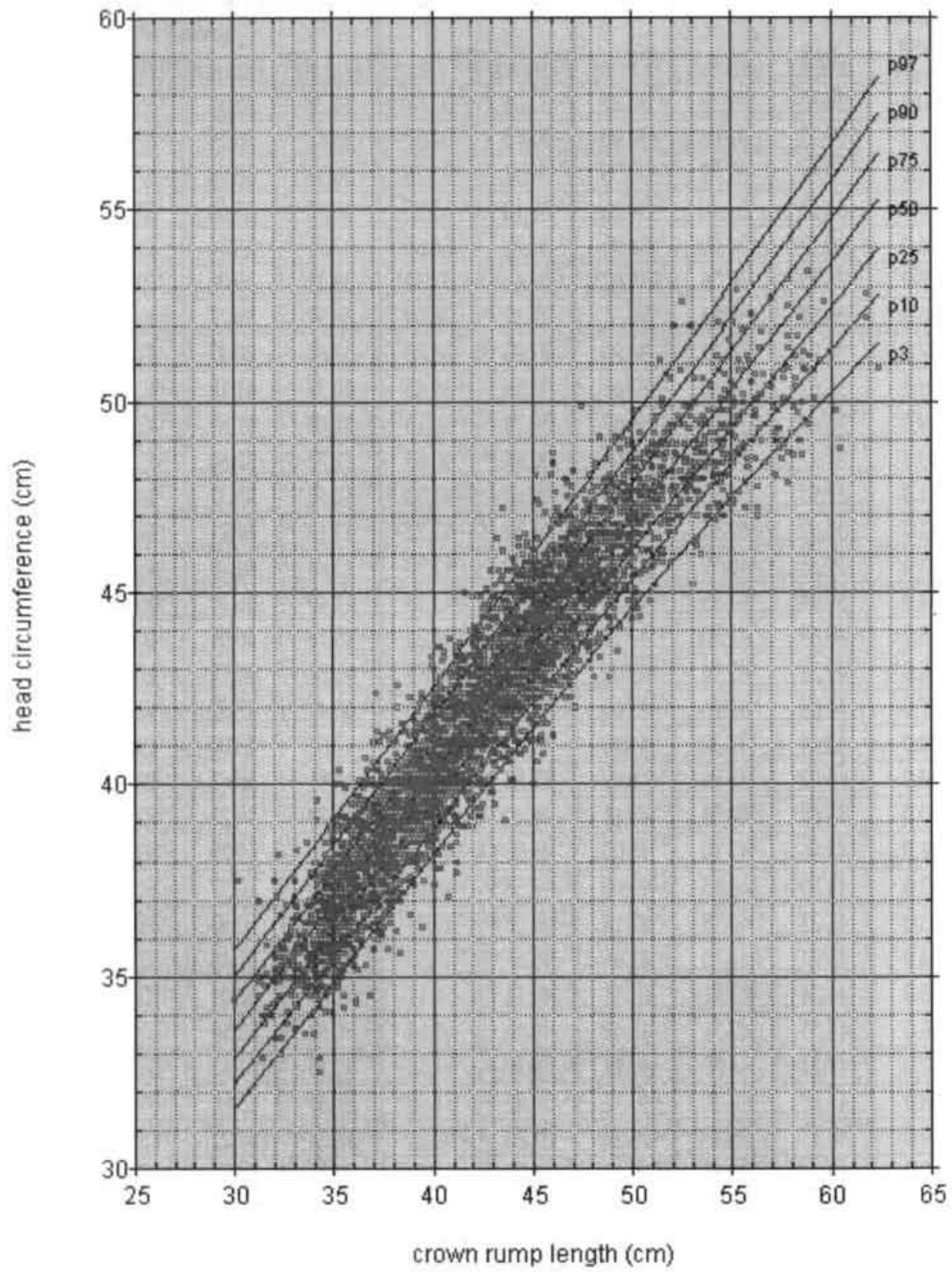


Girls head circumference vs crown rump length; edf 323

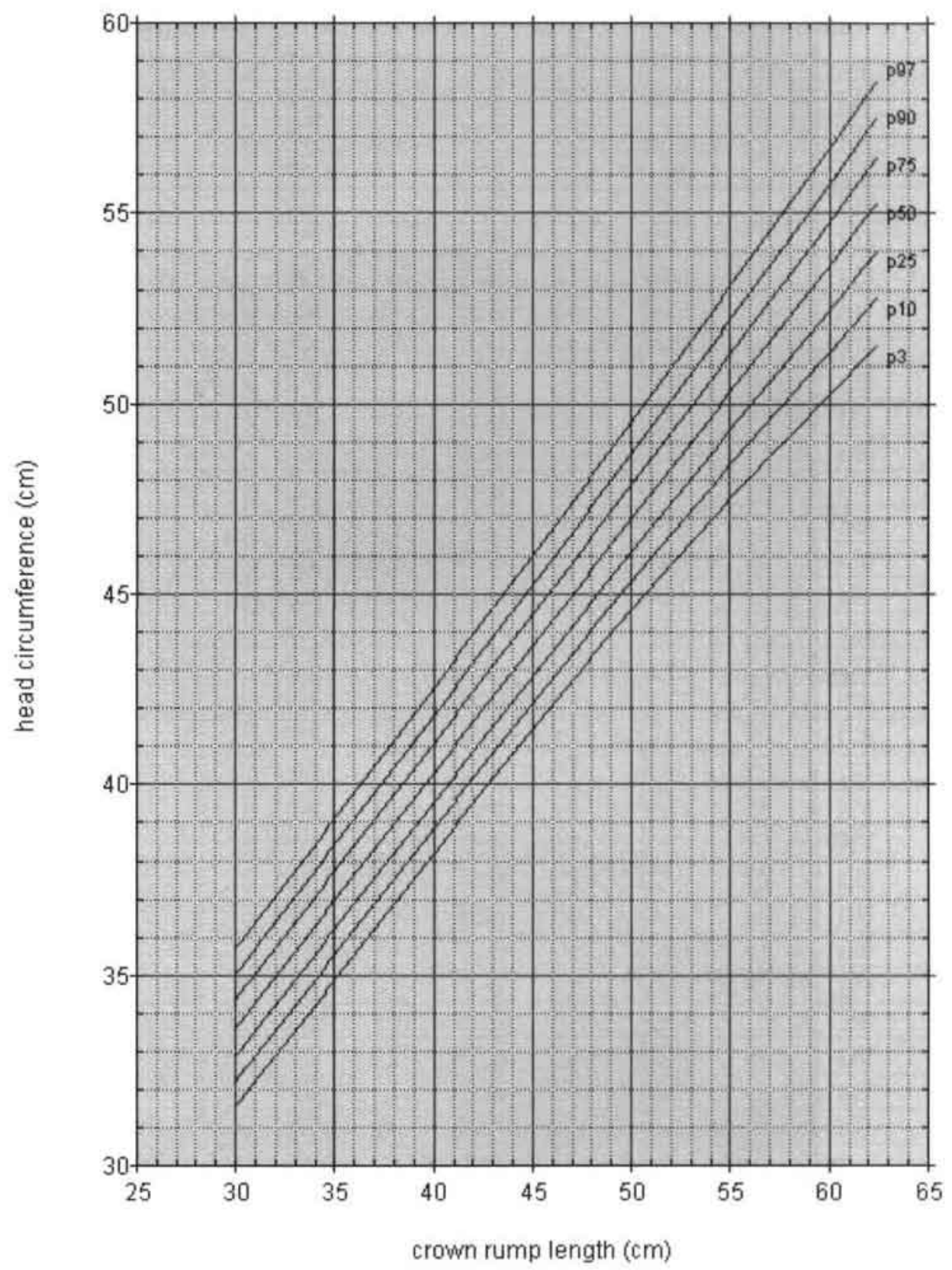


Girls head circumference vs crown rump length; edf 323

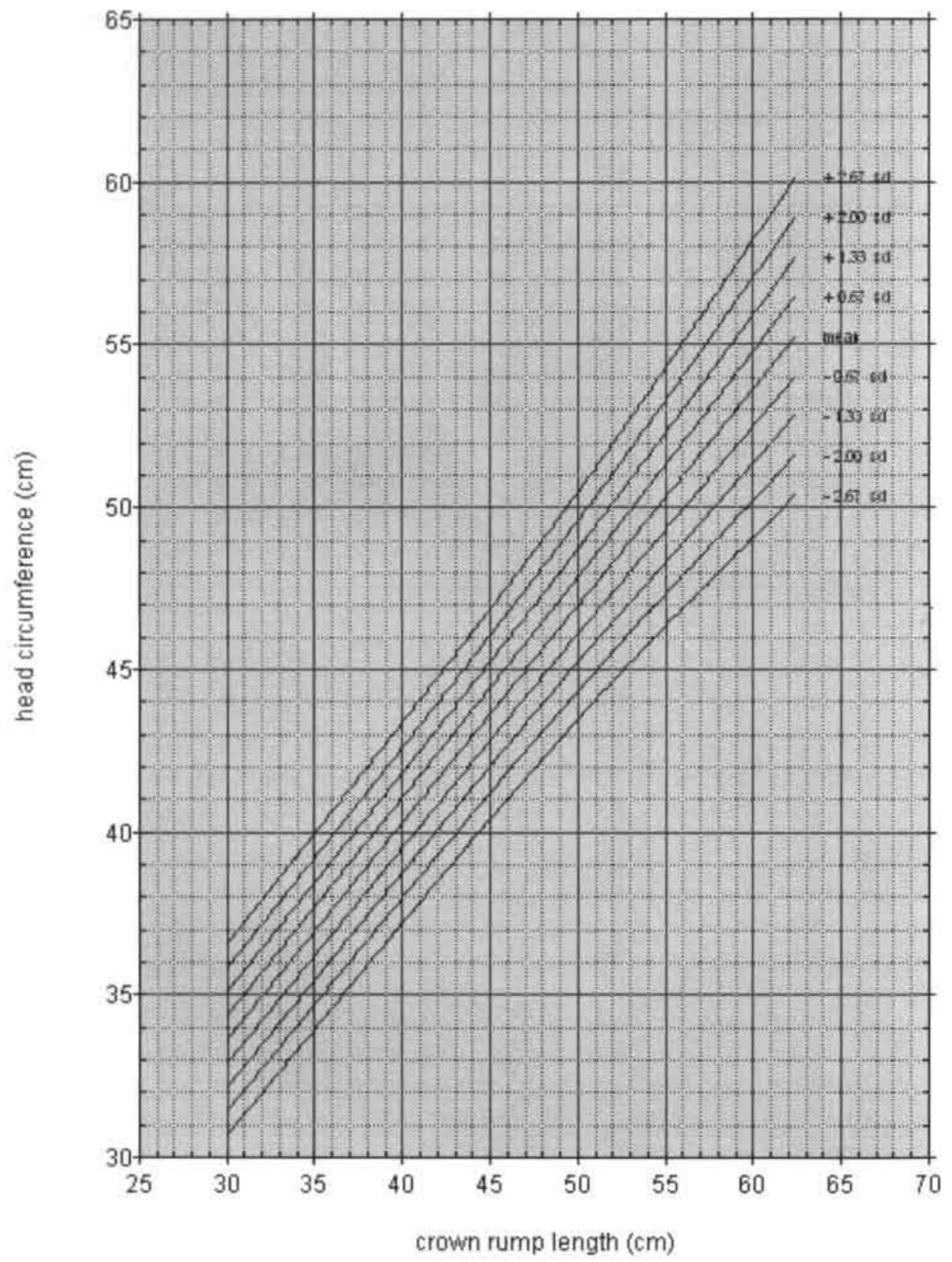




\begin{tabular}{|c|c|c|c|c|}
\hline \multicolumn{5}{|c|}{ Girls head circumference vs crown rump length LMS values ( edf 323 ) } \\
\hline $\begin{array}{l}\text { Crown rump } \\
\text { length }\end{array}$ & $\mathrm{L}$ & M & $\mathrm{S}$ & SD \\
\hline 30.0 & 0.82 & 33.62 & 0.03 & 1.10 \\
\hline 32.0 & 0.82 & 34.95 & 0.03 & 1.11 \\
\hline 33.0 & 0.81 & 35.62 & 0.03 & 1.12 \\
\hline 34.0 & 0.78 & 36.29 & 0.03 & 1.12 \\
\hline 35.0 & 0.72 & 36.96 & 0.03 & 1.13 \\
\hline 36.0 & 0.62 & 37.62 & 0.03 & 1.13 \\
\hline 37.0 & 0.49 & 38.29 & 0.03 & 1.14 \\
\hline 38.0 & 0.33 & 38.96 & 0.03 & 1.14 \\
\hline 39.0 & 0.15 & 39.63 & 0.03 & 1.15 \\
\hline 40.0 & -0.03 & 40.29 & 0.03 & 1.15 \\
\hline 41.0 & -0.21 & 40.96 & 0.03 & 1.16 \\
\hline 42.0 & -0.38 & 41.63 & 0.03 & 1.17 \\
\hline 43.0 & -0.52 & 42.29 & 0.03 & 1.18 \\
\hline 44.0 & -0.62 & 42.96 & 0.03 & 1.20 \\
\hline 45.0 & -0.67 & 43.63 & 0.03 & 1.21 \\
\hline 46.0 & -0.66 & 44.30 & 0.03 & 1.22 \\
\hline 47.0 & -0.61 & 44.96 & 0.03 & 1.24 \\
\hline 48.0 & -0.50 & 45.63 & 0.03 & 1.26 \\
\hline 49.0 & -0.35 & 46.30 & 0.03 & 1.28 \\
\hline 50.0 & -0.17 & 46.97 & 0.03 & 1.31 \\
\hline 51.0 & 0.04 & 47.63 & 0.03 & 1.34 \\
\hline 52.0 & 0.28 & 48.30 & 0.03 & 1.37 \\
\hline 53.0 & 0.55 & 48.97 & 0.03 & 1.41 \\
\hline 54.0 & 0.83 & 49.64 & 0.03 & 1.45 \\
\hline 55.0 & 1.13 & 50.30 & 0.03 & 1.49 \\
\hline 56.0 & 1.44 & 50.97 & 0.03 & 1.53 \\
\hline 57.0 & 1.76 & 51.64 & 0.03 & 1.57 \\
\hline 58.0 & 2.09 & 52.30 & 0.03 & 1.62 \\
\hline 59.0 & 2.44 & 53.04 & 0.03 & 1.67 \\
\hline 60.0 & 2.70 & 53.57 & 0.03 & 1.71 \\
\hline
\end{tabular}




\begin{tabular}{|c|c|c|c|c|c|c|c|}
\hline \multicolumn{7}{|c|}{ Girls head circumference (in cm) vs crown rump length (in cm) } \\
\hline $\begin{array}{c}\text { Crown rump } \\
\text { length }\end{array}$ & P3 & P10 & P25 & P50 & P75 & P90 & P97 \\
\hline 30.0 & 31.57 & 32.22 & 32.88 & 33.62 & 34.36 & 35.03 & 35.70 \\
\hline 32.0 & 32.88 & 33.54 & 34.21 & 34.96 & 35.71 & 36.38 & 37.06 \\
\hline 33.0 & 33.53 & 34.20 & 34.87 & 35.62 & 36.38 & 37.06 & 37.73 \\
\hline 34.0 & 34.19 & 34.86 & 35.53 & 36.29 & 37.05 & 37.73 & 38.41 \\
\hline 35.0 & 34.86 & 35.52 & 36.20 & 36.96 & 37.72 & 38.41 & 39.09 \\
\hline 36.0 & 35.52 & 36.19 & 36.86 & 37.62 & 38.39 & 39.08 & 39.77 \\
\hline 37.0 & 36.19 & 36.85 & 37.53 & 38.29 & 39.06 & 39.76 & 40.46 \\
\hline 38.0 & 36.85 & 37.52 & 38.19 & 38.96 & 39.73 & 40.44 & 41.14 \\
\hline 39.0 & 37.52 & 38.18 & 38.86 & 39.63 & 40.41 & 41.12 & 41.83 \\
\hline 40.0 & 38.18 & 38.84 & 39.52 & 40.29 & 41.08 & 41.80 & 42.52 \\
\hline 41.0 & 38.84 & 39.50 & 40.19 & 40.96 & 41.75 & 42.48 & 43.22 \\
\hline 42.0 & 39.50 & 40.16 & 40.85 & 41.63 & 42.43 & 43.17 & 43.92 \\
\hline 43.0 & 40.16 & 40.82 & 41.51 & 42.30 & 43.11 & 43.85 & 44.61 \\
\hline 44.0 & 40.81 & 41.47 & 42.17 & 42.96 & 43.78 & 44.54 & 45.31 \\
\hline 45.0 & 41.45 & 42.12 & 42.83 & 43.63 & 44.46 & 45.23 & 46.01 \\
\hline 46.0 & 42.09 & 42.77 & 43.48 & 44.30 & 45.14 & 45.91 & 46.70 \\
\hline 47.0 & 42.72 & 43.42 & 44.14 & 44.96 & 45.81 & 46.60 & 47.40 \\
\hline 48.0 & 43.35 & 44.06 & 44.79 & 45.63 & 46.49 & 47.29 & 48.10 \\
\hline 49.0 & 43.97 & 44.69 & 45.44 & 46.30 & 47.18 & 47.98 & 48.80 \\
\hline 50.0 & 44.58 & 45.32 & 46.09 & 46.97 & 47.86 & 48.68 & 49.51 \\
\hline 51.0 & 45.18 & 45.95 & 46.74 & 47.63 & 48.54 & 49.38 & 50.22 \\
\hline 52.0 & 45.77 & 46.57 & 47.38 & 48.30 & 49.23 & 50.08 & 50.93 \\
\hline 53.0 & 46.35 & 47.18 & 48.02 & 48.97 & 49.92 & 50.79 & 51.65 \\
\hline 54.0 & 46.93 & 47.79 & 48.66 & 49.64 & 50.61 & 51.49 & 52.37 \\
\hline 55.0 & 47.50 & 48.39 & 49.30 & 50.30 & 51.30 & 52.20 & 53.09 \\
\hline 56.0 & 48.06 & 48.99 & 49.93 & 50.97 & 52.00 & 52.91 & 53.81 \\
\hline 57.0 & 48.61 & 49.59 & 50.57 & 51.64 & 52.69 & 53.63 & 54.54 \\
\hline 58.0 & 49.16 & 50.18 & 51.20 & 52.30 & 53.38 & 54.34 & 55.26 \\
\hline 59.0 & 49.75 & 50.83 & 51.89 & 53.04 & 54.15 & 55.12 & 56.06 \\
\hline 60.0 & 50.18 & 51.30 & 52.40 & 53.57 & 54.70 & 55.69 & 56.63 \\
\hline
\end{tabular}




\begin{tabular}{|c|c|c|c|c|c|c|c|c|c|}
\hline \multicolumn{10}{|c|}{ Girls head circumference (in $\mathrm{cm}$ ) vs crown rump length (in $\mathrm{cm}$ ) } \\
\hline $\begin{array}{l}\text { Crown } \\
\text { rump } \\
\text { length }\end{array}$ & $-2.76 \mathrm{SD}$ & $-2.00 \mathrm{SD}$ & $-1.33 \mathrm{SD}$ & $-0.67 \mathrm{SD}$ & $0 \mathrm{SD}$ & $+0.67 \mathrm{SD}$ & $+1.33 \mathrm{SD}$ & $+2.00 \mathrm{SD}$ & $+2.67 \mathrm{SD}$ \\
\hline 30.0 & 30.69 & 31.42 & 32.16 & 32.88 & 33.62 & 34.36 & 35.08 & 35.82 & 36.55 \\
\hline 32.0 & 31.98 & 32.73 & 33.47 & 34.21 & 34.95 & 35.69 & 36.43 & 37.17 & 37.92 \\
\hline 33.0 & 32.64 & 33.39 & 34.13 & 34.87 & 35.62 & 36.37 & 37.11 & 37.85 & 38.60 \\
\hline 34.0 & 33.29 & 34.05 & 34.80 & 35.54 & 36.29 & 37.04 & 37.78 & 38.53 & 39.29 \\
\hline 35.0 & 33.95 & 34.71 & 35.46 & 36.21 & 36.96 & 37.72 & 38.46 & 39.21 & 39.97 \\
\hline 36.0 & 34.60 & 35.36 & 36.12 & 36.86 & 37.62 & 38.38 & 39.12 & 39.88 & 40.64 \\
\hline 37.0 & 35.26 & 36.02 & 36.78 & 37.53 & 38.29 & 39.05 & 39.80 & 40.56 & 41.32 \\
\hline 38.0 & 35.92 & 36.68 & 37.44 & 38.20 & 38.96 & 39.72 & 40.48 & 41.24 & 42.00 \\
\hline 39.0 & 36.57 & 37.34 & 38.11 & 38.86 & 39.63 & 40.40 & 41.15 & 41.92 & 42.69 \\
\hline 40.0 & 37.21 & 37.98 & 38.76 & 39.52 & 40.29 & 41.06 & 41.82 & 42.60 & 43.37 \\
\hline 41.0 & 37.86 & 38.64 & 39.42 & 40.18 & 40.96 & 41.74 & 42.51 & 43.28 & 44.06 \\
\hline 42.0 & 38.50 & 39.29 & 40.07 & 40.85 & 41.63 & 42.42 & 43.19 & 43.97 & 44.76 \\
\hline 43.0 & 39.13 & 39.92 & 40.72 & 41.50 & 42.29 & 43.08 & 43.86 & 44.66 & 45.45 \\
\hline 44.0 & 39.77 & 40.57 & 41.37 & 42.16 & 42.96 & 43.76 & 44.55 & 45.35 & 46.15 \\
\hline 45.0 & 40.40 & 41.21 & 42.02 & 42.82 & 43.63 & 44.44 & 45.24 & 46.05 & 46.86 \\
\hline 46.0 & 41.03 & 41.85 & 42.67 & 43.48 & 44.30 & 45.12 & 45.93 & 46,75 & 47.57 \\
\hline 47.0 & 41.65 & 42.48 & 43.31 & 44.13 & 44.96 & 45.79 & 46.61 & 47.44 & 48.27 \\
\hline 48.0 & 42.27 & 43.11 & 43.95 & 44.79 & 45.63 & 46.47 & 47.31 & 48.15 & 48.99 \\
\hline 49.0 & 42.87 & 43.73 & 44.59 & 45.44 & 46.30 & 47.16 & 48.01 & 48.87 & 49.73 \\
\hline 50.0 & 43,48 & 44.35 & 45.23 & 46.09 & 46.97 & 47.85 & 48.71 & 49.59 & 50.47 \\
\hline 51.0 & 44.06 & 44.95 & 45.85 & 46.73 & 47.63 & 48.53 & 49.41 & 50.31 & 51.20 \\
\hline 52.0 & 44.64 & 45.56 & 46.48 & 47.38 & 48.30 & 49.22 & 50.12 & 51.04 & 51.96 \\
\hline 53.0 & 45.21 & 46.16 & 47.10 & 48.03 & 48.97 & 49.91 & 50.84 & 51.78 & 52.73 \\
\hline 54.0 & 45.78 & 46.75 & 47.72 & 48.67 & 49.64 & 50.61 & 51.56 & 52.53 & 53.50 \\
\hline 55.0 & 46.33 & 47.33 & 48.32 & 49.30 & 50.30 & 51.30 & 52.28 & 53.27 & 54.27 \\
\hline 56.0 & 46.89 & 47.91 & 48.94 & 49.95 & 50.97 & 51.99 & 53.00 & 54.03 & 55.05 \\
\hline 57.0 & 47.44 & 48.49 & 49.55 & 50.59 & 51.64 & 52.70 & 53.73 & 54.79 & 55.84 \\
\hline 58.0 & 47.98 & 49.06 & 50.15 & 51.22 & 52.30 & 53.39 & 54.45 & 55.54 & 56.62 \\
\hline 59.0 & 48.58 & 49.70 & 50.82 & 51.92 & 53.04 & 54.16 & 55.26 & 56.38 & 57.50 \\
\hline 60.0 & 49.01 & 50.15 & 51.30 & 52.43 & 53.57 & 54.71 & 55.84 & 56.99 & 58.13 \\
\hline
\end{tabular}


Appendix B 


\section{Appendix C \\ Correlation Table}


Appendix C

\begin{tabular}{|c|c|c|c|c|c|c|c|c|c|c|c|c|c|c|c|c|c|c|c|c|c|c|c|c|c|c|c|}
\hline (1) & 1 & $\frac{8}{3}$ & A & & 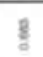 & 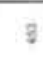 & 要 & $\frac{2}{2}$ & 9 & 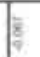 & 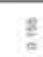 & 3 & E & $a$ & 8 & 递 & : & 3 & $\frac{8}{8}$ & & 5 & & 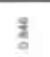 & 3 & & & \\
\hline & 18 & F & j & 8 & :ू. & ₹ & 焉 & 층 & $i$ & $\frac{8}{8}$ & $\frac{8}{0}$ & i & 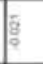 & 8 & ₹ & 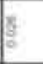 & $\frac{3}{6}$ & ई & 8 & 8 & ह & 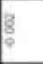 & $g$ & 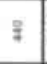 & 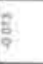 & & $\ddagger$ \\
\hline 1 & 8. & $\frac{?}{8}$ & $\xi$ & E & ! & $\hat{\mathbf{f}}$ & E & 혐 & 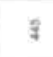 & 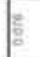 & $\vdots$ & $\$$ & 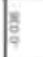 & $\frac{1}{2}$ & $q$ & $\frac{3}{4}$ & ํํㅁ & $\hat{\mathrm{q}}$ & $\frac{a}{0}$ & 8 & ¥ & $\frac{1}{0}$ & 8 & $\hat{\mathrm{z}}$ & $\frac{\pi}{4}$ & & ई \\
\hline है। & 8 & $\frac{1}{8}$ & $\exists$ & 言 & $\frac{\partial}{\partial}$ & g & 8 & ถู & 9 & 8 & $\frac{5}{8}$ & 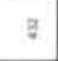 & $\begin{array}{l}3 \\
\\
\end{array}$ & $\frac{g}{0}$ & $\xi$ & ta & 링 & 9 & $\equiv$ & $\bar{g}$ & 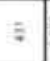 & 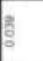 & $\frac{\pi}{8}$ & 7 & $\frac{9}{9}$ & & 9 \\
\hline 11 & 8 & $\frac{3}{0}$ & * & 8 & 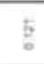 & x & $\bar{B}$ & g & $\nexists$ & 3 & $\frac{g}{8}$ & $x$ & 䄡 & 욤 & ㄴ. & $\frac{3}{8}$ & $\frac{8}{8}$ & $\frac{2}{x}$ & 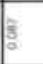 & $\frac{8}{2}$ & $\approx$ & $\frac{8}{3}$ & $\frac{\mathrm{g}}{8}$ & 8 & $\frac{5}{8}$ & है & z \\
\hline |ो| & I & $\frac{5}{8}$ & $\xi$ & 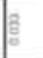 & 8 & 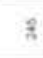 & i & ? & $\approx$ & 8 & $\frac{\Xi}{2}$ & 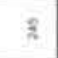 & $\frac{z}{2}$ & క్ & $q$ & 5 & $\underline{\underline{g}}$ & s & $\frac{3}{3}$ & gั & $\approx$ & $\frac{2}{0}$ & 8 & $\approx$ & $\frac{6}{8}$ & & 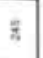 \\
\hline 11 & 3 & $\xi$ & \% & 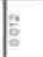 & f & 8 & 8 & $\frac{7}{8}$ & 3 & $\frac{8}{2}$ & ลิ & $\exists$ & $\frac{8}{8}$ & $\frac{9}{0}$ & 8 & 8 & 望 & $\frac{3}{3}$ & 童 & 츰 & 5 & క్ & 영 & 3 & $\frac{9}{8}$ & $\frac{7}{0}$ & 3 \\
\hline 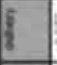 & 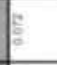 & 5 & 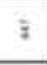 & 然 & ฟै & ₹ & 8 & ลे & 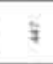 & $\frac{8}{8}$ & $\frac{\pi}{8}$ & $\xi$ & $\frac{5}{8}$ & $\frac{1}{2}$ & I & 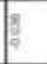 & $\stackrel{q}{9}$ & $\varsubsetneqq$ & 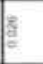 & $\frac{3}{d}$ & F & 8 & $\frac{\pi}{2}$ & i & 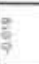 & $\frac{1}{2}=$ & $\$$ \\
\hline if & 8 & $\frac{?}{2}$ & i & \% & $\frac{i}{z}$ & $\xi$ & 3 & $\frac{8}{8}$ & 年 & : & $\frac{2}{2}$ & $\bar{j}$ & $\frac{2}{0}$ & 8 & I & $\frac{8}{2}$ & 3 & $\ddagger$ & $\frac{3}{4}$ & $\frac{x}{2}$ & 3 & 8 & $\frac{n}{3}$ & z & 8 & i. & $\xi$ \\
\hline 18 & 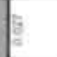 & s. & ì & 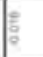 & $\frac{z}{\partial}$ & ? & 8 & 형 & 9 & 8 & 총 & 3 & $\frac{0}{3}$ & 염 & F & 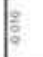 & $\frac{9}{2}$ & $\$$ & 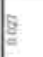 & 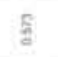 & \& & 8 & $\underline{\partial}$ & $q$ & g & s & à \\
\hline 111 & 8 & 8 & z & . & 8 & $\bar{s}$ & 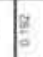 & $\frac{8}{8}$ & $\overline{8}$ & 1 & 8 & i. & 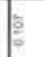 & 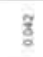 & की & $\frac{5}{0}$ & ‡ั & $\bar{x}$ & $\frac{8}{8}$ & हु명 & $\frac{1}{x}$ & $\underline{8}$ & $\frac{5}{5}$ & 8 & ह. & 8 & 8 \\
\hline $1 \mathbf{P}^{2}$ & $E$ & 8 & I & 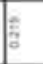 & 8 & s & 8 & $\frac{8}{8}$ & $g$ & i & 8 & $E$ & 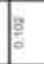 & 충 & 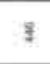 & ? & 8 & $q$ & $\frac{3}{3}$ & ई & ₹ & 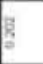 & 8 & $\$$ & $\frac{1}{6}$ & 8 & $\frac{1}{8}$ \\
\hline 而 & 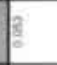 & $\stackrel{9}{0}$ & 8 & 3 & gి & $\xi$ & $\frac{z}{8}$ & g & : & $\underline{3}$ & 8 & $z$ & $\frac{8}{2}$ & $\bar{g}$ & $\xi$ & 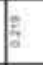 & 8 & $q$ & E & 亏ั & 8 & 8 & $\overline{8}$ & 5 & 8 & $\frac{8}{\alpha}$ & \& \\
\hline 13 & 8 & 텸 & 7 & 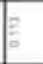 & 5 & \% & 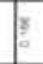 & $\frac{b}{2}$ & $\approx$ & 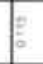 & 亏े & $\frac{3}{4}$ & 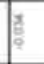 & 气 & 5 & 8 & $\frac{1}{3}$ & $\frac{\pi}{7}$ & $\frac{1}{0}$ & 8 & $q$ & $\frac{x}{3}$ & 8 & $\approx$ & g: & $\frac{3}{3}$ & $\pi$ \\
\hline 1 & 8 & $\pi$ & $i$ & $\frac{1}{8}$ & 高 & $\$$ & 8 & 몀 & के & $\frac{3}{3}$ & $\xi$ & 5 & $\frac{8}{3}$ & s: & $\bar{\ddagger}$ & ; & i & 5 & $\approx$ & 8 & $\xi$ & 8 & 8 & 8 & $\frac{8}{8}$ & Z & t) \\
\hline t) & 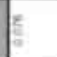 & $?$ & 3 & 8 & 丸ิ & ₹ & E & 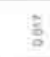 & $\xi$ & 8 & g & 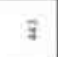 & $\frac{8}{8}$ & g & s & E & $\frac{g}{8}$ & $\xi$ & 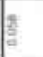 & \& & $q$ & 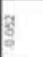 & ్ㅗㅁ & 五 & $\frac{3}{7}$ & 8 & ₹ \\
\hline if & 5 & $\frac{z}{2}$ & 3 & if & $\stackrel{8}{8}$ & i & 8 & $g$ & 8 & $\frac{z}{8}$ & ह & $\frac{3}{2}$ & 㕇 & $\frac{5}{3}$ & 8 & : & 1 & $\exists$ & $\underline{2}$ & 高 & $\overrightarrow{4}$ & $\frac{8}{8}$ & 音 & 8 & $\frac{8}{8}$ & $\frac{\pi}{2}$ & 自 \\
\hline ii & 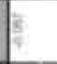 & I & 3 & 墕 & 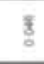 & 9 & 8 & $\frac{8}{8}$ & $?$ & 8 & $\frac{8}{8}$ & 3 & $\frac{8}{8}$ & g & 8 & 8 & 8 & 3 & 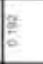 & 8 & 5 & 8 & 8 & $q$ & , & ई & ई \\
\hline 18 & 8 & $\frac{\pi}{2}$ & 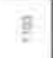 & 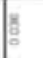 & 臬 & 8 & E & $\frac{8}{8}$ & 8 & 8 & $\frac{5}{8}$ & 8 & ${ }_{8}^{8}$ & $\frac{\bar{g}}{0}$ & 8 & 3 & $\frac{y}{2}$ & 3 & 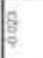 & $\frac{g}{g}$ & $\$$ & 要 & ! & 3 & 8 & $g$ & ộ \\
\hline 11 & 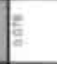 & 8 & 8 & $\frac{8}{8}$ & 8 & $g$ & 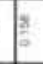 & 8 & $q$ & 3 & \& & $g$ & $\frac{5}{8}$ & $\frac{n}{\partial}$ & f & $\sum_{0}$ & 8 & 3 & 言 & 8 & 5 & 8 & 8 & $q$ & E & $\frac{5}{3}$ & 2 \\
\hline$|3|$ & 8 & ₹ & $\vdots$ & I & 8 & $\vdots$ & B & B & $\vdots$ & $\equiv$ & $\stackrel{g}{g}$ & $\vdots$ & 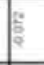 & g & ई & 3 & gू & i & 8 & 8 & 5 & 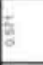 & 8 & 5 & \% & ह5 & $\hat{3}$ \\
\hline 11 & 8 & $\$$ & 7 & 8 & s & 8 & 8 & 8 & 3 & 3 & ؛ & 3 & 8 & s. & 8 & 8 & 8 & 3 & 8 & ร్ & 5 & $\frac{2}{8}$ & g气 & 8 & 3 & $\frac{g}{0}$ & 3 \\
\hline 3 & E & $\frac{\pi}{2}$ & 8 & 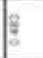 & 8 & 8 & $\xi$ & 吾 & 8 & : & 8 & $g$ & 8 & 8 & 8 & 8 & $\frac{\xi}{2}$ & 8 & F. & $\stackrel{8}{g}$ & 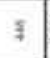 & 8 & $\frac{n}{2}$ & $\xi$ & 8 & 三 & $\stackrel{8}{?}$ \\
\hline 35 & $=$ & 8 & 8 & 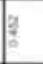 & 8 & 8 & $\equiv$ & 8 & 8 & \& & 8 & 8 & . & 8 & 8 & 3 & g. & 3 & 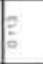 & $\frac{2}{18}$ & 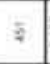 & $\frac{g}{6}$ & $\frac{8}{8}$ & 3 & 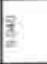 & 용 & $y$ \\
\hline (15) & & $?$ & 8 & . & 8 & 8 & 8 & g & i & 1 & 8 & 8 & 8 & $\frac{7}{\partial}$ & 8 & 3 & 8 & $?$ & 等 & $\frac{f}{2}$ & F & $\frac{8}{8}$ & $\frac{8}{8}$ & $q$ & 8. & $\frac{8}{8}$ & 8 \\
\hline |f: & & $\frac{\pi}{2}$ & 8 & 8 & 8 & i & B & 8 & 8 & 1 & 8 & 8 & 1 & 8 & 8 & 8 & $\frac{3}{3}$ & 3 & : & 8 & $\$$ & 8 & 8 & 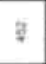 & 8 & $g$ & 8 \\
\hline$\left.\right|_{x}$ & 5 & 8 & 8 & 8 & $\frac{x}{\partial}$ & 8 & $\frac{z}{3}$ & $\frac{5}{3}$ & I & E & 8 & 8 & 言 & $\frac{3}{2}$ & 8 & 8 & 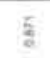 & ส & 8 & हू & 5 & $\bar{z}$ & & 9 & & $\stackrel{3}{3}$ & \\
\hline & & & & & & & & & & & & & & & & & & $=$ & & $\frac{1}{10}$ & $=$ & & & $=$ & & $=\frac{6}{81}$ & \\
\hline & 1 & & & & & & & & & & & & & & & & & & & & & & & & & & \\
\hline
\end{tabular}




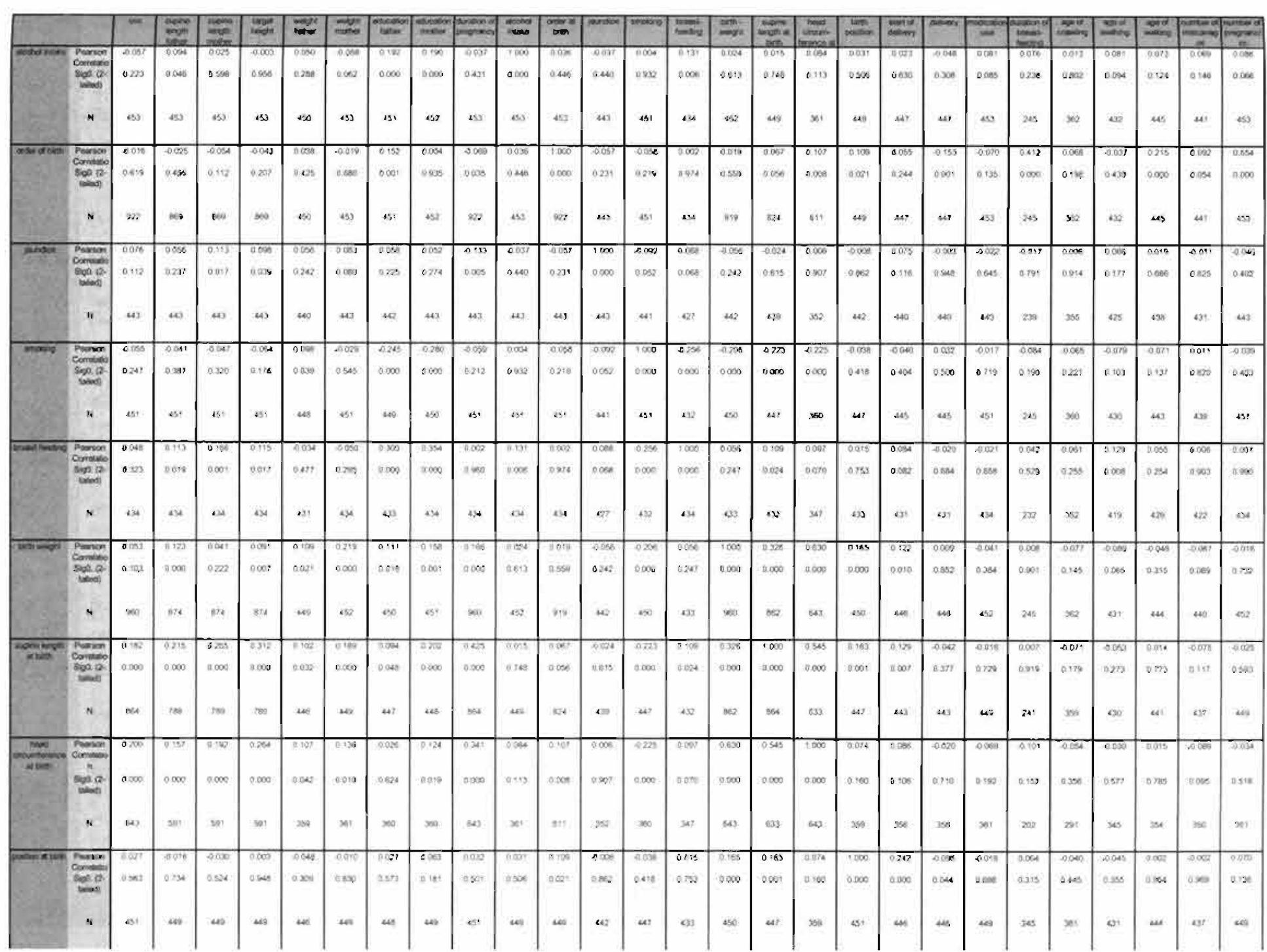


Appendix C

Hi.

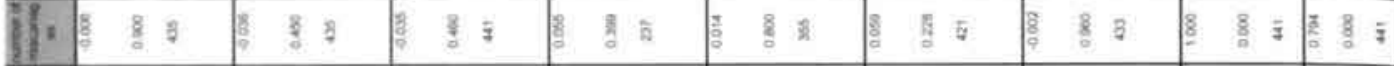

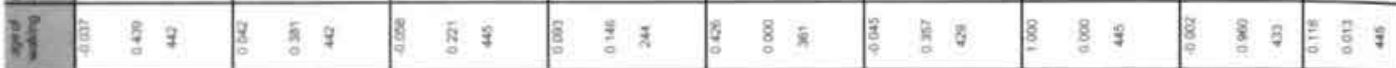

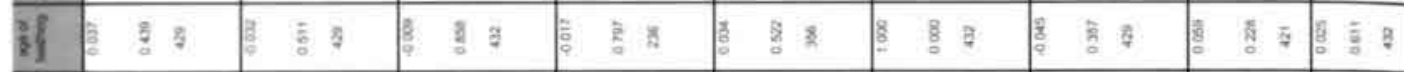

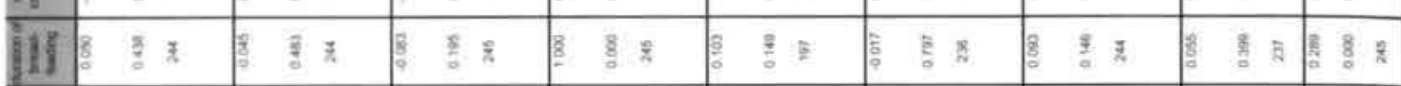

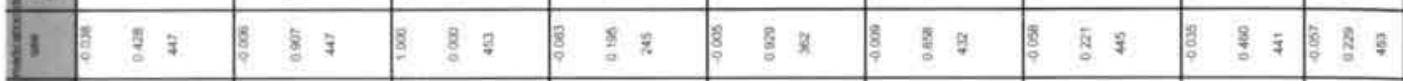

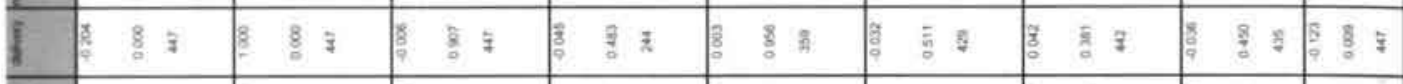

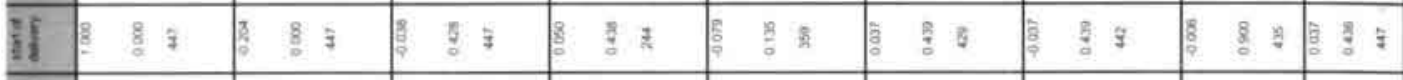

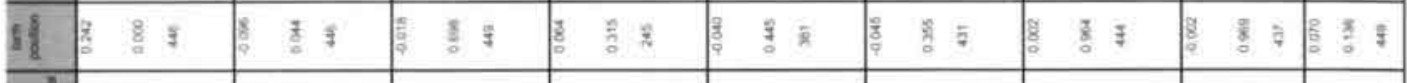

8 s.

$8 \xi$

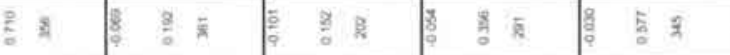

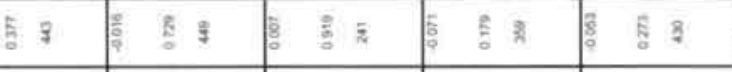

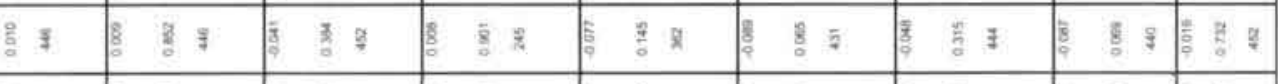

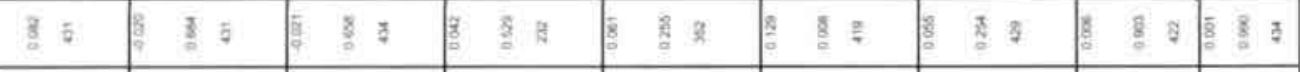

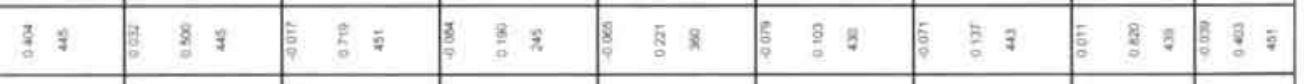

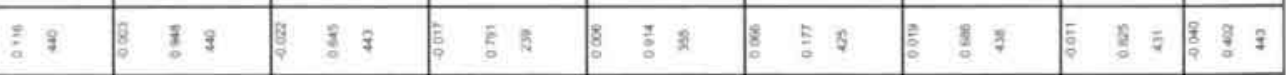

巻 ₹

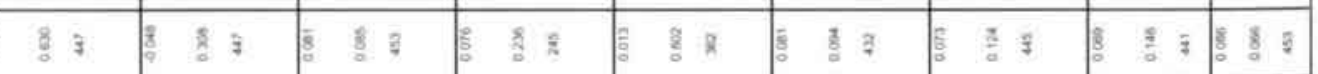
爱

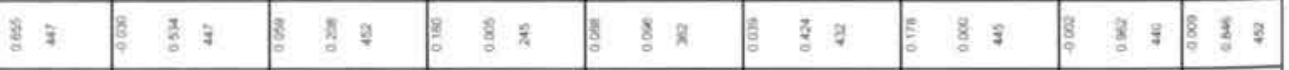

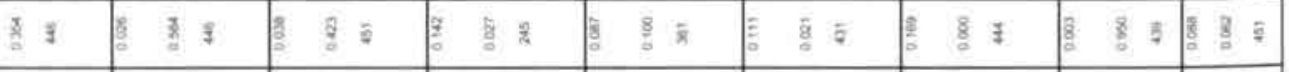

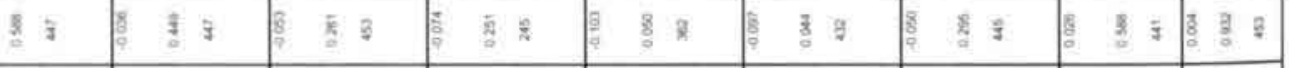

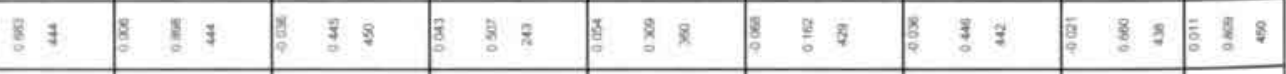

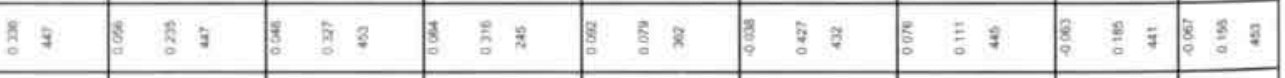

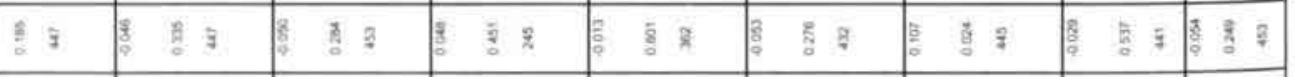

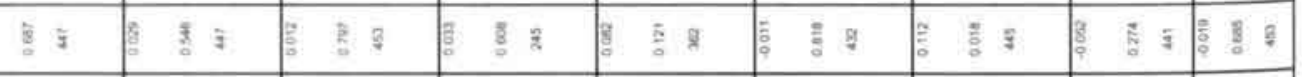

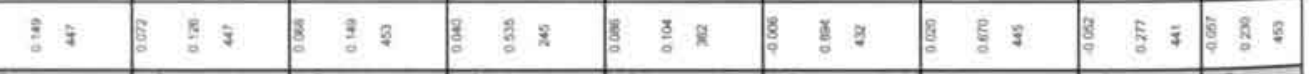

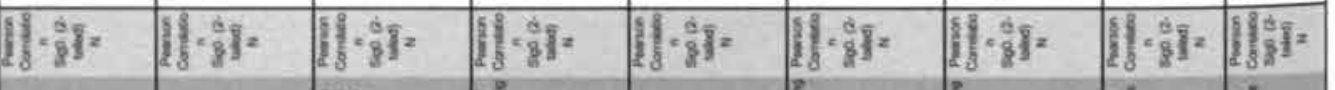

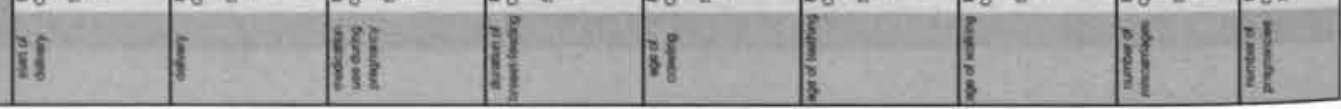




\section{Acknowledgements}

Keep away from people who try to belittle your ambitions. Small people always do that. But the really great make you feel that you too can become great.

- Mark Twain - 
Promoveren doe je voor een groot deel alleen. Je moet de meeste dingen uiteindelijk zelf doen en regelen. Maar ik ben niet gepromoveerd in eenzaamheid. Omringd door lieve familie, vrienden en collega's is het resultaat dat hier ligt tot stand gekomen. Allen wil ik hiervoor bedanken.

Het waren niet alleen de laatste loodjes

Die hebben er altijd wel gezeten

En al die ruggensteuntjes die ik kreeg

Die zal ik nooit vergeten

Een aantal mensen wil ik in het bijzonder bedanken, zonder de anderen te kort te willen doen.

Michael Preece. The inspiring meetings I had at the beginning of this research, made that I had a goal to set up and conduct the trial. It was a privilege for me to have met you the way I did.

Machteld Roede. Dank voor je persoonlijke introductie bij een aantal cruciale personen voor mijn proefschrift. Zullen wij ooit tijd hebben om eens bij te praten?

Roland Hauspie. Het opzetten en uitwerken van de grafieken was onmogelijk geweest zonder de deskundige hulp en je bezielende leiding. Je introductie in KaleidaGraph bleek van essentieel belang voor de grafische weergaven in mijn proefschrift. Brussel is voor mij meer geworden dan alleen maar Wittamer.

Tim Cole. Your enlightening approach to growth, growth curves, the construction of them and correlation matrixes is unique according to me. It was an extraordinary opportunity to work on my thesis at the Institute of Child Health in London with you. Our paths seem have crossed each other on various occasions. I can only hope they will continue to do so in the future.

Marion de Leeuw en Arnold Kester. Statistiek is geen scheikunde; significantie is geen titratie. Dank voor jullie wegwijzingen door het woud dat Statistiek heet.

Joke en Peter Kuijpers. Dank voor jullie tafel(s) in Llupia waar ik menig uur aan dit proefschrift heb gewerkt.

Liz and Philip Parson. Thank you so much for reading and correcting the manuscript to turn it into a readable English thesis. 
Annie en Ad Timmermans. Al lang stond voor mij vast dat Ad mijn paranimf moest zijn, maar zonder de morele steun van Annie was dat natuurlijk niet mogelijk geweest. Lang leve Leatare!

Dank aan alle medewerkers van de participerende consultatiebureaus van Maastricht, voor hun medewerking, hulp bij de werving en meting van de kinderen. Dank aan alle ouders die hun medewerking gaven aan het onderzoek. En dank aan alle kinderen die gewillig en soms wat minder gewillig alle metingen hebben ondergaan. Dat jullie mogen opgroeien en uitgroeien tot unieke mensen.

Mijn ouders, broers en hun gezinnen. Jullie morele, financiële en liefdevolle support maakt dat dit allemaal mogelijk is geweest. Speciaal dank aan Sara voor de gewillige poses voor de foto's en Marc voor het maken hiervan. Zij is het levend bewijs dat groeien snel kan gaan. En dank aan Job, Cédric, Loïc en Sara voor hun tekeningen die hun eigen interpretatie van groei weergeven. Dank aan mijn ouders voor hun nooit aflatende steun en ben dan ook bijzonder blij dat mijn vader mijn paranimf is.

Carlos Blanco. Last but certainly not least. Zonder jouw input en inzet was promoveren nooit mogelijk geweest. Het eindresultaat ligt er. Dus ons gezamenlijk doel is bereikt en daar ging het uiteindelijk om. Hartelijk dank! 


\section{Curriculum Vitae}

1968 Born in Geleen, on 14 april

1988 Graduation Atheneum B - Bernardinus College, Heerlen

1989 Health science - University of Maastricht

1995 Elective Paediatrics - University of Oxford, UK

1995 Elective Genetics - University of Oxford, UK

1996 Conventional medical degree - University of Maastricht

1996 Flexible medical degree - University of Maastricht

Paediatrics, Genetics, Gynaecology

1999 Doctor of medicine degree - University of Maastricht

2002 Registration as Clinical Pharmaceutical Physician

Publications and presentations

- Preliminary finding on the longitudinal growth research of Maastricht Symposium on Problems and Solutions in Longitudinal Research, 31/08/96 - 02/09/96, Noordwijk

- Dutch longitudinal growth study, Auxology and Nutrition Today, 15/10/1996, Zaragoza

- Preliminary finding on the longitudinal growth research of Maastricht International Journal of Sports Medicine, suppl 3; vol 18; july 1997; pg S247

- Partial circumcision in children, 14 years experience (abstract), 5th int congress of the DUA 2-4 sept 1999, Groningen

- Partial circumcision in children (poster), 5th int congress of the DUA 24 sept 1999, Groningen

- Patient retention in longitudinal clinical trials, Smart meeting 13/04/02, Athens

- CRO-SMO: Partners in Business or Business Partners, The Monitor, Spring 2002 vol 16 pg25-28

- CRO in Peadiatric trials: GCPj autumn 2003

- Longitudinal Auxology Evaluation of Maastricht Infants, Human Growth in Sickness and in Health, X International Congress of Auxology, july 2004, Florence 


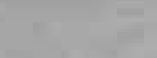

thand

$\sqrt{1}$

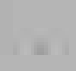

